Bild und Recht - Studien zur Regulierung des Visuellen 5

Eva-Maria Bauer

\title{
Die Aneignung von Bildern
}

Eine urheberrechtliche Betrachtung von der Appropriation Art bis hin zu Memes

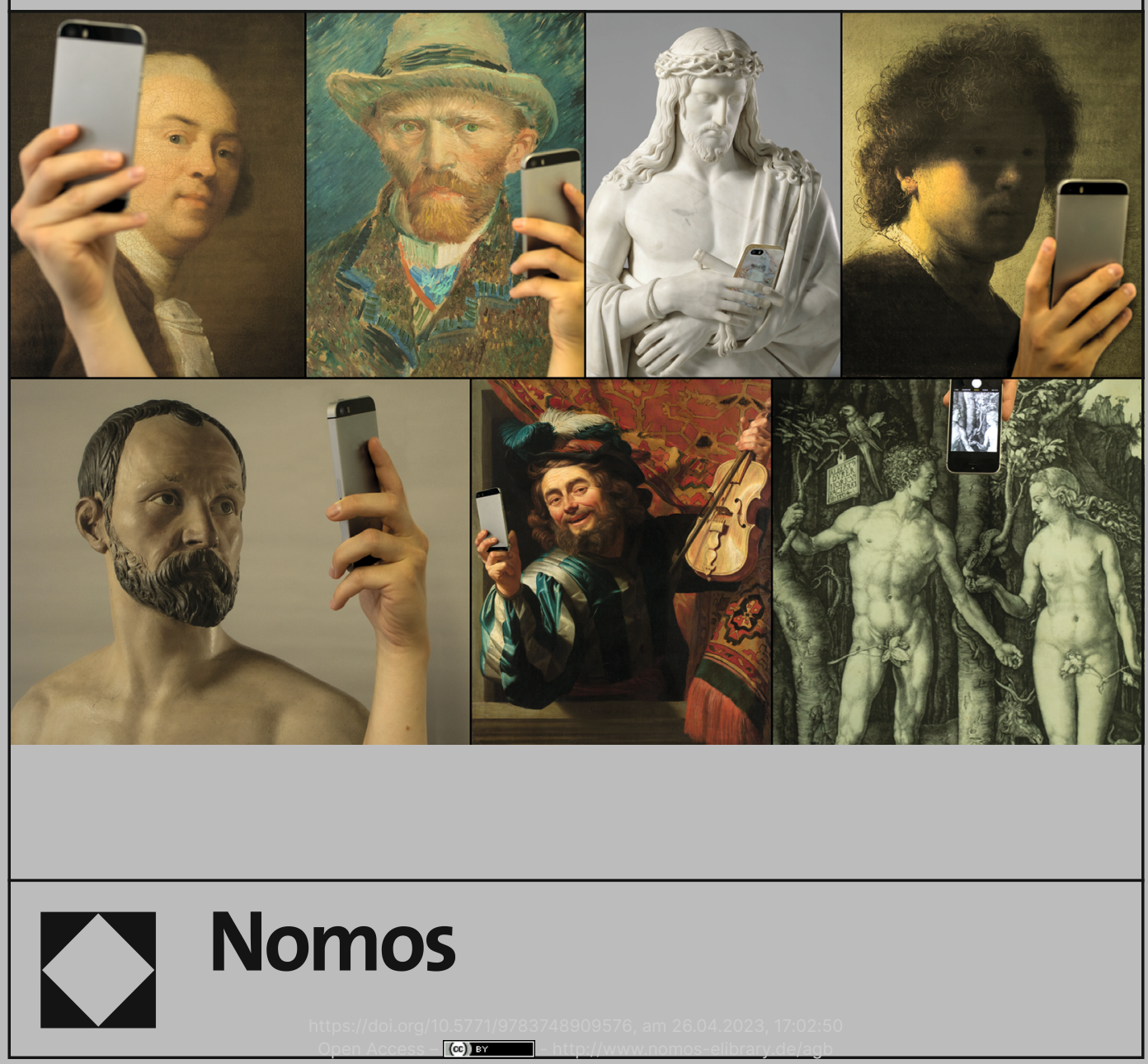


Bild und Recht - Studien zur Regulierung des Visuellen

herausgegeben von

Prof. Dr. Thomas Dreier

PD Dr. Dr. Grischka Petri

Prof. Dr. Wolfgang Ullrich

Prof. Dr. Matthias Weller

Band 5 


\section{Eva-Maria Bauer}

\section{Die Aneignung von Bildern}

Eine urheberrechtliche Betrachtung von der Appropriation Art bis hin zu Memes 
(c) Titelbild: Rijksmuseum/Michael Kirn

The book processing charge was funded by the Baden-Württemberg Ministry of Science, Research and Arts in the funding programme Open Access Publishing and the University of Freiburg.

Dissertation an der rechtswissenschaftlichen Fakultät der Albert-Ludwigs-Universität Freiburg

Dekan: Prof. Dr. Jan von Hein

Mündliche Prüfung 13.05.2020 in Karlsruhe Erstgutachter: Prof. Dr. Thomas Dreier, M.C.J.

Zweitgutachter: Prof. Dr. Maximilian Haedicke, LL.M.

Die Deutsche Nationalbibliothek verzeichnet diese Publikation in der Deutschen Nationalbibliografie; detaillierte bibliografische Daten sind im Internet über http://dnb.d-nb.de abrufbar.

Zugl.: Freiburg i. Br., Univ., Diss., 2020

1. Auflage 2020

(c) Eva-Maria Bauer

Publiziert von

Nomos Verlagsgesellschaft mbH \& Co. KG

Waldseestraße 3-5 | 76530 Baden-Baden

www.nomos.de

Gesamtherstellung:

Nomos Verlagsgesellschaft mbH \& Co. KG

Waldseestraße 3-5| 76530 Baden-Baden

ISBN (Print): 978-3-8487-6861-5

ISBN (ePDF): 978-3-7489-0957-6

DOI: https://doi.org/10.5771/9783748909576

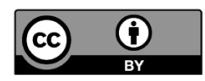

Dieses Werk ist lizensiert unter einer Creative Commons Namensnennung 4.0 International Lizenz. 
Meinen Eltern 


\section{Vorwort}

Die vorliegende Arbeit wurde im Sommersemester 2020 von der rechtswissenschaftlichen Fakultät der Albert-Ludwigs-Universität Freiburg als Dissertation angenommen. Sie entstand während meiner Zeit als akademische Mitarbeiterin am Zentrum für Angewandte Rechtswissenschaft (ZAR) am Karlsruher Institut für Technologie. Rechtsprechung und Literatur sind bis Februar 2020 berücksichtigt.

Mein herzlichster Dank gilt zunächst Herrn Prof. Dr. Thomas Dreier. Er hat mich stets mit hilfreichen Anregungen und Hinweisen unterstützt und mir am Zentrum für Angewandte Rechtswissenschaft den Freiraum ermöglicht, diese Arbeit zu erstellen. Zu Dank verpflichtet bin ich auch Herrn Prof. Dr. Maximilian Haedicke für die rasche Erstellung des Zweitgutachtens.

Franziska Brinkmann und Caroline Janssen danke ich für das sorgfältige Korrekturlesen dieser Arbeit und für zahlreiche Diskussionen über diese Arbeit und die Herausforderungen des Promovierens, die mir geholfen haben, mich zu motivieren und meine Gedanken zu strukturieren. Michael Kirn danke ich für die tolle Gestaltung des Coverbildes. Weiterhin bedanke ich mich bei meinen Kolleginnen und Kollegen vom Zentrum für Angewandte Rechtswissenschaft für die vergnügliche gemeinsame Zeit.

Für die Unterstützung meiner Familie bin ich zutiefst dankbar. Meine Geschwister Julius und Stefanie Bauer stehen mir mit ihrem Humor und ihrem Ratschlag immer zur Seite. Meinen Eltern Katja und Christoph Bauer danke ich für den uneingeschränkten Rückhalt, den sie mir im Leben geben.

Karlsruhe, Juli 2020

Eva-Maria Bauer 


\section{Inhaltsverzeichnis}

A. Problemaufriss: Aneignung als urheberrechtlich relevante Handlung

B. Gang der Darstellung

Erstes Kapitel: Die bildliche Aneignung 24

A. Bildliche Aneignung - eine Definition 24

I. Aneignung als Rechtsbegriff 24

II. Aneignung als kultureller Begriff 27

1. Aneignung als allgemeinsprachlicher Begriff 28

2. Aneignung als philosophischer Begriff 28

3. Aneignung als soziologischer Begriff 30

4. Aneignung als kulturwissenschaftlicher Begriff 31

III. Begriffsbestimmung für die Zwecke dieser Arbeit 32

IV. Begriffliche Einordnung der Aneignung als Sammelbegriff 33

V. Begriff des Bildlichen $\quad 42$

1. Bild als Darstellung $\quad 42$

2. Zwei- oder Dreidimensionalität 45

VI. Fazit: Aneignung als umfassender Sammelbegriff $\quad 45$

B. Untersuchungsgegenstände 46

I. Aneignung in der Kunst: Appropriation Art 46

1. Aneignung als künstlerisches Konzept 47

2. Künstler der Appropriation Art 50

a) Elaine Sturtevant $\quad 51$

b) Sherrie Levine $\quad 52$

c) Richard Prince $\quad 54$

d) Jeff Koons 56

3. Die Rechtsfälle 57

a) Rogers v. Koons $\quad 58$

b) Blanch v. Koons 59

c) Cariou v. Prince 60 
d) Gray v. Koons 61

e) Graham v. Prince 62

f) Weitere Klagen aufgrund der „New Portraits“ gegen Prince 64

g) Bauret v. Koons 67

II. Aneignung durch digitale Technologien 69

1. Phänomene 70

a) Teilen von Bildern in sozialen Netzwerken $\quad 70$

b) Das Museumselfie $\quad 72$

c) Memes 74

d) GIFs 76

e) Die Bildmontage von Kunstwerken 77

f) Virale Hypes $\quad 79$

2. Funktionsweise: kommunikativer Kontext 81

Zweites Kapitel: Die veränderte Nutzung von Aneignungen 83

A. Historische Nutzung der Aneignung 84

I. Die Antike: Aneignung als wertschätzende Auseinandersetzung mit der Vorlage $\quad 84$

1. Platon und die Nachahmung der Wirklichkeit 84

2. Aristoteles und die Nachahmung als Natur des
Menschen

3. Bildhauerei im Römischen Reich: Aneignung griechischer Skulpturen $\quad 85$

4. Imitatio und aemulatio: die wettstreitende Aneignung 86

II. Das Mittelalter und die Renaissance: Aneignung der Antike 87

1. Das Mittelalter und Aneignungen im handwerklichen Lehrverhältnis

2. Renaissance: die Aneignung der Antike 88

3. Rennaissance-Humanismus und die Individualität der Künstlerpersönlichkeit

III. Die Neuzeit: Eigenschöpferisches und Geniekult statt Aneignung

1. Geniekult in Aufklärung und Sturm und Drang 91

2. Klassizismus: abermals Aneignung der Antike 93

IV. Die Moderne: Aneignung als künstlerisches Mittel und Unabhängigkeit von der Vorlage

1. Die Klassische Moderne und die Entwicklung zur Abstraktion

2. Die Collage: Aneignung vorgefundenen Materials 95 
3. Ready-mades: Aneignung von Alltagsgegenständen 96

4. Walter Benjamin und die Aura des Originals 98

5. Pop Art: die Aneignung der Massenkultur 99

6. Konzeptkunst: Aneignung als bloß erneute Ausführung 100

7. Poststrukturalismus und der Tod des Autors 101

8. Baudrillards Simulationstheorie: Aneignungen als Simulacra

B. Heutige Nutzung: Aneignung als Kommunikationsform 104

I. Iconic turn und die digitale Bilderflut 104

II. Das Bild als Medium der Kommunikation im Digitalen 107

III. Prosumer und ihre produktive Nutzung von Bildern 109

IV. Gleichzeitige Steigerung des Kultes von Originalität 113

C. Fazit: Entwicklung der Aneignung zum Massenphänomen 115

Drittes Kapitel: Die urheberrechtliche Einordnung bildlicher Aneignungen

A. Urheberrechtlich geschützte Werke als Gegenstand von Aneignungen Dritter

I. Schutz des angeeigneten Werkes gem. $\$ 2$ Abs. 1, 2 UrhG 119

1. Persönliche geistige Schöpfung 120

a) Schutz der kleinen Münze 121

b) Folgen für Bilder 122

2. Bildschnipsel: Schutz von Werkteilen 124

3. Aneignung des Ready-made: Schutz der Idee? 124

4. Schutz des Stils eines Künstlers und des Motivs eines Bildes

5. Schutzdauer gem. $\$ 64$ UrhG 131

II. Exkurs: verwandte Schutzrechte 132

1. Lichtbilder 132

2. Laufbilder 133

3. Ausübende Künstler und Filmhersteller 134

III. Fazit 134

B. Eingriff in Persönlichkeitsrechte des Urhebers durch Aneignungen Dritter

I. Recht auf Anerkennung der Urheberschaft und Namensnennung gem. $\$ 13$ UrhG 136

II. Schutz vor Entstellung gem. $\$ 14$ UrhG 139 
C. Eingriff in Verwertungsrechte des Urhebers durch Aneignungen Dritter

I. Vervielfältigungsrecht gem. $\$ 16$ UrhG

1. Upload und Download

2. Digitaler Werkgenuss

3. Abgrenzung zur Bearbeitung 144

4. Fazit

II. Verbreitungsrecht gem. $\$ 17$ UrhG

III. Recht der öffentlichen Zugänglichmachung gem. $\$ 19$ a UrhG

1. Die Rechtsprechung des EuGH zum Recht der öffentlichen Wiedergabe

2. Beurteilung von Frame-Links nach nationalem Recht 148

a) Verletzung des $\$ 19$ a UrhG durch Frame-Links

b) Verletzung des unbenannten Rechts der öffentlichen Wiedergabe gem. $\$ 15$ Abs. 2 UrhG durch FrameLinks

aa) Unbestimmte Zahl potenzieller Adressaten und recht viele Personen

bb) Neues technisches Verfahren oder Publikum bei mit Erlaubnis des Urhebers im Internet veröffentlichten Werken

cc) Neues technisches Verfahren oder Publikum bei ohne Erlaubnis des Urhebers im Internet veröffentlichten Werken

dd) Fazit

3. Upload eines Bildes als öffentliche Wiedergabe gem. $\$ 19$ a UrhG

a) Neues technisches Verfahren oder neues Publikum 160

b) Bewertung

4. Fazit

IV. Aneignung als Bearbeitung gem. \$23 UrhG 165

D. Rechtfertigung der urheberrechtlichen Eingriffshandlungen 167

I. Aneignung als freie Benutzung gem. $\$ 24$ UrhG 168

1. Neues, selbständiges Werk 169

a) Idee, Inhalt und Form im Urheberrecht 170

aa) Inhalt und Form als konkretisierte Interessenabwägung

bb) Inhalt und Form als fehlende Individualität $\quad 172$

cc) Begrifflichkeiten: Idee, Inhalt und Form 
dd) Abkehr von der Dichotomie von Inhalt und Form

ee) Zwischenfazit

b) Schutz der Idee bei Appropriation Art?

c) Bei viralen Hypes: Schutz des Konzepts?

d) Schutz des Metatextes eines Memes?

e) Fazit

2. Verblassen

3. Innerer Abstand

a) Entwicklung des inneren Abstandes für die Parodie

aa) Appropriation Art als Parodie

bb) Memes als Parodie

cc) Bildmontagen von klassischen Kunstwerken als Parodie

b) Kunstspezifische Auslegung des $\$ 24$ Abs. 1 UrhG

aa) Kunstspezifische Auslegung für Werke der Appropriation Art

(1) Kunstbegriff des Art. 5 Abs. 3 GG

(2) Überwiegen der Kunstfreiheit

(3) Einschränkungen zur Verhinderung von Missbrauch: keine Konkurrenz zum Original

(4) Grenze: Interessenabwägung im Rahmen des $\$ 14$ UrhG?

bb) Kunstspezifische Auslegung für kommunikative Aneignungen?

cc) Parallele Wertung des $₫ 23$ Abs. 1 Nr. 4 KUG

4. Fazit

5. Quellenangabe gem. $\$ 63$ UrhG

6. Verhältnis von $\$ 24$ UrhG und Art. 5 Abs. 3 der InfoSocRL

II. Aneignung als Zitat gem. $\$ 51$ UrhG

1. Zitatzweck

2. Umfang

3. Selbständigkeit des zitierenden Werkes

4. Änderungsverbot und Quellenangabe gem. $\$ \$ 52,63$ UrhG

III. Panoramafreiheit gem. $\$ 59$ UrhG

IV. Gesetzlich erlaubte Nutzungen für Unterricht, Wissenschaft und Institutionen gem. $\$ 60 \mathrm{aff}$. UrhG

V. Einverständnis des Rechteinhabers 
E. Fazit: Diskrepanz von Recht und Rechtswirklichkeit bei Aneignungen

Viertes Kapitel: Strategien zur Freiraumschaffung für Aneignungen 227

A. Fokus auf den individuellen Urheber 228

I. Definition 228

II. Individualistische Rechtfertigungsgründe des Urheberrechtsschutzes als Grundlage

1. Arbeitstheoretische Rechtfertigung 231

2. Personalistische Rechtfertigung 233

a) Identifikationstheoretisch 233

b) Entwicklungstheoretisch 234

3. Werk-basierte Rechtfertigung 236

III. Ausgestaltung eines individualistischen Ansatzes 236

1. Angemessene Beteiligung des Urhebers 236

2. Grundsatz der engen Auslegung von Schrankenbestimmungen?

IV. Kritische Würdigung

V. Folgen für Aneignungshandlungen

B. Privilegierung des Künstlerischen 243

I. Definition 243

II. Kunstförderung als Rechtfertigung des Urheberrechtsschutzes

1. Kultur-basierte Rechtfertigung nach Fisher 245

2. Der kulturelle Imperativ nach Senftleben 246

III. Ausgestaltung des künstlerischen Ansatzes 248

1. Neudefinition des Werkbegriffs 248

2. Verfassungskonforme Auslegung im Lichte der Kunstfreiheit gem. Art. 5 Abs. 3 GG 250

IV. Kritische Würdigung 251

V. Folgen für Aneignungshandlungen 253

C. Kommunikativer Ansatz 254

I. Definition 254

II. Kollektivistische Rechtfertigungsgründe des
Urheberrechtsschutzes als Grundlage

1. Schranken-basierte Rechtfertigung 257

2. Effizienz-basierte Rechtfertigung 258

3. Demokratie-basierte Rechtfertigung nach Netanel 260 
4. Universalistisch-transzendentale Rechtfertigung nach Stallberg

III. Ausgestaltung des kommunikativen Verständnisses von Urheberrecht innerhalb des bestehenden Rechts

1. Verfassungskonforme Auslegung des $\$ 24$ Abs. 1 UrhG anhand des Kommunikationsgrundrechts aus Art. 5 Abs. 1 GG

a) Kommunikationsfreiheit als Meinungsfreiheit gem. Art. 5 Abs. 1 GG

b) Ausgestaltung der verfassungskonformen Auslegung 268

c) Kritische Würdigung

2. Einwilligungslösung: Ausweitung der VorschaubilderRechtsprechung

IV. Kritische Würdigung

V. Folgen für Aneignungshandlungen

Fünftes Kapitel: Regelungsvorschläge für Aneignungen

A. Neugestaltung des $₫ 24$ UrhG anhand der Vorgaben des

I. Das EuGH-Urteil Pelham/Hütter

II. Folgen des Urteils für die Geltung des $\$ 24$ UrhG

III. Umsetzung der Pastiche-Schranke des Art. 5 Abs. 3 lit. k InfoSoc-RL

1. Begriff des Pastiche

2. Aneignungen als Pastiche

B. Regelungsvorschlag für den kommunikativen Bildergebrauch

I. Einschränkbarkeit der Ausschließlichkeitsrechte des Urhebers

1. Freistellung

2. Gesetzliche Lizenz

3. Zwangslizenz

4. Sonstige Regelungen

II. Neue Schrankenregelung

1. Freistellung im nicht-kommerziellen Gebrauch

2. Gesetzliche Lizenz mit Vergütungspflicht im kommerziellen Gebrauch

3. Grenzen: Urheberpersönlichkeitsrechte, Quellenangabe gem. $\$ 63$ UrhG und Drei-Stufen-Test 
III. Vereinbarkeit mit EU-Recht

C. Regelungsvorschlag zur Umsetzung des Art. 17 der DSM-RL in nationales Recht

I. Die Regelung des Art. 17 der DSM-RL

1. Verantwortlichkeit der Diensteanbieter

2. Der Einsatz von Upload-Filtern

a) Absicherung von Schranken gem. Art. 17 Abs. 7 DSM-RL

b) Gefahr des Overblocking

c) Grundrechtsverletzung durch Art. 17 DSM-RL

II. Spielraum zur Umsetzung der DSM-RL

III. Vorschläge zur Umsetzung des Art. 17 DSM-RL in nationales Recht

Zusammenfassende Thesen

Literaturverzeichnis 


\section{Abbildungsverzeichnis}

Abb. 5.1.: Donald Graham, „Rastafarian smoking a joint“, 1996.

Abb. 5.2.: Richard Prince, Print der „New Portraits“ Reihe, 2014.

Abb 1.1.: Art Rogers, „Puppies“, 1985.

Abb. 1.2.: Jeff Koons, „String of Puppies“, 1988.

Abb 2.1.: Andrea Blanch, „Silk Sandals by Gucci“, 2000.

Abb. 2.2.: Jeff Koons, „Niagara“, 2000.

Abb. 3.1.: Patrick Cariou, Fotografie aus dem Buch „Yes Rasta“, 2000, S. 118.

Abb. 3.2.: Richard Prince, „Graduation“, 2008.

Abb. 4.1.: Gordon's Werbung, 1980er.

Abb. 4.2.: Jeff Koons, „I could go for something Gordon’s“, 1986.

Abb. 6.1.: Dennis Morris, Foto von Sid Vicious, 1970er.

Abb. 6.2.: Richard Prince, Post auf seiner Instagram Seite, 2014.

Abb. 6.3.: Dennis Morris, Fotos von Sid Vicious, 1970er.

Abb. 6.4.: Richard Prince, „Covering Pollock“, 2011.

Abb. 7.1.: Ashley Salazar, o.A.

Abb. 7.2.: Richard Prince, Print der Reihe „New Portraits“, 2014.

Abb. 8.1.: Eric McNatt, Fotografie von Kim Gordon, 2014.

Abb. 8.2.: Richard Prince, Print der Reihe „New Portraits“, 2014. 
Abb. 9.1.: Jean-François Bauret, „Enfants“, 1970.

Abb. 9.2.: Jeff Koons, „Naked“, 1988.

Abb. 10.1.: George F. Mobley/Getty Images, Fotografie, 2009.

Abb. 10.2.: ein Beispiel des Meme „Socially Awkward Penguin“, o.A.

Abb. 11.: Mona Lisa Selfie Montage, o.A. 


\section{Einleitung}

\section{A. Problemaufriss: Aneignung als urheberrechtlich relevante Handlung}

„richardprince1234 hat dein Bild kommentiert.“

Diese Benachrichtigung erhielten 2014 gewiss einige Instagram-Nutzer. Für seine Ausstellung „New Portraits“ in der Gagosian Gallery im Herbst 2014 machte der Künstler Richard Prince Screenshots von Bildern auf dem sozialen Netzwerk Instagram, ließ die Kopien stark vergrößern und auf Leinwände drucken. An den übernommenen Fotos änderte er nichts, er druckte allerdings die Benutzeroberfläche von Instagram mit ab. ${ }^{1}$ Vorher hatte er die Bilder auf der Instagram-App mit einem Kommentar versehen. Dieser Kommentar wurde innerhalb der Benutzeroberfläche ebenfalls abgedruckt. Die „New Portraits“ Werke zeigen allesamt Instagram-Beiträge von anderen, oft Selbstporträts gesellschaftlicher Subkulturen. Eines dieser Bilder verkaufte Prince für 90.000 U.S.-Dollar. ${ }^{2}$ Als der Fotograf Donald Graham entdeckte, dass Prince seine Fotografie „Rastafarian Smoking a Joint" $(1996)^{3}$ im Rahmen der Serie genutzt hatte, verklagte er ihn Ende 2015 auf Schadensersatz und Unterlassung der Nutzung der Fotografie. ${ }^{4}$

Mit diesem Rechtsstreit und weiteren aufgrund der „New Portraits“ Reihe ist die Diskussion über die urheberrechtliche Bewertung der Appropriation Art wieder neu aufgekommen. Die Kunstrichtung der Appropriation Art hatte die Übernahme von Bildern anderer Urheber zum künstlerischen Konzept erhoben. ${ }^{5}$ Als ein Phänomen der 1970er Jahre, das bisher nur in wenigen Einzelfällen U.S.-amerikanische Gerichte beschäftigt hat, hatte man die Appropriation Art in Verbindung mit allen modernen und postmodernen Behauptungen zum Tod des Autors und der Originalität ge-

1 Abb. 5.2.

2 Diener, 90.000 Dollar für ein Instagram-Foto, FAZ vom 26.05.2015, http://www.faz .net/aktuell/feuilleton/kunst/kuenstler-richard-prince-verkauft-instagram-fotos-1361 2527.html.

3 Abb. 5.1.

4 Donald Graham v. Richard Prince, Complaint, No. 1:15- cv-10160, 265 F. Supp. 3d 366 (S.D.N.Y. 2017), S. 10 ff. Ein Urteil steht noch aus. Ausführlicher zur Lage nach U.S.-amerikanischem Recht unter S. 57.

5 Rebbelmund, Appropriation Art, 1999, S. 13. 


\section{Einleitung}

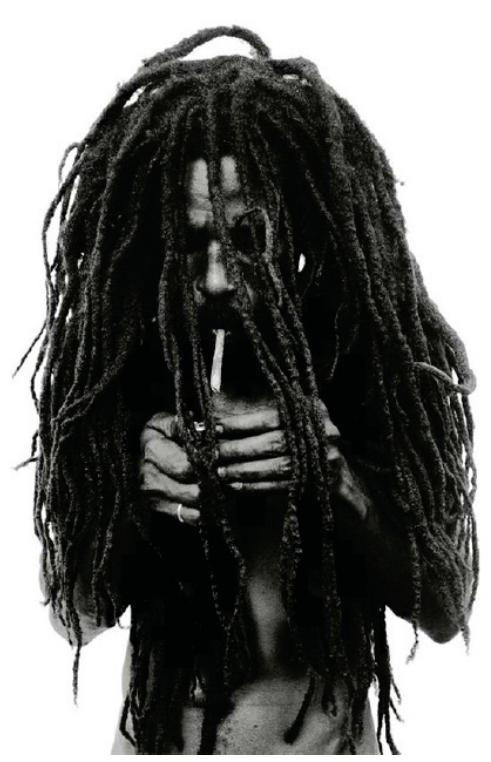

Abb. 5.1.: Donald Graham, „Rastafarian smoking a joint", 1996.

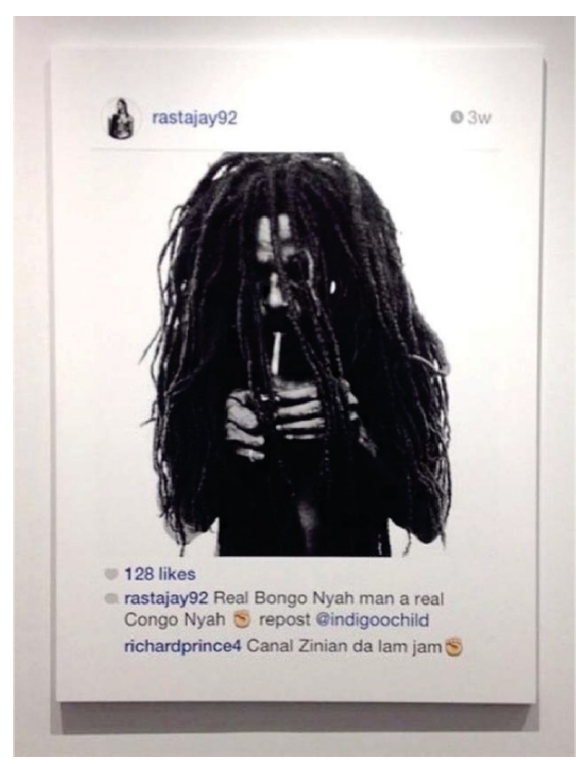

Abb. 5.2.: Richard Prince, Print der "New Portraits" Reibe, 2014.

setzt. ${ }^{6}$ Mit der „New Portraits“ Reihe und mehreren diesbezüglich anhängigen Klagen stellt sich die Frage nach der urheberrechtlichen Zulässigkeit der Appropriation Art neu. Doch nicht nur die Klagen tragen zur erneuten Relevanz dieser Fragestellungen bei, sondern vor allem die veränderte Ausprägung der Appropriation Art: Richard Prince ahmt nun die gängigen Mechanismen der sozialen Netzwerke nach und bringt sie in den Kunstkontext ein. Die Appropriation Art erhebt damit nicht mehr das Kopieren und Transformieren zu einem künstlerischen Prozess, sondern imitiert das alltägliche Kopieren und Transformieren im Internet. Bisher nie dagewesene Möglichkeiten, ein Original ohne Qualitätsverlust mit minimalem Zeitaufwand zu kopieren, haben die Techniken der Appropriation Art demokratisiert und durch die Partizipationskultur im Internet ${ }^{7}$ jedermann daran teilhaben lassen. Die Fragen der Collage, des Remix und Sampling in

6 Zur Appropriation Art, den Rechtsfälle Rogers v. Koons und Blanch v. Koons und der Einordnung nach deutschem UrhG bereits umfassend Huttenlauch, Appropriation Art. Kunst an den Grenzen des Urheberrechts, 2010.

7 Ausführlicher zu der digitalen Bildkultur vgl. S. $104 \mathrm{ff}$. 
der Kunst sind wahrlich keine neuen mehr $^{8}$, doch mit dem Aufkommen digitaler Technologien lösten sich diese Techniken aus dem Kontext der Kunst heraus.

Diese Techniken der Übernahme fremder Urheberrechtswerke sollen unter dem Begriff der Aneignung gemeinsam betrachtet werden. Dieser Begriff soll durch diese Arbeit in die Urheberrechtsdebatte um die Nutzung urheberrechtlich geschützten Materials durch Nutzer eingeführt werden. Er soll deutlich machen, dass zuvor künstlerische Mittel sich im Digitalen zu einem alltäglichen Massenphänomen entwickelt haben, das unser Kommunikationsverhalten grundlegend änderte.

In Zeiten der Massenkommunikation wird verstärkt mit Bildern statt mit Text kommuniziert. Permanent werden Fotos mit dem Smartphone geknipst und geteilt. Statt einer ausführlichen Beschreibung werden Emojis ${ }^{9}$ oder Memes ${ }^{10}$ versendet, die reduziert zusammenfassen, was man ausdrücken möchte. Man lässt das Bild für sich sprechen. Doch dafür müssen ständig Bilder produziert und transformiert werden. Mit dieser Bilderflut verliert aber das einzelne Bild auch an Bedeutung. Geht damit in Zeiten der massenhaften Kommunikation das Verständnis von Originalität verloren? Der iconic turn ${ }^{11}$ hat zu einer neuen Bedeutung der Bildlichkeit in

8 Auch wenn sie von einigen Urheberrechtlern weiterhin als „neue Kulturtechniken“ bezeichnet werden, so z.B. Podszun, Postmoderne Kreativität im Konflikt mit dem Urheberrechtsgesetz und die Annäherung an „fair use“, ZUM 2016, S. 606, 607.

9 Ein Emoji ist ein einem Emoticon ähnliches Piktogramm, das auf Gefühlslagen, Gegenstände, Tiere, Orte o.Ä. verweist, s. Dudenredaktion (Hrsg.), Emoji, in: Duden. Deutsches Universalwörterbuch, 2015. Zur Nutzung von Emojis in der digitalen Bildkultur s. Ullrich, Selfies. Die Rückkehr des öffentlichen Lebens, 2019, S. 39.

10 Memes sind Bild-Text-Kombinationen, die im Internet geteilt werden, bei denen das Bild häufig Fremdmaterial darstellt. Zur ausführlichen Definition s. S. 74.

11 Iconic turn ist ein Begriff von Gottfried Boehm, den er 1994 einführte, und der eine Hinwendung zur Bildwissenschaft bezeichnet und die Auseinandersetzung damit, wie Bilder die Menschen in ihrer Weltwahrnehmung und ihrem Verhalten beeinflussen, vgl. Boehm, Die Wiederkehr der Bilder, in: Boehm (Hrsg.): Was ist ein Bild?, 1994, S. 11 ff. Im Jahr 1992 wurde von W.J.T. Mitchell der pictorial turn ausgerufen, der ähnliche kulturelle Veränderungen im Blick hat, aber stärker ikonologisch (in Anlehnung an Erwin Panofsky) geprägt ist als der iconic turn, der eine Hermeneutik des Bildes etablieren möchte, vgl. Mitchell, The Pictorial Turn, Art Forum Nr.30 (1992), S. 89-95. Vgl. ausführlich dazu auch den Schriftverkehr von Boehm und Mitchell in: Rimmele/Sachs-Hombach/Stiegler (Hrsg.), Bildwissenschaft und Visual Culture, 2014, und grundsätzlich Maar/ 
der Kommunikation geführt - die „Hegemonie der Bilder“12 führt dazu, dass die in unserer Kultur vorherrschende Rolle der gesprochenen und geschriebenen Sprache abgelöst wird durch das Bild. Insbesondere im Internet lässt sich der Wandel von der Text- zur Bildsprache beobachten.

Wenn das Bild aber nun zur Kommunikation notwendig ist, warum sollte der Urheber des Bildes dessen Verwendung noch kontrollieren dürfen? Muss er nicht, wenn er ein Bild ins Internet stellt, damit rechnen, dass es andere Menschen nutzen werden? Nicht zuletzt im Rahmen der Debatte um die „Upload-Filter" der neuen Urheberrechtsrichtlinie ${ }^{13}$ wurde in ganz Europa darüber diskutiert, welche gesellschaftliche Bedeutung die digitale Kommunikation bekommen habe und wie diese Digitalkultur zu schützen sei.

In dieser Arbeit sollen künstlerische und kommunikative Aneignungen gegenübergestellt werden. Da sie mit den gleichen Techniken arbeiten und sich Künstler der Appropriation Art bewusst an digitalen Phänomenen orientieren, stellt sich die Frage, ob sie auch rechtlich gleich behandelt werden.

Aneignungen sind urheberrechtlich häufig problematisch, da sie geschütztes Material nutzen, ohne eine Einwilligung des Urhebers hierfür zu haben. Durch die Aneignungen werden die geschützten Werke vervielfältigt, verbreitet oder öffentlich zugänglich gemacht, zum Teil auch entstellt. In Rechte des Urhebers wird also regelmäßig eingegriffen. Dies machen auch die vielfachen Klagen gegen Richard Prince deutlich. Fraglich ist nur, inwieweit das Urheberrechtsgesetz diese Eingriffe dennoch rechtfertigen kann. $\$ 24$ Abs. 1 UrhG ist im deutschen Urheberrecht für Umnutzungen und Veränderungen urheberrechtlich geschützter Werke vorgesehen. Es wird daher maßgeblich auf die Auslegung des $\$ 24$ Abs. 1 UrhG ankommen, um Aneignungen rechtlich zu privilegieren. Hier soll untersucht werden, ob eine kunstspezifische Auslegung des $\$ 24$ Abs. 1 UrhG gleichermaßen für künstlerische und kommunikative Aneignungen in Betracht kommt. Kann es gerechtfertigt sein, wenn künstlerische und kommunika-

Burda (Hrsg.), Iconic Turn, 2004; Mitchell, Bildtheorie, 2008; Burda, In medias res, 2010; Belting, Bild-Anthropologie, 4. Aufl. 2011; Sachs-Hombach, Das Bild als kommunikatives Medium, 3. Aufl. 2013 und die Webseite www.iconicturn.de, Datum des Zugriffs: 15.01.2020 der Hubert-Burda-Stiftung; vgl. auch die Ausführungen zum iconic turn in der Kulturgeschichte der Aneignung S. $104 \mathrm{ff}$.

12 Bredekamp, Das Bild als Leitbild. Gedanken zur Überwindung des Anikonismus, in: Hoffmann/Joerges/Severin (Hrsg.), LogIcons. Bilder zwischen Theorie und Anschauung, 1997, S. 225, 230.

13 S. dazu ausführlicher S. $305 \mathrm{ff}$. 
tive Aneignungen rechtlich unterschiedlich eingeordnet werden, obwohl sie dieselben Techniken nutzen? Wenn das Urheberrecht mit $\mathbb{} 24$ Abs. 1 UrhG der gesellschaftlichen Realität digitaler Kommunikation nicht angemessen Rechnung tragen kann, müssten andere Privilegierungen für Aneignungshandlungen geschaffen werden. Wie könnten solche rechtlichen Freiräume für Aneignungen ausgestaltet werden? Bei dieser Frage wird ein Schwerpunkt auf die dafür grundlegende Frage gelegt, wen das Urheberrecht überhaupt angemessen privilegieren sollte und wie Freiräume für urheberrechtliche Nutzungshandlungen geschaffen werden können.

\section{B. Gang der Darstellung}

Im ersten Kapitel soll der Begriff der Aneignung in die urheberrechtliche Debatte um die Nutzung fremden, urheberrechtlich geschützten Materials eingeführt werden. Es werden eine Begriffsdefinition vorgenommen und die Untersuchungsgegenstände dieser Arbeit näher erläutert.

Im zweiten Kapitel wird die veränderte Nutzung der Aneignung aufgezeigt. Über lange Zeit ist sie lediglich ein künstlerisches Mittel gewesen; durch die Digitalisierung wurde die Aneignung aber jedermann technisch möglich. Dadurch entwickelte sie sich zu einem kommunikativen Medium und veränderte auch das Kommunikationsverhalten selbst.

Im dritten Kapitel wird zunächst geprüft, gegen welche Urheberpersönlichkeitsrechte und Verwertungsrechte Aneignungen regelmäßig verstoßen. Danach werden die rechtliche Bewertung von künstlerischen Aneignungen und die rechtliche Bewertung von kommunikativen Aneignungen einander gegenübergestellt. Es wird gezeigt, dass insbesondere für kommunikative Aneignungen wenig rechtlicher Freiraum verbleibt.

Im vierten Kapitel soll untersucht werden, welche Strategien der Auslegung und Anwendung des Urheberrechtsgesetzes dazu führen könnten, mehr Freiraum für Handlungen zu schaffen, die Urheberrechte betreffen. Es wird insbesondere analysiert, ob diese Strategien auch für kommunikative Aneignungen ausreichend Freiraum schaffen können.

Im fünften Kapitel werden verschiedene neue Regelungen vorgeschlagen, deren Einführung dazu dienen soll, Aneignungen im Urheberrecht zu privilegieren und rechtlich freizustellen. 


\section{Erstes Kapitel: Die bildliche Aneignung}

Im Folgenden wird die Aneignung als ein Begriff in der Urheberrechtsdebatte um die Nutzung vorgefundenen Materials eingeführt (A.). Der Begriff der Aneignung ist weder dem Urheberrecht originär noch in dessen Rahmen gebräuchlich. Zur Herleitung einer Definition wird der rechtliche (I.) und kulturelle (II.) Gebrauch des Begriffs Aneignung dargestellt. Aus diesem erweiterten Blickwinkel heraus sind die einer Aneignung zugrundeliegenden Prinzipien herauszuarbeiten und dadurch eine Definition für die Zwecke dieser Arbeit zu finden (III). Die Aneignung soll als ein umfassender Sammelbegriff dienen, weshalb sodann die ihm unterfallenden Techniken der Aneignung vorgestellt werden (IV.). Da sich diese Arbeit jedoch insbesondere mit der veränderten Nutzung der Aneignung im Künstlerischen und Kommunikativen beschäftigt, beschränkt sich die Auseinandersetzung allein auf Aneignungen von Bildern und durch Bilder, weshalb der Bildbegriff ebenfalls erläutert wird (V.).

Darauffolgend sollen die genauen Untersuchungsgegenstände der Arbeit dargestellt werden (B.). Das Nutzerverhalten von bildlichen Aneignungen hat sich von einer Verwendung allein zu künstlerischen Zwecken zu einem Massenphänomen in der digitalen Kommunikation gewandelt. Daher prägen diese beiden Aspekte - der künstlerische und der kommunikative - der bildlichen Aneignungen die Auswahl der zu untersuchenden Phänomene.

\section{A. Bildliche Aneignung - eine Definition}

I. Aneignung als Rechtsbegriff

Der Begriff der Aneignung findet sich in einigen wenigen Gesetzestexten verschiedener Rechtsgebiete wieder: in einer Verordnung der EU zu Ursprungs- und geographischen Bezeichnungen, im BGB und im StGB. Aneignung steht dort jeweils in Verbindung zu Fragen der Eigentumsverhältnisse. Diese Rechtsbegriffe der Aneignung sollen nun untersucht werden, um einen Begriff für das Urheberrecht zu definieren.

In Rechtsnormen, die dem geistigen Eigentum zugeordnet werden können, ist der Begriff der Aneignung lediglich in der Verordnung über Quali- 
tätsregelungen für Agrarerzeugnisse und Lebensmittel, VO Nr. 1151/2012 ${ }^{14}$, erwähnt: Art. 13 Abs. 1 lit.b verbietet die Aneignung einer geschützten Ursprungsbezeichnung oder geographischen Bezeichnung. Unter Aneignung versteht man hier, wenn das Erzeugnis, das nicht zur Führung der geographischen Bezeichnung berechtigt ist, diese Bezeichnung nahezu identisch übernimmt. ${ }^{15}$ Die Aneignung meint also eine unrechtmäßige Übernahme, die zu einer Verwirrung beim Verbraucher über die Herkunft des Produktes führen kann. Der Begriff hat damit bereits eine negative Konnotation und steht in Verbindung zum Rechtsbruch und zur Täuschung. Das Begriffsverständnis, dass die Aneignung unkörperlich zu verstehen ist, fügt sich in die Systematik des geistigen Eigentums ein. Es muss gerade keine Übergabe eines Gegenstandes stattfinden (z.B. des Produkts mit der Ursprungsbezeichnung), sondern es wird etwas Immaterielles, die Ursprungsbezeichnung selbst, angeeignet. Trotzdem ist der Begriff der Aneignung hier nur beschränkt nutzbar für eine urheberrechtliche Begrifflichkeit: Angeeignet werden können nur Ursprungs- und geographische Bezeichnungen und das auch nur im geschäftlichen Verkehr, beim Verkauf von Produkten. Dieses enge Begriffsverständnis eignet sich nicht zur Übertragung auf urheberrechtliche Fragestellungen.

Darüber hinaus wird der Begriff der Aneignung in $\$ 928$ Abs. 2 BGB, in $\$ 958$ BGB und in $\$ 956$ BGB explizit erwähnt. Bei $\$ 242$ StGB wird er als die Tatbestandsvoraussetzung der Aneignungsabsicht durch die Auslegung der herrschenden Meinung als Rechtsbegriff eingeführt.

$\$ 928$ Abs. 2 BGB regelt das Recht der Aneignung bei einem aufgegebenen Grundstück. Dieses Recht steht dem Bundesland zu, in dem das aufgegebene Grundstück liegt. Das Aneignungsrecht stellt hier ein dingliches Recht eigener Art dar und kann übertragen werden. ${ }^{16}$ Hier kann sich also nur etwas angeeignet werden, an dem keine Eigentumsrechte mehr bestehen.

Die Parallelvorschrift für bewegliche Sachen ist $\$ 958$ Abs. 1 BGB, der den Aneignungserwerb von herrenlosen Sachen regelt. Auch hier dürfen an der anzueignenden Sache keine Eigentumsrechte mehr bestehen. Die Aneignung findet statt, indem der Erwerber Eigenbesitz im Sinne des

14 Verordnung (EU) Nr. 1151/2012 des Europäischen Parlaments und des Rates vom 21. November 2012 über Qualitätsregelungen für Agrarerzeugnisse und Lebensmittel.

15 s. BeckOK Markenrecht/Schulteis, 19. Ed. 2019, \$135 MarkenG Rn. 9.

16 MüKo/Kanzleiter, 8. Aufl. 2020, \$928 BGB Rn. 12. 
$\$ 872$ BGB an der Sache begründet. Dies setzt voraus, dass er die tatsächliche Sachherschaft ergreift und die Sache für sich besitzen will. ${ }^{17}$

Auch in $\$ 956$ Abs. 1 BGB wird auf den Besitz als maßgebliche Voraussetzung für die Aneignung abgestellt. In dieser Norm ist der Eigentumserwerb durch Aneignung von Erzeugnissen oder sonstigen Bestandteilen einer Sache geregelt. Der Erwerb des Eigentums an diesen Früchten ist nur mit Gestattung des Eigentümers möglich und setzt voraus, dass die Früchte in den Besitz des Erwerbers kommen - entweder durch Besitzüberlassung der Sache oder durch Trennung von der Sache und Besitzergreifung der Früchte. Die Norm ist also für Personen gedacht, die bereits schuldrechtlich berechtigt sind, die Früchte zu ziehen. Zwar ist die Rechtsnatur dieser Norm umstritten ${ }^{18}$, jedoch muss die Aneignung in jedem Falle gestattet worden sein und sie ist abhängig von den Besitzverhältnissen.

In $\$ 242$ StGB wird der Begriff der Aneignung selbst nicht genannt, ist aber als Rechtsbegriff bei der näheren Definition der Tatbestandsvoraussetzungen geläufig. Der Diebstahl nach $\$ 242$ Abs. 1 StGB setzt voraus, dass eine Zueignungsabsicht vorliegt. Dafür muss die Sache dem Opfer enteignet und sich oder einem Dritten angeeignet werden. ${ }^{19}$ Für diese Aneignung muss entweder der Täter oder der Dritte sich zumindest vorübergehend eine eigentümerähnliche Verfügungsgewalt über die Sache anmaßen. ${ }^{20}$ Das heißt, es reicht für die Aneignung nicht bloß die reine Sachentziehung aus, bei der der Täter die Sache zerstören oder beschädigen möchte. Denn Aneignung dient hier der Abgrenzung zur Sachbeschädigung gem. $₫ 303$ Abs. $1 \mathrm{StGB}^{21}$, bei der der Täter lediglich mit Enteignungsvorsatz, nicht aber mit Aneignungsabsicht handelt. Daher muss für die Aneignungsabsicht im Sinne des $\mathbb{2} 242$ Abs. 1 StGB die Sache zumindest vorübergehend positiv, im eigenen Interesse genutzt werden bzw. aus ihr ein unmittelbarer oder mittelbarer wirtschaftlicher Vorteil gewonnen werden. ${ }^{22}$ Ebenso wie in den sachenrechtlichen Vorschriften ist die Aneig-

17 MüKo/Oechsler, 8. Aufl. 2020, \$958 BGB Rn. 6.

18 Nach der Übertragungstheorie handelt es sich um eine antizipierte Verfügung im Sinne des $\$ 929$ S. 1 BGB, die mit der Trennung von der Sache wirksam wird. Nach der Aneignungs- oder Erwerbstheorie handelt es sich um ein Fruchtziehungsrecht, das mit dinglicher Wirkung auf den Erwerber übergeht und aus dem heraus der Erwerber Eigentum erwirbt. Vgl. zu beidem MüKo/Oechsler, 8. Aufl. 2020, $\$ 956$ BGB Rn. 2.

19 BeckOK StGB/Wittig, 37. Ed. 2018, $\$ 242$ StGB Rn. 30.

20 Ders., a.a.O., Rn. 37.

21 Rengier, Strafrecht Besonderer Teil I, 19. Aufl. 2017, \$2 Rn. 138.

22 BGH NStZ 2011, S. 699, 701; BGH NJW 1977, S. 1460. 
nung hier exklusiv zu verstehen, das heißt mit ihr geht immer eine Enteignung einher. Anders als im Sachenrecht ist hier aber eine bestimmte positive Beziehung zu dem angeeigneten Gegenstand notwendig.

Es zeigt sich, dass die sachenrechtlichen und strafrechtlichen Begriffe der Aneignung im Wesentlichen darauf abstellen, dass die Aneignung ausschließlich ist, also immer mit dem Bruch der vorherigen Zuordnung einhergeht oder die Sache bereits herrenlos und niemandem zugewiesen war. Eine Übertragung dieses Prinzips in das Urheberrecht ist schwierig, da die Schutzgegenstände des Urheberrechts unkörperlich und ubiquitär sind. ${ }^{23}$ Der Schutzgegenstand ist gerade ein Immaterialgut, das im Werkexemplar lediglich konkretisiert wurde. Für den Werkgenuss muss niemandem anders etwas weggenommen werden: Ein Werk kann gerade nicht-rivalisierend von allen genutzt werden. Herrenlose Sachen im Urheberrecht sind nicht denkbar. ${ }^{24}$ Für eine Aneignung im Urheberrecht kann das Werk daher auch weiterhin jemandem anders zugewiesen sein, es muss nicht herrenlos oder enteignet werden. Das Verständnis der Aneignung als gleichzeitig körperlicher Verlust des Gegenstandes, der angeeignet wird, passt daher nicht in das System des Urheberrechts.

Die Untersuchung der bisherigen Nutzung des Begriffs der Aneignung im Recht hat also bisher zu dem Ergebnis geführt, dass dieses Begriffsverständnis aufgrund der fehlenden körperlichen Enteignung nicht auf das Urheberrecht übertragbar ist. Um eine dem geistigen Eigentum angemessene Definition zu finden, soll daher im Folgenden die Aneignung als kultureller Begriff untersucht werden, um daraus eine konkretere Definition ableiten zu können.

\section{Aneignung als kultureller Begriff}

Nach der Betrachtung der Aneignung als Rechtsbegriff soll er nun in seiner geisteswissenschaftlichen Nutzung untersucht werden. Dazu wird die Nutzung des Begriffs der Aneignung zunächst allgemeinsprachlich (1.),

23 Schack, Urheber- und Urhebervertragsrecht, 9. Aufl. 2019, Rn. 20 f.; Rehbinder/ Peukert, Urheberrecht, 18. Aufl. 2018, Rn. 28 f.

24 Eine Dereliktion des Urheberrechts ist gerade nicht möglich. Dies folgt aus der Unübertragbarkeit des Urheberrechts als Ganzem gem. \$29 UrhG, vgl. BGH GRUR 1995, S. 673, 675 - Mauer-Bilder; Dreier/Schulze/Schulze, 6. Aufl. 2018, \29 UrhG Rn. 3, 10; Wandtke/Bullinger/Wandtke/Grunert, 5. Aufl. 2019, $\$ 31$ UrhG Rn. 1; Schack, Urheber- und Urhebervertragsrecht, 9. Aufl. 2019, Rn. 20; Osenberg, Die Unverzichtbarkeit des Urheberpersönlichkeitsrechts, 1985, S. 21. 
dann philosophisch (2.), soziologisch (3.) und schließlich kulturwissenschaftlich (4.) vorgestellt.

\section{Aneignung als allgemeinsprachlicher Begriff}

Der Duden nennt für den Begriff der Aneignung drei Bedeutungen in der Alltagssprache: den Eigentumserwerb von herrenlosen Sachen, die widerrechtliche Inbesitznahme und das Lernen im Sinne einer inhaltlichen Aneignung. ${ }^{25}$ Daraus lässt sich jedoch auch noch keine präzise Definition für urheberrechtliche Problemstellungen ableiten. Die drei genannten Bedeutungsvarianten kommen aber ebenso dem Begriff der Appropriation (von lat. appropriare; dt.: erwerben, zu eigen machen) zu. Er ist damit ein Synonym zum Begriff der Aneignung. Deutlich wird aus den drei Bedeutungen, dass es um ein interaktives Verhältnis des Aneignenden zu seiner Umwelt geht - er nimmt etwas aus seiner Umwelt auf. Zunächst ist also eine Vorlage notwendig, derer man sich bedient. Denn etwas sich zu eigen machen kann man nur, wenn es ansonsten jemandem anders zugewiesen ist. Eine Selbstaneignung eigener, früher entstandener Werke ist also nicht möglich.

\section{Aneignung als philosophischer Begriff}

In der Eigentumstheorie nach John Locke stellt die Aneignung das Werkzeug zur Begründung des Eigentums dar. Er selbst nutzt dafür den Begriff der appropriation, der im Deutschen zum Teil nicht mit Aneignung, sondern mit Zueignung übersetzt wurde. Eigentum begründet Locke mit der Appropriation der Natur durch den Menschen: Der Sachwert eines Gutes entstehe durch die Arbeit, die in die Veränderung und Nutzung des Gutes gesteckt wird. ${ }^{26}$ Diese körperliche Arbeitsleistung werde durch das Eigen-

25 Dudenredaktion (Hrsg.), Aneignung, in: Duden. Deutsches Universalwörterbuch, 2015.

26 „Gottes Gebot und seine Bedürfnisse zwangen ihn, zu arbeiten. Worauf er auch immer seine Arbeit richtete, war sein Eigentum, das ihm nicht genommen werden konnte. So erkennen wir, daß die Unterwerfung oder Kultivierung der Erde und die Ausübung von Herrschaft eng miteinander verbunden sind. Das eine verleiht einen Rechtsanspruch auf das andere. Gott gab also durch das Gebot, sich die Erde zu unterwerfen, die Vollmacht, sie sich anzueignen. Und die Bedingung des menschlichen Lebens, das Arbeit und Stoff, der bearbeitet werden kann, er- 
tum belohnt. Die Aneignung wird hier in Bezug zu Eigentumsrechten gesehen, wie es auch schon das rechtliche Begriffsverständnis gezeigt hat. ${ }^{27}$

John Lockes Eigentumstheorie wurde von Karl Marx aufgenommen und weiterentwickelt. Marx verbindet den Begriff der Aneignung mit Eigentumsbildung und Arbeit, aber ebenfalls auch mit menschlicher Erkenntnis und individuellem Lernen ${ }^{28}$, wie es der allgemeinsprachliche Begriff nahelegt. Der Bildungsprozess persönlicher Eigentümlichkeit in Korrelation mit Gemeinschaftlichkeit steht bei ihm sogar im Vordergrund. ${ }^{29}$ Er nutzt die Aneignung aber nicht nur als einen auf die Vernunft zugeschnittenen Begriff der Bildung, sondern spricht auch der sinnlichen Aneignung durch sinnliche Wahrnehmung einen Eigenwert zu. Damit nutzt er den Begriff der Aneignung auch als ästhetischen Begriff. ${ }^{30}$ Nach Marx ist Aneignung ein Prozess der Selbstentwicklung: Der Mensch formt sich selbst, indem er die Natur durch Aneignung schöpferisch verändert. ${ }^{31}$ Dem gegenüber stellt er die Entfremdung, die dadurch gekennzeichnet ist, dass man nicht selbst besitzt, was man produziert hat. Diese Trennung von Arbeit und Eigentum mache dem Menschen eine produktive Form der Weltaneignung unmöglich. Er erfahre dadurch Sinnverlust und Machtlosigkeit. ${ }^{32}$ Erst der Kommunismus könne durch Aufhebung des Privateigentums auch diese

fordert, führt notwendigerweise zum Privatbesitz.", so Locke, Zwei Abhandlungen über die Regierung [1690], 1977, S. 221, $\$ 35$, Hervorhebungen im Original.

27 Unser heutiges Eigentumsrecht ist immer noch stark von Lockes Eigentumstheorie geprägt, die als eine der wenigen Eigentumstheorien ohne einen notwendigen göttlichen Willen bei der Begründung von Eigentum auskommt und damit auch unserem modernen, säkularem Verständnis von Eigentum gerecht werden kann (auch wenn Locke noch von einer göttlichen Vollmacht zur Appropriation spricht).

28 Haug, Aneignung, in: ders./Haug/Jehle/Küttler (Hrsg.), Historisch-kritisches Wörterbuch des Marxismus, 1994, Rn. 233.

29 Franz, Aneignung, in: Barck/Fontius/Schlenstedt/Steinwachs/Wolfzettel (Hrsg.), Ästhetische Grundbegriffe. Historisches Wörterbuch in sieben Bänden, Band 1: Absenz-Darstellung, 2010, S. 153, 182.

30 Ders., a.a.O., S. 182 f.

31 De La Rosa, Aneignung und interkulturelle Repräsentation, 2012, S. 54.

32 „Wie das Privateigentum nur der sinnliche Ausdruck davon ist, daß der Mensch zugleich gegenständlich für sich wird und zugleich vielmehr sich als ein fremder und unmenschlicher Gegenstand wird, daß seine Lebensäußerung seine Lebensentäußerung ist, seine Verwirklichung seine Entwicklung, eine fremde Wirklichkeit ist, so ist die positive Aufhebung des Privateigentums, d.h. die sinnliche Aneignung des menschlichen Wesens und Lebens, des gegenständlichen Menschen, der menschlichen Werke für und durch den Menschen nicht nur im Sinne des unmittelbaren, einseitigen Genusses zu fassen, nicht nur im Sinne des Besitzes, im Sinne des Habens. Der Mensch eignet sich sein allseitiges Wesen auf eine allseiti- 
menschliche Selbstentfremdung aufheben und dadurch „die wirkliche Aneignung des menschlichen Wesen durch und für den Menschen" bewirken. ${ }^{33}$ Die wirkliche Aneignung nach Marx stellt also eine revolutionäre Transformation dar, die sich erst im Kommunismus verwirklichen kann.

Der philosophische Begriff der Aneignung steht damit in Spannung zwischen Eigenheit und Fremdheit, wie es auch schon das rechtliche Begriffsverständnis nahelegt. ${ }^{34}$ Dies macht aber auch deutlich, dass durch die Aneignung das angeeignete Objekt auch zu etwas Eigenem werden muss. Sowohl Locke als auch Marx verstehen die Aneignung produktiv: Sie schafft selbst einen Wert und stellt damit eine positive Nutzung des angeeigneten Gegenstandes dar.

\section{Aneignung als soziologischer Begriff}

In der Soziologie Max Webers ist die Appropriation ein zentraler Begriff. Er nutzt zwar nicht den Begriff der Aneignung selbst, die Appropriation wird aber als ein Synonym zur Aneignung verstanden. ${ }^{35}$ Appropriation bei Weber meint den Ausschluss anderer von Chancen und Vorteilen, indem etwas monopolisiert wird. Er führt den Begriff im Zusammenhang mit offenen und geschlossenen sozialen Beziehungen ein. Die Appropriation führt zu einer geschlossenen sozialen Beziehung, da andere von Chancen und Vorteilen ausgeschlossen werden. ${ }^{36}$ Diese Schließung nach innen, das

ge Art an, also als ein totaler Mensch. Jedes seiner menschlichen Verhältnisse zur Welt, Sehen, Hören, Riechen, Schmecken, Fühlen, Denken, Anschauen, Empfinden, Wollen, Tätigsein, Lieben, kurz aller Organe seiner Individualität [...] ihr Verhalten zum Gegenstand ist die Betätigung der menschlichen Wirklichkeit.“, Marx, Nationalökonomie und Philosophie, in: Landshut (Hrsg.), Die Frühschriften, 1971, S. 225, 239 f., Hervorhebungen im Original.

33 Marx, Privateigentum und Kommunismus, in: Institut für Marxismus-Leninismus beim ZK der SED (Hrsg.), Ökonomisch-philosophische Manuskripte aus dem Jahr 1844, Marx-Engels-Werke (MEW), Ergänzungsband, 1968, S. 465, 536.

34 „In der Idee der Aneignung liegt also ein interessantes Spannungsverhältnis zwischen Vorgegebenem und Gestaltbarem, zwischen Übernahme und Schöpfung, zwischen Souveränität und Abhängigkeit des Subjekts. Entscheidend ist dabei nun das Verhältnis zwischen Fremdheit und Zugänglichkeit: Objekte der Aneignung sind ,weder nur fremd noch nur eigen'.", Jaeggi, Aneignung braucht Fremdheit, Texte zur Kunst Nr. 46 (Juni 2002), https://www.textezurkunst.de/46/aneign ung-braucht-fremdheit/.

35 S. dazu bereits S. 28.

36 Weber, Wirtschaft und Gesellschaft [1922], 5. Aufl. 1972, S. 23. 
heißt innerhalb einer Gruppe, nannte Weber Appropriation. Rechte waren daher für ihn eine Appropriation von Chancen. Appropriation stellt damit einen Prozess der Eigentumsbildung dar, wird aber als sozialer Prozess betrachtet. ${ }^{37}$ Appropriation (oder Aneignung) funktioniert hier auch nur durch den Ausschluss anderer, der aber nicht durch das Eigentumsrecht begründet sein muss. Dies erweitert unser Verständnis von Aneignung dergestalt, dass die Aneignung nun auch auf andere gesellschaftliche Erwerbsprozesse als die des Eigentums übertragen werden kann. Dabei spielt aber der Ausschluss anderer vom angeeigneten Gegenstand weiterhin eine Rolle. Dies lässt sich auf das Grundkonzept des Urheberrechts als Ausschlussrecht übertragen.

\section{Aneignung als kulturwissenschaftlicher Begriff}

Der kulturwissenschaftliche Begriff der cultural appropriation ${ }^{38}$ (kulturelle Aneignung) ist im Rahmen des kulturellen Begriffsverständnisses zu nennen. Er ist jedoch als politischer Begriff nicht wertungsfrei, sondern stellt die Aneignung vor den Hintergrund der Ausbeutung marginalisierter, häufig benachteiligter oder unterdrückter Kulturen. Die Aneignung ist hier eine Verfälschung der Kultur, häufig zu kommerziellen Zwecken, und damit negativ konnotiert. Die kulturelle Aneignung wird zudem in Verbindung zu Debatten um die white supremacy ${ }^{39}$ gesetzt: Der Akt der

37 Appropriation und Eigentum sind nicht gleichzusetzen: „Erblich an Einzelne oder an erbliche Gemeinschaften oder Gesellschaften appropriierte Chancen sollen: 'Eigentum' (der Einzelnen oder der Gemeinschaften oder der Gesellschaften), veräußerlich appropriierte: 'freies Eigentum' heißen.“, so Weber, Wirtschaft und Gesellschaft [1922], 5. Aufl. 1972, S. 23. Weitere Beispiele für Typen von Appropriation und Aneignungsformen, die in der Geschichte aufgetreten sind: ders., a.a.O., S. 135-150.

38 Zum Begriff und ausführlich zur Debatte der kulturellen Aneignung: Young, Cultural Appropriation and the Arts, 2010; Welsch, Transkulturalität. Lebensformen nach der Auflösung der Kulturen, Information Philosophie (Heft 2, 1992), S. 5 ff.; Bruns, What is Wrong with Copying from Other Cultures?, Jahrbuch für Recht und Ethik, Band 26 (2018), S. 25 ff.; Malik, In Defense of Cultural Appropriation, The New York Times vom 14.06.2017, https:/www.nytimes.com/2017/06/14/ opinion/in-defense-of-cultural-appropriation.html.

39 Dt.: Überlegenheit der Weißen; Als Begriff nicht nur innerhalb der Rassenlehre und -ideologie verwendet, sondern auch als soziologischer und politischer Begriff, um strukturellen Rassismus, der Weißen gewisse Macht, Privilegien und Vorteile gewährt, ohne von Rassenideologie getrieben zu sein, und der im $\mathrm{Zu}$ sammenhang zur Dominanz der Weißen steht, so Mills, White supremacy as so- 
Aneignung ist einseitig und demonstriert Macht über diese anderen Kulturen ${ }^{40}$, er stellt damit einen rassistischen Akt dar. Mit diesen kultur- und gesellschaftswissenschaftlichen Dimensionen beschäftigt sich diese Arbeit jedoch nicht. Hier soll vielmehr der Schwerpunkt grundsätzlich auf Akte der Aneignung als kulturelle Mittel gesetzt und das Nutzungsverhalten von Aneignungen aufgezeigt werden, das von urheberrechtlicher Relevanz ist. Diese rechtliche Relevanz kommt der cultural appropriation als kulturtheoretischem Phänomen nicht zu.

\section{Begriffsbestimmung für die Zwecke dieser Arbeit}

Mit der folgenden Definition soll Aneignung als ein urheberrechtlicher Begriff eingeführt werden: Eine Aneignung bezeichnet die direkte physische oder indirekte unkörperliche Übernahme fremden Materials zu eigenen Zwecken.

Die Übernahme ist weit zu verstehen und kann auf verschiedenste Art und Weise vorgenommen werden - die typischerweise dafür genutzten Techniken werden im nächsten Kapitel vorgestellt. ${ }^{41}$ Auch der Begriff des fremden Materials ist umfassend und soll ermöglichen, den Begriff der Aneignung auf möglichst viele kulturelle Praktiken verwenden zu können, unabhängig vom Ausgangsmaterial. Mit der Einschränkung, dass die Übernahme zu eigenen Zwecken vorgenommen werden muss, soll die bloße Darstellung des fremden Materials, also dessen Wiedergabe zum Werkgenuss, ausgeschlossen werden. Wenn man das Verständnis der Aneignung als einer produktiven Nutzung auf das Urheberrecht überträgt, liegt eine Aneignung also nur dann vor, wenn nicht bloß die Wiedergabe des fremden Werkes, sondern eine Änderung des Zuweisungscharakters vorliegt.

ciopolitical system. A philosophical perspective, in: Doane/Bonilla-Silva (Hrsg.), White Out. The Continuing Significance of Racism, 2013, S. 35-48; Ansley, Stirring the Ashes. Race, Class and the Future of Civil Rights Scholarship, Cornell Law Review 74 (1989), S. 993 ff.

40 Ein Beispiel von kultureller Aneignung ist der Verkauf eines Bumerangs durch Chanel für $2.000 €$, der als typisches Symbol der Aborigines eine kulturelle Bedeutung als Instrument der Jagd hat, jetzt jedoch kommerziell genutzt wird. Die kulturelle Aneignung wird hier auch als Ausübung von Dominanz durch Weiße gesehen und damit als rassistischer Akt gewertet, vgl.: Hunt, Chanel's $\$ 2,000$ boomerang criticised for 'humiliating' Indigenous Australian culture, The Guardian vom 16.05.2017, https://www.theguardian.com/fashion/2017/may/16/chanels-200 0-boomerang-criticised-for-humiliating-indigenous-australian-culture.

41 Vgl. S. $33 \mathrm{ff}$. 
Die Darstellung des fremden Materials allein soll lediglich dieses Material präsentieren, es wird damit aber nicht der Zuweisungscharakter des Werkes geändert. Es müssen also fremde Ideen oder Gegenstände dergestalt übernommen werden, dass sie anders genutzt oder präsentiert werden als von demjenigen, dem sie zuvor zugewiesen waren, und dass sie sich dadurch zu eigen gemacht wurden. ${ }^{42}$ Ein Bestandteil der Definition der Aneignung für diese Arbeit muss daher sein, dass das angeeignete Material zu eigenen Zwecken genutzt wird.

Schließlich ist noch die gewisse negative Konnotation des Begriffs der Aneignung anzusprechen. Der Begriff der Aneignung insinuiert die Enteignung und wird damit in Verbindung zum Diebstahl gebracht. Damit könnte damit bereits eine rechtliche Wertung des Begriffs der Aneignung vorweggenommen werden. Die Aneignung umfasst aber ebenso ein grundsätzliches Anknüpfen an Traditionen und die Bezugnahme auf kulturelle Werke innerhalb eines künstlerischen oder gesellschaftlichen Diskurses. Diese Aspekte wiederum sind positiv besetzt. Damit wird deutlich, dass sich der Begriff der Aneignung in einem Spannungsfeld vielfältiger wertender und nichtwertender kultureller Praktiken bewegt. Damit sind die negativen Verknüpfungen dem Begriff der Aneignung nicht wesensnotwendig. Er eignet sich daher für die urheberrechtliche Diskussion um das Spannungsfeld dieser vielfältigen Praktiken.

\section{Begriffliche Einordnung der Aneignung als Sammelbegriff}

Da die Aneignung jeden Akt der Übernahme fremden Materials meint, kann sie durch unterschiedliche Techniken vorgenommen werden. Die Aneignung ist in ihrer Arbeitsweise nicht beschränkt: Sie bildet einen Sammelbegriff für sämtliche Formen des Nachahmens. So entfaltet Michalis Pichler das Begriffsfeld zur Appropriation, einem Synonym der Aneignung ${ }^{43}$ : „Bestimmte Bilder, Objekte, Töne, Texte oder Gedanken würden im Bereich dessen liegen, was Appropriation ist, wenn sie irgendwie ausdrücklicher wären, manchmal strategisch, manchmal schwelgend im Ausleihen, Klauen, Aneignen, Erben, Assimilieren... Beeinflusst-, Inspiriert-,

42 Es muss nicht zwangsläufig etwas Neues oder Künstlerisches geschaffen werden durch die Übernahme; a.A.: Jones, Appropriation and Derogation: When is it wrong to appropriate?, in: Hicks/Schmücker (Hrsg.), The Aesthetics and Ethics of Copying, 2016, S. 187, 187.

43 Vgl. S. 28. 
Abhängig-, Gejagt-, Besessen-Sein, Zitieren, Umschreiben, Überarbeiten, Umgestalten... Revision, Reevaluation, Variation, Version, Interpretation, Imitation, Annäherung, Improvisation, Supplement, Zuwachs, Prequel... Pastiche, Paraphrase, Parodie, Piraterie, Fälschung, Hommage, Mimikry, Travestie, Shan-Zhai, Echo, Allusion, Intertextualität und Karaoke.“44

Diese schier endlose Auflistung von Techniken von Aneignungen machen deutlich, dass diese kulturellen Phänomene schon seit Jahrtausenden intensiv diskutiert wurden. Das erzeugt ein Bedürfnis nach Klarheit und Verständlichkeit. Es soll daher im Folgenden ein Überblick darüber gegeben werden, was alles unter den Sammelbegriff der Aneignung fällt, und diese Untergruppen sollen jeweils erläutert werden. Dabei sind nicht alle der vorgestellten Begrifflichkeiten immer Aneignungen, sie können es aber sein unter gewissen Umständen. Sie beschreiben sowohl Techniken der Aneignung, so wie die Reproduktion, die Collage oder der Remix, als auch Ergebnisse der Aneignung, also das Produkt der Aneignung, so wie User Generated Content oder Fan Art. Da alle Begriffe immer wieder im Zusammenhang mit der Aneignung genannt werden, soll hiermit der Facettenreichtum des Sammelbegriffs der Aneignung illustriert werden. AuBerdem soll die Komplexität der untergeordneten Begriffe aufgezeigt werden. Da die Begriffe der kulturellen Techniken unterschiedlich gehandhabt werden, sich überschneiden oder gar synonym verwendet werden, und sich also insgesamt als vielschichtig und uneinheitlich darstellen, kann die Schwierigkeit ihrer Definition und die Abgrenzung untereinander in dieser Arbeit nur angeschnitten werden.

Der Begriff der Aneignung wird genutzt, um sich bewusst mit den Kategorien der Kopie und des Originals auseinander zu setzen. ${ }^{45}$ Es soll nun ge-

44 Pichler, Statements zur Appropriation, in: Gilbert (Hrsg.), Wiederaufgelegt. Zur Appropriation von Texten und Büchern in Büchern, 2012, S. 27, 28. Hier wird zwar das Aneignen als Mittel der Appropriation aufgelistet. Da diese Begriffe aber bedeutungsgleich sind, vgl. S. 29, ist hier von einem Widerspruch in der Auflistung Pichlers auszugehen. Das Zitat wurde dennoch verwendet, um aufzuzeigen, welch große Anzahl unterschiedlicher Techniken Mittel der Aneignung sein können. Vgl. auch Sollfrank, die Aneignen als Teil eines künstlerischen Statements sieht und Collage, Verfremdung, Readymade, Reprise, Remix, Sampling, Bootleg oder Coverversionen als Methoden der Aneignung versteht, s. Sollfrank, Originale...und andere unethische AutorInnenschaften in der Kunst, in: Djordjevic/ Dobusch (Hrsg.), Generation Remix. Zwischen Popkultur und Kunst, 2014, S. 107, 113.

45 Die bewusste Auseinandersetzung ist zumindest in der Appropriation Art vorhanden und stellt gerade das künstlerische Konzept dieser Kunstrichtung dar, vgl. S. $47 \mathrm{ff}$. 
zeigt werden, dass Aneignungen und Kopien gewisse Überschneidungen haben, wenn auch nicht jede Kopie eine Aneignung ist und gleichfalls nicht jede Aneignung eine Kopie ist. Ebenfalls soll gezeigt werden, dass der Begriff des Originals hoch problematisch ist. Es kann bei der Aneignung nur in einem subjektiven Sinne von einem Original gesprochen werden, also bei kollektiver Anerkennung der Originalität der Aneignung.

Die Kopie (von lat. copia; dt.: Menge, Vorrat) ist eine möglichst genaue Nachbildung oder Wiederholung einer Vorlage. ${ }^{46}$ Die Kopie ist also immer die Positivform einer Negativvorlage. Nach dem Wortsinn ist auch eine Selbstkopie möglich, also die originalgetreue Wiedergabe einer Vorlage, die man selbst erstellt hat. In der Bildenden Kunst dient die Selbstkopie zum Teil dazu, Auftraggeber zu befriedigen oder das eigene Werk bekannter zu machen. Zum Teil ist sie aber auch ein künstlerisches Prinzip. ${ }^{47}$ Giorgio de Chirico beispielsweise kopierte viele seiner eigenen Werke - sein Schaffen entstand also nicht linear, sondern in Schleifen durch Wiederholungen. ${ }^{48}$ Eine Aneignung kann sich der Kopie bedienen, sie muss aber keine Kopie sein. Zwar braucht die Aneignung ebenso wie die Kopie immer eine Vorlage. Die Kopie bildet die Vorlage jedoch möglichst genau ab. Die Aneignung hingegen ist freier; sie kann auch dann vorliegen, wenn die Vorlage kaum noch erkennbar ist. Die subjektive Zielsetzung in der Nutzung von Kopie und Aneignung kann damit eine andere sein, muss es aber nicht, je nach Zweck der Aneignung. Ein weiterer Unterschied besteht darin, dass die Selbstkopie möglich ist, die Selbstaneignung jedoch nicht. ${ }^{49}$

46 Brinkmann, Formen der Kopie. Von der Fälschung bis zur Hommage, in: Dreier/ Jehle (Hrsg.), Original - Kopie - Fälschung, 2020, S. 54, 88; Rebbelmund, Appropriation Art, 1999, S. 22; Almeroth, Kunst- und Antiquitätenfälschungen, 1987, S. 63.

47 Mensger, Kontexte, Motive und Funktionen des Kopierens in Stichworten, in: Mensger (Hrsg.), Déjà-vu? Die Kunst der Wiederholung von Dürer bis Youtube, Ausstellungskatalog der Staatlichen Kunsthalle Karlsruhe, 2012, S. 159, 161.

48 Roos/Mensger, Giorgio de Chirico, in: Mensger (Hrsg.), Déjà-vu? Die Kunst der Wiederholung von Dürer bis Youtube, Ausstellungskatalog der Staatlichen Kunsthalle Karlsruhe, 2012, S. 254. De Chirico datierte seine eigenen Werke zurück, kopierte sich selbst, bezeichnete Reproduktionen als Originale und Originale als Reproduktionen und entzieht sich damit jeglichen Versuchs einer einheitlichen begrifflichen Einordnung, s. Brinkmann, Formen der Kopie. Von der Fälschung bis zur Hommage, in: Dreier/Jehle (Hrsg.), Original - Kopie - Fälschung, 2020, S. 54, 59.

49 Dazu auch bereits S. 28. 
Die Kopie wird begrifflich als Gegensatz zum Original genutzt (von lat. origo; dt.: Urbild, Urtext, Vorlage). Zum Teil werden der Kopie eine andere Qualität und Ästhetik als dem Original zugesprochen. ${ }^{50}$ Häufig wird der Unterschied zwischen beiden Begriffen aber allein im Bearbeitungszeitpunkt gesehen: Die Kopie muss zeitlich nach dem Original hergestellt werden. Doch dies macht die Abgrenzung von Kopie und Original insbesondere beim Druck schwierig. Beim Druckverfahren scheint es mehr um den Unterschied der Bewilligung zu gehen als den unterschiedlichen Bearbeitungszeitpunkt: Der Druck kann gerade ohne Qualitätsunterschied wiederholt werden - der erste Druck und der zweite unterscheiden sich also nicht. Wieso aber sollte man den zweiten Druck als eine Kopie des ersten ansehen? Er ist vielmehr ein wiederholter Druck nach der Druckvorlage. Der Begriff des Originals soll beim Druck also solche betreffen, die mit Zustimmung des Künstlers hergestellt werden können und betrifft damit die Bewilligung des Kunstwerks. Die Kopie ist hier also nicht eine zeitliche Nachbildung des Originals, denn der nicht authentifizierte Druck wird nach Vorlage der Druckform hergestellt und nicht nach Vorlage des Originals, das heißt des bewilligten Drucks. Danach ist also eine Kopie möglich, die kein Original kennt: Wenn nämlich bereits der erste Druck ohne Einwilligung des Künstlers stattfindet. Dieses Beispiel zeigt, dass der zeitlich unterschiedliche Bearbeitungszeitpunkt von Kopie und Original keine notwendige Bedingung der Abgrenzung der Begriffe ist.

Eine Aneignung kann wiederum ein Original werden, wenn es als eigenständig gegenüber der Vorlage wahrgenommen wird, dies hängt aber maßgeblich vom beurteilenden Kunst- oder Gesellschaftskreis ab. Ganz im Sinne Sturtevants („Die Kopie ist das Original.“) ${ }^{51}$ kann auch das Aneignungswerk ein Original sein.

50 So Benjamin, Das Kunstwerk im Zeitalter seiner technischen Reproduzierbarkeit [1936], 4. Aufl. 2015, S. 16 f.; Goodman, Sprachen der Kunst [1973], 8. Aufl. 2015, S. 109, der zwar auch einen ästhetischen Unterschied zwischen Kopie und Original festmacht, dies seiner Ansicht nach aber nicht dazu führe, dass das Original als besser anzusehen sei als die Fälschung; Römer, Künstlerische Strategien des Fake. Kritik von Original und Fälschung, 2001, S. 55; Kulenkampff, Die ästhetische Bedeutung der Unterscheidung von Original und Fälschung, in: Nida-Rümelin/Steinbrenner (Hrsg.), Kunst und Philosophie. Original und Fälschung, 2011, S. 31-50. Weitere Ausführungen dazu, wie diese Begriffe kulturhistorisch zu einander stehen, sind im Kapitel zur Historie der Aneignung zu finden ab S. 83.

51 Sturtevant, Fälschung/Original, in: Deecke (Hrsg.), Originale echt/falsch. Nachahmung, Kopie, Zitat, Aneignung, Fälschung in der Gegenwartskunst, Ausstellungskatalog des Neuen Museum Weserburg, 1999, S. 149, 155. 
Eine Replik oder Reprise meint die meist gleichzeitige Zweitauflage durch den Künstler selbst oder durch Mitglieder seiner Werkstatt. ${ }^{52}$ Eine Reproduktion hingegen bezeichnet die technisch hergestellte Kopie oder entweder die originale (bzgl. Holzschnitt und Lithographie) oder übertragene (z.B. beim Offsetdruck) grafische Technik..$^{53}$ Die Reproduktion kann also das Original oder die Kopie betreffen - sie ist lediglich ein Mittel zur Herstellung eines der beiden. Hier gibt es also gewisse Überschneidungen der Begrifflichkeiten.

Eine Fälschung liegt vor, wenn das Werk eines anderen als eigenes präsentiert wird ${ }^{54}$ Eine Fälschung ist also die Täuschung über die Zuordnung des Werkes, beispielsweise über Urheberschaft, Herkunft oder Alter. ${ }^{55}$ In der Regel wird ein bestehendes Werk eines Künstlers möglichst genau kopiert. Es muss hierfür aber nicht zwangsläufig eine Vorlage nachgeahmt werden, sondern es kann auch eine Fälschung vorgenommen werden, indem im Stil des zu kopierenden Künstlers gemalt wird. ${ }^{56}$ Bei einer klassischen Kunstfälschung wird allerdings nicht nur das Werk, sondern auch die Signatur des kopierten Künstlers nachgeahmt ${ }^{57}$ : Erst mit dieser wird das Werk falsch zugeordnet. Das ist zwar bei Aneignungen selten der Fall,

52 Almeroth, Kunst- und Antiquitätenfälschungen, 1987, S. 64.

53 Doehmer, Zur Soziologie der Kunstfälschung, Zeitschrift für Ästhetik und allgemeine Kunstwissenschaft 1978, S. 76, 76.

54 Juristisch machen sich Kunstfälscher wegen Urkundenfälschung nach $\$ 267$ Var. 2 StGB i.V.m. $₫ 107$ Abs. 1 Nr. 3 UrhG und nach $₫ 263$ Abs. 1 StGB wegen Betrugs strafbar, wenn die Fälschung als echt veräußert wird und es zu einem Vermögensschaden kommt, vgl. Schack, Kunst und Recht, 3. Aufl. 2017, Rn. 53 ff. Urheberrechtlich besteht gem. \$\$ 97, 98 UrhG ein Schadensersatz-, Unterlassensund Vernichtungsanspruch, falls ein Bild einer Vorlage nachgeahmt wurde. Wenn es keine Vorlage für die Fälschung gibt, aber die Signatur eines anderen Künstlers genutzt wurde, kann dieser aus dem Allgemeinen Persönlichkeitsrecht aus $\int \mathbb{S} 823$ Abs. 1, 1004 i.V.m. Art. 2 Abs. 1 GG oder aus dem Namensrecht aus $\$ 12$ BGB Entfernung der Signatur verlangen, so BGH GRUR 1995, S. 668, 671 Emil Nolde.

55 Doehmer, Zur Soziologie der Kunstfälschung, Zeitschrift für Ästhetik und allgemeine Kunstwissenschaft, 1978, S. 76, 77; Brinkmann, Formen der Kopie. Von der Fälschung bis zur Hommage, in: Dreier/Jehle (Hrsg.), Original - Kopie - Fälschung, 2020, S. 54, 59.

56 Der Kunstfälscher und wegen Betrug verurteilte Wolfgang Beltracchi hat z.B. verschollene Bilder von Künstler, von denen nicht mehr bekannt war, wie sie aussahen, gemalt, indem er den Stil der Künstler nachahmte, und schuf so eigene Originale, die allerdings mit der Signatur des nachgeahmten Künstlers versehen wurde und ihm somit untergeschoben wurden.

57 Loeffler, Künstlersignatur und Kunstfälschung - Zugleich ein Beitrag zur Funktion des $\$ 107$ UrhG, NJW 1993, S. 1421, 1422; Doehmer, Zur Soziologie der Kunst- 
da diese in der Regel nicht auf die Täuschung Dritter abzielt, aber auch denkbar. Eine Fälschung ist allerdings nicht von jedem Werk möglich - so macht Goodman darauf aufmerksam, dass es z.B. in der Musik keine Fälschung geben kann, da hier auch eine exakte Kopie nicht als echt gelten kann. ${ }^{58}$ Eine Fälschung liegt nicht vor, wenn die Zuordnung zu einem Werk abgesprochen wird, also sich ein Künstler von seinem Werk zurückzieht. ${ }^{59}$ So hat Richard Prince seinen Namen von einem Bild seiner „New Portraits" Reihe (2014) mit dem Selfie von Ivanka Trump zurückgezogen: „This is not my work. I did not make it. I deny. I denounce. This fake art [sic]."60 Das Absprechen einer Zuordnung reicht für eine Fälschung allerdings nicht aus, zumal keine Täuschung entsteht.

Ein Plagiat ${ }^{61}$ bezeichnet die Übernahme eines fremden Werkes unter Vorgabe der eigenen Urheberschaft. ${ }^{62}$ Es ist damit das Gegenstück zur Fälschung, indem gerade ein fremdes Werk als eigenes ausgegeben wird.

fälschung, Zeitschrift für Ästhetik und allgemeine Kunstwissenschaft, 1978, S. 76, 78.

58 Goodman unterscheidet zwischen allographischen und autographischen Künsten, Goodman, Sprachen der Kunst [1973], 8. Aufl. 2015, S. 113. Bei autographischen Künsten führe auch eine exakte Kopie nicht zu einem Duplikat, sondern sie bleibe ein Replika (z.B. ein Gemälde, das nachgemalt wurde). Bei diesen autographischen Künsten sei die Unterscheidung zwischen Original und Fälschung daher bedeutsam. Allographische Kunstwerke seien solche, bei denen jede exakte Kopie einfach ein neues Werkstück darstellt (z.B. ein Gedicht, das abgeschrieben wird; hier kommt, wenn überhaupt, eine Fälschung der Handschrift o.Ä. in Betracht, nicht aber des Kunstwerks selbst).

59 Seine Urheberschaft am Werk kann ein Urheber nicht aufgeben, allerdings kann er spiegelbildlich zum Recht auf Urhebernennung gem. $\$ 13$ UrhG darauf bestehen, dass er nicht genannt wird, s. Dreier/Schulze/Dreier, 6. Aufl. 2018, $\mathbb{1 3}$ UrhG Rn. 32.

60 Richard Prince, Instagram Post seines Profils @RichardPrince4 am 11.01.2017 um 22:36 Uhr.

61 Von lat. plagiarius; dt.: Menschenräuber. Marcus Valerius Martial (40-102/104 n. Chr.) bezeichnet so seinen Kollegen Fidentinus, der Martials Epigramme als eigene ausgegeben hatte. Martial verglich die Epigramme mit Sklaven, die mit der Veröffentlichung in die Freiheit entlassen wurden, Martial, Liber Epigrammatae I 52; vgl. Kastner, Das Plagiat - literarische und rechtliche Aspekte, NJW 1983, S. 1151, 1151.

62 Ein Plagiat verletzt die Rechte des Urhebers auf Anerkennung der Urheberschaft aus $₫ 13$ UrhG und die Verwertungsrechte des $\$ \$ 16,17$, und 23 UrhG, vgl. BGH GRUR 1960, S. 500, 503 - Plagiatsvorwurf I; BGH GRUR 1992, S. 527, 528 - Plagiatsvorwurf II; Schack, Kunst und Recht, 3. Aufl. 2017, Rn. 334; BeckOK UrhG/Ahlberg, 26. Ed. 2019, $\mathbb{3}$ UrhG Rn. 44. Vgl. zur Abgrenzung von Zitat und Plagiat Schack, Wissenschaftsplagiat und Urheberrecht, in: Dreier/Ohly (Hrsg.), Plagiate. Wissenschaftsethik und Recht, 2013, S. 81, 81: Bei einem Plagiat werde das frem- 
Ebenso wie bei der Fälschung bedarf es einen aus der Täuschung entstehenden Irrtum. Die Begriffe funktionieren genau entgegengesetzt. ${ }^{63}$ Ein Plagiat ist bei Aneignungen allerdings auch selten, da häufig kein Täuschungsverhalten vorliegt, sondern die Übernahme zu eigenen Zwecken erfolgt. $^{64}$

Die Imitation oder auch Nachahmung ist die Übernahme stilistischer oder motivischer Eigenarten eines Künstlers oder einer Schule. ${ }^{65}$ Ein Pastiche ist ebenfalls die Nachahmung des Stils oder konkreter Werke eines Künstlers, die als Begriff aber positiv verstanden ist. Im englischen Sprachraum wird das Pastiche als Oberbegriff unterschiedlichster Formen der Übernahme und Ähnlichkeit verwendet, der in seiner Konnotation sowohl durch den Vorwurf mangelnder Individualität negativ verstanden werden kann als auch positiv synonym mit der Hommage verwendet wird. ${ }^{66}$ Eine Hommage ist das Kopieren eines Bildes als Ausdruck einer besonderen Wertschätzung gegenüber dem Künstler des Originals ${ }^{67}$ und kann als rein

de Werk nicht als Erläuterung der eigenen Ansichten genutzt, sondern als eigenes Werk ausgegeben.

63 Kakies, Kunstzitate in Malerei und Fotografie, 2007, S. 10.

64 Bei der Appropriation Art wird darüber hinaus meist im Titel deutlich Bezug genommen auf den Künstler der Vorlage („After [...]“, „Not [...]“). Vgl. dazu auch zum Urheberpersönlichkeitsrecht S. 136.

65 Doehmer, Zur Soziologie des Kunstfälschers, Zeitschrift für Ästhetik und allgemeine Kunstwissenschaft 1978, S. 76, 76. Grundsätzlich besteht darin keine Beeinträchtigung des Urheberrechts oder des Allgemeinen Persönlichkeitsrechts entschied der Bundesgerichtshof: „[Eine Beeinträchtigung] liegt aber nicht auch darin, dass die Bilder im Stil und nach Motiven Noldes gemalt worden sind. Solche abstrakten Eigenschaften eines Werkes sind im Interesse der allgemeinen künstlerischen Entwicklung als gemeinfrei anzusehen. Sie können von einem Künstler grundsätzlich nicht für sich monopolisiert werden.“, BGH GRUR 1995, S. 668, 671 - Emil Nolde. Nur, wenn zusätzlich eine Signatur des imitierten Künstlers hinzugefügt wird, kann dieser die Beseitigung der Signatur aus seinem Persönlichkeitsrecht gem. Art. 2 Abs. 1 i.V.m. Art. 1 Abs. 1 GG durchsetzen, vgl. BGH GRUR 1995, S. 668, 671 - Emil Nolde; Schack, Kunst und Recht, 3. Aufl. 2017, Rn. 252; Pfennig, Kunstfälschung - eine besondere Art der Werkrezeption, in: FS Wandtke, 2013, S. 79, 85.

66 Brinkmann, Formen der Kopie. Von der Fälschung bis zur Hommage, in: Dreier/ Jehle (Hrsg.), Original - Kopie - Fälschung, 2020, S. 54, 69 m.w.N.

67 Dabei setzt die Hommage eine Ebenbürtigkeit zwischen dem Künstler des Vorbilds und dem der Hommage voraus, so Mensger, Kontexte, Motive und Funktionen des Kopierens in Stichworten, in: Mensger (Hrsg.), Déjà-vu? Die Kunst der Wiederholung von Dürer bis Youtube, Ausstellungskatalog der Staatlichen Kunsthalle Karlsruhe, 2012, S. 159, 159. 
wertender Ausdruck der Beziehung der beiden Werke verstanden werden. ${ }^{68}$

Ein Zitat ist ein bildlich oder wörtlich genau übernommener Ausschnitt aus einem anderen Werk, der vom Betrachter als Zitat erkannt werden soll ${ }^{69}$. In der Kunst- und Architekturgeschichte wird das Zitat auch als Oberbegriff verwendet und weit verstanden, um Übernahmen oder Ähnlichkeiten zu anderen Motiven, Strukturen und Kompositionen festzumachen. ${ }^{70}$ Dabei verwässert allerdings die Verweisfunktion des Zitats, die Erkennbarkeit des Zitats steht dann nicht mehr im Vordergrund. Zum rechtlichen Verständnis des Zitats gem. $\$ 51$ UrhG sei hier auf die unten folgenden Ausführungen verwiesen. ${ }^{71}$ Die Parodie erinnert an ein bestehendes Werk, weist ihm gegenüber aber auch wahrnehmbare Unterschiede auf und stellt einen Ausdruck von Humor oder Verspottung dar. ${ }^{72}$ Sie muss das übernommene Werk nicht antithematisch behandeln.

Die Collage (von frz. coller; dt.: kleben) bezeichnet die Technik des Aufklebens von vorgefundenem Material, häufig Bildern, Texten oder Strukturen. Es kann sich dabei auch gerade um ursprünglich nicht künstlerisches Material handeln. Der Begriff bezeichnet also den technischen Vorgang einer Aneignung. ${ }^{73}$

Auch die Montage kombiniert verschiedene vorgefundene Materialien. Das Verhältnis von Montage und Collage ist nicht geklärt. ${ }^{74}$ Es kann aber nach der Zielsetzung der beiden unterschieden werden: Bei der Montage

68 Brinkmann, Formen der Kopie. Von der Fälschung bis zur Hommage, in: Dreier/ Jehle (Hrsg.), Original - Kopie - Fälschung, 2020, S. 54, 69.

69 Daher wird beispielsweise das schriftliche Zitat mit Anführungszeichen gekennzeichnet, wobei besonders bekannte Zitate gerade nicht mehr gekennzeichnet werden, sondern gar davon ausgegangen wird, dass der Leser oder Betrachter sie vor seinem kulturellen Hintergrund selbst erkennt und versteht.

70 Brinkmann, Formen der Kopie. Von der Fälschung bis zur Hommage, in: Dreier/ Jehle (Hrsg.), Original - Kopie - Fälschung, 2020, S. 54, $71 \mathrm{f}$.

71 S. $211 \mathrm{ff}$.

72 EuGH GRUR 2014, S. 972, 973 Rn. 20 - Deckmyn und Vrijheidsfonds.

73 Vgl. Czernik, Die Collage in der urheberrechtlichen Auseinandersetzung zwischen Kunstfreiheit und Schutz des geistigen Eigentums, 2008, S. 41. Zur Entwicklung der Collage und Bedeutung innerhalb der Kunstgeschichte vgl. S. 95 f.

74 So geht Möbius davon aus, dass die Montage der Oberbegriff sei und die Collage nur das Endprodukt meine, das aus der Kombinationstechnik der Montage entstanden ist, vgl. Möbius, Montage und Collage. Literatur, bildende Künste, Film, Fotografie, Musik, Theater bis 1933, 2000, S. 196. Andere gehen davon aus, dass beide gleichwertig nebeneinanderstehen, so Czernik, Die Collage in der urheberrechtlichen Auseinandersetzung zwischen Kunstfreiheit und Schutz des geistigen Eigentums, 2008, S. 45. Wiederum andere meinen, dass die Montage eine Form 
geht es anders als bei der Collage um die Schaffung eines inhaltlich zusammengehörigen Ganzen. ${ }^{75}$ Das Vorgefundene wird also konstruktiv zusammengefügt.

Die Assemblage setzt Objekte zusammen und kann daher als dreidimensionale Collage verstanden werden.

Das Sampling ist ein „musikalisches Gestaltungsmittel der Verarbeitung von Klängen aus unterschiedlichen Tonquellen (Samples) in einem neuen Musikstück. "76 Dabei kann der Umfang der Samples unterschiedlich stark ausgestaltet sein und die Wiedererkennbarkeit des Originals durchaus beabsichtigt sein. Das Sampling als Technik liegt der Erstellung von Remixen und Mashups zugrunde.

Ein Remix ist die Neumischung einer bereits veröffentlichten Tonaufnahme. ${ }^{77}$ Er referenziert dabei in der Regel erkennbar auf das benutzte Material, erhält aber im Vergleich zu dem benutzten Originalmaterial einen eigenständigen Charakter. ${ }^{78}$ Mashups hingegen kombinieren zwei bestehende Medien, also Musikstücke, Filme oder Internetprogramme zu etwas Neuem oder zur Erzeugung von Synergieeffekten. ${ }^{79}$ Die Begriffe unterscheiden sich also in der Anzahl der angeeigneten Werke.

User Generated Content sind von Internetnutzern erzeugte Medieninhalte, die unmittelbar im Internet der Öffentlichkeit zugänglich gemacht werden, ohne dass sie professionell erstellt oder zu gewerblichen Zwecken veröffentlicht wurden. ${ }^{80}$

Fan Art kann ebenfalls User Generated Content sein. Es ist das kreative Erzeugnis eines Fans, das eine Referenz zu einer öffentlich präsenten rea-

der Collage sei, vgl. Pendzich, Von der Coverversion zum Hit-Recycling, 2008, S. 339 .

75 Vgl. Gelke, Mashups im Urheberrecht, 2013, S. 50 f.; Seibel, Die Formenwelt der Fertigteile. Künstlerische Montagetechnik und ihre Anwendung im Drama, 1988, S. $131 \mathrm{ff}$.

76 BVerfG GRUR 2016, S. 690, BeckRS 2016, 46375 Rn. 2 - Metall auf Metall. Vgl. dort auch zur Frage des Eingriffs in die Rechte von Tonträgerherstellern durch Sampling.

77 Dudenredaktion (Hrsg.), Remix, in: Duden. Deutsches Universalwörterbuch, 2015.

78 Pötzlberger, Kreatives Remixing, 2018, S. 60.

79 Gelke, Mashups im Urheberrecht, 2013, S. 14. Von Gehlen hingegen nutzt Mashup als einen Oberbegriff für gattungsübergreifende kulturelle Praktiken und versteht darunter auch das wissenschaftliche Plagiat oder die Produktion pharmazeutischer Generika, von Gehlen, Mashup. Lob der Kopie, 2011, S. 29 ff., 93 ff.

80 So Definition von C. Bauer, User-generated Content, 2011, S. 26. 
len oder fiktiven Person oder Sache, dem Fanobjekt, aufbaut. ${ }^{81}$ Beide Arten der Aneignung werden regelmäßig von Internetnutzern vorgenommen.

\section{Begriff des Bildlichen}

Wie gesehen kann der Begriff der Aneignung vielfältige Praktiken umfassen. Der Untersuchungsgegenstand dieser Arbeit soll aufgrund der Untersuchung der Aneignung zu kommunikativen und künstlerischen Zwecken auf bildliche Aneignungen beschränkt werden, also solche Aneignungen, die Bilder betreffen und durch Bilder vorgenommen werden. ${ }^{82}$

Der Begriff des Bildes taucht im Urheberrecht im Rahmen der „Werke der bildenden Künste“ gem. $\$ 2$ Abs. 1 Nr. 4 UrhG, in „Lichtbildwerke, einschließlich der Werke, die ähnlich wie Lichtbildwerke geschaffen werden“ des $₫ 2$ Abs. 1 Nr. 5 UrhG und in den „einfachen Lichtbildern“ des $\$ 72$ UrhG auf. Eine nähere Definition des Bildbegriffes ist aber dem Urheberrecht unüblich. ${ }^{83}$ Laut Duden ist ein Bild ein mit künstlerischen Mitteln auf einer Fläche Dargestelltes, Wiedergegebenes. ${ }^{84}$ Zum besseren Verständnis dieser Definition und der daraus erfolgenden Auswahl der zu untersuchenden Phänomene sollen die Aspekte der Darstellung und der Dimensionalität eines Bildes genauer erläutert werden.

\section{Bild als Darstellung}

Ein Bild stellt etwas dar, veranschaulicht also etwas. Scholz definiert ein Bild wie folgt: „Der Terminus ,Bild“ und seine Äquivalente in anderen Sprachen bezeichnen heutzutage primär Dinge wie Gemälde, Zeichnungen und Verwandtes (Kupferstiche, Holzschnitte etc.) nebst ihren vielfältigen technischen und elektronischen Weiterentwicklungen. Bilder in die-

81 Vgl. Summerer, „Illegale Fans“, 2015, S. 26.

82 S. zu dieser Einschränkung des Untersuchungsgegenstands dieser Arbeit S. 24.

83 Vgl. zur Kritik an der fehlenden sauberen Unterscheidung von abgebildetem Objekt, Abbildung und Abbild: Dreier, Bilder im Zeitalter ihrer vernetzten Kommunizierbarkeit, ZGE 2017, S. 135, 138 und Dreier, Bilder und die Werkzeuge des Rechts. Normative Bilderregeln und Visual Images, in: Weller/Kemle (Hrsg.) Kultur im Recht - Recht als Kultur, 2016, S. 113, 118 ff.: Es mache gerade das Wesen der Fotografie aus, dass es gleichzeitig Abbildung und Abbild sei.

84 Dudenredaktion (Hrsg.), Bild, in: Duden. Deutsches Universalwörterbuch, 2015. 
sem Sinne sind Artefakte, künstliche Gegenstände, die in bestimmter [...] Weise etwas darstellen oder zumindest etwas sehen lassen. "85 Das Bild ist in Zeiten, in denen Bilder auch digital hergestellt werden, nicht mehr rein als materielles Objekt (Dia, Abzug der Fotografie, Gemälde) zu verstehen. Ein Bild kann damit materiell vorliegen, aber ebenso sind analoge oder virtuelle Darstellungen möglich, und damit auch analoge oder virtuelle Bilder.

Es ist zu unterscheiden zwischen abgebildetem Objekt, dessen immateriellen Abbild und der dieses Abbild verkörpernden materiellen Abbildung. ${ }^{86}$ Der Begriff Abbildung bezeichnet ein getreues Bild ${ }^{87}$ und umfasst damit auch die Beziehung des Bildes zum abgebildeten Gegenstand. Nach traditionellen Bildtheorien ist zwischen Abbildung und abgebildetem Gegenstand grundsätzlich eine Ähnlichkeitsbeziehung notwendig, damit das Bild den abgebildeten Gegenstand darstellen kann. ${ }^{88}$ Dem liegt zugrunde, dass Bilder als ikonische Zeichen im Sinne von Charles Sanders Peirce ${ }^{89}$ verstanden wurden. Ikonische Zeichen sind gerade solche, die durch eine

85 Scholz, Bild, Darstellung, Zeichen, 2004, S. 5.

86 S. zu dieser Abgrenzung Dreier, Bild und Recht, 2019, S. 30 f.; Dreier, Bilder im Zeitalter ihrer vernetzten Kommunizierbarkeit, ZGE 2017, S. 135, 138; Dreier, Bilder und die Werkzeuge des Rechts: Normative Bildregeln und Visual Images, in: Weller/Kemle (Hrsg.), Kultur im Recht - Recht als Kultur, 2016, S. 113, 118. Zum mentalen Charakter des Bildes, das vom Medium des menschlichen Sehapparates als äußeres Bild empfangen und als inneres Bild erzeugt wird: Belting, Bild-Anthropologie, 4. Aufl. 2011, S. 57 ff.

87 Dudenredaktion (Hrsg.), Abbild, in: Duden. Deutsches Universalwörterbuch, 2015.

88 Grundlegend ist Platons Bildtheorie, deren Vorstellung der Vorbild-Abbild-Relation in Bezug auf die sinnliche Wahrnehmung von Gegenständen zu einem Verständnis des Bildes als Abbild führte, Platon, Der Staat, Zehntes Buch, 2012, Rn. 597a ff. Wittgenstein stellte fest, dass Bild und Abbild sich in ihrer logischen Struktur ähneln und damit eine Isomorphiebeziehung vorliegt, Wittgenstein, Tractatus logico-philosophicus, 2003, $\mathbb{2} .14$ und $\$ 2.151$ ), vgl. zuletzt Rehkämper, Bilder, Ähnlichkeit und Perspektive, 2002; Jonas, Homo pictor. Von der Freiheit des Bildens, in: Boehm (Hrsg.), Was ist ein Bild?, 1994, S. 105-124. Vgl. ansonsten Moser, Sinnbild und Abbild. Zur Funktion des Bildes, in: Naredi-Rainer (Hrsg.), Sinnbild und Abbild. Zur Funktion des Bildes, 1994, S. 3, 3; Hochberg/ Peterson, Bildanalyse in der menschlichen Informationsverarbeitung, in: Schuster/ Woschek (Hrsg.), Nonverbale Kommunikation durch Bilder, 1989, S. 33 ff.; Black, Wie stellen Bilder dar?, in: Gombrich/Hochberg/Black (Hrsg.), Kunst, Wahrnehmung, Wirklichkeit, 1977, S. 115, 146.

89 Vgl. Peirce, Phänomen und Logik der Zeichen, 1983, S. 64 ff. Charles Sanders Peirce ist neben Ferdinand de Saussure der Begründer der modernen Semiotik, der Zeichentheorie. 
Ähnlichkeitsbeziehung zwischen Zeichen und bezeichnetem Objekt geprägt sind.${ }^{90}$ Der Philosoph Nelson Goodman stellt diese Ähnlichkeitsrelation in Frage: „Tatsache ist, daß ein Bild, um einen Gegenstand repräsentieren zu können, ein Symbol für ihn sein, für ihn stehen, auf ihn Bezug nehmen muss; und daß kein Grad von Ähnlichkeit hinreicht, um die erforderliche Beziehung der Bezugnahme herzustellen. Ähnlichkeit ist für Bezugnahme auch nicht notwendig, beinahe alles kann für fast alles andere stehen. "91 Vor allem in der modernen Malerei gibt es viele Bilder, die nicht mit dem Begriff Ähnlichkeit zu fassen sind, da sie nichts nachahmen. Gegen die Ähnlichkeitstheorie spricht auch, dass sich zwei Gegenstände einander ähnlich sein können, ohne dass das eine ein Bild des anderen ist so ein Beispiel von Augustinus, dass zwei Eier sich ähneln, das zweite Ei aber kein Bild des ersten sei, sondern einfach ein zweites Ei. ${ }^{92}$ Ähnlichkeit ist daher nicht als notwendige Voraussetzung einer Abbildung anzusehen. Einig ist man sich jedoch, dass ein Bezug von Abbildung und Abgebildetem vorliegen muss ${ }^{93}$, das Bild muss also für etwas stehen. Ein Bild kann also, muss aber keine Abbildung eines Gegenstandes sein. Es kann einen Gegenstand darstellen, oder für den Gegenstand stehen und ihn repräsentieren, ohne ihn abzubilden.

Filme stellen eine Zusammensetzung von Einzelbildern dar, die eine Filmsequenz erzeugen. Das menschliche Auge erzeugt die Illusion fließender Bewegung ab 18 Bildern pro Sekunde. Deshalb spricht man auch vom Film auch als „bewegte Bilder“. In diesem Sinne werden vom Lichtbildwerkschutz des $₫ 2$ Abs. 1 Nr. 5 UrhG auch Einzelbilder aus Filmen umfasst. ${ }^{94}$ Filmische Bilder können daher auch unter den Untersuchungsge-

90 Im Unterschied zu Bildern besteht Sprache aus symbolischen Zeichen, da die Zuordnung von Zeichen und bezeichnetem Gegenstand arbiträr ist und allein auf Konvention beruht, vgl. Peirce, Phänomen und Logik der Zeichen, 1983, S. 65.

91 Goodman, Sprachen der Kunst [1973], 8. Aufl. 2015, S. 17. Denotation ist für ihn eine Weise der Bezugnahme auf ein Prädikat und damit „Kern der Repräsentation“, a.a.O., S. 17. Goodman selbst liefert keine klare Definition des Begriffes. Sie wird in der Literatur als „Beziehung zwischen einem Prädikat und etwas, worauf es zutrifft [...]“" verstanden, vgl. Betzler/Cojocaru/Nida-Rümelin, Ästhetik und Kunstphilosophie in Einzeldarstellungen. Von der Antike bis zur Gegenwart, 2002, S. 316.

92 Vgl. für das Beispiel Aurelius Augustinus: Dreiundachtzig verschiedene Fragen. De diversis quaestionibus octoginta tribus, 1972, Frage 74, S. $226 \mathrm{f}$.

93 Vgl. zu neueren Forschungen der Abbildtheorie bzw. Ähnlichkeitstheorie: Asmuth, Bilder über Bilder, 2011; Scholz, Bild, Darstellung, Zeichen, 2004; Rehkämper, Bilder, Ähnlichkeiten und Perspektive, 2002.

94 Dreier/Schulze/Schulze, 6. Aufl. 2018, \$2 UrhG Rn. 197. 
genstand dieser Arbeit gefasst werden, sollen aber nicht deren Schwerpunkt darstellen.

\section{Zwei- oder Dreidimensionalität}

Es stellt sich die Frage, welche Dimensionalität ein Bild besitzen kann. Ursprünglich umfasste der Begriff des Bildes auch dreidimensionale Gebilde - das griechische Wort für Bild, eikon, schloss Statuen mit ein, woran noch deutsche Wörter wie Standbild und Bildhauer erinnern. ${ }^{95}$ Ist nun ein 3D-Druck ebenfalls ein Bild des repräsentierten Gegenstandes? Ein Bild zeichnet sich jedoch nach heutigem Verständnis gerade durch seine Flächigkeit aus. ${ }^{96}$ Räumliche Strukturen werden von diesem Bildbegriff nicht mehr umfasst. Daher sei das Bild im Folgenden als zweidimensional verstanden. ${ }^{97}$

\section{Fazit: Aneignung als umfassender Sammelbegriff}

Der Begriff der Aneignung eignet sich als urheberrechtlicher Begriff für zahlreichen verschiedene kulturelle Praktiken. Er soll definiert werden als die direkte physische oder indirekte unkörperliche Übernahme fremden Materials zu eigenen Zwecken. Diese verschiedenen Praktiken der Aneignung wurden bisher häufig ohne Zusammenhang zueinander urheberrechtlich diskutiert und bewertet, so z.B. im Rahmen der Debatten über eigenschöpferisches Schaffen von Fan Art, Musik, Remixes, Mashups, Collagen, gewisse nutzergenerierte Inhalte und Appropriation Art. Der Begriff der Aneignung wirkt dieser Vereinzelung der Debatte entgegen und stellt die verschiedenen kulturellen Praktiken unter einen Sammelbegriff, um bestimmtes, häufiges oder gar allgegenwärtiges Nutzerverhalten mit vorgefundenem Material zu zeigen. Die Gemeinsamkeiten der untersuchenden

95 Scholz, Bild, Darstellung, Zeichen, 2004, S. 6.

96 Vgl. Dudenredaktion (Hrsg.), Abbild, in: Duden. Deutsches Universalwörterbuch, 2015.

97 Dem steht nicht entgegen, dass im Folgenden auch das Verfahren Rogers $v$. Koons diskutiert wird, bei dem das angeeignete Bild in eine dreidimensionale Skulptur umgewandelt wurde. Da es nur wenige Rechtsfälle der Appropriation Art gibt, sollen diese vollständig dargestellt werden, auch wenn eines dieser Rechtsverfahren kein Bild betrifft, vgl. S. $58 \mathrm{f}$. 
Phänomene sollen daher mit dem umfassenden Begriff der Aneignung verdeutlicht werden.

\section{B. Untersuchungsgegenstände}

Untersuchungsgegenstand dieser Arbeit sind allein bildliche Aneignungen. ${ }^{98}$ Im Folgenden sollen beispielhaft bildliche Aneignungen vorgestellt werden, die im Rahmen dieser Arbeit rechtlich eingeordnet werden. Dabei lassen sich zwei Gruppen von bildlichen Aneignungen unterscheiden: die Aneignung in der Kunst und die Aneignung durch digitale Technologien. Auf beide soll nun ausführlicher eingegangen werden.

Diese Unterteilung der Untersuchungsgegenstände ergibt sich aus einer veränderten Nutzung der Aneignung, die im Zweiten Kapitel ausführlicher dargelegt wird. ${ }^{99}$ Die Aneignung war lange Zeit lediglich ein künstlerisches Mittel. Mit der Appropriation Art wurde sie selbst zur Kunstform. Damit war sie jedoch bloß in einer kleinen Sparte der modernen Kunst von Bedeutung. Mit der technologischen Entwicklung wurde die Aneignung demokratisiert - nun konnte jedermann ohne viel Aufwand perfekt ausgeführte Aneignungen vornehmen, indem er scannte, kopierte, einfügte, druckte etc. Die Aneignung war nun nicht mehr bloß in der Kunst relevant, sondern entwickelte sich zu einem Mittel unserer Kommunikation und veränderte unsere Kommunikation grundlegend. ${ }^{100}$ Diese veränderte Nutzung der Aneignung soll durch die Auswahl der Untersuchungsgegenstände im Folgenden abgebildet werden und die ausgewählte Phänomene sollen dazu dienen, diese Nutzungsänderung aufzuzeigen und greifbar zu machen.

\section{Aneignung in der Kunst: Appropriation Art}

Den einen Schwerpunkt sollen bildliche Aneignung als künstlerisches Mittel bilden - ausgehend von der Appropriation Art als der Kunstform, die

98 Fragen des Samplings und Mashups, die zwar ebenfalls Arten der Aneignung darstellen, sollen hier daher nicht genauer thematisiert werden, auch wenn vieles aus der folgenden rechtlichen Einordnung auf sie übertragen werden kann.

99 Vgl. S. $83 \mathrm{ff}$.

100 Ausführlich zur Digitalen Kommunikation durch Bilder S. $107 \mathrm{ff}$. 
bildliche Aneignungen überhaupt erst zur Kunst erklärt hat. ${ }^{101}$ Dazu soll zunächst das künstlerische Konzept der Appropriation Art dargestellt werden (1.) und dann bekannte Künstler der Appropriation Art exemplarisch vorgestellt werden, damit ihr Schaffen besser einzuordnen ist (2.). Mit den hier ausgewählten Künstlern und ihren hier beschriebenen Werken wird die Appropriation Art üblicherweise charakterisiert und sie stehen prototypisch für Künstler der Appropriation Art. Zuletzt sollen die Rechtsfälle dargestellt werden, die sich mit den urheberrechtlichen Fragen der Appropriation Art befassen (3.).

\section{Aneignung als künstlerisches Konzept}

Appropriation Art galt zunächst als Bezeichnung für eine Künstlergruppe in New York in den 1980er Jahren. ${ }^{102}$ Die Gruppe entstand mit der Ausstellung „Pictures“ im New Yorker „Artists Space“ 1977, bei welcher die

101 Angelehnt an die Appropriation Art wurde die Appropriation Literature benannt, die strategisch literarische Werke kopiert. Der Begriff stammt von Annette Gilbert, vgl. dies. (Hrsg.) in: Wiederaufgelegt. Zur Appropriation von Texten und Büchern in Büchern, 2012. Die Kurzgeschichte „Pierre Menard, Autor des Quijote" von Jorge Louis Borges ist der Ursprung dieser Literaturrichtung. Ein in der Öffentlichkeit bekannterer Fall der Appropriation Literatur löste einen Rechtsstreit aus: Der argentinische Autor Pablo Katchadjian hat 2009 die Kurzgeschichte „Das Aleph“von Jorge Louis Borges appropriiert und wurde deshalb verklagt.

Auch der Begriff des Appropriation Cinema hat sich etabliert, häufiger wird es aber Found Footage Film genannt. Dabei wird bereits vorhandenes Filmmaterial übernommen oder nachgestellt. So appropriierte der U.S.-amerikanische Regisseur Gus Van Sant in seinem Werk „Psycho“ den Film „Psycho“ von Alfred Hitchcock und stellte die Szenen 1:1 nach. Da Drehbuch, Ausstattung, Musik und Inszenierung übernommen wurden, handelt es sich nicht um eine Neuverfilmung.

102 Committee for the Visual Arts Inc, Pictures Ausstellungskatalog, 1977. Die Bezeichnung meint hauptsächlich die drei Künstler Sherrie Levine, Mike Bidlo und Philipp Taaffee. Für sie wurden auch der Begriffe „pictures generation“, „pictures generation of appopriation“ oder „iterativism" genutzt, letztlich hat sich aber der Begriff der Appropriation Art durchgesetzt. Der Begriff „pictures generation" geht zurück auf die Retrospektive im Jahr 2009 im Metropolitan Museum of Art, New York, bei der u.a. Cindy Sherman, Sherrie Levine und Richard Prince ausgestellt wurden. „Iterativism“ hieß 1985 eine Ausstellung in der Galerie Rudolf Zwirner, die von Daniel Buchholz kuratiert wurde, und wurde darauffolgend als Stilbegriff genutzt. „The Art of Appropriation“ war der Titel einer Ausstellung im Alternative Museum, New York, Jahr 1985. 
Werke von Sherrie Levine, Robert Longo, Jack Goldstein, Troy Brauntuch und Philip Smith gezeigt wurden. Mittlerweile wird der Begriff der Appropriation Art nicht mehr nur für die ursprüngliche Ausstellungsgruppe von 1977 verwendet, sondern darüber hinaus umfassend für postmoderne Kunst, die sich mit dem Kopieren und Zitieren in der Kunst beschäftigt ${ }^{103}$, sodass auch weitere Künstler unter den Begriff zu fassen sind. ${ }^{104}$ Zwar wird der Begriff der Appropriation Art immer noch mit der Zeit der 1970er und 1980er Jahren, der Stadt New York und bestimmten gesellschaftlichen Debatten um Originalität in Verbindung gebracht. ${ }^{105}$ Mit dieser Arbeit soll die Appropriation Art allerdings im größeren Kontext eines veränderten Verhaltens bei der Nutzung von Kopien gestellt werden, weshalb eine zeitliche Begrenzung des Begriffs dem Zwecke dieser Arbeit nicht dienlich ist. Deshalb wird hier Appropriation Art verstanden als Kunstform des bewussten Einsetzens von Aneignungen zu einem künstlerischen Zweck.

Die Appropriation Art ist eine Kunstform der Aneignung. Sie arbeitet mit sämtlichen Mitteln, die zur Aneignung genutzt werden können, wie der Kopie, Imitation, Collage und anderen. ${ }^{106}$ Appropriation kommt vom lateinischen appropriare, was „zu eigen machen“ bedeutet. Appropriation beschreibt damit den Vorgang, existierende Kunstwerke oder deren Teile in das eigene Kunstwerk zu übernehmen. Dabei kann es entweder direkt physisch integriert oder indirekt durch eigene Herstellung abgebildet werden. Bei letzterem kann die fremde Bildlichkeit derart angeeignet werden, dass Format, Technik, Motiv und Stil möglichst exakt wiederholt werden ${ }^{107}$ - allerdings nicht um zu plagiieren, sondern um eigenständige Kunstwerke zu schaffen. „Die Kopie ist das Original“, proklamierte Elaine Sturtevant. ${ }^{108}$ Mit der Aneignung wird also ein künstlerisches Konzept ver-

103 Rebbelmund, Appropriation Art, 1999, S. 11.

104 Dazu mehr unter S. 50 ff. zu den Künstlern der Appropriation Art.

105 Vgl. Evans, Seven Types of Appropriation, in: ders. (Hrsg.), Appropriation. Documents of Contemporary Art, 2009, S. 15; Rebbelmund, Appropriation Art, 1999, S. 12, 13 f., die den Begriff der Appropriation Art zeitlich definiert, begrenzt auf die Kunstentwicklung der 1980er Jahre.

106 Vgl. zu den unterschiedlichen Bedeutungen dieser Begriffe S. 33 ff.

107 Zuschlag, Die Kopie ist das Original - über Appropriation Art, in: Mensger (Hrsg.), Déjà-vu? Die Kunst der Wiederholung von Dürer bis Youtube, Ausstellungskatalog der Staatlichen Kunsthalle Karlsruhe, 2012, S. 126, 127.

108 Sturtevant, Fälschung/Original, in: Deecke (Hrsg.), Originale echt/falsch. Nachahmung, Kopie, Zitat, Aneignung, Fälschung in der Gegenwartskunst, Ausstellungskatalog des Neuen Museum Weserburg, 1999, S. 149, 155. 
folgt. Die möglichst exakte Wiederholung eines Werkes muss programmatisch praktiziert werden. ${ }^{109}$

Um Plagiate oder Fälschungen handelt es sich auch deshalb nicht, weil der Bezug zu dem kopierten Werk deutlich gemacht und nicht geleugnet wird - so z.B. in den Werken „After Walker Evans“ (1981) von Sherrie Levine oder „Not Pollock“ (1983) von Mike Bidlo, die im Titel klarstellen, auf wen sie sich beziehen. Dadurch entfällt der Täuschungsvorwurf. ${ }^{110}$ Andy Warhol lieh Elaine Sturtevant sogar seine Original-Siebdrucke für ihre Serie "Warhol Flowers“ (1964/65), damit sie mit den Originalmaterialen arbeiten konnte. ${ }^{111}$ Als er einmal gefragt wurde, wie er seine Werke herstelle und was sie bedeuteten, antwortete er: „Ask Elaine“. ${ }^{112}$

Die Appropriation Art leugnet nicht zwangsläufig die Existenz von Originalität - sie setzt sich kritisch mit den Kategorien Original und Originalität, Autorschaft und Authentizität, mit dem Werkbegriff und Wahrnehmungskonventionen der medial geprägten Gesellschaft auseinander. ${ }^{113}$ Die Appropriation Art greift damit eine der letzten Mythen der Kunst an: das Original. Durch die eigenhändige Nachschaffung ist die Kopie auch ein Original. Dieses Paradoxon soll den Betrachter anregen, sich mit den genannten Kategorien kritisch zu befassen. Die Demontage des Originals steht in der Tradition von Marcel Duchamp, Andy Warhol und Sol LeWitt. ${ }^{114}$ Doch auch die Appropriation Art bewegt sich noch innerhalb des bestehenden Originalitätsbegriffs: „Hier besteht die Regelverletzung gerade darin, Originalität zu verweigern, doch indem der Gestus des Traditionsbruchs vehement vorgetragen wird, wird dem Prinzip des Anders-Seins und daher dem Originalitäts-Imperativ nur einmal mehr gehorcht. ${ }^{\text {115 }}$

109 Zuschlag, Die Kopie ist das Original - über Appropriation Art, in: Mensger (Hrsg.), Déjà-vu? Die Kunst der Wiederholung von Dürer bis Youtube, Ausstellungskatalog der Staatlichen Kunsthalle Karlsruhe, 2012, S. 126, 133.

110 S. dazu bereits S. $37 \mathrm{f}$.

111 Kakies, Kunstzitate in Malerei und Fotografie, 2007, S. 16.

112 A. Searle, Elaine Sturtevant: queen of copycats, The Guardian vom 01.07.2013, https:/www.theguardian.com/artanddesign/2013/jul/01/elaine-sturtevant-queencopycats.

113 Zuschlag, Die Kopie ist das Original - über Appropriation Art, in: Mensger (Hrsg.), Déjà-vu? Die Kunst der Wiederholung von Dürer bis Youtube, Ausstellungskatalog der Staatlichen Kunsthalle Karlsruhe, 2012, S. 126, 134.

114 Ausführlicher zur Kulturgeschichte der Aneignung ab S. 83 ff., 94 ff.

115 Ullrich, Gurkyesque: Das Web 2.0, das Ende des Originalitätszwangs und die Rückkehr des nachahmenden Künstlers, in: Nida-Rümelin/Steinbrenner (Hrsg.), Kunst und Philosophie. Original und Fälschung, 2011, S. 93, 111. 
Die Kopie soll auch ein Weg sein, um die geistigen Strukturen des kopierten Werkes zu erkennen und zur Reflexion darüber anzuregen. Ein Werk, das aussieht wie das eines bekannten Künstlers, aber die Signatur eines Appropriation Art Künstlers trägt, verunsichert. Die Diskrepanz zwischen optischem Eindruck und tatsächlicher Identität des Werkes löst eine neue Auseinandersetzung mit dem Werk aus. Durch die Täuschung der Erwartungshaltung kann der Betrachter wieder die ursprüngliche Ästhetik des Werkes erkennen. ${ }^{116}$ Elaine Sturtevant nannte dies die Re-Ästhetisierung des Kunstwerkes. Werke von großen, bekannten Künstlern, wie z.B. Andy Warhol, könnten aufgrund ihrer Bekanntheit und des Ruhmes nicht mehr unvoreingenommen betrachtet werden. Frank Perrin formuliert dies wie folgt: „Die Kunst als Umkehrung betrachtet. Durch den Eigennamen auf den sich aller Augen richten -, wird der eigentliche Blick entführt, er wirkt wie ein Schirm, der uns daran hindert, das Werk zu beurteilen und

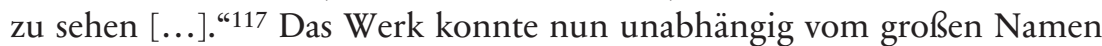
der bekannten Künstler betrachtet werden. Das Wiederholen deckt so das Jetzt der Kunst wieder auf. ${ }^{118}$ Durch die Kopie soll die eigentliche Energie des Werkes zurückgeholt werden - die Kopie bedeutet, den Ursprung des einem Kunstwerk innewohnenden Werkes sichtbar zu machen. ${ }^{119}$

\section{Künstler der Appropriation Art}

Hier sollen ausgewählte Künstler der Appropriation Art exemplarisch vorgestellt werden, um ihre bekannten Werke, die prototypisch für die Appropriation Art selbst stehen, und ihre künstlerischen Konzepte genauer zu erläutern. Dies soll dazu dienen, die Rechtsstreitigkeiten, die bei einigen dieser Künstler entstanden sind, besser einordnen zu können.

116 Kakies, Kunstzitate in Malerei und Fotografie, 2007, S. 17.

117 Perrin, Der Sturtevant-Moment, in: Arning/Felix/u.a. (Hrsg.), Sturtevant. Ausstellungskatalog des Württembergischen Kunstvereins Stuttgart, der Deichtorhallen Hamburg und der Villa Arson Nizza, 1992, S. 20, 22.

118 Perrin, Der Sturtevant-Moment, in: Arning/Felix/u.a. (Hrsg.), Sturtevant. Ausstellungskatalog des Württembergischen Kunstvereins Stuttgart, der Deichtorhallen Hamburg und der Villa Arson Nizza, 1992, S. 20, 28.

119 Rebbelmund, Appropriation Art, 1999, S. 104. 


\section{a) Elaine Sturtevant}

Elaine Sturtevant war eine U.S.-amerikanische Künstlerin, die bereits in den 1960er Jahren Werke anderer kopierte, so zu Beispiel Werke von Andy Warhol, Roy Lichtenstein, Frank Stella, Claes Oldenburg und Joseph Beuys, und gilt daher als eine Vorläuferin der Appropriation Art. ${ }^{120}$ Sturtevant hat sich wiederholt gegen ihre Einordnung als Künstlerin der Appropriation Art gewehrt. ${ }^{121}$ Wenn man die Appropriation Art allerdings nicht als eine zeitlich beschränkte Gruppe von Künstlern versteht, sondern weitergehend als Kunstrichtung der Aneignung, dann ist sie diesen zuzurechnen. ${ }^{122}$

Elaine Sturtevant wollte mit der Kopie die künstlerische Energie eines Werkes nachvollziehen und über die ,interne Ebene von Kunst sprechen".. ${ }^{123}$ Sie unterzog Bilder einer von ihr so bezeichneten Re-Ästhetisierung, indem sie bekannte Bilder übernahm und ohne den Kontext des bekannten Künstlers darstellte, um so die Aufmerksamkeit zurück auf das eigentliche Bild zu richten. Durch die Kopie kann ohne den Schleier des Wirkungskreises und der Bekanntheit die eigentliche Originalität des Wer-

120 Dies., a.a.O., S. 99.

121 So stellte sie klar: „[Den Tod der Originalität zelebrieren] mag die Absicht der ,Appropriationists' sein. Zwischen kritischer Auseinandersetzung der Originalität und der Behauptung, die Originalität sei tot, besteht ein Unterschied. Man müsste geistig zurückgeblieben sein, um den Tod der Originalität zu fordern.“, Sturtevant, Elaine Sturtevant im Gespräch mit Bill Arning, in: Arning/Felix/u.a. (Hrsg.), Sturtevant. Ausstellungskatalog des Württembergischen Kunstvereins Stuttgart, der Deichtorhallen Hamburg und der Villa Arson Nizza, 1992, S. 8, 10. Doch ebenso wie die picture generation nutzte sie die Kopie strategisch als künstlerisches Mittel und bezieht sich ebenso kritisch auf die Macht und Autonomie der Originalität. Man kann ihre Weigerung, mit den Appropriationists der picture generation gleichgesetzt zu werden, auch als allgemeine Verweigerung einer Etikettierung und das Betonen ihrer individuellen künstlerischen Nische verstehen, so Rebbelmund, Appropriation Art, 1999, S. 12.

122 So auch Rebbelmund, Appropriation Art, 1999, S. 12. Anders jedoch Vahrson, Die Radikalität der Wiederholung, 2006, S. 131 f.: Der Unterschied liege in der gewollten Subversion des Originalitätsbegriffs und das Nachvollziehen historischer Sachverhalte durch Wiederholungen bei den Appropriation Art Künstlern, wohingegen Sturtevant die Vorbilder als semantisch entleerte Katalysatoren verstehen will.

123 Sturtevant, Elaine Sturtevant im Gespräch mit Bill Arning, in: Arning/Felix/u.a. (Hrsg.), Sturtevant. Ausstellungskatalog des Württembergischen Kunstvereins Stuttgart, der Deichtorhallen Hamburg und der Villa Arson Nizza, 1992, S. 8, 8. 
kes entdeckt werden. ${ }^{124}$ Dabei gelingt Sturtevant etwas Paradoxes: Durch die Kopie etwas Originelles schaffen und Originalität zeigen. ${ }^{125}$

Elaine Sturtevant wurde meist mit Zustimmung der Künstler tätig, deren Werke sie sich aneignete. ${ }^{126}$ So hat ihr Andy Warhol Schablonen für die Siebdrucke geliehen und Roy Lichtenstein Farbraster ${ }^{127}$ für die Erstellung der möglichst exakten Kopie. Es handelt sich dabei nicht um Reproduktionen, da es ihr nicht um die Wiedergabe der angeeigneten Werke ging. Sturtevant unterzeichnete ihre Werke mit eigener Signatur, sodass weder Plagiat noch Fälschung vorliegt. Ihre Kopien zogen jedoch auch juristische Probleme nach sich: 1992 wollte Elaine Sturtevant für eine Ausstellung den „Fat Chair“ (1964) von Joseph Beuys nachstellen. Dagegen ging dessen Witwe und Rechtsnachfolgerin Eva Beuys gerichtlich vor. ${ }^{128}$ Daraufhin stellte Sturtevant nur die Einzelbestandteile des Fat Chair aus als Installation „Beuys Fat Chair. Work in Progress“. ${ }^{129}$

\section{b) Sherrie Levine}

Sherrie Levine ist eine U.S.-amerikanische Künstlerin, die zur ursprünglichen Gruppe der Appropriation Künstler gezählt wird. ${ }^{130}$ Sie kopierte zunächst Gemälde per Hand, unter anderem von Egon Schiele, Joan Miro und Kasimir Malewitsch, und fertigte Collagen von Zeitungsausschnitten und Werbungen an. Später wurde sie durch ihre Re-Fotografieren bekannt, bei denen sie Fotos anderer Künstler abfotografierte. Häufig nutzte

124 Rebbelmund, Appropriation Art, 1999, S. 102.

125 de Vries, Gerd de Vries im Interview mit Lena Maculan, in: Maculan/Kittelmann (Hrsg.), Elaine Sturtevant, Catalogue raisonné 1964-2004, 2004, S. 23, 26.

126 Dennoch waren nicht alle von der Nachahmung begeistert: „[Claes Oldenburg] war einer meiner größten Anhänger, sowohl in intuitiver als auch in intellektueller Hinsicht, bis ich ,The Store' nachbildete und er daraufhin ausflippte und verrückt spielte.“, so Sturtevant, Elaine Sturtevant im Gespräch mit Bill Arning, in: Arning/Felix/u.a. (Hrsg.), Sturtevant. Ausstellungskatalog des Württembergischen Kunstvereins Stuttgart, der Deichtorhallen Hamburg und der Villa Arson Nizza, 1992, S. 8, 12.

127 Schjedahl, After image, The New Yorker vom 24.11.2014, https://www.newyorke r.com/magazine/2014/11/24/image-3.

128 Osterwold, Vorwort, in: Arning/Felix/u.a. (Hrsg.), Sturtevant. Ausstellungskata$\log$ des Württembergischen Kunstvereins Stuttgart, der Deichtorhallen Hamburg und der Villa Arson Nizza, 1992, S. 6, 6.

129 Ders., a.a.O.

130 Sie gehört zur sog. picture generation, s.o. 
sie bereits vorhandene Reproduktionen als Vorlage, und nicht Originale, wie z.B. Ausstellungskataloge. So hat sie Edward Westons Portrait seines Sohnes Neil abfotografiert und 1981 ausgestellt. Daraufhin wurde sie allerdings von Westons Rechtsverwaltern zur Unterlassung aufgefordert. ${ }^{131}$

Sherrie Levine wurde bekannt für ihre Reihe „After Walker Evans“ $(1981)^{132}$, wofür sie die bekannten Fotos von Walker Evans abfotografierte. Walker Evans porträtierte im Auftrag der Farm Security Administration die verarmte Landbevölkerung der Südstaaten während der Großen Depression der 1930er Jahre. Diese Fotos von Evans waren aufgrund des Auftrags als amtliche Werke nicht urheberrechtsschutzfähig gem. 17 U.S.C. $\$ 105$, sodass keine rechtlichen Probleme mit den Re-Fotografien einhergingen. 1991 stellte sie eine Nachschaffung von Duchamps Urinal aus „Fountain (After Duchamp)“, die sie als Bronzeplastik geschaffen hat. ${ }^{133}$

Zum Thema der Originalität äußerte sich Sherrie Levine wie folgt: „It's not that I don't think that the word originality means anything or has no meaning, I just think it's gotten a very narrow meaning lately. What I think about in terms of my work is broadening the definitions of the word ,original'. I think originality as a trope. There is no such thing as an ahistorical activity (I mean history in terms of one's personal history, too)." 134 Sherrie Levine verfolgte damit doch eine anderes Ziel als Sturtevant: Ihr ging es weniger um die Wieder-Holung im Sinne einer Zurückholung der Originalität, sondern um die Wieder- und Wieder-Holung, die die Originalität entleert: „A picture is a tissue of quotations drawn from the innumerable centers of culture [...] We can only imitate a gesture that is always anterio, never original." 135 Das Original verliert hier also seine Bedeutung, anstatt dass es wie bei Sturtevant erst wieder zum Vorschein kommt.

131 Vgl. Sherrine Levine, in: Marzorati, ART in the (Re)Making, Art News (Mai 1986), S. 90, 97.

132 Die Ausstellung „After Walker Evans“ fand 1981 in der Metro Pictures Gallery in New York statt.

133 Dazu ausführlicher auch S. 125. Oft wurden die Arbeiten Sherrie Levines auch als feministische Kunst verstanden, da sie ausschließlich männliche Künstler kopierte und so die männlich dominierte Kunstgeschichte und den entsprechenden Kunstmarkt aufzeigte, s. Römer, Künstlerische Strategien des Fake. Kritik von Original und Fälschung, 2001, S. 105.

134 So in Siegel, After Sherrie Levine. Interview mit Sherrie Levine, Arts Magazine New York (Juni 1985), S. 141, 141.

135 Levine, Statement [1982], in: Harrison/Wood (Hrsg.), Art in theory 1900-1990, 1997, S. 1066, 1067. 
Durch die Potenzierung der Reproduktionen beginnt eine Reflexion über die Stufen der Authentizität beim Betrachter. ${ }^{136}$

Auch ihre Werke stellen keine Reproduktionen dar, da die Re-Fotografien in einen neuen Kontext gesetzt werden. Wie bei Sturtevant handelt es sich aufgrund der eigenen Signatur auch nicht um ein Plagiat oder eine Fälschung. Die für die Hommage notwendige Huldigung ist nicht klar erkennbar. ${ }^{137}$

\section{c) Richard Prince}

Richard Prince gehört ebenso wie Levine zur picture generation der 1970er Jahre. ${ }^{138}$ Seine ersten Arbeiten der Appropriation Art entstanden 1977 aus Werbebilder aus dem New York Times Magazine, die elaboriert dekorierte Wohnzimmer zeigten, die Prince abfotografierte und „Untitled (Living Rooms)" nannte. Die Collagen verstand er als Kommentar zu den kulturellen Stereotypen in der Werbung. ${ }^{139} 1983$ eignete er sich eine Fotografie an, die Garry Gross von Brooke Shields ${ }^{140}$ machte. Mit Garry Gross

136 Rebbelmund, Appropriation Art, 1999, S. 143. Die technische Reproduktion verliert also nicht an Aura gegenüber dem Original im Sinne von Walter Benjamin (vgl. dazu S. 98), sondern ruft diese Reflexion hervor und macht die Äuthentizität teilbar. Levine kann damit als Versuch der Widerlegung von Walter Benjamins These verstanden werden, so Rebbelmund, Appropriation Art, 1999, S. 144.

137 Dies., a.a.O.

138 Er wurde zwar nicht bei der Ausstellung „Pictures“ im New Yorker Artists Space 1977 ausgestellt, gibt jedoch an, dass Douglas Crimp ihn eingeladen habe dort auszustellen, er jedoch abgelehnt habe, vgl. Lafreniere, 80's then: Richard Prince talks to Steve Lafreniere, Artforum Nr. 71 (März 2003), S. 70, 71. Dies revidierte er jedoch später, vgl. Evans, Seven Types of Appropriation, in: ders. (Hrsg.), Appropriation. Documents of Contemporary Art, 2009, S. 12, 12. In der Retrospektive des Metropolitan Museum of Art in New York 2009 wurde er als Bestandteil dieser Gruppe aufgeführt.

139 Schriftsatz Graham v. Prince, Motion to Dismiss, Filed 26.02.2016, S. 6.

140 Die Schauspielerin Brooke Shields war damals zehn Jahre alt. Gary Gross fotografierte sie mit einem erwachsen geschminkten Gesicht nackt in einer Badewanne stehend. Eines der entstandenen Fotos heißt „The Woman in the Child“ (1980). Die Fotos lösten eine Diskussion über Kinderpornographie und Pädophilie aus. 
einigte sich Prince außergerichtlich auf die Zahlung einer kleinen Summe. ${ }^{141}$

Bekannt wurde er für seine Serie von Re-Fotografien der Marlboro-Man Werbefotos von Jim Kratz. Marlboro nutzte hier das klischeehafte Motiv des amerikanischen Cowboys als weißen Eroberer des Landes. Princes „Untitled (Cowboy)“ (1989) wurde im Solomon R. Guggenheim Museum ausgestellt und erzielte 2005 bei einer Auktion einen Preis von 1,25 Millionen USD. ${ }^{142}$

Prince fotografierte typische Darstellungen der Massenmedien. Ihn interessierten die Strategien in der Werbung, um Aufmerksamkeit zu erzeugen, und die Verankerung dieser Bilder im kollektiven Bildgedächtnis. Als Vorlage seiner Re-Fotografien nutzte er bereits bestehende Kopien, oft aus Magazinen. Prince ging es um die Akzeptanz des Kopierverfahrens als künstlerische Praxis, die sich auf die Manipulation von Ausschnitt, Farbigkeit und Tiefenschärfte beschränkt. ${ }^{143}$ Seinen Intention kann mit dem Zitat aus seinem Buch „Why I Go To The Movies Alone“ von 1983 verstanden werden: „His own desires had very little to do with what came from himself because what he put out, (at least in part) had already been out. His way to make it new was make it again, and making it again was enough for him and certainly, personally speaking, almost him." ${ }^{144}$

Seine neueste Reihe „New Portraits“ wurde 2014 in einer Ausstellung der Gagosian Gallery gezeigt. Hierfür hat er Porträts anderer Fotografen, die unter anderem verschiedene Subkulturen darstellen, aus Instagram kopiert und ließ diese großflächig als Tintenstrahldruck auf Leinwände drucken. Bei Instagram kommentierte Prince zuvor mit seinem Account unter die Fotos, diese Kommentare sind durch die Screenshots ebenfalls mit abgedruckt und werden als Akt der Aneignung verstanden. Bei seinen Werken behielt er die Instagram-Benutzeroberfläche und Kommentarzeile bei. ${ }^{145}$ Die Werke wurden bei der Frieze Art Fair 2005 für 90.000 bis 100.000 USD je Druck verkauft. Von einigen der kopierten Künstler

141 Kennedy, If the Copy is an Artwork, then what's the Original?, The New York Times vom 06.12.2007, https://www.nytimes.com/2007/12/06/arts/design/06prin .html.

142 Pitzke, Mädchen, Mythen und der Marlboro-Mann, Der Spiegel vom 29.09.2007, http://www.spiegel.de/kultur/gesellschaft/us-kuenstler-richard-princ e-maedchen-mythen-und-der-marlboro-mann-a-508512.html.

143 Römer, Künstlerische Strategien des Fake. Kritik von Original und Fälschung, 2001, S. 123.

144 Prince, Why I go to the movies alone, 1994, S. 63.

$145 \mathrm{Zu}$ den Klagen bezüglich dieser Ausstellung vgl. S. 62 ff. 
wurde Prince daraufhin verklagt. Die von ihm kopierten SuicideGirls, ein Pornographie-Portal, nutzten eine andere Strategie: Sie verkauften die gleichen Drucke für je 90 USD. ${ }^{146}$

\section{d) Jeff Koons}

Jeff Koons ist ein U.S.-amerikanischer Künstler, der 1980 seine erste Ausstellung hatte und seit den 1990er-Jahren zu den höchstgehandelten lebenden Künstlern gehört. ${ }^{147} \mathrm{Ihm}$ geht es bei seinen Werken häufig um die Grenze zwischen Kunst und Alltag ${ }^{148}$, weshalb er auch viele Alltagsgegenstände für seine Kunst nutzt. So hat er Plakate und Gegenstände aus der Werbung übernommen, wie z.B. ein Werbefoto von Gordon's Dry Gin für sein Werk „I could go for something Gordon's“ (1986).

Mit seinen Werken zielt Koons auf Tabubrüche ab: So hatte die „Luxury and Degration" Ausstellung von 1986 Alkohol-Konsum und Werbung zum Thema, „Banality“ von 1988 Kitsch und Nippes und „Made in Heaven“ 1990 Pornographie und Sexualität. ${ }^{149}$ Mit seinen Werken will er den Kitsch und die Banalität der Gegenstände, die jeden heute umgeben, verdeutlichen: Der Inhalt und die Bedeutung der Gegenstände haben für den Eigentümer nur noch eine untergeordnete Rolle, ${ }^{150}$ sie dienen mehr dem Dekorativen und Sentimentalen. Indem er diese Objekte der Konsumgesellschaft nachbildet, schafft er eine Kontextveränderung der Gegenstände. Die Diskrepanz von den Werken mit Gegenständen des schlechten Geschmackes und der überzogenen, banalen Ästhetik und der hohen Qualität und handwerklicher Perfektion der Werke spielt mit der Wahrnehmung des Beobachters. ${ }^{151}$ Insofern sind Ähnlichkeiten zur Appropriation Art erkennbar. Auch Koons will Wahrnehmungsweisen bloßstellen und nutzt

146 Heyman, SuicideGirls Respond to Richard Prince in the Best Way Possible, Vogue vom 28.05.2015, https://www.vogue.com/article/suicidegirls-richard-prin ce. Richard Prince twitterte daraufhin: „Much better idea. I started off selling my ,family' tweets for \$ 18 at Karma not long ago. Missy Suicide is smart.“, @richardprince4 vom 28.05.2015, https://twitter.com/richardprince4/status/603874 714201751552?lang=de, Datum des Zugriffs: 15.01.2020.

147 Einen Großteil seiner Werke hat er zeitlich nach den Werken der picture generation geschaffen und wird daher, wenn man Appropriation Art zeit- und gruppenbezogen versteht, nicht als Künstler der Appropriation Art eingeordnet.

148 Rebbelmund, Appropriation Art, 1999, S. 179.

149 Zaunschirm, Kunst als Sündenfall, 1996, S. 66 f.

150 Rebbelmund, Appropriation Art, 1999, S. 180.

151 Zaunschirm, Kunst als Sündenfall, 1996, S. 66. 
dafür die Kopie. Allerdings greift er nicht das Original als etwas Unberührbares an, sondern die verpönte, aber allgegenwärtige Liebe zum Kitschobjekt. ${ }^{152}$ Seine Aneignungen sind damit kein Kommentar zu den Begriffen Kopie und Original, sondern ein Mittel für andere künstlerische Aussagen. Insofern unterscheidet sich sein Konzept in der Verwendung der Kopie von denen der anderen Künstler der Appropriation Art. ${ }^{153}$

\section{Die Rechtsfälle}

In Deutschland gibt es bisher keine Urteile explizit zur Appropriation Art. In den U.S.A. wurden hingegen schon einige Fälle vor Gericht behandelt, wobei manche mit Vergleichen statt Urteilen endeten. Die älteren Prozesse sind bereits Gegenstand einer umfangreichen wissenschaftlichen Literatur, weshalb sie hier nur knapp charakterisiert werden. Anhand der aktuellen Prozesse von 2015 bis 2019 zeigt sich, dass sich die rechtlichen Fragen zur Einordnung der Appropriation Art nicht erschöpft haben.

Die aufgeführten Rechtsfälle wurden mit einer Ausnahme in den U.S.A. verhandelt und nach U.S.-amerikanischen Recht beurteilt. Dabei stand die Fair Use Generalklausel des $₫ 107$ Copyright Act zur erlaubten Nutzung von urheberrechtlich geschützten Werken im Mittelpunkt dieser Verfahren. Es wird gem. $\mathbb{S} 107$ S. 2 U.S.C. nach 4 Faktoren bemessen, ob eine Nutzung einen Fair Use darstellt oder nicht: „In determining whether the use made of a work in a particular case is in fair use the factors to be considered shall include - (1) the purpose and character of the use, including whether such use is of a commerical nature or is for nonprofit educational purposes; (2) the nature of the copyrighted work; (3) the amount and substantiality of the portion used in relation to the copyrightes work as a whole; and (4) the effect of the use upon the potential market for or value of the copyrighted work."

152 Rebbelmund, Appropriation Art, 1999, S. 183.

153 So sagte er auch selbst über sich und den Unterschied zu Richard Prince: „Richard's work has developed more from the position of appropriation, and so appropriation has a little darker side to it, because it's more about theft, where my work's more associated to the ready-made, where it's something that preexists.“, Koons in: Colman, Interview mit Jeff Koons, Interview Magazine vom 26.11.2008, https://www.interviewmagazine.com/film/jeff-koons. 
a) Rogers v. Koons

In Rogers $v$. Koons ging es um die Skulptur „String of Puppies“ (1988) von Jeff Koons. ${ }^{154}$ Das verwendete Motiv basierte auf einem Schwarzweißfoto von Art Rogers („Puppies“, 1985)155, das als Postkarte verkauft wurde. Dieses zweidimensionale Foto verwandelte Koons in eine dreidimensionale Skultpur. Koons hat wie auf dem Foto ein Ehepaar auf einer Bank mit Hundewelpen in dem Armen dargestellt. Die Skulptur weicht von der Vorlage nur in der Farbgebung, der starren Mimik und durch die hinzugefügten Gänseblümchen auf den Köpfen der Personen ab.
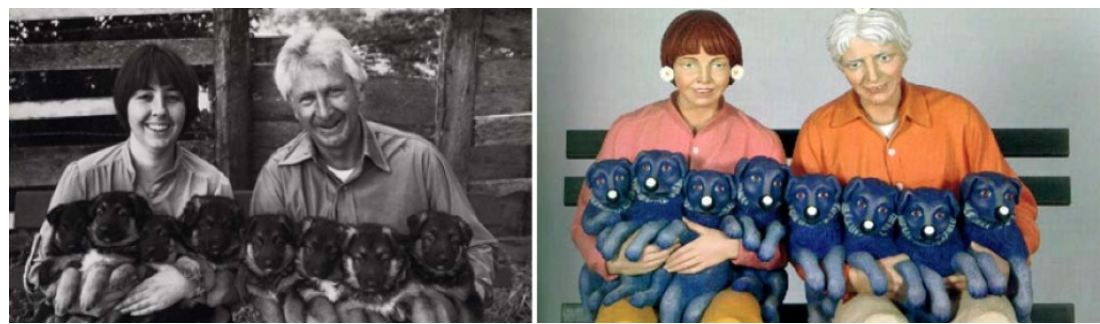

Abb 1.1.: Art Rogers, „Puppies“, 1985. Abb. 1.2.: Jeff Koons, „String of Puppies", 1988.

Das Gericht verurteilte Koons zur Zahlung von Schadensersatz und zur Herausgabe der Skulptur an Rogers. Es stellte fest, dass es sich nicht mehr um einen Fair Use der Vorlage handelte. Insbesondere lehnte es ab, die Skulptur als Parodie anzuerkennen, die eine weitreichendere Benutzung des fremden Werkes erlaubt hätte. Koons kritisiere mit seinem Werk den Massenkonsum, die damit verbundenen Werbebilder und den Materialismus der Gesellschaft als Ganzes. Für eine Parodie hätte er sich konkret auf das Foto der Vorlage beziehen müssen. Wenn nicht die Vorlage das Objekt der Kopie ist, gäbe es auch keinen Grund, es zu nutzen. Zudem sprächen die kommerzielle Nutzung der Skulptur durch Koons und seine Bösgläubigkeit - er riss den Copyright-Vermerk von der Postkarte ab, bevor sie als Druckvorlage verwendet wurde - gegen Fair Use. ${ }^{156}$ Das Gericht nahm da-

154 Abb. 1.2. Ein Bild wird in dieser Arbeit zwar zweidimensional verstanden, dennoch wird dieses Rechtsverfahren um eine Skulptur auch hier erwähnt, um die wenigen Rechtsverfahren der Appropriation Art vollständig darzustellen.

155 Abb. 1.1.

156 Rogers $v$. Koons, 960 F.2d 301, 310 (2d Cir. 1992), S. 313. 
her an, dass der vierte Faktor der Substitutionskonkurrenz vorlag, weil Koons die Skulptur mit Gewinnabsicht herstellte und negative Auswirkungen auf den Postkartenmarkt von Rogers entstehen könnten. ${ }^{157}$ Außerdem hätte Rogers nun weniger Möglichkeiten, „Puppies“ zu lizenzieren. ${ }^{158}$ Dass aber der Familienfotograf Rogers und Koons, der hochpreisige Kunst verkauft, keine überschneidende Käuferzielgruppe haben, wurde nicht gesehen.

b) Blanch v. Koons

In Blanch v. Koons nutzte Jeff Koons Teile eines Fotos von der Werbefotografin Andrea Blanch. Ihre „Silk Sandals by Gucci“ zeigen übereinandergeschlagene Beine einer Frau, die auf dem Oberschenkel eines Mannes liegen. ${ }^{159}$ In Koons Ölgemälde „Niagara“ (2000) ${ }^{160}$ sind vier Frauenfüße zu sehen, die vom oberen Bildrand über den Niagarafällen herabbaumeln. Die Wasserfälle sind von einem Schokoladenbrownie mit Vanilleeis und zwei Schalen Donuts und Apfeltaschen verdeckt. Koons hat die fotografierten Füße also von ihrem Hintergrund bei Blanch gelöst. Er vergrößerte die Füße, verstärkte die Farben und drehte sie, sodass sie nun vom oberen Bildrand nach unten zeigten. Neben der Technik (Ölgemälde statt Fotografie) änderte Koons also auch die Größe und Position der Füße und fügte sie in einen neuen Hintergrund ein.

Hier hat das Gericht die Benutzung durch Koons als Fair Use eingestuft. ${ }^{161}$ „Niagara" setzt sich mit den sozialen und ästhetischen Konsequenzen von Massenmedien auseinander, während das Foto von Blanch in einem Lifestyle-Magazin genutzt wurde, um einen Beitrag über Nagellack zu illustrieren. Es wurde also ein neuer Bedeutungskontext geschaffen, für den Koons das Bild von Blanch nur als Rohmaterial nutzte. Damit wurde die Transformativität der Nutzung (erster Faktor) anerkannt. ${ }^{162}$ Der Transformativität kam jedoch nur eine geringe Bedeutung zu, da das Gericht den vierten Faktor der Fair Use-Defence erfüllt sah. Denn da Koons das Gemälde im Auftrag für eine Galerie herstellte, und Blanch für Modema-

157 Rogers $v$. Koons, a.a.O., S. 312.

158 Rogers $v$. Koons, a.a.O., S. 312.

159 Abb. 2.1.

160 Abb. 2.2.

161 Blanch v. Koons, 467 F.3d 244 (2d Cir. 2006), S. 259.

162 A.a.O., S. 256. 
gazin arbeitete, schöpfe er ihr keine Gewinne ab und zerstöre auch nicht ihren potenziellen Markt für die Nutzung von „Silk Sandals“. ${ }^{163}$

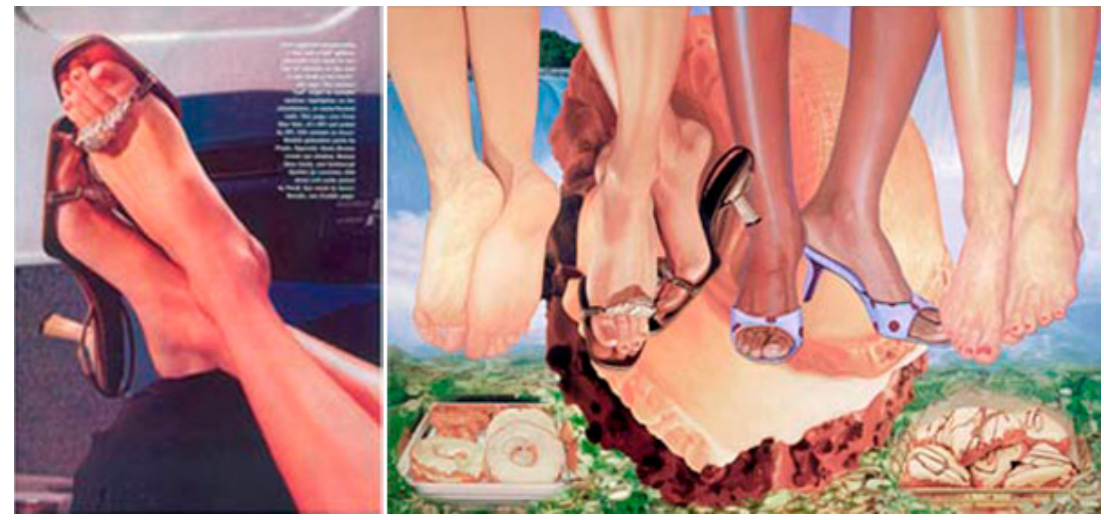

Abb 2.1.: Andrea Blanch, „Silk Sandals by Gucci“, 2000.
Abb. 2.2.: Jeff Koons, „Niagara“, 2000.

c) Cariou v. Prince

In der Rechtssache Cariou v. Prince ${ }^{164}$ hat Richard Prince Fotografien aus der „Yes Rasta“-Serie (2000) von Patrick Cariou genutzt ${ }^{165}$ und stark vergrößert ausgedruckt für seine Serie „Canal Zone“. In „Graduation“ $(2008)^{166}$ z.B. hat Prince mit blauer Farbe die Augen und den Mund des abgebildeten Rastafaris übermalt und das Foto einer Gitarre über dessen Körper eingefügt. Der Second Circuit sah Prince Werk als transformativ und damit als Fair Use an ${ }^{167}$, denn Princes Werk habe eine fundamental unterschiedliche Ästhetik. ${ }^{168}$ Für den vierten Faktor des Fair Use-Tests war wie bei Blanch $v$. Koons ausschlaggebend, dass der hoch gehandelte Prince ein anderes Publikum mit seinen Werken anspreche und deswegen Cariou keinen potenziellen Markt zerstöre. Für fünf Werke aus der Serie hat der Second Circuit die Entscheidung allerdings an die untere Instanz zurück-

163 A.a.O., S. 258.

164 Cariou v. Prince, 714 F. 3d 694 (2d Circ. 2013).

165 Abb. 3.1.

166 Abb. 3.2., eines der 30 streitgegenständlichen Bilder.

167 A.a.O., S. 23.

168 A.a.O., S. 15. 
verwiesen. Bevor diese eine Entscheidung treffen konnte, haben sich Prince und Cariou am 18.03.2014 außergerichtlich geeinigt. Die Entscheidung ist deshalb von geringer praktischer Bedeutung, zeigt aber, dass das Gericht an den Grundsätzen aus der Blanch v. Koons-Entscheidung festgehalten haben.

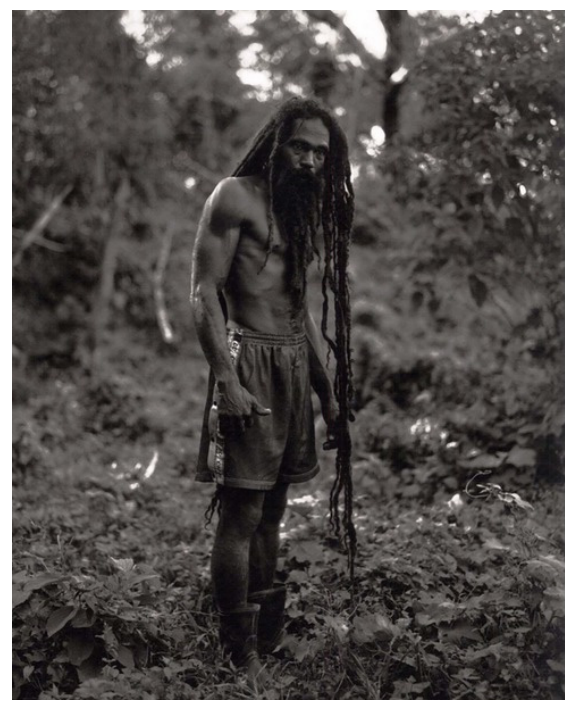

Abb. 3.1.: Patrick Cariou, Fotografie aus dem Buch „Yes Rasta“, 2000, S. 118.

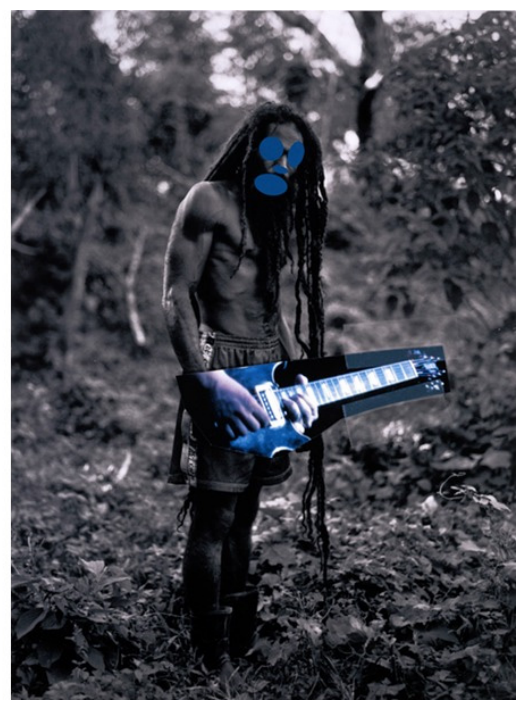

Abb. 3.2.: Richard Prince, „Graduation", 2008.

d) Gray v. Koons

Ende 2015 verklagte Mitchel Gray Jeff Koons wegen der Nutzung seiner Fotografie in dem Gemälde „I could go for something Gordon's“ (1986) ${ }^{169}$ der „Luxury and Degradation“ Ausstellung von Koons. ${ }^{170}$ Gray hatte die Fotografie in den 1980er Jahren als Auftrag für eine Werbekampagne von Gordon's Dry Gin Co. erstellt, die 1986 geschaltet wurde. ${ }^{171}$ Koons nutzte die Fotografie als Vorlage für ein Gemälde, veränderte aber die Flasche,

169 Abb. 4.2.

170 Mitchel Gray v. Jeff Koons, Complaint, No. 1:15-cv-09727 (S.D.N.Y. 2015).

171 Abb. 4.1. 
das Glas und den Slogan von Gordon's Gin. Auch deren Platzierung auf dem Foto und die Schriftart wurden verändert. Koons produzierte davon zwei Gemälde und ein Artist's Proof (Probedruck). Der Artist's Proof von Koons wurde 2008 für 1.028.500 GBP verkauft. Es kam aber im April 2016 zu einem Vergleich zwischen Gray und Koons, sodass der Fall nicht gerichtlich entschieden wurde. ${ }^{172}$

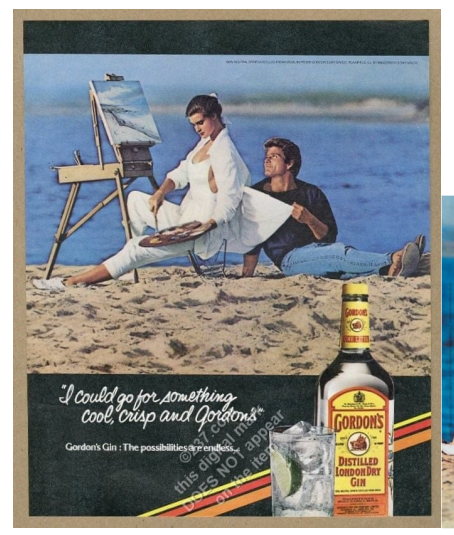

Abb. 4.1.: Gordon's Werbung, 1980er.

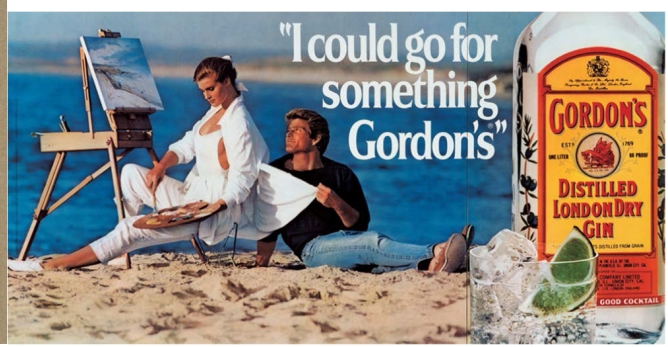

Abb. 4.2.: Jeff Koons, „I could go for something Gordon's “, 1986.

e) Graham v. Prince

Vor dem Southern District of New York streiten sich seit Ende 2015 Donald Graham und Richard Prince ${ }^{173}$ um die Verwendung der Fotografie „Rastafarian Smoking a Joint“ (1996) ${ }^{174}$ von Graham. Prince hat die Fotografie stark vergrößert auf eine Leinwand gedruckt und als Instagram Ausschnitt in seiner „New Portraits“ Ausstellung 2014 in der Gagosian Gallery ausgestellt. ${ }^{175} \mathrm{Er}$ hat an dem Foto nichts geändert, allerdings die Insta-

172 Lucas, Jeff Koons reaches settlement in recent Lawsuit, but Richard Prince is in the Hot Seat again on Fair Use, Art Law Blog Grossmann LLP vom 19.05.2016, https://www.grossmanllp.com/jeff-koons-reaches-settlement-in-recent-lawsuit.

173 Donald Graham v. Richard Prince, Complaint, No. 1:15-cv-10160, 265 F. Supp. 3d 366 (S.D.N.Y. 2017).

174 Abb. 5.1.

175 Abb. 5.2. 
gram-Benutzeroberfläche mit abgebildet und unter das Foto kommentiert als Akt der Aneignung. Die ursprünglich bei Instagram hochgeladene Abbildung der Fotografie von Grahahm wurde also 1:1 ohne Abwandlung übernommen. Es wurde lediglich die Einbettung durch die InstagramMaske verändert. Im Gegensatz zu Blanch v. Koons oder Cariou v. Prince wurde hier also weniger bearbeitet.

Prince argumentiert, dass es sich um eine transformative Benutzung handele, weil er die Benutzeroberfläche von Instagram, Princes Kommentar und die Likes und Kommentare anderer Nutzer aufgenommen habe und damit ikonische Elemente des Internets, die dadurch eine völlig andere Ästhetik vermittelten als das düstere Schwarzweißfoto von Graham. ${ }^{176}$ Damit stehe das Werk in einem neuen Kontext und übermittele eine andere Botschaft als Grahams: Es sei ein Kommentar über die Stärke der sozialen Medien bei der Zugänglichmachung fremder Werke; eine Verurteilung der Eitelkeit der sozialen Medien, ihrer Verbreitung und sexuellen Natur und dem Bedürfnis der Menschen, „likes“ und „comments“ zu erhalten. ${ }^{177}$ Für einen Käufer eines Werkes von Graham stelle es damit kein Substitut des ursprünglichen Werkes von dar. ${ }^{178}$

In einer richterlichen Stellungnahme vom 18.07.2017 machte das Gericht deutlich, dass es sich bei Princes Kunstwerk nicht um Fair Use handele und damit eine Urheberrechtsverletzung vorliege. ${ }^{179}$ Als transformatives Werk sei es nicht anzuerkennen, da Prince das gesamte Foto von Graham nutzte und nur mit mehr Beweisen eine transformative Nutzung hätte anerkannt werden können. ${ }^{180}$ Außerdem sei Grahams Foto noch vollständig erkennbar, es behalte unverändert seine ästhetische Wirkung. Princes Kunstwerk könne daher Grahams Fotos substituieren und seinen potenziellen Markt beeinträchtigen. ${ }^{181}$ Auf die Re-Kontextualisierung ging das Gericht nicht ein. Ein Urteil wurde noch nicht gesprochen.

176 Graham v. Prince, Memorandum Motion to dismiss 26.02.2016, No. 1:15cv-10160 (S.D.N.Y. 2017), S. 14 f.

177 A.a.O., S. 3 und 16.

178 A.a.O., S. 21.

179 Graham v. Prince, Opinion and Order 18.07.2017, No. 1:15-cv-10160 (S.D.N.Y. 2017), S. 3.

180 A.a.O., S. $19 \mathrm{f}$.

181 A.a.O., S. 24. 
f) Weitere Klagen aufgrund der „New Portraits“ gegen Prince

Dennis Morris verklagte Richard Prince am 03.06.2016. ${ }^{182}$ Morris Foto des Sex Pistols Musikers Sid Vicious ${ }^{183}$ hat Prince abfotografiert und auf seinem eigenen Instagram-Account geteilt. ${ }^{184}$ Weiterhin hat Prince einige weitere Bilder von Sid Vicious, die Morris fotografierte ${ }^{185}$, für seine Ausstellung „Covering Pollock“ 2011 genutzt, ${ }^{186}$ ohne Einwilligung von Morris. Hier stellen sich also ähnliche Fragen des Transformative Use wie bei Graham v. Prince. Die Klage von Morris wurde am 12.08.2016 zurückgenommen, es wurde wohl ein außergerichtlicher Vergleich geschlossen. ${ }^{187}$
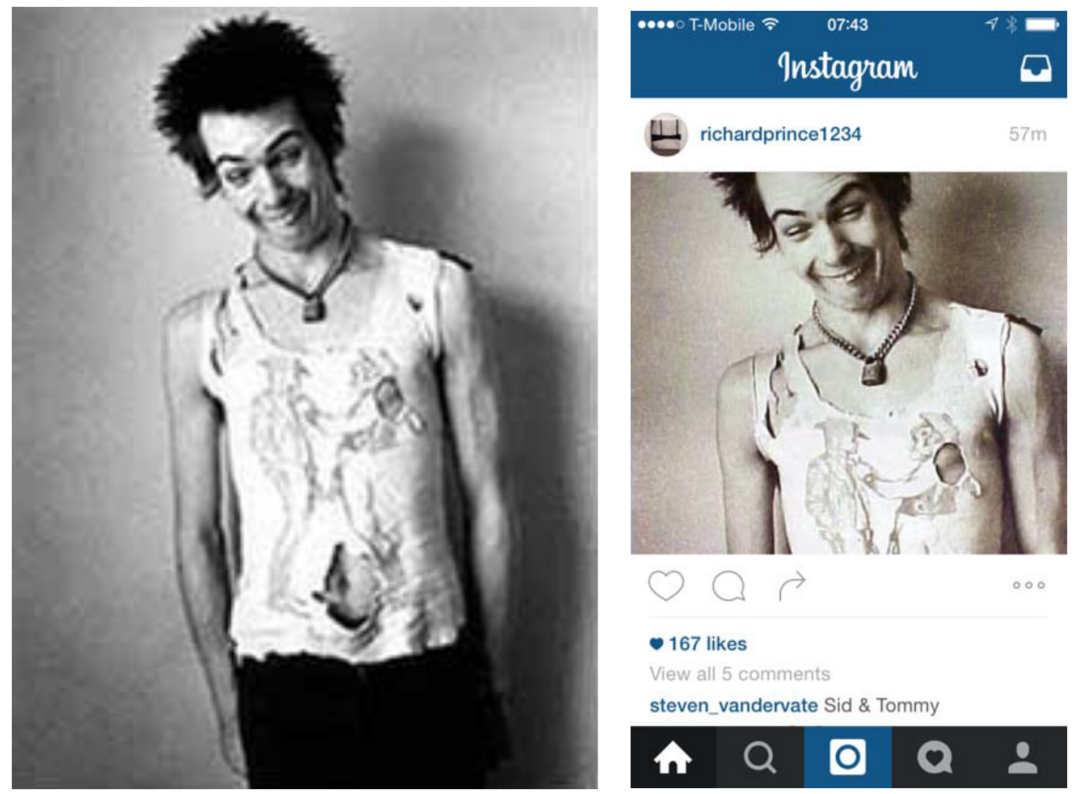

Abb. 6.1.: Dennis Morris, Foto von Sid Vicious, 1970er.
Abb. 6.2.: Richard Prince, Post auf seiner Instagram Seite, 2014.

182 Dennis Morris, LLC v. Prince, Complaint for Copyright Infringement, No. 2:16cv-03924 (C.D. Cal. June 3, 2016).

183 Abb. 6.1.

184 Abb. 6.2.

185 Abb. 6.3.

186 Abb. 6.4.

187 Dennis Morris, LLC v. Prince, Stipulation of Voluntary Dismissal of Entire Action Without Prejudice, No. 2:16-cv-03924-RGK-PJW (C.D. Cal. Aug. 12, 2016). 

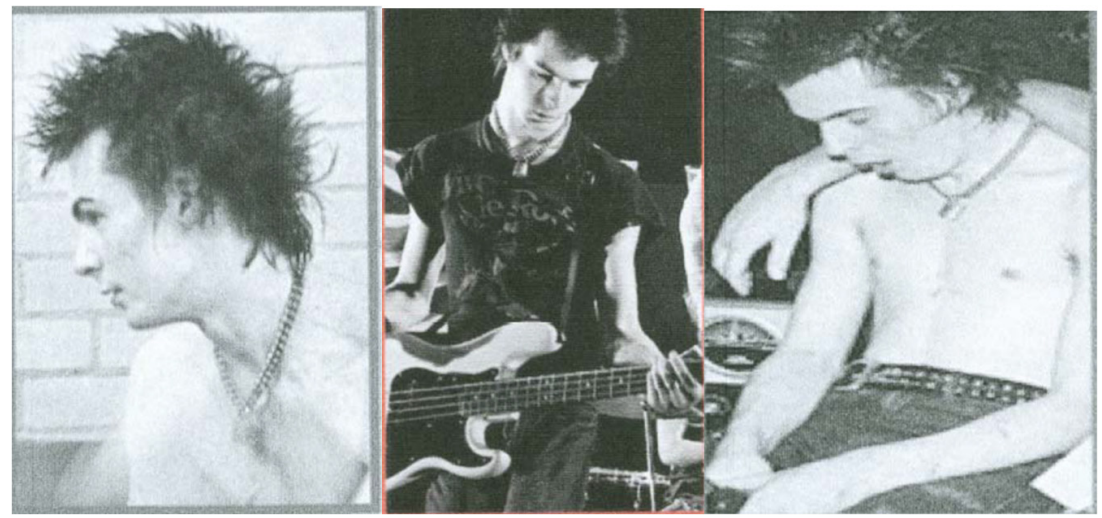

Abb. 6.3.: Dennis Morris, Fotos von Sid Vicious, 1970 er.

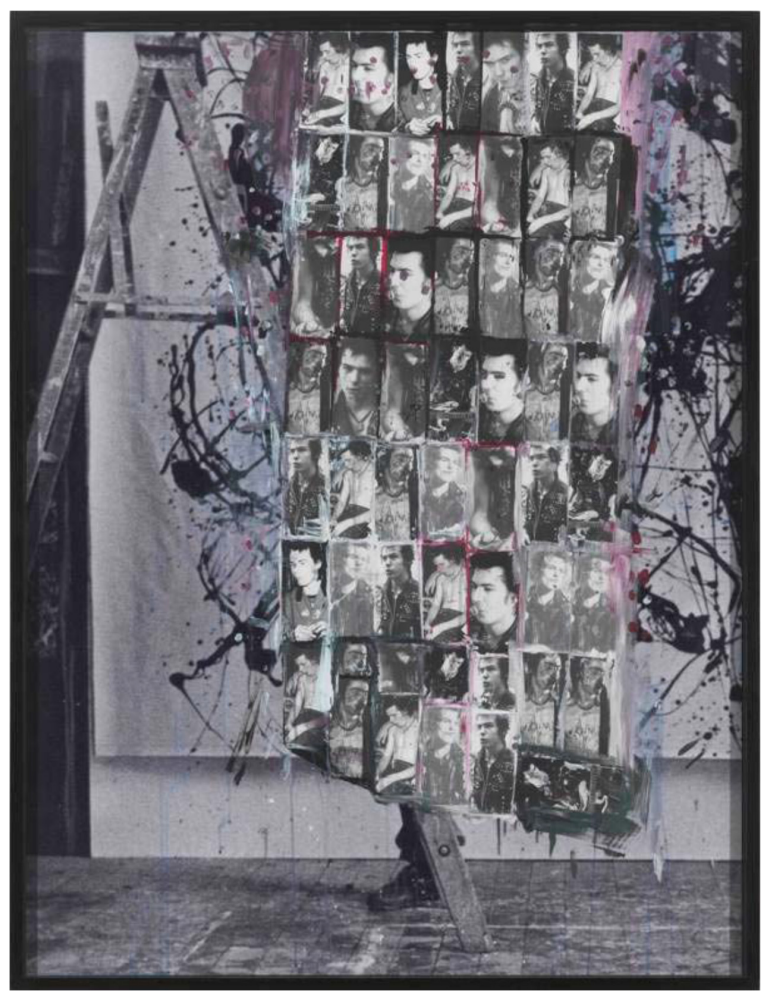

Abb. 6.4.: Richard Prince, „Covering Pollock“, 2011. 
Ebenfalls gegen ein Werk der Reihe „New Portraits“ klagte am 15.06.2016 das Model Ashley Salazar gegen Richard Prince ${ }^{188}$, die Klage wurde ebenfalls zurückgenommen. ${ }^{189}$

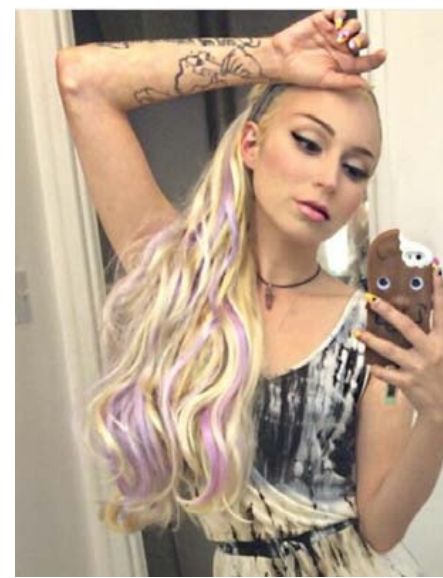

Abb. 7.1.: Ashley Salazar, o.A.

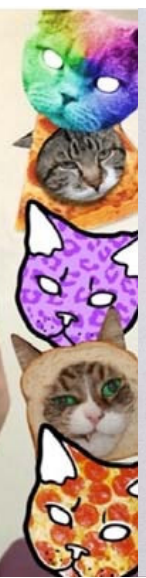

Abb. 7.2.: Richard Prince, Print der Reihe „New Portraits", 2014.

Die Klage von Eric McNatt vom 16.11.2016 gegen die Nutzung seiner Fotografie in der Reihe „New Portraits“ von Prince ist weiterhin anhängig und wurde noch nicht entschieden. ${ }^{190}$

188 Salazar v. Prince, Complaint for Copyright Infringement, No. 2:16-cv-04282 (C.D. Cal. June 15, 2016); Abb. 7.1. und 7.2.

189 Salazar v. Prince, Stipulation of Voluntary Dismissal of Entire Action Without Prejudice, No. 2:16-cv-04282-MWF-FFM (C.D. Cal. Aug. 12, 2016).

190 McNatt v. Prince, Complaint for Copyright Infringement, No. 1:16-cv-08896PGG (S.D.N.Y. 2016), Abb. 8.1. und 8.2. 


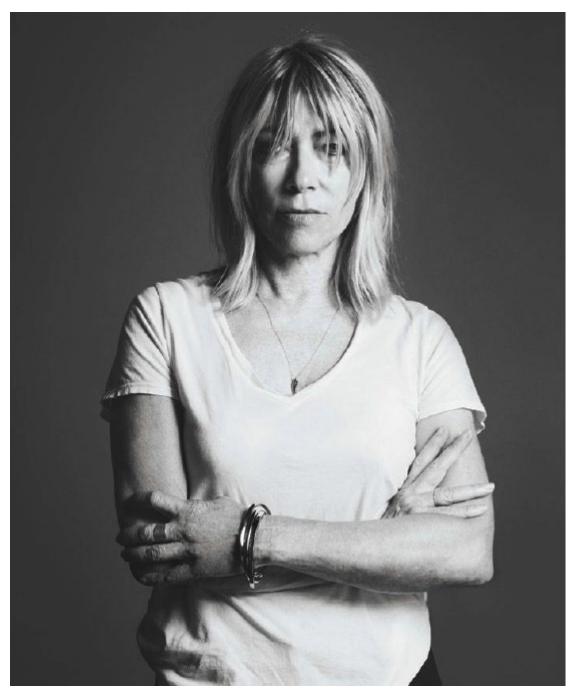

Abb. 8.1.: Eric McNatt, Fotografie von Abb. 8.2.: Richard Prince, Print der Kim Gordon, 2014.

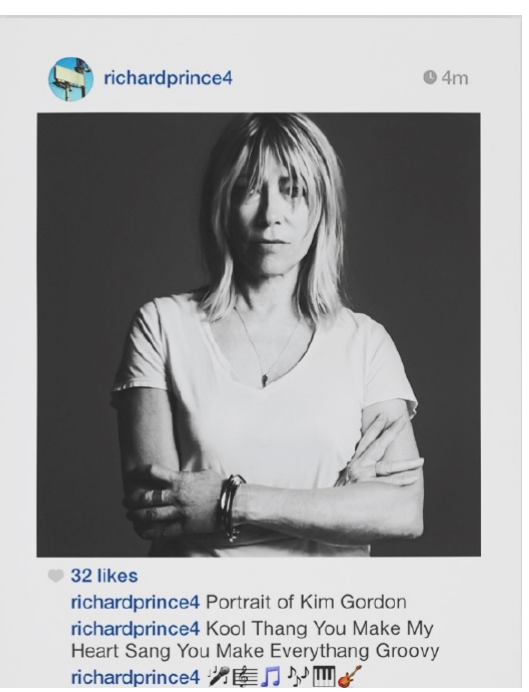

Reibe „New Portraits", 2014.

\section{g) Bauret v. Koons}

Am 09.03.2017 wurde Jeff Koons wegen einer Urheberrechtsverletzung eines Werkes von Jean-François Bauret vor dem Tribunal de Grande Instance de Paris zu Schadensersatz verurteilt. ${ }^{191}$ Bauret hat die schwarzweiße Fotografie „Enfants“ (1970) $)^{192}$ geschaffen, die einen nackten Jungen und ein nacktes Mädchen händchenhaltend zeigen, ihre Blicke auf die Hände gerichtet. Ab 1975 wurde das Motiv auch auf Postkarten gedruckt. Jeff Koons

191 Willsher, Jeff Koons plagiarised French photographer for Naked sculpture, The Guardian vom 09.03.2017, https:/www.theguardian.com/artanddesign/2017/ma r/09/jeff-koons-plagiarised-french-photographer-for-naked-sculpture. Für die Abbildung der Skupltur im Ausstellungskatalog wurden Jeff Koons LLC und das Centre Pompidou zu einer Schadensersatzzahlung von $20.000 €$ verurteilt. Außerdem zeigt Koons auf seiner Webseite eine Fotografie der Skulptur, weshalb er weitere $4.000 €$ Schadensersatz zahlen soll.

192 Abb. 9.1. 
schuf eine Porzellanskulptur zweier nackter Kinder, „Naked“ $(1988)^{193}$, wobei sich hier die Kinder nicht mehr an den Händen halten, sondern der Junge dem Mädchen eine Blume reicht und die beiden auf einer herzförmigen Sockelplatte verziert mit Blumen stehen. Durch die glasierte Porzellanoberfläche glänzen die Körper. Wo es bei Bauret noch Kinder in inniger Zweisamkeit zeigt, die Reinheit und Unschuld ausstrahlen, ist die Szene bei Koons sexuell aufgeladen und kitschig. Die „Naked“-Skulptur sollte ursprünglich im Centre Pompidou Paris bei einer Retrospektive gezeigt werden, ist aber wohl beim Transport nach Paris zerstört worden. ${ }^{194}$ Eine Abbildung der Skulptur war jedoch im Ausstellungkatalog abgedruckt und wurde auf Koons Webseite gezeigt.
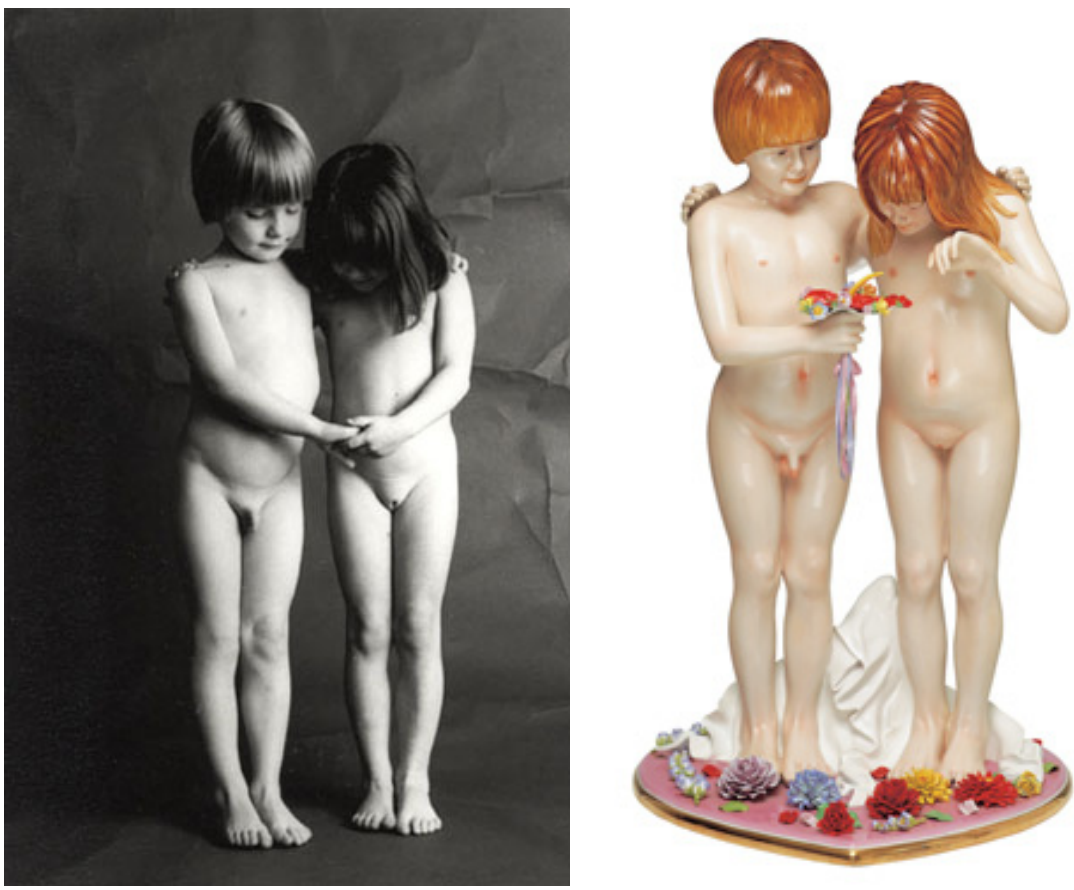

Abb. 9.1.: Jean-François Bauret, „En- Abb. 9.2.: Jeff Koons, „Naked“, 1988. fants", 1970.

193 Abb. 9.2.

194 Die Skulptur wurde daher nicht in Frankreich gezeigt. Es gibt allerdings laut der Angaben von Jeff Koons drei Editionen dieser Skulptur: http://www.jeffkoo ns.com/artwork/banality/naked, Datum des Zugriffs: 15.01.2020. 
Das Gericht stellte fest, dass die Fotografie sichtbar die Grundlage der Skulptur sei und deren Formelemente übernommen worden seien, weshalb es sich um eine Nachahmung handele. ${ }^{195}$ Die Unterschiede, die Koons hinzugefügt hat, verhinderten gerade nicht die Identifikation der Modelle und ihrer durch Bauret gewählten Pose. Koons könne sich nicht auf eine Parodie gem. Article L. 122-5 des code de la propriété intellectuelle berufen. Die Fotografie sei zu unbekannt, als dass Koons mit „Naked“ eine komische Wirkung hervorrufen oder eine Kritik an dem Werk hätte ausüben können. ${ }^{196}$

\section{Aneignung durch digitale Technologien}

Im Folgenden soll anhand von Beispielen dargestellt werden, wie Aneignungen von Bildern durch digitale Technologien vorgenommen werden können (1.), und die Funktionsweise dieser Aneignungen erklärt werden (2.). Die ausgewählten Beispiele stehen exemplarisch für die digitale Kommunikation im Internet. Sie sind selbstverständlich nur einige von vielen denkbaren Beispielen. Mit der hier vorgenommenen Auswahl sollen möglichst verschiedene Aspekte der Kommunikation mit Bildern abgedeckt werden: die Kommunikationsziele können unterschiedlich sein und die Arten der Aneignung unterscheiden sich in der Vorlagenauswahl und dem Grad der Veränderung des übernommenen Werkes. Darüber hinaus wurden solche Aneignungen ausgewählt, die auch urheberrechtliche Fragestellungen aufwerfen.

195 Tribunal de Grande Instance de Paris, Urteil vom 09.03.2017, No. 15/01086, S. 18.

196 A.a.O., S. 19. 


\section{Phänomene}

a) Teilen von Bildern in sozialen Netzwerken

Bilder sind die am meisten geteilten ${ }^{197}$ Inhalte auf sozialen Netzwerken ${ }^{198}$ und stellen mit $43 \%$ fast die Hälfte der gesamten Inhalte dar. ${ }^{199}$ Im Jahr 2014 wurden über Snapchat 703 Millionen Fotos und über Facebook 350 Millionen Fotos pro Tag (!) geteilt. ${ }^{200}$ Dabei handelt es sich nicht immer um Fotos von anderen, die übernommen werden, sondern zum Teil auch um eigene Bilder, die hochgeladen oder geteilt werden. Es liegt daher nicht in jedem Fall eine Aneignung vor. Es gehört jedoch gerade zur Kommunikationsstruktur sozialer Netzwerke, auch fremde Bilder zu teilen. ${ }^{201}$ $\mathrm{Da}$ also häufig fremdes Material genutzt wird, ist das Teilen in sozialen Netzwerken als Phänomen der Aneignung zu diskutieren.

Um eine Aneignung handelt es sich, da das geteilte Bild auf dem eigenen Nutzerkonto dargestellt wird. Das Bild wird als eigener Inhalt wiedergegeben und gegenüber dem sozialen Netzwerk präsentiert. Die Wiedergabe des fremden Bildmaterials geschieht somit auch zu eigenen Zwecken: Es soll nicht nur das Bild wiedergegeben werden, sondern das Bild wird kommunikativ genutzt. Denn das Zielpublikum ist zumeist das eigene soziale Netzwerk aus Freunden, Bekannten und Kollegen ${ }^{202}$, zum Teil aber

197 Der Begriff des Teilens oder auch Social Sharing meint das Weiterverbreiten jeglicher Art von Information, gleich ob Text, Bild oder Video über ein soziales Netzwerk, vgl. Ziegler, Urheberrechtverletzungen durch Social Sharing, 2016, S. 13. Auch dieser Begriff macht schon den kommunikativen Bezug des Vorgangs deutlich: Es geht nicht nur um das Mitteilen, also die Äußerung einer Person, sondern um das Teilen, also die Teilhabe an den Inhalten der Äußerung.

198 Ein soziales Netzwerk ist ein Online-Dienst, über den Benutzer miteinander kommunizieren können, wie z.B. Facebook, Instagram, Twitter oder Whatsapp. $\$ 1$ Abs. 2 NetzDG definiert soziale Netzwerke als mit Gewinnerzielungsabsicht betriebene Plattformen, die dazu bestimmt sind, dass Nutzer beliebige Inhalte mit anderen Nutzern teilen oder der Öffentlichkeit zugänglich machen.

199 Kroker, Was Nutzer in sozialen Netzwerken teilen - und warum: Fotos vor Status-Updates und Artikeln, WiWo Blog vom 13.10.2014, http://blog.wiwo.de/loo k-at-it/2014/10/13/was-nutzer-in-sozialen-netzwerken-teilen-und-warum-fotos-vo r-status-updates-und-artikeln/.

200 Statistik abrufbar unter: https://de.statista.com/statistik/daten/studie/360588/um frage/soziale-netzwerke-nach-anzahl-der-darueber-geteilten-fotos-pro-tag/, Datum des Zugriffs: 15.01.2020.

201 Vgl. zur digitalen Bildkultur S. $104 \mathrm{ff}$.

202 Schmidt, Social Media, 2013, S. 26. 
auch die Öffentlichkeit. Soziale Netzwerke sind gerade auf die Interaktion der Nutzer ausgerichtet - ein Bild wird also geteilt, damit andere darauf reagieren, davon inspiriert werden, es loben, kritisieren oder diskutieren. Damit liegt häufig eine Aneignung vor.

Wenn fremde Bilder genutzt werden, sind verschiedene Abläufe der Aneignung denkbar. Das Bild kann kopiert und gespeichert werden und als selbständiges Posting ${ }^{203}$ wieder hochgeladen werden - dann wird die Aneignung als Kopie vorgenommen. Es kann jedoch auch ein bereits von jemandem anders hochgeladenes Bild abermals geteilt werden mit der „share“-Funktion, die häufig in soziale Netzwerke eingebettet ist. ${ }^{204}$ Diese stellt einen Frame-Link her. ${ }^{205}$ Dann wird die Aneignung zwar auch mit Hilfe der Kopie vorgenommen, durch die Einbettung als geteilten Inhalt liegt aber auch ein Zitat vor.

203 Ein Posting oder Post meint einen einzelnen Beitrag auf einem sozialen Netzwerk.

204 Diese Funktion, fremde Inhalte zu teilen, ist bei Facebook und Twitter integriert. Bei Instagram können die Bilder anderer Nutzer nicht geteilt werden, allerdings können sie in die „Story“ hochgeladen werden, ein Feature, bei dem die Bilder oder Videos nach 24 Stunden wieder verschwinden. In diesem Zeitraum können sie aber allen Instagram-Nutzern oder je nach Privatsphäre-Einstellung nur gewissen Kontakten angezeigt werden. Da die „Stories“ von Instagram mittlerweile mehr genutzt werden als das (dauerhafte) Teilen von Bildern auf dem Profil, kann man also auch mittlerweile hier davon ausgehen, dass fremde Bilder für alle geteilt werden können. Unter jedem Bild, das von jemandem anders geteilt wurde, kann über den Pfeil das Bild seiner „Story“ hinzugefügt werden. Diese beschriebenen Funktionen entsprechen dem technischen Stand dieser Netzwerke von Januar 2020.

205 Der Begriff des Framing oder Frame-Links wird unterschiedlich gehandhabt. Es ist jedoch immer das Einbetten eines fremden Inhalts auf der eigenen Webseite damit gemeint. Frame-Links zeigen nur einen bestimmten Ausschnitt des verlinkten Werkes innerhalb der linksetzenden Seite. Der Nutzer eines FrameLinks wird also nicht aus der verweisenden Webseite herausgeführt. Die Speichertechnik ist jedoch unterschiedlich ausgestaltet, nicht immer werden die Inhalte auch auf der linksetzenden Seite gespeichert. Diese Art des Links wird auch Inline-Link und der im Frame dargestellte Inhalt Embedded Content genannt. S. dazu ausführlich Ziegler, Urheberrechtsverletzungen durch Social Sharing, 2016, S. $103 \mathrm{f}$. 


\section{b) Das Museumselfie 206}

Ein Selfie ist ein digitales Selbstporträt, das meist spontan festgehalten wird. ${ }^{207}$ Es wird oft mit urheberrechtlich geschützten Gegenständen im Hintergrund aufgenommen, um sich selbst im Lichte dieser Gegenstände darzustellen. So ist es üblich geworden, mit Sehenswürdigkeiten, beeindruckenden Bauten oder Kunstwerken im Museum ein Selfie zu knipsen. ${ }^{208}$ Diese Selfies werden dann über soziale Netzwerke geteilt, wobei im Hintergrund ein fremdes Werk oder Bild zu sehen ist. Damit handelt es sich bei dem Museumselfie um eine Aneignung: Das fremde Bild im Hintergrund wird gezeigt, um sich selbst damit ins Bild zu bringen und sich in Beziehung zu dem übernommenen Bild zu setzen.

Das Selfie hat sich zu einer „Weltsprache“209 entwickelt, es ist eine Massenbewegung. Dabei gehen Selfies immer in einer kommunikativen Situation auf: „Es geht darum, andere zu überraschen und zu unterhalten sowie einen an sich schon emotional starken Moment durch ein Selfie noch in-

206 Neben dem Museumselfie sind selbstverständlich auch sämtliche andere Arten der Fotografie im Museum in sozialen Netzwerken präsent. Die Vielfalt dieser Museumsfotografien reicht von der Reproduktionsfotografie, Porträtfotos neben Gemälden oder Skulpturen hin zu Fotos, bei denen Gesichtsausdrücke oder Körperhaltungen von Figuren des ausgestellten Werkes nachgeahmt werden. Das Selfie wurde hier exemplarisch für diese Museumsfotografien ausgewählt, weil es sich dabei um eine speziell in sozialen Netzwerken präsenten Art der Fotografie handelt.

207 Dudenredaktion (Hrsg.), Selfie, in: Duden. Deutsches Universalwörterbuch, 2015. Ausführlich zur Bedeutung von Selfies für die digitale Bildkultur s. Ullrich, Selfies. Die Rückkehr des öffentlichen Lebens, 2019.

208 Vgl. zu den Menschenmassen, die Selfies mit der Mona Lisa im Louvre machen, sodass man das Bild selbst häufig kaum noch betrachten kann: Reyburn, What the Mona Lisa Tells Us About Art in the Instagram Era, New York Times vom 27.04.2018, https://www.nytimes.com/2018/04/27/arts/design/mona-lisa-instagra m-art.html. Dazu auch das Video von Daniel McKee, der ein Video aus Selfies mit der Mona Lisa zusammengeschnitten hat, die er bei Instagram gefunden hat: https://vimeo.com/240696384, Datum des Zugriffs: 15.01.2020.

209 Ullrich, Selfies als Weltsprache, in: Müller-Tamm/Schäfer (Hrsg.), Ich bin hier! Von Rembrandt zum Selfie, Ausstellungskatalog der Staatlichen Kunsthalle Karlsruhe, des Musée des Beaux-Arts in Lyon und der National Galleries of Scotland in Edinburgh, 2015, S.32, 32. Damit meint er, dass die ausgedrückten Emotionen bei Selfies meist weltweit verstanden werden. Dies liege unter anderem an der expressiven Zuspitzung in Selfies durch aufgerissene Augen, herausgestreckte Zungen, breites Lächeln oder Kussschnuten (sog. Duckface), ders., a.a.O., S. 34 . 
tensiver zu erleben." ${ }^{210}$ Selfies sind damit kommunikative Handlungen, die das Ich in das Wahrnehmungszentrum von Selfie-Produktion und -Rezeption rücken. ${ }^{211}$ Gleichzeitig sind sie auch Teil der Inszenierung der eigenen Person und der medialen Symbiose zwischen Aufführung/Performance und Wahrnehmung durch und mit Medien. ${ }^{212}$ Derjenige, der ein Selfie aufnimmt, macht also nicht nur ein Bild von sich, sondern macht sich selbst zum Bild. 213

Zur Konstruktion des eigenen Selbstbildes werden seit einigen Jahren häufig Selfies mit ausgestellten Bildwerken in Museen gemacht und dadurch auf Idole der Kunstgeschichte zurückgegriffen. ${ }^{214}$ Sie lassen den Museumsbesucher eine aktive Rolle einnehmen und die „Beschäftigung mit Kunst als kreative Reaktion auf die Werke [...] begreifen." ${ }^{215}$ Außerdem verheißen sie eine Teilhabe an der Kunst - durch das Selfie darf sich jeder für einen Moment als Künstler und Porträtist fühlen ${ }^{216}$ und durch die Selfies können die Werke direkt mit der eigenen Lebenswelt verknüpft werden. Diesem Bedürfnis nach Selfies kommen mittlerweile auch die Museen selbst nach. Häufig ist zwar das Fotografieren in Ausstellungsräumen noch verboten. Es werden teilweise jedoch sog. Instawalks angeboten als exklusive Führungen, die ausdrücklich zu Selfies mit den ausgestellten Bildwerken aufrufen. ${ }^{217}$ Bei dieser Aktion werden die Werke im Museum so ausgestellt, dass besonders gute Fotos für das soziale Netzwerk Instagram geschossen werden können. Außerdem haben zahlreiche Museen am Museum Selfie Day ${ }^{218}$ teilgenommen und für diesen Tag Fotografierverbo-

210 Ders., a.a.O., S. 35.

211 Stiegler, Selfies und Selfie Sticks. Automedialität des digitalen Selbstmanagements, in: Stiegler/Breitenbach/Zorbach (Hrsg.), New Media Culture, Mediale Phänomene der Netzkultur, 2015, S. 67, 67.

212 Ders., a.a.O., S. 68.

213 Ullrich, Selfies. Die Rückkehr des öffentlichen Lebens, 2019, S. 12.

214 Fritz, Comeback. Kunsthistorische Renaissancen in der Gegenwart, in: Kunsthalle Tübingen/Fritz (Hrsg.), Comeback. Kunsthistorische Renaissancen, 2019, S. 11, 18.

215 Ullich, Der kreative Mensch, 2016, S. 98.

216 Ders., a.a.O., S. 98.

217 So wurden Instawalks beispielsweise bereits vom Städel Museum Frankfurt, Bode Museum in Berlin, Lehmbruck Museum, Deutschen Nationalmuseum Bonn, Frankfurter Kunstverein und vom Landesmuseum Hannover veranstaltet.

218 Jeweils der 17.01. eines Jahres. Die Aktion wurde 2014 von Mar Dixon ins Leben gerufen. 
te gekippt. ${ }^{219}$ Am 01.04.2018 öffnete in Los Angeles gar ein „Museum of Selfies“ für wenige Monate, in der die Geschichte des Selfies dargestellt wurde mit interaktiven Installationen, mit denen selbst wiederum Selfies gemacht werden konnten. ${ }^{220}$

Die Aneignung als Museumselfie funktioniert meist durch eine Kopie, indem das Bildwerk eines anderen mit abgelichtet wird. Zudem kann es je nach Kontext auch eine Hommage darstellen oder eine Parodie, letzteres insbesondere bei Veränderung des ursprünglichen Bildgehalts durch das Selfie. ${ }^{221}$

\section{c) Memes}

Memes sind Bild-Text-Kombinationen, die im Internet geteilt werden, bei denen das Bild häufig Fremdmaterial darstellt. ${ }^{222}$ Der Begriff des Meme stammt ursprünglich von Richard Dawkins. Er meinte ein kulturelles Pendant zur Evolution, also kulturelle Einheiten, die wie die Gene zur Genetik stehen. ${ }^{223}$ Die Kulturwissenschaftlerin Shifman hat digitale Memes wie folgt definiert: „(a) eine Gruppe digitaler Einheiten, die gemeinsame Eigenschaften im Inhalt, in der Form und/oder der Haltung aufweisen, die (b) in bewusster Auseinandersetzung mit anderen Memen erzeugt und (c) von vielen Usern im Internet verbreitet, imitiert und/oder transformiert wurden."224 Auf Webseiten wie memegenerator.net kann nach vorhandenen, bereits typisierten Bildern gesucht werden und durch Einfügen eines

219 Vgl. Cords, Der „Museum Selfie Day“ sorgt für Besucherandrang, DW vom 17.01.2018, http://www.dw.com/de/der-museum-selfie-day-sorgt-für-besucheran drang/a-42176075. Bilder sind unter \#MuseumSelfieDay in den sozialen Netzwerken abrufbar.

220 Meier, Geplantes Museum of Selfies. Die Hölle ist Millenial Pink, Monopol Magazin vom 30.01.2018, https://www.monopol-magazin.de/das-museum-selfies-di e-hoelle-ist-millennial-pink.

221 So z.B., wenn Gesichtsausdrücke der fotografierenden Person dem Selfie eine bestimmte Bedeutung geben.

222 Maier, Meme und Urheberrecht, GRUR-Prax 2016, S. 397, 397.

223 „Examples of memes are tunes, ideas, catch-phrases, clothes fashions, ways of making pots or of building arches. Just as genes propagate themselves in the gene pool by leaping from body to body via sperms or eggs, so memes propagate themselves in the meme pool by leaping from brain to brain via a process which, in the broad sense, can be called imitation.", Dawkins, The Selfish Gene [1976], 2006, S. 192.

224 Shifman, Meme. Kunst, Kultur und Politik im digitalen Zeitalter, 2014, S. 44. 
Textes ein neues Meme geschaffen werden. Die Texte des Memes werden immer wieder modifiziert, sodass das Meme immer neue Kontexte und neue Bedeutungen produziert. Mit den Veränderungen des Textes, aber dem immer gleichen Bild oder der Grafik verstetigt sich das Konzept des Memes - es bekommt ein Eigenleben und einen Metatext. Dieser Metatext sind die abstrakten Eigenschaften, wie das Meme inhaltlich und formal genutzt wird, wie man es korrekt ergänzt und erweitert. ${ }^{225}$ Dieser Metatext gehört zu einem Meme Type. ${ }^{226}$ Meme Typen können durch immer wieder neu generierte Token fortgeführt werden (bekannte Typen sind z.B. „Grumpy Cat", „Overly Attached Girlfriend“, „Success Kid“, „Socially Awkward Penguin“ 227 oder „Scumbag Steve“).

Memes werden durch Aneignung vorgenommen, da ein vorgefundenes Bild genutzt und übernommen wird, das durch einen eigenen Text ergänzt wird. Nur der Text stellt die Abweichung dar zu anderen Token dieses Memes. Das Bild wird hier also genutzt, um ein neues Meme zu erzeugen und dieses Meme soll innerhalb der Internetkultur und sozialen Netzwerken wiederum kommunikativ genutzt werden. ${ }^{228}$ Die Aneignung wird explizit als ein Merkmal von Memes angesehen. ${ }^{229}$ Techniken der Aneignung sind zumeist die 1:1-Kopie des Bildes oder eine Nachahmung oder Imitation des für dieses Meme üblichen Bildes. Häufig wird auch das Zitat genutzt, wenn der Allgemeinheit bekannte Bilder Teil des Memes sind. Darüber hinaus kann je nach Kontext und Aussage des Memes auch eine

225 Grünewald-Schukalla/Fischer, Überlegungen zu einer textuellen Definition von Internet-Memes, kommunikation @ gesellschaft 19 (2018), S. 7.

226 vgl. auch Herwig, Viralität als Sonderfall: über Selfies, Serialität und die Wahrscheinlichtkeit der Kommunikation im Social Web, komunikation@gesellschaft, 19 (2018), S. 4.

227 Abb. 10.2. Dieses Meme wurde in verschiedenen Varianten drei Jahre lang vom Tech Blog GetDigital genutzt. Dafür erhielten sie im April 2015 eine Abmahnung in Höhe von 785,40 Euro von Getty Images, der Fotoagentur, die die Rechte an dem Bild hält, s. Kühl, Socially Awkward Urheberrecht, Die Zeit vom 04.09.2015, https://www.zeit.de/digital/internet/2015-09/getty-images-urheberre cht-meme-socially-awkward-penguin/komplettansicht. Denn das Foto des Adelie-Pinguins wurde von George F. Mobley für National Geographic aufgenommen, vgl. Abb. 10.1. Für das Meme „Socially Awkward Penguin“wurde dieses Foto übernommen und vor einen anderen Hintergrund positioniert. Mittlerweile ist auch eine neue, gemeinfreie Version des "Socially Awkward Penguin" verfügbar, abrufbar unter: https://memegenerator.net/New-Socially-A wkward-Penguin/caption, Datum des Zugriffs: 15.01.2020.

228 Vgl. ausführlicher zur digitalen Netzkultur S. $107 \mathrm{ff}$.

229 So von Grünwald-Schukalla/Fischer, Überlegungen zu einer textuellen Definition von Internet-Memes, kommunikation @ gesellschaft 19 (2018), S. 7. 


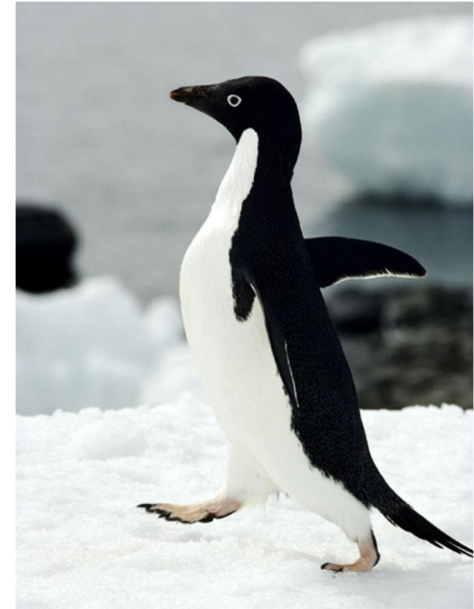

Abb. 10.1.: George F. Mobley/Getty Images, Fotografie, 2009.

\section{START TELLTNG JOKE}

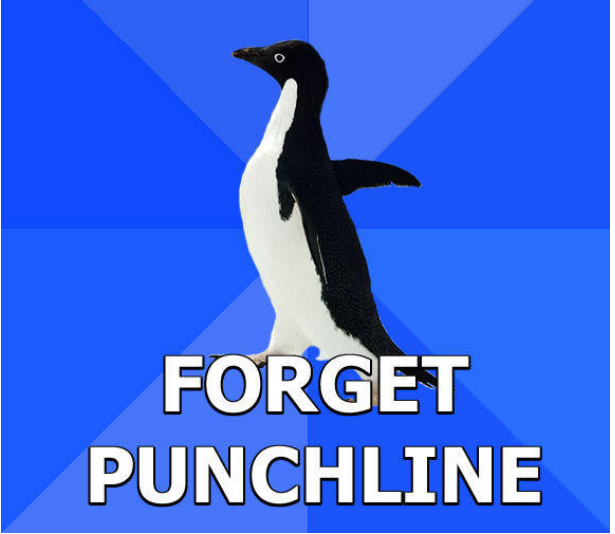

Abb. 10.2.: ein Beispiel des Meme „Socially Awkward Penguin", o.A.

Parodie oder Hommage vorliegen. ${ }^{230}$ Mit jeder neuen Bild-Text-Kombination eines neu erstellten Memes kann zudem von einem Original gesprochen werden.

\section{d) GIFs}

GIFs sind Bilder oder kleine Filme in Endlosschleife, die nur zwei bis fünf Sekunden lang sind. Der Name bezeichnet eigentlich einen Dateityp von 1987: Das Graphics Interchange Format, mit dem mehrere Einzelbilder übereinander abgespeichert werden, die durch das Betrachtungsprogramm als Animation dargestellt werden. GIF kann sowohl ein einzelnes Bild bezeichnen, das rotiert, blinkt, oder ähnlich animiert ist, als auch mehrere

230 Der Medienwissenschaftler Wershler sieht Memes als die digitalen Sprösslinge der Pop Art, Performance Kunst und Konzeptkunst an, da Memes deren konzeptuelle Techniken übernehmen, um sich gegen Vorgänger aufzulehnen und den Status quo zu unterlaufen, s. Bucknell, What Memes Owe to Art History, Artsy vom 30.05.2017, https://www.artsy.net/article/artsy-editorial-memes-owe-a rt-history. 
Bilder, die das GIF als Animation darstellen lassen. ${ }^{231}$ Dabei lassen die Einzelbilder gemeinsam das GIF wie einen kurzen Filmausschnitt wirken, die einzelnen Frames der Einzelbilder bleiben aber deutlich sichtbar. Die Nutzung von GIFs im Internet ist weit verbreitet - so nutzen 55 Millionen Menschen jeden Monat die Webseite giphy.com, wo jeden Tag Millionen GIFs hochgeladen werden. ${ }^{232}$ Auch Whatsapp, Twitter und der FacebookMessenger greifen auf diese Datenbank zurück, damit GIFs direkt in ihren Apps genutzt werden können.

GIFs bestehen ganz überwiegend aus fremden Bildern, häufig solchen aus Filmen oder Serien. Es liegt also eine Übernahme fremden Materials vor, meist sind die Mittel dieser Aneignung die Kopie oder das Zitat. GIFs werden genutzt, um schnell und effizient Reaktionen, Kommentare und Gefühle online austauschen zu können. ${ }^{233}$ Damit wird das Fremdmaterial auch zu eigenen Zwecken genutzt, nämlich zu kommunikativen.

\section{e) Die Bildmontage von Kunstwerken}

Die Bildmontage ist eine Verfremdung von Bildern - es wird vorgefundenes Material genutzt und neu kombiniert. ${ }^{234}$ Bilder werden mit anderen zusammengeschnitten, Farben verändern, Personen eingefügt oder die porträtierte Person verändert. Oft werden auch popkulturelle Phänomene oder Gegenstände imitiert und eingefügt. Auch bei größeren Ereignissen entstehen solche Bildmontagen: Berühmte Vorbilder werden so variiert und kombiniert, sodass sie das jeweilige Ereignis grotesk kommentieren und zugleich mit dem kollektiven Bildgedächtnis in Beziehung setzen. ${ }^{235}$ Die Bildmontage nutzt gerne bekannte, im Gedächtnis verankerte Bilder. Dadurch wird die Verfremdung offensichtlich, wodurch ein humoristischer oder sogar parodistischer Effekt entstehen kann. Deshalb sind Kunstwerke von der Montage häufig betroffen.

231 Zur Definition: Cambridge Dictionary (Hrsg.), „GIF“, Cambridge University Press, und Tanriverdi, Ein Gif sagt mehr als 1000 Worte, SZ vom 14.09.2015, http://www.sueddeutsche.de/digital/bewegte-bilder-ein-gif-sagt-mehr-als-worte-1 .2643863 .

232 So Leibsohn, der COO von Giphy, in: Tanriverdi, a.a.O.

233 Vgl. dazu auch Pachali, Die Kommerzialisierung der Gifs, irights info vom 29.03.2018, https://irights.info/artikel/die-kommerzialisierung-der-gifs/29036.

234 Vgl. auch die Definition der Montage als Mittel der Aneignung auf S. 40.

235 Ullich, Rebloggen als Kulturtechnik, in: Landwehr (Hrsg.), Public Domain. Edition Digital Culture 3, 2015, S. 92, 94. 


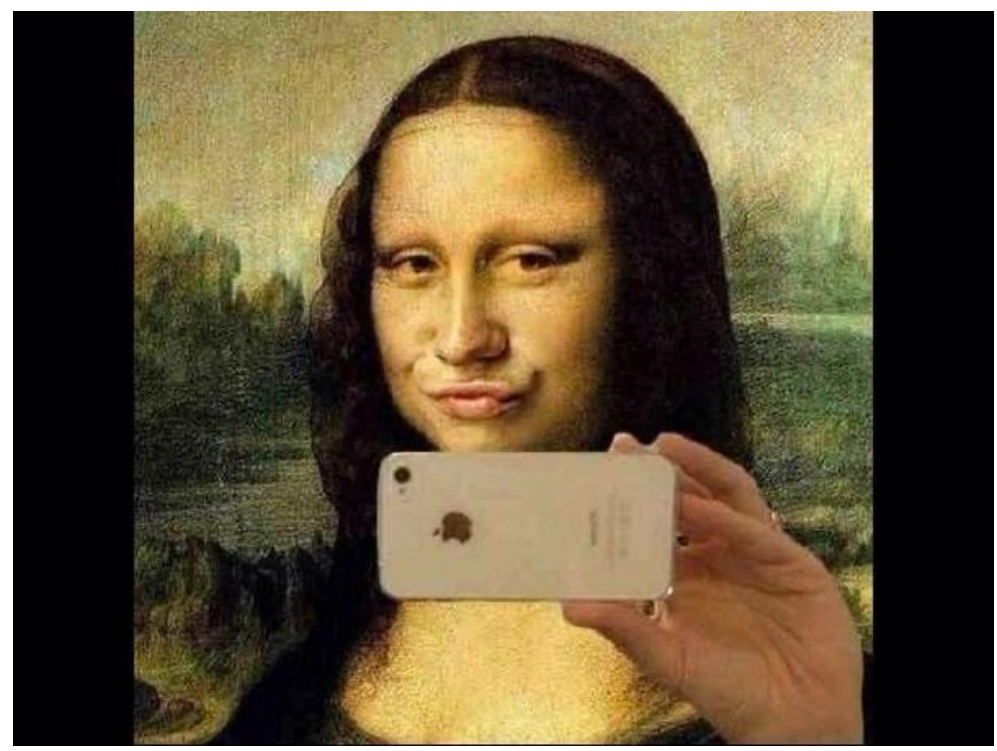

Abb. 11.: Mona Lisa Selfie Montage, o.A.

Dies soll durch eine Auswahl unterschiedlicher Beispiele verdeutlicht werden. Die „Mona Lisa“ (1503-1506) von Leonardo da Vinci - als das bekannteste Gemälde der Welt - wird im Internet häufig abgewandelt und verfremdet. Eine bekannte Montage zeigt sie mit dem typischen Selfie Kussmund („Duckface“) und mit einem Handy in der Hand. ${ }^{236}$ Sie wird verschleiert oder in traditioneller Kleidung anderer Kulturen gezeigt, sie bekommt Tattoos, sie wird mit Lego-Steinen oder einer Barbiepuppe nachgebaut, ihr Gesicht wird ersetzt durch Gesichter von Mr. Bean oder Barack Obama. ${ }^{237}$ Auch der „Schrei“ (1893) von Edvard Munch wird im Internet für immer neue Montagen genutzt: So gibt es ihn als Kürbis zu sehen, aus Pappe oder Lego und mit Figuren der Serie Simpsons. ${ }^{238}$ Die Seite „Classical Art Memes" ${ }^{\text {“239 }}$ zeigt Memes bekannter Kunstwerke, die durch digitale

236 Abb. 11.

237 Für eine Übersicht der Abwandlungen der Mona Lisa: http://knowyourmeme.c $\mathrm{om} /$ search?context=images\&q=mona+lisa, Datum des Zugriffs: 15.01.2020.

238 Für eine Sammlung der kreativen Variationen vgl.: https://rp-online.de/digitales /so-kreativ-feiert-das-netz-der-schrei_bid-9603675, Datum des Zugriffs: 15.01.2020.

239 https://www.facebook.com/classicalartmemes/, Datum des Zugriffs: 15.01.2020. 
Verfremdungen oder ergänzende Kommentare überraschend zeitgenössische Zusammenhänge herstellen. ${ }^{240}$ Aus der vermeintlichen Verbindung einer jahrhundertealten Szene mit einer allseits bekannten, gegenwärtigen Situation ergibt sich eine besondere Komik. ${ }^{241}$ Die Sammlung „Museum of Selfies" von Olivia Muus arrangiert bekannte Porträts so, als würden die porträtierten Personen selbst Selfies aufnehmen. ${ }^{242}$ Sie fotografiert dafür eine Hand mit einem Handy so, als würde die Person auf dem Porträt auf das Handy schauen. Der Künstler Alexey Kondakov montiert Figuren aus klassischen Kunstwerken in Fotos von Alltagssituationen der heutigen Zeit und schafft so eine moderne Interpretation der Kunstwerke. ${ }^{243}$ So findet man William-Adolphe Bouguereaus "Virgin of the Angels“ (1881) in einem leeren Zugabteil fahren oder Maria Magdalena aus Franceso Furinis „Die büßende Maria Magdalena (Halbfigur)“ (um 1630/1635) in dem Schaufenster eine Cafés sitzen. Die Menschen der Kunstwerke werden durch diese Montagen Teil unserer Realität.

Die Aneignung von Bildmontage funktioniert immer durch die Übernahme des angeeigneten Kunstwerkes: Es wird kopiert oder imitiert. Durch die Veränderung und Verfremdung des ursprünglichen Bildes sollen Emotionen besser ausgedrückt werden können oder eine Reflektion über veränderte Kulturpraktiken und den Wandel der Zeit stattfinden. Oft sind die Bildmontagen auch Hommagen und Parodien, je nachdem, wie die Veränderung vorgenommen wird und welche Aussage mit ihr getroffen wird. Die Bildmontage selbst kann auch ein Original sein.

\section{f) Virale Hypes}

Unter dem Stichwort Virale Hypes sollen hier Videos und Bilder besprochen werden, die von Tausenden Menschen angeschaut werden, sich im Internet schnell verbreiten und dadurch viral ${ }^{244}$ werden. Hype meint die

240 Hartel, Ein Selfie mit Mona Lisa. Alte Meister in der Populärkultur, in: Kunsthalle Tübingen/Fritz (Hrsg.), Comeback. Kunsthistorische Renaissancen, 2019, S. $47,48$.

241 Dies., a.a.O., S. 48.

242 Vgl. http://museumofselfies.tumblr.com, Datum des Zugriffs: 15.01.2020.

243 Für eine Bilderreihe vgl. Monopol Magazin vom 6.11.2015, https://www.monop ol-magazin.de/engel-der-u-bahn, Datum des Zugriffs: 15.01.2020.

244 Worthintergrund aus der Medizin: Die Hypes entwickeln sich ähnlich wie Ansteckungen bei Epidemien. Zur viralen Form der Kommunikation im Digitalen vgl. Han, Im Schwarm. Ansichten des Digitalen, 4. Aufl. 2017, S. 74 ff. 
Welle der Begeisterung ${ }^{245}$, die durch die Videos ausgelöst wird. Die Viralität wird verstärkt, wenn Menschen dazu ermuntert werden, den Hype nicht nur zu teilen, sondern damit verbundene Aktivitäten auszuführen ${ }^{246}$ und selbst ein Video oder Bild des viralen Hypes aufzunehmen.

Beispiele von viralen Hypes sind Planking, die Ice Bucket Challenge und der Harlem Shake. Beim Planking lassen sich Menschen fotografieren, die sich steif wie ein Brett mit dem Gesicht nach unten an ungewöhnlichen Orten hinlegen. Dieser Foto-Trend aus dem Jahr 2011 ist aus der Facebook-Truppe „The Lying Down Game“ entstanden, die damals über 100.000 Mitglieder und 20.500 Fotos beinhaltete. ${ }^{247}$

Die Ice Bucket Challenge aus dem Jahr 2014 bezeichnet Mutprobe-Videos, bei denen sich der Teilnehmer mit einem Eimer eiskalten Wasser überschütten lässt, um auf die Nervenkrankheit Amyotrophe Lateralsklerose (ALS) aufmerksam zu machen. Die Teilnehmer nominierten jeweils andere Personen, die auch ein solches Video drehen und 10 Dollar an die ALS Association spenden sollten - oder, wenn sie sich nicht mit einem Eimer Wasser überschütten wollten, 100 Dollar an die ALS Association spenden sollten. So kamen zwischen dem 15.07. und 21.08.2014 bei der ALS Association 41,8 Millionen USD Spenden ein. ${ }^{248}$

Der Harlem Shake im Jahre 2013 war ein Hype selbstgedrehter Videos, in denen Menschen wie bei einem Flashmob ${ }^{249}$ aufeinander trafen und dann mit zuckenden Bewegungen zu einem Song von Harry Rodrigues,

245 Dudenredaktion (Hrsg.), Hype, in: Duden. Deutsches Universalwörterbuch, 2015.

246 Vgl. dazu die Definition von Shifman zu Viralität: Shifman, Meme. Kunst, Kultur und Politik im digitalen Zeitalter, 2014, S. 70. Hemsly und Mason nennen drei Merkmale von Viralität im Internet: 1. die Verbreitung von Mensch zu Mensch, 2. eine hohe Geschwindigkeit, die durch Social-Media-Plattformen noch beschleunigt wird, 3. eine große Reichweite, die erreicht wird, indem mehrere Netzwerke überbrückt werden, vgl. Hemsley/Mason, The Nature of Knowledge in the Social Media Age: Implications for Knowledge Management Models, Journal of Organizational Computing and Electronic Commerce, $\mathrm{Nr}$ 12 (2013), S. 138, 138.

247 S. http://knowyourmeme.com/memes/lying-down-game, Datum des Zugriffs: 15.01.2020.

248 S. Pressemitteilung der ALS Association vom 21.08.2014, http://www.alsa.org/n ews/media/press-releases/ice-bucket-challenge-082114.html, Datum des Zugriffs: 15.01.2020.

249 Ein Flashmob ist ein Phänomen, bei dem sich eine Gruppe Fremder an einem öffentlichen Ort versammelt, plötzlich simultan eine bestimmte Handlung ausführt und den Schauplatz danach blitzartig verlässt, vgl. Shifman, Meme. Kunst, Kultur und Politik im digitalen Zeitalter, 2014, S. 98. 
bekannt als DJ Baauer, tanzten. ${ }^{250}$ Ausgelöst wurde der Video-Hype von Filthy Frank, der das erste Harlem Shake-Video bei YouTube hochlud. Er fand 40.000 Nachahmer weltweit. 251

Virale Hypes entstehen also, indem die Komposition, Handlung, Bildabfolge bestimmter Videos übernommen wird. Hier wird nicht 1:1 kopiert, sondern das Konzept des Bildes oder Videos immer wieder nachgeahmt. Jede Nachahmung fügt etwas Eigenes hinzu - darin besteht der Teilnahmeeffekt dieser Hypes. ${ }^{252}$ Die Vorlage muss deutlich erkennbar bleiben, aber die immer neu entstehenden Abwandlungen, z.B. durch Aufnahmen an besonderen Orten oder mit besonderen Verkleidungen, machen das Anschauen dieser Bilder- und Video-Hypes abwechslungsreich und humoristisch. Die Übernahme liegt hier also in der Nachahmung des Konzepts mit dem Zweck der Teilnahme an einem Hype zu humoristischen, kommunikativen Zwecken. Die Aneignung geschieht durch Imitation und stellt eine Hommage oder ein Zitat dar. Da die meisten Videos etwas Eigenes, Neues hinzufügen und eine gewisse Abweichung zum Ausgangsvideo aufweisen, können sie unter Umständen auch als Original bezeichnet werden.

\section{Funktionsweise: kommunikativer Kontext}

Aneignungen werden häufig durch neue, oft digitale Technologien durchgeführt, denn nie ließ sich etwas so leicht kopieren, verändern und wiederverwerten wie heute. Die Auswahl der soeben vorgestellten Phänomene bildlicher Aneignung durch neue Technologien basiert darauf, dass sie eine ähnliche Funktionsweise aufweisen. Die vorgestellten Phänomene der Aneignung erfolgen hauptsächlich online in sozialen Netzwerken. Diese sozialen Medien sind in ihrer Grundstruktur bereits auf Konversation ausgerichtet. ${ }^{253}$ Mithilfe des stets mitgeführten Smartphones wird mittlerweile „unterwegs, zwischendurch, pausenlos und in Fragmenten“ 254 kommu-

250 Schmidt, Social Media, 2013, S. 9.

251 Mayr, Zappeln, was das Zeug hält, Spiegel Online vom 13.02.2013, http://www. spiegel.de/panorama/gesellschaft/harlem-shake-erobert-das-internet-a-882955.ht $\mathrm{ml}$.

252 Vgl. Dobusch, Digitale Remixkultur, in: Landwehr (Hrsg.) Public Domain. Edition Digital Culture 3, 2015, S. 89, 89.

253 Schmidt, Social Media, 2013, S. 27.

254 Tanriverdi, Ein Gif sagt mehr als 1000 Worte, SZ vom 14.09.2015, http://www.su eddeutsche.de/digital/bewegte-bilder-ein-gif-sagt-mehr-als-worte-1.2643863. 
niziert. Das vorgefundene Material wird genutzt, um schneller Konversation zu betreiben - ein Bild kopiert und versendet, anstatt Gedanken ausführlich niederzuschreiben. Außerdem werden vorgefundene Bilder genutzt, um Empfindungen oder Gefühle verständlicher ausdrücken zu können - dies funktioniert insbesondere mit solchen Bildern, die bereits stark im kollektiven Gedächtnis verankert sind, wie bei Memes, GIFs und Bildermontagen zu sehen ist. ${ }^{255}$

255 Vgl. auch hierzu detailliert die Funktionsweise der digitalen Kommunikation, S. $107 \mathrm{ff}$. 


\section{Zweites Kapitel: Die veränderte Nutzung von Aneignungen}

Die Aneignung als die Übernahme fremden Materials zu eigenen Zwecken $^{256}$ wird seit jeher praktiziert. Das folgende Kapitel wird die Nutzung der Aneignung und die ihr zugeschriebene Bedeutung historisch untersuchen. Dabei soll die veränderte Nutzung der Aneignung nachvollzogen werden: Zunächst als ein künstlerisches Mittel sind nun durch die Digitalisierung jedermann technische Geräte zur Aneignung zugänglich, sodass sie sich zu einem kommunikativen Medium entwickelte.

Es sollen zunächst die Richtungen der Bildenden Kunst vorgestellt werden, deren Mittel solche der Aneignung waren (A.). Welchen Bedeutungswandel bildliche Aneignungen mit der Digitalisierung und der dadurch veränderten Bildkultur erfahren haben, soll zum Schluss dieses Kapitels aufgezeigt werden (B.). Die Aneignung muss in den größeren Kontext der Kunst- und Kulturgeschichte eingeordnet werden. Erst durch den Blick zurück in die Kulturgeschichte und durch die Darstellung des diskursiven Rahmens, innerhalb dessen sich die Aneignung bewegt, kann die Zielrichtung und Bedeutung ihrer Nutzung verstanden werden. Der Fokus liegt hierbei zunächst auf philosophischen und kunsthistorischen Konzepten, die Aneignungen thematisieren. Nicht immer geht es dabei um die bildliche Aneignung, jedoch statuieren viele philosophische Konzepte ein grundlegendes Kunstverständnis, sodass diese mittelbar auch Auswirkungen auf das Verständnis von Bildern und Bildender Kunst haben. Der Bedeutungswandel, den die Aneignung von Bildern erfahren hat durch die Digitalisierung und Vernetzung des Internets, kann erst verstanden werden, wenn die vorher bestehende Kulturtechnik der Aneignung in der Kunst verdeutlicht wird.

256 S. zu dieser Definition S. $32 \mathrm{f}$. 


\section{A. Historische Nutzung der Aneignung}

I. Die Antike: Aneignung als wertschätzende Auseinandersetzung mit der Vorlage

\section{Platon und die Nachahmung der Wirklichkeit}

Bereits Platon setzt sich mit der Aneignung in der Kunst auseinander, um seine Vorstellungen von Dichtung darzustellen. Im zehnten Buch der Politeia prägte er den Begriff der mimesis, was so viel wie Nachahmung der Wirklichkeit bedeutet. Platon ging davon aus, dass die Welt zu unterteilen ist in eine sinnlich wahrnehmbare und eine Welt der Ideen, zwischen denen das Verhältnis der Teilhabe oder Nachahmung besteht. Die sinnlich wahrnehmbare Welt ist dabei bereits ein Abbild der Ideenwelt. ${ }^{257}$ Die Künste befassen sich nur mit dieser sinnlich wahrnehmbaren Welt, also den Abbildern, und produzieren damit Abbilder von Abbildern. ${ }^{258}$ Damit seien die Künste zu weit entfernt von den platonischen Ideen und können keinen Aussagewert für die Erkenntnis von Wahrheit liefern. Die Nachahmungen durch die Dichtung seien daher Trugbilder - unvollkommen und scheinhaft. ${ }^{259}$ Mimesis habe also wenig Erkenntniswert für die Menschen, Aneignungen haben damit wenig Bedeutsamkeit.

\section{Aristoteles und die Nachahmung als Natur des Menschen}

Aristoteles setzt mit seiner Poetik dieser Kritik durch Platon eine Rehabilitation der mimesis entgegen. Zunächst meint Aristoteles, dass sich platonische Idee der Dinge in den sinnlich wahrnehmbaren Gegenständen verwirkliche, deren Abbildung ist also bereits die Wirklichkeit selbst. ${ }^{260}$ Damit schaffe die Kunst nicht allein Trugbilder. Außerdem versteht Aristoteles mimesis als grundsätzliches Mittel zum Erkenntnisgewinn der Menschen: „Denn sowohl das Nachahmen selbst ist den Menschen angeboren [...] als auch die Freude, die jedermann an Nachahmungen hat."261

257 Platon, Der Staat, 2012, 10. Buch, Rn. 597a ff.

258 Gebauer/Wulf, Mimesis. Kultur, Kunst, Gesellschaft, 2. Aufl. 1998, S. 58.

259 Dies., a.a.O., S. 59.

260 Aristoteles, Poetik, 3. Aufl. 1972, S. 159.

261 Ders., a.a.O., S. 11. 
Menschliches Handeln ist also mimesis der Natur und dem Menschen ureigen.

Speziell in der Kunst kommt der mimesis nach Aristoteles zudem eine ethische Wirkung zu. In seiner Tragödienlehre vertritt er, dass erst durch mimesis das Reinigen von Gefühlen, die katharsis möglich ist. ${ }^{262}$ Durch die Anteilnahme werden die Zuschauer von ihren eigenen Affekten geläutert, von ihren Lüsten und Ängsten. Nur durch das Erkennen, das durch die mimesis hergestellt wird, sei diese Läuterung möglich, die den Charakter der Menschen stärkt. Die Aneignung in der Kunst dient hier also als Ventil für die Menschen und soll ihnen die emotionale Teilhabe an der Wirklichkeit ermöglichen, indem die Wirklichkeit künstlich wiederholt wird.

\section{Bildhauerei im Römischen Reich: Aneignung griechischer Skulpturen}

Das Kopieren bereits vorhandenen Materials aus der Bilderhauerei fand im Römischen Reich seinen ersten Höhepunkt. Mit der Eroberung griechischer Gebiete übernahmen die Römer auch griechisches Kulturgut. ${ }^{263}$ Zum Teil wurde dieses Kulturgut „römisiert“, also an die römische Geschichte und Kultur angepasst. ${ }^{264}$ Die griechische Formensprache wurde Vorbild für römische Bildhauer. Die meisten römischen Marmor-Skulpturen sind Kopien von griechischen Bronzegüssen.265 Dabei war die Intention nicht, die Reproduktion so genau anzufertigen, dass das Original in ihr zu erkennen ist. Vielmehr hatte man damals nur begrenzte Darstellungsthemen: Die Darstellungsthemen wurden standardisiert realisiert, damit

262 Die Tragödie zeigt einen Helden, der durch einen charakterlichen Fehler ins Unglück stürzt. Es kommt in der Tragödie immer zu einem Umschlag von Glück ins Unglück. Dabei hätte der Held den Fehler nicht vermeiden können, er handelt also ohne Schuld. Die Zuschauer erkennen den charakterlichen Fehler des Helden und können den Umschlag ins Unglück erkennen und damit das tragische Schicksal des Helden ahnen. Dieses Wiedererkennen im Helden führt beim Zuschauer zu Jammern und Schaudern vor seinem Schicksal.

263 Barbanera, Original und Kopie. Bedeutungs- und Wertewandel eines intellektuellen Begriffspaares seit dem 18. Jahrhundert in der Klassischen Archäologie, in: Akzidenzen 17. Flugblätter der Winckelmann-Gesellschaft (2006).

264 Heutzutage würde dies wohl als kulturelle Aneignung bezeichnet werden. Vgl. zu dem Begriff S. $31 \mathrm{f}$.

265 Stähli, Die Kopie. Überlegungen zu einem methodischen Leitkonzept der Plastikforschung, in: Junker/Stähli/Kunze (Hrsg.), Original und Kopie, 2008, S. 15, 15 . 
eine bessere Lesbarkeit der Themen, die die Skulptur darstellte, möglich war. ${ }^{266}$

Mit diesem Interesse der Römer an griechischen Skulpturen und Kunstwerken entwickelte sich das Sammeln derselben zu einer Beschäftigung wohlhabender Bürger. Um die Nachfrage zu befriedigen, entstand ein gewisses Kopistentum, das fabrikartig arbeitete. Einen weiteren Vorteil der vielen Kopien kann man erst heute schätzen: Die griechischen Vorbilder sind häufig nicht mehr erhalten, sodass es heute möglich ist, durch die römischen Reproduktionen noch deren Vorbilder zu sehen.267

\section{Imitatio und aemulatio: die wettstreitende Aneignung}

Auch philosophisch setzte man sich in der Antike mit der Aneignung in der Kunst auseinander. In den Rhetorik-Schulen dienten die Begriffe imitatio und aemulatio für verschiedene Strategien, um die möglichst perfekte Rede zu halten. Die Strategien wurden aber auch schon von Cicero in eine literarische Nachahmungstheorie eingebettet und später in der Renaissance als Begrifflichkeiten mit der Bildenden Kunst und der Kunstgeschichte verbunden. ${ }^{268}$ In letzterem Kontext meint imitatio das Kopieren von Kunstwerken anderer zur eigenen Weiterentwicklung ${ }^{269}$ - vom Original zu lernen, indem man es nachvollzieht. Erst durch die perfekte Nachahmung kann das Handwerk der Vorbilder verstanden werden. Aemulatio meint die Nacheiferung nach einem Vorbild. Durch sie soll die Überbietung des Vorbildes ermöglicht werden. Diese Nachahmung wurde in der Rhetorik im Rahmen eines institutionalisierten Wettstreits der Künstler ausgeführt, der zu einer Qualitätssteigerung führen sollte. ${ }^{270}$ Nachahmung und Aneignung stehen hier also nicht im Gegensatz zu Originalität, sondern werden gerade als Voraussetzungen für gutes Handwerk und eigenes kreatives Schaffen verstanden.

266 Ders., a.a.O., S. 30.

267 Almeroth, Kunst- und Antiquitätenfälschungen, 1987, S. 9.

268 B. Bauer, aemulatio, in: Ueding (Hrsg.), Historisches Wörterbuch der Rhetorik, 1992, S. 141, 142.

269 Blunck, Wann ist ein Original?, in: Nida-Rümelin/Steinbrenner (Hrsg.), Kunst und Philosophie. Original und Fälschung, 2011, S. 9, 19.

270 Müller/Pfisterer, Der allgegenwärtige Wettstreit in den Künsten der Frühen Neuzeit, in: dies. (Hrsg.), Aemulatio, Kulturen des Wettstreits in Text und Bild (1450-1620), 2011, S. 1, 3. 


\section{Das Mittelalter und die Renaissance: Aneignung der Antike}

\section{Das Mittelalter und Aneignungen im handwerklichen Lehrverhältnis}

Während des Mittelalters kam dem Original noch keine eigenständige Bedeutung zu. ${ }^{271}$ Bildende Kunst wurde in Schulen gelehrt, sodass die Einreihung in die Tradition der Vorgänger wichtig war. Bei der Beurteilung eines Kunstwerkes standen die Beherrschung des Handwerks und die verwendeten, möglichst kostbaren Materialien im Vordergrund. ${ }^{272}$ Außerdem war zunächst das Sammeln von Kunst in der Gesellschaft selten; so wurde hauptsächlich klerikale Kunst im Auftrag der Kirche geschaffen. Doch auch hier war schon anerkannt, dass Kopieren auch das Hervorbringen neue Werke fördern kann. ${ }^{273}$

Maler und Bildhauer waren im Mittelalter in Gilden oder Zünften als Organisationseinheiten zusammengeschlossen, aus denen sie sich erst im 15. Jahrhundert langsam lösten. ${ }^{274}$ Die Ausbildung der bildenden Künstler und der Bildhauer fand innerhalb eines handwerklichen Lehrverhältnisses statt. Kunst war also im Mittelalter (wie auch in der Antike) ein Ausbildungsberuf, der betrieben wurde wie andere Handwerke auch - das Schüler-Meister-Verhältnis dominierte die Ausbildung. Die Schüler lernten bei einem Meister, hielten dessen Lehren ein und arbeiteten in dessen Werkstatt. Dabei entwickelte sich in den Werkstätten Arbeitsteilung: Der Meis-

271 Als Beispiel neben der Kunst kann hier auch das Phänomen der Urkundenfälschungen bis Mitte des 13. Jahrhunderts herangezogen werden. Für solche gefälschten Urkunden, die aber inhaltlich den Tatsachen entsprachen, oder solche, die den Tatsachen entsprachen, wie sie sein sollten (!), fehlte das Unrechtsbewusstsein. Ein Grund hierfür mag darin liegen, dass die Unterscheidung von formalem Recht und Gerechtigkeit noch nicht ausgereift war, und damit Manipulationen und Fälschungen zulässig waren, um die „gerechte“ Ordnung herzustellen - auch wenn sie formal nicht rechtens waren, so Kölzer, Urkundenfälschungen im Mittelalter, in: Corino (Hrsg.), Gefälscht! Betrug in Politik, Literatur, Wissenschaft, Kunst und Musik, 1994, S. 15, 16. So wird geschätzt, dass $40 \%$ der Urkunden Karl des Großen „gefälscht" sind. Als die bekannteste Urkundenfälschung ist die sog. Konstantinische Schenkung in die Geschichte eingegangen - eine Urkunde, in der der römische Kaiser Konstantin I. dem Papst Silvester I. und sämtlichen Nachfolgern die Herrschaft über die Westhälfte des Römischen Reiches vermachte sowie ihm kaiserliche Ehrenrechte und Insignien verlieh.

272 Almeroth, Kunst- und Antiquitätenfälschungen, 1987, S. 11.

273 Gebauer/Wulf, Mimesis. Kultur, Kunst, Gesellschaft, 2. Aufl. 1998, S. 96.

274 Ausführlich zur Loslösung der bildenden Künste aus dem Handwerk vgl. Zilsel, Die Entstehung des Geniebegriffes, 1926, S. 144 ff. 
ter traf die Entscheidungen bezüglich der Komposition und der Motive, die Schüler führten die einzelnen Arbeiten aus. Der Meister vervollständigte das Bild und kümmerte sich häufig nur noch um Details, die mehr Können verlangten oder für ihn typisch waren. ${ }^{275}$ Wenn ein Gemälde also vom Werkstattmeister signiert wurde, bedeutete das nicht, dass er es eigenständig gemalt hatte, sondern dass es dem Anspruch der Werkstatt entsprach. Die Schüler hingegen waren angehalten, sich am Meister zu orientieren und in seinem Stil zu malen. ${ }^{276}$ So schrieb Cennino Cennini in seinem Lehrbuch über die Malerei von 1400, das zum einflussreichsten Lehrbuch des Spätmittelalters wurde: „Vergnüge dich unermüdlich mit dem Nachahmen der besten Sachen, die du in den Händen der großen Meister finden kannst!“. ${ }^{277}$ Mit den Lockerungen der Kunst vom Handwerk, lockerten sich auch die Abhängigkeiten des Schülers vom Meister. Doch auch in den Kunstakademien, die ab Mitte des 16. Jahrhunderts entstanden ${ }^{278}$, wurde durch das Nachahmen der alten Künstler gelehrt: Die Schüler gingen in die Galerien und Museen, um die „alten Meister“ zu kopieren und so von ihnen zu lernen. ${ }^{279}$

\section{Renaissance: die Aneignung der Antike}

Mit der Renaissance im 15. und 16. Jahrhundert wurde die Antike wiederbelebt (wörtlich auch „Wiedergeburt“). ${ }^{280}$ Ganz bewusst kopierte man Elemente des Gedankenguts der Antike: Die Formensprache bei Baudenkmä-

275 So hat Raffael meist nur die Hände und Gesichter in seinen Gemälden selbst gemalt, Whistler, Raffaels Hände, in: Gnann (Hrsg.), Raffael. Ausstellungskatalog der Albertina Wien, 2017, S. 41, 42.

276 Zilsel, Die Entstehung des Geniebegriffes, 1926, S. $211 \mathrm{ff}$.

277 Cennini, Das Buch von der Kunst oder Il Libro dell'Arte [1871], 2015, Kapitel 27, S. 53.

2781563 wurde die Accademia delle Arti del Disgeno in Florenz gegründet, die erste reine Lehranstalt.

279 Darauf basierte unter anderem das Ausbildungsmodell der Académie des Beaux Arts in Paris, das im 17. Jahrhundert als Vorbild für andere Kunstakademien galt. Dem Lehrplan gemäß wurden zunächst Zeichnungen der großen Meister kopiert und erst in der zweiten Stufe klassische Gipsmodell und lebende Akte kopiert. Vgl. dazu Vogt, Von Kunstworten und -werten, 2010, S. 168.

280 Mit der Wiederbelebung der Antike wollte man sich auch bewusst von der Vorstellungswelt des Mittelalters abwenden, insbesondere von der christlichen Betonung des Jenseits und der christlichen Geschichtsbetrachtung, vgl. Rebbelmund, Appropriation Art, 1999, S. 47. Diese Abwendung zeigt sich auch an der 
lern und Skulpturen wurde übernommen und in der Philosophie widmeten man sich den Texten und Ideen antiker Schreiber. Im Geist der Antike sah man die eigenen Vorstellungen und Weltanschauungen widergespiegelt. ${ }^{281}$ Damit lebten auch die rhetorischen Traditionen wieder auf und Begriffe wie imitatio und aemulatio. Die Rhetorik als Bestandteil des mittelalterlichen Bildungskanons führte dazu, dass diese Begriffe Eingang in die Literaturtheorie und -erstellung fanden. So wurden sie genutzt für die Bezugnahme auf griechische und römische Klassiker in der Literatur und Bildenden Kunst.

Über die rhetorischen Traditionen fand auch der Begriff der inventio wieder Einzug. Dieser beschrieb zunächst das erste Produktionsstadium beim Verfassen einer Rede: das Auffinden des Themas und Organisieren der Gedanken dazu. In der Renaissance wurde er für als Begriff der Bilderfindung genutzt. In seiner Abhandlung „Über die Malerei“ schrieb Ludovico Dolce 1557, dass die Malerei anhand der Erfindung (inventio), der Komposition und dem geistigen Konzept der Zeichnung (disegno) und dem Kolorit (colorito) zu beurteilen sei. Der Begriff der disegno wurde insbesondere durch Giorgio Vasari, einem der ersten Kunsthistoriker, im Jahre 1547 geprägt. ${ }^{282}$ Hier wurde also bereits zwischen der materiellen Verwirklichung und der künstlerischen Idee unterschieden. Die Komposition wurde damit unabhängig von ihrer Ausführung in Farbe oder Stein bewertet und diente als zentrales Kriterium der fachlichen Beurteilung des Kunstwerks. ${ }^{283}$ Mit der intellektuellen Präzisierung seines bildnerischen Einfalls konnte ein Künstler seine Qualität beweisen, die Ausführung war für die fachliche Beurteilung dann nicht mehr notwendig. ${ }^{284}$ Damit war

Begriffseinführung des „Mittelalters“ durch die Humanisten zu Beginn der Renaissance im 14. Jahrhundert. Mit der Antike als Ideal und der Renaissance als Rückkehr zu diesem Ideal, wurden die Jahre dazwischen nur als medium aevum, als mittleres Zeitalter, verstanden. Da sich im Mittelalter vom antiken Ideal abgewandt wurde, stellt es aus Sicht der Humanisten ein Zeitalter des Zerfalls und kulturellen Niedergangs dar. Daher kommt auch der Begriff des „dunklen Zeitalters", aetas obscura, für das Mittelalter.

281 So Rebbelmund, Appropriation Art, 1999, S. 48.

282 Kemp, Disegno. Beiträge zur Geschichte des Begriffs zwischen 1547 und 1607, Marburger Jahrbuch für Kunstwissenschaft 19 (1974), S. 219, 224.

283 Vgl. Stoschek, Anfänge der vervielfältigten Kunst und die leidige Frage nach dem Original, in: Tietjen/Weibel (Hrsg.), Kunst ohne Unikat, Ausstellungskatalog der Neuen Galerie am Landesmuseum Joanneum, im Künstlerhaus Graz, 1998, S. 14.

284 Ullich, Raffinierte Kunst. Übung vor Reproduktionen, 2009, S. 11. 
auch eine Arbeitsteilung zwischen Komposition und Ausführung möglich, wie sie in den Werkstätten organisiert wurde.

\section{Rennaissance-Humanismus und die Individualität der Künstlerpersönlichkeit}

Durch das Aufkommen des Renaissance-Humanismus im 15. und 16. Jahrhundert stand nun der Mensch als Individuum im Mittelpunkt und damit auch die einzelne Künstlerpersönlichkeit und nicht mehr schwerpunktmäßig das handwerkliche Können. Kunst wurde zum ersten Mal als Ausdruck der Persönlichkeit verstanden. Dass ein neuer Begriff von Subjektivität entstand, erkennt man auch an dem damaligen Aufkommen von Konzepten wie der Autobiographie und Portraitkunst. Immer mehr fürstliche Mäzene, und nicht mehr allein die Kirche ${ }^{285}$, verteilten Aufträge an Künstler, sodass sich der Künstler von klerikalen Vorgaben lösen konnte und die Themen und Darstellungen in der Kunst weniger beschränkt waren. Mit der Vielfalt der Themen stieg wiederum die Bedeutsamkeit der Künstlerpersönlichkeit, die nun auch den Inhalt selbst schaffen konnte. Dabei orientierten sich die Künstler zwar auch noch an den „Alten“, sie wurden aber als Stilvorbilder angesehen und weniger als konkrete Normen, an die man sich bei der Produktion von Kunst zu halten hatte. ${ }^{286}$

Die neuen Techniken der Reproduktion durch Druckgraphiken (Holzschnitt und Kupferstich) führten zu einer „Massenproduktion“. Dabei kam damals der Unterscheidung zwischen Unikat und Reproduktion keine wertende Beurteilung zu. Die Auflagenhöhen der Druckgraphiken wird erst seit 1880 festgelegt und dadurch zwischen Künstlergraphik und Reproduktionsgraphik unterschieden. ${ }^{287}$

Mit der Verschiebung zu fürstlichen Auftraggebern entstand auch eine Sammelleidenschaft ${ }^{288}$ an den Fürstenhöfen. Dadurch verbreiteten sich

285 So Almeroth, Kunst- und Antiquitätenfälschungen, 1987, S. 13.

286 Gebauer/Wulf, Mimesis. Kultur, Kunst, Gesellschaft, 2. Aufl. 1998, S. 122.

287 Stoschek, Anfänge der vervielfältigten Kunst und die leidige Frage nach dem Original, in: Tietjen/Weibel (Hrsg.), Kunst ohne Unikat, Ausstellungskatalog der Neuen Galerie am Landesmuseum Joanneum, im Künstlerhaus Graz, 1998, S. 13, 24.

288 Die Sammelleidenschaft begann zunächst mit sog. Kunstkammern, in denen sich naturgeschichtliche und wissenschaftliche Gegenstände finden ließen. Sie drückten das zeitgenössische Bemühen aus, die gesamte göttlich-kosmische Ordnung des Universums im Kleinen, den Makrokosmos im Mikrokosmos, abzu- 
Kunstfälscher, wobei ihnen keine grundsätzlichen Bedenken des Erstellens von Kopien entgegengehalten wurden, sondern eher Fragen der Authentizität von Werken. ${ }^{289}$ Beispielhaft hierfür wird oft das Vorgehen Albrecht Dürers gegen Kopien seiner Holzschnitte angeführt. Dürer verklagte 1506 angeblich $^{290}$ den Künstler Marantonio Raimondi in Venedig, da er einen Druck des „Marienlebens“ (1502) von Dürer in Kupfer gegossen habe. Dabei sei Ziel des Prozesses allerdings nicht gewesen, den Druck der Kopie zu untersagen, sondern gegen das Nutzen des Monogramms AD durch Raimondi vorzugehen, mit dem Dürer seine Werke gekennzeichnet hat. ${ }^{291}$

\section{Die Neuzeit: Eigenschöpferisches und Geniekult statt Aneignung}

\section{Geniekult in Aufklärung und Sturm und Drang}

Im 18. Jahrhundert änderte sich die Vorstellung über den Künstler und den Schaffensvorgang. Die voranschreitende Säkularisierung und die Auf-

bilden, um so auch den imperialen Charakter der Fürstenhöfe zu betonen. Mit der Hofkunst, der Beauftragung von Künstlern durch Fürsten, wurden auch immer mehr Werke der Bildenden Kunst gesammelt. Die Kunstkammern wie die Kunstsammlungen sollten die Gelehrsamkeit und die ihrem Rang gemäße Machtfülle ihrer Besitzer widerspiegeln, s. Stolzenberger, Höfisches Sammeln und internationale Tendenzen in der Kunst um 1600, in: Hess/Hirschfelder (Hrsg.), Renaissance, Barock, Aufklärung. Kunst und Kultur vom 16. bis zum 18. Jahrhundert, 2010, S. 270, 271, 282.

289 Stähli, Die Kopie. Überlegungen zu einem methodischen Leitkonzept der Plastikforschung, in: Junker/Stähli/Kunze (Hrsg.), Original und Kopie, 2008, S. 15, 16.

290 Diese Anekdote berichtete der Maler und Schriftsteller Giorgio Vasari, sie gilt aber als nicht plausibel und hat so wohl nicht stattgefunden, s. Petri, Der Fall Dürer vs. Raimondi. Vasaris Erfindung, in: Münch/Tacke/Herzog/Heudecker (Hrsg.), Fälschung - Plagiat - Kopie. Künstlerische Praktiken der Vormoderne, 2014, S. 52, 62.

291 Stoschek, Anfänge der vervielfältigten Kunst und die leidige Frage nach dem Original, in: Tietjen/Weibel (Hrsg.), Kunst ohne Unikat, Ausstellungskatalog der Neuen Galerie am Landesmuseum Joanneum, im Künstlerhaus Graz, 1998, S. 13, S. 18 f. Seinen Serien „Apokalypse“, „Holzschnittpassion“ und „Marienleben“, die er erneut 1511 als Bücher verlegte, fügte er allerdings eine Warnung hinzu: „Hüte dich, heimlicher Neider und Dieb fremder Arbeit und Erfindung, lass deine Hände von diesen unseren Werken.“, übersetzt aus dem Lateinischen nach Decker, Dürer. Konstruktion eines Vorbildes, in: Beck (Hrsg.), Dürers Verwandlung in der Skulptur zwischen Renaissance und Barock, Ausstellungskata$\log$ des Liebighaus, 1981, S. 397, 422. 
klärung führten zu einer Entzauberung der Welt292, aber auch zu einer Aufwertung des Menschen - er übernimmt jetzt das, was bisher dem Göttlichen zugeschrieben wurde. ${ }^{293}$ Damit war Raum für den Genie-Gedanken geschaffen. Immanuel Kant bezeichnete Genie als ein „Talent, dasjenige, wozu sich keine bestimmte Regel geben lässt, hervorzubringen." ${ }^{294}$ Ein Genie ist damit der unabhängig von Kultur und Tradition schöpferische Mensch, der sich gegen die Normen der Kunst wendet und vielmehr durch seine Leidenschaft Kunst schafft. Es vollzog sich eine Hinwendung zum Individuellen, Ursprünglichen, Irrationalen und Exzentrischen des Schöpfers. ${ }^{295}$ Die individuelle Empfindung wurde nun als Grundlage der Erkenntnis verstanden. Insbesondere im Sturm und Drang um 1770 wurde dies von Autoren aufgegriffen, die das "Originalgenie“ verherrlichten. Shakespeare wurde als dessen Verkörperung angesehen - obwohl gerade Shakespeare sich viel an Mythologien, an Handlungen und Texten anderer Schriftsteller bediente.

Viele dieser Genie-Auffassungen wurden von Juristen rezipiert und fanden Einfluss in das deutsche Urheberrechtsgesetz, das 1871 verabschiedet wurde. ${ }^{296}$ Vom Geniegedanken lässt sich die Vorstellung des Urhebers als Schöpfer ableiten. Auch wurde das Schaffen eines Werkes verstanden als das Entäußern eines Teils der Persönlichkeit nach außen: „Die Verfertigung eines Buchs, es sey was es für eins wolle, ist eine wahre Schöpfung, das Manuscript ist ein Theil seiner Substanz, welche der Schriftsteller aus sich herausgibt.“"297 Eigenhändigkeit und Individualität als maßgebliche Kriterien des urheberrechtlichen Schutzes sind auch auf die genieästhetische Konzeption des Künstlers zurückzuführen. ${ }^{298}$

Gleichzeitig wurde nun die Lehrmethode des Kopierens der Meister im Lehrverhältnis mit dem Aufkommen des Neuhumanismus im 18. Jahrhundert, der Aufklärung und der Genie-Ästhetik des Sturm und Drang im-

292 Weber, Wissenschaft als Beruf [1919], in: ders., Schriften 1894-1922, 2002, S. $474,488$.

293 Schmidt, Die Geschichte des Genie-Gedankens in der deutschen Literatur, Philosophie und Politik: 1750-1945, 3. Aufl. 2004, S. 6.

294 Kant, Kritik der Urteilskraft [1790], in: Kant/Weischelde (Hrsg.), Werkausgabe, 13. Aufl. 1994, Bd. 10, $\$ 46$ S. 241 f.

295 Schmidt, Die Geschichte des Genie-Gedankens in der deutschen Literatur, Philosophie und Politik: 1750-1945, 3. Aufl. 2004, S. $110 \mathrm{ff}$.

296 Bosse, Autorschaft ist Werkherrschaft, 2014, S. 10.

297 Linguet, Des Herrn Linguets Betrachtungen über die Rechte des Schriftstellers und seines Verlegers, 1778, S. 48.

298 Blunck, Wann ist ein Original?, in: Nida-Rümelin/Steinbrenner (Hrsg.), Kunst und Philosophie. Original und Fälschung, 2011, S. 9, 13. 
mer mehr kritisiert. So formulierte Johann David Passavant seine Ablehnung dieser Ausbildung: „Übrigens halte ich überhaupt bei angehenden Künstlern das viele Copieren für sehr nachteilig, da sie dadurch zu sehr verleitet werden, nur eine gewisse practische Fertigkeit zu suchen und es sie dagegen verhindert, ihre Individualität auszubilden, wodurch sie ihre Selbständigkeit verlieren und in eine falsche Nachahmung großer Meister gerathen. " ${ }^{299}$ Andererseits sah man in der Lehrmethode des Kopierens jetzt auch mehr Raum für eine schöpferische Nachahmung. So ist in Goethes Gedicht „Künstlers Apotheose“, in dem ein Schüler in einer Gemäldegalerie die großen Meister nachmalt, vom Meister zu hören:

„Meister: Allein du übst die Hand,

Du übst den Blick, nun üb' auch den Verstand.

Dem glücklichsten Genie wird's kaum einmal gelingen, sich durch Natur und durch Instinkt allein

Zum Ungemeinem aufzuschwingen:

Die Kunst bleibt Kunst! Wer sie nicht durchgedacht,

Der darf sich kein Künstler nennen;

Hier hilft das Tappen nichts; eh' man Gutes macht,

Muß man es erst recht sicher kennen. “300

Das Kopieren sieht der Meister im Gedicht als notwendig an, um künstlerische Fertigkeiten zu erlangen. Allerdings ist auch dadurch erst eine differenzierte, schöpferische Nachahmung möglich:

„Meister: Erkenne, Freund, was er geleistet hat, Und dann erkenne, was er leisten wollte.“301

2. Klassizismus: abermals Aneignung der Antike

Mit dem Aufkommen des Klassizismus im späten 18. Jahrhundert bis zum frühen 19. Jahrhundert wurden wieder der Formenkanon der Antike ${ }^{302}$ sowie Motive und Mythologie der römischen und griechischen Antike rezi-

299 Passavant, Ansichten über die bildenden Künste und Darstellung des Ganges derselben in Toscana, 1820, S. $111 \mathrm{f}$.

300 Goethe, Werke. Hamburger Ausgabe, 1998, Band 1, S. 71 f., Vers 92-98.

301 Ders., a.a.O, S. 73, Vers $131 \mathrm{f}$.

302 Nach Winckelmann zeichneten sich diese durch ihre „edle Einfalt“ und „stille Größe" aus, vgl. Winckelmann, Gedancken über die Nachahmung der Griechischen Wercke in der Mahlerey und Bildhauer-Kunst [1755], 2013, S. 27. 
piert. ${ }^{303}$ Maler und Bildhauer orientierten sich aber auch an der Renaissance. Johann Joachim Winckelmann, der geistige Begründer der Klassizismus, forderte die Nachahmung in der Kunst: „Der einzige Weg für uns, groß, ja wenn es möglich ist, unnachahmlich zu werden, ist die Nachahmung der Alten [...]."304 Damit beeinflusste er auch wesentlich die Weimarer Klassik, die gemeinsame Schaffensperiode von Goethe und Schiller ab $1786 .^{305}$

\section{Die Moderne: Aneignung als künstlerisches Mittel und Unabhängigkeit von der Vorlage}

\section{Die Klassische Moderne und die Entwicklung zur Abstraktion}

Mit dem Beginn der Klassischen Moderne änderte sich die thematische Auseinandersetzung in der Kunst. Mit der Entwicklung einer massentauglichen Fotografie 1888 und des Filmes mit Erfindung des Kinetoskops 1891 wurde eine rein abbildende Kunst überflüssig. Im Hinblick auf die Nachahmung waren beide Medien der Bildenden Kunst überlegen. Dies führte einerseits zur Abstraktion in der Kunst hin zur Nichtgegenständlichkeit. Kunst musste nicht mehr zwangsläufig eine Referenz zur Welt transferieren, sie musste nicht mehr mimetisch die Natur und Gegenstände abbilden. Insbesondere der Kubismus öffnete hierzu die Tür, der den

303 Der Purismus und die einfachen, klaren Formen der Antike wurden als Gegenmodell zur dekorativen und ornamentalen Kunst des Rokokos und späten Barocks gesehen, die mit dem Feudalismus assoziiert wurden. Es war noch nicht bekannt, dass die antiken Skulpturen ursprünglich bunt bemalt waren, also viel weniger puristisch waren als ihre heutige Erscheinungsform es vermuten lässt.

304 Winckelmann, Gedancken über die Nachahmung der Griechischen Wercke in der Mahlerey und Bildhauer-Kunst [1755], 2013, S. 10. Dabei herrschte zur Zeit des Klassizismus allerdings noch kein Bewusstsein dafür, dass die Mehrzahl der damals bekannten Skulpturen als römische Kopien griechischer Originale anzusehen sind, vgl. dazu S. 85 f. und Barbanera, Original und Kopie. Bedeutungsund Wertewandel eines intellektuellen Begriffspaares seit dem 18. Jahrhundert in der Klassischen Archäologie, Akzidenzen 17, Flugblätter der WinckelmannGesellschaft (2006), S. 8.

305 Dies zeigt sich auch am neuhumanistischen Bildungsideal von Wilhelm von Humboldt: Das Studium der griechischen Sprache und Kultur sei ein wirksames Mittel zur Persönlichkeitsentwicklung, denn in der griechischen Antike sei das Menschsein schon fast zur Vollendung gereift, vgl. Humboldt, Über das Studium des Altertums und des Griechischen insbesondere [1793], 1932. 
Schwerpunkt auf die Form des Werkes verlagerte und versuchte, die geschlossene Form der dargestellten Gegenstände und Körper zu sprengen. So wollte man im Kubismus Simultaneität schaffen, also einen Gegenstand gleichzeitig aus verschiedenen Perspektiven darstellen. Die Form eines Gegenstandes wurde also in mehrere Formen unterteilt. Als wohl radikalstes abstraktes Gemälde kann Kasimir Malewitschs „Das schwarze Quadrat auf weißem Grund" von 1915 gelten. ${ }^{306}$

Eine weitere Entwicklung neben der Abstraktion war die Hinwendung zur Analyse der Kunst selbst und ihrer Prozesse. Es fand nun in Kunstwerken auch eine Auseinandersetzung darüber statt, was Kunst überhaupt sei und wie sie stattfindet. Dies ließ neue Kunstrichtungen entstehen, die neue Medien und Darstellungsformen nutzten. Damit einher ging das Aufgeben eines universalen Wahrheitsanspruchs der Kunst. Abbildung der Wirklichkeit war nun nicht mehr Hauptaufgabe der Kunst - der Schwerpunkt verlagerte sich vom Darzustellenden auf die Darstellungsformen. Dies führte dazu, dass sich zahlreiche Strömungen und Bewegungen mit unterschiedlichen Erscheinungsformen von Kunst neu entwickelten und parallel existierten. Dieser Stilpluralismus ist prägend für die Moderne.

Außerdem entwickelten sich das Kaufen und die Produktion von Kunst hin zu einem Kunstmarkt. Sammlungen von Privatleuten wurden bedeutender und nahmen museumsartige Ausmaße an - erst später wurden diese tatsächlich in öffentliche Museen umgestaltet oder die Privatsammlung verliehen. Mit der Entwicklung des Kunsthandels wurde auch der finanzielle Wert der Kunst wichtiger und damit auch die Unterscheidung zwischen Original und Kopie. Mit der Aufwertung des Gegensatzpaares Original und Kopie ging eine Abwertung des zweiten Begriffs einher. ${ }^{307}$

\section{Die Collage: Aneignung vorgefundenen Materials}

Die Collage ${ }^{308}$ als Technik in der Bildenden Kunst fand durch George Braque und Pablo Picasso Einzug. Mit dem Kubismus begannen sie, andere Materialien aufzumalen (z.B. Holzstrukturen), später nutzten sie Zei-

306 Das Gemälde wurde bei der Ausstellung „0,10“ 1915 in Petrograd ausgestellt. Hier war der eigentliche Skandal nicht die radikale Abstraktion des Gemäldes, sondern seine Hängung. Es wurde in einer ganz oben in der Ecke des Raumes schräg nach unten befestigt.

307 Vgl. Rebbelmund, Appropriation Art, 1999, S. 59.

308 Zur Definition als Technik des Aufklebens von vorgefundenem Material s. S. 40 . 
tungsausschnitte, Glas, Musiknoten, Tapetenreste, Stoff und andere Gegenstände, um sie direkt in ihre Kunstwerke zu inkorporieren (sog. papier collé). Dabei wurde die Materialität dieser Gegenstände hervorgehoben die Kunst ahmte nicht mehr die Wirklichkeit nach, sondern integrierte sie direkt in das Kunstwerk.

Diese Arbeit mit vorgefundenem Material, aus dem etwas Neues geschaffen wird, prägte auch später die Appropriation Art. Louis Aragon sieht Duchamps Ready-mades in der Tradition der Collage: „To me these are the logical consequences of the initial gesture of collage. What is now maintained, is on the one hand, the negation of technique, as in collage, as well of the ,technical personality'; the painter, if we can still call him that, is no longer bound to his canvas by a mysterious physical relationship analogous to procreation." ${ }^{309}$

Die Künstler des Dadaismus ${ }^{310}$ griffen die Technik der Collage auf. Sie haben allerdings nicht nur Materialien, sondern auch ganze Gegenstände in ihre Kunstwerke eingebunden. Ebenso arbeiteten sie mit der Fotomontage, einer Collage aus fotografischem Material, und der Assemblage, der Collagetechnik bei dreidimensionalen Objekten. Vorgefundene Gegenstände, die in ein Kunstwerk integriert wurden, wurden als objets trouvés bezeichnet.

\section{Ready-mades: Aneignung von Alltagsgegenständen}

Auch Ready-mades ${ }^{311}$ arbeiten wie Collagen und objets trouvés mit bereits vorhandenem Material. Dabei gingen die Künstler hier sogar noch einen

309 Aragon, The Challenge to Painting [1930], in: Evans (Hrsg.), Appropriation. Documents of Contemporary Art, 2009, S. 27, 27.

310 Eine künstlerische und literarische Gruppe, die 1916 in Zürich gegründet wurde. Der Dadaismus verfolgte ein „Anti-Kunst“, die nicht mehr zu einer Sinnstiftung für den Menschen beitrug. Die Folgen des Ersten Weltkrieges zerstörten den Glauben an absolute menschliche Normen, gesellschaftliche Moral und den Individualismus. Der Dadaismus wollte keine Wirklichkeitsabbildung mehr schaffen, sondern aus sich selbst heraus wirken. Dabei musste die Kunst gerade keinen Realitätsbezug aufweisen, keine Referenz in die Welt tragen. In der Literatur zeigt sich das durch Lautgedichte, bei denen Sprache als Material verwendet wird - nicht die Bedeutung steht im Vordergrund, sondern der Klang.

311 Der Begriff des Ready-made kommt ursprünglich aus der Modeindustrie und bezeichnet Konfektionsbekleidung anstatt von Ware nach Maß, s. Rebbelmund, Appropriation Art, 1999, S. 77. 
Schritt weiter: Es wird ein Alltagsgegenstand vollständig und ohne weiteres Hinzutun in den Kunstkontext überführt - und nicht lediglich als Teil in das Kunstwerk übernommen. Anders als beim objet trouvé wird also der Alltagsgegenstand vollständig als Kunstwerk präsentiert.

Bekannte Beispiele von Ready-mades hat Marcel Duchamp geschaffen: Seine Skulptur „Fountain“ von 1917 ist ein zur Seite gekipptes, handelsübliches Urinal, dass er mit dem Pseudonym R. Mutt unterzeichnet hat. Dies reichte er im April 1917 bei der Ausstellung der Society of Independent Artists in New York ein. Dort kam es zu einem Eklat und „Fountain“ wurde von der Ausstellung ausgeschlossen - woraufhin Duchamp aus der Society austrat. Ein noch radikaleres Ready-made von Duchamp ist der „Flaschentrockner" von 1914: Hier wurde der Gegenstand in seiner reinen, unveränderten Form aus seinem Gebrauchskontext gelöst und in den Kunstkontext gestellt.

Nach Marcel Duchamp fehlt Ready-mades jede Einmaligkeit, die sonst üblicherweise Kunstwerken zugeschrieben wurde: „Another aspect of the ,readymade' is its lack of uniqueness - the replica of a ,readymade delivering the same message; in fact nearly every one of the ,ready mades ${ }^{6}$ existing today is not an original in the conventional sense. "312 Mit dem Ready-made stellt sich die Frage nach dem Wesen der Kunst: Der künstlerische Akt liegt hier nur noch in der Auswahl und der Umdefinition. Kann allein die Re-Kontextualisierung einen Gegenstand zum Kunstwerk machen? Gemäß Kosuth ändert die Kunst mit dem Ready-made ihre Ausrichtung von der Form auf das Gesagte. ${ }^{313}$ Auch die Appropriation Art arbeitet mit der Umwidmung von Vorgefundenem, auch wenn sie anderes künstlerisches Material nutzt und weniger Alltagsgegenstände. Insofern ähnelt Appropriation Art den Ready-mades - sie setzt sich ebenso selbstreflexiv mit dem Wesen von Kunst auseinander. ${ }^{314}$ Allerdings findet keine Re-Kontextualisierung in das Kunstumfeld statt wie beim Ready-made. Der Appropriation Art Künstler Mike Bidlo stellt sich auch ganz bewusst in den Kontext von Duchamp: „Duchamp praktizierte vielleicht als erster von allen die Appropriation, als er ein Pissoir nahm, es in Fountain umtaufte, und signierte.

312 Duchamp, Apropos of Ready Mades [1961], in: Evans (Hrsg.), Appropriation. Documents of Contemporary Art, 2009, S. 40, 40.

313 Kosuth, Theft after Kant, in: Tietjen/Weibel (Hrsg.), Kunst ohne Unikat, Ausstellungskatalog der Neuen Galerie am Landesmuseum Joanneum, im Künstlerhaus Graz, 1998, S. 91, 92.

314 Deswegen wird Duchamp auch als geistiger Vorläufer der Appropriation Art gesehen, so Vahrson, Die Radikalität der Wiederholung, 2006, S. $54 \mathrm{f}$. 
Wenn ich eine Reproduktion von Picasso anfertige, sie signiere und erkläre, dies sei Kunst, dann ist das Kunst! Duchamp hat es 1917 bewiesen. “315

\section{Walter Benjamin und die Aura des Originals}

Eine gezielte Auseinandersetzung mit den ästhetischen Unterschieden zwischen Original und Reproduktion findet man in Walter Benjamins Essay „Das Kunstwerk im Zeitalter der technischen Reproduzierbarkeit“, den er 1936 in der Zeitschrift für Sozialforschung veröffentlicht hat. Anlass war die massenhafte Reproduktion von Kunst, die durch die technisch fortgeschrittene Entwicklung von Film und Fotografie möglich ist. „Was im Zeitalter der technischen Reproduzierbarkeit des Kunstwerks verkümmert, das ist seine Aura. ${ }^{316}$ Mit Aura meint er das Hier und Jetzt eines Kunstwerkes, sein einmaliges Dasein an dem Ort, an dem es sich in der Geschichte befindet. ${ }^{317}$ Diese Aura sei nicht reproduzierbar: „Die Reproduktionstechnik [...] löst das Reproduzierte aus dem Bereich der Tradition ab. Indem sie Reproduktion vervielfältigt, setzt sie an die Stelle seines einmaligen Vorkommens sein massenweises." 318 Die Entwertung des Originals sei auch auf politischer Ebene kritisch zu sehen. Durch die Reproduktionsmöglichkeiten entstehe eine kollektive Ästhetik: „Die technische Reproduzierbarkeit des Kunstwerks verändert das Verhältnis der Masse zur Kunst.“319 Dadurch entstehe die Gefahr der politischen Vereinnahmung durch Kunst. Wenn Kunst kein kultisches Ritual mehr darstellt, könne Politik diese Leere füllen und die Politik „ästhetisieren“, so wie es im zeitgenössischen Faschismus geschieht. ${ }^{320}$ Dieser Essay wurde viel rezipiert, gilt als zentraler Text der Medientheorie und wird häufig angeführt, um ein ästhetisches Urteil über die Kopie und damit auch die Aneignung zu fällen.

315 Bidlo, im Gespräch mit Andrea Juno, in: Deecke (Hrsg.), Originale echt/falsch. Nachahmung, Kopie, Zitat, Aneignung, Fälschung in der Gegenwartskunst, Ausstellungskatalog des Neuen Museum Weserburg, 1999, S. 145, 146.

316 Benjamin, Das Kunstwerk im Zeitalter seiner technischen Reproduzierbarkeit [1936], 4. Aufl. 2015, S. 16.

317 Ders., a.a.O., S. 13.

318 Ders., a.a.O., S. 16.

319 Ders., a.a.O., S. 55.

320 Ders., a.a.O., S. 73 f. 
5. Pop Art: die Aneignung der Massenkultur

Mit der Pop Art fanden weitere Elemente des Alltags Einzug in die Kunst, insbesondere solche aus der Populärkultur. Die visuellen Eindrücke aus der Unterhaltungskultur und der Konsumwelt wurden in der Kunst aufgegriffen. Dabei konnten die Bildgegenstände auch trivial sein: Comics, Werbetafeln, Starporträts und Konsumgütern wurden übernommen - alles Gegenstände, die ikonenhaft in der Massenkultur funktionieren und deshalb wiederholbar sind. Das Kunstwerk selbst sollte nichts Einmaliges sein, sondern ebenso ein Massenprodukt werden. So schuf Andy Warhol nicht nur eine Brillo Box, sondern etliche. Der Alltagsgegenstand wurde nicht mehr wie noch in der Collage oder beim Ready-made kontextualisiert. Die Multiplizierung von Bildern basierte auf einer Idee von Unkreativität, bei dem das Kunstwerk und der Mythos des Künstlers entsinnlicht werden. ${ }^{321}$ Warhol selbst sagte: „I want to be a machine.“322 und nannte seine Werkstatt „Factory“. Das mechanische Herstellen von Bildern wurde durch technische Reproduktionstechniken wie den Siebdruck ermöglicht. Das Kunstwerk musste nicht mehr vom Künstler selbst geschaffen werden, auch Dritte konnten die Multiplizierung durch das Druckverfahren durchführen.

Pop Art wird als ein strategischer Vorläufer für die Verfahrensweise der Aneignung in der Appropriation Art angesehen. ${ }^{323}$ Jeff Koons und Richard Prince eignen sich ebenso populäre Bilder und Gegenstände der Werbung an, z.B. Princes Cowboys, die von einer Marlboro-Werbekampagne abfotografiert wurden, oder Koons Skulpturen von Hoover-Staubsaugern. Die vielen Wiederholungen machen das Bildermalen zur leeren Geste, mit der nichts Neues erzeugt, sondern Bestehendes entwertet wird. ${ }^{324}$

321 Rebbelmund, Appropriation Art, 1999, S. 92.

322 Warhol, Interview with Gene Swensson 1963, in: Harrison/Wood (Hrsg.), Art in theory 1900-1990, 1997, S. 730, 732.

323 Römer, Künstlerische Strategien des Fake. Kritik von Original und Fälschung, 2001, S. 54 f.

324 Ullrich, Tiefer hängen. Über den Umgang mit Kunst, 5. Aufl. 2013, S. 90. 


\section{Konzeptkunst: Aneignung als bloß erneute Ausführung}

Die Konzeptkunst ${ }^{325}$ erklärt die Idee zum Kunstwerk. Es komme nicht mehr auf die Ausführung oder Form an, sondern allein die Idee als schöpferisches Element mache das Kunstwerk aus: „When an artist uses a conceptual form of art, it means that all of the planning and decisions are made beforehand and the execution is a perfunctory affair. The idea becomes a machine that makes the art." ${ }^{\text {" }} 26$ Die Idee muss nicht mehr in eine wahrnehmbare Form gebracht werden, sie braucht keine Materialisierung oder diese ist lediglich zweitranging bei der Beurteilung des Kunstwerkes. Kosuth formulierte es 1996 so: „Konzeptuelle Kunst ging, einfach ausgedrückt, von der grundlegenden Voraussetzung aus, dass Künstler mit Bedeutungen arbeiten und nicht mit Formen, Farben oder Materialien.“327 Dies verändert die Trennung von Künstler und Kurator - der Künstler schafft nur noch die Auswahl der Werke, die vorgefunden sein können, und diese Zusammenstellung selbst wird als Kunstwerk ausgestellt. Mit der Konzeptkunst geht ebenso die Idee der autorlosen Kunst einher. ${ }^{328}$ John Baldessari beauftragte für seine „Commissioned Paintings“ (1969) Fotografen dafür, bei einem Spaziergang Dinge zu fotografieren, die sie interessierten. Die so entstandenen Fotografien schickte er an 14 Maler, die Gemälde nach den Fotos malten. Wer ist also bei einem solchen Prozess noch der Künstler? Der Fotograf, der die Grundlage geschaffen hat, der Maler des einzelnen Bildes oder Baldessari als Künstler aller 14 Bilder? Oder hat Baldessari lediglich als Kurator die Schaffung 14 einzelner Werke durch die Maler angeleitet?

Kunst ist hier die Geste des Zeigens durch den Künstler - und damit kann auch bei der Konzeptkunst fremdes Material genutzt werden. „As artists we all begin to construct with what is given. We take, we steal, we appropriate fragments of meaning from the detritus of culture and construct other meanings, our own." ${ }^{329}$, so Kosuth. Kunst als Zeigegeste ist

325 Als erste Ausstellung der Konzeptkunst gilt häufig Mel Bochners „Working Drawings and Other Visible Things On Paper Not Necessarily Meant To Be Viewed As Art" von 1966 in der Galerie der School of Visual Arts in New York.

326 LeWitt, Paragraphs on Conceptual Art [1928], in: Harrison/Wood (Hrsg.), Art in theory 1900-1990, 1997, S. 834, 834.

327 Godfrey, Konzeptuelle Kunst, 2005, S. 14.

328 Goldsmith, Uncreative Writing, 2017, S. 188.

329 Kosuth, Theft after Kant, in: Tietjen/Weibel (Hrsg.), Kunst ohne Unikat, Ausstellungskatalog der Neuen Galerie am Landesmuseum Joanneum, im Künstlerhaus Graz, 1998, S. 91, 93. 
eine Vorstellung von Kunst, die auch viele Appropriation Art Künstler aufgreifen. Bei der Beurteilung der Konzeptkunst ist aber die zugrundeliegende Idee maßgeblich - bei der Appropriation Art wird eine bereits bestehende Form mit einer anderen Bedeutung aufgeladen. Bei letzterer ist also die Form des Kunstwerkes präsent, während sie bei der Konzeptkunst auch abwesend sein kann. Zur Aneignung der Konzeptkunst wird geradezu aufgerufen: Wenn die Idee das Kunstwerk ausmacht, dann ist die Ausführung unbeachtlich. Und dann ist auch jede angeeignete Ausführung, jede Übernahme der Ausführung ohne Belang.

\section{Poststrukturalismus und der Tod des Autors}

Die Poststrukturalisten der 1960er Jahre setzten sich kritisch mit dem Verhältnis von Sprache und Wirklichkeit auseinander. Diese Entwicklung fand parallel über verschiedene wissenschaftliche Disziplinen hinweg statt und wurde von verschiedensten Autoren aufgegriffen.

Die Psychoanalytikerin Julia Kristeva stellte die Dialogizität von Texten in den Vordergrund. Mit ihrem Aufsatz „Bakhtine, le mot, le dialoque et le roman" von 1967 begründete sie die literaturwissenschaftliche Methodik der Intertextualität. Sie bezeichnet den Text als „Mosaik von Zitaten“330: Jeder Text stehe in einem relationalen Gefüge mit vorausgehenden Texten, auf die angespielt wird. Er ist ein „Geflecht von unterschiedlichen sozialen und kulturellen Kodes“. Erkenntnisziel der Intertextualitätsforschung ist nicht mehr, den Sinn eines Textes aufzufinden, sondern die Sinnbildung des Textes ${ }^{331}$ als Zusammenführung von Zitaten zu verfolgen.

Die Vorstellung der autorlosen Kunst prägt Roland Barthes Essay „Tod des Autors“, der 1968 erschien. ${ }^{332}$ Barthes möchte den Autor nicht mehr

330 Kristeva, Le mot, le dialogue et le roman, in: dies. (Hrsg.), Semeiotike. Recherches pour une sémanalyse, 1969, S. 143, 145.

331 Der Text wird dabei nicht mehr als eine verbundene Sinneinheit verstanden, sondern es soll gerade die Konstruiertheit des Textes offengelegt werden, der Versuch der Sinnbildung innerhalb des Textes nachvollzogen werden. Damit gehört die Intertextualität dem Dekonstruktivismus nach Jacques Derrida im weiteren Sinne an. Unter Dekonstruktivismus versteht Derrida die Unmöglichkeit, einen Text mittels Sprache eindeutig und endgültig zu verstehen. Die Analyse eines Textes richtet sich nicht mehr auf das, was der Text dem Leser mitteilen möchte, sondern auf eine Metaebene - die Gemachtheit des Textes und dadurch die Bedeutungszuschreibungen des Lesers offenlegen.

332 Originaltitel: La mort de l'auteur. 
als Bezugsgröße eines Textes verstehen, sondern den Leser, womit er die Vorstellung des Autors als kreativen Schöpfer entsakralisiert. Vielmehr sieht Barthes literarische Texte als „Gewebe von Zitaten“.333 Der Autor kann also gar nicht autonom, aus sich heraus schöpferisch tätig werden: Der Autor als Ursprung aller Bedeutung aufgrund seiner Leidenschaften, Stimmungen und Gefühle wird abgelöst durch den Schreiber, der den Text aus dem Wörterbuch seiner Kultur zusammenbaut. ${ }^{334}$ Das Geschriebene als Sinneinheit setzt sich erst beim Leser zusammen. Deshalb sieht Barthes den Tod des Autors als Geburt des Lesers. Diese Vorstellung von Kunst greift die Appropriation Art Künstlerin Sherrie Levine auf, wenn sie Barthes Aussage für die Bildende Kunst abwandelt: „A painting's meaning lies not in its origin, but in its destination. The birth of the viewer must be at the cost of the painter." 335

Die These Barthes greift Michel Foucault in seinem Vortrag "Was ist ein Autor?"“ auf, den er 1969 hielt. Dabei spricht er vom „Verschwinden“ des Autors - es geht nicht mehr um das Subjekt, sondern die Funktionen des Autors. Der Autor ist nur noch ein Etikett für seinen Text, eine Instanz für die diskursiven Einheiten des Textes. Die Aneignung des Textes ist dabei eine Funktion des Autors: „Der Autor ist genaugenommen weder der Eigentümer seiner Texte, noch ist er verantwortlich dafür; er ist weder ihr Produzent noch ihr Erfinder." 336 Der Autor hat nur noch klassifikatorische Funktion und dient der Markierung von „Existenz-, Verbreitungs- und Funktionsweisen bestimmter Diskurse in einer Gesellschaft“. ${ }^{337}$

Vor dem Hintergrund der autorlosen Kunst ist eine Aneignung nicht möglich. Wenn das Material niemandem zugewiesen wird, niemand dafür verantwortlich ist, dann stellt eine Kopie nicht klar eine Übernahme fremden Materials dar - das Material ist vielmehr offen verfügbar und kann von jedermann neu zusammengefügt werden. Jeder Kunstschaffende bedient sich des Materials seines Kulturraumes, weshalb die Nutzung fremden Materials nicht negativ bewertet werden kann.

333 Barthes, Der Tod des Autors [1967], in: Jannidis (Hrsg.), Texte zur Theorie der Autorschaft, 2012, S. 185, 190.

334 Ders., a.a.O., S. 185, 186, 190.

335 Levine, Statement [1982], in: Harrison/Wood (Hrsg.), Art in theory 1900-1990, 1997, S. 1066, 1066.

336 Foucault, Was ist ein Autor? [1969], in: Jannidis (Hrsg.), Texte zur Theorie der Autorschaft, 2012, S. 198, 199.

337 Ders., a.a.O., S. 198, 210. 


\section{Baudrillards Simulationstheorie: Aneignungen als Simulacra}

Mit der Simulationstheorie von Jean Baudrillard wird der Verweischarakter von Kopien auf ein Original angegriffen. ${ }^{338}$ Baudrillard untersucht die Beziehungen von Zeichensystemen und ihren Verweisen auf die Realität. Für ihn existiert nichts Reales mehr außerhalb medialer Zeichensysteme. Er nennt mediale Zeichen „simulacres“, denn sie verweisen auf kein Referenzobjekt in der Wirklichkeit mehr und reproduzieren damit nicht mehr die gegenständliche Wirklichkeit, sondern die „Hyperrealität“. Durch die mediale Welt wird damit eine Welt der Simulation geschaffen: „Simulation is no longer that of territory, a referential being, or a substance. It is the generation by models of a real without origin or reality: a hyperreal.“339 Damit ist die Unterscheidung zwischen Realität und Fiktion hinfällig geworden. Auch Kopien werden als eine Form der Simulacra verstanden: Kopien verweisen nicht mehr auf ein Original und die Unterscheidung zwischen Original und Kopie ist unmöglich geworden. Appropriation Art wird daher in Zusammenhang zu Baudrillard gestellt und die Frage aufgeworfen, ob es sich bei den Aneignungen um Simulacra handele ${ }^{340}$. Douglas Crimp, der Kurator der „Pictures“-Ausstellung, sieht den Zusammenhang zur Simulationstheorie Baudrillards darin, dass Appropriation Art Künstler die Kopie als Repräsentation und Referenz auf ein Original hinterfragen: „Those processes of quotation, excerptation, framing and stating that constitutes the strategies of the work I have been discussing necessitate uncovering strata of representation. Nedless to say, we are not in search of sources or origins, but structures of signification: underneath each picture there is always another picture. “341

338 Seine Simulationstheorie veröffentlichte er zunächst in „Der symbolische Tausch und der Tod" von 1976, später grundlegend ausgeführt in seinem Werk „Simulacres et Simulation“ von 1981.

339 Baudrillard, The Precession of Simulacra [1981], in: Evans (Hrsg.), Appropriation. Documents of Contemporary Art, 2009, S. 80, 80.

340 So Zuschlag, Die Kopie ist das Original - über Appropriation Art, in: Mensger (Hrsg.), Déjà-vu? Die Kunst der Wiederholung von Dürer bis Youtube, Ausstellungskatalog der Staatlichen Kunsthalle Karlsruhe, 2012, S. 126, 134; Huttenlauch, Appropriation Art. Kunst an den Grenzen des Urheberrechts, 2010, S. 48 f.; Vahrson, Die Radikalität der Wiederholung, 2006, S. 119; Römer, Künstlerische Strategien des Fake. Kritik von Original und Fälschung, 2001, S. 72 f.

341 Crimp, Pictures [1979], in: Evans (Hrsg.), Appropriation. Documents of Contemporary Art, 2009, S. 76, 78. 


\section{B. Heutige Nutzung: Aneignung als Kommunikationsform}

Kopieren, Ausschneiden und Einfügen sind nicht nur die Standardfunktionen von Computerprogrammen, sondern mit der Digitalisierung zunehmend Mittel unserer Kultur geworden. Digitale Kopien lassen sich vom Original nicht mehr unterscheiden, sodass die traditionelle Zuschreibung dieser Begriffe entwertet wird: Die Kopie hat keine mindere Qualität, ist nicht mehr sekundär. Mit der Digitalisierung hat sich aber nicht nur die Möglichkeit des Aneignens verbessert, sondern auch die Funktion dieser Aneignungshandlungen: Expressivität, die Fähigkeit, etwas Eigenes zu kommunizieren, gilt nicht mehr nur als Eigenschaft von Künstlern, sondern wird in die breiten Schichten der Gesellschaft verlagert. ${ }^{342}$ Die Aneignung ist nicht mehr nur in der Kunst relevant. Mit den digitalen Medien produziert und verändert nun jeder Nutzer Bilder zum Zwecke der Kommunikation - und dank der digitalen Kommunikationsmöglichkeiten sind diese Bilder nun überall und kontinuierlich verfügbar.

\section{Iconic turn und die digitale Bilderflut}

Der sog. iconic turn beschreibt die Begründung einer Wissenschaft des Bildes in Folge einer neuen Bedeutung von Bildlichkeit. Der Begriff wurde 1994 von Gottfried Boehm eingeführt und sollte eine neue Auseinandersetzung damit anregen, wie Bilder die Menschen in ihrer Weltwahrnehmung und ihrem Verhalten beeinflussen. ${ }^{343}$ Dem Bild wurde nicht mehr eine bloß dienende, illustrierende Rolle zugeschrieben, sondern es wurde als eigener „sinnstiftender Akt“, als „logos“344 verstanden. So Boehm: „Bilder schöpfen sich nicht darin, das Reale visuell zu substituieren, sie bringen ein Zeigen eigenen Rechts zustande. " ${ }^{435}$ Das Bild und seine Deixis wurden damit Objekte der Wissenschaft. Im Jahr 1992 wurde von W.J.T. Mitchell der sog. pictorial turn ausgerufen, der ähnliche kulturelle Veränderungen im Blick hat, aber stärker von der Ikonologie Erwin Panofskys

342 Vgl. Stadler, Kultur der Digitalität, 2016, S. 93.

343 Vgl. Boehm, Die Wiederkehr der Bilder, in: Boehm (Hrsg.), Was ist ein Bild?, 1994, S. $11 \mathrm{ff}$.

344 Boehm, Ein Briefwechsel, in: Rimmele/Sachs-Hombach/Stiegler (Hrsg.), Bildwissenschaft und Visual Culture, 2014, S. 19, 22.

345 Boehm, Jenseits der Sprache? Anmerkungen zur Logik der Bilder, in: Rimmele/ Sachs-Hombach/Stiegler (Hrsg.), Bildwissenschaft und Visual Culture, 2014, S. 67,73 . 
geprägt ist als der iconic turn, welcher eine Hermeneutik des Bildes etablieren wollte. 346

Beide Begriffe wurden in bewusster Abgrenzung zum sog. linguistic turn $^{347}$ entwickelt, der zu Beginn des 20. Jahrhunderts die Hinwendung zur Sprachphilosophie verdeutlicht hat. Sprachliche Beziehungen wurden analysiert, Sprache als Medium der Erkenntnis anerkannt und die Logik der Sprache ${ }^{348}$ untersucht, die eine Grenze der Erkenntnis darstellt. ${ }^{349}$ Dem linguistic turn einher ging eine gewisse Abwertung der Bilder gegenüber der Sprache, da ihr eine differenziertere kommunikative Funktion zugesprochen wurde. Insbesondere hiergegen wendete sich der iconic turn. Er sah die vorherrschende Rolle der Sprache in unserer Kultur abgelöst durch das Bild und einen Wandel von der Text- zu einer Bildsprache. So Mitchell: „Es [das Ergebnis des pictorial turn ${ }^{350}$ ] ist die Erkenntnis, dass die Formen des Betrachtens (das Sehen, der Blick, der flüchtige Blick, die Praktiken der Beobachtung, Überwachung und visuellen Lust) ein ebenso tiefgreifendes Problem wie die verschiedenen Formen des Lesens (das Entziffern, Decodieren, Interpretieren etc.) darstellen [...]." ${ }^{351}$ Ausgelöst durch die Bilderflut im 20. und 21. Jahrhundert gewann das Bild an Status und wurde als eigene Sinneinheit anerkannt.

Die Bilderflut meint die heutige exponentielle Vermehrung von Bildern ${ }^{352}$ als Folge der Herrschaft des Visuellen in den Massenmedien. Sowohl in ihrer Produktion als auch in ihrer Reproduktion sind Bilder eine Sache preiswerter, allgemein zugänglicher Technik geworden. ${ }^{353}$ Bilder be-

346 Vgl. Mitchell, The Pictorial Turn, Art Forum Nr. 30 (1992), S. 89-95.

347 Der Begriff wurde 1967 von Richard Rorty eingeführt.

348 Daraus folgten die Entwicklungen des Strukturalismus um Ferdinand de Saussure und der Hermeneutik um Hans-Georg Gadamer.

349 Dass Erkenntnis durch Sprache erfolgt und damit auch der Logik der Sprache unterliegt, postulierte Wittgenstein in seinem Tractatus: „Der Satz kann die logische Form nicht darstellen, sie spiegelt sich in ihm. Was sich in der Sprache spiegelt, kann sie nicht darstellen. Was sich in der Sprache ausdrückt, können wir nicht durch sie ausdrücken. Der Satz zeigt die logische Form der Wirklichkeit. Er weist sie auf.“, Wittgenstein, Tractatus logico-philosophicus [1921], 2003, $\$ 4.121$.

350 Das Zitat Mitchells bezieht sich auf den pictorial turn, der aber in weiten Teilen dem iconic turn ähnelt, s. S. $104 \mathrm{f}$.

351 Mitchell, The Pictorial Turn, Art Forum Nr. 30 (1992), S. 89, 95.

352 So Ganz/Thürlemann, Singular und Plural der Bilder, in: Ganz/Thürlemann (Hrsg.), Das Bild im Plural. Mehrteilige Bildformen zwischen Mittelalter und Gegenwart, 2010, S. 7, 7.; Ullrich, Tiefer Hängen. Über den Umgang mit der Kunst, 5. Aufl. 2013, S. 66 ff.

353 Ullrich, Tiefer Hängen. Über den Umgang mit der Kunst, 5. Aufl. 2013, S. 66. 
stimmen das alltägliche Leben. Mit Smartphones werden ständig Bilder produziert und transformiert ${ }^{354}$ : Jedes Outfit, jedes Mittagessen, jedes Konzert - ja, jedes Erlebnis wird bildlich festgehalten. Über schnelle Datenverbindungen können all diese Bilder mit Freunden geteilt oder an die Öffentlichkeit gestreamt werden. Nachrichten sind visualisiert, aus jedem Krisengebiet der Welt werden aktuelle Videos empfangen. Mit Google Street View kann man per Bildschirm durch fast jede Straße der Welt laufen. Die Wettervorhersage wird durch Satellitenbilder veranschaulicht, Börsencharts zeigen Kursveränderungen. Mit CTs und Scans des Körperinneren werden Krankheiten diagnostiziert. Das einzelne Bild verliert damit auch an Bedeutung - nicht jedes kommt mehr zur Geltung.

Burda nennt zwei technische Entwicklungen, die die Bilderflut produziert und den iconic turn angestoßen haben: Erstens die Erfindung von Fotografie und Film, die dazu führte, dass Bilder nicht mehr nur ortsgebunden betrachtet werden konnten. Man musste z.B. nicht mehr ins Museum fahren, um dort das Kunstwerk zu erblicken, sondern konnte eine Reproduktion anschauen. Das Bild wurde von seinem Träger gelöst: „Keine Holztafel, kein Papier musste mehr von einem Boten an einen anderen Ort gebracht werden. Die technischen Systeme der Bildcodierung und -übertragung ermöglichten es, Bilder von einem Ort zum anderen körperlos und materiallos zu transferieren. " 355 Und zweitens die Digitalisierung durch Fernsehen und Internet, ${ }^{356}$ mit der ein Massenpublikum zeitgleich an verschiedensten Orten Bilder wahrnehmen konnte. Durch diese technische Übertragung wurde die historische Einheit von Raum und Zeit zerstört. ${ }^{357}$ Die Bedingungen der Bildübertragung änderten sich noch einmal grundlegend. Dadurch ist die Macht der Bilder gestiegen. Nach jahrhundertelanger Prägung unserer Kultur durch Schrift und Text ist nun die visuelle Kommunikation in den Vordergrund gerückt. ${ }^{358}$

354 Han, Im Schwarm. Ansichten des Digitalen, 4. Aufl. 2017, S. 40.

355 Weibel, Ortlosigkeit und Bilderfülle. Auf dem Weg zur Telegesellschaft, in: Burda/Maar (Hrsg.), Iconic Turn. Die neue Macht der Bilder, 2004, S. 216, 224.

356 Burda, In media res. Zehn Kapitel zum Iconic Turn, 2010, S. 18 ff.

357 Weibel, Ortlosigkeit und Bilderfülle. Auf dem Weg zur Telegesellschaft, in: Burda/Maar (Hrsg.), Iconic Turn. Die neue Macht der Bilder, 2004, S. 216, 221.

358 Burda, In media res. Zehn Kapitel zum Iconic Turn, 2010, S. 59. Mit dem Schwerpunktprogramm „Das digitale Bild“ hat die Deutsche Forschungsgemeinschaft im Jahr 2019 Projekte angestoßen, die erstens auf den Anteil des Bildes im Prozess der Digitalisierung reflektieren in der Absicht, zu einer Theorie des digitalen Bildes in der Verwendung in Kunst, Wissenschaft, Kultur beizutragen; die sich zweitens beschreibend und interpretierend dem Phänomen, den Erscheinungsformen und Praktiken des „Digital Turn“ in seiner visuellen 


\section{Das Bild als Medium der Kommunikation im Digitalen}

Nicht nur die Bildübertragung hat sich verbessert, sondern auch die Kopiermöglichkeiten im Digitalen. Das ermöglicht massenhafte Aneignungshandlungen. Durch die Digitalisierung sind zahlreiche Kopien ohne Qualitätsverlust innerhalb kurzer Zeit produzierbar. Kopieren und Vervielfältigen sind technisch so einfach geworden, dass sie zu banalen Handlungen werden. Gleichzeitig bietet das Internet die Verbreitungsmöglichkeit für angeeignete Bilder und damit auch die Verwertungsmöglichkeit für Aneignungen. Diese Verbindung aus einfacher Produktion und einfacher Verbreitung von Bildern war so noch in keiner Kultur vorher möglich. Sowohl die Verwertungstechniken als auch die interaktiven Verfahren vereinfachen die Umgestaltung und Kombination von Werken erheblich ${ }^{359}$ und machen die Aneignung zu einer Alltagshandlung. Die Kommunikation verlagert sich also nicht nur ins Digitale, sondern das Kommunikationsverhalten ändert sich.

Dieses veränderte Kommunikationsverhalten soll nun genauer beschrieben werden. Maßgeblich sind soziale Netzwerke ${ }^{360}$, da sie am häufigsten für die Verbreitung von Bildern genutzt werden. Diese Plattformen stellen eine Infrastruktur, die gerade auf eine vermehrte Verbreitung von Bildern und Interaktion mit Bildern ausgerichtet ist. Durch die sozialen Netzwerke können Nutzer ihre eigene, persönliche Öffentlichkeit schaffen ${ }^{361}$ - ein Beziehungsnetzwerk von Bekannten, Freunden, Kollegen oder sogar Fremden, die untereinander Informationsströme teilen. Durch die Demokratisierung der Kommunikationsmittel und des Zugangs zur Technik, was sich an der rasant steigenden Anzahl von Smartphones und sozialen Netzwerken zeigt, splittert sich die Öffentlichkeit in Teilöffentlichkeiten auf und verschiebt damit die Grenze, die Privatheit und Öffentlichkeit vonein-

Dimension zuwenden, wozu zum Beispiel auch die Beschreibung und Interpretation von Formen der bildenden Kunst im digitalen Raum gehören; und die drittens auf die Praxis der Technologien des digitalen Bildes zielen, beispielsweise die Entwicklung innovativer Formen des Einsatzes des digitalen Bildes als Medium der Erkenntnis im Umfeld der Wissenschaft betreiben, vgl. https://ww w.dfg.de/foerderung/info_wissenschaft/2018/info_wissenschaft_18_14/index.ht $\mathrm{ml}$, Datum des Zugriffs: 15.01.2020. Es ist daher mit vielen neuen wissenschaftlichen Beiträgen zu diesem Thema zu rechnen.

359 Klass, Werkgenuss und Werknutzung in der digitalen Welt: Bedarf es einer Harmonisierung des Urheberpersönlichkeitsrechts?, ZUM 2015, S. 290, 298.

360 Zur Begriffsdefinition vgl. S. 70.

361 Schmidt, Social Media, 2013, S. 26. 
ander trennt. ${ }^{362}$ Was zuvor als rein privat galt, wird nun im geschützten Teilbereich des öffentlichen Raumes vorgenommen: Die geteilten Bilder sind öffentlich einsehbar oder zumindest von einer kaum zu überschaubaren Gruppe der Vernetzten eines sozialen Netzwerkes. Dennoch wird die Kommunikation und das Bilderteilen von den Teilnehmern der sozialen Netzwerke weiterhin als private Selbstdarstellung verstanden. Dieser Wandel hin zum Verwischen von Öffentlichkeit und Privatheit bzw. einer stärkeren Privatheit im öffentlichen Raum beeinflusst auch die - zuvor rein private - Nutzung von Bildern. Häufig ist bereits die Produktion von Bildern darauf ausgerichtet, in den sozialen Netzwerke geteilt zu werden. Damit wird die Produktion von Bildern zu einem Akt der Massenkommunikation. Das Teilen von Bildern und die Produktion von Bildern zum Zweck des Teilens machen die digitale Bildkultur ${ }^{363}$ aus. Und auch anders herum sind nicht nur Bilder auf soziale Netzwerke ausgerichtet, sondern diese auch auf Bilder: Was nicht visualisiert ist, existiert nicht. ${ }^{364}$

Doch was macht Bilder so beliebt in den sozialen Netzwerken? Sie dienen einerseits der Inszenierung derjenigen, die sie produzieren und teilen. ${ }^{365}$ Oft entstehen die Bilder bereits mit der Ausrichtung an bestimmte Adressaten: Sie sollen die eigenen Emotionen und Gedanken dem Betrachter mitteilen und diese Emotionen auch bei ihm erzeugen. Das macht sie zu einem wirkungsvollen Kommunikationsmittel, mit denen jeder Einzelne sehr individuell und situationsabhängig die eigene Stimmung ebenso reflektieren wie kommunizieren kann. ${ }^{366}$ Bilder lösen dabei die Sprache als vorrangiges Medium der Kommunikation ab, denn mit ihnen lässt sich

362 S. dazu Ullrich, Selfies. Die Rückkehr des öffentlichen Lebens, 2019, S. 25; Dreier, Bild und Recht, 2019, S. 67 f.; Marl, Der Begriff der Öffentlichkeit im Urheberrecht, 2017, S. 69 ff.; Ladeur, Das Medienrecht und die Ökonomie der Aufmerksamkeit, 2007, S. 55 f.

363 Begriff nach Magauer, Vom Teilen und Stehlen. Künstlerische Aneignung in der digitalen Bildkultur, in: Huss/Winkler (Hrsg.), Kunst \& Wiederholung. Strategie, Tradition, ästhetischer Grundbegriff, 2017, S. 203, 203.

364 So werden zeitgenössische Ereignisse, von denen keine Bilder existieren, nicht von der Gesellschaft rezipiert und Personen, von denen kein Foto digital auffindbar ist, als suspekt angesehen.

365 Ullich, Der kreative Mensch. Streit um eine Idee, 2016, S. 64.

366 Ullrich, Selfies. Die Rückkehr des öffentlichen Lebens, 2019, S. 34 f.; ders., Rebloggen als Kulturtechnik, in: Landwehr (Hrsg.), Public Domain. Edition Digital Culture 3, 2015, S. 92, 101. 
prägnanter, subtiler, manchmal vielschichtiger kommunizieren. ${ }^{367} \mathrm{Nicht}$ umsonst heißt es, dass ein Bild mehr als tausend Worte sagt. Diese Effizienz in der Kommunikation hat zu der veränderten Funktion von Bildern und dem massiven Anstieg bildlicher Aneignungen beigetragen.

Mit der Digitalisierung werden Bilder nun als Mittel genutzt werden. Bei der Kopie eines Bildes geht es nicht mehr darum, das Bild selbst zu zeigen. Es dient stattdessen der Illustration, der Veranschaulichung von etwas anderem. Deshalb sind nun auch Aneignungshandlungen von Bildern so beliebt geworden, denn bei der Aneignung wird das Bild gerade nicht um seiner selbst willen gezeigt, sondern für andere, eigene Zwecke. ${ }^{368}$ Die Funktion der bildlichen Aneignung im Digitalen ist die Kommunikation das Bild wird geteilt, um damit etwas zu kommunizieren. Damit funktioniert das Bild als Medium, als Vermittler. Die digitalen Kommunikationsmöglichkeiten haben das Bild zu etwas gemacht, was es vorher nie gewesen ist: zu einem flexiblen und weltweiten Kommunikationsmittel. ${ }^{369}$

\section{Prosumer und ihre produktive Nutzung von Bildern}

Mit der Digitalisierung hat sich aber nicht nur der Zweck der Bildnutzung hin zu einer Kommunikationsfunktion von Bildern geändert, sondern auch die Art des Umgangs mit Bildern. Wie gesehen, ist durch die Digitalisierung die Quantität der nutzbaren Bilder drastisch angestiegen - und gleichzeitig sind die technischen Möglichkeiten, ein Bild einfach und qualitativ hochwertig zu kopieren, günstig jedermann verfügbar geworden. Mit der Entwicklung der Technologie wurden neue Wege der Kommunikation, der Kollaboration und der Zirkulation von Ideen ermöglicht, die es den Konsumenten erlauben, ihre eigenen Inhalte zu generieren und zu verbreiten. Dies ändert neben der Funktion der Bilder auch den Umgang mit diesen.

Nicht mehr nur Spezialisten und Fachexperten haben die Möglichkeiten zur produktiven Nutzung von Bildern, sondern dieser Zugang ist allen möglich und wurde damit demokratisiert. Jeder ist nun in der Lage, die

367 Ders., Selfies. Die Rückkehr des öffentlichen Lebens, 2019, S. 54 f.; ders., Rebloggen als Kulturtechnik, in: Landwehr (Hrsg.), Public Domain. Edition Digital Culture 3, 2015, S. 92, $94 \mathrm{f}$.

368 Vgl. dazu S. $32 \mathrm{f}$.

369 So Boehm, Jenseits der Sprache? Anmerkungen zur Logik der Bilder, in: Rimmele/Sachs-Hombach/Stiegler (Hrsg.), Bildwissenschaft und Visual Culture, 2014, S. 67,68 . 
Bilder kreativ zu nutzen. Damit hat sich auch die Rolle des Konsumenten von Bildern hin zu einem produktiven Konsumenten geändert. Ein produktiver Konsument ist, wer die Bilder nicht nur passiv wahrnimmt, sondern sie aktiv nutzt. Alvin Toffler prägte dafür auch den Begriff des Prosumer, der Produzent und Konsument in einem ist. ${ }^{370}$ Die simple Funktion des Copy-Paste wird zur Kultur erhoben - und Appropriation damit zu einem Alltagsphänomen. Das Angeeignete bleibt jedoch im neuen Bild klar und deutlich erkennbar und ist keine reine Neuschöpfung. ${ }^{371}$ In der Digitalkultur gehört es zur Wahrnehmung von Bildern dazu, sie zu verändern, Dinge hinzuzufügen oder Ausschnitte des Bildes durch Photoshop in andere Kontexte zu stellen. Das zeigt sich an der Masse von Bildmontagen, die über soziale Netzwerke produziert werden, wenn ein aufsehenerregendes Bild viral geht: So z.B. die Variationen zu Mario Balotellis ikonischer Jubelpose beim EM-Halbfinale $2012^{372}$ oder die des Selfies von Ellen Degeneres mit vielen Hollywood Stars bei der Oscar Verleihung 2014. ${ }^{373}$ Der digitale Konsument reagiert also auf Bilder bedeutender Ereignisse

370 Toffler, The Third Wave. The Classic Study of Tomorrow, 1980. Er meinte damit allerdings Konsumenten von Dienstleistungen oder Produkten, indem sie Produkte nach ihren Bedürfnissen mit designen oder durch eigenes Tätigwerden mit herstellen. Seit Anfang des 21. Jahrhunderts wird der Begriff aber zunehmend auch für die Digitalkultur und insbesondere User Generated Content genutzt, vgl. Miller, Understanding Digital Culture, 2011, S. $87 \mathrm{ff}$.

371 Vgl. Dobusch, Generation Remix. Popkultur und Kunst im rechtsfreien Raum?, in: Djordjevic/ Dobusch (Hrsg.), Generation Remix. Zwischen Popkultur und Kunst, 2014, S. 9, 11.

372 Ein Überblick über die verschiedenen Bildmontagen: https://www.focus.de/spor t/fussball/em-2012/tid-26367/neue-meme-zur-jubelpose-internet-hype-um-balotel li-geht-immer-weiter_aid_775817.html, Datum des Zugriffs: 15.01.2020.

$373 @$ @theellenshow vom 03.01.2014, https://twitter.com/theellenshow/status/440322 224407314432?lang=de, Datum des Zugriffs: 15.01.2020. Dieses Selfie war lange Zeit der meistgeteilte Tweet auf Twitter und hat ebenfalls zu zahlreichen Bildmontagen und Parodien geführt: Auffindbar mit der Google Bildersuche und dem Begriff Oscar Selfie Parody oder unter https://mashable.com/2014/03/03/ell en-oscar-selfie-parody/?europe=true, Datum des Zugriffs: 15.01.2020. 
durch eine produktive und partizipative ${ }^{374}$ Bildnutzung. Dadurch hat sich auch für das Bild im Digitalen eine Remixkultur ${ }^{375}$ entwickelt.

Der Begriff der Remixkultur geht zurück auf Lawrence Lessig ${ }^{376}$ und meint die durch digitale Technologien ausgelöste Veränderung, wie Kultur konsumiert wird. Er unterscheidet zwischen der Remix- oder auch Read-Write-(RW)-Kultur und der Read-Only-(RO)-Kultur. In der RO-Kultur wird Performativität oder Amateur-Kreativität wenig gelebt, Kultur wird simpel konsumiert. ${ }^{377}$ Diese RO-Kultur hat sich im 20. Jahrhundert besonders stark entwickelt, da Kopien technisch sehr teuer und qualitativ dem Original unterlegen waren. Doch diese natürlichen Restriktionen der analogen Welt wurden mit der Geburt der digitalen Technologie beseitigt: "What before was both impossible and illegal is now just illegal.“378 Doch auch heute findet sich RO-Kultur noch im Digitalen, indem durch Digital Rights Management und technische Schutzmaßnahmen der Zugang zu und der Umgang mit Kulturgütern eingeschränkt und kontrolliert wird.

Ansonsten dominiert im Digitalen allerdings die RW-Kultur. ${ }^{379}$ Der ROKultur gegenübergestellt zeichnet sie sich gerade durch eine reziproke Beziehung von Konsument und Werkschöpfer aus - das Schaffen von Kultur

374 Henry Jenkins prägte in Bezug auf die Digitalkultur den Begriff der participatory culture, die er wie folgt definiert: „A participatory culture is a culture with relatively low barriers to artistic expression and civic engagement, strong support for creating and sharing one's creations, and some type of informal mentorship whereby what is known by the most experienced is passed along to novices.“, Jenkins/Ito/Boyd, Participatory Culture in a Networked Era. A Conversation on Youth, Learning, Commerce and Politics, 2016, S. 4. Er meinte damit auch soziale Netzwerke, die keinen passiven Medienkonsum mehr zulassen, die Ausbreitung von nicht kommerzieller Amateur-Kreativität fördern und den Brauch des Teilens kultureller Produktionen geschaffen haben. Ders., Fans, Bloggers, and Gamers. Exploring Participatory Culture, 2016, S. 138 ff.

375 Wobei es sich bei Bildern nicht um Remixe, sondern um Montagen handelt, vgl. S. 40 f. Viele nutzen aber den Begriff Remix, um die veränderte Nutzung vorgefundenen Materials im Digitalen zu erklären. So auch die Filme von Kirby Ferguson „Everything is a Remix“ abrufbar unter https://vimeo.com/139094998, Datum des Zugriffs: 15.01.2020, mit denen er veranschaulicht, dass das Kopieren und Transfomieren von bestehendem Material schon immer ein großer Bestandtteil unserer Kultur war.

376 Lessig, Remix. Making Art and Commerce Thrive in the Hybrid Economy, 2008, S. $28 \mathrm{ff}$.

377 Ders., a.a.O., S. 28.

378 Ders., a.a.O., S. 38.

379 Definition nach Lessig: „ordinary citizen ,read' their culture by listening to it or by reading representations of it $[\ldots]$ and add to the culture they read by creating and re-creating the culture around them $[\ldots]$ using the same tools the professio- 
erfolgt hier nicht mehr nur in eine Richtung. Die Hierarchien sind flach. Die Grenzen zwischen Urheber und Nutzer verschwimmen. ${ }^{380}$ Die von Joseph Beuys proklamierte Kunsttheorie „Jeder Mensch ist ein Künstler" findet damit in der Digitalkultur ihre praktische Realisierung. Doch Lessig betont auch, dass die Kreativität der RW-Kultur nicht den Markt des kreativen Ursprungswerks schwächen oder mit ihm in Konkurrenz steht, da diese Werke komplementär zueinander stehen, nicht kompetitiv. ${ }^{381}$

Die produktive Nutzung von Bildern funktioniert nur durch einen Auswahlprozess. Im Internet ist alles jederzeit abrufbar - damit entzieht es sich der Einordnung nach Zeitpunkten. Wenn alles immer verfügbar ist, dann wird auf das Datum des Erstellens weniger geachtet. Außerdem bezieht man sich sowohl auf alte als auch auf neue, auf unbekannte wie auch bekannte Bilder. Es ist ein Zeitalter der fehlenden Geschichtlichkeit. Zeit oder Ort sind nicht mehr die Strukturen, nach denen Bilder wahrgenommen werden. Die produktive Nutzung von Bildern selbst bringt Struktur in die Bilderflut im Digitalen. Durch das Auswählen eines Bildes wird es aus der überbordenden, chaotischen Umwelt der Bilderflut gelöst und etwas Besonderes an diesem Bild aufgezeigt. Mit der Darstellung des Bildes im Digitalen geht daher häufig eine Geste des Zeigens ${ }^{382}$ einher: Schau her, das habe ich gefunden, und damit sage ich etwas über $x$ aus. ${ }^{383}$ Dieser offene, freie Umgang mit Bildern lässt vielfältige Verknüpfungen und Variationen zu. Durch die produktive Bildkultur ist die Kreativität der Massen möglich: Jeder kann auswählen, jeder geht produktiv mit Bildern um, also kann jeder Künstler sein. Zusätzlich ist das Werk des Urhebers keine Einbahnstraße mehr - Bildkonsum im Digitalen funktioniert nicht mehr einseitig, sondern Menschen involvieren sich und nutzen das Bild weiter.

Die bildliche Aneignung ist nun im Digitalen ein Mittel der Kommunikation - und aufgrund der produktiven Nutzung von Bildern besonders

nal uses.“, Lessig, Remix. Making Art and Commerce Thrive in the Hybrid Economy, 2008, S. 28.

380 Kreutzer, Remix-Culture und Urheberrecht, in: Djordjevic/Dobusch (Hrsg.), Generation Remix. Zwischen Popkultur und Kunst, 2014, S. 42, 42.

381 Ders., a.a.O., S. 56.

382 Begriff nach Dreier, Bilder im Zeitalter ihrer vernetzten Kommunizierbarkeit, ZGE 2017, S. 135, 145.

383 Nach Han beendet die digitale Fotografie die Zeit der Repräsentation, die zuvor die Fotografie kennzeichnete, und präsentiert stattdessen eine Hyperrealität, in der Zitate aus dem Realen aufeinander bezogen und mit dem Imaginären vermischt werden, s. Han, Im Schwarm. Ansichten des Digitalen, 4. Aufl. 2017, S. $82 \mathrm{ff}$. 
gut als solches geeignet. Bilder lassen sich immer wieder ergänzen, mit Text versehen oder in neue Kontexte stellen und können so in immer neuen Montagen und Variationen für immer neue Kommunikationskontexte genutzt werden. Die produktive Bildnutzung im Digitalen ist damit elementare Voraussetzung dafür, dass die digitale Bildkommunikation so erfolgreich ist.

\section{Gleichzeitige Steigerung des Kultes von Originalität}

Mit der Bilderflut und der permanenten Produktion von Bildern kann man jedoch gleichzeitig eine Steigerung des Kultes von Originalen und Originalität feststellen. Die Möglichkeit, mühelos Bilder zu produzieren und Reproduktionen anzufertigen, fördert das Bedürfnis nach Abgrenzung zu den „wahren Meisterwerken“. Es besteht die Sorge, dass selbst die wertvollsten Bilder infolge häufiger Reproduktion gleichgültig würden. ${ }^{384}$ Ganz im Sinne von Walter Benjamin wird daher ein Unterschied von Original und Reproduktion beschworen - nur das Original könne die Aura des Hier und Jetzt vermitteln - eine Reproduktion könne die Kunsterfahrung des Originals gerade nicht ersetzen. Eine Ursache dafür kann man sogar in den nahezu perfekten Reproduktionen sehen: Durch ihre Erhabenheit fördern sie Autorität und demütig-schweigende Bewunderung von Kunst und damit die Fetischisierung des Originals. ${ }^{385}$ Der moderne Kult des Meisterwerkes ist damit die Kehrseite der Bilderschwemme. ${ }^{386}$

Auch die Demokratisierung der Produktion von Kunst führt gerade nicht zu einem demokratisierten Kunstverständnis. Zwar kann jeder Kunst produzieren und frei veröffentlichen; es wird jedoch am Geniegedanken festgehalten. Aus Angst vor der Bedeutungslosigkeit wird nach dem Ein-

384 Ullrich, Tiefer hängen. Über den Umgang mit der Kunst, 5. Aufl. 2013, S. 76.

385 Ullrich, Raffinierte Kunst. Übung vor Reproduktionen, 2009, S. 76; Hartel, Ein Selfie mit Mona Lisa. Alte Meister in der Populärkultur, in: Kunsthalle Tübingen/Fritz (Hrsg.), Comeback. Kunsthistorische Renaissancen, 2019, S. 47, 55.

386 So auch Ganz/Thürlemann, Singular und Plural der Bilder, in: Ganz/Thürlemann (Hrsg.), Das Bild im Plural. Mehrteilige Bildformen zwischen Mittelalter und Gegenwart, 2010, S. 7, 7. Fritz sieht die Wertschätzung der alten Meister darin begründet, dass sie ein Symbol für Beständigkeit sind und identitätsstiftend wirken. Die Wertschätzung sei damit auch eine Reaktion auf die beschleunigte Digitalisierung und Virtualisierung der Welt, so Fritz, Comeback. Kunsthistorische Renaissancen in der Gegenwart, in: Kunsthalle Tübingen/Fritz (Hrsg.), Comeback. Kunsthistorische Renaissancen, 2019, S. 11, 13. 
zigartigen verzweifelt gesucht. Für die Qualität eines Kunstwerkes ist damit seine Originalität und Kreativität ausschlaggebend. Wenn der Unterschied von Kunst und Nicht-Kunst, zwischen Künstler und Hobby-Fotograf kaum noch auszumachen ist, wenn die Veröffentlichung eines Bildes keine Instanz für seine Qualität mehr ist, sondern jeder seine Bilder veröffentlichen kann - dann scheint die Folge eine pauschale Höherstellung des Künstlers als Genie zu sein. Ganz nach der post-romantischen Idee der Selbstverwirklichung ist Künstler, wer sein Innerstes offenbart. Denn darin sei noch der Unterschied zu machen: Wenn jeder Mensch individuell ist, ist auch jedes von dieser Individualität eines Menschen geprägte Bild unverwechselbar. Der Künstler ist also jemand, der alles aus sich heraus bringt - als Schöpfer, ganz in Analogie zu Gott. ${ }^{387}$ Damit wird der Akt des Kunstschaffens unteilbar, mit Bedeutung aufgeladen und zu einem Mysterium. ${ }^{388}$ Das zeigt sich auch daran, dass der Werkstattbetrieb heute wieder als Tabu gilt: Denn wie solle man etwas Individuelles, der eigenen Seele Entspringendes schaffen können, wenn man die Ausführung jemandem anders überlässt? Die Eigenschaften des „Genies“ sind im Kunstbetrieb gefragt und offenkundiger denn je ein Marktfaktor. ${ }^{389}$

Die aufgezeigte Art der produktiven Nutzung und Interaktivität von Bildern lassen Fragen nach Autorschaft und Originalität aufkommen, auch in

387 Ullrich, Tiefer hängen. Über den Umgang mit der Kunst, 5. Aufl. 2013, S. 131.

388 Ders., a.a.O., S. 131.

389 Ders., a.a.O., S. 144. Darin scheint auch ein Erfolg des Kunstfälschers Wolfgang Beltracchi begründet zu sein, der nicht einfach nur Gemälde nachmalte, sondern solche Gemälde nachahmte, die verschollen waren und von denen nicht mehr bekannt war, wie sie aussahen. Indem sich Beltracchi den Stil des Originalkünstlers aneignete, wurden seine Fälschungen für ein authentisches Werk gehalten. Er kopierte nicht, sondern schaffte eigenständige Originale, da es ja gerade keine Vorlage für seine Bilder gab. Für diese „Kunst“, den Stil eines Künstlers so originalgetreu nachahmen zu können, wird er bewundert und häufig selbst als Genie bezeichnet, s. Mahro, Wolfgang Beltracchi: Ein gefallenes Genie, Badische Zeitung vom 09.06.2017, http://www.badische-zeitung.de/kunst-1/ wolfgang-beltracchi-ein-gefallenes-genie--137860549.html; Dirksen, Der Fälscher Beltracchi als Filou und Genie, Der Westen vom 26.01.2014, https://www.derwe sten.de/kultur/der-faelscher-beltracchi-als-filou-und-genie-id8917443.html; von Becker, Genie des Künstlers, Wahnsinn des Marktes, Der Tagesspiegel vom 08.03.2012, https://www.tagesspiegel.de/kultur/kunst-genie-des-kuenstlers-wahn sinn-des-markts/6299652.html. Diese Faszination führte auch zum Erfolg seiner Autobiographie („Selbstporträt“, 2014), der Entwicklung einer eigenen Serie bei 3Sat („Meisterfälscher“), bei der er Prominente im Stil bestimmter Künstler porträtiert, und des Dokumentarfilms über ihn von Arne Birkenstock aus dem Jahr 2014. 
der Kunst. Neben der digitalen Kommunikation arbeitet auch die Kunst in Zeiten der Digitalisierung immer wieder mit Aneignungen und lässt sich von der digitalen Bildkultur inspirieren. Dem liegt jedoch lediglich ein anderes Verständnis von Originalität zugrunde. Für die produktive Bildnutzung in der Digitalkultur und Kunst ist das Auswählen von zentraler Bedeutung. Nach Wolfgang Ullrich ist Originalität aufgrund der Komplexität und der jederzeitigen Verfügbarkeit von Bildern nun umzudeuten: „Die Originalität einer künstlerischen Position besteht somit in Auswahlund Anordnungsprinzipien - in dem, was zwischen den Bildern passiert, und nicht mehr in deren individueller Gestaltung. Die Bilder sind Rohstoff, selbst ein Material und nicht das Ziel der Kunst. ${ }^{\text {“390 }}$ Goldsmith formuliert es ähnlich: „,...] statt der Erschaffung schätzen wir die Manipulation und die Umwidmung." "391 Der Aneignung von Bildern in der Kunst kann heute daher auch etwas Originelles zukommen, sie kann als künstlerisches Mittel wertgeschätzt werden.

\section{Fazit: Entwicklung der Aneignung zum Massenphänomen}

Deutlich wird durch die vorhergehende Kulturgeschichte der Aneignung, dass sich die Einstellung ihr gegenüber und damit auch ihre Nutzung immer wieder verändert hat.

Bis zur Neuzeit war das Aneignen immer ein Hinbewegen zum Original. Durch verschiedene künstlerische Techniken wurde versucht, dem Original möglichst nahe zu kommen. So haben die Römer dem griechischen Ideal nachgeeifert und ihre Marmorstaturen nach griechischen Bronzegüssen geschaffen. Der immer wieder aufkommende Begriff der aemulatio ist besonders interessant, der das Nacheifern nach einem Vorbild meint - und durch dieses Nacheifern die Überbietung des Vorbildes ermöglichen soll. Auch hier vermittelt die Aneignung Nähe und steht in enger Anlehnung an das angeeignete Objekt. Eine weitere Steigerung war das Lernen der Künstler durch Kopien - in ihren Verhältnissen zum Werkstattmeister oder später an Kunstakademien. Innerhalb der Werkstatt war es wichtig, im Stil des Meisters zu malen, um einheitliche Qualitätsstandards zu gewährleisten. Durch die Aneignung seines Stils konnten sie zeigen, wie nahe sie ihrem Werkstattmeister kommen. Die Schüler an Kunst-

390 Ullrich, Tiefer hängen. Über den Umgang mit der Kunst, 5. Aufl. 2013, S. 87.

391 Goldsmith, Uncreative Writing. Sprachmanagement im digitalen Zeitalter, 2017, S. 316 . 
akademien kopierten, um vom Original zu lernen und dadurch möglichst so malen zu können wie der Künstler des Originalwerkes. Hier ließ sich die eigene Kunst auch steigern, indem sie durch die Aneignung in Verbindung mit anderen, bereits bedeutenden Künstlern gesetzt werden kann. Die Aneignung war in dem Zusammenhang gleichzeitig Ausdruck von Bewunderung wie auch Lehrmittel - durch das Aneignen des Bildes sollten sich auch die dazu notwendigen Fähigkeiten angeeignet werden. Damit war die Aneignung noch keine Handlung von eigenständiger Bedeutung, sondern häufig nur ein Mittel, um künstlerische Techniken zu erlernen. Die Aneignung war das Medium, um dem Original nahe zu kommen.

Diese Nutzung veränderte sich mit der späten Neuzeit und dem Einsetzen der Moderne. Die Aneignung diente nun nicht mehr vorrangig der Auseinandersetzung mit dem Original, sondern drückte Eigenes aus und war aus sich heraus künstlerisch wertvoll. Die Aneignung war nun ein Sich Wegbewegen vom Original.

Zunächst wurde die Aneignung als Stilmittel genutzt, um einem anderen künstlerischen Zweck zu dienen als dem des Originals. So funktionierte z.B. die Collage nur durch das Kopieren zweckentfremdeter Materialien, die neu zusammengesetzt werden. Ähnlich war es auch bei dem Ready-made oder der Pop Art, die die Kopie in einem neuen Kontext darstellten und durch diese Kontextveränderung (von Alltag zu Kunst) ihre Werke schufen. Ebenso wurde die Kopie genutzt, um eigene Reflexionen über das Original auszudrücken und damit mehr als das Original selbst auszusagen durch diese eigenständige Reflexion stellte diese Kopie dann eine Aneignung dar. Als Höhepunkt dieser Entwicklung ist schließlich die Appropriation Art anzusehen, bei der sich das komplette Werk eines anderen angeeignet wurde - damit aber gerade etwas Anderes als mit dem Original ausgesagt wird. Das Aneignen avancierte nun zu einer künstlerischen Strategie und die Aneignung selbst zu Kunst.

Es sind mehrere grundsätzliche Entwicklungen innerhalb der Moderne und Postmoderne für die veränderte Nutzung der Aneignung ausschlaggebend: zunächst die Entwicklung hin zur Nichtgegenständlichkeit in der Kunst und weiterhin die Selbstthematisierung und Selbstreflexion des Kunstprozesses innerhalb des Kunstwerkes. ${ }^{392}$ Durch immer stärkere Abstraktion sollten Objekte neu gesehen und wahrgenommen werden - es sollten aber auch die Grenzen der Wahrnehmung und des Abbildbaren

392 Vgl. ausführlich zu diesen Entwicklungen, insbesondere zum Erweiterungsund Auflösungsanspruch in der modernen Kunst: Fuchs, Avantgarde und erweiterter Kunstbegriff, 2000, S. 77 ff. 
aufgezeigt werden. Die Kunst wurde also ungegenständlicher, weil sie nicht mehr die Wirklichkeit abbilden konnte und sollte. Damit bildete auch die Kopie nicht mehr zwangsläufig das Original ab. Aber auch die Selbstreflexion innerhalb der Kunst veränderte die Einstellung gegenüber der Kopie. Bei der Beschäftigung mit der Frage „Was ist Kunst?“ war die Kopie nicht als Verweis auf das Original die Antwort - die Kopie gab vielmehr als eigenständiges Werk selbst eine Antwort. Mit dieser Selbstreflexion innerhalb der Kunst trat die Konzeption eines Werkes an die vorderste Stelle zur Beurteilung eines Werkes und die Ausführung in den Hintergrund. Auch damit wurde ein anderer Rahmen für das Nutzen von Kopien gesetzt. Wenn die Ausführung nicht mehr wichtig war, konnte auch die Kopie genutzt werden - denn sie trifft als Aneignung eine andere künstlerische Aussage als das angeeignete Werk, indem ihr eine andere Konzeption zugrunde liegt oder sie in einen neuen Kontext gesetzt wird.

Mit der Digitalisierung löste sich die Aneignung aus dem künstlerischen Bereich. Von einer künstlerischen Strategie mit theoretischem Fundament entwickelte sie sich zu einem Mittel der Kommunikation. ${ }^{393}$ Kopien dienen im Schwerpunkt nicht mehr der Reflexion über die Vorlage. Vielmehr werden Bilder in der Digitalkultur als Rohstoff genutzt - sie werden ständig verändert, kombiniert und in neuen Kontext gesetzt. Durch diese produktive und flexible Nutzungsmöglichkeit von Bildern eignen sie sich besonders gut als Kommunikationsmittel im Internet. Die Kommunikation verlagert sich also nicht nur ins Digitale, sondern das Kommunikationsverhalten ändert sich. Die Aneignung wird nun zu Zwecken der Kommunikation vorgenommen, sie wird zu einem kommunikativen Medium. Die Aneignung wird aus dem Kontext der Kunst gelöst und wieder - wie in voraufklärerischen Zeiten - funktional genutzt und als Werkzeug betrachtet. Mit der Entwicklung der Aneignung zu einem kommunikativen Massenphänomen entsteht ein kulturelles Freihaltebedürfnis für diese Nutzungshandlung und ihr kommt eine rechtliche Relevanz zu, die im nächsten Kapitel untersucht werden soll.

393 Huss/Winkler, Wiederholung. Revision eines ästhetischen Grundbegriffs, in: Huss/Winkler (Hrsg.), Kunst \& Wiederholung. Strategie, Tradition, ästhetischer Grundbegriff, 2017, S. 7, 8 f. 


\section{Drittes Kapitel: Die urheberrechtliche Einordnung bildlicher Aneignungen}

Nachdem die Aneignung von Bildern im vorherigen Kapitel kulturhistorisch betrachtet wurde, soll dem nun die rechtliche Einordnung der Aneignung nach dem UrhG gegenübergestellt werden. Die Leitfrage ist dabei, ob sich eine Differenz der verbreiteten und intensiven Nutzung der Aneignung in Kunst und Kommunikation einerseits und deren rechtlicher Beurteilung andererseits ergibt. Dabei stellt sich auch die Frage, ob das Urheberrecht einen Unterschied in der rechtlichen Bewertung macht zwischen Aneignungen zu künstlerischen Zwecken und solchen zu kommunikativen Zwecken. Es soll gezeigt werden, ob und inwieweit der Urheber eines geschützten Werkes den Umgang mit demselben kontrollieren darf und welche Nutzungen eines urheberrechtlich geschützten Werkes unabhängig von ihm vorgenommen werden dürfen. Dazu wird nach dem klassischen Prüfungsschema zunächst dargestellt, welche Gegenstände von Aneignungen als urheberrechtlich geschützte Werke zu qualifizieren sind (A.). Dann wird gezeigt, wann und warum Aneignungen in Urheberpersönlichkeitsrechte (B.) sowie Verwertungsrechte des Urhebers (C.) eingreifen können. Schließlich wird die Rechtfertigung dieser Eingriffe durch Schrankenregelungen geprüft (D.). Es soll zudem herausgearbeitet werden, ob das Urheberrecht aufgrund seiner Struktur und Ausrichtung grundsätzlich Schwierigkeiten mit Aneignungen hat und wie es bisher mit den der Digitalisierung einhergehenden Veränderungen der Kommunikation durch Aneignungen umgeht (E.). Einige der Prüfungspunkte gehören bereits zum Stand der Forschung und werden deshalb knapp gehalten. Wenn neue, umfassendere oder eingehendere Lösungsvorschläge gemacht werden, sind die Ausführungen entsprechend detaillierter.

\section{A. Urheberrechtlich geschützte Werke als Gegenstand von Aneignungen Dritter}

Die Werkarten, die angeeignet werden können, sind vielfältig, gar unüberschaubar. Daher kann hier keine umfassende, abschließende Analyse der urheberrechtlichen Einordnung der Aneignung vorgenommen werden, sondern sie soll sich auf die oben vorgestellten Untersuchungsgegenstän- 
de ${ }^{394}$ der bildlichen Aneignung beschränken, die charakteristisch und repräsentativ für die verschiedenen Nutzungsformen stehen.

Urheberrechtsverletzungen durch Aneignung sind nur dann möglich, wenn das angeeignete Werk urheberrechtlich geschützt ist (I.). Auf die Verletzung der verwandten Schutzrechte soll nur knapp eingegangen werden (II.), da die von bildlichen Aneignungen betroffenen verwandten Schutzrechte häufig parallel oder in starker Anlehnung zum urheberrechtlichen Schutz ausgestaltet sind.

Urheber ist nach dem Schöpferprinzip ${ }^{395}$ des $\$ 7$ UrhG allein der Schöpfer des Werkes. Damit ein urheberrechtlich geschütztes Werk im Sinne des $\$ 2$ Abs. 1 UrhG entstehen kann, ist eine persönliche Schöpfung erforderlich. Das heißt es bedarf immer eines Schöpfungsaktes durch einen Menschen - ein solcher durch ein Tier oder einen Computer ist gerade nicht ausreichend. ${ }^{396}$ Damit ist ebenso immer nur eine natürliche Person Urheber; eine juristische Person kann nie selbst Urheber werden. ${ }^{397}$ Gemeinsame Schöpfer können Miturheber gem. $\$ 8$ UrhG sein. Der urheberrechtliche Schutz entsteht mit der Schöpfung als Realakt und bedarf keiner Registrierung oder Anmeldung. ${ }^{398}$

\section{Schutz des angeeigneten Werkes gem. $\$ 2$ Abs. 1, 2 UrhG}

Ein Gegenstand ist urheberrechtlich geschützt, wenn es sich gem. $\$ 1$ UrhG um ein Werk der Literatur, Wissenschaft oder Kunst handelt und dieses eine persönliche geistige Schöpfung im Sinne des $\$ 2$ Abs. 2 UrhG ist. Der Werkkatalog des $\ 2$ Abs. 1 UrhG ist nur beispielhaft, sodass es nicht unter eine der dort genannten Werkarten fallen muss. ${ }^{399}$ Vorlage bildlicher Aneignungen sind in der Regel aber Gemälde, Zeichnungen, Skulpturen, Videos oder Fotos, sodass es sich bei dem angeeigneten Gegenstand meist um ein Werk der bildenden Künste (Nr. 4), ein

394 Vgl. S. $46 \mathrm{ff}$.

395 Rehbinder/Peukert, Urheberrecht, 18. Aufl. 2018, Rn. 279; Schack, Urheber- und Urhebervertragsrecht, 9. Aufl. 2019, Rn. 300.

396 Dreier/Schulze/Schulze, 6. Aufl. 2018, \$2 UrhG Rn. 8; Rehbinder/Peukert, Urheberrecht, 18. Aufl. 2018, Rn. 284. Allerdings kann sich der Urheber bei der Schaffung seines Werkes des Computers als Hilfsmittel bedienen.

397 Schack, Urheber- und Urhebervertragsrecht, 9. Aufl. 2019, Rn. 301.

398 Ders., a.a.O., Rn. 302.

399 Dies zeigt sich an der Nutzung des Wortes „insbesondere“ in $\$ 2$ Abs. 1 UrhG. 
Lichtbildwerk (Nr. 5) $)^{400}$ oder ein Filmwerk (Nr. 6) ${ }^{401}$ handeln wird. Unter einem Werk der bildenden Künste versteht die Rechtsprechung eine „eigenpersönliche Schöpfung, die mit den Darstellungsmitteln der Kunst durch formgebende Tätigkeit hervorgebracht und vorzugsweise für die ästhetische Anregung des Gefühls durch Anschauung bestimmt ist. " ${ }^{402}$ Es ist also nicht jedes Kunstwerk auch ein urheberrechtlich geschütztes Werk. ${ }^{403}$ Maßgeblich ist als Schutzvoraussetzung, ob eine persönliche geistige Schöpfung gem. $\$ 2$ Abs. 2 UrhG vorliegt. Sie soll daher nun genauer dargestellt werden.

\section{Persönliche geistige Schöpfung}

Eine persönliche geistige Schöpfung gem. $\$ 2$ Abs. 2 UrhG setzt voraus, dass der Schöpfer eine natürliche Person ist, dass das Werk einen geistigen Gehalt aufweist, der sich in einer wahrnehmbaren Formgestaltung konkretisiert hat, und dass das Werk die Individualität des Urhebers ausdrückt es also individuelle Züge aufweist, derentwegen es dem Urheber zugeord-

400 Ein Lichtbildwerk ist die Aufzeichnung und Wiedergabe eines vorhandenen Motivs, Abbild oder Bildgegenstandes durch ein beliebiges technisches Verfahren, sei es chemikalisch-physikalisch, elektronisch (digital) oder andersartig, s. Dreier/Schulze/Schulze, 6. Aufl. 2018, $\mathbb{2}$ UrhG Rn. 189; Schricker/Loewenheim/Loewenheim, 5. Aufl. 2017, \$2 UrhG Rn. 208.

401 Ein Filmwerk ist ein Werk eigener Art, bei dem die benutzten Werke (z.B. Sprachwerke oder Musikwerke) zu einer Einheit verschmolzen und ins Bildliche umgewandelt werden, s. amtl. Begründung BT-Drs. IV/270, S. 38; Dreier/ Schulze/Schulze, 6. Aufl. 2018, $\$ 2$ UrhG Rn. 204. Unter Werken, die ähnlich wie Filmwerke gem. $\$ 2$ Abs. 1 Nr. 6 UrhG geschaffen werden, versteht man unter anderem Computeranimationen und Computerspiele, die wie oben gesehen ebenfalls von bildlichen Aneignungen betroffen sein können.

402 BGH GRUR 1988, S. 690, 692 - Kristallfiguren; BGH GRUR 1981, S. 517, 519 Rollhocker; BGH GRUR 1972, S. 38, 39 - Vasenleuchter. Maßgeblich ist der für die Kunst empfängliche und mit Kunstanschauung einigermaßen vertraute Verkehrskreis, vgl. OLG München GRUR 1987, S. 290, 291 - Wohnanlage.

403 Der Werkbegriff des Art. 5 Abs. 3 GG ist weiter als der urheberrechtliche Werkbegriff, denn nicht für jedes Kunstwerk liegen die Schutzgründe für das Urheberrecht vor, s. Dreier/Schulze/Schulze, 6. Aufl. 2018, \$2 UrhG Rn. 149; Schack, Kunst und Recht, 3. Aufl. 2017, Rn. 4, mit Beispielen zu verschiedenen problematischen Kunstrichtungen Rn. 11 ff. Zur Kritik dieser Diskrepanz, die insbesondere bei avantgardistischen Werken wie Ready-mades, Konzeptkunst oder Aktionskunst entsteht, s. Fuchs, Avantgarde und erweiterter Kunstbegriff, 2000, S. 127 und Huttenlauch, Appropriation Art. Kunst an den Grenzen des Urheberrechts, 2010, S. 89 f. 
net wird. ${ }^{404}$ Grundsätzlich gilt, je größer der Gestaltungsspielraum des Urhebers ist, das heißt je weniger die Ausführung des Werkes durch vorgegebene Zwecke, übliche Gestaltungsmittel oder technische Zwänge vorgegeben ist, desto eher ist Urheberrechtsschutz zu bejahen. ${ }^{405}$

Die Bilder, die von Aneignungen betroffen sein können, sind äußerst vielfältig. Sie reichen von den berühmtesten Kunstwerken aller Zeiten zu banalen Urlaubs- und Partybildern. Bei Aneignungen zu künstlerischen Zwecken kann wohl noch eher davon ausgegangen werden, dass auch das angeeignete Bild selbst künstlerisch wertvoll ist. Doch bei Aneignungen zu kommunikativen Zwecken werden gerade auch triviale Inhalte gerne verbreitet. Der künstlerische oder ästhetische Wert eines Bildes ist jedoch nicht maßgeblich für seinen urheberrechtlichen Schutz. ${ }^{406}$ Es stellt sich also die Frage nach der Untergrenze urheberrechtlichen Werkschutzes bzw. dem Mindestmaß schöpferisch-individueller Leistung.

\section{a) Schutz der kleinen Münze}

Die Rechtsprechung stellt keine allzu hohen Anforderungen an das Maß der Individualität und lässt einen recht geringen Grad an schöpferischer Eigentümlichkeit genügen. Das Minimum an Schöpfungshöhe markiert die sog. kleine Münze. Mit diesem Begriff wird die weltweite Tendenz zur

404 Wandtke/Bullinger/Bullinger, 5. Aufl. 2019, \2 UrhG Rn. 21 ff.; Schricker/ Loewenheim/Loewenheim, 5. Aufl. 2017, \2 UrhG Rn. 32 f.; Rebbinder/Peukert, Urheberrecht, 18. Aufl. 2018, Rn. 199; Schack, Urheber- und Urhebervertragsrecht, 9. Aufl. 2019, Rn. 181 ff. Im EU-Recht wird nur eine „eigene geistige Schöpfung“ verlangt bei Computerprogrammen, Datenbank- und Lichtbildwerken, s. dazu Art. 1 Abs. 3 Computer-RL 91/250/EWG; Erwägungsgrund 16 und Art. 3 Abs. 1 S. 2 DatenbankRL 1996/9/EG sowie Erwägungsgrund 16 und Art. 6 Schutzdauer-RL 2006/116/EG. Zudem wird von der „Originalität“ und nicht von der „Individualität“ eines Werkes gesprochen, vgl. EuGH GRUR 2012, S. 386 Rn. 40 - Football Dataco/Yahoo, mit Hinweis auf Erwägungsgrund 16 Datenbank-RL. Es ist jedoch strittig, ob diese Kriterien nur für die drei genannten Werkarten gelten oder der Werkbegriff damit umfassend unionsrechtlich harmonisiert wurde. S. zum Streit Dreier/Schulze/Schulze, 6. Aufl. 2018, $\mathbb{2}$ UrhG Rn. 22 und zu den Argumenten gegen eine umfassende Harmonisierung Riesenhuber, Der Schutzgegenstand und die Rechtsinhaber, in: ders. (Hrsg.), Systembildung im Europäischen Urheberrecht, 2007, S. 126.

405 Dreier/Schulze/Schulze, 6. Aufl. 2018, \$2 UrhG Rn. 33.

406 Rehbinder/Peukert, Urheberrecht, 18. Aufl. 2018, Rn. 207. 
Senkung der Schutzvoraussetzungen im Urheberrecht bezeichnet. ${ }^{407}$ So werden mittlerweile auch herkömmliche Formulare ${ }^{408}$, Adressbücher ${ }^{409}$, Rechentabellen ${ }^{410}$ und Kunstreproduktionen ${ }^{411}$ vom Urheberrecht geschützt, also Gegenstände mit geringer subjektiv-individueller Leistung. Diese Entwicklung wurde maßgeblich von der europäischen Rechtsentwicklung vorangetrieben: In den Richtlinien zu Computerprogrammen und Datenbanken wurden ausdrücklich geringe Anforderungen an die urheberrechtliche Schutzfähigkeit postuliert. ${ }^{412}$ Dies führte dazu, dass auch „wirtschaftlich relevante, aber kulturell völlig bedeutungslose Produkte“413 in den Genuss des Urheberrechtsschutzes kommen.

\section{b) Folgen für Bilder}

Je nach Werkart können die Anforderungen an die notwendige Individualität unterschiedlich ausfallen. Während die kleine Münze schon früh für Literatur, Musik und Computerprogramme galt, wurde bei Werken der bildenden Kunst und der angewandten Kunst bis vor kurzem ein strenge-

407 Der Ausdruck kommt von Elster, Gewerblicher Rechtsschutz, umfassend Urheber- und Verlagsrecht, Patent- und Musterschutzrecht, Warenzeichenrecht und Wettbewerbsrecht, 1921, S. 40; zur Entwicklung des Begriffs Thoms, Der urheberrechtliche Schutz der kleinen Münze, 1980, S. $76 \mathrm{ff}$.

408 OLG Nürnberg GRUR 1972, S. 435 - Standesamtliche Formulare.

409 RGZ 116, S. 292.

410 RGZ 121, S. 357.

411 BGH GRUR 2019, S. 284 - Museumsfotos, wobei hier die Einordnung unter $\$ 2$ Abs. 1 Nr. 5 UrhG offengelassen wurde und zumindest ein Schutz als Lichtbild im Sinne des $₫ 72$ UrhG angenommen wurde; BGH GRUR 1990, S. 669 Bibelreproduktion.

412 S. dazu auch S. 121 Fn. 404.

413 So Schack, Urheber- und Urhebervertragsrecht, 9. Aufl. 2019, Rn. 294. Zur Kritik an der kleinen Münze und mit der Forderung der Anhebung der Schutzschwelle: Rehbinder/Peukert, Urheberrecht, 18. Aufl. 2018, Rn. 201; Knöbl, Die „kleine Münze“ im System des Immaterialgüter- und Wettbewerbsrechts, 2002; Schulze, Die kleine Münze und ihre Abgrenzungsproblematik bei den Werkarten des Urheberrechts, 1983, S. 279 ff.; Thoms, Der urheberrechtliche Schutz der kleinen Münze, 1980, S. 271; Schack, Weniger Urheberrecht ist mehr, in: FS Wandtke, 2013, S. 9 ff.; a.A.: Schricker, Abschied von der Gestaltungshöhe im Urheberrecht, in: FS Kreile, 1994, S. 715, 715, der die kleine Münze als angemessene Antwort auf das wirtschaftliche Schutzbedürfnis ansieht. 
rer Maßstab angelegt. ${ }^{414}$ Ähnlich war es zunächst auch bei den Lichtbildwerken, an die früher strenge Anforderungen gestellt wurden, da für weniger individuelle Leistungen ja bereits das Leistungsschutzrecht des $\$ 72$ UrhG bestehe. Mittlerweile sind Fotografien gem. Art. 6 der Schutzdauer-RL 2006/116/EG ${ }^{415}$ bereits dann als Lichtbildwerke geschützt, wenn sie „das Ergebnis der eigenen geistigen Schöpfung ihres Urhebers sind.“ Seitdem gilt die kleine Münze auch für sie und infolgedessen kommen nun auch Gegenstandsfotos und andere Zweckfotos als urheberrechtliche Werke in Betracht, soweit nicht blindlings geknipst, sondern gezielt für eine aussagekräftige Aufnahme fotografiert wird. ${ }^{416}$ Ebenso gilt die kleine Münze auch bei Filmwerken, für die die geringen Schutzvoraussetzungen der Lichtbildwerke entsprechend gelten. ${ }^{417}$

Die Unterscheidung von urheberrechtlich geschützten Lichtbildwerken und den nur über $\$ 72$ UrhG geschützten Lichtbildern bleibt mit der kleinen Münze weiterhin schwierig. Knipsbilder und Schnappschüsse sollen typischerweise nicht als urheberrechtliche Werke geschützt werden. Das bloße „Draufhalten“ genügt nicht, um einer Fotografie individuellen Charakter zu verleihen. ${ }^{418}$ Regelmäßig sind also Bilder, die spontan mit der Handykamera aufgenommen werden, keine Werke im Sinne des Urheberrechts. Dennoch ist die Aneignung solcher Fotos oder Videos nicht unbe-

414 Schack, Kunst und Recht, 3. Aufl. 2017, Rn. 227. Um die Abgrenzung zum Designschutz zu wahren, verlangte der BGH für Werke der angewandten Kunst (solche unterscheiden sich durch ihren reinen Gebrauchszweck von Werken der bildenden Kunst, vgl. BGH GRUR 2012, S. 58, 58 Rn. 17 - Seilzirkus) bisher „ein deutliches Überragen der Durchschnittsgestaltung“, BGH GRUR 1995, S. 581, 582 - Silberdiestel. Mittlerweile werden an die angewandte Kunst jedoch die gleichen Anforderungen wie an Werke der bildenden Künste gestellt. Es muss jedoch weiterhin eine künstlerische Gestaltung vorliegen, die nicht allein dem Gebrauchszweck geschuldet sein darf, so BGH GRUR 2014, S. 175, 177 Rn. 26 - Geburtstagszug; OLG Schleswig GRUR-RR 2015, S. 1 - Geburtstagszug II.

415 Richtlinie (EU) des Europäischen Parlaments und des Rates vom 12. Dezember 2006 über die Schutzdauer des Urheberrechts und bestimmter verwandter Schutzrechte.

416 Dreier/Schulze/Schulze, 6. Aufl. 2018, $\$ 2$ UrhG Rn. 195.

417 Vgl. Schricker/Loewenheim/Loewenheim, 5. Aufl. 2017, \$2 UrhG Rn. 222; Dreier/Schulze/Schulze, 6. Aufl. 2018, \$2 UrhG Rn. 211.

418 So auch die Argumentation in LG Berlin ZUM-RD 2014, S. 105, 107 - Technoviking, auch wenn es hier um $\$ 23$ Abs. 1 Nr. 4 KUG ging und nicht um $\$ 2$ Abs. 1, 2 UrhG. S. dazu auch S. 208. 
denklich, da $₫ 72$ UrhG Lichtbildern den gleichen Schutz wie Lichtbildwerken zugesteht. ${ }^{419}$

Keinen Einfluss auf den Schutz als Lichtbildwerk hat die Größe bzw. das Format des Bildes, so dass auch stark verkleinerte und in schlechter Auflösung wiedergegebene Vorschaubilder (Thumbnails) geschützt sein können. ${ }^{420}$

\section{Bildschnipsel: Schutz von Werkteilen}

Wie umfangreich der Schutz von Werkteilen ist, ist insbesondere für Bildermontagen relevant, bei denen häufig nur Bildschnipsel zu sehen sind, und für GIFs, für die nur einzelne Frames eines Videos zu sehen sind. Es ist jedoch nicht nur das Werk insgesamt, sondern auch in seinen Teilen urheberrechtlich geschützt, wenn der jeweilige Teil auch für sich hinreichend individuell ist. ${ }^{421}$ An die Werkteile sind also jeweils dieselben Anforderungen zu stellen wie an die Schutzfähigkeit des Werkes insgesamt. ${ }^{422}$ Es kommt also bei Aneignungen jeweils darauf an, ob auch das einzelne übernommen Teile schutzfähig ist oder nicht.

\section{Aneignung des Ready-made: Schutz der Idee?}

Auch ein Ready-made kann Gegenstand einer Aneignung sein, sofern der Alltagsgegenstand einen Zuweisungsgehalt aufweist, denn die Aneignung beinhaltet den Bruch des Zuweisungsgehaltes eines Objekts. ${ }^{423}$ Das sog. Ready-made ist ein Kunstwerk, das aus der Präsentation eines alltäglichen oder bekannten Gegenstandes besteht, und dieses durch die Präsentation zu Kunst erklärt. ${ }^{424}$ Der „Fountain“ (1917) von Marcel Duchamp ist ein

419 S. dazu S. 132 f.

420 BGH GRUR 2010, S. 628, 628 f. Rn.9, 16 - Vorschaubilder I; Ziegler, Urheberrechtsverletzungen durch Social Sharing, 2016, S. 54.

421 Dreier/Schulze/Schulze, 6. Aufl. 2018, \$2 UrhG Rn. 76.

422 Vgl. Ullmann, Schutz der Elemente - elementarer Schutz der immaterialen Güter, GRUR 1993, S. 334, 336.

423 Vgl. dazu S. 32 f. Denkbar ist dies beispielsweise, indem der Alltagsgegenstand den Bezug zu einer Firma o.Ä. aufzeigt.

424 Dreier/Schulze/Schulze, 6. Aufl. 2018, $\$ 2$ UrhG Rn. 154. Zu einer ausführlicheren Definition und kunstgeschichtlichen Einordnung des Ready-made vgl. S. $96 \mathrm{ff}$. 
auf die Seite gekipptes handelsübliches Urinal, das er mit der Aufschrift „R. Mutt 1917“ versah. Als ein Schlüsselwerk der modernen Kunst inspirierte es Appropriation Art Künstler und wurde als Referenzgegenstand genutzt: Elaine Sturtevant schuf 1973 einen dem Duchampschen Urinal sehr ähnlichen „Duchamp Fountain“425; Sherrie Levine stellte eine vergoldete Bronzeskulptur eines Urinals her; Mike Bidlo fertigte unzählige Zeichnungen eines „Fountain“ und 2015 eine bronzene, zerbrochen und wieder zusammengesetzte Skulptur als „Fractured Fountain (Not Duchamp Fountain 1917)“ an. Diese Hommagen sind jedoch urheberrechtlich erst von Relevanz, wenn auch die Vorlage Urheberschutz genießt, wenn also ein solches Ready-made auch als Werk im Sinne des Urheberrechtsgesetzes geschützt ist.

Zunächst ist festzustellen, dass nicht jedes Kunstwerk auch ein Werk gem. $\$ 2$ Abs. 1, 2 UrhG und damit einen urheberrechtlichen Schutzgegenstand darstellt. ${ }^{426}$ Denn die Schutzrichtung des Urheberrechts ist nicht, die Freiheit des Kunstschaffens zu fördern, sondern sie sichert die persönlichen und vermögensrechtlichen Interessen eines Künstlers an seinem Werk. ${ }^{427}$ Das Urheberrecht schützt den Künstler damit nur mittelbar, über das Ergebnis seines Schaffens. ${ }^{428}$ Das Ready-made stellt zwar ohne Frage ein Kunstwerk dar. Gegen den Schutz als urheberrechtliches Werk werden im Wesentlichen aber zwei Argumente vorgebracht: Es fehle am menschlichen Schöpfungsakt, und die schöpferische Idee sei in dem Gegenstand nicht hinreichend konkretisiert.

425 Dieser kann gerade auch als Wieder-Holung des „Fountain“ gesehen werden, da der Original Fountain von Duchamp verschollen ist. Mit Sturtevants Kopie lebt auch das Original wieder auf. Als Vorlage hierfür nahm sie die einzig noch existierende Fotografie des Original Fountain von Duchamp von Alfred Stieglitz sie nahm also gleich eine doppelte Aneignung vor, so Zuschlag, Die Kopie ist das Original - über Appropriation Art, in: Mensger (Hrsg.), Déjà-vu? Die Kunst der Wiederholung von Dürer bis Youtube, Ausstellungskatalog der Staatlichen Kunsthalle Karlsruhe, 2012, S. 126, 129.

426 Vgl. auch Dreier/Schulze/Schulze, 6. Aufl. 2018, $\$ 2$ UrhG Rn. 149; Schricker/ Loewenheim/Loewenheim, 5. Aufl. 2017, \$2 UrhG Rn. 157. Diese Diskrepanz zwischen dem Begriff des Kunstwerks im Sinne des Art. 5 Abs. 3 GG und dem Werkbegriff des Urheberrechts kann aber zu einer verminderten Anerkennung des Urheberrechts führen, wenn es im Ergebnis bedeutenden Kunstwerken des 20. Jahrhunderts keinen Schutz erteilt. Der Werkbegriff des Urheberrechts wird daher von Teilen der Literatur als veraltet angesehen, so Fuchs, Avantgarde und erweiterter Kunstbegriff, 2000, S. 129 f.

427 Schack, Kunst und Recht, 3. Aufl. 2017, Rn. 4.

428 Ulmer, Urheber- und Verlagsrecht, 3. Aufl. 1980, S. 1. 
Als Werk im Sinne des $₫ 2$ Abs. 2 UrhG wird nur geschützt, was das Ergebnis einer menschlich-gestalterischen Tätigkeit ist. Laut Schack fehle es hieran, da kein menschlicher Schöpfungsakt vorläge ${ }^{429}$ und überdies eine persönliche Ausführung der Gestaltung des Schutzgegenstandes vonnöten wäre. ${ }^{430}$ Auch Maaßen vertritt, dass eine schutzfähige Schöpfung nur vorläge, wenn etwas noch nicht da Gewesenes geschaffen worden sei. ${ }^{431}$ Als ausreichend erachtet die herrschende Meinung der Literatur jedoch die neue Kombination mehrerer Alltagsgegenstände zu einem Kunstwerk ${ }^{432}$ : So schuf Picasso seinen Stierkopf „Tête de taureau“ (1943) aus einem Fahrradlenker, der die Hörner bildet, und einem Fahrradsattel, der den Schädel darstellt. ${ }^{433}$ Ebenso liegt eine persönliche geistige Schöpfung dann vor, wenn der Alltagsgegenstand ausreichend individualisiert wurde. Die vergoldete Bronze-Version des Urinals von Duchamp, die Sherrie Levine geschaffen hat ${ }^{434}$, verändert das Material dergestalt, dass es sich nun gerade nicht mehr um ein gewöhnliches Massenprodukt handelt, sondern um ein hochwertiges Einzelstück. Es ist damit urheberrechtlich geschützt. ${ }^{435}$

429 Schack, Kunst und Recht, 3. Aufl. 2017, Rn. 224.

430 Ders., a.a.O., Rn. 15.

431 Maaßen, Plagiat, freie Benutzung oder Kunstzitat? Erscheinungsformen der urheberrechtlichen Leistungsübernahme in Fotografie und Kunst, in: FS Pfennig, 2012, S. 135, 138.

432 Schack, Kunst und Recht, 3. Aufl. 2017, Rn 16.; P. Raue, Ready-Mades und Appropriation Art. „Werke“ im Sinne des Urhebergesetzes?, in: FS Pfennig, 2012, S. 199, 200: Eine solche „frappierende Kombination“ sei zweifelsfrei urheberrechtlich geschützt. Anders jedoch gerade Kummer, Das urheberrechtlich schützbare Werk, 1968, S. 69 und 100: Der Schädel habe keine Individualität, denn weder sei die Zusammenstellung außergewöhnlich noch die Möglichkeiten der Kombination besonders reich.

433 Eine solche Kombination stellt jedoch nicht im engeren Sinne ein Ready-made dar. Denn hier geht es nicht mehr um die Erklärung eines Alltagsgegenstandes zu einem Kunstwerk. Es wird gerade nicht im Alltagsgegenstand allein künstlerisches Potenzial gesehen, sondern erst in der Kombination und Neuordnung dieses Gegenstandes. Damit ist der Stierschädel von Picasso im Zusammenhang mit der Arbeit mit vorgefundenem Material wie etwa bei der Collage einzuordnen.

434 „Fountain (after Marcel Duchamp)“ von 1991. Durch die Nutzung der teuren und hochwertigen Materialien wird bei ihr aus dem Ready-made wieder ein individualisiertes Objekt, es ist gerade kein Exemplar der Massenproduktion mehr.

435 Es handelt sich dabei auch nicht um eine Bearbeitung oder freie Benutzung des „Fountain" von Marcel Duchamp, da dieser gerade nicht urheberrechtlich geschützt ist, s. S. 124 ff. Das führt zum Ergebnis, dass das Urinal von Duchamp 
Zum Teil wird jedoch eingewandt, dass der schöpferische Akt beim Ready-made in der Präsentation des Alltagsgegenstandes als Kunstwerk liegt. So nimmt Kummer mit seiner Präsentationslehre an, dass Individualität auch in der Auswahl, Anordnung und Präsentation eines Gegenstandes liegen kann. ${ }^{436}$ In eine ähnliche Richtung geht Kehrli, der dann urheberrechtlichen Schutz verleihen will, wenn der Gegenstand durch die Präsentation einen innovativen Charakter erhält. ${ }^{437}$ Schulze entwickelt dies weiter dahingehend, dass es ausreiche, wenn aus der Vielzahl ein bestimmter Gegenstand ausgewählt, aus seinem bisherigen Rahmen herausgenommen und in den ganz anderen Rahmen einer Kunstausstellung versetzt wird, sodass er eine völlig neue Bedeutung, einen innovativen Charakter erhält. ${ }^{438}$ Haberstumpf spricht von einem Akt der Sinngebung ${ }^{439}$ durch den Künstler.

Die Verschiebung der schöpferischen Tätigkeit von der Produktion des Werkes auf die Auswahl scheint urheberrechtlich vertretbar, zumal eine ähnliche Entwicklung bei der Anerkennung der Schutzfähigkeit der Foto-

durch die Appropriation Art frei, das Urinal von Levine jedoch nur unter den Voraussetzungen des $\$ 23$ oder $\$ 24$ UrhG genutzt werden kann.

436 Kummer, Das urheberrechtlich schützbare Werk, 1968, S. 43: „Jede Individualität ist letztlich darauf zurückzuführen, dass aus einer Menge von Einzelelementen einzelne ausgewählt und zusammengefügt oder dass zumindest Entscheidungen (Auswahlen) für die Anordnung getroffen werden." Er nimmt jedoch an, dass Duchamps Flaschentrockner gerade nicht schutzfähig ist, da Massenprodukten die individuelle Form fehle - seine Präsentationslehre wendet er also nicht auf industriell gefertigte Ready-mades an. Vielmehr möchte er das „Aufdecken und Sichtbarmachen des bislang achtlos Übergangenen“ schützen und gibt als Beispiel eine Föhrenwurzel, die aufgrund ihrer individuellen Formung die Illusion einer Tänzerin hervorruft und in gleicher Form in der Natur nicht auffindbar ist, vgl. ders., a.a.O., S. 103 f. Die damit vorgenommene Unterscheidung zwischen dem Auswählen und Präsentieren solcher Zufallsprodukte der Natur und Industrieprodukten ist jedoch abzulehnen, da doch beiden eigen ist, dass der Künstler in ihnen einen besonderen Ausdruck erkennt. Zudem kann diese statistische Einmaligkeit der Föhrenwurzel allein auf ein Produkt des Zufalls zurückzuführen sein, diesem wollte der Gesetzgeber den urheberrechtlichen Schutz aber gerade versagen, so Ulmer, Der urheberrechtliche Werkbegriff und die moderne Kunst - Rezensionsabhandlung, GRUR 1968, S. 527, 528 f.

437 Kehrli, Der urheberrechtliche Werkbegriff im Bereich der bildenden Kunst, 1989, S. $128 \mathrm{ff}$.

438 Dreier/Schulze/Schulze, 6. Aufl. 2018, $\$ 2$ UrhG Rn. 154.

439 Haberstumpf, Nichtgegenständliche Werke im Urheberrecht, in: FS Schulze, 2017, S. 3, 8. 
grafie stattgefunden hat. ${ }^{440}$ Problematisch ist allerdings, dass dann der Künstler allein darüber entscheiden kann, was urheberrechtlich schutzwürdig ist, da allein seine Auswahl und Präsentation ausreichen. Im Sinne eines kollektiv verstandenen Urheberrechts, das auch die Interessen der Allgemeinheit am Zugang zu Werkstücken berücksichtigt ${ }^{441}$, kann dieses Ergebnis so nicht erwünscht sein.

Den dargestellten Meinungen, die sich für eine Schutzfähigkeit von Ready-mades aussprechen, ist jedoch zugute zu halten, dass sie versuchen, sich von den klassischen Parametern des Urheberrechts zu lösen, die vielen Formen der zeitgenössischen Kunst nicht gerecht werden können. ${ }^{442}$ Denn das Problem des Ready-made scheint vielmehr zu sein, dass das Urheberrecht einen Fokus auf die äußere Formgestaltung eines Werkes setzt. In dieser Formgestaltung müsste sich das schöpferische Element und die Individualität ausdrücken. Konträr dazu zeichnen sich Ready-mades jedoch gerade durch die neue Idee aus, mit der ein bereits existierender Gegenstand durch die Präsentation als Kunstwerk aufgeladen wird. Doch reicht die Idee als schöpferischer Akt eines Menschen aus? ${ }^{243}$ Grundsätzlich sind reine Ideen urheberrechtlich nicht schutzfähig ${ }^{444}$, sondern nur in ihrer konkreten Ausführung. Sind sie also mit der Darstellung im Ready-made hinreichend konkretisiert? Auch hier liefe man wieder Gefahr, dem Künstler das Deutungsmonopol über den urheberrechtlichen Schutzgegenstand in die Hand zu legen, wenn man die Verknüpfung vorgefundener Gegenstände mit einer Idee ausreichen lassen würde. ${ }^{445}$ Diese Überlegung führt zu

440 Hier konnte die schöpferische Tätigkeit nicht mehr in dem Fotografieren, also dem Aufnehmen des Bildes, selbst gesehen werden, da dies nun maschinell vorgenommen wurde. Daher deutete man die schöpferische Tätigkeit um hin zum Arrangement des Abzubildenden. Das Abzubildende wurde nun durch Lichtund Schattenkontraste, Schärfe, Bildausschnitt, Perspektive etc. inszeniert und so individuell präsentiert, dass das Abbild dessen wiederum urheberrechtlich geschützt ist.

441 S. dazu S. 254 ff., $256 \mathrm{ff}$.

442 So Huttenlauch, Appropriation Art. Kunst an den Grenzen des Urheberrechts, 2010, S. 91 und Fuchs, Avantgarde und erweiterter Kunstbegriff, 2000, S. 129 f.

443 Ausführlicher zur Abgrenzung von Idee und Form des urheberrechtlich geschützten Werkes ab S. 170.

444 BGH GRUR 1979, S. 119, 120 - Modeschmuck; Dreier/Schulze/Schulze, 6. Aufl. 2018, \2 UrhG Rn. 37; Schricker/Loewenheim/Loewenheim, 5. Aufl. 2017, 2 UrhG Rn.73; Schack, Kunst und Recht, 3. Aufl. 2017, Rn. 16; P. Raue, ReadyMades und Appropriation Art. „Werke“ im Sinne des Urhebergesetzes, in: FS Pfennig, 2012, 199, S. 201.

445 So Schack, Appropriation Art und Urheberrecht, in: FS Nordemann, 2004, S. 107, 108. 
dem Ergebnis, dass in der Regel in der Aneignung eines Ready-made durch einen Künstler der Appropriation Art keine Urheberrechtsverletzung vorliegt, da es an einem schutzfähigen Gegenstand fehlt. ${ }^{446}$

\section{Schutz des Stils eines Künstlers und des Motivs eines Bildes}

Bildliche Aneignungen betreffen nicht nur das komplette Werk, teilweise wird nur die Komposition eines Bildes oder die Bildabfolge bestimmter Videos übernommen. Es wird dann nicht 1:1 angeeignet, sondern das Konzept eines Bildes oder Videos nachgeahmt. So funktionieren virale Hypes beispielsweise nur, indem bestimmte Grundelemente immer wieder übernommen werden und damit ein Video oder Bild als ein Folgewerk innerhalb des viralen Hypes verstanden wird. Auch Memes funktionieren nur durch einen Metatext, der vorschreibt, innerhalb welcher kommunikativen Situationen und mit welchen stilistischen Mitteln dieses Meme genutzt werden kann. Fraglich ist daher, ob auch so abstrakte Konzepte wie der Stil des Künstlers oder das Motiv des angeeigneten Bildes urheberrechtlich geschützt sein können, sodass eine Aneignung derselben eine urheberrechtliche Verletzung darstellt.

Grundsätzlich darf jeder im Stile eines anderen malen - der Stil ist nicht geschützt. ${ }^{447}$ Solche abstrakten Eigenschaften eines Werkes seien „im Interesse der allgemeinen künstlerischen Entwicklung als gemeinfrei anzusehen“. ${ }^{448}$ Denn die Idee, in einem bestimmten Stil zu malen, ist abermals nicht urheberrechtlich geschützt, sondern nur deren konkrete Ausführung, das heißt das konkrete Gemälde in dem Stil. Die Grenze zur unfreien Bearbeitung ist jedoch dann überschritten, wenn umfangreich konkrete stilprägende Einzelelemente übernommen wurden. ${ }^{449}$ Eine Bildmontage

446 Vgl. Huttenlauch, Appropriation Art. Kunst an den Grenzen des Urheberrechts, 2010, S. 91; Dreier/Schulze/Schulze, 6. Aufl. 2018, \$2 UrhG Rn. 154, Schricker/ Loewenheim/Loewenheim, 5. Aufl. 2017, \$2 UrhG Rn. 173.

447 BGH NJW 1990, S. 1986, 1987 f. - Emil Nolde; Schack, Kunst und Recht, 3. Aufl. 2017, Rn. 235.

448 BGH NJW 1990, S. 1986, 1988 - Emil Nolde. Die Entfernung einer gefälschten Signatur auf dem stilistischen einem anderen Urheber untergeschobenen Gemälde kann jedoch aus dem Persönlichkeitsrecht gem. Art. 2 Abs. 1 i.V.m. Art. 1 Abs. 1 GG verlangt werden - nicht jedoch die Zerstörung der „Fälschung" oder deren Kenntlichmachung, vgl. a.a.O., S. 1988.

449 Schack, Kunst und Recht, 3. Aufl. 2017, Rn. 235. 
im Stil eines anderen Künstlers zu erstellen ist damit grundsätzlich urheberrechtlich unproblematisch.

Auch das Motiv, das das urheberrechtlich geschützte Werk zeigt, ist nicht selbst geschützt. ${ }^{450}$ Denn das Motiv betrifft lediglich den abgebildeten Gegenstand, ${ }^{451}$ es kann also niemals von dem Recht an einer Abbildung desselben monopolisiert werden. ${ }^{452}$ Zudem sind urheberrechtlich nur konkrete Ausführungen individualisierter Ideen schutzwürdig und damit nicht abstrakte Ideen, an einem bestimmten Ort eine Abbildung vorzunehmen. So ist beispielsweise das wiederkehrende Motiv eines roten Sofas, auf dem Menschen fotografiert werden, nicht durch das Urheberrecht geschützt ${ }^{453}$, die jeweils konkreten Ausführungen dieser Gestaltungsideen sind jedoch als Einzelwerke geschützt. ${ }^{454}$ Ebenfalls steht es jedem frei, denselben Ort aufzusuchen, der in der Vorlage abgebildet wurde, und ihn selbst abermals abzubilden. Das Urheberrecht hindert nicht daran, dasselbe Motiv vom selben Standort mit derselben Technik oder denselben technischen Apparaten abzubilden. So haben beispielsweise bereits zahlreiche Künstler den Berg Sainte-Victoire gemalt und zahlreiche Hobby-Fotografen das durch Gurskys „Montparnasse“ (1993) berühmt gewordene Hoch-

450 OLG Hamburg ZUM-RD 1997, S: 217, 221 - Troades; LG Hamburg ZUM 2009, S. 165, 167 - Mauerspringer; Bullinger/Garbers-von Boehm, Der Blick ist frei. Nachgestellte Fotos aus urheberrechtlicher Sicht, GRUR 2008, S. 24, 25 und Maaßen, Plagiat, freie Benutzung oder Kunstzitat? Erscheinungsformen der urheberrechtlichen Leistungsübernahme in Fotografie und Kunst, in: FS Pfennig, 2012, S. $135,146$.

451 Zur Unterscheidung von abgebildetem Gegenstand, Abbild und Abbildung vgl. S. 43.

452 Anders allerdings, wenn ein Eigentumsrecht am abgebildeten Gegenstand besteht und die Abbildung vom selbigen Grundstück aus vorgenommen wird, vgl. BGH NJW 2013, S. 1809 - Preußische Gärten und Parkanlagen II und zuvor bereits BGH NJW 2011, S. 749 - Preußische Gärten und Parkanlagen.

453 Das rote Sofa ist zwar das verbindende Element der jeweils für sich geschützten Bilder, eine solche gestalterische Grundidee sei aber nicht selbst durch das Urheberrecht geschützt, vgl. LG Hamburg Urteil v. 04.03.1997, Az. 308 O 272/95 Rote Couch I; LG Hamburg Urteil v. 21.09.2005, Az. 308 O 435/05 - Rote Couch II; LG Köln Urteil v. 12.12.2013, Az. 14 O 613/12 - Rotes Sofa.

454 Und so kann auch die Nachfotografie von Menschen auf einer roten Couch, die wie eine Schaukel an einem Baum befestigt ist, untersagt werden, wenn alle wesentlichen gestalterischen Elemente des Vorbildes übernommen worden sind, vgl. LG Hamburg Urteil v. 21.09.2005, Az. 308 O 435/05 - Rote Couch II. 
haus fotografiert. ${ }^{455}$ Etwas anderes gilt nur dann, wenn es sich bei dem Motiv nicht um ein feststehendes Objekt, sondern um ein künstlerischen Arrangement des Fotografen handelt, das eine eigenschöpferische Leistung darstellt. ${ }^{456}$ Bei viralen Hypes und ihren Nachahm-Videos kommt es also auf den Einzelfall an, ob lediglich das Konzept und die gestalterische Komposition des Videos übernommen oder ob umfangreich konkrete Gestaltungsideen des Ursprungsvideos im Aneignungsvideo erneut umgesetzt wurden.

\section{Schutzdauer gem. $\$ 64$ UrhG}

Nach $\$ 64$ UrhG erlischt der Urheberrechtsschutz 70 Jahre nach dem Tod des Autors. Das Werk ist dann gemeinfrei und kann von jedermann uneingeschränkt genutzt werden. Aneignungen von Werken, deren Schutzdauer abgelaufen ist, sind damit urheberrechtlich unproblematisch.

Bei Aneignungen zu kommunikativen Zwecken gibt es keine durchgängigen Nutzungsmuster, was das Alter der angeeigneten Werke betrifft. Hier kommt es also jeweils auf den Einzelfall an, ob ein urheberrechtlicher Schutz noch besteht oder nicht. Museumselfies und Montagen von Kunstwerken nutzen häufig bereits gemeinfreie Werke. Beliebt sind z.B. Montagen von Edvard Munchs „Der Schrei“ (1893), der seit 2015 gemeinfrei ist. ${ }^{457}$ Sowohl Duchamps berühmte Aneignung der Mona Lisa „L.H.O.O.Q.“ (1919), bei der er ihr einen Schnurrbart aufmalte und sie mit dem genannten anzüglichen ${ }^{458}$ Titel versah, als auch Selfies mit der

455 Beispielsweise Felix Lamouroux, s. https://500px.com/photo/19249841/gursky-smontparnasse-revisited-by-felix-lamouroux, Datum des Zugriffs: 15.01.2020, Beispiel nach Ullrich, Gurkyesque: Das Web 2.0, das Ende des Originalitätszwangs und die Rückkehr des nachahmenden Künstlers, in: Nida-Rümelin/ Steinbrenner (Hrsg.), Kunst und Philosophie. Original und Fälschung, 2011, S. 93, 93.

456 Maaßen, Plagiat, freie Benutzung oder Kunstzitat? Erscheinungsformen der urheberrechtlichen Leistungsübernahme in Fotografie und Kunst, in: FS Pfennig, 2012, S. 135, 147; OLG Hamburg ZUM-RD 1997, S. 217, 221 - Troades, LG Hamburg ZUM 2009, 165, 167 - Mauerspringer, a.A.: Hüper, Zum Schutz vor Nachfotografie und Nachbildungen von urheberrechtlich geschützten Fotoaufnahmen, AfP 2004, S. 511, 512 f.

457 Edvard Munch starb im Jahre 1944, sodass die Schutzfrist gem. $\$ 69$ UrhG im Jahr 1945 zu laufen begann und mit Ende des Jahres 2015 auslief.

458 Spricht man die Buchstaben französisch aus, ergibt sich der Satz „Elle a chaud au cul“ (dt. etwa: Sie hat einen heißen Hintern). 
Mona Lisa sind unproblematisch, da diese bereits 1506 von Leonardo da Vinci geschaffen wurde und mangels damals geltenden Urheberrechts gar keinen solchen Schutz genoss. Solche Aneignungen sind folglich urheberrechtlich erlaubt.

Die Künstler der Appropriation Art eignen sich jedoch meist Werke von Zeitgenossen an - dies liegt zum Teil an ihrer Ausrichtung auf die bewusste Verletzung von Urheberrecht, andererseits aber auch daran, dass Werke durch die Aneignung wiedergeholt werden sollen, die massenhaft gesehen und genutzt werden. Und dies betrifft insbesondere Werke der Pop Art, der Werbung oder virale Bilder der Internetkultur wie bei Princes Instagram-Bildern. Angeeignete Werke der Appropriation Art sind damit in der Regel noch urheberrechtlich geschützt.

\section{Exkurs: verwandte Schutzrechte}

Aneignungen nutzen natürlich auch solche Bilder, die keine persönliche geistige Schöpfung darstellen und daher den Schutzanforderungen des urheberrechtlichen Werkes nicht genügen. Solche Bilder sind nicht per se gemeinfrei, sondern es können dem Urheberrecht verwandte Schutzrechte greifen. Für bildliche Aneignungen sind insbesondere der Lichtbildschutz gem. $\$ 72$ UrhG, der Schutz der Filmhersteller gem. $\$ \$ 88 \mathrm{ff}$. UrhG und der Laufbildschutz gem. $\$ 95$ UrhG relevant. Es sei vorangestellt, dass verwandte Schutzrechte selbständig neben dem Urheberrecht stehen und die wirtschaftliche, organisatorische oder technische Leistung schützen ${ }^{459}$, die meist der Vermittlung eines urheberrechtlichen Werkes in der Öffentlichkeit dient. ${ }^{460}$

\section{Lichtbilder}

Lichtbilder sind solche Fotografien, die nicht der Schwelle des $\$ 2$ Abs. 2 UrhG zum schutzfähigen Werk genügen. Gem. $\$ 72$ Abs. 1 UrhG sind jedoch solche Lichtbilder wie Lichtbildwerke, die im Gegensatz eine persönliche geistige Schöpfung darstellen und damit Urheberrechtsschutz genießen, geschützt. Daher müssen Lichtbilder und Lichtbildwerke in der Regel nicht voneinander abgegrenzt und unterschieden werden, sondern

459 Dreier/Schulze/Dreier, 6. Aufl. 2018, Vor $\$ \$ 70$ UrhG Rn. 2.

460 Schack, Urheber- und Urhebervertragsrecht, 9. Aufl. 2019, Rn. 657. 
es lässt sich festhalten, dass der Schutz aller Fotografien meist gleich ausgestaltet ist. ${ }^{461}$ Ein wesentlicher Unterschied besteht jedoch in der Schutzdauer: Gem. $\$ 72$ Abs. 3 UrhG erlischt der Lichtbildschutz 50 Jahre nach Erscheinen des Lichtbildes ${ }^{462}$, und ist damit um einiges kürzer als der Lichtbildwerkschutz.

Für bildliche Aneignungen besonders relevant ist, dass auch Reproduktionsfotografien gemeinfreier Werke aufgrund der aufwendigen handwerklich-technischen Leistung Lichtbildschutz genießen. ${ }^{463}$ Wenn also eine Reproduktion zur digitalen Erstellung von Memes oder Montagen von Kunstwerken genutzt wird, kann diese Aneignung urheberrechtlich problematisch sein, selbst wenn das abgebildete Werk gemeinfrei ist, da die dieses verkörpernde materielle Abbild als Reproduktion geschützt ist. ${ }^{464}$ Auch Einzelbilder aus Filmen - wie sie häufig für GIFs verwendet werden - sind unabhängig vom Filmwerk- und Laufbildschutz als Lichtbilder geschützt. ${ }^{465}$

\section{Laufbilder}

Der Laufbildschutz gem. $\$ 95$ UrhG verhält sich zum Filmwerkschutz wie Lichtbilder zum Schutz von Lichtbildwerken. Die Abgrenzung zu Filmwerken kann schwierig sein. Es wird angenommen, dass Laufbilder bei Li-

461 Dreier/Schulze/Schulze, 6. Aufl. 2018, $\$ 72$ UrhG Rn. 16. Aufgrund der gem. Art. 6 der Schutzdauer-RL niedrigen Anforderungen an die Gestaltungshöhe im Rahmen des $\$ 2$ Abs. 2 UrhG werden die meisten Fotografien als Lichtbildwerke im Sinne des $\$ 2$ Abs. 1 Nr. 5 UrhG geschützt, s. dazu auch S. 123. Einer besonderen schöpferischen Gestaltung bedarf es nicht. Als einfache Lichtbilder bleiben daher nur Aufnahmen, bei denen es einzig um die technisch einwandfreie Wiedergabe geht oder "blindlings geknippst“ wird, vgl. BGH ZUM 2000, S. 233, 234 - Werbefotos; OLG Düsseldorf GRUR 1997, S. 49, 50 - Beuys-Fotografien; Dreier/Schulze/Schulze, 6. Aufl. 2018, $\mathbb{2}$ UrhG Rn. 195.

462 Oder, wenn seine erste erlaubte öffentliche Wiedergabe früher erfolgt ist, nach dieser, jedoch bereits fünfzig Jahre nach der Herstellung, wenn das Lichtbild innerhalb dieser Frist nicht erschienen oder erlaubterweise öffentlich wiedergegeben worden ist, $\$ 72$ Abs. 3 UrhG a.E.

463 BGH GRUR 2019, S. 284, 287 Rn. 24 ff., 30 - Museumsfotos; und zuvor OLG Stuttgart GRUR 2017, S.905, 907 Rn. 71 - Reiss-Engelhorn-Museen; LG Berlin ZUM 2016, S. 766, 769 f. - Reproduktionsfotografie.

464 Vgl. zu dieser Unterscheidung von abgebildetem Objekt, immateriellem Abbild und materieller Abbildung auch den Bildbegriff auf S. 43.

465 Dreier/Schulze/Schulze, 6. Aufl. 2018, $\$ 72$ UrhG Rn. 5. 
ve-Übertragungen mit einzelner, feststehender Kamera ${ }^{466}$ entstehen, also z.B. Filmaufnahmen bei Sport- oder politischen Veranstaltungen. ${ }^{467}$ Dem Hersteller von Laufbildern werden die gleichen Rechte wie nach $\$ 94$ UrhG dem Filmhersteller zugesprochen. Auch hier ist der Schutz nur auf 50 Jahre befristet, vgl. $\$ \$ 95,94$ Abs. 3 UrhG.

\section{Ausübende Künstler und Filmhersteller}

Der Schutz ausübender Künstler der $\$ \$ 73 \mathrm{ff}$. UrhG ist betroffen, wenn auf den Bildern oder Videos die Darbietung eines Schauspielers, Tänzers, Sängers oder Musikers zu sehen ist. ${ }^{468}$ Dessen Rechte können durch Mitschnitte und Video-Ausschnitte der Darbietung, die für Aneignungen wie beispielsweise GIFs oder virale Hypes genutzt werden, beeinträchtigt werden. Eine solche Verletzung hängt jedoch stark vom konkreten Einzelfall ab.

Eine Verletzung der Rechte von Filmhersteller gem. $\$ 94$ UrhG durch bildliche Aneignungen ist nicht möglich. Dieser regelt das Recht am Bildund Tonträger, z.B. dem Filmstreifen. ${ }^{469}$ Eine bildliche Aneignung des Trägermaterials ist nicht möglich.

\section{Fazit}

Bildliche Aneignung sind zulässig, soweit der angeeignete Gegenstand nicht urheberrechtlich oder durch ein verwandtes Schutzrecht geschützt ist oder die Schutzfähigkeit bereits abgelaufen ist. Der Schutzumfang verwandter Schutzrechte, ist häufig ähnlich zum Urheberrechtsschutz ausgestattet. Daraus folgt, dass für sie in der Regel die im Anschluss an dieses

466 Dreier/Schulze/Schulze, 6. Aufl. 2018, \$95 UrhG Rn. 10.

467 So bald hier aber mit verschiedenen Blickwinkeln, Detail- und Großaufnahmen gearbeitet wird, was mittlerweile auch bei Live-Übertragungen sehr häufig angewandt wird, kann die Anordnung, Auswahl und Zusammenstellung dieser Bilder Werkqualität annehmen, vgl. BGH GRUR 1984, S. 730, 732 - Filmregisseur und OLG München NJW 2003, S. 683, 684 - Alpensinfonie.

468 Ausübender Künstler ist, wer ein Werk oder eine Ausdrucksform der Volkskunst aufführt, singt, spielt oder auf eine andere Weise darbietet oder an einer solchen Darbietung künstlerisch mitwirkt, gem. $\$ 73$ UrhG.

469 Schack, Urheber- und Urhebervertragsrecht, 9. Aufl. 2019, Rn. 713. 
Kapitel folgenden Ausführungen zu Persönlichkeitsrechten ${ }^{470}$, Verwertungsrechten und Rechtfertigungen von Eingriffen ebenfalls gelten, sofern nicht für verwandte Schutzrechte diese Rechte ausdrücklich vom Schutzumfang ausgenommen sind. Da die Schutzanforderungen an die persönliche geistige Schöpfung gem. $\$ 2$ Abs. 2 UrhG jedoch recht niedrig sind, ist in der Regel davon auszugehen, dass die genutzten Bilder urheberrechtlich geschützt sind. Der Gegenstand bildlicher Aneignung ist somit in der Regel durch das Urheberrecht oder die sonstigen Rechte geschützt.

\section{B. Eingriff in Persönlichkeitsrechte des Urhebers durch Aneignungen Dritter}

Das Urheberrecht schützt die geistigen und persönlichen Beziehungen des Urhebers zu seinem Werk und dessen Nutzung gem. $\$ 11$ UrhG. Dies umfasst neben den vermögensrechtlichen auch die ideellen Interessen des Urhebers, die durch die Urheberpersönlichkeitsrechte des $\$ \$ \$ 12-14$ UrhG geregelt sind. Verstöße gegen dieselben begründen eine Urheberrechtsverletzung und lösen damit Ansprüche auf Unterlassung und Schadensersatz gem. $\$ 97$ Abs. 1, 2 UrhG aus. Eine solche Verletzung der Urheberpersönlichkeitsrechte kommt auch durch bildliche Aneignungen in Betracht. Im Folgenden sollen daher $\mathbb{1} 13$ und $\mathbb{\$} 14$ UrhG genauer untersucht werden. Das Veröffentlichungsrecht gem. $\$ 12$ UrhG, das dem Urheber die Entscheidung darüber zugesteht, ob, wann und unter welchen Umständen ein Werk veröffentlicht wird ${ }^{471}$, ist hier nicht ausführlich zu behandeln, da Aneignungen in der Regel Werke nutzen, die bereits veröffentlicht wurden. Sollte dies nicht der Fall sein, ist selbstverständlich auch dieses Urheberpersönlichkeitsrecht betroffen.

470 Obwohl verwandte Schutzrechte grundsätzlich keine Persönlichkeitsrechte umfassen, ist auch ein Schutz der Persönlichkeitsrechte für Lichtbilder jedoch gem. $\$ 72$ UrhG unmittelbar vorgesehen und für Filmhersteller und den Laufbildschutz gem. $\$ \$ 95,94$ Abs. 1 S. 2 UrhG ein Schutz vor Entstellung im Sinne des $\$ 14$ UrhG vorgesehen.

471 Schack, Kunst und Recht, 3. Aufl. 2017, Rn. 249; Schricker/Loewenheim/Dietz/ Peukert, 5. Aufl. 2017, 12 UrhG Rn. 7; Dreier/Schulze/Schulze, 6. Aufl. 2018, $\$ 12$ UrhG Rn. 6. 
I. Recht auf Anerkennung der Urheberschaft und Namensnennung gem. $\$ 13$ UrhG

$\mathbb{\$} 13$ UrhG umfasst in S. 1 das Recht auf Anerkennung der Urheberschaft und in S. 2 das Recht auf Anbringung einer Urheberbezeichnung. S. 1 schützt damit davor, dass die Urheberschaft in Abrede gestellt wird oder sich ein anderer die Urheberschaft anmaßt. ${ }^{472}$ S. 2 wird in der Regel durch eine Signatur sichergestellt, mit der ein Künstler sein Werk kennzeichnet. ${ }^{473}$ Überdies wird in Rechtsprechung und Literatur von einem generellen Urhebernennungsrecht bei jeder Nutzung des Werkes ausgegangen. ${ }^{474}$ Dies hat eine Zuordnungsfunktion und soll das geistige Band zwischen Werk und Urheber aufzeigen. Die Rechte aus $₫ 13$ UrhG gelten nicht nur für das Original, sondern auch für Vervielfältigungsstücke wie Kopien und Bearbeitungen im Sinne des $\mathbb{2 3}$ UrhG. ${ }^{475}$ Eine Verletzung kommt also in Betracht, wenn der Urheber nicht genannt wird. Sobald jedoch eine durch Schranken gerechtfertigte Nutzung des Werkes vorliegt, ist eine Verletzung des $\$ 13$ UrhG ausgeschlossen. ${ }^{476}$

Bei der Appropriation Art wird häufig im Titel des neu geschaffenen Kunstwerkes auf den Vorlagenschöpfer Bezug genommen: so z.B. die „Warhol Flowers“ (1965) von Sturtevant, „Johns Flag“ (1965/66) von Sturtevant, „Not Pollock“ (1983) von Bidlo und „Fountain (After Duchamp)“ (1991) von Levine. ${ }^{477}$ Auch bei den Instagram Fotos von Prince wird deutlich, dass das Foto von jemand anderem ist, da er die gesamte Nutzeroberfläche mit abdruckt und damit auch der Nutzername angezeigt wird, der

472 BT-Drs. IV/270, S. 44.

473 Dies dient der Vorsorge vor Verwechslung aber auch dem Ausdruck dafür, dass der Künstler sein Werk für vollendet hält. Zum Teil wird vertreten, \13 S. 2 UrhG gelte nur für körperliche Werkstücke, nach herrschender Meinung ist er jedoch auf alle Werknutzungen anwendbar, BGH GRUR 1972, S. 713, 714 -Im Rhythmus der Jahrbunderte; Dreier/Schulze/Schulze, 6. Aufl. 2018, $\$ 13$ Rn. 3; Schricker/Loewenheim/Dietz/Peukert, 5. Aufl. 2017, $\$ 13$ UrhG Rn. 5.

474 Vgl. dazu die Begründung in Dreier/Schulze/Schulze, 6. Aufl. 2018, $\$ 13$ UrhG Rn. 3 ff.; obwohl nach der amtl. Begründung zu $\mathbb{1} 13$ UrhG dieser gerade kein solch allgemeines Recht konstituieren sollte.

475 Dreier/Schulze/Schulze, 6. Aufl. 2018, $\$ 13$ UrhG Rn. 9.

476 So z.B., wenn eine freie Benutzung gem. $\$ 24$ UrhG vorliegt, vgl. Huttenlauch, Appropriation Art. Kunst an den Grenzen des Urheberrechts, 2010, S. 144.

477 Anders jedoch, wenn lediglich der Titel des angeeigneten Werkes genannt wird und nicht dessen Urheber wie bei Damian Loebs „Blow Job (Three Little Boys)“ (1999), vgl. Huttenlauch, Appropriation Art. Kunst an den Grenzen des Urheberrechts, 2010, S. 144. 
das Bild ursprünglich geteilt hat. Dieser Nutzer ist jedoch nicht unbedingt der Urheber des Werkes. In diesem Fall würde eine Verletzung des $\$ 13$ UrhG vorliegen, wenn nicht im Titel unterhalb des Bildes noch eine Urheberbezeichnung angebracht ist. Ansonsten ist das Risiko einer fälschlichen Zuordnung des angeeigneten Werkes damit explizit ausgeschlossen. ${ }^{478}$ Eine Verletzung des $₫ 13$ UrhG kommt also nur in Betracht, wenn der Schöpfer des angeeigneten Werkes in keiner Weise erkennbar ist.

Bei viralen Hypes wird ähnlich vorlagenbezogen gearbeitet wie bei der Appropriation Art. Hier wird jedoch meist nicht der Urheber des angeeigneten Videos, sondern häufig dessen Titel in der Aneignung selbst genannt, so z.B. bei der Ice Bucket Challenge oder den Harlem Shake-Videos. Hier liegt also meist eine Verletzung des $\mathbb{S} 13$ UrhG vor. Bei Memes und GIFs wird der Urheber des Clips oder Bildes fast nie benannt. Bei Museumselfies ist selten der Urheber genannt, eventuell aber das Anbringungsschild im Museum, auf dem der Urheber genannt ist, mit abfotografiert.

Beim Upload von Bildern in sozialen Netzwerken kann zwar der Eindruck erweckt werden, dass der Profilinhaber auch Urheber des geteilten Fotos ist, dennoch liegt darin meist keine Anmaßung der Urheberschaft. Häufig wird jedoch der Name des Urhebers nicht genannt, sodass eine Verletzung des Namensnennungsrecht anzunehmen ist. ${ }^{479}$ Bei Hyperlinks auf im Netz hochgeladene Werke werden die Werke dem Linksetzer nicht zugeordnet, da sich die URL ändert beim Aufrufen des Linkes. Hier muss daher der Name des Urhebers nicht genannt werden. 480

Anders sieht es jedoch bei Frame-Links aus. Bei Frame-Links wird fremder Inhalt so auf der eigenen Webseite integriert, dass es den Eindruck erwecken kann, als würde es sich um eigenen Inhalt handeln. Daher kommt hier häufig eine Verletzung von $\$ 13$ UrhG in Betracht. ${ }^{481}$ Für das Anerkennungsrecht des Urhebers im Internet müsste es zwar ausreichen, wenn

478 So auch Huttenlauch, Appropriation Art. Kunst an den Grenzen des Urheberrechts, 2010, S. 144. Anders Schack: Eine Anmaßung der fremden Urheberschaft liege nichtsdestotrotz vor, die Benennung des Vorlagenschöpfers im Titel lasse lediglich den Täuschungsvorwurf entfallen, Schack, Appropriation Art und Urheberrecht, in: FS Nordemann, 2004, S. 107, 111.

479 Ziegler, Urheberrechtsverletzungen durch Social Sharing, 2016, S. 138.

480 Dies., a.a.O., S.139; Ott, Urheber- und wettbewerbsrechtliche Probleme von Linking und Framing, 2004, S. 276; Schack, Urheberrechtliche Gestaltung von Webseiten unter Einsatz von Links und Frames, MMR 2001, S. 9, 14.

481 Vgl. Ott, Urheber- und wettbewerbsrechtliche Probleme von Linking und Framing, 2004, S. 284; Fröhlich, Zentrale Institutionen des deutschen Urheber- 
ersichtlich ist, dass der Inhalt von einem anderen Anbieter stammt, indem die URL gewechselt wird, wenn der fremde Inhalt angeklickt wird. ${ }^{482}$ Für das Benennungsrecht reicht das aber nicht unbedingt aus - insbesondere dann nicht, wenn lediglich das fremde Bild integriert wird, nicht aber die dazugehörige Textdatei, die die Urheberbezeichnung enthält. ${ }^{483}$ Viele soziale Netzwerke generieren allerdings automatisch für jeden Frame-Link eine Quellenangabe, die auch die zugehörige Textdatei übernimmt, sodass der Nutzer hier klar erkennen kann, dass und von welchem Fremdanbieter ein Bild oder Video stammt. Problematisch ist dies nur, wenn der Uploader des Inhalts nicht der Rechteinhaber ist und der Rechteinhaber auch nicht genannt wird. ${ }^{484}$ Bei den Vorschaubildern von Suchmaschinen wird im Schrifttum zum Teil angenommen, dass eine Nennung der Urheber hier nicht verkehrsüblich und daher nicht notwendig sei. ${ }^{485}$ Eine solche Privilegierung ließe sich allerdings nicht auf Vorschaubildern in sozialen Netzwerken übertragen.

Damit kommt eine Verletzung des Urheberbenennungsrechts bei bildlichen Aneignungen häufig in Betracht. Das Gebot der Quellenangabe gem. $\$ 63$ UrhG macht deutlich, dass auch bei freigestellten Nutzungshandlungen durch Schrankenregelungen das Urheberbenennungsrecht aus $\$ 13$ UrhG weiterhin zu wahren ist. ${ }^{486}$

rechts und des französischen Droit d'auteur auf dem Prüfstand der elektronischen Netzwerke, 2001, S. 73; Ziegler, Urheberrechtsverletzungen durch Social Sharing, 2016, S. 140.

482 Schack, Urheberrechtliche Gestaltung von Webseiten unter Einsatz von Links und Frames, MMR 2001, S. 9, 14.

483 Ott, Urheber- und wettbewerbsrechtliche Probleme von Linking und Framing, 2004, S. 284.

484 Ziegler, Urheberrechtsverletzungen durch Social Sharing, 2016, S. 141. So kann das insbesondere bei YouTube-Videos der Fall sein, die das urheberrechtlich geschützte Video eines andere nochmals hochladen, in der Videobeschreibung allerdings nicht den Urheber nennen.

485 Fabl, Die Bilder-und Nachrichtensuche im Internet. Urheber-, persönlichkeitsund wettbewerbsrechtliche Aspekte, 2010, S. 58, 148; Schneider, Offene Fragen zur Urheberbenennung nach Pixelio. Widersprüche in der aktuellen Rechtsprechung zum Urheberbenennungsrecht und Lösungsmöglichkeiten, CR 2016, S. 37, 41. Anders Ziegler, Urheberrechtsverletzungen durch Social Sharing, 2016, S. $145 \mathrm{f}$., die eine solche Privilegierung nur dann für gerechtfertigt hält, wenn die Werke in einer Weise genutzt werden, die berechtigte Interessen des Urhebers nicht zu gefährden geeignet ist.

486 Schricker/Loewenheim/Dietz/Spindler, 5. Aufl. 2017, \$63 UrhG Rn. 1. 


\section{Schutz vor Entstellung gem. $\$ 14$ UrhG}

Der Schutz vor Entstellung gem. $\$ 14$ UrhG schützt den Bestand und die Integrität eines urheberrechtlichen Werkes. Da im Werk die individuelle Schöpfungskraft des Urhebers ihren Ausdruck gefunden hat, steht ihm das Recht zu, es der Öffentlichkeit in seiner unveränderten individuellen Gestaltung zugänglich zu machen. ${ }^{487}$ Eine Verletzung des $\$ 14$ UrhG erfolgt durch eine dreistufige Prüfung: Zunächst muss eine Entstellung oder sonstige Beeinträchtigung 488 des Werkes vorliegen, die zweitens geeignet sein muss, die Urheberinteressen zu gefährden, und abschließend wird eine Interessenabwägung vorgenommen, die zugunsten des Urhebers ausfallen muss, um eine Verletzung des $₫ 14$ UrhG zu begründen. ${ }^{489}$

Eine Beeinträchtigung ist jede objektiv nachweisbare Änderung des Werkes in seinem geistig-ästhetischen Gesamteindruck. Für eine Beeinträchtigung ist jedoch nicht notwendig, dass das Werk selbst verändert wird, sondern ausreichend, wenn ein geschütztes Werk in ein neues „Gesamtkunstwerk" derart integriert wird, dass es als Teil dessen erscheint. ${ }^{490}$ Größenveränderungen, wie die automatische Verkleinerung eines Bildes für ein Thumbnail, allein reichen jedoch nicht aus, um eine Entstellung des Werkes anzunehmen, auch wenn mit der herabgesetzten Auflösung und Bildschärfe die Eigenarten einer Fotografie oder eines Bildes verloren gehen können. ${ }^{491}$ Denn mit solchen Formatanpassungen geht selten auch

487 BGH GRUR 1974, S.675, 676 - Schulerweiterung; Dreier/Schulze/Schulze, 6. Aufl. 2017, $\$ 14$ UrhG Rn. 3.

488 Die Entstellung ist ein besonders schwerwiegender Fall der Beeinträchtigung, vgl. Schricker/Loewenheim/Dietz/Peukert, 5. Aufl. 2017, 14 UrhG Rn. 14.

489 Amtl. Begründung BT-Drs. IV/270, S. 45; Dreier/Schulze/Schulze, 6. Aufl. 2017, $\$ 14$ UrhG Rn. 8 f; a.A.: Wandtke/Bullinger/Bullinger, 5. Aufl. 2019, \14 UrhG Rn. 9 und 11: keine Gefährdungsprüfung der Interessen notwendig bei der Entstellung.

490 BGH GRUR 2002, S. 532, 534 - Unikatrahmen: so z.B., wenn das geschützte Werk in Verbindung mit Zutaten von dritter Hand (hier: eines Rahmens, der durch Bemalung im Stil der eingerahmten Vorlage das Bild vergrößert) als „Gesamtkunstwerk" des Originalurhebers angesehen werden kann.

491 Man könnte hier auch überlegen, ob auch Vorschaubilder einen Verstoß gegen $\$ 14$ UrhG begründen, wenn man die Argumentation zu BGH GRUR 2009, S. 395, 397 Rn. 14 - Klingeltöne für Mobiltelefone auf Vorschaubilder anwendet und meint, das Werk sei hier nur noch Instrument einer effizienten Internetsuche und wird nicht mehr in seinem künstlerischen Gehalt wahrgenommen; so Schrader/Rautenstrauch, Urheberrechtliche Verwertung von Bildern durch Anzeige von Vorschaugrafiken (sog. Thumbnails) bei Internetsuchmaschinen, UFITA 2007/III, S. 761, 765. Doch die Vorschaubild-Funktion als solche wirkt 
eine Veränderung des Gesamteindrucks des Werkes einher. Vielmehr bleibt das Werk in seinen Wesenszügen erhalten. ${ }^{492}$ Dahingegen ist die Veröffentlichung von Bildausschnitten oder von Retuschen bei einem Lichtbildwerk in der Regel entstellend. ${ }^{493}$

In der Interessenabwägung ist in der Regel vom Bestandsinteresse des Urhebers an seinem Werk auszugehen. ${ }^{49} \mathrm{Im}$ Rahmen der gesetzlichen Schrankenregelungen sind bestimmte Eingriffe ausdrücklich gestattet. Nutzungen, die der freien Benutzung gem. $\$ 24$ UrhG oder dem Zitatrecht gem. $\$ 51$ UrhG unterliegen, setzen sich daher im Rahmen der Interessenabwägung durch. ${ }^{495}$ Ansonsten bestünde die Gefahr, dass diese Normen durch $\mathbb{1} 14$ UrhG unterlaufen werden, da der freien Benutzung und dem Zitat gerade immanent ist, dass das Werk auch entstellt werden kann. ${ }^{496}$ Ist eine Werknutzung über die Schranken des Urheberrechts ( $\$ \$$ 44a ff. UrhG) zulässig, bestimmt sich die Frage der Zulässigkeit von Werkänderungen nach $\$ 62$ i.V.m. $\$ 14$ UrhG. Im Rahmen des Änderungsverbots gem. $\$ 62$ UrhG ist $\$ 24$ UrhG nicht anwendbar, da im Fall der freien Benutzung gerade keine Werkänderung mehr vorliegt - das benutzte Werk dient nur als Anregung für das selbständige Werkschaffen und die

sich nicht auf die Wahrnehmung des Werkes aus und ist auch nicht mit einer Herabstufung verbunden, vgl. Ziegler, Urheberrechtsverletzungen durch Social Sharing, 2016, S. 154.

492 Ziegler, Urheberrechtsverletzungen durch Social Sharing, 2016, S. 150; Fahl, Die Bilder- und Nachrichtensuche im Internet. Urheber-, persönlichkeits- und wettbewerbsrechtliche Aspekte, 2010, S. 55; a.A.: Fröhlich, Zentrale Institutionen des deutschen Urheberrechts und des französischen Droit dàcteur auf dem Prüfstand der elektronischen Netzwerke, 2001, S. 74.

493 BGH GRUR 1971, S. 525 - Petite Jacqueline, bei dem lediglich die Augenpartie der Aufnahme eines Mädchenkopfes verwendet wurde; OLG Köln Schulze OLGZ 129 - Mein schönstes Urlaubsfoto, dort wurde eine der vier Personen weggeschnitten und an den Ecken des Bildes Amateurfotoecken retouchiert; LG München ZUM 1995, S. 57, 58 - Venus der Lumpen, dort wurde die das fotografierte Kunstwerk umgebende Räumlichkeit weggeschnitten.

494 Dreier/Schulze/Schulze, 6. Aufl. 2017, $\$ 14$ UrhG Rn. 16.

495 Schricker/Loewenheim/Dietz/Peukert, 5. Aufl. 2017, 14 UrhG Rn. 8; Dreier/ Schulze/Schulze, 6. Aufl. 2017, $\mathbb{1} 14$ UrhG Rn. 24; Hess, Urheberrechtsprobleme der Parodie, 1993, S. 167; Huttenlauch, Appropriation Art. Kunst an den Grenzen des Urheberrechts, 2010, S. $140 \mathrm{f}$.

496 Die ideellen Urheberinteressen sind zudem bereits im Rahmen des $\$ 24$ UrhG umfassend berücksichtigt, weshalb eine Korrektur über $\mathbb{1 4}$ UrhG nicht notwendig, s. Huttenlauch, Appropriation Art. Kunst an den Grenzen des Urheberrechts, 2010, S. 140 f. Vgl. dazu auch BGH GRUR 1994, S. 206, 209 - Alcolix, der klarstellt, dass eine Entstellung gem. $\$ 14$ UrhG davon abhängt, ob eine freie Benutzung vorliegt oder nicht. 
ursprüngliche Werkform ist verblasst. ${ }^{497}$ Bei der für $₫ 62$ UrhG erforderlichen Interessenabwägung ${ }^{498}$ ist aber der zulässige Benutzungszweck des $\$ 24$ UrhG zu beachten. 499

Für die Aneignungen der Appropriation Art bedeutet dies, dass eine Verletzung des $\mathbb{1 4}$ UrhG hauptsächlich von der Frage abhängt, ob eine freie Benutzung gem. $\$ 24$ UrhG oder ein Zitat nach $\$ 51$ UrhG vorliegen. Ist dies nicht der Fall, können die Appropriation Art Werke durchaus Entstellungen darstellen..$^{500}$

Im Internet sind die Bearbeitungs- und damit auch Entstellungsmöglichkeiten besonders vielfältig. Insbesondere bei Bildmontagen, die das Werk mit einem anderen Bild verbinden, kann der geistig-ästhetische Gesamteindruck des Werkes immens verändert werden und damit zu einer Verletzung von $₫ 14$ UrhG führen. Auch bei Memes kann durch die Verbindung mit einem Text der Kontext eines Bildes komplett verändert werden. So kann die Nutzung des Werkes auf einer rechtsextremistischen Webseite oder die Nutzung des Werkes als Meme, das beispielsweise in der Kommunikation der Alt-Right-Bewegung genutzt wird (z.B. „Pepe the Frog“), eine Entstellung begründen. ${ }^{501}$ Auch die Verschiebung eines Werkes in einen sexuellen Kontext kann eine Entstellung begründen, so also auch die Nutzung eines Bildes auf pornographischen Webseiten oder Bildmontagen. ${ }^{502}$ Nutzerkommentare unter geteilten Bildern lassen den Gesamteindruck des

497 Schricker/Loewenheim/Dietz/Peukert, 5. Aufl. 2017, \$14 UrhG Rn. 9.

498 Diese ergibt sich durch den Verweis auf $\$ 39$ UrhG; vgl. Schricker/Loewenheim/ Dietz/Peukert, 5. Aufl. 2017, $\$ 14$ UrhG Rn. 8.

499 Schricker/Loewenheim/Dietz/Peukert, 5. Aufl. 2017, $\$ 14$ UrhG Rn. 9.

$500 \$ 107$ Abs. 1 Nr. 2 UrhG verbietet zudem auf einem Vervielfältigungsstück, einer Bearbeitung oder Umgestaltung eines Werkes der bildenden Künste die Urheberbezeichnung ( $\$ 10$ Abs. 1 ) auf eine Art anzubringen, die dem Vervielfältigungsstück, der Bearbeitung oder Umgestaltung den Anschein eines Originals gibt, oder ein derart bezeichnetes Vervielfältigungsstück, eine solche Bearbeitung oder Umgestaltung zu verbreiten. Da die Appropriation Art jedoch in der Regel den Bezug oder gar Unterschied zum angeeigneten Werk offenlegt und diskutiert, ist eine Verletzung des $₫ 107$ Abs. 1 Nr. 2 UrhG meist abzulehnen.

$501 \mathrm{Ott}$, Urheber- und wettbewerbsrechtliche Probleme von Linking und Framing, 2004, S. 293. So auch das OLG Frankfurt für einem Sampler bei Darbietungen rechtsradikaler Musikgruppen, OLG Frankfurt GRUR 1995, S.215, 216 Springtoifel.

502 Laut BGH kann die Verschiebung aber auch zulässig sein, so z.B. bei AsterixPersiflagen, die die Sexfeindlichkeit der Asterix-Comics thematisieren und damit eine werkbezogene Auseinandersetzung darstellen, BGH GRUR 1994, S. 191, $194-$ Asterix-Persiflagen. 
Werkes hingegen unberührt und können somit keine Verletzung des Rechts aus $\$ 14$ UrhG begründen.

\section{Eingriff in Verwertungsrechte des Urhebers durch Aneignungen Dritter}

Grundsätzlich hat der Urheber die ausschließliche Befugnis zu Verwertung seines Werkes. Neben den Persönlichkeitsrechten stehen dem Urheber daher Verwertungsrechte an seinem Werk zu, um seine wirtschaftlichen Interessen an diesem zu wahren. Verstöße gegen diese Verwertungsrechte begründen eine Urheberrechtsverletzung und damit Ansprüche des Urhebers auf Unterlassung und Schadensersatz gem. $\$ 97$ Abs. 1, 2 UrhG. Welche dieser Rechte des Urhebers durch Aneignungen betroffen sind, soll im Folgenden untersucht werden.

\section{Vervielfältigungsrecht gem. $\$ 16$ UrhG}

Das Vervielfältigungsrecht gem. $\$ 16$ UrhG ordnet dem Urheber jede körperliche Festlegung zu, die geeignet ist, das Werk mit den menschlichen Sinnen wahrnehmbar zu machen. ${ }^{503}$ Dabei ist unbeachtlich, ob es sich um eine erstmalige Fixierung des Werkes oder eine wiederholte Festlegung handelt. ${ }^{504}$ Der Begriff der Vervielfältigung greift insofern weiter als der der Kopie: Die Kopie braucht die Vorlage, die sie möglichst genau nachbildet. ${ }^{505}$ Aufgrund dieses weiten Verständnisses der Vervielfältigung ist es auch dieses Verwertungsrecht bei Aneignungen fast immer betroffen denn Aneignungen ist immanent, dass durch sie auch der angeeignete Gegenstand sinnlich wahrnehmbar gemacht wird. Der EuGH stellt mit dem Urteil Pelham/Hütter für die Annahme einer Vervielfältigung gem. Art. 2 der RL 2001/29/EG zur Harmonisierung bestimmter Aspekte des Urheberrechts und der verwandten Schutzrechte in der Informationsgesellschaft (InfoSoc-RL) auf die Wiedererkennbarkeit des Werkes ab. ${ }^{506}$ Auch eine

503 BT-Drs. IV/270, S. 47.

504 BGH GRUR 1982, S. 102, 103 - Masterbänder; BGH GRUR 1955, S. 492, 493 Grundig-Reporter.

505 So auch Fischer, Digitale Kunst und freie Benutzung, 2018, S. 53; s. zur Definition der Kopie S. 35.

506 EuGH GRUR 2019, S. 929, 931 Rn. 31 - Pelham/Hütter. 
solche Wiedererkennbarkeit, die an das Kriterium des Verblassens im Rahmen des $\$ 24$ UrhG erinnert, liegt bei Aneignungen regelmäßig vor.

\section{Upload und Download}

Die Digitalisierung eines urheberrechtlich geschützten Werkes ist eine Vervielfältigung, da eine digitale Kopie erstellt wird. ${ }^{507}$ Auch die Digitalisierung einer Reproduktion eines Gemäldes betrifft das Vervielfältigungsrecht, wenn die Reproduktion selbst urheberrechtlich geschützt ist - auch dann, wenn das reproduzierte, abgebildete Werk bereits gemeinfrei ist. ${ }^{508}$

Ebenso stellt der Download eines digitalen Bildes eine Vervielfältigung dar, da das Bild dafür auf einen Server und auf den Speicher des Computers geladen werden muss. Ein Bild herunterzuladen, um es dann in sozialen Netzwerken selbst wieder hochzuladen, ist also eine urheberrechtlich relevante Aneignung. Auch der Upload wiederum stellt eine Vervielfältigung dar, da das Bild dafür technisch auf dem Server des jeweiligen sozialen Netzwerkes gespeichert werden muss. ${ }^{509}$

\section{Digitaler Werkgenuss}

Doch auch der bloße digitale Werkgenuss stellt schon häufig eine Vervielfältigung dar. Jede Nutzung digitaler Inhalte führt zu einer Verarbeitung und Zwischenspeicherung auf elektronischen Geräten, worin eine urheberrechtliche Vervielfältigung zu sehen ist. ${ }^{510}$ Es ist nicht relevant, ob die Vervielfältigung kurzfristig oder dauerhaft erfolgt, sodass auch eine sich später selbst löschende Speicherung im Arbeitsspeicher das Urheberrecht betrifft.

507 Vgl. BGH GRUR 2015, S. 1101, 1103 Rn. 25 - Elektronische Leseplätze II; BGH GRUR 2013, S. 503, 503 Rn. 8 - Elektronische Leseplätze.

508 S. dazu OLG Stuttgart GRUR 2017, S. 905, 907 - Reiss-Engelhorn-Museen, bestätigt durch BGH GRUR 2019, S. 284 - Museumsfotos. Es besteht also keine mit $\$ 51$ S. 3 UrhG vergleichbare Norm.

509 Ziegler, Urheberrechtsverletzungen durch Social Sharing, 2016, S. 80; Schricker/ Loewenheim/Loewenheim, 5. Aufl. 2017, $\$ 16$ UrhG Rn. 21.

510 B. Raue, Das subjektive Vervielfältigungsrecht. Eine Lösung für den digitalen Werkgenuss?, ZGE 2017, S. 515, 514. 


\section{Abgrenzung zur Bearbeitung}

Auch wenn das angeeignete Bild im Sinne des $\$ 23$ UrhG bearbeitet wird, liegt eine Vervielfältigungshandlung vor, da jede Umgestaltung gem. $\$ 23$ UrhG auch eine Vervielfältigung gem. $\$ 16$ UrhG beinhaltet. ${ }^{511}$ Das heißt, eine mit der Vervielfältigung einhergehende Bearbeitung oder Umgestaltung ändert nichts daran, dass das Verwertungsrecht des $\$ 16$ UrhG berührt ist. Nach $\$ 23$ UrhG ist die Herstellung der Bearbeitung oder Umgestaltung allerdings erlaubt, lediglich die Veröffentlichung und Verwertung derselben stehen unter dem Einwilligungsvorbehalt des Urhebers. Wie sind $\$ 16$ und $\$ 23$ UrhG also voneinander abzugrenzen? Man könnte annehmen, dass $\mathbb{1} 16$ UrhG bei Bearbeitungen und Umgestaltungen im privaten Bereich eingeschränkt ist und von $\$ 23$ UrhG als lex specialis verdrängt wird, sodass die Vervielfältigung des Werkes dann auch ohne Erlaubnis des Urhebers möglich ist. ${ }^{512}$ Welche Fälle umfasst dann $\$ 16$ UrhG überhaupt noch? Hier kann nicht an die Schöpfungshöhe angeknüpft werden, da $₫ 23$ UrhG auch nicht-schöpferische Umgestaltungen umfasst. ${ }^{513}$ Nach Fischer ist $\mathbb{S} 16$ UrhG dann nur noch für identische Kopien einschließlich aller Änderungen anzuwenden, die den Gesamteindruck unberührt lassen, also solche, die keinen eigenständigen schöpferischen Gehalt besitzen, wie Änderungen des Formats oder der Größe. ${ }^{514}$ Dem ist zu folgen.

511 BGH GRUR 2014, S. 65, 70 - Beuys-Aktion; BGH GRUR 1963, S. 441, 443 - Mit Dir allein; Dreier/Schulze/Schulze, 6. Aufl. 2018, $\mathbb{1 6}$ UrhG Rn. 5; Schricker/ Loewenheim/Loewenheim, 5. Aufl. 2017, $\mathbb{1 6}$ UrhG Rn. 8. In der Literatur wird z.T. vertreten, dass es sich um ein Stufenverhältnis zwischen Vervielfältigung, Bearbeitung und freier Benutzung handelt, die nach Dichte des Abstands zur Vorlage gegliedert werden. Nach dieser Ansicht fallen Bearbeitungen und Umgestaltungen im Sinne des $₫ 23$ UrhG nicht unter das Vervielfältigungsrecht, s. BeckOK UrhG/Kroitzsch/Götting, 26. Ed. 2019, \$16 UrhG Rn. 10, 22; Fromm/ Nordemann/Dustmann, 12. Aufl. 2018, 16 UrhG Rn. 11; Gabler, Die urheberrechtliche Drittnutzung zwischen Vervielfältigung, Bearbeitung und freier Benutzung, 2018, S. $172 \mathrm{f}$.

512 So Dreier/Schulze/Schulze, 6. Aufl. 2018, $\$ 16$ UrhG Rn. 5 und Wandtke/Bullinger/Heerma, 5. Aufl. 2019, $\$ 16$ UrhG Rn. 10.

513 Schricker/Loewenheim/Loewenheim, 5. Aufl. 2017, \$16 Rn. 5.

514 Fischer, Digitale Kunst und freie Benutzung, 2018, S. 54. 
4. Fazit

Das Vervielfältigungsrecht ist bei Aneignungen üblicherweise verletzt. Sowohl die Appropriation Art als auch kommunikative Aneignungen funktionieren durch die Übernahme der Vorlage: Museumselfies, Memes, GIFs und auch Bildmontagen machen immer auch das urheberrechtlich geschützte angeeignete Bild sinnlich wahrnehmbar. Das Teilen von Bildern in sozialen Netzwerken ist ebenfalls häufig ein Eingriff in das Vervielfältigungsrecht des Urhebers, sofern es um die Digitalisierung und den Upload von Bildern geht. Das Verlinken auf bereits im Internet bestehende Bilder innerhalb von sozialen Netzwerken ist allerdings keine Vervielfältigung, da die Verlinkung nur als Verweis funktioniert und die relevante Vervielfältigung erst mit dem Aufrufen des Links getätigt wird, nicht durch die Verlinkung selbst. ${ }^{515}$ Bei viralen Hypes ist das Vervielfältigungsrecht nur selten betroffen. Für das Erstellen eines eigenen Videos, das sich den viralen Hype aneignet, muss in der Regel nicht das Originalvideo erneut sichtbar gemacht werden, es wird also nicht vervielfältigt. Vielmehr werden bestimmte Gestaltungselemente übernommen und nachgeahmt. Hier kommt es auf den Einzelfall an, ob die gestalterische Komposition so konkretisiert ist, dass sie urheberrechtlich geschützt ist. ${ }^{516}$ Ist das der Fall, dann stellt auch die Aneignung eines viralen Hypes eine urheberrechtliche Vervielfältigungshandlung dar.

\section{Verbreitungsrecht gem. $\$ 17$ UrhG}

Das Verbreitungsrecht umfasst gem. $\mathbb{\$} 17$ Abs. 1 UrhG das Recht, das Original oder Vervielfältigungsstücke des Werkes der Öffentlichkeit anzubieten oder in Verkehr zu bringen. Mit Verbreitung ist nur die Verbreitung körperlicher Werkexemplare gemeint, nicht die Wiedergabe des Inhalts. ${ }^{517}$ Ein Eingriff in dieses Verbreitungsrecht kommt daher nur in Betracht, wenn die Aneignung sich überhaupt eines körperlichen Mediums bedient, was wohl nur bei der Aneignung zu künstlerischen Zwecken, also der Herstellung eines Kunstwerkes, der Fall ist. Allerdings kann auch dieses bloß digital hergestellt und der Öffentlichkeit gezeigt werden. Die Aneignung zu kommunikativen Zwecken findet hingegen nur digital und damit im-

515 Schricker/Loewenheim/Loewenheim, 5. Aufl. 2017, \$16 UrhG Rn. 24.

516 S. zum Schutz des Motivs und des Inhalts S. 129 f., $173 \mathrm{ff}$.

517 Rehbinder/Peukert, Urheberrecht, 18. Aufl. 2018, Rn. 345. 
mer unkörperlich statt. Weiterhin kommt eine Verletzung nur in Betracht, solange noch keine Erschöpfung gem. $₫ 17$ Abs. 2 UrhG eingetreten ist. Dies ist allerdings dann der Fall, sobald das Ausgangswerk selbst in den Verkehr gebracht wurde. Die Verwendung bereits veröffentlichter Bilder oder Reproduktionen stellt damit keinen Eingriff in das Verbreitungsrecht dar. ${ }^{518}$

\section{Recht der öffentlichen Zugänglichmachung gem. \19a UrhG}

Das Verwertungsrecht gem. $₫ 19$ a UrhG ist das Recht des Urhebers, sein Werk dergestalt drahtgebunden oder drahtlos zugänglich zu machen, dass es Mitgliedern der Öffentlichkeit von Orten und zu Zeiten ihrer Wahl zugänglich ist. ${ }^{519}$ Es umfasst einerseits die Eröffnung des Zugriffs auf das Werk für Dritte, indem dessen Inhalt bereitgestellt wird (Bereithaltungsrecht), aber auch die anschließende Übermittlung des Werkes, also die Abrufübertragung selbst (Abrufübertragungsrecht).520

Aneignungen zur digitalen Kommunikation stellen Bilder in das Internet (Upload), nutzen aber auch bereits im Internet vorhandene Bilder, indem diese angezeigt oder durch Frame-Links eingebettet werden. Eine Verletzung von $\$ 19$ a UrhG kommt daher häufig in Betracht.

Es ist zu berücksichtigen, dass Art. 3 Abs. 1 InfoSoc-RL das Recht der öffentlichen Wiedergabe vollständig harmonisiert und die Mitgliedstaaten das durch diese Vorschrift begründete Schutzniveau daher weder unterschreiten noch überschreiten dürfen. ${ }^{521}$ Für die Frage, wie das Recht der öffentlichen Wiedergabe nach $\$ 19$ a UrhG zu verstehen und richtlinienkonform auszulegen ist, ist daher die Rechtsprechung des Europäischen Gerichtshofes (EuGH) zur öffentlichen Wiedergabe von Bedeutung.

518 Ebenso ist das Ausstellungsrecht gem. $₫ 18$ UrhG nur dann betroffen, wenn das Werk noch unveröffentlicht war.

519 BT-Drs. 15/38, S. 16.

520 S. Dreier/Schulze/Dreier, 6. Aufl. 2018, $\$ 19$ a UrhG Rn. 1; Schricker/Loewenheim/von Ungern Sternberg, 5. Aufl. 2017, \$19a UrhG Rn. 3.

521 EuGH GRUR 2014, S. 360, 361 Rn. 37 - Svensson/Retriever Sverige. Daher ist auch, soweit Art. 3 Abs. 1 InfoSoc-RL weitergehende Rechte als die in $\$ 15$ Abs. 2 S. 2 UrhG benannten Rechte der öffentlichen Wiedergabe gewährt, in richtlinienkonformer Auslegung des $\$ 15$ Abs. 2 UrhG ein unbenanntes Recht der öffentlichen Wiedergabe anzunehmen, so BGH GRUR 2016, S. 171, 171 Rn. 10 ff. - Die Realität II. 
1. Die Rechtsprechung des EuGH zum Recht der öffentlichen Wiedergabe

Der EuGH hat mit seiner Rechtsprechung zum Recht der öffentlichen Wiedergabe das bis dahin geltende Verständnis einer Öffentlichkeit im Sinne des $\$ 15$ Abs. 3 UrhG abgelöst. ${ }^{522}$ Insgesamt versteht der EuGH den Begriff „öffentliche Wiedergabe“ weit und richtet sich dabei am Hauptziel der InfoSoc-RL aus, ein hohes Schutzniveau für Urheber zu erreichen. ${ }^{523}$ Er setzt zwei kumulative Tatbestandmerkmale voraus: Die Handlung der Wiedergabe eines Werkes und die Öffentlichkeit dieser Wiedergabe. ${ }^{524}$

Als Wiedergabe lässt der EuGH jede Übertragung geschützter Gegenstände genügen, unabhängig von den genutzten technischen Mitteln (die erst im Rahmen des Öffentlichkeitsbegriffs relevant werden). ${ }^{525}$ Eine Wiedergabe liegt vor, wenn ein Nutzer fremder Werke in voller Kenntnis der Folgen seines Verhaltens tätig wird, um Dritten einen Zugang zum geschützten Werk zu verschaffen. ${ }^{526}$

Der EuGH verlangt, dass die Öffentlichkeit einer Wiedergabe aus einer „unbestimmten Zahl potenzieller Leistungsempfänger und recht vielen Personen“ besteht, die alle potenzielle Empfänger sind. ${ }^{527}$ Zudem muss die

522 Der BGH verstand unter der Öffentlichkeit eine Mehrzahl von Personen, wobei er hier bereits wenige Personen ausreichen ließ, vgl. BGH GRUR 2009, S. 845, 848 Rn. 35 - InternetVideorecorder I und BGH GRUR 2013, S. 618, 621 Rn. 43 InternetVideorecorder II. Diese stellten dann keine Öffentlichkeit dar, wenn sie durch persönliche Beziehungen miteinander verbunden waren, s. $\ 15$ Abs. 3 UrhG.

523 Vgl. EuGH GRUR 2017, S. 790, 791 Rn. 21 f. - Stichting Brein/Ziggo; EuGH GRUR 2018, S. 68, 69 Rn. 40 - VCAST/RTI, die die Erwägungsgründe 9 und 10 der Richtlinie heranziehen; ein weites Verständnis ergibt sich überdies auch ausdrücklich aus Erwägungsgrund 23 der Richtlinie.

524 EuGH GRUR 2014, S. 360 - Svensson/Retriever Sverige; EuGH GRUR 2016, S. 60 - SBS Belgium; EuGH GRUR 2016, S. 684 - Reha Training; EuGH GRUR 2016, S. 1152 - GS Media.

525 EuGH GRUR 2016, S. 684, 686 Rn. 38 - Reha Training.

526 EuGH GRUR 2007, S. 225 - SGAE/Rafael; EuGH GRUR 2012, S. 156 - Football Association Premier League und Murphy; EuGH GRUR 2014, S. 360 - Svensson/ Retriever Sverige; EuGH GRUR 2014, S. 473 - OSA/Léčebné láznè; EuGH GRUR 2014, S. 468 - UPC Telekabel/Constantin Film und Wega.

527 EuGH GRUR 2007, S. 225, 227 Rn. 37 f. - SGAE/Rafael; EuGH GRUR 2012, S. 593, 596 Rn. 83 ff. - SCF; EuGH GRUR 2012, S. 597, 598 Rn. 33 ff. - Phonographic Performance (Ireland); EuGH GRUR 2013, S. 500, 502 Rn. 32 - ITV Broadcasting/TVC; EuGH GRUR 2014, S. 360, 361 Rn. 21 - Svensson/Retriever Sverige; EuGH GRUR 2014, S. 473, 475 Rn. 27 - OSA/Léćebné lázně; EuGH GRUR 2014, S. 1196 - Best Water International; EuGH GRUR 2016, S. 1152- GS Media. 
Wiedergabe für die Öffentlichkeit bestimmt sein, also auf einen Empfängerkreis abzielen, der öffentlich ist. ${ }^{528}$ Anders als bisher im deutschen Recht liegt der Fokus des Verständnisses von Öffentlichkeit auf der Abgrenzbarkeit des Personenkreises anstatt auf der persönlichen Verbundenheit derjenigen, denen das Werk wahrnehmbar gemacht wird. Für die Anzahl der Personen muss nun auch eine gewisse Mindestschwelle überschritten werden, während der BGH früher bereits wenige Personen für eine Öffentlichkeit ausreichen ließ.529 Diese Rechtsprechung des BGH wurde mit dem Vorlagenbeschluss Die Realität I aufgegeben und die Kriterien des EuGH zur öffentlichen Wiedergabe übernommen. ${ }^{530}$

Weiterhin berücksichtigt der EuGH für das Vorliegen einer Öffentlichkeit, ob sich die Handlung der Wiedergabe eines anderen technischen Verfahrens als die ursprüngliche öffentliche Wiedergabe bedient oder ein neues Publikum erreicht. Erfolgt also die Wiedergabehandlung innerhalb derselben technischen Kommunikationsübermittlung, ist ein neues Publikum erforderlich. Ein neues Publikum ist ein solches, das vom Rechteinhaber nicht berücksichtigt wurde, als er der Nutzung durch Wiedergabe an das ursprüngliche Publikum zugestimmt hat. ${ }^{531}$ Es ist zudem nicht unerheblich, ob die Wiedergabe Erwerbszwecken dient. ${ }^{532}$

\section{Beurteilung von Frame-Links nach nationalem Recht}

Nun soll untersucht werden, wie Frame-Links rechtlich zu beurteilen sind bei Anwendung der Kriterien des EuGH zur öffentlichen Wiedergabe. Bildliche Aneignungen zur digitalen Kommunikation finden unter anderem durch das Teilen in sozialen Netzwerken statt. Solches Teilen erfolgt häufig durch Frame-Links, zum Teil auch durch einfache Hyperlinks. ${ }^{533}$

528 EuGH GRUR 2014, S.360, 361 Rn. 19 - Svensson/Retriever Sverige; Schricker/ Loewenheim/von Ungern-Sternberg, 5. Aufl. 2017, \$15 UrhG Rn. 364.

529 BGH GRUR 2009, S. 845, 848 Rn. 35 - Internet Videorecorder I; BGH GRUR 2013, S. 618, 621 Rn. 43 - Internet Videorecorder II.

530 BGH GRUR 2013, S. 818 - Die Realität I; Schricker/Loewenheim/von UngernSternberg, 5. Aufl. 2017, \$15 UrhG Rn. 70.

531 EuGH GRUR 2014, S. 360, 361 Rn. 24 - Svensson/Retriever Sverige.

532 Dazu mehr in der rechtlichen Beurteilung des Frame-Links auf rechtswidrig hochgeladene Inhalte, s. S. 154 ff. EuGH GRUR 2012, S. 156 - Football Association Premier League und Murphy; EuGH GRUR 2012, S. 593 - SCF, EuGH GRUR 2012, S. 597 - Phonographic Performance (Ireland); EuGH GRUR 2016, S. 1152 GS Media.

533 Vgl. zur begrifflichen Abgrenzung S. 71. 
a) Verletzung des $₫ 19$ a UrhG durch Frame-Links

Nach nationalem Recht wird keine Verletzung des $\$ 19$ a UrhG durch Frame-Links angenommen, da das Setzen eines Frame-Link noch keine Wiedergabehandlung ist. Denn derjenige, der bloß einen Link zu einem geschützten Werk setzt, hat keine Kontrolle darüber, ob das Werk wirklich zu Verfügung steht oder nicht. Wenn das Werk auf der ursprünglichen Webseite nicht mehr angezeigt wird, führt auch der Link ins Leere. Der Frame-Link ist damit nur eine elektronische Verknüpfung zu der Datei, die das geschützte Werk enthält, über dessen Darstellung der Linksetzende keine Verfügungsgewalt hat. ${ }^{534}$ Dem steht auch nicht entgegen, dass der unzutreffende Anschein erweckt wurde, der Frame-Link-Setzende würde das Werk selbst zum Abruf bereithalten. ${ }^{535}$

Der BGH hält auch nach der EuGH Rechtsprechung zur öffentlichen Wiedergabe an dieser Argumentation fest, dass sich das Werk nicht in der Zugriffsphäre des Linksetzenden befindet und er keine Einfluss auf dessen Darstellung hat. ${ }^{536} \$ 19$ a UrhG erfordere aber gerade, dass der Verletzer selbst das Werk bereitstellt und anderen den Zugang dazu eröffnet.

b) Verletzung des unbenannten Rechts der öffentlichen Wiedergabe gem. $\$ 15$ Abs. 2 UrhG durch Frame-Links

Um die Rechtsprechung des EuGH zu Frame-Links zu berücksichtigen, bedient sich der BGH des unbenannten Rechts der öffentlichen Wiedergabe gem. $\mathbb{1} 15$ Abs. 2 UrhG. Denn „soweit Art. 3 Abs. 1 InfoSocRL weitergehende Rechte als die in $\$ 15$ Abs. 2 S. 2 benannten Rechte der öffentlichen Wiedergabe gewährt, ist in richtlinienkonformer Auslegung des $\$ 15$ Abs. 2 UrhG ein unbenanntes Recht der öffentlichen Wiedergabe anzunehmen". ${ }^{537}$ Für dieses sind die vom EuGH entwickelten Voraussetzungen der Wiedergabehandlung und der Öffentlichkeit dieser Wiedergabe notwendig. 538

534 BGH GRUR 2003, S. 958, 962 - Paperboy; BGH GRUR 2010, S. 616, 618 Rn. 21 - marions-kochbuch.de; BGH GRUR 2013, S. 818, 818 Rn. 9 - Die Realität I.

535 Schricker/Loewenheim/von Ungern-Sternberg, 5. Aufl. 2017, \$19a UrhG Rn. 92.

536 BGH GRUR 2016, S. 171, 172 Rn. 12 ff. - Die Realität II.

537 BGH GRUR 2016, S. 171, 172 Rn. 17 - Die Realität II.

538 Früher wurde versucht, Frame-Links unter dem Aspekt des Zueigenmachens von Inhalten als urheberrechtliche Nutzungshandlung einzuordnen und die Verletzung eines unbenannten Rechts der öffentlichen Wiedergabe gem. 
Im Gegensatz zum BGH hat der EuGH ein grundsätzlich weites Verständnis der Wiedergabehandlung ${ }^{539}$, welches sich auf Erwägungsgrund 23 der InfoSoc-RL stützt, sodass Frame-Links auf bereits im Internet bereitgestellten Inhalten als Wiedergabehandlung zu qualifizieren sind.

Für das Vorliegen einer Öffentlichkeit müsste sich das Werk an eine unbestimmte Zahl potenzieller Adressaten und recht viele Personen richten (aa) sowie ein neues technisches Verfahren nutzen oder ein neues Publikum erreichen. Hierbei ist zwischen Werken, die mit Erlaubnis des Urhebers im Internet veröffentlicht wurden (bb), und ohne Erlaubnis im Internet veröffentlichten Werken zu unterscheiden (cc).

\section{aa) Unbestimmte Zahl potenzieller Adressaten und recht viele Personen}

Frame-Links sind in der Regel allen Internetnutzer zugänglich, sodass sie sich zumeist an eine unbestimmte Zahl potenzieller Adressaten und recht viele Personen richten.

Etwas anderes könnte für „private“ Profile in sozialen Netzwerken gelten. Je nach Privatsphäre-Einstellung werden die Links im Netzwerk nur den eigenen sozialen Kontakten oder „Freunden“ angezeigt. Klassischerweise, in vordigitalen Zeiten, wurde der Freundeskreis nicht nur als privat eingestuft, sondern dem Kern der Privatsphäre, teils sogar der Intimsphäre zugeordnet. Mit der Entwicklung der digitalen Kommunikation geht aber auch ein Strukturwandel des Verständnisses von Öffentlichkeit einher. ${ }^{540}$ Situationen werden als privat empfunden, die unter hergebrachten Gesichtspunkten der Öffentlichkeit zugeordnet wurden, insbesondere da sie viele Personen umfassen. ${ }^{541}$ Der Begriff der Freunde wird in der digitalen Kommunikation zwar häufig inflationär genutzt. Es handelt sich meist nicht um eine enge persönliche Verbundenheit, auch wenn es darauf

$\$ 15$ Abs. 2 UrhG anzunehmen. Damit wurde versucht, den ökonomischen Auswirkungen der verschiedenen Linksetzungen gerecht zu werden: Denn der Setzer eines Frame-Links erspart sich das eigene Bereitstellen des Werkes, für das er die Zustimmung des Urhebers benötigte, so BGH GRUR 2013, S. 818, 821 Rn. 26 - Die Realität I. Mittlerweile hat der EuGH das Verständnis des Rechts der öffentlichen Wiedergabe so geprägt, dass der Gesichtspunkt des Zueigenmachens nicht mehr herangezogen wird.

539 EuGH GRUR 2014, S. 360, 361 Rn. 17 ff. - Svensson/Retriever Sverige.

540 Marl, Der Begriff der Öffentlichkeit im Urheberrecht, 2017, S. 397.

541 Dreier/Schulze/Dreier, 6. Aufl. 2018, Einl. Rn. 28; $\mathbb{1 5}$ UrhG Rn. 29 a.E. 
rechtlich jetzt nicht mehr ankommt. ${ }^{542}$ Dennoch haben sich durch die digitale Kommunikationsmöglichkeit auch Bekanntschaften und Freundschaften verändert. Digital ist es leichter, Kontakt zu halten und sich nicht aus den Augen zu verlieren. Da es viel einfacher ist, am Leben des anderen teilzuhaben als noch im analogen Zeitalter, kann auch bei einer großen Anzahl von Personen, mit denen man Inhalte teilt, noch das Gefühl von Privatheit herrschen. Eine solch soziologische Einschätzung des Begriffs der „unbestimmten Anzahl potenzieller Adressaten“ wird jedoch nicht vorgenommen.

Häufig liegt die Zahl der Kontakte bei sozialen Netzwerken bei einigen Hunderten, sodass selbst bei der Einstellung, dass eigene Inhalte und damit auch Frame-Links nur den eigenen Kontakten angezeigt werden, eine hohe Zahl von Personen erreicht wird. ${ }^{543}$ Meist wird daher bei sozialen Netzwerken von einer Öffentlichkeit ausgegangen, selbst wenn Privatsphäre-Einstellungen bestehen und nicht jedermann die Beiträge sehen kann. ${ }^{544}$ Marl differenziert danach, ob die Kommunikation selbst eher nach persönlichen und vertraulichen Maßstäben abläuft. ${ }^{545}$ Wenn die Kommunikation so strukturiert ist, dass mit dem werkbezogenen Posting eine Stellungnahme bzw. Standortbestimmung in einen freien, offenen und kritischen Diskurs gegeben wird, dann sei die Kommunikation der Öffentlichkeit und einer unbestimmten Anzahl potenzieller Adressaten zuzuordnen. ${ }^{546}$ So wird auch eine geschlossene Gruppe innerhalb eines sozialen Netzwerkes trotz beschränkter Mitgliederanzahl als Öffentlichkeit qualifiziert, wenn nicht der Kreis der Personen bestimmt abgegrenzt ist. ${ }^{547}$ Nach Marl kommt es zudem auch auf das soziale Netzwerk an, das genutzt wird: So sei Twitter z.B. von jeher nicht für private Kommunikation konzi-

542 So ursprünglich das deutsche Verständnis zur Öffentlichkeit im Sinne des $\$ 15$ Abs. 3 UrhG; zur Veränderung des Begriffs der öffentlichen Wiedergabe durch den EuGH s. S. $147 \mathrm{ff}$.

543 Zwar kann auch die Privatsphäre der geteilten Inhalte so eingestellt werden, dass lediglich man selbst die eigenen Inhalte sehen kann - da dies aber dem Sinn eines sozialen Netzwerkes entgegenläuft, wird das nicht häufig der Fall sein.

544 So Ziegler, Urheberrechtverletzungen durch Social Sharing, 2016, S. 97, 123; Wandtke/Bullinger/Heerma, 5. Aufl. 2019, $\mathbb{1} 15$ UrhG Rn. 23; Marl, Der Begriff der Öffentlichkeit im Urheberrecht, 2017, S. 398; Sammer, Der Öffentlichkeitsbegriff im Urheberrecht, 2009, S. 210.

545 Marl, Der Begriff der Öffentlichkeit im Urheberrecht, 2017, S. 401.

546 Ders. a.a.O.

547 LG München I ZUM-RD 2018, S. 427, 429 Rn. 27. 
piert, sondern für den Austausch von Ansichten im Diskurs. ${ }^{548}$ Dies scheint ein hilfreiches Kriterium zu sein, ob sich der Inhalt an eine unbestimmte Anzahl recht vieler Personen wendet. Die bildbezogene Plattform Instagram lässt jedoch einen so hohen Grad an Differenzierung zu, wie ein Profil und die Einstellung zum Teilen von Inhalten ausgerichtet werden, dass hier ein Pauschalurteil schwierig erscheint. Hinzuzufügen sei noch, dass das Vermerken von Hashtags unter einem Bild, die der Auffindbarkeit des Bildes unter dem Schlagwort des Hashtags helfen sollen, wohl dafür spricht, dass sich das geteilte Bild an einen unbestimmten potenziellen Adressatenkreis richtet.

bb) Neues technisches Verfahren oder Publikum bei mit Erlaubnis des Urhebers im Internet veröffentlichten Werken

Es müsste sich auch um ein neues technisches Verfahren oder ein neues Publikum handeln im Vergleich zur ursprünglichen Wiedergabe, zu der der Urheber eingewilligt hat. Wenn das geschützte Werk bereits mit der Erlaubnis des Urhebers im Internet veröffentlicht wurde, dann handelt es sich nicht um ein neues technisches Verfahren, da es in beiden Fällen um die digitale Anzeige auf Webseiten geht. ${ }^{549}$

Nach Ansicht des EuGH fehlt es für den einfachen Hyperlink am neuen Publikum, da das Werk bereits für alle Internetznutzer ins Internet gestellt wurde. ${ }^{550}$ Soweit das Werk auf der Webseite, auf die der Internetlink verweist, frei zugänglich ist, ist davon auszugehen, dass die Inhaber des Urheberrechts, als sie diese Wiedergabe erlaubten, „an alle Internetnutzer als Publikum" dachten ${ }^{551}$ und der EuGH also von einem einheitlichen Publikum der Internetnutzer ausgeht. Ebenso sah es der EuGH beim FrameLink. ${ }^{552}$ Anders liegt der Fall wohl dann, wenn durch die Linksetzung technische Schutzmaßnahmen umgangen werden: Dann handelt es sich um ein neues Publikum, da der Inhalt bisher nicht für alle abrufbar war.

548 Marl, Der Begriff der Öffentlichkeit im Urheberrecht, 2017, S. 403.

549 So BGH GRUR 2019, S. 725, 728 Rn. 27 -Deutsche Digitale Bibliothek.

550 EuGH GRUR 2014, S. 360 - Svensson/Retriever Sverige; EuGH GRUR 2016, S. 1152 - GS Media. Er stellt also anders als der BGH gerade auf die Verfügungsgewalt über den Inhalt ab.

551 EuGH GRUR 2014, S. 360 - Svensson/Retriever Sverige; EuGH GRUR 2016, S. 1152 - GS Media.

552 EuGH, GRUR 2014, S. 1196, 1197 Rn. 17 f. - Best Water International; EuGH GRUR 2016, S. 1152, 1154 - GS Media. 
Nach Ansicht des BGH hat der Rechteinhaber an das Publikum, das die Werke im Wege der Einbettung in andere Webseiten wahrnimmt, nicht im Sinne der Rechtsprechung des EuGH gedacht, als er die ursprüngliche Maßnahme erlaubte. ${ }^{553}$ Der Link ist dann wohl als eine öffentliche $\mathrm{Zu}$ gänglichmachung einzustufen. ${ }^{554}$ Diese Frage hat der BGH dem EuGH vorgelegt, eine Entscheidung steht aber noch aus. ${ }^{555}$

Dieses Verständnis eines einheitlichen Publikums der Internetnutzer lässt kaum Raum für das vom BGH entwickelte Rechtsinstitut der schlichten Einwilligung für Suchmaschinen, die online gestellte Bilder als Thumbnail (oder auch Vorschaubild) wiedergeben. Hier hatte der BGH ein öffentliches Zugänglichmachen gem. \19a UrhG zwar bejaht, aber angenommen, dass wer ein Bild ohne technische Vorkehrungen gegen das Auffinden und Anzeigen der Abbildung ins Internet stellt, in die Nutzung des Bildes einwilligt, da dann mit den Umständen üblicher Nutzungen zu rechnen sei. ${ }^{556}$ Diese Rechtsprechung erstreckte der BGH nicht nur auf selbst online gestellte Bilder, sondern auch auf solche, die durch Dritte mit Einwilligung online gestellt wurden. ${ }^{557}$ Dieses dogmatisch kritisierte Rechtsinstitut, das als reine Hilfskonstruktion diente, um zum gewünschten Ergebnis zu kommen, ${ }^{558}$ scheint nun hinfällig $\mathrm{zu}$ sein, da es nach Rechtsprechung des EuGH bereits an der öffentlichen Zugänglichma-

553 BGH GRUR 2019, S. 725, 729 Rn. 35 - Deutsche Digitale Bibliothek.

$554 \mathrm{Zu}$ Frame-Links s. die Vorlage vor den EuGH von BGH GRUR 2019, S. 725, 728 Rn. 32 - Deutsche Digitale Bibliothek; EuGH GRUR 2016, S. 1152, 1154 Rn. 39 ff. - GS Media zu Hyperlinks; BGH GRUR 2011, S. 56, 59 Rn. 30 - Session ID, der allerdings noch nicht auf das neue Publikum abgestellt hat, sondern darauf, dass erkennbar sei, dass der Zugang zu dem Werk von bestimmten Vorgaben abhängig sein soll. Die technischen Schutzmaßnahmen müssen auch nicht wirksam im Sinne des $₫ 95$ a UrhG sein. Damit begründet $\$ 19$ a UrhG allerdings einen Schutz, der über den Umgehungsschutz des $\$ 95$ a UrhG hinaus reicht. Kritisch dazu: Dreier, Vom urheberrechtlichen Dürfen und den technischen sowie vertraglichen Grenzen des Könnens, in: FS Bornkamm, 2014, S. 749, 755 .

555 BGH GRUR 2019, S. 725 - Deutsche Digitale Bibliothek.

556 BGH GRUR 2010, S. 628, 631 Rn. 33 -Vorschaubilder I.

557 BGH GRUR 2012, S. 602 - Vorschaubilder II.

558 Spindler, Bildersuchmaschinen, Schranken und konkludente Einwilligung im Urheberrecht. Besprechung der BGH-Entscheidung „Vorschaubilder“, GRUR 2010, S. 785, 791, der es als „Krücke“ bezeichnet; Klass, Neue Internettechnologien und das Urheberrecht: Die schlichte Einwilligung als Rettungsanker?, ZUM 2013, S. 1, 4 f. 
chung gem. $\$ 19$ a UrhG bzw. des unbenannten Rechts der öffentlichen Wiedergabe $\$ 15$ Abs. 2 UrhG fehlt. ${ }^{559}$

cc) Neues technisches Verfahren oder Publikum bei ohne Erlaubnis des Urhebers im Internet veröffentlichten Werken

Bei Werken, die ohne Erlaubnis des Urhebers im Internet wiedergegeben werden, stellt sich ebenfalls die Frage, ob durch die Wiedergabe ein neues technisches Verfahren im Einsatz ist oder ein neues Publikum erreicht wird.

Auf die Frage, ob dies bereits ein neues technisches Verfahren darstellt und es daher gar nicht mehr auf das neue Publikum ankommt, geht der EuGH im Fall GS Media nicht weiter ein. Denn beim Verlinken auf ein Werk sowie beim Hochladen ohne Zustimmung handelt es sich um digitale Nutzungen. Wenn das Werk jedoch ohne Erlaubnis des Urhebers digital wiedergegeben wurde, handelt es sich auf jeden Fall nicht mehr um die Technik, zu der der Urheber seine Zustimmung ehemals gegeben hatte (z.B. Vervielfältigung, Verbreitung). Es liegt also auch ein neues technisches Verfahren im Vergleich zur Erstwiedergabe vor. Diese Argumentation beachtet der EuGH jedoch nicht, sodass eine öffentliche Wiedergabe nicht aus diesen Gesichtspunkten anzunehmen ist. Selbstverständlich ist, dass wenn für die Weiterübertragung ein anderes technisches Verfahren

559 Auf das Konstrukt der schlichten Einwilligung geht der BGH in seiner Vorlagefragen an den EuGH in Sachen Framing nicht mehr ein, s. BGH GRUR 2019, S. 725 - Deutsche Digitale Bibliothek. Er legt vor, ob es eine öffentliche Wiedergabe im Sinne des Art. 3 Abs. 1 InfoSoc-RL darstellt, wenn ein mit Einwilligung des Urhebers ins Internet gestellten Werkes auf die Internetseite eines Dritten mittels Framing eingebettet wird und dies unter Umgehung von Schutzmaßnahmen gegen das Framing erfolgt, die der Rechtsinhaber getroffen oder veranlasst hat. Dies wird wohl zu bejahen sein. So ist auch das EuGH Cordoba-Urteil zu verstehen, bei dem es zwar nicht um Linking, sondern um den eigenständigen Upload ging. Nichtsdestotrotz macht der EuGH dort deutlich, dass eine öffentliche Wiedergabe im Sinne des Art. 3 Abs. 1 InfoSoc-RL nicht ausgeschlossen ist, wenn das Werk zuvor auf einer anderen Webseite ohne beschränkende Maßnahmen, die ein Herunterladen verhindern, und mit Zustimmung des Urhebers veröffentlicht wird; vgl. EuGH GRUR 2018, S. 911, 913 Rn. 36 - Cordo$b a$. Demnach müssen nicht erst technische beschränkende Maßnahmen des Rechtsinhabers ergriffen werden, um eine Urheberrechtsverletzung auszuschlieBen. Der Fall behandelte zwar das Linking und nicht wie bei der Vorschaubilder-Rechtsprechung das Auffinden und Anzeigen von Bildern durch Crawler, der Rechtsgedanke sollte aber übertragbar sein. 
als bei der Erstwiedergabe eingesetzt wird, der Nutzer der Weiterübertragung zwangsläufig auch ein neues Publikum erreicht. ${ }^{560}$

Auf dieses neue Publikum geht der EuGH im Fall GS Media detaillierter ein und nimmt an, dass ein solches nicht vorliegt, wenn auf Inhalte per Hyperlink verlinkt wird, die ohne Zustimmung des Urhebers durch Dritte im Internet veröffentlicht wurden. ${ }^{561}$ Denn es müsse berücksichtigt werden, dass der Betreffende nicht weiß und vernünftigerweise nicht wissen kann, dass dieses Werk im Internet ohne Erlaubnis des Urheberrechtsinhabers veröffentlicht wurde. ${ }^{562}$ Denn auf das Werk kann bereits auch ohne den Hyperlink das gesamte Internetpublikum zugreifen. Eine öffentliche Zugänglichmachung liegt damit in der Regel nicht vor, außer der Betreffende hätte wissen müssen, dass der von ihm gesetzte Hyperlink Zugang zu einem unbefugt ins Internet veröffentlichten Werk verschafft. ${ }^{563}$

Auch hier kommen Zweifel an der Dogmatik des EuGH auf, denn - im Vergleich zur Ursprungswiedergabe - hat ja der Rechtsinhaber die Zugänglichmachung gerade nicht erlaubt, konnte damit zwangsläufig auch nicht das Internetpublikum im Blick haben. ${ }^{564}$ Dann wäre das Internetpublikum gerade ein neues Publikum und es läge eine öffentliche Wiedergabe vor. Der EuGH vergleicht hier also das Publikum durch die Hyperlinksetzung nicht mit dem Publikum, das der Urheber ursprünglich im Blick hatte, sondern mit dem Publikum, das bereits durch die digitale Veröffentlichung ohne Zustimmung des Urhebers geschehen ist, auf die verlinkt wird. Allerdings kann man den EuGH auch so verstehen, dass es für das

560 So Grünberger, Bedarf es einer Harmonisierung der Verwertungsrechte und Schranken?, ZUM 2015, S. 273, 276; ders., Einheit und Vielfalt im Recht der öffentlichen Wiedergabe, GRUR 2016, S. 977, 981.

561 EuGH GRUR 2016, S. 1152, 1154 Rn. 43 - GS Media. Es ging hier zwar nur um Hyperlinks und nicht bereits um Frame-Links. Er übernimmt die bisherige Argumentation von Hyperlinks aber auch für die Fälle des Frame-Links in der Entscheidung Best Water International. Dies dürfte auch für die Grundsätze des Urteils GS Media gelten, so auch der BGH in seiner EuGH Vorlage, BGH GRUR 2019, S. 725, 728 Rn. 25 ff. - Deutsche Digitale Bibliothek.

562 EuGH GRUR 2016, S. 1152, 1154 Rn. 47 - GS Media.

563 EuGH GRUR 2016, S. 1152, 1155 Rn. 49 - GS Media.

564 Vgl. Leistner, Urheberrecht an der Schnittstelle zwischen Unionsrecht und nationalem Recht, GRUR 2014, S. 1145, 1154; Höfinger, Anmerkung zu EuGH, Urteil vom 13. Februar 2014 - C-446/12 - Nils Svensson u.a./Retriever Sverige AB, ZUM 2014, S. 293, 295; Jani/Leenen, Anmerkung zu EuGH Nils Svensson u.a./Retriever Sverige, GRUR 2014, S. 362, 363; unterscheidend danach, ob die Rechtswidrigkeit des ohne Zustimmung des Rechtsinhabers erfolgten Zugänglichmachens offensichtlich ist: Grünberger, Bedarf es einer Harmonisierung der Verwertungsrechte und Schranken?, ZUM 2015, S. 273, $280 \mathrm{ff}$. 
neue Publikum darauf ankommt, welches Publikum der Rechtsinhaber aus Sicht des Verkehrs ursprünglich im Blick hatte. ${ }^{565}$ Bei einem ohne Erlaubnis des Rechtsinhabers ins Internet gestellten Werkes ist für den Verkehr nämlich gerade nicht ersichtlich, dass er das Internetpublikum nicht im Blick hatte. Somit würde mit diesem objektiven Verständnis das gleiche Publikum vorliegen beim Hyperlink. Mit dieser Argumentation lässt sich auch verstehen, warum der EuGH wie oben gesehen nicht von einem neuen technischen Verfahren ausgeht: Denn aus Sicht des Verkehrs wird für das Verlinken dasselbe technische Verfahren verwendet wie beim im Internet veröffentlichten Werk. Der EuGH macht zwar nicht deutlich, dass es auf ein solches objektives Verständnis ankommt, aus seiner Argumentation bezüglich des neuen Publikums beim Hyperlinking lässt sich dies allerdings wie erfolgt ableiten.

Dieses objektive Verständnis aus Sicht des Verkehrs kann dann widerlegt werden, wenn der Verlinkende hätte wissen müssen, dass das Werk ohne Zustimmung des Rechteinhabers online gestellt wurde. Dieser Einschränkung wird zum Teil mit Unverständnis begegnet. Einerseits aus dogmatischen Gründen, denn mit einem traditionellen Verständnis der Verwertungsrechte ist das Abstellen auf dieses subjektive Tatbestandsmerkmal „irritierend“. ${ }^{566}$ Doch da der EuGH in ständiger Rechtsprechung die Zielsetzung der InfoSoc-RL, ein möglichst hohes Schutzniveau für den Urheber zu erreichen, zur Auslegung der Verwertungsrechte heranzieht ${ }^{567}$, lässt sich eine solche subjektive Einschränkung nachvollziehen.

Problematisch ist hier wiederum, dass für den Verlinkenden häufig nicht erkennbar ist, ob die Quelle mit Zustimmung des Rechteinhabers veröffentlicht wurde oder nicht, ${ }^{568}$ sodass es schwierig ist, den Maßstab des fahrlässigen Nichtwissens festzusetzen. Diesen kann man abstrakt oder konkret ansetzen: Für ein abstraktes Kennenmüssen würde das Wissen um

565 Dagegen spricht allerdings der Wortlaut der Formulierung des EuGH, EuGH GRUR 2014, S. 1196, 1197 Rn. 33 - Best Water International: „Denn sofern und soweit dieses Werk auf der Webseite, auf die der Internetlink verweist, frei zugänglich ist, ist davon auszugehen, dass die Inhaber des Urheberrechts, als sie diese Wiedergabe erlaubt haben, an alle Internetnutzer als Publikum gedacht haben."

566 Von Ungern-Sternberg, Die Rechtsprechung des EuGH und des BGH zum Urheberrecht und zu den verwandten Schutzrechten im Jahr 2017, GRUR 2018, S. $225,229 \mathrm{f}$.

567 EuGH GRUR 2016, S. 1152, 1153 Rn. 30 - GS Media.

568 So die berechtigte Kritik von Grünberger, Bedarf es einer Harmonisierung der Verwertungsrechte und Schranken?, ZUM 2015, S. 273, 280. 
die Tatsache, dass ein Server massenhaft für Urheberrechtsverletzungen eingesetzt wird, ausreichen, sodass ein Hyperlink hierauf nicht zulässig wäre. ${ }^{569}$ Laut EuGH liegt Kennenmüssen auf jeden Fall dann vor, wenn der Hyperlinksetzende vom Urheberrechtsinhaber auf die fehlende Erlaubnis hingewiesen wurde, also konkretes Kennenmüssen vorhanden ist. ${ }^{570} \mathrm{Wie}$ jedoch selbst bei Hinweis des Rechtsinhabers Zweifel an dem fahrlässigen Nichtwissen aufkommen können, zeigt sich am Sachverhalt des Falles Best Water International ${ }^{571}$. Dort wurde das Video der Klägerin ohne Zustimmung auf die Plattform YouTube hochgeladen, dieses Video hat der Beklagte auf seine Webseite mittels Framing eingebettet. Auch die Klägerin hat das Video wiederum auf ihrer Webseite eingebunden per Inline-Link. Doch wenn schon der Rechteinhaber auf YouTube verlinkt, warum sollte dann ein Dritter veranlasst sein, an der Rechtmäßigkeit dieser Zugänglichmachung zu zweifeln?572 Grünberger wirft die Frage auf, ob in einem solchen Fall nicht die Behauptung des Rechteinhabers, das Video sei ohne Zustimmung online gestellt worden, ein venire contra factum proprium darstelle. ${ }^{573}$

Diesen Sachverhalt löst der EuGH, indem er besondere Prüfpflichten des Frame-Linksetzenden annimmt, wenn die Linksetzung mit Gewinnerzielungsabsicht erfolgt. In einem solchen Fall kann vom Linksetzenden erwartet werden, dass er die erforderlichen Nachprüfungen vornimmt, um sich zu vergewissern, dass das betroffene Werk auf der Webseite, zu der die Hyperlinks oder Frame-Links führen, nicht unbefugt veröffentlicht wurde. ${ }^{574}$ Damit führt der EuGH für geschäftliche Handlungen eine Beweislastumkehr ein. Das LG Hamburg lässt es für die Gewinnerzielungsabsicht bereits ausreichen, dass die Hyperlinksetzung im Rahmen eines Internetauftritts erfolgt, der insgesamt zumindest auch einer Erzielung von Gewinnen dient. ${ }^{575}$ Es setzt für das Vorliegen also einen niedrigen Standard an.

569 So auch die ähnliche Wertung des $₫ 53$ Abs. 1 UrhG zur offensichtlich rechtswidrigen Vorlage. Vgl. Leistner, „In jedem Ende liegt ein neuer Anfang“. Das BGH Urteil „Vorschaubilder III“, seine Bedeutung für die Bildersuche und für die weitere Entwicklung des Haftungssystems im Urheberrecht, ZUM 2018, S. 286, 288.

570 EuGH GRUR 2016, S. 1152, 1155 Rn. 49 - GS Media.

571 EuGH GRUR 2014, S. 1196 - Best Water International.

572 So fragt zurecht Grünberger, Bedarf es einer Harmonisierung der Verwertungsrechte und Schranken?, ZUM 2015, S. 273, 280.

573 Ders. a.a.O.

574 EuGH GRUR 2016, S. 1152, 1155 Rn. 51 - GS Media; BGH GRUR 2016, S. 171, 174 Rn. 37 - Die Realität II.

575 LG Hamburg GRUR-RR 2017, S. 216 - Architekturfotos. 
Diese Vermutung der Fahrlässigkeit bei Gewinnerzielungsabsicht ist durchaus kritisch zu sehen. Auch hier greifen wieder dogmatische Gründe: Ein solches Kriterium ist dem System der Verwertungshandlungen an sich fremd ${ }^{576}$ - für eine öffentliche Wiedergabe kann es gerade nicht auf deren Zweck ankommen.

Das Kriterium der Gewinnerzielungsabsicht soll dann nicht gelten, wenn eine automatisierte Einbeziehung von Links durch eine Datenbank vorgenommen wird. Eine solche Nutzung widerlegt die Vermutung der fahrlässigen Nichtkenntnis. Das ist zu begrüßen, denn gem. Art. 15 der ECommerce-RL 2000/31/EG577 soll es gerade keine allgemeine Kontrollpflicht für Anbieter von Vermittlungsdienste (wie Datenbankhersteller) geben. In diesem Sinne wird die Gewinnerzielungsabsicht ebenso widerlegt bei Suchmaschinenbetreibern, die ebenfalls die Rechtswidrigkeit der ursprünglichen Veröffentlichung vernünftigerweise nicht erkennen können und keiner allgemeinen Kontrollpflicht unterliegen. ${ }^{578}$

Fraglich bleibt, ob auch eine Beschränkung durch Nutzungsbestimmungen möglich ist. Hierbei stellt sich insbesondere die Frage zur Anwendung der Vorschaubilder-Rechtsprechung, die davon ausgeht, dass die schlichte Einwilligung durch Hochladen eines Bildes sich auch auf die Nutzungshandlungen Dritter an diesem Bild erstreckt. ${ }^{579}$ Bisher ist jedoch nicht davon auszugehen, dass die Grundsätze der Vorschaubilder-Rechtsprechung aufgehoben sind, da diese allesamt Fälle betreffen, in denen unmittelbare Eingriffe vorliegen und nicht nur mittelbare Fälle des Linking oder Framing. ${ }^{580}$

Mit diesem Verständnis des neuen Publikums bleibt kaum Raum für die traditionelle Störerhaftung der deutschen Rechtsprechung ${ }^{581}$, die für mittelbare Verursachungsbeiträge wie z.B. das Linking gedacht war. ${ }^{582}$ So geht der BGH in Vorschaubilder III und in der EuGH-Vorlage Deutsche Digitale

576 So Ohly, Anmerkung zu EuGH GS Media/Sanoma u.a, GRUR 2016, S. 1155, 1156; Fischer, Digitale Kunst und freie Benutzung, 2018, S. 155.

577 Richtlinie (EU) des Europäischen Parlaments und des Rates vom 08. Juni 2000 über bestimmte rechtliche Aspekte der Dienste der Informationsgesellschaft, insbesondere des elektronischen Geschäftsverkehrs, im Binnenmarkt („Richtlinie über den elektronischen Geschäftsverkehr").

578 BGH GRUR 2018, S. 178, 185 Rn. 60 ff. - Vorschaubilder III.

579 Vgl. BGH GRUR 2012, S. 602, 605 Rn. 26 - Vorschaubilder II in Fortführung von BGH GRUR 2010, S. 628 - Vorschaubilder I.

580 So Ohly, Anmerkung zu BGH Vorschaubilder III, GRUR 2018, S. 187, 188.

581 S. z.B. BGH GRUR 2010, S. 633, 634 Rn. 17 - Sommer unseres Lebens.

582 So Ohly, Anmerkung zu BGH Vorschaubilder III, GRUR 2018, S. 187, 188; Leistner, „In jedem Ende liegt ein neuer Anfang“. Das BGH Urteil Vorschaubil- 
Bibliothek auch nicht mehr von einer Störerhaftung aus. ${ }^{583}$ Die Verletzung von Prüfpflichten führt nun nach den Urteilen des EuGH zu einer täterschaftlichen Haftung.

Es lässt sich also festhalten, dass ein Frame-Link nach Rechtsprechung des EuGH nur dann eine öffentliche Wiedergabe darstellt, wenn der Inhalt durch technische Schutzmaßnahmen geschützt ist oder der Inhalt ohne Einwilligung des Urhebers online hochgeladen wurde und der Verlinkende mit Gewinnerzielungsabsicht handelt. Dies kann also insbesondere bei YouTube-Videos eine Rolle spielen, auf die in sozialen Netzwerken häufig per Frame-Link Bezug genommen wird. Ebenso spielt dies bei der App Instagram eine Rolle. In den Instagram Stories ${ }^{584}$ können Beiträge anderer mittels Frame-Link einbezogen werden und in der eigenen Instagram Story geteilt werden. Hier wird bei rein privaten Nutzungen selten mit Gewinnerzielungsabsicht gehandelt. Anders kann der Fall aber bei den Instagram-Profilen von Unternehmen und sog. Influencern liegen: Hier wird wohl in der Regel nach dem oben genannten weiten Verständnis eine Gewinnerzielungsabsicht vorliegen, sodass eine Vermutung dafür vorliegt, dass der Verlinkende hätte wissen müssen, dass der Beitrag rechtswidrig online gestellt wurde.

\section{dd) Fazit}

Mangels neuen Publikums stellt also der Frame-Link bei mit Erlaubnis des Urhebers ins Internet gestellten Inhalten meist keine Verletzungshandlung dar. Anders sieht es aus, wenn die Erlaubnis des Urhebers nie vorlag oder wieder entzogen wurde oder wenn technische Schutzmaßnahmen umgangen wurden.

der III, seine Bedeutung für die Bildersuche und für die weitere Entwicklung des Haftungssystems im Urheberrecht, ZUM 2018, S. 286, 289 f.; Jaworski/Nordemann, Gehilfenhaftung von Intermediären bei Rechtsverletzungen im Internet, GRUR 2017, S. 567, 571 f. Mit der Folge, dass nun für die Verletzung der Prüfpflichten nicht nur Unterlassung, sondern auch Schadensersatz gefordert werden kann.

583 BGH GRUR 2019, S. 725 - Deutsche Digitale Bibliothek; BGH GRUR 2018, S. $178,186 \mathrm{f}$. - Vorschaubilder III.

584 Instagram Stories ist ein Feature, das Privatusern und Unternehmensprofilen die Möglichkeit gibt, Fotos oder kurze Videos einzustellen, die 24 Stunden nach der Veröffentlichung automatisch verschwinden, vgl. bereits S. 71. 
3. Upload eines Bildes als öffentliche Wiedergabe gem. $₫ 19$ a UrhG

Bilder werden innerhalb der digitalen Kommunikation jedoch nicht nur per Linking weiterverbreitet, sondern auch durch das Herunterladen und den erneuten Upload. In der digitalen Kommunikation werden häufig Bilder wiedergegeben, die ebenfalls online verfügbar sind. So leben Museumselfies, Bildmontagen, Memes und GIFs von der Nutzung anderer digitaler Bilder. Auch das Teilen eines Bildes in sozialen Netzwerken kann anstatt eines Re-Post per Frame-Link auch durch einen Re-Upload vorgenommen werden. ${ }^{585}$ Einige soziale Netzwerke, wie Instagram, wollen dies zwar gezielt verhindern, indem sie das Abspeichern eines Bildes auf den Handyspeicher innerhalb der App nicht zulassen, sodass dies nur durch einen Screenshot möglich ist. Man kann allerdings Bilder innerhalb der App Instagram „speichern“, ohne sie auf den eigenen Handyspeicher herunterzuladen. Um einen Re-Post möglich zu machen, kann jedoch auch eine eigene App dafür heruntergeladen werden (z.B. „Repost for Instagram“), die Bilder von Instagram im Handyspeicher speichert und den Upload vereinfacht.

Im Unterschied zum Linking wird beim erneuten Upload der Schutzgegenstand auf dem Server des Nutzers bereitgehalten. Beim Upload wird ein bereits öffentlich zugänglich gemachtes Werk kopiert, auf der eigenen Webseite hochgeladen und auf einem eigenen Rechner - und damit unabhängig von der ursprünglichen Quelle - vorgehalten. Auf diese Weise wird die Kontrolle über die Bereithaltung des Werkes ausgeübt. ${ }^{586}$ Eine solche Nutzungshandlung stellt nach Urteilen des EuGH und BGH eine öffentliche Zugänglichmachung gem. \19a UrhG dar. ${ }^{587}$

a) Neues technisches Verfahren oder neues Publikum

Der EuGH prüft im Fall Cordoba das Vorliegen eines neuen technischen Verfahrens abermals nicht. ${ }^{588}$ Er nimmt lediglich an, dass es sich bei der

585 S. dazu die Untersuchungsgegenstände, S. $70 \mathrm{ff}$.

586 BGH GRUR 2018, S. 178, 180 Rn. 19 - Vorschaubilder III; Dreier/Schulze/Dreier, 6. Aufl. 2018, \19a UrhG Rn. 6a.

587 BGH GRUR 2019, S. 813 - Cordoba II; EuGH GRUR 2018, S. 911 - Cordoba; BGH GRUR 2018, S. 178 - Vorschaubilder III.

588 EuGH GRUR 2018, S.911, 912 Rn. 25 - Cordoba. So auch schon zuvor keine Prüfung des neuen technischen Verfahrens im EuGH-Urteil GS Media, vgl. S. 154. 
erneuten Wiedergabe eines Werkes auf einer Webseite um das gleiche technische Verfahren handelt wie bei der vorherigen Wiedergabe auf einer Webseite durch den Urheber. Dabei hätte er das Kriterium des neuen technischen Verfahrens schärfen können, indem er auf die Handlung des Uploads abstellt und auf die erneute Speicherung auf einem Server für den Upload. Es liegt gerade kein Anknüpfen an den bereits erfolgten Upload durch den Urheber vor - wie es beim Framing oder Hyperlinking der Fall ist - sondern eine eigenständige, technische Handlung. ${ }^{589}$ Der BGH geht in seiner Folgeentscheidung allerdings von dem gleichen technischen Verfahren aus, da das Werk ursprünglich und später ebenfalls auf einer Webseite wiedergegeben wurde. ${ }^{590}$

Stattdessen nimmt der EuGH an, dass es sich um ein neues Publikum handele. ${ }^{591}$ Schlüssig ist dies, wie oben gesehen, bei einem Werk, das ohne Einwilligung des Urhebers online gestellt wird. Schwer nachvollziehbar ist es hingegen bei einem bereits mit Einwilligung des Urhebers im Internet vorhandenen Bild, wie es im Cordoba-Urteil der Fall war, da sich ein solches Bild nach Willen des Urhebers an das allgemeine Internetpublikum richtet - und sich die abermalige Wiedergabe wiederum an dieses Internetpublikum richtet. Hier von dem gleichen Publikum auszugehen würde jedoch auf eine Erschöpfung des Rechts der öffentlichen Wiedergabe hinauslaufen und das widerspräche dem Art. 3 Abs. 3 der InfoSocRL. ${ }^{592}$ Daher sei ein neues Publikum anzunehmen, denn ,unter solchen Umständen besteht das Publikum, an das der Urheberrechtsinhaber gedacht hatte, als er der Wiedergabe seines Werks auf der Webseite zugestimmt hatte, auf der es ursprünglich veröffentlicht wurde, nur aus den Nutzern dieser Webseite und nicht aus den Nutzern der Webseite, auf der das Werk später ohne Zustimmung des Urheberrechtsinhabers eingestellt worden ist, oder sonstigen Internetnutzern. ${ }^{\text {" }} 93$

589 So die Kritik von Pfeifer, Urheberrechtliche Zulässigkeit der Weiterverwertung von im Internet abrufbaren Fotos, NJW 2018, S. 3490, 3492.

590 BGH GRUR 2019, S. 813, 817 Rn. 44 - Cordoba II.

591 EuGH GRUR 2018, S. 911, 913 Rn. 35 - Cordoba.

592 EuGH GRUR 2018, S.911, 913 Rn. 32 f. - Cordoba. Eine Erschöpfung des Rechts der öffentlichen Wiedergabe lehnte der EuGH zuletzt ab in seinem Urteil zum Wiederverkauf von E-Books, s. EuGH GRUR 2020, S. 179 - NUV/Tom Kabinet.

593 EuGH GRUR 2018, S. 911, 913 Rn. 35 - Cordoba. So auch der BGH sodann in BGH GRUR 2019, S. 813, 817 Rn. 46 - Cordoba II. 
b) Bewertung

Ein solches enges Verständnis des neuen Publikums hatte der EuGH zuvor in GS Media gerade nicht angenommen, sondern ist von einem allgemeinen, einheitlichen Publikum der Internetnutzer ausgegangen. ${ }^{594} \mathrm{Die}$ im Urteil Cordoba vorgenommene Einengung ist schwer nachvollziehbar, da auch bei einem eigenständigen Upload das Werk für alle abrufbar ist. Die Kriterien, die an das neue Publikum angewendet werden, sind also unterschiedlich je nachdem, ob es sich um einen Hyperlink/Frame-Link oder einen erneuten Upload handelt. Der EuGH begründet diese unterschiedliche Bewertung damit, dass „Hyperlinks zum guten Funktionieren des Internets beitragen, indem sie die Verbreitung von Information in diesem Netz ermöglichen, das sich durch die Verfügbarkeit immenser Informationsmengen auszeichnet". $595 \mathrm{Zu}$ diesem Ziel trägt der erneute Upload eines Werkes ohne Zustimmung des Urhebers nicht bei. Das Internet sei für die in Art. 11 der Charta der Grundrechte der Europäischen Union (GrCh) gewährleistete Freiheit der Meinungsäußerung und Informationsfreiheit von besonderer Bedeutung und Hyperlinks tragen zum Meinungs- und Informationsaustausch im Netz bei. ${ }^{596}$ Diese Argumentation mag bei Hyperlinks und Deep Links überzeugen - allerdings nicht bei Frame-Links, die den fremden Inhalt in die eigene Webseite einbinden. Beim Frame-Link jedoch hatte der EuGH bisher auch das gleiche weite Verständnis des neuen Publikums angewendet wie bei Hyperlinks, was dafür spräche, es auch beim erneuten Upload bei diesem Verständnis zu belassen. Die Argumentation des EuGH zum neuen Publikum erscheint jedoch wie vorgenommen wenig überzeugend und davon getragen zu sein, das gewünschte Ergebnis herbeizuführen. Mit den Kriterien des neuen technischen Verfahrens oder neuen Publikums wollte der EuGH eigentlich eine neue Dogmatik in die öffentliche Wiedergabe einführen und deren Grenzen anhand bestimmter Kriterien aufzeigen. Durch diese Cordoba-Rechtsprechung werden diese Kriterien allerdings nun undeutlich und unverständlich. Überzeugender ist die Argumentation des BGH in der Vorlageentscheidung zum EuGH, die auf die Zugriffsphäre abstellt. Ein Nutzer - wie hier im Fall - eröffnet der Öffentlichkeit den Zugriff auf das in seiner Zugriffsphä-

594 EuGH GRUR 2016, S. 1152, 1154 Rn. 42 - GS Media.

595 EuGH GRUR 2018, S. 911, 914 Rn. 40 - Cordoba.

596 EuGH GRUR 2016, S. 1152, 1154 Rn. 45 - GS Media; BGH GRUR 2017, S. 514, 516 Rn. 35 - EuGH Vorlage zum Begriff des "öffentlichen Zugänglichmachen" - Cordoba. 
re befindende Werk und nimmt damit eine eigene Verwertungshandlung vor, weshalb eine öffentliche Wiedergabe zu bejahen sei. ${ }^{597}$ Dies hätte, wie oben gesehen, im Rahmen des neuen technischen Verfahrens als Kriterium aufgestellt werden können.

Fraglich erscheint auch, ob die grundsätzliche Unterschiedlichbehandlung von Links und Uploads gerechtfertigt ist. Es zeichnet sich dadurch eine Unterscheidung zwischen mittelbaren und unmittelbaren Wiedergabehandlungen ab. ${ }^{598}$ Der Generalanwalt beim EuGH Campos SánchezBordona schlug in seiner Stellungnahme vor, die Verantwortung zwischen Internetnutzer und Rechteinhaber zu teilen.599 Wenn der Rechteinhaber einen Inhalt frei ins Netz einstelle, müsse er deutlich machen, dass er einer Anschlussverwendung nicht zustimme. Ohne einen Vorbehalt komme dem ungeschützten Einstellen von Inhalten ins Netz der Erklärungswert $\mathrm{zu}$, dass sie von anderen weiterverwendet werden dürfen. Er argumentiert ähnlich wie der BGH in seiner Vorschaubilder-Rechtsprechung, stellt aber auf eine vermutete Einwilligung ab. Wie auch beim Hyperlink erst das Umgehen von technischen Schutzmaßnahmen des Urhebers eine Verletzung des Wiedergaberechts darstellt, müsste der Urheber hier gegen einen Upload technische Schutzmaßnahmen ergreifen, wenn er eine akzessorische Nutzung nicht wünscht. Ein solcher Wille scheint aber - wie auch bereits bei der BGH Vorschaubilder-Rechtsprechung - konstruiert und weit hergeholt. Ein so weites Verständnis im Sinne von „Einmal im Internet immer frei" ${ }^{600}$ kann sich nicht allein aus einer fehlenden Öffentlichkeit ergeben. Wollte man ein solches weitrechendes Nutzungsrecht von Internetnutzern ermöglichen, bräuchte man dafür eine neue Schrankenregelung oder müsste die digitale Erschöpfung regeln. ${ }^{601}$

Noch nicht geklärt ist, ob auch Vorschaubilder, die eine Suchmaschine vorbehält und einen erneuten Upload vornimmt, einen Eingriff in $\$ 19$ a UrhG darstellen. Im Vorschaubilder III-Urteil des BGH ging es nur um eine Suchmaschine, die nicht selbst die Bilder vorbehält, sondern um die Verlinkung auf Bildern einer Suchmaschine. Damit lag auch dort lediglich

597 BGH GRUR 2017, S. 514, 517 Rn. 36 - EuGH Vorlage zum Begriff des „öffentlichen Zugänglichmachen" - Cordoba.

598 So Ohly, Unmittelbare und mittelbare Verletzung des Rechts der öffentlichen Wiedergabe nach dem „Córdoba“-Urteil des EuGH, GRUR 2018, S. 996, 996.

599 Generalanwalt Campos Sánchez-Bordona, Schlussantrag vom 25.04.2018, Rs. C-161/17 (Cordoba), ECLI:EU:C:2018:279, ZUM 2018, S. 506, 512 Rn. $77 \mathrm{ff}$.

600 So bezeichnet es Pfeifer, Urheberrechtliche Zulässigkeit der Weiterverwertung von im Internet abrufbaren Fotos, NJW 2018, S. 3490, 3491.

601 Dazu S. 271 ff., S. 293 ff. 
eine akzessorische Nutzung vor. Nach den EuGH-Urteilen ist noch nicht klar, wie der Upload durch die Suchmaschine rechtlich zu beurteilen wäre. ${ }^{602}$ Es müsste für sie aber wie auch bei rechtswidrigen Hyperlinks eine Ausnahmeregelung gelten, die sich in der besonderen Notwendigkeit von Suchmaschinen für das Funktionieren des Internets begründet. Wenn aus der Bedeutung für Meinungs- und Informationsfreiheit für Hyperlinks und Frame-Links ein anderes Verständnis des neuen Publikums vorgenommen wird, muss dies auch für den Upload eines urheberrechtlichen Werkes von Suchmaschinen gelten.

\section{Fazit}

Aneignungen zur digitalen Kommunikation werden wohl häufig das Recht des Urhebers zur öffentlichen Zugänglichmachung gem. $\$ 19$ a UrhG verletzen. Frame-Links und Hyperlinks, die für die Aneignungshandlung genutzt werden, stellen zwar selten eine Verletzung dar. Jedoch liegt eine solche immer vor, wenn technische Schutzmaßnahmen umgangen werden oder wenn das Werk ohne Zustimmung des Urhebers im Internet hochgeladen wurde und der Aneignende dies kennen musste. Eine Vermutung des Kennenmüssen wegen Gewinnerzielungsabsicht liegt bei der digitalen Kommunikation wohl selten vor. Sollte vor das Aufrufen der Aneignung auf einer Webseite oder im sozialen Netzwerk allerdings Werbung geschaltet sein, liegt damit auch eine Gewinnerzielungsabsicht vor.

Ansonsten wird für den Aneignenden auch selten erkennbar sein, ob das Bild mit Zustimmung des Urhebers ins Internet gestellt wurde oder nicht. Auch wird das Kontaktnetz in sozialen Netzwerken trotz eventueller Privatsphäre-Einstellungen häufig eine Öffentlichkeit im Sinne des $\$ 15$ Abs. 3 UrhG darstellen. Für Memes oder YouTube-Videos, die durch Links in sozialen Netzwerken geteilt werden, kommt es also auf den Einzelfall an, ob eine Rechtsverletzung vorliegt.

Der erneute Upload eines urheberrechtlichen Werkes zur digitalen Kommunikation stellt in jedem Fall eine öffentliche Wiedergabe dar. Dies betrifft insbesondere Bildmontagen, aber auch Museumselfies, GIFs, Memes und das Teilen in sozialen Netzwerken. Virale Hypes stellen meist kei-

602 Darauf hinweisend: Ohly, Unmittelbare und mittelbare Verletzung des Rechts der öffentlichen Wiedergabe nach dem „Córdoba“-Urteil des EuGH, GRUR 2018, S. 996, 1001. 
ne Verletzung des Rechts gem. $\$ 19$ a UrhG dar, da die Idee der Ausführung nicht geschützt wird und nur das eigene Video, nicht jedoch das Ursprungsvideo öffentlich zugänglich gemacht wird.

\section{Aneignung als Bearbeitung gem. $\$ 23$ UrhG}

Zum Urheberrecht gehört auch das Kontrollrecht ${ }^{603}$ des Urhebers für Bearbeitungen und Umgestaltungen ${ }^{604}$ seines Werkes gem. $\$ 23$ UrhG. Dies soll einen angemessenen Ausgleich der unterschiedlichen Interessen an dem Werk sichern: Solange das Ursprungswerk noch in seinen wesentlichen Zügen erkennbar ist, soll die Kontrolle darüber auch dem Urheber zugeordnet sein und allein er bestimmen dürfen, in welcher Form sein Werk der Öffentlichkeit zugänglich ist. ${ }^{605}$ Für Bearbeitungen und Umge-

603 Strittig ist, ob es sich bei dieser Norm um eine Schutzbereichsbestimmung oder um ein selbständiges Verwertungsrecht handelt. Die fehlende Erwähnung des $\$ 23$ UrhG innerhalb der Auflistung der Verwertungsrechte im $\$ 15$ UrhG spricht gegen letzteres - allerdings ist die Auflistung auch explizit nur beispielshaft. Außerdem geht die Norm zurück auf Art. 8 und 12 der Revidierten Berner Übereinkunft (RBÜ), die von einem ausschließlichen Recht sprechen (BT-Drs. IV/270, S. 51). Die herrschende Meinung nimmt daher ein selbständiges Verwertungsrecht an, s. Dreier/Schulze/Schulze, 6. Aufl. 2018, \23 UrhG Rn. 9; Schack, Urheber- und Urhebervertragsrecht, 9. Aufl. 2019, Rn. 468; Fromm/ Nordemann/A. Nordemann, 12. Aufl. 2018, $\$ 23$ UrhG Rn. 2; tendenziell wohl auch Schricker/Loewenheim/Loewenheim, 5. Aufl. 2017, \$23 UrhG Rn.1 und 24; a.A.: BeckOK UrhG/Ablberg, 26. Ed. 2019, \$2 23 UrhG Rn. 7 f.; Loschelder, Vervielfältigung oder Bearbeitung? Zum Verhältnis des $₫ 16$ UrhG zu $₫ 23$ UrhG, GRUR 2011, S. 1078, 1082. Nur wenn es sich um ein solches Verwertungsrecht handelt, kann der Urheber anderen ein Bearbeitungsrecht mit dinglicher Wirkung einräumen.

604 Der Unterschied zwischen Bearbeitung und Umgestaltung wird nach amtl. Begründung darin gesehen, ob sie dem Originalwerk dienen oder nicht. Demnach passen Bearbeitungen das Originalwerk bestimmten Zwecken an, um dessen Verwertungsmöglichkeiten zu erweitern, wie z.B. Übersetzungen, Dramatisierungen oder Verfilmungen, s. Dreier/Schulze/Schulze, 6. Aufl. 2018, $\mathbb{2 3}$ UrhG Rn. 5. Umgestaltungen sind sonstige Handlungen, wie das Plagiat oder die gescheiterte freie Benutzung, s. amtl. Begründung BT-Drs. IV/270, S. 51. Die Unterscheidung ist nach einigen Stimmen der Literatur überholt und es solle vielmehr darauf abgestellt werden, dass Bearbeitungen selbst urheberrechtlich geschützt sein können gem. $\$ 3$ UrhG, wohingegen Umgestaltungen die notwendige Individualität fehle, s. Fromm/Nordemann/A. Nordemann, 12. Aufl. 2018, \23 UrhG Rn. 10; BeckOK UrhG/Ablberg, 26. Ed. 2019, \$23 UrhG Rn. 6.

605 Dreier/Schulze/Schulze, 6. Aufl. 2018, $\$ 23$ UrhG Rn. 17. 
staltungen ist daher nach Satz 1 seine Einwilligung erforderlich - allerdings nur für die Veröffentlichung und Verwertung des bearbeiteten Werkes, nicht bereits für die Herstellung der Bearbeitung oder Umgestaltung. ${ }^{606}$ Diese Differenzierung ist in der Digitalkultur aber nicht mehr von großer Unterscheidungskraft: Denn auch die privaten, kommunikativ innerhalb eines Freundeskreises gebrauchten Bearbeitungen werden heute nicht mehr analog auf einem Träger weitergegeben, sondern öffentlich zugänglich ins Internet gestellt. Die Grenzen zwischen Privatheit und Öffentlichkeit verschwimmen immer mehr ${ }^{607}$, sodass sowohl bei Aneignungen im künstlerischen als auch im digitalen Bereich in der Regel von einer Veröffentlichung ausgegangen werden kann.

Anders als bei $\mathbb{} 24$ UrhG muss für die Bearbeitung oder Umgestaltung die Individualität des ursprünglichen Werkes gerade beibehalten werden. ${ }^{608}$ Die Normen unterscheiden sich also im Grade der Abweichung vom Originalwerk: Bei Fällen des $\$ 23$ UrhG besteht gerade noch eine Abhängigkeit vom Original, wohingegen bei $\$ 24$ UrhG das Originalwerk „verblasst“. .09

Für Aneignungen ist es grundsätzlich eine Frage der Umstände des Einzelfalles, ob eine Bearbeitung oder Umgestaltung oder eine freie Benutzung vorliegt, da es gerade darauf ankommt, inwieweit die ursprüngliche Individualität des Werkes gewahrt wird (dann $\$ 23$ UrhG und Einwilligung notwendig) oder bereits verblasst ist (dann $\$ 24 \mathrm{UrhG}$ ). Eine Einwilligung des Urhebers des angeeigneten Werkes wird aber sowohl in der Appropriation Art als auch in der Digitalkultur die Ausnahme darstellen ${ }^{610}$, sodass hier in der Regel von einem Eingriff in dieses Verwertungsrecht ausgegangen werden kann.

Das Teilen von sozialen Medien zeigt meist das Originalwerk selbst, sodass hier bloßes öffentliches Zugänglichmachen und keine Bearbeitung oder Umgestaltung vorliegt. ${ }^{611}$ Bei viralen Hypes, die Ursprungsvideos oder Bilder nachahmen und variieren, könnte man im Falle weniger Ab-

606 Mit der Ausnahme des $₫ 23$ S. 2 UrhG, der für die vorliegende Fragestellung aber nicht relevant ist.

607 Vgl. dazu zuvor S. 150 f. und Marl, Der Begriff der Öffentlichkeit im Urheberrecht, 2017, S. $330 \mathrm{ff}$.

608 Rehbinder/Peukert, Urheberrecht, 18. Aufl. 2018, Rn. 257.

609 Dazu ausführlicher unter S. $184 \mathrm{ff}$.

610 Ausführlicheres zur Einwilligung, vgl. S. 220.

611 Vgl. auch zu Thumbnails und Snippets, die bloß als Vervielfältigung gem. $\$ 16$ UrhG und nicht als Umgestaltung angesehen werden, Ziegler, Urheberrechtverletzungen durch Social Sharing, 2016, S. $129 \mathrm{f}$. 
weichungen vom angeeigneten Bild eine Bearbeitung sehen. Ebenso bei GIFs, die die Bilder kaum variieren, aber sie animiert haben. Bei Memes werden die Bilder mit Text kombiniert und bei der Bildmontage mit anderen Bildern in Zusammenhang gestellt, sodass das angeeignete Werk hier eher eine untergeordnete Rolle spielt und schon nicht mehr von einer Bearbeitung oder Umgestaltung ausgegangen werden kann.

\section{Rechtfertigung der urheberrechtlichen Eingriffshandlungen}

Eingriffe in urheberrechtlich geschützte Persönlichkeits- oder Verwertungsrechte können durch Schrankenregelung ( $\$ \$ 44 \mathrm{aff}$. UrhG) oder aufgrund des Einverständnisses des Rechteinhabers gerechtfertigt werden. Diese Rechtfertigungsmöglichkeiten sollen im Folgenden dahingehend überprüft werden, wie viel rechtlicher Freiraum für bildliche Aneignungen gegenwärtig verbleibt.

Als Schrankenregelungen kommen bei bildlichen Aneignungen insbesondere die freie Benutzung gem. $\$ 24 \mathrm{UrhG}^{612}$, das Zitatrecht gem. $\$ 51$ UrhG, die Panoramafreiheit gem. $\$ 59$ UrhG und die erlaubten Nutzungen für Unterricht, Wissenschaft und Institutionen gem. \$60a ff. UrhG in Betracht. Insbesondere das Recht der freien Benutzung und das Zitatrecht stellen sicher, dass die Allgemeinheit Zugang zu fremden Werken hat und eine freie geistige Auseinandersetzung mit diesen Werken stattfinden kann. Beide Vorschriften sind geprägt von der Vorstellung, dass Werke nicht „im luftleeren Raum“ entstehen, sondern immer auf vorangegangenem Werkschaffen aufbauen. ${ }^{613}$ Diese Vorschriften sind daher für Aneignungen von besonderer Relevanz. Die vorübergehende Speicherung

612 Es ist zwar strittig, ob es sich bei $\$ 24$ UrhG um eine Schrankenregelung handelt, da sie nicht im 6. Abschnitt des UrhG geregelt ist. Die Norm rechtfertigt aber ebenso wie Schrankenregelungen Eingriffe in die Rechte des Urhebers und wirkt somit funktional wie eine Schranke, vgl. Dreier/Schulze/Schulze, 6. Aufl. 2018, 24 UrhG Rn. 1; Maier, Remixe auf Hosting-Plattformen, 2018, S. 44; C. Bauer, User-generated Content, 2011, S. 330; a.A. Schutzumfangsbestimmung: BeckOK UrhG/Ablberg, 26. Ed. 2019, $\$ 24$ UrhG Rn. 2; Chakraborty, Das Rechtsinstitut der freien Benutzung im Urheberrecht, 1997, S. 25 f.; Hess, Urheberrechtsprobleme der Parodie, 1993, S.28. Ob es sich dogmatisch also um eine Schrankenregelung oder eine Schutzbereichsbestimmung handelt, hat für diese Arbeit keine Auswirkungen.

613 Dreier/Schulze/Schulze, 6. Aufl. 2018, \$24 UrhG Rn. 1; Wandtke/Bullinger/Bullinger, 5. Aufl. 2019, $\$ 24$ UrhG Rn. 1; Wandtke/Bullinger/Lüft, 5. Aufl. 2019, \51 UrhG Rn. 1. 
von urheberrechtlichen Werken, z.B. im Arbeitsspeicher des Computers, um den Werkgenuss zu ermöglichen oder Inhalte zu übermitteln, ist gem. $\$ 44 a$ UrhG freigestellt. Alle genannten Schrankenregelungen sind gem. $\$ 72$ UrhG auch auf Lichtbilder und gem. $\$ 95,94$ Abs. 4 UrhG auch auf Laufbilder anwendbar.

\section{Aneignung als freie Benutzung gem. $\$ 24$ UrhG}

Wenn eine freie Benutzung gem. $\$ 24$ UrhG $^{614}$ vorliegt, darf das Werk ohne Zustimmung des Urhebers des benutzten Werks veröffentlicht und verwertet werden. Dafür müssen die zwei Tatbestandsvoraussetzungen vorliegen: Es muss erstens ein neues selbständiges Werk vorliegen, das zweitens in freier Benutzung geschaffen wurde. Wie bereits oben bei $\$ 23$ UrhG gesehen, unterscheiden sich diese beiden Tatbestände nach dem Grad der Abweichung vom Original und damit nach der Abstandsbestimmung zum benutzten Werk. Für eine freie Benutzung gem. $\$ 24$ UrhG müssen die genutzten urheberrechtlich geschützten Elemente hinter dem neuen Werk verblassen. ${ }^{615}$ Der Einwilligungsvorbehalt des $\$ 23$ UrhG entfällt also dann, wenn ein Fall des $₫ 24$ UrhG vorliegt. ${ }^{616}$

$\$ 24$ UrhG ist nach herrschender Meinung auch auf die verwandten Schutzrechte anwendbar. ${ }^{617} \$ 72$ UrhG verweist für Lichtbilder direkt auf den gesamten ersten Teil des UrhG und damit auch auf $\$ 24$ UrhG. Bei allen anderen verwandten Schutzrechten fehlen zwar vergleichbare Verweisnormen. ${ }^{618}$ Dennoch wird $\$ 24$ UrhG für Laufbilder ${ }^{619}$ und Tonträger ${ }^{620}$ analog angewandt. Denn das Rechtsinstitut der freien Benutzung dient dazu, kulturelle Schöpfungen zu privilegieren, die auf anderen Schöpfungen aufbauen. Kulturelle Auseinandersetzungen mit bestehendem Material be-

614 Zur Frage, ob $\$ 24$ UrhG unionsrechtswidrig ist, s. S. $281 \mathrm{ff}$.

615 Dazu gleich ausführlicher S. $184 \mathrm{ff}$.

616 S. dazu bereits oben S. 166; Dreier/Schulze/Schulze, 6. Aufl. 2018, $\$ 23$ UrhG Rn. 4; Fischer, Digitale Kunst und freie Benutzung, 2018, S. 65 f.

617 Maier, Remixe auf Hosting-Plattformen, 2018, S. 45; C. Bauer, User-generated Content, 2011, S. 337.

618 Bei $\$ \$ 83,85,87$ und 94 UrhG ist damit von planwidrigen Regelungslücken auszugehen.

619 BGH GRUR 2008, S. 693, 694 Rn. 24 - TV Total; BGH GRUR 2000, S. 703, 704 - Kalkofes Mattscheibe.

620 BGH GRUR 2009, S. 403, 405 Rn. 21 - Metall auf Metall I. 
dürfen dieses Freiraums - ob nun das genutzte Material urheberrechtlich oder leistungsschutzrechtlich geschützt ist. ${ }^{621}$

\section{Neues, selbständiges Werk}

Die Schaffung eines neuen, selbständigen Werkes meint, dass die Aneignung ihrerseits schutzfähig sein muss, also eine persönliche geistige Schöp-

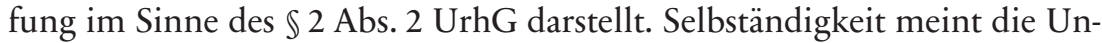
abhängigkeit von den Elementen des benutzten Werkes. ${ }^{622} \mathrm{Ob}$ Werke der Aneignung schutzfähig sind, kommt damit auf den Einzelfall an. Das Teilen von Bildern oder Videos in sozialen Netzwerken allein wird nicht ausreichen, auch nicht in Verbindung mit einem Kommentar. Bei den kurzen Beiträgen fehlt es in der Regel an einer schöpferischen Leistung. ${ }^{623}$ Auch GIFs werden in der Regel nicht ausreichend unabhängig vom benutzten Werk sein, da sie die Bilder oder Videos typischerweise ohne Bearbeitung nutzen, sie lediglich verkürzt darstellen und keine eigenpersönliche Leistung erbracht wird, die der Schöpfungshöhe genügen würde. Anders kann es jedoch bei Bildmontagen, Memes, Museumselfies und viralen Hypes der Fall sein, da hier das angeeignete Werk stärker bearbeitet wird.

Bei Werken der Appropriation Art wird zum Teil die Individualität des Aneignungswerkes in Frage gestellt. ${ }^{624}$ Denn es bestehe keine persönliche Beziehung des Schöpfers zu seinem Werk, nur die des ursprünglichen Schöpfers zum angeeigneten Werk. Dadurch könne die eigene geistige Leistung gegenüber der Aneignung nicht ausreichend hervortreten. Huttenlauch nimmt dies bei solchen Werken der Appropriation Art an, die

621 So auch BVerfG GRUR 2016, S. 690, 693 Rn. 87 - Metall auf Metall. Zwar passt dies nicht so recht zu der Natur der verwandten Schutzrechte, getätigte Investitionen zu schützen. Doch durch die Begründung der Schutzfähigkeit bereits kleinster Teile in den verwandten Schutzrechten wurde der Ausschließlichkeitsschutz weit ausgedehnt, weshalb ein Bedürfnis für die Freihaltung bestimmter kreativer Weiternutzungen erst recht bestehe, so Dreier/Leistner, Urheberrecht im Internet: die Forschungsherausforderungen, GRUR 2013, S. 881, $884 \mathrm{f}$.

622 BGH GRUR 1961, S. 631, 632 - Fernsprechbuch; Dreier/Schulze/Schulze, 6. Aufl. 2018, $\$ 24$ UrhG Rn. 5; Schricker/Loewenheim/Loewenheim, 5. Aufl. 2017, $\mathbb{2} 24$ UrhG Rn. 9.

623 So lehnt auch Ziegler, Urheberrechtverletzungen durch Social Sharing, 2016, S. 172 die Werkqualität von Facebook-Beiträgen ab.

624 Schack, Kunst und Recht, 3. Aufl. 2017, Rn. 358; Huttenlauch, Appropriation Art. Kunst an den Grenzen des Urheberrechts, 2010, S. 99; Schack, Appropriation Art und Urheberrecht, in: FS Nordemann, 2004, S. 107, 108. 
sich auf die identische Übernahme einer Vorlage beschränken, ohne einen neuen Kontext im Bildraum selbst zu schaffen. ${ }^{625}$ Dies sei z.B. bei Sherrie Levines „After Walker Evans“ Reihe von 1981 und bei Princes Serie der abfotografierten Marlboro „Cowboys“ (1980er) der Fall. Diese Argumentation ist wenig nachvollziehbar, da ja durch die Re-Fotografie und das Deutlichmachen der Aneignung im Titel immer ein neuer Kontext geschaffen wird. Zwar erkennt auch Huttenlauch, dass das Neue in der Re-Kontextualisierung und damit einhergehenden Bedeutungsverschiebung des Werkes zu sehen ist. Doch meint sie, dieser Re-Kontextualisierung käme keine eigene Werkqualität zu. ${ }^{626}$ Auch Kakies lehnt das Vorliegen eines persönlichen geistigen Schöpfung bei Werken der Appropriation Art ab, da der geistige Gehalt der Aneignung nicht in der konkreten Werkgestaltung seines Ausdruck finde, da diese ja vom angeeigneten Werk übernommen ist. ${ }^{627}$ Damit liege keine individuelle Form des Aneignungskünstlers vor. Ähnlich argumentiert Schack, wenn er die Schutzfähigkeit der Appropriation Art damit ablehnt, dass hier eine bereits bestehende Form mit einer neuen Idee verknüpft werde - die bestehende Form aber bereits durch den Urheber des angeeigneten Werkes geschützt ist und Ideen alleine gerade nicht schutzfähig seien. ${ }^{628} \mathrm{Um}$ die Schutzfähigkeit der Werke der Appropriation Art feststellen, erscheint es also lohnenswert, die Unterscheidung zwischen Inhalt und Form und den fehlenden Schutz der Idee im Urheberrecht genauer zu analysieren.

a) Idee, Inhalt und Form im Urheberrecht

Aneignungen spielen damit, die gleiche Form des angeeigneten Werkes zu nutzen, damit jedoch einen anderen Inhalt zu vermitteln. Inwieweit Inhalt und Form eines Werkes geschützt sind und ob die Aufladung einer Form mit einer neuen Idee zu einer Schutzfähigkeit der Idee führt, soll im Folgenden geklärt werden. Dazu sollen die Begriffe Idee, Inhalt und Form genauer untersucht werden. Zunächst soll abgegrenzt werden, ob es sich bei Inhalt und Form bloß um eine konkretisierte Interessenabwägung handelt

625 Huttenlauch, Appropriation Art. Kunst an den Grenzen des Urheberrechts, 2010, S. 99.

626 Dies., a.a.O., S. 101.

627 Kakies, Kunstzitate in Malerei und Fotografie, 2007, S. 121.

628 Schack, Appropriation Art und Urheberrecht, in: FS Nordemann, 2004, S. 107, 108. 
oder ob die Begriffe bereits durch eine genaue Prüfung der Individualität eines Werkes ausreichend die Schutzfähigkeit eines Werkes bestimmen lassen.

aa) Inhalt und Form als konkretisierte Interessenabwägung

Die Unterscheidung zwischen Form und Inhalt eines Werkes wird mit dem Urheberrecht als System der Interessenabwägung in Verbindung gebracht. ${ }^{629}$ Die Entscheidung, dass grundsätzlich nur die Form und nicht der Inhalt vom Urheberrecht geschützt ist, stellt einen Ausgleich der verschiedenen Interessen am Urheberrechtswerk dar. ${ }^{630}$ Nicht alle Teile eines Werkes sollen durch das Urheberrecht monopolisierbar sein, sondern der Allgemeinheit zur Verfügung bleiben. ${ }^{631}$ Die Abgrenzung von Inhalt und Form könnte damit als eine besondere Form einer Interessenabwägung des Urheberrechts angesehen werden.

Die Unterscheidung zwischen Inhalt eines Werkes und dessen Form wird in der Literatur zum Teil aufgegeben zugunsten einer allgemeinen Interessenabwägung zur Bewertung der Schutzfähigkeit eines Werkes. So

629 Schack, Urheber- und Urhebervertragsrecht, 9. Aufl. 2019, Rn. 188; Kopp, Die Freiheit der Idee und der Schutz von Schriftwerken, 2014, S. 179 ff.; Stamer, Der Schutz der Idee unter besonderer Berücksichtigung von Unterhaltungsproduktionen für das Fernsehen, 2007, S. 36; Berking, Die Unterscheidung von Inhalt und Form im Urheberrecht, 2002, S. 18; Pabud, Zur Begrenzung des Urheberrechts im Interesse Dritter und der Allgemeinheit, UFITA 2000/I, S. 99, 121; Ulmer, Urheber- und Verlagsrecht, 3. Aufl. 1980, S. 122.

630 Der Urheber hat zunächst ein Vergütungsinteresse. Er will sein Werk wirtschaftlich verwerten, damit er die Kosten und die Arbeit, die er für das Werkschaffen aufgewendet hat, aufwiegen kann. Weiterhin hat der Urheber ideelle und persönliche Interessen an dem Werk, da es seine individuellen Züge trägt. Die Allgemeinheit hingegen hat Interesse an einem möglichst umfassenden Zugang zu dem Werk zu möglichst geringen Kosten. Mit der Veröffentlichung wird das Werk zudem Kulturgut: Es tritt aus dem privaten Bereich heraus und prägt das kulturelle und geistige Bild der Zeit. Dennoch hat die Allgemeinheit auch ein Interesse am Entstehen vielzähliger unterschiedlicher Kulturgüter und damit am Schaffen von urheberrechtlichen Werken. Vgl. zu diesen Interessenlagen auch ausführlicher Schack, Urheber- und Urhebervertragsrecht, 9. Aufl. 2019, Rn. 10; Rehbinder/Peukert, Urheberrecht, 18. Aufl. 2018, Rn. 50 ff., 67 ff.; Pahud, Zur Begrenzung des Urheberrechts im Interesse Dritter und der Allgemeinheit, UFITA 2000/I, S. 99, 118 und siehe hierzu auch die Strategien zur Freiraumschaffung im Urheberrecht ab S. $227 \mathrm{ff}$.

631 Rehbinder/Peukert, Urheberrecht, 18. Aufl. 2018, Rn. 68. 
will Haberstumpf die von ihm so bezeichnete „Paradoxie der Form“632 überwinden, indem durch eine allgemeine Interessenabwägung im Einzelfall ermöglicht würde, auch den geistigen Gehalt eines Werkes zu schützen und damit auch Inhalte - und nicht bloß die Form. ${ }^{63}$

Der Interessenkonflikt zwischen Urheber und Allgemeinheit liegt der Unterscheidung zwischen Inhalt, Idee und Form zugrunde. Die Entscheidung, dass nur die Form eines Werkes geschützt ist, ist jedoch bereits eine Konkretisierung der allgemeinen Interessenabwägung von Urheber und Allgemeinheit. Die verschiedenen Interessen stellen also nur den zugrundeliegenden Interessenkonflikt dar. ${ }^{634}$ Die Entscheidung, zwischen Idee, Inhalt und Form eines Werkes zu trennen, soll jedoch als Hilfe bei dieser Interessenabwägung dienen. Deshalb sollte die konkretisierte Abwägung nicht wiederum durch eine allgemeine ersetzt werden. Vielmehr zeigt sich, dass die konkretisierten Begriffe der Idee, Inhalt und Form noch nicht ausreichend Klarheit schaffen und eine genauere Definition notwendig ist. Bei einer Spezifizierung und Definition dieser Begriffe muss aber wiederum die allgemeine Interessenlage zwischen Urheber und Allgemeinheit berücksichtigt werden.

\section{bb) Inhalt und Form als fehlende Individualität}

Von einigen Stimmen in der Literatur wird die Unterscheidung zwischen Idee, Inhalt und Form als undefinierbar und unbrauchbar abgelehnt. ${ }^{635}$ Unter einer Idee verstehe man ohnehin schon solch allgemeine Gedanken oder Grundsätze, dass diese häufig nicht die erforderliche Individualität

632 Er meint damit die Paradoxie, dass fiktionale Figuren zwar keine sinnlich wahrnehmbare Formgestaltung haben, aber dennoch urheberrechtlich schutzfähig sind, obwohl ein geschütztes Werk nur dann vorliege, wenn eine sinnlich wahrnehmbare Formgestaltung vorgenommen wurde, Haberstumpf, Die Paradoxien des Werkbegriffs, ZGE 2012, S. 284, 291.

633 Haberstumpf, Handbuch des Urheberrechts, 2. Aufl. 2000, Rn. 88; ders., Die Paradoxien des Werkbegriffs, ZGE 2012, S. 284, 319.

634 So auch Berking, Die Unterscheidung von Inhalt und Form im Urheberrecht, 2002, S. 18.

635 Schack, Urheber- und Urhebervertragsrecht, 9. Aufl. 2019, Rn. 188; Kopp, Die Freiheit der Idee und der Schutz von Schriftwerken, 2014, S. 260 f.; Berking, Die Unterscheidung von Inhalt und Form im Urheberrecht, 2002, S. 55; Haberstumpf, Zur Individualität wissenschaftlicher Sprachwerke, 1982, S.60; Ulmer, Urheber- und Verlagsrecht, 3. Aufl. 1980, S. 122. 
aufweisen können. ${ }^{636}$ Daher wird immer wieder vertreten, dass die Unterscheidung zwischen schutzloser Idee, Inhalt und schutzfähiger Form hinfällig sei und die Funktion dieser Unterscheidung ebenso gut durch eine saubere Prüfung der Individualität eines Werkes abgedeckt werden könne. ${ }^{637}$ Die individuellen Züge des Werkes seien per se so sehr von der Persönlichkeit geprägt, dass sie urheberrechtlich schutzfähig seien, wohingegen die nicht individuellen Züge für die Allgemeinheit weiterhin zur Verfügung stünden. ${ }^{638}$

Dies führt jedoch zu einem Zirkelschluss. Denn die Individualität als Abgrenzung zwischen Gemeingut und Individuellem besagt nur, dass das Urheberrecht nichtindividuelle Teile nicht schützt. Dies ist zwar richtig, hilft für eine genauere Bestimmung des Schutzgegenstandes allerdings nicht weiter. Diese Literaturmeinung gibt lediglich den Wortlaut des $\$ 2$ Abs. 2 UrhG wieder und führt damit zu nicht mehr als der Aussage, dass das Urheberrecht nicht schützt, was es nicht schützt - einer Tautologie. ${ }^{639}$ Eine Ersetzung der Begriffe Inhalt und Form durch den ebenso auslegungsbedürftigen Begriff der Individualität erscheint nicht weiterführend.

cc) Begrifflichkeiten: Idee, Inhalt und Form

Weder der Grundsatz der fehlenden Schutzfähigkeit der Idee noch der der Dichotomie von Inhalt und Form sind gesetzlich normiert. Es handelt sich also um ungeschriebene Grundsätze des Urheberrechts. \$69a Abs. 2 S. 2 UrhG hält jedoch fest, dass Ideen und Grundsätze, die einem Element eines Computerprogramms zugrunde liegen, nicht geschützt sind. Sollte dies zum Umkehrschluss führen, dass bei Fällen des $\$ 2$ Abs. 2 UrhG Ideen schutzfähig sind? Vielmehr scheint $\$ 69$ a Abs. 2 S. 2 UrhG klarstellenden Charakter zu haben und ist auf die Übernahme der Formulierung des Art. 1 Abs. 2 S. 2 der RL 2009/24/EG über den Rechtsschutz von Computerprogrammen (ComputerprogrammRL) zurückzuführen.

636 Schricker/Loewenheim/Loewenheim, 5. Aufl. 2017, \$2 UrhG Rn. 73.

637 So Schack, Urheber- und Urhebervertragsrecht, 9. Aufl. 2019, Rn. 188.

638 Vgl. Ulmer, Urheber- und Verlagsrecht, 3. Aufl. 1980, S. 122.

639 So auch Sellnick, Der Gegenstand des Urheberrechts, 1995, S. 33. 
Der Grundsatz der schutzlosen Idee besagt, dass Urheberschutz erst beginnt, wenn die Idee eine konkrete Gestalt angenommen hat. ${ }^{640}$ Auch in den Fällen des schutzlosen Inhalts heißt es, dieser Inhalt sei nur in seiner konkreten Ausgestaltung, seiner Form, schutzfähig. ${ }^{641}$ Häufig wird der Begriff der Idee jedoch als Synonym zu dem des Inhalts verwendet. ${ }^{642}$ Daher sollen die drei Begriffe Idee, Inhalt und Form nun genauer erläutert werden.

Als Idee werden in der Literatur allgemeine Gedanken oder Gedankensplitter bezeichnet, die häufig nicht die erforderliche Individualität aufweisen. ${ }^{643}$ Hier zeigt sich abermals, wie sehr diese Begriffe als zusätzliche Interessenabwägung oder Prüfung der Individualität verstanden werden. Unter Idee wird aber darüber hinaus auch die geistige Grundlage eines Werkes verstanden, alle abstrakt hinter dem Werk stehenden Gedanken, Motive, Stoffe, Thematiken, Theorien. ${ }^{644}$ Diese Idee muss schutzlos bleiben, da sie noch keinerlei wahrnehmbare Form angenommen hat - es fehlt also noch am Rechtsobjekt. ${ }^{645}$ Wenn man bereits die Idee schützen würde, dann wäre die Werkschaffung, also die gegenständliche Form, bereits die erste Vervielfältigung des Werkes. Das kann nicht gewollt sein.

640 OLG Hamburg ZUM 2002, S. 647, 653 - Brown Girl II; Dreier/Schulze/Schulze,

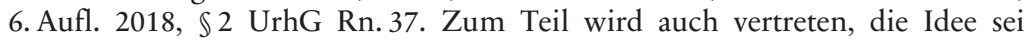
schutzfähig, aber das Freihaltungsinteresse der Allgemeinheit gestatte die Vervielfältigung und Bearbeitung, um sich mit der Idee auseinanderzusetzen als ungeschriebene gesetzliche Lizenz, vgl. Oechsler, Die Idee als persönliche geistige Schöpfung, GRUR 2009, S. 1101, 1106.

641 Dreier/Schulze/Schulze, 6. Aufl. 2018, $\$ 2$ UrhG Rn. 43. Die Unterscheidung von Inhalt und Form geht zurück auf Fichte, Beweis der Unrechtmäßigkeit des Büchernachdrucks [1793], UFITA 106 (1987), S. 155 ff.

642 Berking, Die Unterscheidung von Inhalt und Form im Urheberrecht, 2002, S. 31; Dreier/Schulze/Schulze, 6. Aufl. 2018, $\$ 2$ UrhG Rn. 43; Feudner, Die Möglichkeiten eines Ideenschutzes nach deutschem und englischem Recht, 1966, S. 20 ff. Dieses Verständnis liegt wohl auch BGH GRUR 2011, S. 134, 137 Rn. 36 - Perlentaucher zugrunde, wenn aus der Notwendigkeit geistiger Auseinandersetzung mit dem Inhalt auf die Schutzlosigkeit der Idee geschlossen wird, so auch Kopp, Die Freiheit der Idee und der Schutz von Schriftwerken, 2014, S. 137.

643 Haberstumpf, Handbuch des Urheberrechts, 2. Aufl. 2000, Rn. 82.

644 Feudner, Die Möglichkeiten eines Ideenschutzes nach deutschem und englischem Recht, 1966, S. 21.

645 Schack, Urheber- und Urhebervertragsrecht, 9. Aufl. 2019, Rn. 187. Ohne eine wahrnehmbare Form kann auch keine Abstraktion vorgenommen werden. Daraus folgt: „Was allein in der Phantasie des Schöpfers lebt, ist urheberrechtlich irrelevant.", Haberstumpf, Handbuch des Urheberrechts, 2. Aufl. 2000, Rn. 71. 
Der Inhalt wird oft als das Mitgeteilte beschrieben und die Form als die Art und Weise der Mitteilung. ${ }^{646}$ Berking bezeichnet den Inhalt als das, was gleichbleibt, wenn sich das äußere Erscheinungsbild ändert. ${ }^{647}$ Diese Definition passt jedoch nicht auf Werke der Kunst, Fotografie oder des Films, die vom äußeren Erscheinungsbild auch inhaltlich maßgeblich geprägt sind. ${ }^{648}$ Hubmann versteht unter Inhalt dasjenige, was der Geist des Urhebers in sich aufgenommen, verarbeitet und einem Ausdrucksmittel anvertraut hat, um es anderen mitzuteilen. ${ }^{649}$ Der Inhalt ist damit eine bereits eingetretene Konkretisierung der Idee, ein Bezug auf die tatsächliche Welt.

Idee und Inhalt stellen damit verschiedene Abstufungen einer Konkretisierung des Werkes dar. Eine Idee kann im Inhalt oder in der Form eines Werkes konkretisiert werden. Sie kann gewissermaßen als Vorstufe zu beidem betrachtet werden und sich auf beides gleichermaßen beziehen. ${ }^{650}$ Die Idee bezeichnet damit solche Elemente, die nicht hinreichend konkretisiert sind, sondern noch einen hohen Abstraktionsgrad aufweisen. ${ }^{651}$ Eine hinreichende Konkretisierung der Idee kann immer dann vorliegen, wenn ausreichend Gestaltungsspielraum verbleibt: Gibt es mehrere Möglichkeiten, eine Idee auszuführen, ist dies ein Indiz für die Schutzfähigkeit der jeweils konkreten Ausgestaltung. ${ }^{652}$ Es ist also zu prüfen, ob im konkreten Fall ein Gestaltungsspielraum für die Ausführung der Idee besteht, der nicht bekannt, naheliegend, technisch-bedingt oder anderweitig vorgegeben ist, wie groß dieser Gestaltungsspielraum ist, und ob vom ihm in individueller Weise Gebrauch gemacht wurde. ${ }^{653}$ Die Bestimmung der hinreichenden Konkretisierung folgt damit auch generellen Abwägungsinter-

646 De Boor, Urheberrecht und Verlagsrecht, 1917, S. 73; Haberstumpf, Die Paradoxien des Werkbegriffs, ZGE 2012, S. 284, 316: Bei Romanen sei das, was erzählt wird, der Inhalt, und die Art und Weise der Erzählung die Form.

647 Berking, Die Unterscheidung von Inhalt und Form im Urheberrecht, 2002, S. 35

$648 \mathrm{Zu}$ der starken Verbundenheit von Inhalt und Form bei Bildwerken sogleich noch detailliertere Ausführungen, S. $176 \mathrm{f}$.

649 Hubmann, Urheber- und Verlagsrecht, 1978, S. $31 \mathrm{f}$.

650 Kopp, Die Freiheit der Idee und der Schutz von Schriftwerken, 2014, S. 139.

651 Dies., a.a.O., S. 288.

652 Dreier/Schulze/Schulze, 6. Aufl. 2018, \$2 UrhG Rn. 37; auch Schack, Kunst und Recht, 3. Aufl. 2017, Rn. 11 macht deutlich, dass mit Konkretisierung nicht etwa die Materialisierung im Sinne einer Fixierung des Werkes „in any tangible medium of expression" gemeint ist, wie sie das U.S.-amerikanische Urheberrecht in $\$ 102$ (a) Copyright Act, 1976 fordert.

653 Dreier/Schulze/Schulze, 6. Aufl. 2018, $\$ 2$ UrhG Rn. 49. 
essen der Unterscheidung zwischen Gemeingut und individuellen Zügen eines Werkes.

Die Form bezeichnet die wahrnehmbare Konkretisierung des Inhalts. Wie oben bereits erwähnt, wird sie häufig als die Art und Weise der Mitteilung des Inhalts beschrieben. In der Literatur unterscheidet man zwischen innerer und äußerer Form eines Werkes. ${ }^{654}$ Die äußere Form ist die Ausdrucksweise, in der der geistige Gehalt für die Sinne unmittelbar wahrnehmbar vermittelt wird. ${ }^{655}$ Die innere Form ist die Art und Weise der Aneinanderreihung und Verbindung der einzelnen Gedanken und Ideen, der Geschehnisablauf, die Ausgestaltung der Charaktere, die Bildabfolge oder das Konzept, also die innere Ordnung der schöpferischen Leistung. ${ }^{656}$ Beide sind gleichermaßen urheberrechtlich schutzfähig.

\section{dd) Abkehr von der Dichotomie von Inhalt und Form}

Die Unterscheidung von Form und Inhalt eines Werkes ist jedoch nicht sinnvoll und kaum möglich. ${ }^{657}$ Die Inhalte beeinflussen die Formgebung und diese die Inhalte. Wird die Form ausgetauscht, ändert sich auch der Inhalt. ${ }^{658}$ Die Einheit des Werkes wird zerstört, wenn man eins vom anderen trennen wollte. ${ }^{659}$ Insbesondere bei Bildwerken ist die Verbindung von Idee und Form sehr stark - und nochmals stärker bei abstrakter Kunst. Denn in der abstrakten Kunst besteht kein Korrelat der Form in der tatsächlichen Welt; es gibt keinen Bezugspunkt, sodass die Form dort auch immer gleichzeitig der Inhalt ist. Aber auch bei sonstigen Bildern und

654 Unterscheidung nach Kohler, Die Idee des geistigen Eigentums [1887], UFITA 123 (1993), S. 81-167; Hubmann, Das Recht des schöpferischen Geistes, 1954, S. 26 ff.; de Boor, Urheberrecht und Verlagsrecht, 1917, S. 84; Ulmer, Urheberund Verlagsrecht, 3. Aufl. 1980, S. 120; Rehbinder/Peukert, Urheberrecht, 18. Aufl. 2018, Rn. 152.

655 Kohler, Das Autorrecht, 1880, S. $166 \mathrm{ff}$.

656 Kobler, Das Autorrecht, 1880, S. 168 f.; Hubmann, Das Recht des schöpferischen Geistes, 1954, S. 26; Haberstumpf, Zur Individualität wissenschaftlicher Sprachwerke, 1982, S. 55.

657 Troller, Immaterialgüterrecht Bd. I, 1983, S. 372 f.; Kummer, Das urheberrechtlich schützbare Werk, 1968, S. 20; Kopp, Die Freiheit der Idee und der Schutz von Schriftwerken, 2014, S. 124; Berking, Die Unterscheidung von Inhalt und Form im Urheberrecht, 2002, S. 34; Elster, Idee und Formgebung, UFITA 8 (1935), S. 44, 45.

658 Troller, Immaterialgüterrecht Bd. I, 1983, S. 372.

659 Haberstumpf, Die Paradoxien des Werkbegriffs, ZGE 2012, S. 284, 316. 
Werken der Kunst bilden nichtdeskriptive Bedeutungselemente, die der Form zugerechnet werden, eine wichtige Rolle für den Inhalt. ${ }^{660}$ Neben dem Inhalt des Gemäldes beeinflussen die verwendeten Farben, Linien, Formen und die Komposition den Ausdruckscharakter des Bildes und würden ihn bei geringfügigen Änderungen im Ganzen verändern. ${ }^{661}$ Bei Bild- und Kunstwerken lassen sich Form und Inhalt also nicht voneinander trennen. ${ }^{662}$

In der Literatur herrscht bereits die Meinung, dass sich die Dichotomie von Form und Inhalt nicht aufrechterhalten lasse. In der Rechtsprechung wird zwar noch an ihr festgehalten, doch das lässt sich wohl auch damit erklären, dass hier nicht klar zwischen dem Grundprinzip der Schutzlosigkeit der Idee und dem der Dichotomie von Inhalt und Form unterschieden wird und sich die Ausführungen zum nicht schutzfähigen Inhalt wohl eher auf das beziehen, was unter Idee eines Werkes verstanden wird. ${ }^{663} \mathrm{Zu}$ mal der Inhalt eines Werkes bereits durch Urteile anerkannt wurde. So ist der Schutz der Fabel bei literarischen Werken bereits anerkannt ${ }^{664}$, ebenso der Schutz eines Konzepts, sofern es hinreichend konkretisiert und individuell ist ${ }^{665}$, und der Schutz erfundener Figuren ${ }^{666}$. Hier wird auch die Abgrenzung der inneren Form vom Inhalt eines Werkes deutlich schwierig:

660 Ders., Handbuch des Urheberrechts, 2. Aufl. 2000, Rn. 77.

661 Ders., a.a.O., Rn. 78. Zur Wirkung der Form auf den Inhalt eines Kunstwerkes, s. von Hildebrand, Das Problem der Form in der Bildenden Kunst, 1893, und Panofsky, Sinn und Deutung in der bildenden Kunst, 1975.

662 Haberstumpf, Handbuch des Urheberrechts, 2. Aufl. 2000, Rn. 77 f.; Kummer, Das urheberrechtlich schützbare Werk, 1968, S. 34; Ulmer, Urheber- und Verlagsrecht, 3. Aufl. 1980, S. 120; Schricker/Loewenheim/Loewenheim, 5. Aufl. 2017, \2 UrhG Rn. 53; Kummer, Das urheberrechtlich schützbare Werk, 1968, S. 16 f., 20; Kehrli, Der urheberrechtliche Werkbegriff im Bereich der bildenden Kunst, 1989, S. 16 f.

663 So in BGH GRUR 2011, S. 134, 137 Rn. 36 - Perlentaucher, siehe bereits oben, da hier die Idee als Synonym verwendet wird für den Inhalt, vgl. Kopp, Die Freiheit der Idee und der Schutz von Schriftwerken, 2014, S. 137; Haberstumpf, Anmerkungen zu BGH, Urteil vom 1. Dezember 2010 - I ZR 12/08 - Perlentaucher, ZUM 2011, S. 158, 159.

664 KG GRUR 1926, S. 441, 442 - „Alt-Heidelberg - Jung-Heidelberg“. Und für den inneren Handlungskern eines Romans OLG München ZUM 1999, S. 149, 151 Das doppelte Lottchen.

665 OLG München GRUR 1990, S. 674, 675 - Forsthaus Falkenau.

666 BGH GRUR 2014, S. 258, 260 Rn. 29 - Pippi-Langstrumpf-Kostüm; BGH GRUR 1994, S. 206, 207 - Alcolix, wonach nicht nur die Darstellung der Figur, sondern auch die zugrunde liegenden Gestalten als solche schutzfähige seien; LG Hamburg ZUM 2003, S. 403, 406 - Die Päpstin. 
Was ist noch Art und Weise der inneren Gedanken, was sind bereits die Gedanken? Was ist noch Konzept der Charaktere, was ist bereits der Charakter?

ee) Zwischenfazit

Die Dichotomie von Inhalt und Form lässt sich mit den angestellten Überlegungen nicht beibehalten und sollte aufgegeben werden. Dies lässt sich auch auf die amtliche Begründung zum Urheberrecht stützen, nach der sowohl Inhalt als auch Form die Schutzfähigkeit begründen sollen können. ${ }^{667}$ Und was die Schutzfähigkeit begründet, muss auch Schutzinhalt sein. Der Grundsatz der Schutzlosigkeit der Idee hingegen lässt sich nachvollziehen und sollte aufrechterhalten werden. Die Unterscheidung von schutzloser Idee und bereits schutzfähigem Inhalt ist anhand der Konkretisierung des Werkes festzumachen, die wiederum abhängig vom Gestaltungsspielraum ist, der bei der Konkretisierung bestehen kann.

b) Schutz der Idee bei Appropriation Art?

Werke der Appropriation Art übernehmen die Form des angeeigneten Werkes, wollen damit jedoch einen anderen Inhalt als das angeeignete Werk vermitteln. Daher wird in der Literatur, insbesondere von Schack, häufig vorgebracht, die Werke der Appropriation Art seien nicht schutzfähig, denn eine Kopie könne nie zu einem schutzfähigen Werk werden, indem ihr eine andere Idee unterlegt wird, denn die Idee sei nie schutzfähig, auch nicht die Idee, den Originalitätsbegriff zu kritisieren. ${ }^{668}$ Bei Schack werden die Begriffe Idee und Inhalt nicht definiert und auch nicht sauber voneinander getrennt. Vielmehr scheint er auch eigentlich den Inhalt eines Werkes zu meinen und nicht die Idee - und damit läuft auch sein Argument leer, denn der Inhalt eines Werkes kann durchaus schutzfähig sein.

Es kommt also vielmehr darauf an, ob sich die Idee der Appropriation Art in dem Werk - entweder im Inhalt oder in der Form - hinreichend konkretisiert hat. Die Konkretisierung ist unabhängig davon, ob die Form

667 BT-Drs. IV/270, S. 38.

668 Schack, Kunst und Recht, 3. Aufl. 2017, Rn. 359; ders., Appropriation Art und Urheberrecht, in: FS Nordemann, 2004, S. 107, 113. 
eines Werkes übernommen wird oder neu geschaffen wird. Die Idee bezeichnet, wie oben gesehen, solche Elemente des Werkes, die nicht hinreichend konkretisiert sind, sondern noch einen hohen Abstraktionsgrad aufweisen. Daher soll nun untersucht werden, ob bei der Appropriation Art eine Formgebung stattgefunden hat und ob ein ausreichender Gestaltungsspielraum vorliegt, sodass eine Konkretisierung anzunehmen ist. Zuletzt soll im Rahmen der Konkretisierung auch eine Interessenabwägung zwischen Gemeingut und individuellen Zügen des angeeigneten Werkes vorgenommen werden.

Nach Kakies scheitert die Schutzfähigkeit der Appropriation Art daran, dass die Idee der Appropriation Art nicht ausreichend sinnlich wahrnehmbar gemacht wurde, also keine ausreichende Formgebung des Werkes vorgenommen wurde. ${ }^{669}$ Der geistige Gehalt finde in den konkreten Werken der Appropriation Art nicht seinen Ausdruck, sondern könne erst durch Kenntnis der Theorie der Appropriation Art verstanden werden, die allerdings außerhalb der konkreten Formgestaltung liege. ${ }^{670}$ Der Appropriation Art kann aber fehlende Formgebung nicht vorgeworfen werden. Denn ein Werkexemplar, indem sich eine Idee konkretisieren könnte, liegt in jedem Fall vor. In der Appropriation Art wird gerade kein vorgefundener Gegenstand genutzt, sondern das Werk beim Kopieren selbst geschaffen der Arbeitsprozess fällt keineswegs weg. Die Unterscheidung zur Idee eines Werkes meint schwerpunktmäßig dessen Konkretisierung in einer Form, sodass kein Werk abstrakt nur in Gedanken besteht. ${ }^{671}$ Kakies missversteht zudem die sinnliche Wahrnehmbarkeit: Es geht nicht darum, dass ein Werk aus sich heraus verständlich ist und der Bezug zu den zugrundeliegenden künstlerischen Theorien aus der Form ersichtlich ist. Ebenso wenig wie Werke der Appropriation Art lassen Gedichte, Musik oder andere urheberrechtlich schutzfähige Werke schon aus ihrer konkreten Formgestaltung kunsttheoretische und philosophische Theorien zu ihren Hintergründen ableiten. Im Gegenteil: Bei welchen Werken, wenn nicht bei solchen der Appropriation Art, lässt sich die Kunsttheorie direkt erkennen hier wird der Angriff des Originals und die künstlerische Strategie der Aneignung doch gerade auch äußerlich kenntlich gemacht!

669 Kakies, Kunstzitate in Malerei und Fotografie, 2007, S. 121.

670 Dies.a.a.O.

671 Ausführlich zur Konkretisierung und der Bedeutung der Unterscheidung zwischen Idee und Form: Kopp, Die Freiheit der Idee und der Schutz von Schriftwerken, 2014, S. 217 ff., 253 f.; Berking, Die Unterscheidung von Inhalt und Form im Urheberrecht, 2002, S. $50 \mathrm{f}$. 
Ob es sich bei der Appropriation Art also noch um eine schutzlose, abstrakte Idee oder bereits um einen schutzfähigen Inhalt handelt, hängt davon ab, ob konkret ausreichend Gestaltungsspielraum für die Ausführung der Idee besteht.

Es spricht nicht schon gegen eine Konkretisierung der Idee, dass die Appropriation Art abstrakte Kunst ist und bereits dadurch ein hoher Abstraktionsgrad der Werkelemente verbleibt (der für das Vorliegen einer schutzlosen Idee sprechen würde). Die abstrakte Kunst setzt sich gerade mit der Analyse der Kunst selbst und ihrer Prozesse auseinander. Sie soll erkunden, was Kunst überhaupt ist, wie Bilder funktionieren, und nutzt dafür neue Darstellungsformen. ${ }^{672}$

Eine hinreichende Konkretisierung einer Idee liegt dann vor, wenn noch ausreichend Gestaltungsspielraum verbleibt, es also mehrere Möglichkeiten gibt, eine Idee auszuführen. ${ }^{673}$ Die Appropriation Art kann auf viele verschiedene Art und Weise vorgenommen werden - die Vielfalt ihrer Möglichkeiten wird durch ihre vielen Ausformungen durch unterschiedliche Künstler verdeutlicht. Der Grad der Übernahme ist nicht immer derselbe. So umfassen Werke der Appropriation Art sowohl solche, die das angeeignete Werk parodistisch überzeichnend aufgreifen wie bei Koons, solche, die es re-kontextualisieren wie bei Princes Instagram „New Portraits" (2014) und solche, die möglichst originalgetreu bleiben und die die Aneignung nur anhand des Titels erkennbar machen wie bei Levines Walker Evans Fotografien (1981) oder Sturtevants "Warhol Flowers“ (1964/65). Zum Teil wird das Äußere stark verändert wie bei Koons „String of Puppies“ (1988), zum Teil wird sogar auf die gleichen Werkzeuge zurückgegriffen wie bei Sturtevants „Warhol Flowers“ (1964/65), die die gleichen Schablonen für die Siebdrucke wie Warhol nutzte. ${ }^{674}$ Zur Ausführung der Appropriation Art besteht also ein Gestaltungsspielraum, der nicht naheliegend ist oder sich zwangsläufig daraus ergibt, dass es sich um Appropriation Art handeln soll. Was jedoch den Gestaltungsspielraum einschränkt, ist die Notwendigkeit der Übernahme eines fremden Werkes. Welches das ist, bleibt wiederum frei: Es kann sich um berühmte Künstler wie Warhol, professionelle Fotografen wie Patrick Cariou oder um unbekannte Nutzer sozialer Medien wie bei Princes „New Portraits“ (2014) handeln. Der Gestaltungsspielraum dessen, wie die Idee der Appropriation Art konkretisiert werden kann, ist damit breit gefächert. Er ist nicht allein

672 Siehe ausführlicher dazu bereits S. $94 \mathrm{ff}$.

673 S.o. S. $175 \mathrm{f}$.

674 Vgl. dazu S. 49. 
dadurch eingeschränkt, dass die Werke der Appropriation Art die Strategie der Aneignung nutzen. Damit geht es bei der Appropriation Art nicht um den Schutz der Idee, wie von Schack behauptet, sondern um den des Inhaltes. Und der ist nicht per se schutzlos, sondern kann unter bestimmten Umständen auch geschützt werden.

Des Weiteren ist zu prüfen, ob vom Gestaltungsspielraum auch auf individuelle Weise Gebrauch gemacht wurde. Dies entspricht einer generellen Abwägung zwischen Gemeingut und individuellen Zügen eines Werkes. Hierbei ist jedoch insbesondere zu berücksichtigen, dass die Übernahme für die Appropriation Art eine künstlerische Notwendigkeit ist. Die individuellen Züge des angeeigneten Werkes müssen übernommen werden, sonst funktioniert die Appropriation Art nicht: Sie bedarf der Wiedererkennung des Originals. Auch reine Re-Kontextualisierungen und 1:1-Übernahmen, die alle individuellen Züge des angeeigneten Werkes weiterhin beinhalten, können daher grundsätzlich schutzfähig sein. ${ }^{675}$ Die Frage, ob bei solchen 1:1-Übernahmen eine Ausbeutung des Originals stattfindet, ist nicht eine der Schutzfähigkeit, sondern des Abstandes im Rahmen des \$24 UrhG. Daher soll die Appropriation Art nicht an der Voraussetzung des neuen, selbständigen Werkes scheitern, sondern die Abstandsprüfung des $\$ 24$ UrhG sollte zur Verhinderung des Missbrauchs von Aneignungen die Prüfung beinhalten, ob lediglich der Wert des Originals ausgebeutet wurde oder ob die Eigenständigkeit der Aneignung überwiegt. ${ }^{676}$

Es könnte auch überlegt werden, die Appropriation Art als Sprachwerke zu schützen. Bei literarischen Werken geht es auf ähnliche Wiese um den Schutz der Metaebene (z.B. bestimmte Charaktere), unabhängig von der konkreten Form (z.B. Schutz des Charakters auch über die genauen Sätze hinaus, die den Charakter beschreiben). Bei Werken der Appropriation Art ist dieser abstrakte Inhalt ähnlich bedeutsam. Schrift und abstrakte Kunst ähneln sich in der Hinsicht, dass sie keine Struktur in der empirischen Realität vermitteln. Schriftzeichen sind ebenso ein theoretisches Konstrukt und werden lediglich als Medium genutzt - wie die Bilder, die genutzt werden, um Inhalte der Appropriation Art zu vermitteln. Denn auch dort geht es nicht mehr um das Bild an sich, sondern dieses Bild wird

675 Anders Huttenlauch, Appropriation Art. Kunst an den Grenzen des Urheberrechts, 2010, S. 100.

676 Siehe dazu S. 199 ff. 
lediglich als Medium genutzt. Beides sind Medien der Repräsentation. ${ }^{677}$ Beiden liegt auch ein ähnlicher Zeichengebrauch zugrunde: Bei abstrakter Kunst handelt es sich nicht mehr um Ikonen (Abbildungen), sondern um Symbole; ebenso bei Schriftzeichen. ${ }^{678}$ Der Zusammenhang von Zeichen und Bezeichnetem ist eine generalisierende Abstraktion, sie entsteht aus dem Kontext. ${ }^{679}$ Das abstrakte Kunstwerk hat keinen immanenten BildZeichen-Zusammenhang, wie er sich bei gegenständlichen Darstellungen beobachten lässt. ${ }^{680}$ Es wird damit zu einem Symbol, dessen Verständnis abhängig von der Kontextualisierung ist. Dieser Fokus auf den Inhalt und die abstrakten Merkmale des Werkes ist bei der Schutzfähigkeit von literarischen Werken bereits anerkannt. Indem man Appropriation Art ähnlich als System von Symbolen versteht, kann auch hier ein Schutz des Inhalts erreicht werden.

\section{c) Bei viralen Hypes: Schutz des Konzepts?}

Viralen Hypes liegt ein Konzept zugrunde, aus dem sich gestalterische Kriterien für Videos dieses Typs ergeben. Dies kann beispielsweise die Komposition, die Handlung oder die Bildabfolge betreffen. Jedes Video dieses viralen Hypes erfolgt nach diesem Konzept, und Abweichungen werden nur außerhalb des vorgeschriebenen Konzepts vorgenommen. Das Konzept wird jedoch in der Regel nicht schutzfähig sein, da dies meist schon daran scheitert, dass kein Werkexemplar besteht; denn das Konzept wird nicht festgehalten. Das erste virale Video könnte jedoch als Werkexemplar des Konzepts angesehen werden. Dennoch kommt auch dann Urheberrechtsschutz selten in Betracht, da das Konzept viele verschiedene Ausführungen und einen hohen Gestaltungsspielraum zulässt, von dem noch kein Gebrauch gemacht wurde. Nur wenn die Realisierungsanweisungen

677 Krämer, „Schriftbildlichkeit“ oder: Über eine (fast) vergessene Dimension der Schrift, in: Krämer/Bredekamp (Hrsg.), Bild, Schrift, Zahl, 2. Aufl. 2009, S. 157, 168.

678 „Sprache und Bild sind als disjunke symbolische Ordnungen zu verstehen.“, so Krämer, „Schriftbildlichkeit“ oder: Über eine (fast) vergessene Dimension der Schrift, in: Krämer/Bredekamp (Hrsg.), Bild, Schrift, Zahl, 2. Aufl. 2009, S. 157, 157.

$679 \mathrm{Zu}$ den Unterscheidungen der Zeichen Ikon, Symbol und Index siehe bereits S. $43 \mathrm{f}$.

680 Wunsch, Schriftenwelten zwischen Konstruktion und Ästhetik, 2012, S. 186. 
hinreichend konkret sind, können sie schutzfähig sein. Ansonsten sind die Konzepte hinter viralen Hypes als bloße Ideen nicht schutzfähig.

\section{d) Schutz des Metatextes eines Memes?}

Hinter Memes steht ein Metatext, der die abstrakten Eigenschaften, wie das Meme inhaltlich und formal genutzt wird, wie man es korrekt ergänzt und erweitert, umfasst. ${ }^{681}$ Hier stellt sich ebenso wie bei viralen Hypes das Problem des Werkexemplars: Auch hier wird der Metatext nur in seltenen Fällen festgehalten worden sein, sodass die Schutzfähigkeit zumeist schon am konkreten Werkexemplar scheitern wird. Ebenso wie das Konzept des viralen Hypes wird der Metatext außerdem zu unkonkret sein, um als schutzfähiger Inhalt qualifiziert werden zu können. Vielmehr lässt er noch so viel Gestaltungsspielraum zu, dass es sich um ein abstrakt hinter dem möglichen Werkexemplar stehendes Konstrukt handelt und damit um eine bloße Idee.

\section{e) Fazit}

Wie gesehen, werden die Begriffe Idee, Inhalt und Form häufig unklar oder falsch verwendet. Insbesondere Inhalt und Idee eines Werkes werden immer wieder vermischt. Darauf ist auch das Argument zurückzuführen, mit der Schutzfähigkeit der Appropriation Art würde die bloße Idee urheberrechtlich schutzfähig gemacht. Vielmehr ist bei der Appropriation Art das Problem, ob der Inhalt bereits schutzfähig ist, also ob die Idee im Inhalt hinreichend konkretisiert wurde und für das Werk ausreichend Gestaltungsspielraum besteht außerhalb des konkreten Werkexemplars, sodass die konkrete Ausführung nicht auf Notwendigkeiten zurückzuführen ist. Damit sind auch bloße Re-Fotografien, also reine 1:1-Übernahmen, als urheberrechtliche Werke denkbar, denn die Appropriation Art drückt darin einen anderen Inhalt als der des angeeigneten Werkes aus. Zudem bedarf die Appropriation Art der genauen Übernahme, um ihre künstlerische Strategie ausüben zu können. Hier könnte es hilfreich sein, die Appropriation Art ähnlich abstrakt wie ein literarisches Kunstwerk zu verste-

681 Grünewald-Schukalla/Fischer, Überlegungen zu einer textuellen Definition von Internet-Memes, kommunikation @ gesellschaft 19 (2018), S. 7. S. dazu auch bereits S. 75 . 
hen, bei dem auch abstrakte Inhalte schutzfähig sind, die über die bloße konkrete Ausführung der Form hinausgehen.

Bei digitalen Aneignungen zur Kommunikation stellt sich in der Regel kein Problem von Idee und Inhalt. Für die abstrakten Konzepte, die der kommunikativen Funktionsweise von Memes oder viralen Hypes zugrunde liegen, greift jedoch der Grundsatz der Schutzlosigkeit der Idee, da diese Konzepte noch zu abstrakt bleiben, um als urheberrechtlicher Schutzgegenstand qualifiziert werden zu können.

Bei einigen Formen kommunikativer Aneignung geht es jedoch lediglich um das Zeigen der konkreten Form des Ursprungswerkes, sodass keine eigene neue Schöpfung vorgenommen wird. So ist es etwa beim Teilen in sozialen Netzwerken und bei GIFs. Hier kommt eine Rechtfertigung über $\$ 24$ UrhG nicht in Betracht.

Bei der Appropriation Art, bei Bildmontagen, Memes oder Museumselfies scheitern hingegen Aneignungen in der Regel nicht an der Voraussetzung des neuen selbständigen Werkes im Rahmen des $\mathbb{2 4}$ Abs. 1 UrhG.

\section{Verblassen}

Für eine freie Benutzung kommt es auf den „Abstand an, den das neue Werk zu den entlehnten eigenpersönlichen Zügen des benutzten Werkes hält“. ${ }^{682}$ Dieser Abstand wird durch das äußerliche „Verblassen“ des benutzten Werkes festgestellt, wenn also angesichts der Eigenart des neuen Werkes die entlehnten eigenpersönlichen Züge des geschützten älteren Werkes verblassen. ${ }^{63}$ Dabei hängt das Verblassen auch vom Grad der Individualität des benutzten Werkes und des neuen Werkes ab, die zueinander in Wechselwirkung stehen: Je individueller das benutzte Werk ist, desto weniger werden die übernommenen Eigenarten im neu geschaffenen Werk verblassen; und umgekehrt je individueller die Neuschöpfung ist, desto eher liegt ein Verblassen des benutzten Werkes vor. ${ }^{64}$

682 So BGH GRUR 2016, S. 1157, 1159 Rn. 19 - auffett getrimmt.

683 BGH GRUR 2008, S. 693, 695 Rn. 29 - TV Total; BGH GRUR 1994, S. 191, 193 - Asterix-Persiflagen; Wandtke/Bullinger/Bullinger, 5.Aufl. 2019, $\$ 24$ UrhG Rn. 10; Dreier/Schulze/Schulze, 6. Aufl. 2018, \$24 UrhG Rn. 8; Schricker/ Loewenheim/Loewenheim, 5. Aufl. 2017, $\mathbb{2} 4$ UrhG Rn. 10. Diese sog. Verblassens-Formel geht zurück auf Ulmer, Urheber- und Urhebervertragsrecht, 3. Aufl. 1980, S. 275.

684 Dreier/Schulze/Schulze, 6. Aufl. 2018, $\$ 24$ UrhG Rn. 8. 
Die Prüfung des Verblassens wird in einem ersten Schritt durch einen Werkvergleich der individuellen Merkmale vorgenommen. Dabei kommt es zunächst darauf an, dass schutzfähige Eigenarten übernommen wurden, da ansonsten die Rechte des Urhebers des benutzten Werkes nicht betroffen wären. Hier ist zu beachten, dass je individueller ein Werk ist, desto größer auch sein Schutzbereich ist, der dem Urheber zugewiesen ist. Schwerpunkt des Werkvergleichs sind die Übereinstimmungen der beiden Werke, nicht deren Abweichungen. ${ }^{655}$ Dann wird der Umfang der Entlehnung festgestellt, und schließlich werden der Umfang der Übereinstimmungen und die vorhandenen Abweichungen in einer abschließenden Gesamtbetrachtung gegenübergestellt. ${ }^{686}$

Wie eine solche Prüfung des Verblassen von angeeigneten Bildelementen aussehen kann, wird in der Power of Blue-Entscheidung des OLG Hamburg deutlich. George Pusenkoff nutzte eine Schwarz-Weiß-Fotografie eines weiblichen Aktes („Miss Livingstone I, Beverly Hills 1981“) von Helmut Newton, um sein Gemälde „Power of Blue“ (2003) zu schaffen. Der Hintergrund des Gemäldes ist in einem starken Blau gehalten, in der Bildmitte ist der Akt, allerdings abstrahiert, wiedergegeben. Dessen Körpermitte wird durch ein gelbes Quadrat verdeckt, das das Blau kontrastiert. Hier nahm das OLG Hamburg ein Verblassen der individuellen Züge der Fotografie von Newton an: „Zum einen tritt die Figur auf dem dunklen Blau ohnehin kaum besonders hervor und ist deshalb fast ebenso gut geeignet, das Blau des kräftigeren Mittelfeldes weiter zu strukturieren. Zum anderen vermittelt die Figur einen gedanklichen Inhalt, der einen Zugang zu dem erleichtert, was in dem Bilde steckt, nämlich die ,Kraft des Blaus', das in der Figur seine Metapher findet." ${ }^{687}$ Der Akt hat hier kaum noch etwas Individuelles. Schattierungen und Einzeltöne der Fotografie sind entfallen. Die Verdeckung der Körpermitte durch das Quadrat nimmt zudem das prägende Element des Aktes, die Nacktheit und damit auch das sinnliche Moment der Fotografie hinweg. ${ }^{688}$ Damit sind die individuellen Züge

685 BGH GRUR 1994, S. 191, 193 - Asterix-Persiflagen; BGH GRUR 1981, S. 267, 269 - Dirlanda; BGH GRUR 2003, S. 786, 787 - Innungsprogramm.

686 Dreier/Schulze/Schulze, 6. Aufl. 2018, \$24 UrhG Rn. 16.

687 OLG Hamburg NJW 1996, S. 1153, 1154 - Power of Blue.

688 Maaßen meint dazu, es bleibe kaum etwas, was Pusenkoff noch hätte tun können, um sich von dem Newton-Bild zu entfernen, ohne die Wiedererkennbarkeit zu gefährden und auf die beabsichtigte Bezugnahme ganz verzichten zu müssen, s. Maaßen, Plagiat, freie Benutzung oder Kunstzitat? Erscheinungsformen der urheberrechtlichen Leistungsübernahme in Fotografie und Kunst, in: FS Pfennig, 2012, S. 135, 156. 
des Werks Newtons im Werk Pusenkoffs nicht mehr prägend. Das OLG Hamburg zeigt, wie anhand von Linienführung, Farbe und Kontrasten strukturiert ein Verblassen eines Bildes geprüft werden sollte.

In Werken der Appropriation Art soll jedoch das angeeignete Bild erkennbar bleiben ${ }^{69}$ und sogar unverändert dargestellt werden. Das Ziel der Appropriation Art liegt gerade darin, dass angeeignetes und aneignendes Werk formal äußerlich übereinstimmen, ${ }^{690}$ und sich erst aus dem Kontext wie einem Rahmenbild, dem Titel oder der Angabe des Künstlers ergibt, dass es sich um ein angeeignetes Werk handelt. Die individuellen Züge des angeeigneten Werkes sind also weiter in vollem Umfang vorhanden - sie sollen gerade nicht verblassen, sondern in ihrer ganzen Schönheit, Skurrilität und Einmaligkeit übernommen werden. ${ }^{691}$ Ein Verblassen des ursprünglichen Werkes kommt bei der Appropriation Art nur in Betracht, wenn das Appropriation Art Kunstwerk aus mehreren übernommenen Werken besteht und wie eine Collage zusammengesetzt wird oder wenn kein spezielles Werk nachgemalt wird, sondern lediglich ein Werk nachempfunden wird, indem dessen Stilmittel übernommen werden, wie es beispielsweise bei Mike Bidlos Serie „Not Pollock“ (1983) der Fall ist.

Ähnlich liegt der Fall bei Memes und GIFs. Auch hier muss das übernommene Werk sichtbar bleiben, um als Meme oder GIF zu funktionieren, und wird gerade nicht hinter den Zügen des neuen Werkes verblas-

689 Die Wiedererkennbarkeit ist bisher kein Kriterium des $\$ 24$ UrhG. Die Verblassensprüfung ist weniger streng als eine Prüfung der Wiedererkennbarkeit, s. Homar, Enge Handlungsspielräume für das Sampling, ZUM 2019, S. 731, 736. Im EuGH-Urteil Pelham/Hütter wird jedoch die Wiedererkennbarkeit als wesentlicher Bestandteil eines Zitats angesehen. Der EuGH nimmt an, dass Sampling durch das Zitatrecht des Art. 5 Abs. 3 lit. d InfoSoc-RL gerechtfertigt sein kann, wenn die Nutzung das Ziel habe, mit dem geschützten Werk zu interagieren und die weiteren Voraussetzungen erfüllt seien, insbesondere die Pflicht zur Quellenangabe. Eine Interaktion sei jedoch nicht gegeben, wenn das zitierte Werk nicht zu erkennen sei, s. EuGH GRUR 2019, S.929, 931 Rn. 31 f. - Pelham/Hütter. Das Kriterium der Wiedererkennbarkeit wird damit für Übernahmen fremder Werke relevant. Das Zitatrecht wird im deutschen Recht jedoch von $₫ 51$ UrhG geregelt, sodass es bezüglich $₫ 24$ UrhG wohl nicht auf die Wiedererkennbarkeit ankommen wird. Bisher hatte sich der BGH auch ausdrücklich gegen das Kriterium der Erkennbarkeit ausgesprochen, da es zu „Abgrenzungsschwierigkeiten und damit zu Rechtsunsicherheit“ führe, s. BGH GRUR 2009, S. 403, 404 Rn. 13 - Metall auf Metall I.

690 Vgl. auch Huttenlauch, Appropriation Art. Kunst an den Grenzen des Urheberrechts, 2010, S. 116.

691 P. Raue, Ready-Mades und Appropriation Art. „Werke“ im Sinne des Urhebergesetzes, in: FS Pfennig, 2012, S. 199, 203. 
sen. Memes als Bild-Text-Kombination führen zwar durch das Hinzufügen eines Textes eine neue, zusätzliche oder gar gegensätzliche Bedeutungsebene hinzu. Diese zeigt sich allerdings gerade nicht im äußerlichen Verblassen der Züge des Bildes - auch bei Hinzufügen eines Textes bleibt das Bild mit all seinen individuellen Zügen in Gänze bestehen. Von einem Verblassen der individuellen Züge und damit einem ausreichend äußerlichen Abstand kann hier nicht die Rede sein.

Die Verblassensformel, die allein auf die äußere Form und deren Veränderung abzielt, versagt, wenn das neue Werk bewusst äußerlich mit dem ursprünglichen Werk übereinstimmt und ein neuer Kontext oder eine zusätzliche Aussage des Werkes sich nicht in der äußeren Form niederschlagen.

\section{Innerer Abstand}

Unter bestimmten Voraussetzungen soll jedoch auch ein sog. innerer Abstand zum Werk ausreichen. In welchen Fällen ein solcher innerer Abstand anwendbar ist, wie er ausgestaltet ist und ob er bei Fällen der Appropriation Art oder der kommunikativen Aneignung gewahrt wird, soll im Folgenden untersucht werden.

a) Entwicklung des inneren Abstandes für die Parodie

Das Kriterium des inneren Abstandes, auch „Verblassen im weiteren Sinne“ oder „rein geistiger Abstand“, hat der BGH für Fälle der Parodie entwickelt. ${ }^{692}$ Denn bei der Parodie ist es gerade ausgeschlossen, dass die Züge des benutzten Werkes äußerlich verblassen, da die Parodie davon lebt, dass die Vorlage erkannt wird. In solchen Fällen soll es für den erforderlichen Abstand zum genutzten Werk trotz deutlicher Übernahmen der Formgestaltung genügen, wenn der Abstand auf andere Weise erreicht wird. Dazu reicht aus, wenn das neue Werk zu den entlehnten eigenper-

692 BGH GRUR 1994, S. 191, 193 - Asterix-Persiflagen. Der innere Abstand wird jedoch nicht nur in Fällen der Parodie angewandt, sondern gilt als Kriterium auch bei anderen Kunstformen, bei denen sich mit einem fremden Werk in eigenständiger Form auseinandergesetzt wird, vgl. Dreier/Schulze/Schulze, 6. Aufl. 2018, \$24 UrhG Rn. 16; Wandtke/Bullinger/Bullinger, 5. Aufl. 2019, \$24 UrhG Rn. 14. 
sönlichen Zügen des älteren Werkes einen so großen inneren Abstand hält, dass das neue Werk seinem Wesen nach als selbständig anzusehen ist. ${ }^{693}$

Für das Vorliegen einer Parodie hat der BGH eine antithematische Behandlung des genutzten Werkes gefordert. ${ }^{694}$ Zudem soll die parodistische Behandlung objektiv für denjenigen erkennbar sein, der auch das parodierte Werk kennt. ${ }^{695}$ Mit der Deckmyn-Entscheidung des EuGH wurde der Parodiebegriff jedoch wesentlich erweitert. ${ }^{696}$ Bei der Beurteilung einer Parodie ist zu beachten, dass das Unionsrecht eine eigenständige Schrankenregelung für Fälle der Parodie vorsieht, die in Art. 5 Abs. 3 lit. k der InfoSoc-RL 2001/29/EG verankert ist. Diese Schrankenregelung hat der deutsche Gesetzgeber nicht direkt umgesetzt, weshalb die Regelung des $\$ 24$ UrhG insoweit richtlinienkonform auszulegen ist, als es um die urheberrechtliche Zulässigkeit von Parodien geht. ${ }^{67}$ Nach der Rechtsprechung des EuGH ist der Parodiebegriff der InfoSoc-RL ein eigenständiger Begriff des Urheberbegriffs und deshalb einheitlich auszulegen. ${ }^{698}$ Die Merkmale einer Parodie bestehen danach darin, an ein bestehendes Werk zu erinnern, gleichzeitig ihm gegenüber wahrnehmbare Unterschiede aufzuweisen und zum anderen einen Ausdruck von Humor oder Verspottung darzustellen. ${ }^{699}$ Damit ist gerade nicht mehr notwendig, dass die Parodie das ursprüngliche Werk selbst betrifft oder dieses Werk angibt ${ }^{700}$, wie es zuvor noch vom BGH gefordert wurde. Damit ist nun eine parodistische Nutzung fremder Werke möglich, ohne dass das benutzte Werk Bezugspunkt der Parodie sein muss - eine antithematische Behandlung ist also gerade nicht mehr notwendig. Darüber hinaus muss die Parodie keine persönliche geistige Schöpfung im Sinne des $\$ 2$ Abs. 2 UrhG darstellen, sondern es reicht aus, wenn die Parodie einen eigenständigen ursprünglichen Charakter hat, der nicht nur darin besteht, gegenüber dem parodierten ursprünglichen Werk wahrnehmbare Unterschiede aufzuweisen. ${ }^{701}$ Auch

693 BGH GRUR 1994, S. 191, 193 - Asterix-Persiflagen.

694 Vgl. BGH GRUR 1971, S. 588, 589 - Disney-Parodie; BGH GRUR 1958, S. 354, 356 - Sherlock Holmes.

695 BGH GRUR 1994, S. 206, 209 - Alcolix.

696 EuGH GRUR 2014, S. 972 - Deckmyn und Vrijheidsfonds.

697 BGH GRUR 2016, S. 1157, 1159 Rn. 24 - auffett getrimmt.

698 EuGH GRUR 2014, S. 972, 973 Rn. 17 - Deckmyn und Vrijheidsfonds.

699 EuGH GRUR 2014, S. 972, 974 Rn. 33 - Deckmyn und Vrijheidsfonds.

700 EuGH GRUR 2014, S. 972, 974 Rn. 33 - Deckmyn und Vrijheidsfonds.

701 EuGH GRUR 2014, S.972, 974 Rn.33 - Deckmyn und Vrijheidsfonds; BGH GRUR 2016, S. 1157, 1159 Rn. 25 - auffett getrimmt. 
dies ist eine Erleichterung der Vorgaben für das Vorliegen einer Parodie. Die Ausführungen zum neuen selbständigen Werk oben sind daher hier nur eingeschränkt übertragbar. ${ }^{702}$ Wie genau ein solch eigenständig ursprünglicher Charakter ausgeprägt sein muss im Gegensatz zur persönlich geistigen Schöpfung, ist noch offen. Als eine Verschärfung der Voraussetzungen der Parodie wird die vom EuGH eingeführte zusätzliche nachgelagerte Interessenabwägung gesehen, die einen angemessenen Ausgleich zwischen den Interessen und Rechten des Rechteinhabers und der Meinungsfreiheit des Parodisten herstellen soll. ${ }^{703}$ Insbesondere ist hierbei zu berücksichtigen, ob die Parodie diskriminierend ist. ${ }^{704}$

\section{aa) Appropriation Art als Parodie}

Die Appropriation Art weist strukturelle Ähnlichkeit zur Parodie auf: Auch sie benötigt die Übernahme fremder Werkgestaltungen und ihr wesentlicher Bestandteil ist die Wiedererkennung des übernommenen Werkes beim Betrachter. ${ }^{705}$ Nur durch diese Wiedererkennung kann die künstlerische Intention der Appropriation Art umgesetzt werden. Die Kopie soll dazu anregen, die geistigen Strukturen des kopierten Werkes zu erkennen. Die Diskrepanz zwischen optischem Eindruck (Werk eines bekannten Künstlers) und tatsächlicher Identität des Werkes (Nachahmung der Appropriation Art) soll eine neue Auseinandersetzung auch mit dem übernommenen Werk auslösen. Die Appropriation Art baut so eine Erwartungshaltung des Betrachters auf, die aber bei der Feststellung, dass es sich um ein Werk der Appropriation Art handelt, getäuscht und umgewandelt wird. Somit funktioniert auch die Appropriation Art wie die Parodie nur durch die äußerlich formale Übereinstimmung mit dem benutzten Werk, dass erst durch die Wiedererkennung seine künstlerische Aussage zum Ausdruck bringen kann. Da die Appropriation Art als Titel oder Signatur den Künstler der Übernahme nennt, wird ein wohl noch ausreichender wahrnehmbarer Unterschied zum benutzten Werk geschaffen, wie es das

702 Vgl. dazu S. $169 \mathrm{ff}$.

703 Dazu kritisch: von Becker, Die entstellende Parodie. Das EuGH-Urteil „Vrijheidsfonds/Vandersteen" und die Folgen für das deutsche Recht, GRUR 2015, S. 336, 338; Haedicke, Beschränkung der Parodiefreiheit durch europäisches Urheberrecht?, GRUR Int. 2015, S. 664, 669.

704 EuGH GRUR 2014, S. 972,974 Rn. 29 - Deckmyn und Vrijheidsfonds.

705 So zu Recht Huttenlauch, Appropriation Art. Kunst an den Grenzen des Urheberrechts, 2010, S. $116 \mathrm{f}$. 
EuGH Verständnis der Parodie erfordert. Die Appropriation Art ist jedoch nicht geprägt von Humor oder Verspottung. Auch wenn sie komische Effekte haben kann, ist die Komik selbst kein Wesenszug der Appropriation Art. ${ }^{706}$ Zwar ist das Aufbauen von Erwartungen und dann der Bruch dieser Erwartung auch ein beliebtes Element, das Komik hervorruft. Doch das Ziel der Appropriation Art ist gerade nicht, durch den Bruch der Erwartung Komik hervorzurufen. Die Definition von Parodie des EuGH muss dahingehend verstanden werden, dass die die erkennbare Intention des Schöpfers zur Komik ausschlaggebend ist. ${ }^{707}$

Im Prozess Rogers $v$. Koons wurde versucht, sich auf eine Parodie zu berufen, die im amerikanischen Recht ebenfalls das Vorliegen einer Urheberrechtsverletzung ausschließen würde. Im amerikanischen Recht herrscht jedoch ein anderes Verständnis von Parodie: Dort muss sich die parodistische Kritik direkt auf die Vorlage beziehen. Da Koons mit seinem Werk jedoch den Massenkonsum, Werbebilder und Materialismus in der Gesellschaft als Ganzes kritisiert hat, urteilten die Richter, dass es sich vielmehr um Gesellschaftssatire handele und die Parodieausnahme damit nicht greife. ${ }^{708}$ Ein solch enges Verständnis von Parodie wurde im europäischen und auch deutschen Recht wie oben gesehen spätestens durch die DeckmynEntscheidung aufgehoben, sodass der Fall dort wohl anders zu beurteilen gewesen wäre.

\section{bb) Memes als Parodie}

Ein Meme kann, muss aber keine Parodie darstellen. Nach Maier sind Memes in ihrer Hauptfunktion Internet-Witze, die das verwendete Fremdmaterial überraschend und humorvoll „brechen“.709 Deshalb greife ihrer Auffassung nach zumeist die Parodieschranke für Memes, weshalb sie nach deutschem Recht in der Regel zulässig seien. Eine Ausnahme macht sie jedoch: Bei der oben beschriebenen Interessenabwägung, die der EuGH fordert, sei insbesondere zu prüfen, ob die Parodie diskriminierend sei. Maier sieht jedoch bei Memes ein nahes Beieinanderliegen von subversivem $\mathrm{Hu}$ -

706 Vgl. ausführlicher dazu Huttenlauch, Appropriation Art. Kunst an den Grenzen des Urheberrechts, 2010, S. $122 \mathrm{f}$.

707 So auch für das frühere Verständnis vor der Deckmyn-Enscheidung des EuGH: Hess, Urheberrechtsprobleme der Parodie, 1993, S. 134.

708 Rogers $v$. Koons, 960 F.2d 301, 310 (2d Cir. 1992).

709 Maier, Meme und Urheberrecht, GRUR-Prax 2016, S. 397, 398. 
mor und Diskriminierung, sodass eine urheberrechtliche Zulässigkeit von Memes in Einzelfällen hieran scheitere.

Mit dieser Einschätzung greift Maier jedoch zu kurz. Memes funktionieren wie Witze nur innerhalb eines bestimmten Metatextes, also innerhalb bestimmter Rahmenbedingungen. Nur innerhalb dieser Rahmenbedingungen wird ein Meme korrekt genutzt und ist als Meme eines bestimmten Types erkennbar und verständlich. Ebenso bestehen für Witze gewisse Strukturen, innerhalb derer Modifikationen möglich sind (z.B. BlondinenWitze, Ostfriesen-Witze o.Ä.). Maier versteht hier Ullrich falsch, der ein Meme mit einem Witz vergleicht: Er vergleicht nicht den humoristischen Effekt, sondern den Mechanismus zum Verständnis eines Meme in der Kommunikation. Wie auch bei einem Witz verselbständigt sich bei einem Meme auch der Metatext und wird ständig fortgeführt, indem das Meme ständig verändert wird..$^{710}$

Ein Meme kann jedoch auch selbst Ausdruck von Humor darstellen. Ebenso wie ein Witz besteht es häufig aus Setup und Punchline - über ein Bild wird oben ein Setup als Textteil gesetzt, das bestimmte Erwartungen hervorruft, die im unteren Teil des Bildes in einem zweiten Textteil ${ }^{711}$ gebrochen werden. Dieser Bruch von Erwartungen kann Komik hervorrufen. Anders als bei der Appropriation Art kann dies durchaus auch die Intention des Erstellers des Memes sein. In diesem Sinne können Memes also durchaus Ausdruck von Komik darstellen und damit auch als Parodie verstanden sein. Allerdings kann ein Meme auch korrekt im Sinne seines Metatextes genutzt werden, ohne dass es humoristische Effekte hervorruft. Der Metatext setzt Humor oder Verspottung nicht voraus und auch der häufige Aufbau eines Memes durch zwei Textbausteine funktioniert ohne Humor. Humor oder Verspottung sind damit keine konstitutiven Bestandteile eines Meme. Ihre Hauptfunktion ist die Kommunikation, nicht die Ausrichtung darauf, ein (humoristisches) Werk zu sein. ${ }^{712}$ Nur in wenigen Einzelfällen wird also ein Meme den Anforderungen an die Parodie genügen und damit einen ausreichenden inneren Abstand zum genutzten Werk im Rahmen des $\$ 24$ Abs. 1 UrhG erreichen.

710 Ullrich im Interview mit Steinhau, Wolfgang Ullrich: „Urheberrechte für die sozialen Netzwerke gänzlich suspendieren“, irights info vom 18.05.2015, https://ir ights.info/artikel/wolfgang-ullrich-urheberrechte-fuer-die-sozialen-netzwerke-ga enzlich-suspendieren/25429.

711 S. dazu auch oben genauer, S. $74 \mathrm{ff}$.

712 So Ullrich, Das Wetteifern der Bilder: Eine Archäologie der Mem-Kultur, irights info vom 26.04.2016, https://irights.info/artikel/das-wetteifern-der-bilder-eine-ar chaeologie-der-mem-kultur/27306. 
cc) Bildmontagen von klassischen Kunstwerken als Parodie

Bildmontagen von klassischen Kunstwerken hingegen sind häufig von $\mathrm{Hu}$ mor oder Verspottung geprägt. Das klassische Kunstwerk wird verändert, gewisse Eigenschaften überzeichnet oder in einen neuen Kontext gesetzt. Dadurch wird die Aussage des angeeigneten Kunstwerks ins Lächerliche gezogen und mit ihr gebrochen. Durch diese offensichtliche Verfremdung des Bildes soll gerade ein humoristischer Effekt entstehen, weshalb derartige Bildmontagen in der Regel als Parodie einzuordnen sind. In der Regel wenn die Parodie nicht gerade diskriminierend ist - werden die Interessen des Parodieerstellers auch im Rahmen der Interessenabwägung überwiegen, sodass zumeist ein ausreichend innerer Abstand gewahrt ist.

b) Kunstspezifische Auslegung des $\ 24$ Abs. 1 UrhG

Ebenso kann ein innerer Abstand auch durch eine kunstspezifische Auslegung des $\mathbb{2} 24$ Abs. 1 UrhG erreicht werden, wenn durch die Übernahme der eigenpersönlichen Züge des älteren Werkes ein eigenständiges Kunstwerk entsteht. ${ }^{713}$ Die Kunstfreiheit gem. Art. 5 Abs. 3 GG schafft einen rechtlichen Freiraum für Kunst, der auch im Rahmen des Urheberrechts notwendigerweise zu beachten ist. Dieser Freiraum kann ebenfalls als innerer Abstand im Rahmen des $\$ 24$ Abs. 1 UrhG berücksichtigt werden. Dann können die Eigentumsinteressen des Urhebers oder Leistungsschutzberechtigen aus Gründen der Kunstfreiheit zurückgedrängt werden:

713 BVerfG GRUR 2016, S. 690, 693 Rn. 86 - Metall auf Metall; BVerfG GRUR 2001, S. 149, 151 - Germania 3. Das Urteil Metall auf Metall bezieht sich allerdings auf die Übernahme kleinster Teile (Tonfetzen) als Verletzung der Rechte des Tonträgerherstellers und damit gerade nicht auf ein Zurückdrängen der Urheberrechte. Die Grundsätze des Urteils zur kunstspezifischen Auslegung des $\$ 24$ Abs. 1 UrhG gelten allerdings nicht nur für Leistungsschutzrechte, sondern auch für Urheberrechte. Der Germania 3-Beschluss bezieht sich zwar auf die Zitierfreiheit gem. $₫ 51$ UrhG, die aufgestellten Grundsätze sind aber übertragbar, vgl. Dreier/Schulze/Schulze, 6. Aufl. 2018, \$24 UrhG Rn. 25; Summerer, „Illegale Fans", 2015, S. 94; Wegmann, Der Rechtsgedanke der freien Benutzung des $\mathbb{} 24$ UrhG und die verwandten Schutzrechte, 2013, S. 195; Huttenlauch, Appropriation Art. Kunst an den Grenzen des Urheberrechts, 2010, S. 153 f.; a.A.: Ohly, Hip Hop und die Zukunft der "freien Benutzung" im EU-Urheberrecht, GRUR 2017, S. 964, 967, der eine Abwägung zwischen Schutz des Urhebers und der Kunstfreiheit jenseits der anerkannten Fallgruppe des inneren Abstands ablehnt. 
„[...] die kunstspezifische Betrachtungsweise verlangt, bei der Auslegung und Anwendung der urheberrechtlichen Ausnahmeregelungen die Übernahme fremder Werkausschnitte in eigene Werke als Mittel künstlerischen Ausdrucks und künstlerischer Gestaltung anzuerkennen und damit diesen Vorschriften für Kunstwerke zu einem Anwendungsbereich zu verhelfen, der weiter ist als bei einer anderen, nichtkünstlerischen Nutzung." ${ }^{\text {"114 }}$ In solchen Fällen kann die gestalterische Verwendung fremden, urheberrechtlich geschützten Materials also zulässig sein. Dies gilt jedoch nur, solange dem übernommenen Werk oder der Leistung keine Konkurrenz gemacht wird und dem Urheber oder Leistungsschutzberechtigen kein Schaden zugefügt wird. ${ }^{715}$

Die kunstspezifische Auslegung des $₫ 24$ Abs. 1 UrhG scheint mittlerweile anerkannt zu sein. In der Vergangenheit wurde eine erweiternde Auslegung der Schranken mit dem Dogma der engen Schrankenauslegung abgelehnt. ${ }^{716}$ Man ging davon aus, dass kein Freiraum für eine kunstspezifische Auslegung anhand der Grundrechte bestehe, da bereits die Regelungen des Urheberrechts selbst die kollidierenden Grundrechte in einen angemessenen Ausgleich bringen. ${ }^{717}$ Jüngst wurde die Möglichkeit einer kunstspezifi-

714 BVerfG GRUR 2016, S. 690, 693 Rn. 86 - Metall auf Metall.

715 Vgl. BVerfG GRUR 2016, S. 690, 695 Rn. 101 f. - Metall auf Metall; BVerfG GRUR 2001, S. 149, 151 - Germania 3; Dreier/Schulze/Schulze, 6. Aufl. 2018, $\$ 24$ UrhG Rn. 10a. Kritisch dazu Stieper, der meint, dem Urheber stehe auch ein Vergütungsanspruch zu, ohne dass eine unmittelbare Konkurrenz drohe, vgl. Stieper, Anmerkung zu BVerfG, Urteil vom 31. Mai 2016 - 1 BvR 1585/13, ZUM 2016, S. 637, 638.

716 BGH GRUR 1985, S. 874, 875 f. - Schulfunksendung; BGH GRUR 1983, S. 28, 29 - Presseberichterstattung und Kunstwerkwiedergabe II; BGH GRUR 1968, S.607, 608 - Kandinsky I; Schricker/Loewenheim/Melichar/Stieper, 5. Aufl. 2017, Vor \$S 44a ff. Rn. 36; Stieper, Rechtfertigung, Rechtsnatur und Disponibilität der Schranken des Urheberrechts, 2009, S. 65 m.w.N.; Schack, Urheber- und Urhebervertragsrecht, 9. Aufl. 2019, Rn. 86, 480; Schack, Urheberrechtliche Schranken, übergesetzlicher Notstand und verfassungskonforme Auslegung, in: FS Schricker, 2005, S. 511, 515; P. Raue, Zum Dogma von der restriktiven Auslegung der Schrankenbestimmungen des Urheberrechtsgesetzes, in: FS Nordemann, 2004, S. 327, 328; Schulze, Spielraum und Grenzen richterlicher Rechtsfortbildung im Urheberrecht, in: FS Erdmann, 2002, S. 173, $180 \mathrm{f}$.

717 So hatte es das BVerfG auch zuvor für $\$ 50$ UrhG gesehen: Dort wurde eine eigene Grundrechtsabwägung im Rahmen von $\$ 50$ UrhG abgelehnt, da die vorzunehmende Interessenabwägung widerstreitender Grundrechtspositionen bereits durch den Gesetzgeber, also durch die Ausgestaltung der Schrankenregelung selbst, vorgenommen wurde, BVerfG GRUR 2012, S. 389, 390 - Online-Archiv. Grundsätzlich kann dies aber für jede Norm des Urheberrechts unterschiedlich gehandhabt werden. 
schen Auslegung durch den Generalanwalt Szpunar in seinen Schlussanträgen zum Verfahren Metall auf Metall in Frage gestellt: „Was das Urheberrecht betrifft, nimmt es diese Abwägung [zwischen dem Grundrecht auf Eigentum und dem auf freie Meinungsäußerung und der Freiheit der Kunst] schon selbst vor, indem es eine Reihe von Ausnahmen und Beschränkungen vorsieht. Diese sind dazu bestimmt, ein angemessenes Gleichgewicht zwischen den Rechten und Interessen der Inhaber von Urheber- und verwandten Rechten einerseits und den verschiedenen anderen öffentlichen und privaten Interessen einschließlich des Interesses am Schutz der Grundrechte andererseits sicherzustellen." ${ }^{718}$

Doch von der Rechtsprechung wird eine kunstspezifische Auslegung regelmäßig vorgenommen. Auch das BVerfG sah bisher diese Möglichkeit explizit für Regelungen des Urheberrechts vor, sodass nicht davon auszugehen ist, dass eine Grundrechtsabwägung bereits durch die Regelungen des Urheberrechts selbst vorgenommen wurde. ${ }^{719}$ Auch der EuGH geht in dem Urteil Pelham/Hütter davon aus, dass bei der Auslegung der InfoSocRL die Grundrechte der GrCh zu berücksichtigen seien, so insbesondere Art. $13 \mathrm{GrCh}$ bei der Einordnung eines Zitats im Sinne des Art. 5 Abs. 3 lit.d InfoSoc-RL. ${ }^{720}$ Zudem wird das Dogma der engen Schrankenregelung als inhaltlich verkürzt angesehen und vom EuGH ebenfalls gerade nicht anerkannt: Ausnahmen sollen korrekt und nicht unbedingt eng ausgelegt werden. ${ }^{721}$ Bei Auslegung der InfoSoc-RL muss eine solche Auslegung gewählt werden, die nicht mit den Grundrechten oder allgemeinen Grundsätzen des Unionsrechts kollidiert. Der EuGH geht davon aus, dass unter Berücksichtigung des Gebots der praktischen Wirksamkeit der Schrankenregelung ein Ausgleich zwischen den Rechten und Interessen der Rechteinhaber einerseits und den Rechten und Interessen der Nutzer auf der anderen Seite zu sichern ist. ${ }^{722}$ Es hat sich damit eine Ausle-

718 Schlussanträge des EuGH Generalanwalts Szupnar vom 12.12.2018 zu Rs. C-476/17, ZUM 2019, S. 237, 247 Rn. 90.

719 BVerfG GRUR 2016, S. 690, 693 Rn. 85 f. - Metall auf Metall; BVerfG GRUR 2001, S. 149, 151 - Germania 3.

720 EuGH GRUR 2019, S. 929, 933 Rn. 72 - Pelham/Hütter.

721 EuGH GRUR 2019, S. 934, 939 Rn. 68 ff. - Funke Medien NRW/Deutschland; BVerfG NJW 1974, S. 1751, 1757.

722 EuGH GRUR 2019, S. 934, 938, 939 Rn. 51, 70 ff. - Funke Medien NRW/Deutschland. 
gung anhand der betroffenen Interessen durchgesetzt. ${ }^{723}$ Eine kunstspezifische Auslegung des $\$ 24$ Abs. 1 UrhG anhand der Grundrechte ist damit möglich.

aa) Kunstspezifische Auslegung für Werke der Appropriation Art

Für eine kunstspezifische Auslegung des $\$ 24$ Abs. 1 UrhG für Werke der Appropriation Art müssten diese unter den Kunstbegriff des Art. 5 Abs. 3 GG fallen. ${ }^{724}$

(1) Kunstbegriff des Art. 5 Abs. 3 GG

Der verfassungsrechtliche Kunstbegriff soll die Freiheit, Autonomie, Pluralität und immanente Eigengesetzlichkeit von Kunst schützen. ${ }^{725}$ Deshalb

723 Stieper, Rechtfertigung, Rechtsnatur und Disponibilität der Schranken des Urheberrechts, 2009, S. 68; Roder, Die Methodik des EuGH im Urheberrecht, 2016, S. 129 m.w.N.; Dreier/Schulze/Dreier, 6. Aufl. 2018, Vor $\$ 44 a$ Rn. 7.

724 Im Folgenden wird die Abwägung anhand Art. 5 Abs. 3 GG vorgenommen und nicht anhand von Art. $13 \mathrm{GrCh}$, da es bei mitgliedsstaatlichem Handeln im Rahmen von Umsetzungsspielräumen den nationalen Gerichten frei bleibt, die nationalen grundrechtlichen Schutzstandards anzuwenden, sofern das Schutzniveau der Charta, die Einheit und die Wirksamkeit des Unionsrechts dadurch nicht beeinträchtigt werden, vgl. EuGH GRUR 2019, S.929, 934 Rn. 80 - Pelham/Hütter. Es ist also jeweils zu prüfen, ob eine vollständige Harmonisierung auf EU-Ebene vorgenommen wurde (dann Prüfung anhand der GrCh) oder ob den Mitgliedsstaaten Umsetzungsspielräume verbleiben (dann Prüfung anhand der nationalen Grundrechte), s. Stieper, Der Trans Europa Express ist aus Luxemburg zurück - auf dem Weg zu einer Vollharmonisierung der urheberrechtlichen Schranken, ZUM 2019, S. 713, 714. Bei Art. 5 Abs. 3 lit. c und d InfoSocRL wird nicht von einer vollständigen Harmonisierung ausgegangen, s. Leistner, Das Urteil des EuGH in Sachen „Funke Medien NRW/Deutschland" - gute Nachrichten über ein urheberrechtliches Tagesereignis, ZUM 2019, S. 720, 725. Inwieweit $\$ 24$ UrhG noch Umsetzungsspielraum der InfoSoc-RL ausschöpft, oder anhand von Art. 5 Abs. 3 lit. k InfoSoc-RL teleologisch zu reduzieren ist, oder gar unionsrechtswidrig und daher unwirksam ist, ist in Zukunft zu klären. In dieser Arbeit wird davon ausgegangen, dass $\$ 24$ UrhG wohl unionsrechtswidrig ist, s. S. $281 \mathrm{ff}$. Da diese Fragen aber noch durch Literatur und Rechtsprechung zu klären sind, wird die Abwägung der Grundrechte hier zunächst weiterhin anhand der nationalen Grundrechte des Grundgesetzes vorgenommen.

725 Maunz/Dürig/Scholz, 86. EL 2019, Art. 5 Abs. 3 GG Rn.37. Vgl. auch BVerfG NJW 1971, S. 1645, 1645 - Mephisto. 
muss der Staat auf alle stilistischen, ästhetischen, politischen oder ideologischen Werturteile bei der Bestimmung des Kunstbegriffs verzichten. ${ }^{726}$ Zur Definition der Kunst im Rahmen des Art. 5 Abs. 3 GG werden verschiedene Ansätze vorgebracht: der formal-typologische, der materielle und der offene und relationale Kunstbegriff. Der formal-typologische Kunstbegriff knüpft an eine Tätigkeit und deren Ergebnis an, beispielsweise das Malen, Bildhauen, Dichten oder Musizieren. ${ }^{727}$ Wenn ein solcher gängiger Werktypus vorliegt, wird vermutet, dass es sich dabei um Kunst handelt. Die Appropriation Art nutzt solch gängige Werktypen wie Gemälde, Drucke, Fotografien oder Skulpturen und unterfällt daher diesem Kunstbegriff. ${ }^{728}$ Der materielle Kunstbegriff erkennt als „das Wesentliche der künstlerischen Betätigung die freie schöpferische Gestaltung, in der Eindrücke, Erfahrungen und Erlebnisse des Künstlers durch das Medium einer bestimmten Formensprache zu unmittelbarer Anschauung gebracht werden. " ${ }^{\text {27 } 29}$ Dabei wird das künstlerische Schaffen als Ausdruck der individuellen Persönlichkeit des Künstlers verstanden und weniger als kommunikativer Akt der Mitteilung. Der offene und relationale Kunstbegriff geht von der Unmöglichkeit einer begrifflichen Definition von Kunst aus. ${ }^{730}$ Es sei gerade Merkmal der Kunst, „[...] dass es wegen der Mannigfaltigkeit ihres Aussagegehaltes möglich ist, der Darstellung im Wege einer fortgesetzten Interpretation immer weiterreichende Bedeutungen zu entnehmen, sodass sich eine praktisch unerschöpfliche, vielstufige Informationsvermittlung ergibt. ${ }^{\text {"731 }}$ Kunst wird hier als Kommunikationsprozess verstanden.

Fuchs geht darüber noch hinaus und vertritt einen avantgardistischen Kunstbegriff, der den Begriff der Konzeptualisierung in den Vordergrund rückt. ${ }^{72}$ Damit meint sie, dass sich zunehmend ein Reflexionsanteil der künstlerischen Tätigkeit im Werk niederschlägt. Diese Fundamentalkon-

726 Maunz/Dürig/Scholz, 86. EL 2019, Art. 5 Abs. 3 GG Rn. 38.

727 BVerfG NJW 1985, S. 261, 262 - Anachronistischer Zug; vgl. Müller, Freiheit der Kunst als Problem der Grundrechtsdogmatik, 1969, S. 42 ff.

728 So auch Huttenlauch, Appropriation Art. Kunst an den Grenzen des Urheberrechts, 2010, S. 158.

729 BVerfG NJW 1971, S. 1645, 1645 - Mephisto; BVerfG NJW 1971, S. 2163, 2163 Schulbuchprivileg; Maunz/Dürig/Scholz, 86. EL 2019, Art. 5 Abs. 3 GG Rn. 28.

730 BVerfG NJW 1985, S. 261, 262 - Anachronistischer Zug.

731 BVerfG NJW 1985, S. 261, 262-Anachronistischer Zug.

732 Fuchs, Avantgarde und erweiterter Kunstbegriff, 2000, S. $100 \mathrm{f}$. 
zeption soll ebenfalls unter den Kunstbegriff fallen. ${ }^{733}$ Im Gegensatz zum urheberrechtlichen Werkbegriff ${ }^{34}$ verlangt der Kunstbegriff des Art. 5 Abs. 3 GG keine starre Trennung von Idee und Form, sodass die Konzeption des Kunstwerkes hier schutzbegründend und in den Schutzumfang einbezogen sein kann.

Die Appropriation Art hat einen stark ausgeprägten konzeptuellen Ansatz, deren kunsttheoretischen Hintergründe bereits im Ersten und Zweiten Kapitel ausführlicher erläutert wurde. ${ }^{735}$ Die Kopie wird als Mittel genutzt, um die geistigen Strukturen des kopierten Werkes zu erkennen und zur Reflexion darüber anregen. Ein Werk, das aussieht wie das eines bekannten Künstlers, aber die Signatur eines Appropriation Art Künstlers trägt, verunsichert. Die Diskrepanz zwischen optischem Eindruck und tatsächlicher Identität des Werkes löst eine neue Auseinandersetzung mit dem Werk aus. Durch die Täuschung der Erwartungshaltung kann der Betrachter wieder die ursprüngliche Ästhetik des angeeigneten Werkes erkennen. Diese Re-Ästhetisierung eines Werkes und die Auseinandersetzung mit den Begriffen Original und Kopie sind Konzept der Appropriation Art. Wie man dieses künstlerische Konzept qualitativ bewertet, darf gerade keinen Einfluss auf die Beurteilung als Kunst im Sinne des Art. 5 Abs. 3 GG haben. Damit kann die Appropriation Art als Kommunikationsprozess sowohl dem offenen als auch dem avantgardistischen Kunstbegriff unterfallen. Allein im Rahmen des materiellen Kunstbegriff könnte man der Appropriation Art entgegenhalten, dass das angeeignete Werk gerade nicht auf der schöpferischen Gestaltung des Appropriation Art Künstlers, sondern auf der des angeeigneten Künstlers beruht.

(2) Überwiegen der Kunstfreiheit

Da die Appropriation Art wohl nach allen Kunstbegriffen als Kunst im Sinne des Art. 5 Abs. 3 GG zu verstehen ist, müsste für eine kunstspezifische Auslegung des $\$ 24$ Abs. 1 UrhG nun auch die Kunstfreiheit der Nutzer die Eigentumsfreiheit des Urhebers zurückdrängen. Bei der Beurteilung des inneren Abstands der Appropriation Art darf es nicht auf die

733 „Die Leistung besteht darin, dass über die künstlerische Gestaltungstätigkeit hinaus die traditionellen Form- und Gestaltungsprinzipien subjektiv umformuliert werden“, so Fuchs, Avantgarde und erweiterter Kunstbegriff, 2000, S. 105.

734 S. dazu S. $119 \mathrm{ff}$.

735 S. S. $94 \mathrm{ff}$. 
Sicht eines Durchschnittsbetrachters des Werkes ankommen. ${ }^{736}$ Denn ebenso wie bei der Parodie lässt sich das Konzept der Appropriation Art nur verwirklichen, wenn die Aneignung vom Betrachter wiedererkannt wird. Es muss also aus Sicht von jemandem beurteilt werden, der ein gewisses Vorverständnis der kunsttheoretischen Hintergründe hat und die Vorlage erkennt. Ansonsten könnte sich die Appropriation Art nur sehr bekannter, ikonischer Werke bedienen, die auch ein in Kunstdingen nicht bewanderter Betrachter erkennen würde. Dies würde allerdings die künstlerische Freiheit der Appropriation Art zu sehr einengen.

Schack schließt grundsätzlich ein Überwiegen der Kunstfreiheit in Fällen der Appropriation Art aus, da die Appropriation Art Künstler selbst den Abstand zum angeeigneten Werk „bewusst auf Null reduzier[en]“.737 Der Appropriation Art ist jedoch gerade zu eigen, dass die äußere Form übernommen wird. Dass auch ein innerer Abstand auf Null reduziert wird, kann nicht behauptet werden - Werke der Appropriation Art haben eine grundlegend andere künstlerische Aussage als die Werke, die sie sich angeeignet haben. Zudem argumentiert Schack, dass die urheberrechtliche Wertung eindeutig zugunsten der Originalurhebers ausfällt ${ }^{738}$ und damit die Kunstfreiheit nicht die Eigentumsinteressen des Urhebers zurückdrängen kann. Doch eine solche Wertung ist den Grundsätzen des EuGH und des BVerfG zur kunstspezifischen Auslegung des $\$ 24$ Abs. 1 UrhG gerade nicht zu entnehmen.

Pfeifer und Schack wollen eine kunstspezifische Auslegung des $\$ 24$ Abs. 1 UrhG zudem dann scheitern lassen, wenn sich der Künstler das gesamte Werk angeeignet hat oder viele Übereinstimmungen mit dem Original bestehen. ${ }^{739}$ Damit wollen sie wohl einem Missbrauch der kunstspezifischen Auslegung für Fälschungen und Ähnlichem entgegenwirken. Dieser Wunsch ist zwar nachvollziehbar, die dafür angebrachten Ein-

736 So zu Recht Huttenlauch, Appropriation Art. Kunst an den Grenzen des Urheberrechts, 2010, S.171. Ebenso darf es auch bei der Parodie nicht auf den Durchschnittsbetrachter ankommen, sondern es ist der Standpunkt desjenigen maßgeblich, der die Vorlage kennt und das erforderliche kognitive Verständnis besitzt, vgl. BGH GRUR 2000, S.703, 704 - Mattscheibe; BGH GRUR 1994, S. 191, 193 - Asterix-Persiflagen; BGH GRUR 1971, S. 588, 590 - Disney-Parodie.

737 Schack, Appropriation Art und Urheberrecht, in: FS Nordemann, 2004, S. 107, 109.

738 Ders., a.a.O.

739 Ders., a.a.O.; ders., Kunst und Recht, 3. Aufl. 2017, Rn. 354; Pfeifer, Appropriation und Fan Art - geknebelte Kreativität oder klare Urheberrechtsverletzung?, in: FS Wandtke, S. 99, 107. 
schränkungen jedoch gerade nicht. Im Ergebnis würden sie sonst darauf hinauslaufen, jede Form der kunstspezifischen Auslegung der Appropriation Art zu verhindern. Die Appropriation Art kann ihre künstlerische Zielsetzung nur erreichen, wenn sie das angeeignete Werk auch in seinem vollen Umfang nutzen darf - sie muss geradezu möglichst viele Übereinstimmungen zum Original haben, damit sie noch Appropriation Art ist. Wenn die Appropriation Art auf nur teilweise Übernahmen beschränkt wird, könnte sie nur noch Techniken wie die Collage nutzen und verlöre damit ihre Eigenständigkeit in Abgrenzung zu anderen Richtungen der abstrakten und modernen Kunst. Diese Einschränkungen für die kunstspezifische Auslegung greifen daher nicht.

Im Rahmen der Abwägung der kunstspezifischen Auslegung des $\$ 24$ Abs. 1 UrhG für die Appropriation Art muss damit die Kunstfreiheit regelmäßig die Urheberinteressen überwiegen, da die Appropriation Art sonst gar nicht ausgeübt werden könnte.

(3) Einschränkungen zur Verhinderung von Missbrauch: keine Konkurrenz zum Original

Eine kunstspezifische Auslegung des $\$ 24$ Abs. 1 UrhG birgt die Gefahr, dass die Abgrenzung zu Nachahmungen, die lediglich den Wert des Originals ausnutzen wollen und keinen eigenständigen Mehrwert schaffen, schwer zu ziehen ist. Rein nach der äußeren Form wird man Aneignungen nicht von solchen ausnutzenden Nachahmungen auseinanderhalten können, da auch die Aneignung ein komplettes Werk äußerlich nutzen und dennoch inhaltlich etwas anderes damit aussagen kann als das ursprüngliche Werk. ${ }^{740}$ Um die Grenze zu einer Aneignung zu ziehen, die durch die Kunstfreiheit geschützt im Rahmen der kunstspezifischen Auslegung überwiegt, ist zunächst die Frage zu stellen, welche Art von Aneignung nicht mehr zulässig sein soll, also wo die Grenze zu ziehen ist zur missbräuchlichen Nutzung urheberrechtlich geschützter Werke.

Aneignungen im Sinne dieser Arbeit sind nur solche Nutzungen fremden Materials, die über den reinen Werkgenuss hinausgehen. Das Material muss also produktiv genutzt werden, indem mit ihm etwas eigenes ausgesagt wird, was über das hinaus geht, was auch das Originalwerk selbst aussagt. ${ }^{741}$ In einem ähnlichen Sinne argumentiert auch Huttenlauch, die ver-

740 Vgl. zur Unterscheidung von Form und Inhalt eines Werkes S. $173 \mathrm{ff}$.

741 S. $32 \mathrm{f}$. 
langt, dass ein Werk der Appropriation Art nur dann im Rahmen einer kunstspezifischen Auslegung zulässig sein soll, wenn durch das Werk eine eigene Aussage erkennbar wird. ${ }^{742}$ Pfeifer lehnt eine solche eigene Aussage dann $a b$, wenn eine Auseinandersetzung mit dem Original nicht erkennbar ist. ${ }^{743}$ Aus der Deckmyn-Entscheidung des EuGH dürfte man jedoch auch auf $\$ 24$ Abs. 1 UrhG übertragen, dass sich die eigenständige Aussage nicht zwangsläufig in einer kritischen Auseinandersetzung mit dem Original wiederfinden muss, sondern auch darüber hinaus gehen kann. Schack sieht die Grenze zur missbräuchlichen Nutzung dann überschritten, wenn die künstlerischen Zwecke der Verwendung nicht eindeutig überwiegen und es zu einer Ersetzung des Originals kommt. ${ }^{744}$

Alle diese Ansätze spiegeln das wider, was auch das BVerfG in seiner Metall auf Metall-Entscheidung klargestellt hat: Dass die Kunstfreiheit im Rahmen der Abwägung hier nur überwiegt, solange dem übernommenen Werk oder der Leistung keine Konkurrenz gemacht wird und dem Urheber (oder Leistungsschutzberechtigten) keine Nachteile zugefügt werden. ${ }^{75}$ Diese Konkurrenz zum Original ist als eine wirtschaftliche zu verstehen. Huttenlauch begründet eine solche wirtschaftliche Betrachtungsweise für den inneren Abstand mit einer Entlehnung des Substitutionskriteriums aus der Fair Use-Prüfung (4. Faktor). ${ }^{746}$ Eine solche Entlehnung ist rechtlich gar nicht notwendig, da das BVerfG selbst von einer Konkurrenz spricht, die dem Urheber keine wirtschaftlichen Nachteile zufügen darf. Die dogmatische Herleitung dieses wirtschaftlichen Kriteriums scheint dennoch nicht ganz klar. Dabei lässt sich diese ökonomische Interpretation der Interessen des Rechtsinhabers nicht allein dadurch begründen, dass es im Urteil Metall auf Metall um Leistungsschutzrechte ging und diese häufig aus ökonomischen Gesichtspunkten als Schutzgut normiert wurden. Vielmehr nimmt das BVerfG diese ökonomische Perspektive ebenso

742 Huttenlauch, Appropriation Art. Kunst an den Grenzen des Urheberrechts, 2010, S. 147 ff. Ähnlich auch Schulze, Beuys-Aktion 1964. Aspekte zum Urheberrechtsschutz bei multimedialen Werken, in: Mosimann/Schönenberger (Hrsg.), Kunst \& Recht 2013, 2014, S. 35, 42, 47 f.

743 Pfeifer, Appropriation und Fan Art - geknebelte Kreativität oder klare Urheberrechtsverletzung?, in: FS Wandtke, S. 99, 107.

744 Schack, Appropriation Art und Urheberrecht, in: FS Nordemann, 2004, S. 107, 107.

745 Vgl. BVerfG GRUR 2016, S. 690, 695 Rn. 101 f. - Metall auf Metall; BVerfG GRUR 2001, S. 149, 151 - Germania 3. S. oben S. $193 \mathrm{ff}$.

746 Huttenlauch, Appropriation Art. Kunst an den Grenzen des Urheberrechts, 2010, S. 175 ff. Vgl. zur Fair Use-Doktrin und den vier Faktoren S. 57. 
für das Urheberrecht ein: Schon in Germania 3 hat es den Eingriff in das Recht mit der „Gefahr merklicher wirtschaftlicher Nachteile (z.B. Absatzrückgänge)“ abgewogen. ${ }^{77}$ Die erzielte Ersparnis des Nutzers eines urheberrechtlichen Werkes, die dadurch entsteht, dass er keine Lizenzkosten zahlen musste, hat das hingegen BVerfG nicht als einen wirtschaftlichen Vorteil des Nutzers eingeordnet, der zu einem wirtschaftlichen Nachteil des Rechteinhabers führen würde. Ein solcher wirtschaftlicher Nachteil könne nur angenommen werden, wenn beide in einem konkreten Wettbewerbsverhältnis stehen ${ }^{748}$ - denn dann hätte der Rechteinhaber tatsächlich einen Nachteil, wenn er selbst für z.B. Samples zahlen würde, sein Konkurrent aber nicht. Eine ökonomische Interpretation der beiderseitigen Interessen am Werk ist also auch im klassischen Urheberrecht möglich. Dies muss nicht aus Fair Use hergeleitet werden, sondern kann im Rahmen der Interessenabwägung der praktischen Konkordanz vorgenommen werden.

Das wirtschaftliche Konkurrenzverhältnis kann aber ähnlich wie bei Fair Use anhand der Nachfragesubstituierbarkeit festgestellt werden. Das heißt, es kommt darauf an, ob das neue Werk das Original auf dem Markt ersetzen kann. Ist dies der Fall, dann legt das eine Zielsetzung der Aneignung nahe, die missbrauchend ist und Investitionen sparen will. ${ }^{749} \mathrm{Wenn}$ der Markt der Aneignung jedoch ein anderer ist, tritt das Werk der Appropriation Art nicht in Konkurrenz, sodass von einer missbräuchlichen Nutzung des Originalwerkes nicht ausgegangen werden kann. In der Regel führen Werke der Appropriation Art nicht zu einer Nachfragesubstitution, da sie das Original meist leicht ändern und auch Titel oder Signatur zeigen, dass es sich nicht um eine Ersetzung des Originals handeln soll. So wird niemand, der beispielsweise die Fotografie „Rastafarian Smoking a Joint" (1996) von Donald Graham besitzen möchte, einen Instagram Print der „New Portrait“ (2014) Reihe von Richard Prince ${ }^{750}$ als adäquaten Ersatz dafür ansehen, nur weil darin auch die Fotografie von Graham mit abgedruckt ist. Vielmehr würde sich der Käufer an der Instagram Benutzeroberfläche des Prints und Princes Signatur stören, da er an dieser gerade

747 S. dazu auch Podszun, Postmoderne Kreativität im Konflikt mit dem Urheberrechtsgesetz und die Annäherung an „fair use“, ZUM 2016, S. 606, 610.

748 BVerfG GRUR 2016, S. 690, 695 Rn. 105 - Metall auf Metall.

749 Huttenlauch, Appropriation Art. Kunst an den Grenzen des Urheberrechts, 2010, S. 177.

$750 \mathrm{Zu}$ den Bildern Abb. 5.1. und 5.2. 
kein Interesse hat. ${ }^{751}$ Auch 1:1-Übernahmen, die reine Re-Kontextualisierungsarbeiten sind, führen nicht zwangsläufig zu einer Gefahr der Ersetzung des Originals, wenn der Markt sie nicht als äquivalent ansieht. Auch wenn das Werk also gleich aussieht, wie beispielsweise bei den Levines ReFotografien von Walker Evans, wird der Markt sie aufgrund Levines Bedeutung als Appropriation Art Künstlerin als Werke von Levine kaufen und kein Evans Sammler hätte Interesse daran. Hier kommt es also auch darauf an, inwieweit der aneignende Künstler eine eigenständige künstlerische Position bezieht und für diese bekannt ist - oder ob er als reiner Reproduktionskünstler angesehen wird.

\section{(4) Grenze: Interessenabwägung im Rahmen des $\$ 14$ UrhG?}

Eine Eingrenzung der urheberrechtlichen Zulässigkeit der Appropriation Art könnte auch vorgenommen werden, indem eine nachgelagerte Interessenabwägung in der Prüfung des $\mathbb{1 4}$ UrhG vorgenommen wird und so eine zusätzliche Korrektur des Ergebnisses erfolgt.

In der Prüfung der Entstellung des Werkes gem. $\mathbb{\$} 14$ UrhG ist eine Interessenabwägung vorzunehmen, in welcher sich die Wertungen der $\$ 24$ und $\$ 51$ UrhG durchschlagen. Das heißt, Nutzungen, die ein freie Benutzung oder ein Zitat darstellen, setzen sich im Rahmen der Interessenabwägung durch. Diese Interessenabwägung könnte man auch erweitert auslegen, sodass es bei Aneignungen nicht mehr allein darauf ankommt, ob die Aneignung im Rahmen einer kunstspezifischen Auslegung von $\$ 24$ oder $\$ 51$ UrhG freigestellt wird, sondern dass darüberhinausgehende Gründe berücksichtigt werden können. In einer solchen Interessenabwägung könnte die Verhältnismäßigkeit der Aneignung geprüft werden.

Bisher hatte der BGH keine nachgelagerte Interessenabwägung vorgenommen und die Frage der Entstellung gem. $\$ 14$ UrhG abhängig davon beurteilt, ob die $\mathbb{} 24$ oder $\mathbb{S} 51$ UrhG greifen. ${ }^{752}$ Dass die Wertung der

751 Anders sieht dies Schack, der davon ausgeht, dass die Appropriation Art regelmäßig die Vermarktungschancen des Originalurhebers beeinträchtigt, indem die Wertschätzung seiner bekannten Werke ausgenutzt wird, s. Schack, Kunst und Recht, 3. Aufl. 2017, Rn. 355.

752 BGH GRUR 1994, S. 206, 209 - Alcolix; so auch die h.M.: Schricker/Loewenheim/Dietz/Peukert, 5. Aufl. 2017, $\mathbb{1 4}$ UrhG Rn.11d; Fischer, Digitale Kunst und freie Benutzung, 2018, S. 247; Huttenlauch, Appropriation Art. Kunst an den Grenzen des Urheberrechts, 2010, S. 140 f.; Chakraborty, Das Rechtsinstitut der freien Benutzung im Urheberrecht, 1997, S. 108 f.; Hess, Urheberrechtspro- 
$\mathbb{S} \mathbb{2 4}$, 51 UrhG sich durchschlagen, wird damit begründet, dass in diesen Fällen bereits ein ausreichender Abstand zum übernommenen Werk geprüft und angenommen wurde, sodass auch im Rahmen von $\mathbb{\$} 14$ UrhG nicht die Gefahr einer Entstellung oder Beeinträchtigung besteht, die geeignet ist, die Interessen des Urhebers zu gefährden. ${ }^{753}$ Denn der freien Benutzung und dem Zitat ist gerade immanent, dass das Werk auch entstellt werden kann. ${ }^{754}$ Indem man die Wertung der $\mathbb{S} 24$, 51 UrhG für $\$ 14$ UrhG übernimmt, stellt man sicher, dass diese Wertungen nicht unterlaufen werden. Bei ausreichendem inneren Abstand im Sinne des $\$ 24$ UrhG ist nach hier vertretener Ansicht zudem eine wirtschaftliche Konkurrenz zum Original bereits tatbestandlich ausgeschlossen. ${ }^{755}$ Die übernommene Wertung kommt zudem daher, dass die monistische Theorie des Urheberrechts nicht nur das Urheberrecht insgesamt, sondern auch einzelne Normen prägt. ${ }^{756}$ Das heißt, auch die Norm des $\$ 24$ UrhG berücksichtigt neben den Verwertungsrechten auch die ideellen Interessen des Urhebers, sodass kein Konflikt zu $₫ 14$ UrhG entsteht. ${ }^{757}$ Das Vorliegen dieses ideellen Gehalts des $\$ 24$ UrhG wird mit der Gesetzessystematik begründet: $\$ 24$ UrhG steht zwar unter dem Unterabschnitt 3 der Verwertungsrechte, so allerdings auch $\$ 23$ UrhG, der unstreitig auch einen persönlichkeitsrechtliche Kern enthält. ${ }^{758}$ Wenn also $\mathbb{2 4}$ UrhG bereits alle persönlichkeitsrechtlichen Interessen des Urheberrechts beinhaltet und eine freie Benutzung gem. $\$ 24$ UrhG angenommen wird, wäre es überflüssig, nochmals die Verletzung von Persönlichkeitsinteressen des Urhebers im Rahmen des $₫ 14$ UrhG zu prüfen..$^{759}$

Dieses Abstufungsverhältnis wird durch das Deckmyn-Urteil des EuGH in Frage gestellt. Danach kommt nun eine parallele Anwendung des $\$ 14$ UrhG und des $\$ 24$ UrhG grundsätzlich in Betracht. Um die Auswir-

bleme der Parodie, 1993, S. 165 ff.; Haedicke, Beschränkung der Parodiefreiheit durch europäisches Urheberrecht?, GRUR Int. 2015, S. 664, 666.

753 BGH GRUR 1994, S. 206, 209 - Alcolix; Fischer, Digitale Kunst und freie Benutzung, 2018, S. 244.

754 BGH GRUR 1994, S. 206, 209 - Alcolix; Huttenlauch, Appropriation Art. Kunst an den Grenzen des Urheberrechts, 2010, S. $140 \mathrm{f}$.

755 Vgl. S. $199 \mathrm{ff}$.

756 Vgl. Specht/Koppermann, Vom Verhältnis der $\$ \mathbb{S} 14$ und 24 UrhG nach dem „Deckmyn“-Urteil des EuGH, ZUM 2016, S. 19, 20.

757 So auch Fischer, Digitale Kunst und freie Benutzung, 2018, S. 245.

758 BeckOK UrhG/Ablberg, 26. Ed. 2019, $\$ 23$ UrhG Rn. 2; Dreier/Schulze/Schulze, 6. Aufl. 2018, $\$ 23$ UrhG Rn. 2.

759 Specht/Koppermann, Vom Verhältnis der $\$ \$ 14$ und 24 UrhG nach dem „Deckmyn"-Urteil des EuGH, ZUM 2016, S. 19, 20. 
kungen genauer beurteilen zu können, soll zunächst das Urteil dargestellt werden und in einem zweiten Schritt die Auswirkungen für die Interessenabwägung des $\$ 14$ UrhG untersucht werden.

In der Deckmyn-Entscheidung hat der EuGH sich mit den Voraussetzungen der Parodie gem. Art. 5 Abs. 3 lit. k der InfoSoc-Richtlinie befasst und dabei festgestellt, dass es nicht auf eine antithematische Behandlung des Ausgangswerks ankommt. ${ }^{760}$ Damit wurde der Parodiebegriff wesentlich ausgeweitet. Nun kommt es beim inneren Abstand des $\$ 24$ UrhG also nicht mehr auf die Antithematik der Parodie an. Man nahm vor der Deck$m y n$-Entscheidung an, dass die Voraussetzung der Antithematik dafür sorge, dass die Parodie von der Öffentlichkeit nicht dem Urheber zugerechnet werde. Aufgrund der antithematischen Behandlung bestehe keine Verwechslungsgefahr von Ausgangswerk und parodiertem Werk, sodass auch für $\$ 14$ UrhG kein Raum bliebe, der schließlich auch vor der falschen $\mathrm{Zu}$ rechnung von Werken und dem verfälschten Eindruck des Werkschaffen des Urhebers schützt. Wenn nun allerdings keine antithematische Behandlung mehr notwendig ist, vermindert sich der im Rahmen des $\$ 24$ UrhG notwendige innere Abstand. Darüber hinaus kann nun auch der Anwendungsbereich des $\$ 14$ UrhG wieder eröffnet sein, da die Parodie nicht mehr erkennbar machen muss, dass die Urheber des parodierten und des parodierenden Werkes personenverschieden sind, sodass das Integritätsinteresse des Urhebers berührt sein kann. ${ }^{761}$ Nach der Deckmyn-Entscheidung ist daher eine parallele Anwendung von $\$ 24$ UrhG und $\$ 14$ UrhG denkbar. Damit kommt $\mathbb{1} 14$ UrhG auch in Betracht, um Freiraum zu schaffen bei Aneignungshandlungen. Denn auch bei Aneignungen kann der Eindruck entstehen, dass die Aneignung vom Urheber des angeeigneten Werkes stammt und so ein verfälschter Eindruck seines Werkschaffens entsteht. ${ }^{762}$

Dieses weite Verständnis der Parodie grenzt der EuGH mit einer Interessenabwägung wieder ein. Diese Interessenabwägung zieht er aus Erwägungsgrund 31 der InfoSoc-RL, wonach ein ,angemessener Ausgleich“ der Rechten und Interessen von Rechteinhabern und Nutzern von Schutzge-

760 EuGH GRUR 2014, S.972, 974 Rn. 33 - Deckmyn und Vrijheidsfonds; Specht/ Koppermann, Vom Verhältnis der $\$ \$ \$ 14$ und 24 UrhG nach dem „Deckmyn“-Urteil des EuGH, ZUM 2016, S. 19, 19; Haedicke, Beschränkung der Parodiefreiheit durch europäisches Urheberrecht?, GRUR Int. 2015, S. 664, 670.

761 Fischer, Digitale Kunst und freie Benutzung, 2018, S. 245; Specht/Koppermann, Vom Verhältnis der $\$ \$ 14$ und 24 UrhG nach dem „Deckmyn“-Urteil des EuGH, ZUM 2016, S. 19, 24.

762 S. dazu bereits S. $139 \mathrm{ff}$. 
genständen sichergestellt werden soll. ${ }^{763}$ In diese Interessenabwägung sind die Wertungen des Diskriminierungsverbots der RL 2000/43/EG sowie Art. 21 Abs. $1 \mathrm{GrCh}$ einzubeziehen. ${ }^{764}$ Eine solche nachgelagerte Interessenabwägung könnte eingefügt werden in die im Rahmen des $\$ 14$ UrhG ohnehin vorzunehmende Interessenabwägung. Diese Interessenabwägung könnte dadurch eine zusätzliche Korrektur zu der vorher vertretenen weiten Auslegung des $\$ 24$ UrhG darstellen. Darüber hinaus könnte hier eine Einschränkung von Aneignungen durch die Interessenabwägung vorgenommen werden, indem eine Verwechslungsgefahr geprüft wird. Liegt eine solche Gefahr der Zurechnung der Aneignung an den Urheber des angeeigneten Werkes oder eine Gefahr des verfälschten Eindrucks des Werkschaffens vor, dann wäre die Grenze zu einer „Misappropriation“ überschritten. Für das Vorliegen einer solchen „Misappropriation“ müssten alle Umstände des Einzelfalles in Betracht gezogen und umfassend beurteilt werden. So bleibt dem Urheber auch bei fehlender wirtschaftlicher Konkurrenz (sodass eine Rechtfertigung gem. $\$ 24$ UrhG gegeben ist) die Möglichkeit, gegen besonders grobe Entstellungen vorzugehen. Doch das Bedürfnis für eine solche ausgeweitete Interessenabwägung besteht regelmäßig nicht: Durch das weite Verständnis des $\$ 24$ UrhG werden bereits die Interessen von Urhebern und Nutzern des Werkes einbezogen. Gerade in einer verfassungskonformen Auslegung des $\$ 24$ UrhG werden den Eigentumsinteressen des Urhebers und den Nutzungsinteressen der Allgemeinheit hinreichend Rechnung getragen. Es scheint nicht notwendig, diese Interessen abermals im Rahmen von $\$ 14$ UrhG miteinander abzuwägen. Die Einführung einer nachgelagerten Interessenabwägung wäre hier außerdem zu unbestimmt, da sich noch keine ausreichenden Abgrenzungskriterien in Rechtsprechung oder Literatur entwickelt haben. Damit unterliegt eine solche Interessenabwägung der Gefahr der immer stärkeren Ausweitung. ${ }^{765}$ Letztendlich kommt es auch zu einer Konfusion mit den Wertungen des $\$ 24$ UrhG. Wenn ein ausreichender innerer Abstand zu einem übernommenen Werk angenommen wird, dann kann auch keine Zuordnungsverwirrung gem. $\$ 14$ UrhG angenommen werden, denn diese setzt gerade voraus, dass kein Abstand der Werke voneinander ersichtlich ist. Einer Gefahr der missbräuchlichen Aneignung von Werken kann besser entgegnet werden, indem in der Auslegung des $\$ 24$ UrhG eine solche

763 EuGH GRUR 2014, S. 972, 974 Rn. 26 f. - Deckmyn und Vrijheidsfonds.

764 EuGH GRUR 2014, S. 972, 974 Rn. 30 f. - Deckmyn und Vrijheidsfonds.

765 Haedicke, Beschränkung der Parodiefreiheit durch europäisches Urheberrecht?, GRUR Int. 2015, S. 664, 669. 
missbräuchliche Aneignung geprüft wird, die nach hier vertretener Ansicht angenommen werden soll, wenn das übernommene Werk lediglich den Wert des Originals ausnutzen will und keinen eigenständigen Mehrwert schaffen soll. Dies ist immer dann der Fall, wenn die Aneignung in wirtschaftliche Konkurrenz zum Original tritt, also vom Markt die Aneignung als Substitut für das Original angesehen wird. ${ }^{766}$

Insgesamt zeigt sich, dass eine erweiterte Verhältnismäßigkeitsprüfung im Rahmen der Interessenabwägung gem. $\mathbb{1} 14$ UrhG nach dem DeckmynUrteil des EuGH zwar wohl rechtlich vertretbar ist. Eine umfassende Prüfung des $\$ 24$ UrhG mit einer Missbrauchsprüfung im Rahmen des inneren Abstands erscheint jedoch weiterhin als das geeignetere Mittel, um die Interessen umfassend zu berücksichtigen und miteinander abzuwägen. Einer weiteren Interessenabwägung bei der Prüfung des $\$ 14$ UrhG bedarf es dann nicht.

bb) Kunstspezifische Auslegung für kommunikative Aneignungen?

Ebenso müssten kommunikative Aneignungen wie Memes, GIFs oder auch Bildmontagen Kunst im Sinne des Art. 5 Abs. 3 GG sein, um in ihren Fällen eine kunstspezifische Auslegung von $₫ 24$ Abs. 1 UrhG vorzunehmen.

Unter den formal-typologischen Kunstbegriff sind die meisten Formen kommunikativer Aneignungen nicht zu subsumieren. Bei diesen neuartigen Phänomenen handelt es sich gerade nicht um gängige Werktypen der Kunst. Bei Bildmontagen könnte man wohl noch davon ausgehen, dass digitale Montagen mittlerweile ein solch gängiger Werktypus sind.

Auch unter den materiellen Kunstbegriff sind kommunikative Aneignungen zumeist nicht zu fassen. Danach ist Kunst das Ergebnis freier schöpferischer Gestaltung und Ausdruck der eigenen Persönlichkeit. ${ }^{767}$ Eine schöpferische Gestaltung kann man in Einzelfällen je nach Umständen bei einigen Aneignungen annehmen, so wie auch in Einzelfällen kommunikative Aneignungen schöpferisch im Sinne des $\$ 2$ Abs. 2 UrhG sein können. ${ }^{768}$ Doch mit kommunikativen Aneignungen soll gerade nicht die Persönlichkeit selbst ausgedrückt werden, sondern es soll mit ihnen effek-

766 Vgl. S. $199 \mathrm{ff}$.

767 So auch Wandtke, Persönlichkeitsschutz versus Internet, MMR 2019, S. 142, 143.

768 Vgl. dazu S. $120 \mathrm{ff}$. 
tiv kommuniziert werden. ${ }^{769}$ Die Produktion dieser Bildphänomene ist von Anfang an auf das Teilen in Kommunikationsstrukturen ausgerichtet: Die Produktion von Bildern ist ein Akt der Massenkommunikation geworden. ${ }^{770}$ Es geht damit nicht um die Darstellung der Persönlichkeit des Aneignenden.

Der offene und relationale Kunstbegriff versteht Kunst als Kommunikationsprozess mit vielschichtigen Bedeutungsebenen. Bei kommunikativen Aneignungen kann man gerade von der Anfertigung dieser für den Kommunikationsprozess ausgehen. Durch die digitalen Kommunikationsmöglichkeiten ist das Bild ein beliebtes, da flexibles und effizientes Kommunikationsmittel geworden. Stärker noch stellt dieser Begriff jedoch auf die Mannigfaltigkeit und die Interpretationsfähigkeit des Aussagegehalts ab. ${ }^{771}$ Memes und Bildmontagen können zwar überzeichnet und zugespitzt sein. ${ }^{772}$ Dennoch ist regelmäßig nicht von vielschichtigen Bedeutungsebenen auszugehen. Memes, GiFs, Bildmontagen, Museumselfies, virale Hypes und das Teilen im Internet sind regelmäßig zwar interpretationsfähig, aber nicht sonderlich interpretationsbedürftig. Sie sind gerade dazu gedacht, um mit ihnen schnell und effizient zu kommunizieren. Dafür müssen sie auch vom Kommunikationspartner leicht verstanden werden. Kommunikative Aneignungen sind daher häufig begrenzt in ihrer Bedeutung und rasch durchschaubar. Es ist kein weiteres Nachsinnen über ihren Sinn und ihre Aussage notwendig. Sie sollen vielmehr gerade so schnell funktionieren, dass sie auch schneller als ein kurzer Text verstanden werden können. Daher sind kommunikative Aneignungen zumeist nicht vom offenen und relationalen Kunstbegriff erfasst.

Eine kunstspezifische Auslegung kommt für kommunikative Aneignungen wie Memes, GIFs und Bildmontagen damit regelmäßig nicht in Betracht. ${ }^{773}$

769 Vgl. zur Kommunikation durch Bilder im digitalen Zeitalter S. $107 \mathrm{ff}$.

$770 \mathrm{Zu}$ einer möglichen kommunikationsspezifischen Auslegung des $\$ 24$ Abs. 1 UrhG im Lichte des Art. 5 Abs. 1 S. 1 GG s. S. 265 ff.

771 BVerfG NJW 1985, S. 261, 262 - Anachronistischer Zug.

772 Aus diesen Gründen nimmt Wandtke an, dass Memes unter den offenen Kunstbegriff zu fassen sind, s. Wandtke, Persönlichkeitsschutz versus Internet, MMR 2019, S. 142, 143.

773 So im Ergebnis auch Maier, Meme und Urheberrecht, GRUR-Prax 2016, S. 397, 397. 
cc) Parallele Wertung des $₫ 23$ Abs. 1 Nr. 4 KUG

Der $₫ 23$ Abs. 1 Nr. 4 KUG sieht eine Ausnahme zugunsten der Kunstfreiheit für den Bildnisschutz des $\$ 22$ KUG vor. ${ }^{774}$ Es dürfen dann Bildnisse auch ohne Einwilligung des Abgebildeten verbreitet oder öffentlich zur Schau gestellt werden, sofern diese Verbreitung oder Schaustellung einem höheren Interesse der Kunst dient. Dies gilt jedoch nur für Bildnisse, die nicht auf Bestellung gefertigt sind. Diese Privilegierung umfasst nicht urheberrechtlich geschützte Werke, sondern nur Kunstwerke im Sinne des Art. 5 Abs. 3 GG. ${ }^{775}$ So kann eine parallele Wertung des $\$ 24$ UrhG für die Nutzung urheberrechtlicher Werke zu $\$ \$ 23$ Abs. 1, 22 KUG für die Nutzung von Bildnissen erreicht werden.

Im Fall Technoviking ging es um ein Video, das auf der Berliner Fuckparade 2000 aufgenommen wurde, auf dem ein Mann mit freiem Oberkörper tanzt. Dieses Video ging später viral, erreichte mehrere Millionen Aufrufe und wurde als Meme „Technoviking“ bekannt. ${ }^{776}$ Hierfür wurde eine Einordnung des Videos als Kunst im Sinne des $\$ 23$ Abs. 1 Nr. 4 KUG vom Berliner Landgericht abgelehnt. ${ }^{777}$ Bei Bildern, für die die Kunstfreiheit in Anspruch genommen wird, sei „bei der gebotenen Abwägung auch in Bezug zu nehmen, wie weit sich die Lebensbilddarstellung von der bebilderten Realität“ entferne. ${ }^{778}$ Das bloße „Draufhalten“, das Abfilmen der Realität wurde nicht als künstlerisch aufgefasst. Dies ist keine plausible Argumentation, da Phänomene wie Street Photography als Kunstform etabliert sind. ${ }^{779}$ Dass der Technoviking sich als Phänomen verselbständigt hat und er später als Kunstfigur wahrgenommen wurde, hat das Gericht ebenfalls nicht berücksichtigt. ${ }^{780}$ Diese Entscheidung zeigt abermals, dass es nicht gelingen wird, kommunikative Aneignungen im Digitalen unter die Kunstfreiheit zu fassen.

774 Dreier/Schulze/Specht, 6. Aufl. 2018, $\$ 23$ KUG Rn. 1.

775 Dies., a.a.O., Rn. 44.

776 S. https://de.wikipedia.org/wiki/Techno_Viking, Datum des Zugriffs: 15.01.2020.

777 LG Berlin ZUM-RD 2014, S. 105, 107 - Technoviking.

778 LG Berlin ZUM-RD 2014, S. 105, 107 - Technoviking.

779 Zur Street Photography und der Kunstfreiheit s. auch explizit das Urteil des LG Berlin, ZUM 2014, S. 729.

780 Ullrich im Interview mit Steinhau, Wolfgang Ullrich: „Urheberrechte für die sozialen Netzwerke gänzlich suspendieren“, irights info vom 18.05.2015, https://ir ights.info/artikel/wolfgang-ullrich-urheberrechte-fuer-die-sozialen-netzwerke-ga enzlich-suspendieren/25429. 
4. Fazit

In der Verblassensformel zeigt sich das Gewicht, das im Urheberrecht auf die äußere Form eines Werkes gelegt wird, um eine freie Benutzung gem. $\$ 24$ Abs. 1 UrhG zu beurteilen. Wie oben gesehen, ist aber neben der Form auch der Inhalt eines Werkes schutzfähig. Deshalb ist die Beurteilung der freien Benutzung nach dem inneren Abstand zum übernommenen Werk grundsätzlich geboten, um auch die inhaltlichen Aussagen des neuen Werkes zu berücksichtigen.

Werke der Appropriation Art werden regelmäßig einen ausreichend inneren Abstand zum Original aufweisen, da im Rahmen einer kunstspezifischen Auslegung die Kunstfreiheit des Art. 5 Abs. 3 S. 1 GG das Eigentumsinteresse des Urhebers überwiegen wird. Dies gilt lediglich dann nicht, wenn die Werke der Appropriation Art missbräuchlich sind, sie also in ein wirtschaftliches Konkurrenzverhältnis zum angeeigneten Werk treten. Für kommunikative Aneignungen im Digitalen kann die kunstspezifische Auslegung jedoch nicht greifen, hier ist daher der innere Abstand regelmäßig zu verneinen. Diese Unterschiedlichbehandlung ist schwer nachvollziehbar: Appropriation Art und kommunikative Aneignungen arbeiten mit den gleichen Mitteln und führen sogar häufig zu ähnlichen Werken. Dennoch soll das eine erlaubt sein, während das andere eine Urheberrechtsverletzung darstellt.

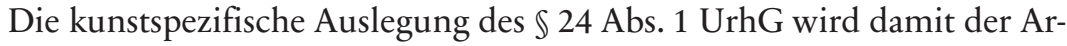
beitsweise von Aneignungen nicht gerecht. Sie ist nur eingeschränkt nützlich, um bereits etablierte Phänomene urheberrechtlich zu legitimieren. Das Kriterium des inneren Abstandes zeigt sich bisher allerdings nicht ausreichend flexibel, um auch neue, ähnliche Phänomene zu erfassen, denen nicht bereits über die Kunstfreiheit des Art. 5 Abs. 3 S. 1 GG ein Sonderstatus zugeschrieben wird. Der innere Abstand, wie er bisher verstanden und ausgelegt wird, ist damit ein ungeeignetes Kriterium, um Aneignungen im Urheberrecht entwicklungsoffen zu beurteilen.

\section{Quellenangabe gem. \$63 UrhG}

$\$ 63$ UrhG verlangt eine Quellenangabe, damit das Recht auf Anerkennung der Urheberschaft gem. $\mathbb{1} 13$ UrhG auch bei einer Rechtfertigung durch Schrankenregelungen gilt. ${ }^{781} \mathbb{\$} 24$ UrhG wird in

781 Dreier/Schulze/Schulze, 6. Aufl. 2018, \$ 63 UrhG Rn. 1. 
$\$ 63$ Abs. 1 S. 1 UrhG zwar nicht als eine solche Schrankenregelung genannt. ${ }^{782}$ In der Literatur wird zum Teil dafür plädiert, $\$ 63$ UrhG hier analog anzuwenden ${ }^{783}$, da $₫ 63$ UrhG bei vielen anderen urheberrechtlich relevanten Nutzungen ebenfalls zur Anwendung kommt, insbesondere bei $\$ 51$ UrhG. Da $\$ 51$ UrhG in seinen Anforderungen für künstlerische Auseinandersetzungen mit dem $\$ 24$ UrhG vergleichbar sei, müsste auch das Pflichtenprogramm der beiden Normen angeglichen werden. ${ }^{784}$ Diese Ansicht verkennt jedoch, dass $₫ 51$ UrhG sehr viel strengere Voraussetzungen für eine Auseinandersetzung mit anderen Werken vorschreibt, insbesondere da ein Zitatzweck gefordert wird. ${ }^{785} \$ 51$ UrhG zielt gerade nicht wie $\$ 24$ UrhG auf eine künstlerische Auseinandersetzung mit fremden Werk $\mathrm{ab}$, die Normen sind daher in ihrem Pflichtenprogramm nicht vergleichbar. $\$ 24$ UrhG ist die offenere Regelung und sollte daher auch mehr Freiheiten für die Nutzer zulassen. Für die Ablehnung einer analogen Anwendung des $\$ 63$ UrhG spricht auch, dass nach herrschender Meinung eine Verletzung des $\mathbb{1} 13$ UrhG gerade ausgeschlossen ist, sobald eine freie Benutzung gem. $\$ 24$ UrhG vorliegt. ${ }^{786}$

\section{Verhältnis von $₫ 24$ UrhG und Art. 5 Abs. 3 der InfoSoc-RL}

Inwieweit $\$ 24$ UrhG mit Art. 5 Abs. 3 lit. $\mathrm{k}$ InfoSoc-RL vereinbar ist, wird im Rahmen der Regelungsvorschläge für Aneignungen diskutiert. ${ }^{787} \mathrm{Ob}$ $\$ 24$ UrhG wegen des abschließenden Schrankenkatalogs der InfoSocRL europarechtswidrig ist, steht seit dem EuGH-Urteil Pelham/Hütter vom 29.07.2019 in Frage. Wenn schon $\$ 24$ UrhG wohl die unionsrechtliche Ermächtigungsgrundlage fehlt, dann auch erst recht der kunstspezifischen Auslegung des $\$ 24$ UrhG. Selbst wenn also $\$ 24$ UrhG nicht unionsrechtswidrig sein sollte, sondern anhand von Art. 5 Abs. 3 lit. k InfoSoc-RL redu-

782 Wie unter S. 167 Fn. 612 bereits beschrieben, ist auch strittig, ob es sich bei $\$ 24$ UrhG um eine Schrankenregelung oder eine Schutzbereichsbestimmung handelt.

783 Huttenlauch, Appropriation Art. Kunst an den Grenzen des Urheberrechts, 2010, S. 190, 204; Dreier/Schulze/Schulze, 6. Aufl. 2018, \$24 UrhG Rn. 52.

784 Huttenlauch, Appropriation Art. Kunst an den Grenzen des Urheberrechts, 2010, S. 190.

785 S. dazu ausführlicher S. $211 \mathrm{ff}$.

786 S. dazu bereits S. $136 \mathrm{ff}$.

787 Vgl. S. $278 \mathrm{ff}$. 
ziert ausgelegt wird, wird dies auch für die kunstspezifische Auslegung des $\$ 24$ UrhG gelten.

\section{Aneignung als Zitat gem. $\mathbb{S} 51 \mathrm{UrhG}$}

Die Zitierfreiheit des $₫ 51$ UrhG ist für die freie geistige Auseinandersetzung mit anderen Werken geschaffen worden ${ }^{788}$ und gestattet die Vervielfältigung, Verbreitung und öffentliche Wiedergabe eines urheberrechtlich geschützten Werkes zum Zwecke des Zitats. Im Gegensatz zur freien Benutzung gem. $\$ 24$ Abs. 1 UrhG ist gerade die unveränderte Übernahme des Werkes geschützt, da es sich nur dann um eine korrekte Wiedergabe des Zitats handelt. $\$ 24$ UrhG verlangt hingegen ein Verblassen des übernommenen Werkes. ${ }^{789}$ Die Zitierfreiheit betrifft damit nur solche Aneignungen, bei denen das fremde Werk unverändert übernommen wird.

Die Voraussetzung für das Vorliegen der Zitatschranke sind, dass ein Zitatzweck verfolgt wird (1.), das Zitat innerhalb des durch den Zitatzweck vorgegebenen Umfang erfolgt (2.) und ein selbständiges Werk geschaffen wird (3.). Zudem sind die $\$ \$ S 62,63$ UrhG zu beachten (4.).

\section{Zitatzweck}

Der Zitatzweck erfordert, dass eine „innere Verbindung“ zwischen dem zitierten und dem zitierenden Werk besteht. ${ }^{790}$ Das zitierte Werk muss zur Erläuterung des Inhalts des zitierenden, nicht des zitierten Werkes genutzt werden. ${ }^{791}$ Das Zitat darf damit gerade nicht zum Ziel haben, sich selbst eigene Ausführungen zu ersparen ${ }^{792}$, oder allein der Illustration dienen. ${ }^{793}$ Für die innere Verbindung ist daher der Belegcharakter der zitierten Stelle

788 Dreier/Schulze/Dreier, 6. Aufl. 2018, $\$ 51$ UrhG Rn. 1.

789 S. dazu auch bereits oben S. $184 \mathrm{ff}$.

790 BGH GRUR 1968, S. 607, 609 - Kandinsky I.

791 OLG München AfP 2012, S. 395 - „Mein Kampf“; Dreier/Schulze/Dreier, 6. Aufl. 2018, 551 UrhG Rn. 3; Schricker/Loewenheim/Schricker/Spindler, 5. Aufl. 2017, \51 UrhG Rn. 14, 39.

792 KG GRUR 1970, S. 616, 618 - Eintänzer.

793 BGH GRUR 2016, S. 368, 370 Rn. 25 - Exklusivinterview. 
für eigene Ausführungen entscheidend ${ }^{794}$ : Das Zitat muss als Erörterungsgrundlage dienen, zur Entwicklung des eigenen Gedankenganges oder zur kritischen Auseinandersetzung mit dem übernommenen Werk. ${ }^{795}$ Der EuGH geht davon aus, dass wesentliches Merkmal eines Zitats im Sinne des Art. 5 Abs. 3 lit. d InfoSoc-RL sei, „dass ein Werk oder ganz allgemein ein Auszug aus einem Werk von einem Nutzer, der nicht dessen Urheber ist, genutzt wird, um Aussagen zu erläutern, eine Meinung zu verteidigen oder eine geistige Auseinandersetzung zwischen dem Werk und den Aussagen des Nutzers zu ermöglichen, so dass der Nutzer eines geschützten Werkes, der sich auf die Ausnahme für Zitate berufen will, das Ziel verfol-

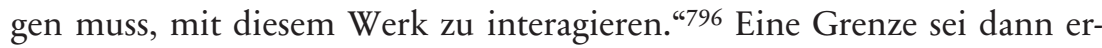
reicht, wenn das zitierte Werk nicht mehr zu erkennen sei, dann komme keine entsprechende Interaktion in Betracht. ${ }^{797}$ Dieses neue europarechtliche Verständnis des Zitats steht im Grundsatz im Einklang mit dem nationalen Verständnis des Zitatzwecks. ${ }^{798}$

Eine kunstspezifische Auslegung des $\$ 51$ UrhG erkennt das Zitat aufgrund der Kunstfreiheit gem. Art. 5 Abs. 3 GG als ästhetisches Medium an und lockert die Anforderungen an die „innere Verbindung“ für Kunstwerke. ${ }^{799}$ Dafür muss das Zitat aber als Mittel künstlerischen Ausdrucks und künstlerischer Gestaltung eingesetzt werden, um eine eigene künstlerische Aussage zu treffen. ${ }^{800}$ Zur genaueren Herleitung und dem Umfang der kunstspezifischen Auslegung sei hier auf die Ausführungen zur kunstspezifischen Auslegung des $₫ 24$ Abs. 1 UrhG verwiesen. ${ }^{801}$ Das Zitatrecht geht dann über die reine Belegfunktion hinaus. ${ }^{802}$

794 BGH GRUR 2011, S. 415, 417 Rn. 22 - Kunstausstellung im Online-Archiv; BGH GRUR 2010, S. 628, 630 Rn. 26 - Vorschaubilder I, BGH GRUR 1987, S. 34, 35 Liedtextwiedergabe I; BGH GRUR 1987, S. 362, 363 - Filmzitat.

795 Dreier/Schulze/Dreier, 6. Aufl. 2018, 551 UrhG Rn. 4; Schricker/Loewenheim/ Schricker/Spindler, 5. Aufl. 2017, \$51 UrhG Rn. 17 ff.

796 EuGH GRUR 2019, S. 929, 933 Rn. 71 - Pelham/Hütter.

797 EuGH GRUR 2019, S. 929, 933 Rn. 73 - Pelham/Hütter.

798 Leistner, „Ende gut, alles gut“... oder „Vorhang zu und alle Fragen offen“? Das salomonische Urteil des EuGH in Sachen „Pelham [Metall auf Metall]“, GRUR 2019, S. 1008, 1012.

799 BVerfG GRUR 2001, S. 149, 151 - Germania 3; BGH GRUR 2008, S. 693, 696 Rn. 44 - TV Total; OLG Brandenburg GRUR 2011, S. 141, 142 - Literarische Collage.

800 BVerfG GRUR 2001, S. 149, 151 - Germania 3.

801 S. $192 \mathrm{ff}$.

802 BGH GRUR 2008, S. 693, 696 Rn. 44 f. - TV Total. 
Dies ist bei der Appropriation Art dann denkbar, wenn mit ihr ein künstlerischer Zweck verfolgt wird. Hier stellen sich die gleichen Probleme wie bei der kunstspezifischen Auslegung des $₫ 24$ UrhG. Ebenso wie dort ist auch hier in der Regel von einem Überwiegen der Kunstfreiheit auszugehen, unter der Einschränkung jedoch, dass kein wirtschaftliches Konkurrenzverhältnis zum zitierten Werk entsteht, um das missbräuchliche Berufen auf die Kunstfreiheit zu verhindern. ${ }^{803}$ Die Appropriation Art - sofern es sich um eine unveränderte Übernahme eines fremden Werkes handelt - kann also dem Zitatzweck des $₫ 51$ UrhG genügen. So ist dies wohl insbesondere bei der Reihe „New Portraits“ (2014) von Richard Prince der Fall. Hier wird das angeeignete Werk unverändert übernommen, aber eingebettet in die Instagram-Nutzeroberfläche abgedruckt, ihm also noch eine Ebene hinzugefügt. Die Übernahme dient auch gerade als Mittel künstlerischen Ausdrucks und künstlerischer Gestaltung, sodass von einem kunstspezifischen Zitatzweck auszugehen ist. Es gibt auch gerade keine Substitutionskonkurrenz zwischen Richard Prince Drucken und den Fotografien, derer er sich angeeignet hat, da die Reihe von Richard Prince nicht als wirtschaftliches Konkurrenzprodukt zu den Fotografien angesehen wird. Hier ist ein wichtiges Argument, dass die Drucke von Prince durch die starke Vergrößerung die angeeigneten Bilder verpixelt darstellen, da sie von kleinen Screenshots auf große Leinwände gezogen wurden. Diese Verpixelung ist von Prince gewollt, denn dadurch soll deutlich werden, dass es sich bei den Drucken um Screenshots handelt. Für Abnehmer der angeeigneten Fotografien hingegen spricht die Verpixelung gerade dagegen, die Drucke von Prince als Substitute anzusehen.

Wie oben gesehen, greift die kunstspezifische Auslegung für Aneignungen des Digitalen meist nicht. ${ }^{804}$ Bei Memes wird die innere Verbindung zum zitierten Bild meist nicht ausreichen. Das Bild hat in der Regel keine Belegfunktion ${ }^{805}$, da es nicht der Erläuterung eigener Ausführungen dient, sondern Hauptbestandteil des Memes ist. Beim Teilen in sozialen Netzwerken kann die Belegfunktion erfüllt sein, wenn entsprechend eigene Ausführungen gemacht werden. Der Zitatzweck kann jedoch nicht bereits dann als erfüllt angesehen werden, wenn der Nutzer beim Upload oder

803 S.o. S. $199 \mathrm{ff}$.

804 S. $206 \mathrm{ff}$.

805 Vgl. auch Maier, Meme und Urheberrecht, GRUR-Prax 2016, S. 397, 397. 
Verlinken nur einen kurzen Kommentar hinzufügt. ${ }^{806}$ Denn dann stünde weiterhin das geteilte Bild im Vordergrund. Auch Vorschaubildern von Frame-Links bleiben problematisch, da diese in der Regel nur der Illustration dienen und nicht der inhaltlichen Auseinandersetzung. ${ }^{807}$

\section{Umfang}

Das Zitat ist nur innerhalb des vom Zitatzweck gebotenen Umfangs zulässig. Dadurch soll verhindert werden, dass die Nutzung des zitierten Werkes durch das Zitat ersetzt wird. ${ }^{808}$ Der zulässige Umfang ist unter Abwägung aller Umstände des Einzelfalles zu bestimmen, wobei insbesondere zu beachten ist, ob durch das Zitat die dem Rechteinhaber zustehenden Verwertungsmöglichkeiten beeinträchtigt werden. ${ }^{809}$ Vom Zitatzweck gedeckt kann aber ausnahmsweise auch die Übernahme ganzer Werke (sog. großes Kleinzitat) sein, insbesondere bei Werken der bildenden Kunst, Lichtbildwerken oder Lichtbildern, da die vom Zitatzweck notwendige Auseinandersetzung mit dem zitierten Werk die Kenntnis des gesamten Werkes voraussetzt. Dieses sog. Bildzitat ist grundsätzlich von der Generalklausel des $₫ 51$ UrhG erfasst. ${ }^{810}$

Darüber hinaus geht der EuGH in dem Urteil Spiegel Online/Beck davon aus, „dass die Nutzung des zitierten Werkes gegenüber den Aussagen des Nutzers akzessorischer Natur sein muss", da ansonsten die normale Verwertung des Werkes durch den Urheber beeinträchtigt wäre. ${ }^{811}$ Eine solche akzessorische Nutzung liegt bei Aneignungen jeglicher Art jedoch re-

806 Ziegler, Urheberrechtverletzungen durch Social Sharing, 2016, S. 171; Sievers, Ist erlaubt, was gefällt? Urheberrechtsverletzungen und Verantwortlichkeit beim Social Sharing, GRUR-Prax 2012, S. 229, 231.

807 Für Vorschaubilder von Bildersuchmaschinen hat der BGH entschieden, dass hier der Zitatzweck fehlt, BGH GRUR 2012, S. 602, 603 Rn. 14 - Vorschaubilder II; BGH GRUR 2010, S. 628, 630 Rn. 25 - Vorschaubilder I.

808 BGH GRUR 1987, S. 362, 364 - Filmzitat; BGH GRUR 1986, S. 59, 61 - Geistchristentum.

809 BGH GRUR 2016, S. 368, 371 Rn. 33 - Exklusivinterview.

810 LG Berlin GRUR 2000, S. 797, 797 - Screenshots; OLG Hamburg GRUR 1993, S. 666, 666 - Altersfoto; OLG Hamburg GRUR 1990, S. 36, 37 - Foto-Entnahme; Dreier/Schulze/Dreier, 6. Aufl. 2018, $\$ 51$ UrhG Rn. 24; Schricker/Loewenheim/ Schricker/Spindler, 5. Aufl. 2017, \$51 UrhG Rn. 45; Fischer, Digitale Kunst und freie Benutzung, 2018, S.73; Huttenlauch, Appropriation Art. Kunst an den Grenzen des Urheberrechts, 2010, S. 95 f.

811 EuGH GRUR 2019, S. 940, 945 Rn. 79 - Spiegel Online/Beck. 
gelmäßig nicht vor. Eine Akzessorietät, die nicht die normale Verwertung beeinträchtigt, greift auch weiter als die oben vorgeschlagene Einschränkung bei Substitutionskonkurrenz zum zitierten Werk, da auch bei fehlender Substitutionskonkurrenz eine Aneignung nicht als nebensächlich oder abhängig vom angeeigneten Werk zu verstehen ist. An dieser Voraussetzung würden Aneignungen daher regelmäßig scheitern.

\section{Selbständigkeit des zitierenden Werkes}

Das zitierende Werk muss selbständig sein vom zitierten Werk. Diese Selbständigkeit hatte der BGH bisher dann angenommen, wenn ein urheberrechtlich schutzfähiges Werk vorliegt. ${ }^{812}$ Nach dem Painer-Urteil des EuGH lässt sich zwar eigentlich vermuten, dass die Werkqualität des zitierenden Werkes nicht notwendig sei. ${ }^{813}$ Unter Selbständigkeit wird jedoch bisher verstanden, dass das zitierende vom zitierten Werk unabhängig sein muss, es sich also nicht um eine Bearbeitung oder sonstige Umgestaltung im Sinne des $\$ 23$ UrhG handeln darf. ${ }^{814}$ Es muss auch ohne die zitierten Stellen eine geistige Schöpfung bestehen bleiben. ${ }^{815}$ Diese Abgrenzung anhand von $\$ 23$ UrhG scheint im Ergebnis allerdings doch wieder die persönliche geistige Schöpfung vorauszusetzen: Denn eine Nutzung eines fremden Werkes, die sich weit genug vom Original entfernt, um nicht mehr als Bearbeitung oder sonstige Umgestaltung des $₫ 23$ UrhG eingeordnet zu werden, ist klassischerweise die persönliche geistige Schöpfung, die der $\$ 24$ UrhG voraussetzt. $\$ 23$ und $\$ 24$ UrhG unterscheiden sich gerade anhand ihrer Abweichung vom Original, wobei diese bei $\$ 24$ UrhG eben derart selbständig ist, dass die Benutzung selbst Werkqualität bekommt. ${ }^{816}$ Trotz des Painer-Urteils des EuGH ist daher davon auszugehen, dass das zitierende Werk weiterhin Werkqualität aufweisen muss.

Bei Bildmontagen wird es häufig an dieser Voraussetzung scheitern: Hier handelt es sich meist nur um eine Bearbeitung im Sinne des

812 So noch BGH AfP 2002, S. 444, 448 - Titelblattgestaltung; BGH GRUR 1994, S. 800, $802-$ Museumskatalog.

813 So EuGH GRUR 2012, S. 166, 171 Rn. 130 - Painer.

814 Dreier/Schulze/Dreier, 6. Aufl. 2018, 551 UrhG Rn. 7; Schricker/Loewenheim/ Schricker/Spindler, 5. Aufl. 2017, \$51 UrhG Rn. 21.

815 BGH GRUR 1994, S. 800, 803 - Museumskatalog; BGH GRUR 1992, S. 382, 384 - Leitsätze.

816 S. zur Voraussetzung der persönlich geistigen Schöpfung im Rahmen des \$24 UrhG S. $169 \mathrm{ff}$. 
$\$ 23$ UrhG, sodass die Montage ohne das zitierte Werk nicht ausreichend selbständig ist. ${ }^{817}$ Auch die bei Memes einfügten Texte oder bei sozialen Netzwerken eingefügten Kommentare vor Postings werden in der Regel die Anforderungen an die Selbständigkeit nicht erfüllen können. Werke der Appropriation Art sind jedoch häufig als persönliche geistige Schöpfungen im Sinne des $₫ 2$ Abs. 2 UrhG einzuordnen. ${ }^{818}$

\section{4. Änderungsverbot und Quellenangabe gem. $\$ \$ 62,63$ UrhG}

Für das Zitat gilt das Änderungsverbot gem. $\$ 62$ Abs. 1 UrhG, das zitierte Werk darf grundsätzlich also nicht verändert werden. Zulässig sind nach Abs. 3 einzig Größen- und Auflösungsänderungen oder technische bedingte Änderungen, die für das Vervielfältigungsverfahren notwendig sind. Eine Verletzung des Änderungsverbot löst einen Unterlassungsanspruch aus $\$ 97$ Abs. 1 UrhG analog aus. Auch dies zeigt, dass das Zitatrecht gem. $\$ 51$ UrhG für Aneignungen zu künstlerischen Zwecken selten den gewünschten Freiraum bieten kann, da für die Appropriation Art nur unveränderte Übernahmen erlaubt sind. Solche nutzt Prince zwar mit seiner Serie „New Portraits“ (2014), häufiger hingegen sind zumindest kleine Änderungen des angeeigneten Werkes, wie beispielsweise die Blaufärbung der Gesichter der Rastafari bei Princes „Graduation“ (2008).

Das Gebot der Quellenangabe gilt für $\$ 51$ UrhG direkt gem. $\$ 63$ Abs. 1 S. 1 UrhG. Eine fehlende Quellenangabe führt jedoch nicht zu einer unzulässigen Benutzung des angeeigneten Werkes, sondern begründet einen Unterlassungsanspruch aus $\$ \$ 97$ Abs. 1, 63 UrhG analog. ${ }^{819} \mathrm{Zur}$ Quellenangabe gem. $\$ 63$ UrhG zählt insbesondere die Urheberbezeichnung, aber in der Regel auch der Titel des genutzten Werkes. ${ }^{820}$ Für Fälle der Vervielfältigung gem. $\$ 63$ Abs. 1 S. 1 UrhG muss die Quellenangabe

817 So zur Nutzung sprachlicher Werke als künstlerische Technik der Collage oder Montage, vgl. BGH GRUR 2012, S. 819, 821 Rn. 18 - Blühende Landschaften. Zuvor noch anders: OLG Brandenburg GRUR 2011, S. 141, 142 - Literarische Collage.

818 S. oben S. $178 \mathrm{ff}$.

819 Huttenlauch, Appropriation Art. Kunst an den Grenzen des Urheberrechts, 2010, S. 107; Wandtke/Bullinger/Bullinger, 5.Aufl. 2019, \$63 UrhG Rn.31; Dreier/Schulze/Dreier, 6. Aufl. 2018, $\$ 51$ UrhG Rn. 28.

820 Dreier/Schulze/Schulze, 6. Aufl. 2018, $\$ 63$ UrhG Rn. 11. 
nicht auf der Vervielfältigung, also dem Bild, selbst angebracht werden ${ }^{821}$, sondern es wird als ausreichend erachtet, wenn die Quellenangabe neben der Darstellung bei einer Ausstellung, ansonsten in der Werkbeschreibung im Katalog, auf der Rückseite der Leinwand oder im Titel des Werkes selbst genannt wird. ${ }^{822}$ Auch bei der öffentlichen Zugänglichmachung ist gem. $\$ 63$ Abs. 2 S. 1 UrhG die Quelle anzugeben, wenn und soweit die Verkehrssitte dies erfordert.

Ausnahmsweise entfällt gem. $\$ 63$ Abs. 1 S. 3 UrhG die Verpflichtung zur Quellenangabe, wenn die Quelle nicht bekannt ist und sich nicht durch zumutbare Anstrengungen ermitteln lässt. In der Literatur wird überdies überlegt, eine „allgemeine Bekanntheit“ des genutzten Werkes ausreichen zu lassen, um das Gebot der Quellenangabe entfallen zu las$\operatorname{sen}^{823}$, da in dem Fall die Anerkennung der Leistung des Urhebers bereits gewahrt ist. Von einer solchen allgemeinen Bekanntheit ist dann auszugehen, wenn sie in den für diese Kunstart empfänglichen und interessierten Kreisen gegeben ist. ${ }^{824}$ Dies würde insbesondere Bildmontagen bekannter Kunstwerke befreien. Eine solche weite Auslegung für bekannte Werke lässt $\$ 63$ Abs. 1 UrhG jedoch nicht $\mathrm{zu}^{825}$ : Dort sind die Ausnahmen des Quellengebots aufgelistet, die als abschließend gelten müssen. Für darüberhinausgehende Ausnahmen besteht kein Anhaltspunkt im Wortlaut der Norm.

Das Gebot der Quellenangabe gem. $\$ 63$ Abs. 1 S. 1 UrhG wird durch Aneignungen der Appropriation Art verletzt, wenn nicht eine Quellenbe-

821 Das würde den Gesamteindruck des Bildes erheblich stören, vgl. Wandtke/ Bullinger/Bullinger, 5. Aufl. 2019, $\$ 63$ UrhG Rn. 16.

822 Huttenlauch, Appropriation Art. Kunst an den Grenzen des Urheberrechts, 2010, S. 108; Kakies, Kunstzitate in Malerei und Fotografie, 2007, S. 136; Schricker/Loewenheim/Dietz/Spindler, 5. Aufl. 2017, $\$ 63$ UrhG Rn. 15a.

823 So Maier, Remixe auf Hosting-Plattformen, 2018, S. 40 für Remixe; Huttenlauch, Appropriation Art. Kunst an den Grenzen des Urheberrechts, 2010, S. 108 für die Bildende Kunst; Kakies, Kunstzitate in Malerei und Fotografie, 2007, S. 136 f. für Zitate; von Becker, Parodiefreiheit und Güterabwägung. Das „Gies-Adler“Urteil des BGH, GRUR 2004, S. 104, 109 für Parodien und Hertin, Das Musikzitat im deutschen Urheberrecht, GRUR 1989, S. 159, 164 für Musikzitate. Dies lässt sich wohl aus OLG Brandenburg ZUM-RD 1997, S. 483, 485 - Stimme Brecht ableiten, wonach es ausreichen soll, wenn das Zitat in einem Sprachwerk kursiv gedruckt ist und für den verständigen Betrachter aus dem Zusammenhang identifizierbar ist.

824 So Huttenlauch, Appropriation Art. Kunst an den Grenzen des Urheberrechts, 2010, S. $108 \mathrm{f}$.

825 So auch Fischer, Digitale Kunst und freie Benutzung, 2018, S. 75; Maier, Meme und Urheberrecht, GRUR-Prax 2016, S. 397 f. 
zeichnung angebracht wird. Da die Werke der Appropriation Art das Original explizit thematisieren wollen, wird häufig im Titel des Appropriation Art das Originalwerk genannt. Auch bei Princes „New Portraits“ (2014) müsste ausreichen, dass erkennbar ist, wer das Bild ursprünglich hochgeladen hat, sofern es sich dabei um den Urheber des Bildes handelt. Bei viralen Hypes wird der Titel des Werkes, auf das Bezug genommen wird, häufig angegeben. Ansonsten wird das Gebot bei kommunikativen Aneignungen im Digitalen fast immer verletzt, da der Urheber dort meist nicht genannt wird. ${ }^{826}$

\section{Panoramafreiheit gem. $\$ 59 \mathrm{UrhG}$}

Nach der sog. Panoramafreiheit (oder auch Straßenbildfreiheit) gem. \59 UrhG ist es zulässig, Werke, die sich bleibend ${ }^{827}$ an öffentlichen Wegen, Straßen oder Plätzen ${ }^{828}$ befinden, mit Mitteln der Malerei oder Graphik, durch Lichtbild oder durch Film zu vervielfältigen, zu verbreiten oder öffentlich wiederzugeben. Damit sind im öffentlichen Raum befindliche Werke ohne Erlaubnis nutzbar. Nach der amtlichen Begründung beruht die Vorschrift „auf der Erwägung, dass die Aufstellung eines Kunstwerkes an öffentlichen Orten zum Ausdruck bringt, dass damit das Werk

826 Es greift im Internet und in sozialen Netzwerken jedoch auch nicht die Ausnahme des $\$ 63$ Abs. 2 S. 1 UrhG, der eine Quellenangabe bei der öffentlichen Wiedergabe nur bei Verkehrssitte fordert. Auch wenn die Quellenangabe dort unüblich ist, stehen dort gerade keine technischen Gründe der Urhebernennung entgegen, da die Fundstelle ohne Weiteres eingeblendet werden könnte, vgl. Dreier/Schulze/Schulze, 6. Aufl. 2018, $\$ 63$ UrhG Rn. 25; Schricker/Loewenheim/Dietz/Spindler, 5. Aufl. 2017, \$63 UrhG Rn. 15a.

827 Für das Merkmal „bleibend“ wird auf die anfängliche Widmungsbestimmung abgestellt, mit der das Kunstwerk aufgestellt worden ist, s. BGH GRUR 2002, 605, 606 - Verhüllter Reichstag, bei dem die anfängliche Zweckbestimmung durch Christo als Künstler war, das Kunstwerk „Verhüllter Reichstag“ nach Ende der Aktion endgültig zu entfernen.

828 Öffentlich sind Wege, Straßen oder Plätze, wenn sie jedermann frei zugänglich sind, unabhängig davon, ob sie in öffentlichem oder privatem Eigentum stehen, BGH GRUR 2017, S. 798, 800 Rn. 23 - Aida Kussmund; Dreier/Schulze/Dreier, 6. Aufl. 2018, $\$ 59$ UrhG Rn. 2; Schricker/Loewenheim/Vogel, 5. Aufl. 2017, 559 UrhG Rn. 16. Dies erstreckt sich auch auf Werke an Fahrzeugen, die bestimmungsgemäß im öffentlichen Straßenverkehr eingesetzt werden, s. BGH GRUR 2017, S. 798, 801 Rn. 29 - Aida Kussmund, da ansonsten das Fotografieren und Filmen im öffentlichen Raum erheblich eingeschränkt werden würde. 
der Allgemeinheit gewidmet wird“. ${ }^{829}$ Umfasst sind Werke der bildenden Kunst wie Denkmäler, Skulpturen und Brunnen und Werke der Baukunst, bei denen sich die Befugnis allerdings auf die Außenansicht beschränkt. ${ }^{830}$ Nicht umfasst sind Veränderungen des Abbildes des Werkes. ${ }^{831}$ Auf den Zweck der Vervielfältigung kommt es nicht an, sodass auch die gewerbliche Verwertung des geschützten Werkes erlaubt ist. ${ }^{832}$

$\$ 59$ UrhG kann damit insbesondere Eingriff in Urheberrechte durch Selfies rechtfertigen, die in sozialen Netzwerken geteilt werden und solche geschützten Werke mit abbilden. Museumselfies hingegen können nicht über $₫ 59$ UrhG gerechtfertigt werden, denn in der amtlichen Begründung ist die Anwendung der Regelung auf Kunstwerke, die in öffentlichen Museen ausgestellt sind, ausdrücklich abgelehnt. ${ }^{833}$ Auch bei Bildmontagen, die solche Werke, die sich an öffentlichen Orten befinden, nutzen, greift $\$ 59$ UrhG nur in Einzelfällen - nicht zulässig sind durch digitale Bildbearbeitung verfälschte Abbildungen. ${ }^{834}$

Für Bildersuchmaschinen wurde überlegt, $\mathbb{} 59$ UrhG analog für Vervielfältigungen im Internet fruchtbar zu machen. ${ }^{835}$ Denn auch im Internet befindliche Bilder seien jedermann zugänglich und das Internet sei ebenfalls ein öffentlicher Raum. Wer sein Werk ungeschützt im Internet zur Verfügung stelle, widme es in gleicher Weise wie der Urheber eines Werkes im realen öffentlichen Raum der Allgemeinheit. ${ }^{836}$ Doch dies würde im Ergebnis zu einer Erschöpfung des Rechts der öffentlichen Wiedergabe hinauslaufen, was dem Art. 3 Abs. 3 der InfoSocRL widerspräche. ${ }^{837} \mathrm{Zu}$ dem lässt sich $\$ 59$ UrhG laut BGH kein allgemeine Geltung beanspruchender Rechtsgedanke entnehmen, wonach an allgemein zugänglichen Gestaltungen durchweg ein Freihaltebedürfnis der Öffentlichkeit den Be-

829 BT-Drs. IV/270, S. 76.

830 Vgl. Dreier/Schulze/Dreier, 6. Aufl. 2018, $\$ 59$ UrhG Rn. 2.

831 LG Mannheim GRUR 1997, S. 364, 366 - Freiburger Holbein-Pferd.

832 BGH GRUR 2017, S. 390, 392 Rn. 21 - East Side Gallery.

833 BT-Drs. IV/270, S. 76.

834 OLG Köln GRUR-RR 2012, S. 457 - Liebe deine Stadt.

835 Brunn, Cache me if you can. Verfassungsrechtliche Aspekte der urheberrechtlichen Einordnung von Suchmaschinen, 2013, S. 149; Leistner/Stang, Die Bildersuche im Internet aus urheberrechtlicher Sicht - Einige grundlegende Überlegungen aus Anlass des Urteils des OLG Jena vom 27.2.2008, CR 2008, S. 499, 502.

836 Dies., a.a.O., S. 502.

837 S. dazu bereits ausführlicher S. 161. 
langen des Urhebers vorzuziehen ist. ${ }^{838}$ Eine Analogiefähigkeit der Norm scheint damit schwer vertretbar.

\section{Gesetzlich erlaubte Nutzungen für Unterricht, Wissenschaft und Institutionen gem. $\$ 60$ aff. UrhG}

Die durch das UrhWissG neu hinzugefügten $\$ \mathbb{S} 60 \mathrm{a}-\mathrm{h}$ UrhG regeln Nutzungsbefugnisse an Werken für die Bereiche der Bildung und Wissenschaft. Dabei ist Vervielfältigung, Verbreitung und öffentliche Zugänglichmachung eines Werkes in diesen privilegierten Institutionen zulässig (so $\$ 60$ a Abs. 1 UrhG für die Veranschaulichung des Unterrichts und der Lehre, $\$ 60$ b Abs. 1 UrhG für Unterrichts- und Lehrmedien, $\$ 60$ c Abs. 1 UrhG für die wissenschaftliche Forschung, $\$ 60 \mathrm{~d}$ Abs. 1 UrhG für Text und Data Mining, $\$ 60 \mathrm{e}$ Abs. 1 und Abs. 4 UrhG für Bibliotheken und $\$ 60 f$ Abs. 1, Abs. 2 UrhG für Archive, Museen und Bildungseinrichtungen, wenn sie jeweils nicht kommerziell handeln). Bei all diesen Handlungen geht es jedoch immer um die bloße Werkwiedergabe und nicht um die Umnutzung eines Bildes durch eine Zuordnungsveränderung, weshalb Aneignungen durch diese Schrankenregelungen nicht privilegiert sind. Zudem finden weder Aneignungen im künstlerischen Bereich noch Aneignungen zu kommunikativen Zwecken im Digitalen im Rahmen der hier benannten Institutionen der Bildung und Wissenschaft statt.

\section{Einverständnis des Rechteinhabers}

Eine Einräumung von Nutzungsrechten gem. $\$ 31$ UrhG, die schuldrechtliche Gestattung ${ }^{839}$ oder die schlichte Einwilligung des Rechteinhabers gem. $\mathbb{1} 183$ BGB führt dazu, dass ein Eingriff in Urheberrechte nicht rechtswidrig ist. Zwischen Künstlern der Appropriation Art und den Rechteinhabern der angeeigneten Werke ist regelmäßig keinerlei Vertragsbeziehung vorhanden. Auch im Internet sind solche vertraglichen Abreden und Verfügungen selten. Für GIFs wird jedoch häufig die Suchmaschine und

838 BGH GRUR 2001, S. 51, 53 - Parfumflakon.

839 Die schuldrechtliche Gestattung ist die Verpflichtung, bestimmte Nutzungshandlungen zu dulden und Verbotsrechte nicht auszuüben, Dreier/Schulze/ Schulze, 6. Aufl. 2018, $\$ 31$ UrhG Rn. 6; Schricker/Loewenheim/Obly, 5. Aufl. 2017, $\$ 29$ UrhG Rn. 29. 
Datenbank Giphy genutzt, die auch in die sozialen Netzwerke WhatsApp, Facebook und Facebook Messenger technisch eingebunden wurde, und die sich vertraglich die Nutzungsrechte an viele Film- und Serienausschnitten von beispielsweise $\mathrm{HBO}$, Disney, Universal und NBC hat einräumen lassen. ${ }^{840}$ Häufig geben diese sogar selbst Memes heraus an Giphy, die genutzt werden dürfen und die von Giphy verschlagwortet werden. Doch als Nutzer der Giphy Community können Nutzer auch selbst GIFs erstellen, das aus urheberrechtlich geschütztem Material bestehen kann, ohne dass hierfür eine vertragliche Absprache mit dem Urheber vorliegt. ${ }^{841}$ Die durch Giphy genutzten GIFs können daher auch rechtswidrig sein.

Anders ist es bei Memes, für die es keine so zentrale Datenbank und Suchmaschine gibt, sondern die häufig frei von Nutzern entstehen und nicht technisch unter Einbindung einer bestimmten App die vertragliche Nutzung der Urheberrechte kontrollieren können.

Für Vorschaubilder bei der Nutzung von Suchmaschinen hat der BGH das Institut der schlichten Einwilligung entwickelt. Wer seine Bilder ohne technische Vorkehrung gegen Crawler ins Internet frei zugänglich stellt, erklärt sich demnach mit der Speicherung und Anzeige des Bildes in Suchmaschinen einverstanden. ${ }^{842}$ Dies gilt auch trotz der neuen europäischen Rechtsprechung zur öffentlichen Wiedergabe weiterhin, da sich diese auf Linking und Framing, also mittelbare Verwertungen der Bilder, bezieht und nicht auf das eigenständige Hochladen von Bildern. ${ }^{843}$ Das Hochladen von Bildern in sozialen Netzwerken könnte also unter Umständen von einer schlichten Einwilligung gedeckt sein. Das Rechtsinstitut wurde zwar bisher nur für Suchmaschinen angewendet und damit begründet, dass diese für das Funktionieren des Internets unabdingbar seien. Doch ebenso lässt sich argumentieren, dass heutzutage auch damit gerechnet werden muss, dass Bilder von Nutzern in soziale Netzwerke gestellt werden, wenn dies nicht durch technische Vorkehrungen verhindert wird. ${ }^{844}$ Dagegen spricht jedoch erstens, dass es keinen vergleichbaren technischen Standard

840 Tanriverdi, Ein Gif sagt mehr als 1000 Worte, SZ vom 14.09.2015, http://www.su eddeutsche.de/digital/bewegte-bilder-ein-gif-sagt-mehr-als-worte-1.2643863.

841 GIFs können beispielsweise durch Einbindung eines YouTube-Videos erstellt werden, aus dem die GIF Animation dann gebastelt wird, s. https://giphy.com/c reate/gifmaker, Datum des Zugriffs: 15.01.2020.

842 BGH GRUR 2010, S. 628 - Vorschaubilder I. Ausführlicher dazu bereits auf S. $153 \mathrm{ff}$.

843 Vgl. bereits S. $160 \mathrm{ff}$.

844 Dazu ausführlicher bei Ziegler, Urheberrechtverletzungen durch Social Sharing, 2016, S. 189 ff.; a.A.: Rosenbaum/Tölle, Aktuelle rechtliche Probleme im Bereich 
wie den Robots Exclusion Standard zur Verhinderung von Crawlern gibt, der das Herunterladen von Bildern verhindern könnte. Außerdem fehlt es ein einem vergleichbaren Automatismus der Bildvervielfältigung und -veröffentlichung, der für Vorschaubilder von Suchmaschinen typisch ist: Die schlichte Einwilligung wurde vom BGH schließlich auch deshalb herangezogen, weil eine individuelle Überprüfung, ob ein Rechteinhaber der Bildernutzung widersprochen habe, durch Suchmaschinenbetreiber nicht möglich ist. Von Nutzern sozialer Netzwerke kann dieses individuelle Überprüfen jedoch verlangt werden, da jedes Posting seiner individuellen Kontrolle zugänglich ist. Der Gedanke der schlichten Einwilligung kann hier daher nicht fruchtbar gemacht werden. Inwieweit das Institut der schlichten Einwilligung ausgeweitet werden kann auf den sozial üblichen Gebrauch von Bildern im Internet wird unter den Lösungsansätzen im Vierten Kapitel diskutiert. ${ }^{845}$

\section{E. Fazit: Diskrepanz von Recht und Rechtswirklichkeit bei Aneignungen}

Der Gegenstand bildlicher Aneignungen ist in der Regel durch das Urheberrecht oder sonstige Rechte geschützt (vgl. A. III.), da die Schutzanforderungen an persönliche geistige Schöpfungen gem. $\$ 2$ Abs. 2 UrhG niedrig sind und überdies Fotos ansonsten als Lichtbild gem. $\$ 72$ UrhG geschützt sind. Daraus ergibt sich, dass Aneignungen zumeist sowohl Persönlichkeits- als auch Verwertungsrechte des Urhebers verletzen. Insbesondere eine Verletzung des Urheberbenennungsrecht gem. $\$ 13$ UrhG und das Gebot der Quellenangabe gem. $\$ 63$ UrhG kommen häufig in Betracht (B. I.). Aneignungen greifen zudem fast immer in das Vervielfältigungsrecht des Urhebers gem. $\$ 16$ UrhG ein (C. I.). Aneignungen zur digitalen Kommunikation werden häufig auch das Recht des Urhebers zur öffentlichen $\mathrm{Zu}$ gänglichmachung gem. $\$ 19 \mathrm{a}$ UrhG bzw. das unbenannte Recht der öffentlichen Wiedergabe gem. $\ 15$ Abs. 2 UrhG verletzen (C.III. 5.). Insbesondere dann, wenn technische Schutzmaßnahmen durch Linksetzungen umgangen werden oder wenn das Werk ohne Zustimmung des Urhebers im Internet hochgeladen wurde und der Aneignende dies kennen musste. Diese zwei Voraussetzungen liegen allerdings bei digitalen Aneignungen nur im Einzelfall vor. Auch der erneute Upload eines urheberrechtlichen

Social Media - Überblick über die Entscheidungen der Jahre 2011 und 2012, MMR 2013, S. 209, 212.

845 S. $271 \mathrm{ff}$. 
Werkes zur digitalen Kommunikation kann eine öffentliche Wiedergabe im Sinne des $\$ 19$ a UrhG darstellen.

Für Aneignungen greifen häufig keine Schrankenregelungen. Für künstlerische Aneignungen, insbesondere der Appropriation Art, ist allerdings eine Rechtfertigung über eine kunstspezifische Auslegung des $\$ 24$ Abs. 1 UrhG denkbar (D. I. 3. b), bei der in der Regel die Interessen an der Nutzung des Werkes die Eigentumsinteressen des Urhebers überwiegen werden. Eine Ausnahme greift zur Einschränkung von Missbrauch bei Substitutionskonkurrenz des Originals, also wenn die Aneignung in ein wirtschaftliches Konkurrenzverhältnis zum Aneignungsgegenstand tritt (D. I. 3. b) aa) (3)). Für kommunikative, digitale Aneignungen greifen meist keine Schrankenregelung ein, da diese gerade nicht als Kunst im Sinne des Art. 5 Abs. 3 GG geschützt werden. Damit wird eine erweiterte Auslegung des inneren Abstandes des $\$ 24$ Abs. 1 UrhG der Arbeitsweise von Aneignungen insgesamt nicht gerecht, sondern zeigt sich als nicht ausreichend flexibel, um auch auf neue Phänomene einzugehen.

Im Zweiten Kapitel wurde gezeigt, dass es sich bei Aneignungen mittlerweile um ein Massenphänomen handelt und nicht mehr um eine Technik, die lediglich eine kleine Künstlergruppe der Appropriation Art betrifft. Bilder sind in der Digitalkultur ein Rohstoff, der ständiger Veränderung und Kombination unterliegt. Aufgrund ihrer produktiven und flexiblen Nutzungsmöglichkeiten eignen sich Bilder besonders gut als Kommunikationsmittel im Internet. Diese Entwicklung der Aneignung zum Massenmedium spiegelt sich rechtlich nicht wider. Es entsteht eine Diskrepanz aus der starren rechtlichen Bewertung der Aneignung einerseits und dem geänderten Kommunikationsverhalten andererseits. Das Urheberrecht regelt Handlungen eines Nutzers in Bezug auf ein fremdes Werk - um eine solche Nutzungshandlung geht es den mithilfe Aneignungen Kommunizierenden jedoch nicht. ${ }^{846}$ Sie wollen nicht in Bezug auf das Werk handeln, sondern nutzen es lediglich als Medium, um etwas anderes damit auszusagen oder das Werk lediglich ihrem Kommunikationspartner zu zeigen. Dieser Handlungsprozess wird urheberrechtlich aber vom Werk aus betrachtet - das Urheberrecht ist fixiert auf den Begriff der Vervielfältigung, nicht jedoch auf die Einordnung der Handlungen, die das Werk als Mittel nutzen. ${ }^{847}$ Das Urheberrecht setzt sich mit Kommunikationsbedin-

846 Dreier, Bild und Recht, 2019, S. 71.

847 Vgl. Lessig, Remix. Making Art and Commerce Thrive in the Hybrid Economy, 2008, S. 268 ff. 
gungen und -normen nicht auseinander. ${ }^{848}$ Es trägt damit der Realität der Kommunikation keine Rechnung. Doch verfehlt ein solches Urheberrecht nicht sein Ziel? Sollte ein Gesetz nicht den gesellschaftlichen Realitäten entsprechen?

Das Auseinanderfallen von Recht und Rechtswirklichkeit begründet und verschärft die schon oft ausgemachte Legitimationskrise im Urheberrecht. ${ }^{849}$ Zwar muss das Recht sich nicht zwangsläufig an die Rechtwirklichkeit anpassen, doch Aufgabe der Rechtswissenschaft sollte neben der Beschäftigung mit dem geltenden Recht auch immer die Auseinandersetzung damit sein, wie das Recht sein sollte. ${ }^{850}$ Oder wie Rousseau an den damaligen König Ludwig den 16. appellierte: „Si vous voulez qu'on obéisse à vos lois, faites qu'on les aime. [Wenn Sie wollen, dass wir Ihre Gesetze beachten und gehorchen, schreiben Sie diese so, dass wir sie lieben können.]." ${ }^{851}$ Die gesellschaftliche Wirklichkeit ist damit immer zugleich Grundlage und Grund der Rechtsordnung ${ }^{852}$ : Die Rechtsordnung ist nicht ein Ideengebilde, sondern ihr Ausgangspunkt ist immer die Ordnung zwischenmenschlicher Beziehungen als gesellschaftliche Realität. ${ }^{853}$

Ein grundlegendes Problem der Anpassung des Rechts an die Rechtswirklichkeit ist die beschleunigte Technikentwicklung. Der rechtspoliti-

848 Peukert, Das Urheberrecht und die zwei Kulturen der Online-Kommunikation, GRUR-Beilage 2014, S. 77, 82.

849 So ist von der Legitimationskrise bei Marl, Der Begriff der Öffentlichkeit im Urheberrecht, 2017, S. 1; Hansen, Warum Urheberrecht?, 2009, S. 40 ff.; Stallberg, Urheberrecht und moralische Rechtfertigung, 2006, S. 25 ff.; B. Raue, Informationsfreiheit und Urheberrecht, JZ 2013, S. 280, 280; Leistner/Hansen, Die Begründung des Urheberrechts im digitalen Zeitalter. Versuch einer Zusammenführung von individualistischen und utilitaristischen Rechtfertigungsbemühungen, GRUR 2008, S. 479, 479; Geiger, Die Schranken des Urheberrechts als Instrumente der Innovationsförderung, GRUR Int. 2008, S. 459, 468; Pahud, Zur Begrenzung des Urheberrechts im Interesse Dritter und der Allgemeinheit, UFITA 2000/I, S. 99, 110 ff. zu lesen.

850 Eidenmüller, Effizienz als Rechtsprinzip, 4. Aufl. 2015, S. 2, 393 ff.; a.A. Kelsen, Reine Rechtslehre, 2. Aufl. 1960, S. 72 f.; S. 112, der eine Trennung des Seins und des Sollens von Recht (sog. Trennungsthese) postuliert. Das Sein, also der faktische Zustand, des Rechts sei allein Aufgabe der Rechtswissenschaft. Bei Moral, also Recht, wie es sein sollte, handele es sich um ein Wertesystem, das vom Recht unabhängig sei.

851 Nach Geiger, Die Schranken des Urheberrechts im Lichte der Grundrechte. Zur Rechtsnatur der Beschränkungen des Urheberrechts, in: Hilty/Peukert (Hrsg.), Interessenausgleich im Urheberrecht, 2004, S. 143, 157.

852 Troller, Rechtwirklichkeit und Rechtskonstruktion im Gewerblichen Rechtsschutz und Urheberrecht, GRUR 1980, S. 522, 523.

853 Ders., a.a.O., S. 523 f. 
sche Handlungsspielraum ist immer begrenzt durch die lange Dauer der Gesetzgebung; die technische Entwicklung vollzieht sich jedoch rasch. Daraus ergibt sich eine zeitliche Differenz. ${ }^{854}$ Das Recht will die technische Entwicklung zwar regulieren, kann auf sie aber nur mit zeitlicher Verzögerung reagieren. ${ }^{855}$ Durch eine nachträgliche Regelung kann das Recht nicht mehr gestalterisch wirken, sondern tatsächliche Entwicklungen nur noch nachzeichnen. Doch dem Rechtssystem kommt gerade in Zeiten veränderter Lebensumstände durch beschleunigte Technikentwicklung eine innovationsfördernde und koordinative Funktion zu. ${ }^{856}$

Die Legitimationskrise des Urheberrechts findet ihren Grund in der Diskrepanz zwischen einem Rechtssystem, das für das analoge Zeitalter entwickelt wurde, und einer Rechtswirklichkeit des digitalen Zeitalters. Diese Legitimationskrise korreliert auch mit einem Akzeptanzverlust des Urheberrechts und beide bedingen sich gegenseitig. ${ }^{.57}$ Das Urheberrecht sanktioniert im Digitalen alltäglich gewordene Nutzungshandlungen und wird deshalb nicht mehr respektiert, weil es nicht mehr glaubwürdig legitimiert erscheint (Akzeptanzverlust durch Legitimationskrise). 858 Umgekehrt führt die fehlende Befolgung des Urheberrechts zu einem steigenden Legitimationsdruck auf das Urheberrecht (Legitimationskrise durch Akzeptanzverlust). ${ }^{859}$ Das Urheberrecht kann aber nur effektiv zwischenmenschliche Beziehungen regulieren, wenn es auch akzeptiert und befolgt wird. ${ }^{860}$ Wenn also das Urheberrecht nicht mehr die gesellschaftliche Realität widerspiegelt und deshalb nicht mehr vom gesellschaftlichen Konsens getragen wird, ist auch die Effektivität des Urheberrechts in Gefahr. ${ }^{861}$

Daher soll nun im nächsten Kapitel nach Strategien gesucht werden, die rechtlichen Freiraum für kommunikative digitale Aneignungshandlungen

854 Vgl. dazu auch Dreier, Bild und Recht, 2019, S. 64.

855 Karl, Wettlauf von Technik und Recht, 2018, S. 78; Schricker/Loewenheim/ Loewenheim, 5. Aufl. 2017, Einl. Rn. 3.

856 Karl, Wettlauf von Technik und Recht, 2018, S. 78.

857 Hansen, Warum Urheberrecht?, 2009, S. 2, S. $74 \mathrm{ff}$.

858 Ders., a.a.O., S. 74.

859 Ders., a.a.O., S. 74.

860 Es gab zwar schon immer rechtliche Vorgaben, die nicht befolgt wurden, aber dennoch notwendig sind, wie z.B. im Bereich des Schwarzfahrens oder der Steuerhinterziehung. Nichtbefolgung des Rechts führt nicht automatisch zum Verlust der Berechtigung der rechtlichen Regelung. Doch ebenso wenig kann man gesellschaftliche Wirklichkeit vom Recht fernhalten und davon ausgehen, dass die Rechtswirklichkeit nicht ohne Rückwirkung auf die Legitimität einer Norm bleibt, vgl. Hansen, Warum Urheberrecht?, 2009, S. 74 f.

861 Ders., a.a.O., S. 75. 
schaffen können. Dabei soll gezeigt werden, dass das Urheberrecht durchaus so ausgelegt werden kann, dass gesellschaftlicher Rechtswirklichkeit Rechnung getragen wird. Das kulturelle Freihaltebedürfnis für bestimmte Aneignungsformen soll damit eine rechtliche Grundlage im Urheberrecht finden. 


\section{Viertes Kapitel: Strategien zur Freiraumschaffung für Aneignungen}

In diesem Kapitel sollen Strategien für das Urheberrecht entwickelt und dahingehend evaluiert werden, wie viel rechtlichen Freiraum sie für Aneignungshandlungen schaffen können. Ziel ist, eine Strategie zu finden, die der gesellschaftlichen Rechtswirklichkeit der massenhaften Nutzung von Aneignungen Rechnung trägt (s. dazu das Zweite Kapitel). Diese Aneignungen sind zumeist rechtlich bisher unzulässig (s. dazu das Dritte Kapitel). Es soll eine rechtliche Grundlage im Urheberrecht für das kulturelle Freihaltebedürfnis für bestimmte Aneignungsformen gefunden werden. Dabei stellt sich die Frage, was das Urheberrecht überhaupt leisten soll und welche Strategien dem Urheberrecht zugrunde gelegt werden können, um grundsätzlich Freiraum für Handlungen zu schaffen. Diese Strategien sollen dann jeweils in Bezug auf das Freihaltebedürfnis für Aneignungen beurteilt werden.

Im Mittelpunkt des folgenden Kapitels steht die Überlegung, dass das Urheberrecht seine Regeln nicht aus sich heraus generiert, sondern verschiedene Strategien oder Ansätze verfolgt werden können zum Verständnis des Urheberrechts, die jeweils unterschiedliche Auswirkungen auf die verschiedenen Akteure des Urheberrechts (Urheber, Nutzer, Verwerter, Allgemeinheit) haben. Die Auslegung und Anwendung des Urheberrechts ist in hohem Maße davon abhängig, welcher moralischen Konzeption des Urheberrechts man anhängt. ${ }^{862}$ Bei der Rechtsfindung spielt immer das Vorverständnis des Rechtsanwenders eine Rolle und das Ergebnis ist durch sein Rechtsverständnis geprägt. Esser spricht vom Anwendungszirkel einer dogmatischen Interpretation: Der Anwendungsakt ist von der Verständnismöglichkeit abhängig und die Verständnismöglichkeit von der Anwendungsvorstellung. ${ }^{863}$ Für das Rechtsverständnis ist daher immer der Standpunkt zum „Warum“, zum Geltungsgrund des Rechts ${ }^{864}$ aufzufinden. Bei der Frage, wie Freiraum für urheberrechtliche Handlungen geschaffen

862 S. dazu Stallberg, Urheberrecht und moralische Rechtfertigung, 2006, S. 29.

863 Esser, Vorverständnis und Methodenwahl in der Rechtsfindung, 1970, S. 136.

864 Rüthers/Fischer/Birk, Rechtstheorie mit juristischer Methodenlehre, 10. Aufl. 2018, Rn. 620. 
werden kann, ist dabei maßgeblich auf die moralische Rechtfertigung des Urheberrechts überhaupt abzustellen.

Als Strategien, die grundsätzlich Freiräume für Handlungen schaffen können, sollen hier die drei folgenden untersucht werden: Der Fokus auf den individuellen Urheber (A.), die Privilegierung des Künstlerischen (B.) und ein kommunikatives Verständnis des Urheberrechts (C.). Es soll untersucht werden, wie die jeweilige Strategie definiert werden kann (jeweils I.), wie sie legitimiert werden kann durch die Schutzgründen des Urheberrechts insgesamt (jeweils II.) und wie sie ausgestaltet sein kann zur Freiraumschaffung (jeweils III.). Jede Strategie soll kritisch beurteilt werden dahingehend, in Bezug auf wen der jeweilige Ansatz das Urheberrecht angemessen ausgestaltet (jeweils IV.). Dann sollen die Auswirkungen der Strategie auf das Freihaltebedürfnis für Aneignungen untersucht werden (jeweils V.). Insbesondere soll untersucht werden, inwieweit mithilfe der Strategie das Recht der Rechtswirklichkeit von Aneignungen angeglichen werden kann und dadurch die Effektivität des Urheberrechts gesteigert werden kann.

Die vorgestellten Strategien stellen dabei selbstverständlich nur einige der insgesamt denkbaren dar - es sind aber die, die Aneignungen im besonderen Maße betreffen. Eine erschöpfende Analyse kann in diesem Rahmen nicht geleistet werden, sondern wäre eine eigenständige wissenschaftliche Arbeit. Zudem sei darauf hingewiesen, dass die Einordnungen zu den Rechtfertigungsgründen des Urheberrechts dem Stand der Forschung entsprechen und sich die Einordnung auf die darin entwickelten Rechtfertigungsgründe stützt. ${ }^{865}$

\section{A. Fokus auf den individuellen Urheber}

\section{Definition}

Ein individualistischer Ansatz setzt den Fokus auf die Beziehung des Urhebers zu seinem Werk und steht damit im Gegensatz zu einem kollektivistischen Ansatz, der die Beziehung der Gesellschaft zum urheberrechtlichen

865 Zum Stand der Forschung der moralischen Rechtfertigungsgründe des Urheberschutzes s. Hansen, Warum Urheberrecht?, 2009; Stallberg, Urheberrecht und moralische Rechtfertigung, 2006; Oberndörfer, Die philosophische Grundlage des Urheberrechts, 2005 und Marl, Der Begriff der Öffentlichkeit im Urheberrecht, 2017, der sich ebenfalls mit den drei zuvor genannten auseinandersetzt. 
Werk würdigt. ${ }^{866}$ Das Urheberrecht betrifft zwar die Interessen von Urhebern, Verwertern, Nutzern und der Allgemeinheit, die im Rahmen einer Interessenabwägung miteinander abgewogen werden müssen. Nach dem individualistischen Ansatz haben diese Interessen dabei aber nicht alle das gleiche Gewicht, sondern dem Schutz des schöpferisch tätigen Urhebers kommt eine besondere Bedeutung zu. ${ }^{867}$ Individualrechtliche Aspekte des Urheberrechts stehen hier also im Vordergrund. ${ }^{868}$ Durch den Fokus auf den individuellen Urheber wird mit diesem Ansatz Freiraum geschaffen für die Interessen des Urhebers und seine Verwertung des Werkes.

Dieser Ansatz lässt sich zum einen damit begründen, dass in Deutschland ein „Urheberrechtsgesetz“ das Urheberrecht regelt - und nicht ein „copyright“. Hier zeigt sich bereits begrifflich die Person des Urhebers als maßgeblich für das Verständnis dieses Rechts - und nicht die Nutzungshandlung mit dem Urheberwerk wie beim „copyright“. Auch stellt durch die Paragraphen $\mathbb{1} 1$ und $\mathbb{1 1}$ UrhG schon die Konstruktion des Urheberrechtsgesetzes den Urheber in den Mittelpunkt des Gesetzes ${ }^{869}$ und funktioniert als Ausgangspunkt für die folgende rechtliche Regelung des Urheberrechts. Ebenfalls steht die Individualität des Werkes, also die Prägung des Werkes durch die Persönlichkeit des Urhebers, als maßgebliches Kriterium für die Schutzfähigkeit eines Werkes. Der Schutzgegenstand und die Schutzbedingungen sind also abermals von der Person des Urhebers her gedacht. Weiterhin lässt sich dieser Auslegungsansatz durch die Ausgestaltung des Urheberrechtsgesetzes legitimieren: Der Werkkatalog und das System der Verwertungsrechte sind offen und generalklauselartig formuliert, der Schrankenkatalog hingegen ist geschlossen und steht zusätzlich sogar unter dem Vorbehalt des Dreistufentests. ${ }^{870}$

866 Diese Definition ist angelegt an die Definition der individualistischen Rechtfertigung des Urheberrechts, vgl. Stallberg, Urheberrecht und moralische Rechtfertigung, 2006, S. 48; Hansen, Warum Urheberrecht?, 2009, S. 87.

867 Obly, Urheberrecht in der digitalen Welt, Gutachten F zum 70. Deutschen Juristentag, 2014, S. 19.

868 So auch Rehbinder/Peukert, Urheberrecht, 18. Aufl. 2018, Rn. 75; Schack, Urheber- und Urhebervertragsrecht, 9. Aufl. 2019, Rn. 61; Hubmann, Das Recht des schöpferischen Geistes, 1954, S. 5 ff.

869 Hansen, Warum Urheberrecht?, 2009, S. 40.

870 Ohly, Urheberrecht in der digitalen Welt, Gutachten F zum 70. Deutschen Juristentag, 2014, S. 19. 
II. Individualistische Rechtfertigungsgründe des Urheberrechtsschutzes als Grundlage

Zum Verständnis der Ausprägung eines individuellen Verständnisses des Urheberrechts soll zurückgegriffen werden auf Begründungsmodelle für Urheberrechtsschutz. Diese analysieren, wie das Urheberrecht moralisch gerechtfertigt werden kann. ${ }^{871}$ Diese Begründungsansätze prägen, wie oben gesehen, die Auslegung und Anwendung des Urheberrechts. Stallberg, Hansen und Marl unterscheiden die verschiedenen Rechtfertigungsmöglichkeiten des Urheberrechtsschutzes nach den Kategorien individualistisch vs. kollektivistisch. ${ }^{872}$ Unter den möglichen Begriffskategorien deontologisch/teleologisch ${ }^{873}$; utilitaristisch/nicht-utilitaristisch ${ }^{874}$ und individualistisch/kollektivistisch zeichnet sich letztere Kategorisierung dadurch aus, dass damit das Werk als Ausgangspunkt verwendet wird und die Begriffe neutraler und damit spezifischer sind. ${ }^{875}$ Schließlich ist die Unterscheidung in individualistisch vs. kollektivistisch auch deshalb über-

871 Stallberg, Urheberrecht und moralische Rechtfertigung, 2006, S. 55.

872 Vgl. Stallberg, Urheberrecht und moralische Rechtfertigung, 2006, S. 47 ff.; Hansen, Warum Urheberrecht?, 2009, S. 83 ff.; Marl, Der Begriff der Öffentlichkeit im Urheberrecht, 2017, S. 40 ff.

873 Die Unterscheidung in deontologisch und teleologisch bezieht sich auf die zwei wesentlichen Strömungen der normativen Ethik, wobei die Deontologie Handlungen nach dem Willen des Handelnden oder seinen zugrundeliegenden Erwägungen bewertet und die teleologische Ethik eine Handlung nach ihren Folgen beurteilt, so Hansen, Warum Urheberrecht?, 2009, S. 83; Stallberg, Urheberrecht und moralische Rechtfertigung, 2006, S. 47 m.w.N.

874 Utilitaristisch meint die Orientierung an einem allgemeinen gesellschaftlichen Nutzen, wohingegen nicht-utilitiaristisch gerade keine solche Orientierung aufweist, Hansen, Warum Urheberrecht?, 2009, S. 85; Stallberg, Urheberrecht und moralische Rechtfertigung, 2006, S. 47.

875 Marl, Der Begriff der Öffentlichkeit im Urheberrecht, 2017, S. 43; Stallberg, Urheberrecht und moralische Rechtfertigung, 2006, S. 47. Insbesondere die Unterscheidung utilitaristisch/nicht-utilitaristisch wird häufig genutzt, um pauschal über das anglo-amerikanische Copyright im Vergleich zum kontinentaleuropäischen droit d'auteur-System zu sprechen und meinte damit nicht mehr den klassischen Theoriegehalt des Utilitarismus nach Bentham, so Hansen, Warum Urheberrecht?, 2009, S. 84 f. Bentham hingegen meint mit Utilitarismus das "größte Glück der größten Zahl“, also ein Prinzip der maximalen Bedürfnis- und Interessenbefriedigung innerhalb der sozialen Ordnung, vgl. Bentham, An Introduction to the Principles of Morals and Legislation [1789], 1996, S. $11 \mathrm{ff}$. 
zeugend, weil sie nicht so unspezifisch ist wie das Denken in Handlungsfolgen der normativen Ethik. ${ }^{876}$

Die Unterscheidung zwischen individualistischen und kollektivistischen Rechtfertigungsgründen stellt das Denken in Beziehungen zum Werk in den Vordergrund und die Frage, für wen geistige Werke Bedeutung haben. ${ }^{877}$ Stallberg kommt mit dieser Frage zu den Unterscheidungen zwischen den Beziehungen von Urheber und Werk einerseits und von Gesellschaft und Werk andererseits. ${ }^{878} \mathrm{Er}$ meint damit eine moralische Beziehung (Primärbeziehung), auf deren Grundlage eine rechtliche Beziehung (Sekundärbeziehung) begründet wird. ${ }^{879}$ Der individualistische Ansatz setzt dabei den Fokus auf die Beziehung des Urhebers zu seinem Werk. ${ }^{880}$ Der Urheber als Individuum steht mit seinen ideellen und materiellen Interessen im Zentrum, und seine Bedürfnisse haben grundsätzlich Vorrang vor den Bedürfnissen der Gemeinschaft. ${ }^{881}$ Individualistische Ansätze entspringen damit immer der Vorstellung, ohne das Urheberrecht sei die Freiheit oder die Gerechtigkeit in Bezug auf den Urheber beeinträchtigt. ${ }^{82}$

Dieser individualistische Ansatz wird von verschiedenen Rechtfertigungsvarianten vertreten, die im Folgenden knapp skizziert werden sollen. Dabei wird die Untergliederung Stallbergs in arbeits-basierte, persönlichkeits-basierte und werk-basierte Rechtfertigungstheorien übernommen. ${ }^{883}$

\section{Arbeitstheoretische Rechtfertigung}

Arbeitstheoretische Rechtfertigungen stellen die Schöpfungshandlung des Urhebers in den Vordergrund. ${ }^{884}$ Durch die Handlung habe der Urheber ein Anrecht auf das Produkt dieser Handlung. Diese Rechtfertigungstheorie ist häufig naturrechtlich geprägt: Das Urheberrecht wird als ein a priori vorstaatlich vorgegebenes und grundsätzlich unbeschränktes Recht be-

876 Stallberg, Urheberrecht und moralische Rechtfertigung, 2006, S. 47 f.; Hansen, Warum Urheberrecht?, 2009, S. 85.

877 Stallberg, Urheberrecht und moralische Rechtfertigung, 2006, S. 48.

878 Ders. a.a.O., S. 48.

879 Ders. a.a.O., S. 48.

880 Ders. a.a.O., S. $46 \mathrm{ff}$.

881 Hansen, Warum Urheberrecht?, 2009, S. 85.

882 Marl, Der Begriff der Öffentlichkeit im Urheberrecht, 2017, S. 46.

883 Stallberg, Urheberrecht und moralische Rechtfertigung, 2006, S. 58.

884 Ders., a.a.O., S. 58. 
trachtet. ${ }^{885}$ Sie geht zurück auf die Arbeitstheorie John Lockes, die auf die Entstehung des Werkes durch die Arbeit eines Menschen aufbaut und nach der dem Menschen ein natürliches Recht an den Früchten seiner Arbeit zusteht. ${ }^{886}$ Lockes Arbeitstheorie bezieht sich zwar auf Sacheigentum, wurde aber häufig übertragen für die Rechtfertigung von Eigentum an Immaterialgütern ${ }^{887}$ und insbesondere in Deutschland in der Diskussion um das geistige Eigentum im späten 18. Jahrhundert von Kant und Fichte rezipiert. Nach Fichte besitzt der Verfasser ein „natürliches, angeborenes, unzuveräußerndes Eigentumsrecht “888. Dieses Eigentumsrecht führt er zurück auf den Schaffensprozess des Werkes: „Diese Bildung der Dinge durch eigene Kraft (Formation) ist der wahre Rechtsgrund des Eigentums." "889 Etwas anders als Locke verstehen Fechner und Hubmann die das Eigentum begründende Handlung. Fechner sieht die „Leistung“890 als zentrales Element für die Begründung des Schutzes geistigen Eigentums und Hubmann den „Aufwand an seelischer Energie oder an körperlichen Kräften “. ${ }^{891}$ Diese Leistung oder dieser Aufwand sollen durch das Urheberrecht belohnt werden. Auch Kohler knüpft an die schöpferische Arbeit als Legitimationsquelle des Urheberrechts an: „Die philosophische Begründung des Eigenthums und des Immaterialrechts liegt in der Arbeit, richtiger, in der Güterschöpfung; wer ein neues Gut schafft, hat das natürliche Anrecht

885 Hansen, Warum Urheberrecht?, 2009, S. 88.

886 Locke, Zwei Abhandlungen über die Regierung [1690], 1977, S. 217 f., $\$ 28$, Hervorhebungen im Original: „Es war meine Arbeit, die sie dem gemeinsamen Zustand, in dem sie sich befanden, enthoben hat und die mein Eigentum an ihnen bestimmt hat." Vgl. bereits zur Eigentumsbegründung durch Aneignung nach John Locke S. 28 ff.

887 Dies kritisiert Oberndörfer, Die philosophische Grundlage des Urheberrechts, 2005, S. $126 \mathrm{ff}$. damit, dass es an einem greifbaren geistigen Gut fehle, an dem ein Aneignungsrecht begründet werden könne. Das Prinzip der Endlichkeit der natürlichen Ressourcen fehle im Gebiet des geistigen Eigentums, weshalb ein immaterielles Gut durch Konsum oder Bearbeitung in seiner Existenz nicht beeinträchtigt werde. Deshalb sei eine Übertragung der Arbeitstheorie Lockes auf die Legitimationsgründe des geistigen Eigentums nicht stichhaltig.

888 Fichte, Beweis der Unrechtmäßigkeit des Büchernachdrucks [1793], UFITA 106 (1987), S. 155, 163.

889 Fichte, Beitrag zur Berichtigung der Urtheile des Publicums über die französische Revolution [1793], in: Schulz/Strecker (Hrsg), Werke Bd. 1 Staatsphilosophische Schriften, 1919, S. 83.

890 Fechner, Geistiges Eigentum und Verfassung, 1999, S. $130 \mathrm{ff}$.

891 Hubmann, Das Recht des schöpferischen Geistes, 1954, S. 33. 
daran. “892 In diesem Sinne wird auch auf die naturrechtliche Fundierung des Urheberrechts verwiesen, indem das Urheberrecht als „Ausdruck des naturrechtlichen Grundsatz suum cuique ${ }^{\prime 893}$ verstanden wird: Der Gesetzgeber muss das Urheberrecht also nicht erst verleihen, sondern es anerkennen und durchsetzen. ${ }^{894}$ Ein solches naturrechtliches Fundament des Urheberrechts hat zunächst auch der BGH vertreten in der Grundig-ReporterEntscheidung: „Die Herrschaft des Urhebers über sein Werk [...] wird ihm hiernach [nach dem modernen Urheberrecht] nicht erst durch den Gesetzgeber verliehen, sondern folgt aus der Natur der Sache, nämlich seinem geistigen Eigentum, das durch die positive Gesetzgebung nur seine Anerkennung und Ausgestaltung findet. ${ }^{\text {" }} 995$

\section{Personalistische Rechtfertigung}

Die personalistische Rechtfertigung stellt die Persönlichkeit des Urhebers in den Mittelpunkt: Urheber und Werk haben ein personales Abhängigkeitsverhältnis, das durch die Verleihung von Urheberrechtsschutz zu schützen sei. ${ }^{896}$ Stallberg und Marl unterscheiden die personalistischen Rechtfertigungen nach identifikationstheoretischen und entwicklungstheoretischen Typen. ${ }^{897}$ Beiden Ansätzen liegt als Prämisse die Freiheit des Urhebers zugrunde, sodass Urheberrechtsschutz auch als Schutz der Freiheit des Urhebers verstanden wird. ${ }^{898}$

\section{a) Identifikationstheoretisch}

Nach dem identifikationstheoretischen Typus kommt das Werkschaffen durch eine psychische Beziehung von Urheber und Werk zustande. Diese

892 Kohler, Das Autorrecht, 1880, S. 98 f.; Hansen, Warum Urheberrecht?, 2009, S. 88 Fn. 356.

893 Schack, Urheber- und Urhebervertragsrecht, 9. Aufl. 2019, Rn. 5; Hubmann, Das Recht des schöpferischen Geistes, 1954, S. 6 ff.

894 Hubmann, Das Recht des schöpferischen Geistes, 1954, S. 74; Hansen, Warum Urheberrecht?, 2009, S. 88.

895 BGH GRUR 1955, S. 492, 496 - Grundig-Reporter.

896 Stallberg, Urheberrecht und moralische Rechtfertigung, 2006, S. 58.

897 Ders., a.a.O., S. 111; Marl, Der Begriff der Öffentlichkeit im Urheberrecht, 2017, S. 55.

898 Stallberg, Urheberrecht und moralische Rechtfertigung, 2006, S. 112. 
Beziehung sei zu schützen, um sie als Teil der Identität des Urhebers zu schützen. Demnach integriert der Urheber seine Persönlichkeit in sein Werk. ${ }^{899}$ Als Bestandteil seiner Persönlichkeit müsse das Werk daher geschützt werden, da dem Urheber ansonsten Identitätsstörungen drohen. ${ }^{900}$ Ebenso repräsentiert das Werk auch die Persönlichkeit des Urhebers und wird mit ihm identifiziert. ${ }^{901}$ Die Individualität eines Werkes und damit die Prägung durch den Urheber selbst sei schließlich maßgeblicher Schutzgrund des Urheberrechts und damit auch zentrale Legitimationsquelle des Urheberschutzes. ${ }^{902}$ Zum Teil wird sogar von einer metaphysischen Verbindung von Urheber und Werk ausgegangen: In der Literatur wird immer wieder von einem geistigen Band zwischen Werk und Urheber gesprochen. ${ }^{903}$ Ulmer bezeichnet das Werk gar als „geistiges Kind“ des Urhebers. ${ }^{904}$ Dieses Verständnis hat zur Entwicklung der Lehre vom Urheberrecht als Persönlichkeitsrecht geführt, bei der selbst die vermögenswerten Teile des Urheberrechts bloß als Ausfluss des persönlichkeitsrechtlich begründeten Urheberrechts verstanden wurden. ${ }^{905}$

\section{b) Entwicklungstheoretisch}

Der entwicklungstheoretische Typus geht auf Grundlage der Eigentumstheorie von Hegel davon aus, dass Urheberrecht notwendig sei, um die Entwicklung des Urhebers zur Person zu gewährleisten. ${ }^{906}$ Für Hegel ist Privateigentum die notwendige Bedingung für menschliche Freiheit. ${ }^{907}$

899 Integrationsthese nach ders., a.a.O., S. 140.

900 Dies begründet Stallberg damit, dass ansonsten die personale Identität, die durch seine Eigenschaft als Urheber des Werkes mitkonstituiert wird, mit der soziale Identität, die diese Eigenschaft ausschließt und leugnet, in Konflikt geraten würde, Ders., a.a.O., S. 140.

901 Repräsentationsthese nach Ders., a.a.O., S. 142.

902 Pfeifer, Individualität im Zivilrecht, 2001, S. 128.

903 Ulmer, Urheber- und Verlagsrecht, 3. Aufl. 1980, S. 114 f.; Hubmann, Das Recht des schöpferischen Geistes, 1954, S. 33.

904 Ulmer, Urheber- und Verlagsrecht, 3. Aufl. 1980, S. 118.

905 Rehbinder/Peukert, Urheberrecht, 18. Aufl. 2018, Rn.148; von Gierke, Deutsches Privatrecht Bd. I: Allgemeiner Teil und Personenrecht [1895], Nachdruck in UFITA 125 (1994), S. 103, 116; Rehbinder, Felix Dahn und Karl Gareis zur Theorie des Urheberrechts, UFITA 129 (1995), S. 69 ff.

906 Stallberg, Urheberrecht und moralische Rechtfertigung, 2006, S. 111; Marl, Der Begriff der Öffentlichkeit im Urheberrecht, 2017, S. 55.

907 Hegel, Grundlinien der Philosophie des Rechts [1821], 2015, S. 102 ff., $\mathbb{} 41 \mathrm{ff}$. 
Hegel geht dabei von einem anderen Menschenbild aus als Locke: Sein Ausgangspunkt ist der aufgrund seines denkenden Geistes freie Mensch, der als Person zunächst jedoch nur abstrakt existiert. ${ }^{908}$ Durch den äußeren Gegenstand, der dem Menschen rechtlich zugeordnet wird, wird sich dieser seiner Existenz reflexiv bewusst. ${ }^{909}$ „Die Person muß sich eine äußere Sphäre ibrer Freiheit geben, um als Idee zu sein. "910, so Hegel. Ausdruck dieser äußeren Sphäre sei das Eigentum und damit sei das Eigentum Verwirklichung der Willensfreiheit. ${ }^{911}$ Eigentum entsteht nach Hegel durch die Kennzeichnung als Eigenes und damit einer Übertragung des inneren Willens in die äußere Welt. ${ }^{912}$

Auf das Urheberrecht übertragen bedeutet das, dass sich der Urheber nur zur Person entwickeln kann, wenn das Urheberrecht als Schutz der spezifischen Beziehung zwischen Urheber und Werk verliehen wird. ${ }^{913}$ Hierzu hat sich Hegel selbst wie folgt geäußert: „Kenntnisse, Wissenschaften, Talente usf. sind freilich dem freien Geiste eigen und ein Innerliches desselben, nicht ein Äußerliches, aber ebensosehr kann er ihnen durch die Äußerung ein äußerliches Dasein geben und sie veräußern [...]. "914 Das Individuum kann also das Geistige in die Äußerlichkeit, also in die Sphäre des Eigentums, entlassen. Hegel geht davon aus, dass eine Aneignung der erbrachten Leistungen durch geistige Arbeit zunächst im Inneren der Person stattfindet, dann aber eine äußere Formgebung voraussetzt. ${ }^{915}$ Das Eigentum an diesen geistigen Leistungen ermögliche es dem Individuum, sein Person-Sein gegenständlich und erfahrbar zu machen, indem sein subjektiver Wille, eine Sache besitzen zu wollen, anerkannt und damit objektiv wird. ${ }^{916}$ Das Urheberrecht wird damit zur Notwendigkeit, in der der Urheber sich selbst als Person findet. ${ }^{917}$

908 Oberndörfer, Die philosophische Grundlage des Urheberrechts, 2005, S. 103.

909 Stallberg, Urheberrecht und moralische Rechtfertigung, 2006, S. 121.

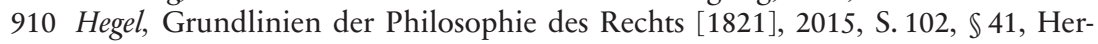
vorhebung im Original.

911 Ders., a.a.O., S. 114 f., $\ 49$ Zusatz, $\$ 51$.

912 Ders., a.a.O., S. 121, $\$ 56$.

913 Stallberg, Urheberrecht und moralische Rechtfertigung, 2006, S. $112 \mathrm{f}$.

914 Hegel, Grundlinien der Philosophie des Rechts [1821], 2015, S. 104, $\$ 43$, Hervorhebung im Original.

915 Vgl. dazu auch Marl, Der Begriff der Öffentlichkeit im Urheberrecht, 2017, S. 59.

916 Stallberg, Urheberrecht und moralische Rechtfertigung, 2006, S. 121.

917 Ders., a.a.O., S. 113. 


\section{Werk-basierte Rechtfertigung}

Die werk-basierte Rechtfertigung des Urheberrechtsschutzes rekurriert auf die Immaterialität von Werken. Aufgrund ihrer Immaterialität hängen Werke auch nach ihrer Erschaffung weiterhin vom Urheber ab. ${ }^{918}$ Mit der Autortheorie von Kant wird dies kommunikationstheoretisch begründet: Das Werk als „Rede des Verfassers an das Publikum“919 ist kommunikativ abhängig von seinem Autor. Die inhaltliche und sprachliche Erfassung des Werkes ist nur mit dem Autor möglich ${ }^{920}$, weshalb eine Zurechnung des Werkes an ihn notwendig sei. Nur so könne die Kommunikation des Autors geschützt werden. Die Autortheorie von Fichte begründet den Urheberrechtsschutz exklusivitätstheoretisch: Fremder Gedanken und Inhalte (des Werkes) könnten nie in der Form des fremden Gedankengangs (des Autors) aufgenommen werden, sondern immer nur im eigenen Gedankengang. ${ }^{921}$ Damit könne sich nur der Urheber des Werkes dessen geistige Form aneignen, weshalb sie ihm zugewiesen sein sollte.

\section{Ausgestaltung eines individualistischen Ansatzes}

Im Folgenden soll gezeigt werden, wie die Anwendung des individualistischen Ansatzes sich praktisch auswirken kann und wie dadurch Freiraum für urheberrechtliche Handlungen geschaffen werden kann. Dazu soll auf die angemessene Beteiligung des Urhebers (1.) und auf den Grundsatz der engen Auslegung von urheberrechtlichen Schrankenbestimmungen (2.) eingegangen werden.

\section{Angemessene Beteiligung des Urhebers}

Der Fokus auf den individuellen Urheber bei der Auslegung des Urheberrechts zeigt sich beispielsweise am Grundsatz der angemessenen Beteiligung des Urhebers. Das BVerfG sieht die vermögenswerten Interessen des

918 Ders., a.a.O., S. 58.

919 Kant, Von der Unrechtmäßigkeit des Büchernachdrucks [1785], UFITA 106 (1987), S. 137, 138.

920 So Marl, Der Begriff der Öffentlichkeit im Urheberrecht, 2017, S. 63.

921 Fichte, Beweis der Unrechtmäßigkeit des Büchernachdrucks [1793], UFITA 106 (1987), S. 155, 155; Marl, Der Begriff der Öffentlichkeit im Urheberrecht, 2017, S. 67. 
Urhebers in der Eigentumsgarantie des Art. 14 GG verankert. ${ }^{922}$ Es bezeichnet diese angemessene Beteiligung sogar als Kern der urheberrechtlichen Befugnisse: „Die grundsätzliche Zuordnung des vermögenswerten Ergebnisses der schöpferischen Leistung an den Urheber sowie die Freiheit, in eigener Verantwortung darüber zu verfügen und seine Leistung wirtschaftlich zu angemessenen Bedingungen verwerten zu können, genießen des Schutz des Eigentumsgrundrechts; sie machen den grundgesetzlich geschützten Kern des Urheberrechts aus. “923 Dieser Grundsatz findet sich mittlerweile auch in $\$ 11$ S. 2 UrhG wieder. Doch auch schon vor der Schaffung des Urheberrechtsgesetzes von 1965 galt bereits der Grundsatz, dass der Urheber an dem wirtschaftlichen Nutzen zu beteiligen ist, der aus seinem Werk gezogen wird. ${ }^{924}$

Der Grundsatz der angemessenen Beteiligung des Urhebers spielte insbesondere bei der Neugestaltung des UrhG durch das Gesetz zur Stärkung der vertraglichen Stellung von Urhebern und ausübenden Künstlern vom 22.03.2002 ${ }^{925}$ und zuletzt durch das Gesetz zur Stärkung der vertraglichen Stellung von Urhebern und ausübenden Künstlern vom 20.12.2016926 eine große Rolle. Mit ihnen wurden die $\$ \$ 32 \mathrm{ff}$. UrhG erweitert und sollten den Urheber besser absichern als bisher, da er aufgrund der zunehmenden Konzentration und Macht der Medien die zunehmend schwächere Vertragspartei ist. ${ }^{927} \mathbb{S} 32$ UrhG regelt nun das Prinzip der angemessenen Vergütung als wesentlichen Grundgedanken des Urhebervertragsrechts und gilt für die Einräumung von Nutzungsrechten und die Erlaubnis zur Werknutzung. ${ }^{928}$ Gem. $\ 32$ a Abs. 1 S. 1 UrhG kann der Urheber sogar eine weitere Beteiligung an der Verwertung seines Werkes verlangen, wenn er anderen ein Nutzungsrecht zu Bedingungen eingeräumt hat, die dazu führen, dass die vereinbarte Gegenleistung in einem auffälligen Missverhältnis zum Ertrag aus der Nutzung des Werkes steht.

922 BVerfG GRUR 2018, S. 829, 830 Rn. 25 - Verlegeranteil; BVerfG GRUR 2014, S. 169, 170 f. Rn. 72 - Übersetzerhonorare; BVerfG NJW 1971, S. 2163, 2163 Schulbuchprivileg.

923 BVerfG GRUR 2014, S. 169, 172 Rn. 87 - Übersetzerhonorare.

924 Vgl. BGH GRUR 1954, S. 216, 219 - Romfassung m.w.N.

925 BGBl. I S. 1155 (2002).

926 BGBl. I S. 3037 (2016).

927 Schack, Neuregelung des Urhebervertragsrechts, ZUM 2001, S. 453, 465; Dreier/ Schulze/Schulze, 6. Aufl. 2018, Vor 31 Rn. 2.

928 Dreier/Schulze/Schulze, 6. Aufl. 2018, 332 Rn. 1, 7. $\$ 32$ UrhG gilt allerdings nicht für andere Leistungen oder gesetzliche Lizenzen; vgl. BGH GRUR 2016, S. 67, 71 Rn. 43 - GVR Tageszeitungen II; Stieper, Rechtfertigung, Rechtsnatur und Disponibilität der Schranken des Urheberrechts, 2009, S. 201. 
Der Grundsatz der angemessenen Beteiligung sichert also den wirtschaftlichen Freiraum des Urhebers ab. In diesem Sinne ist auch die Entscheidung Übersetzungshonorare des BVerfG zu verstehen, die die Regelung des $₫ 32$ Abs. 1 S. 3 UrhG als verfassungsgemäß erklärt, wonach der Urheber die Einwilligung des Vertragspartners in eine Vertragsanpassung auf angemessene Vergütung verlangen kann. Gegen diese Norm hatte sich ein Verlag gewehrt, der darin eine Verletzung seiner Vertragsfreiheit und Privatautonomie im Rahmen seiner Berufsfreiheit gem. Art.12 Abs. 1 GG sah. Das BVerfG hingegen machte den Grundsatz der angemessenen Beteiligung des Urhebers stark und befand daher, dass die Regelung des $\$ 32$ Abs. 1 S. 3 GG die Grundrechte der Betroffenen in einen angemessenen Ausgleich bringe. ${ }^{929}$

\section{Grundsatz der engen Auslegung von Schrankenbestimmungen?}

Der Grundsatz der engen Auslegung von Schrankenbestimmungen besagt, die Schranken seien als Ausnahmebestimmungen zu den urheberrechtlichen Ausschließlichkeitsrechten grundsätzlich eng auszulegen. ${ }^{930}$ Dies wird häufig mit der systematischen Stellung der Schranken als Ausnahmen zu den umfassend formulierten Verwertungsrechte der Urhebers begründet. ${ }^{931}$ In seiner früheren Rechtsprechung hat der BGH die enge Auslegung von Schrankenbestimmungen überdies mit dem Grundsatz der angemessenen Beteiligung des Urhebers an der Verwertung seines Werkes begründet. ${ }^{932}$ Später war nicht mehr von der umfassenden Beteiligung des Urhebers die Rede, sondern umgekehrt davon, dass der Urheber aufgrund des Beteiligungsgrundsatzes in Bezug auf seine Verwertungsrechte „nicht

929 BVerfG GRUR 2014, S. 169, 171 Rn. 83 - Übersetzerhonorare.

930 BGH GRUR 1985, S. 874, 875 f. - Schulfunksendung; BGH GRUR 1983, S. 28, 29 - Presseberichterstattung und Kunstwerkwiedergabe II; BGH GRUR 1968, S.607, 608 - Kandinsky I; Schricker/Loewenheim/Melichar/Stieper, 5. Aufl. 2017, Vor $\mathbb{S}$ 44a ff. Rn. 36; P. Raue, Zum Dogma von der restriktiven Auslegung der Schrankenbestimmungen des Urheberrechtsgesetzes, in: FS Nordemann, 2004, S. 327, 328; Schulze, Spielraum und Grenzen richterlicher Rechtsfortbildung im Urheberrecht, in: FS Erdmann, 2002, S. 173, 180 f.; Stieper, Rechtfertigung, Rechtsnatur und Disponibilität der Schranken des Urheberrechts, 2009, S. 65 m.w.N.

931 Vgl. dazu Stieper, Rechtfertigung, Rechtsnatur und Disponibilität der Schranken des Urheberrechts, 2009, S. 65.

932 BGH GRUR 2001, S. 51, 52 - Parfumflakon; zu diesem Grundsatz der angemessenen Beteiligung s. S. $236 \mathrm{ff}$. 
übermäßig beschränkt werden" dürfe. ${ }^{933}$ Damit hat der BGH den Ausnahmecharakter der Schrankenbestimmungen bereits stückweise aufgegeben. ${ }^{934}$

Mittlerweile ist der Grundsatz der engen Auslegung von Schrankenbestimmungen weitestgehend aufgegeben worden. In der juristischen Methodenlehre gibt es keinen Grundsatz, wonach Ausnahmebestimmungen generell eng auszulegen seien. ${ }^{935}$ Und selbst wenn man einen solchen annähme: Es ist nicht klar, dass es sich bei Schrankenbestimmungen um Ausnahmebestimmungen handelt. Die Schranken wären nur Ausnahmebestimmungen, wenn die Schrankensystematik Ausdruck eines gesetzgeberischen Willens zugunsten möglichst umfassender Verwertungsrechte des Urhebers wären. ${ }^{936}$ Zwischen $\$ \mathbb{S} 15 \mathrm{ff}$. UrhG einerseits und $\$ \mathbb{S} 44 \mathrm{fff}$. UrhG andererseits besteht jedoch kein Rangverhältnis, das die Annahme rechtfertigen würde, die Schrankenregelungen seien eng auszulegende Ausnahmen der Rechte des Urhebers. ${ }^{937}$ Ob eine einzelne Schranke eine Ausnahmevorschrift sei, kann sich daher erst durch Auslegung ergeben. ${ }^{938}$ Das Urheberrecht soll außerdem nicht nur die Interessen des Urhebers, sondern auch die der Verwerter, Nutzer und der Allgemeinheit beachten. So hat auch der BGH verlangt, Drittinteressen müssen „schon bei der Auslegung der dem Urheber zustehenden Befugnisse, in jedem Fall aber bei der Auslegung der Schrankenbestimmungen berücksichtigt werden“939. Dies könne „im Einzelfall dazu führen, dass eine enge, am Gesetzeswortlaut orientierte Auslegung einer großzügigeren, dem Informations- und Nutzungsinteresse der Allgemeinheit Rechnung tragenden Interpretation weichen muss. "940 Schranken sind in der Regel also Bestimmungen, die Inhalt und Grenzen es Urheberrecht festlegen, und nicht Ausnahmen zum Recht des Urhebers. ${ }^{941}$ Auch aus der Eigentumsgarantie des Art. 14 Abs. 1 GG kann

933 BGH GRUR 2002, S. 605, 606 - Verhüllter Reichstag.

934 Stieper, Rechtfertigung, Rechtsnatur und Disponibilität der Schranken des Urheberrechts, 2009, S. 71.

935 Larenz, Methodenlehre, 6. Aufl. 1991, S. 355.

936 Stieper, Rechtfertigung, Rechtsnatur und Disponibilität der Schranken des Urheberrechts, 2009, S. 67.

937 Ders., a.a.O., S. 68.

938 Pahud, Zur Begrenzung des Urheberrechts im Interesse Dritter und der Allgemeinheit, UFITA 2000/I, S. 99, 135.

939 BGH GRUR 2003, S. 956, 957 - Gies-Adler.

940 BGH GRUR 2003, S. 956, 957 - Gies-Adler.

941 Hansen, Warum Urheberrecht?, 2009, S. 395; Geiger, Die Schranken des Urheberrechts im Lichte der Grundrechte. Zur Rechtsnatur der Beschränkungen des 
sich nichts anderes ergeben. ${ }^{942}$ Denn bei der Abwägung steht kein Interesse (wie z.B. das des Urhebers) im Vordergrund, sondern es werden alle zugrundeliegenden Grundrechte miteinander abgewogen und in einen möglichst schonenden Ausgleich im Rahmen der praktischen Konkordanz gebracht. 943

Auch im europäischen Recht besteht kein Grundsatz enger Schrankenauslegung. Auch hier ist, unter Berücksichtigung des Gebots praktischer Wirksamkeit der Schrankenvorschriften, ein gleichwertiger Ausgleich der betroffenen Interessen und Grundrechte zu suchen. ${ }^{944}$ Dies macht der EuGH in seinem Funke Medien NRW/Deutschland-Urteil deutlich, in dem er dort ausdrücklich festhält, dass die Ausnahmen und Beschränkungen gemäß Art. 5 InfoSoc-RL ,selbst Rechte zugunsten der Nutzer von Werken und anderen Schutzgegenständen"945 enthielten.

Einen Grundsatz der engen Auslegung von Schrankenbestimmungen gibt es also nicht. Vielmehr ist auf den Zweck der einzelnen Schrankenbestimmungen abzustellen und sind die durch die Schrankenbestimmung geschützten Interessen zu beachten. ${ }^{946}$ Schranken sind damit weder eng noch weit, sondern anhand des Auslegungskanons grammatisch, historisch, systematisch und teleologisch auszulegen..$^{947}$

Im Rahmen eines individualistischen Verständnisses von Urheberrecht könnte zwar weiterhin für eine enge Schrankenauslegung plädiert werden, da nach diesem Ansatz die Interessen des Urhebers denen der anderen vorzuziehen sind. Eine solcher Grundsatz wird allerdings von der herrschenden Meinung mittlerweile abgelehnt. Enge Schrankenbestimmungen wür-

Urheberrechts, in: Hilty/Peukert (Hrsg.), Interessenausgleich im Urheberrecht, 2004, S. 143, 150 f.; Pahud, Zur Begrenzung des Urheberrechts im Interesse Dritter und der Allgemeinheit, UFITA 2000/I, S. 99, 154.

942 Pahud, Zur Begrenzung des Urheberrechts im Interesse Dritter und der Allgemeinheit, UFITA 2000/I, S. 99, $134 \mathrm{f}$.

943 BVerfG GRUR 2001, S. 149, 151 - Germania 3.

944 EuGH GRUR 2019, S. 934, 938, 939 Rn. 51, 70 ff. - Funke Medien NRW/Deutschland; Leistner, „Ende gut, alles gut“... oder „Vorhang zu und alle Fragen offen“? Das salomonische Urteil des EuGH in Sachen „Pelham [Metall auf Metall]", GRUR 2019, S. 1008, 1012.

945 EuGH GRUR 2019, S. 934, 940 Rn. 76 - Funke Medien NRW/Deutschland.

946 BGH GRUR 2005, S. 670, 671 - Wirtschafts-Woche; BGH GRUR 2003, S. 1035, 1037 - Hundertwasser-Haus I; BGH GRUR 2002, S. 963, 966 - Elektronischer Pressespiegel.

947 Hansen, Warum Urheberrecht?, 2009, S. 390; Stieper, Rechtfertigung, Rechtsnatur und Disponibilität der Schranken des Urheberrechts, 2009, S. 69 für eine Auslegung anhand des Regelungsgrundes und Zwecks der jeweiligen Schrankenbestimmungen, was die historische und teleologische Auslegung meint. 
den dem Urheber insoweit Freiraum verschaffen, als dann seine Rechte möglichst umfassend verstanden werden.

\section{Kritische Würdigung}

Sowohl die individualistische Rechtfertigung des Urheberrechtsschutzes als auch die Ausgestaltungen des individuellen Ansatzes sind Kritik ausgesetzt.

Gegen den arbeitstheoretischen Ansatz wird vorgebracht, dass die Arbeitstheorie Lockes nicht ohne Weiteres auf das geistige Eigentum übertragbar sei, denn bei einem Immaterialgut handele es sich nicht um die von Locke geforderte „creatio ex nihilo“.948 Wenn die Schutzfähigkeit geistigen Eigentums an geistiger Arbeit festgemacht wird, ist außerdem nicht schlüssig, warum der Grundsatz der Schutzlosigkeit der Idee im Urheberrecht gilt: Hier zeigt sich, dass die arbeitstheoretische Rechtfertigung nicht zur Erklärung des bestehenden Urheberrechts ausreicht. ${ }^{949}$ Die Schutzwürdigkeit geistiger Arbeit vermag daher nur ein Gesichtspunkt unter vielen zu sein, um das Urheberrecht zu rechtfertigen. ${ }^{950}$

Gegen den personalistischen Ansatz scheint bereits der bestehende Schutz der kleinen Münze zu sprechen, der gerade keine allzu hohen Anforderungen an das Maß der Individualität setzt und einen recht geringen Grad an schöpferischer Eigentümlichkeit ausreichen lässt. Werke müssen damit nicht derart von der Persönlichkeit des Urhebers geprägt sein, wie es dieser Begründungsansatz vertritt. An der identifikationstheoretischen Rechtfertigung kommt insbesondere Kritik an der vermuteten Identitätskrise des Urhebers auf, die entstehen würde, wäre sein Werk nicht urheberrechtlich geschützt. Diese scheint schwerlich empirisch überprüfbar. ${ }^{951}$

Gegen die werkbasierte Rechtfertigung wird die inkonsistente Argumentation Kants vorgebracht, ${ }^{952}$ insbesondere sei die Vorstellung nicht plausibel, der öffentliche Gebrauch der Vernunft funktioniere nur, wenn

948 Oberndörfer, Die philosophische Grundlage des Urheberrechts, 2005, S. 126 f.; Marl, Der Begriff der Öffentlichkeit im Urheberrecht, 2017, S. 54.

949 Ähnlich Marl, Der Begriff der Öffentlichkeit im Urheberrecht, 2017, S. 54.

950 Hansen, Warum Urheberrecht?, 2009, S. 97; Oberndörfer, Die philosophische Grundlage des Urheberrechts, 2005, S. 131.

951 Stallberg, Urheberrecht und moralische Rechtfertigung, 2006, S. 164 f.; Marl, Der Begriff der Öffentlichkeit im Urheberrecht, 2017, S. 63.

952 Vgl. dazu ausführlich Stallberg, Urheberrecht und moralische Rechtfertigung, 2006, S. $164 \mathrm{ff}$. 
man im eigenen Namen sprechen könne, das heißt, wenn eine Namensnennung erfolge und das Werk dem Autor zugerechnet werden könne.953

Insgesamt zeigt sich, dass eine rein individualistische Grundlegung des Urheberrechts kaum überzeugen kann. ${ }^{954}$ Die individualistische Betrachtungsweise lässt außer Acht, dass das Individualgut zum Kulturgut werden kann: Mit der wiederholten Nutzung des Werkes wird das Ursprungswerk ein überall greifbares, bekanntes und von allgemeiner Anerkennung weitergetragenes Werk. ${ }^{95}$ Als Kulturgut ist es nicht mehr Ausdruck höchstpersönlicher Gedanken, sondern ein Orientierungspunkt für die geistige und kulturelle Auseinandersetzung der Zeit. ${ }^{956}$ Als Kulturgut hat sich das Werk vom Urheber gelöst und verselbständigt. Hier könnte das Kommunikationsverständnis des urheberrechtlichen Werkes, auf das die werkbasierte Rechtfertigung ebenfalls stützt, eine fruchtbare Argumentationsgrundlage sein.

Neben diesen Kritikpunkten an der individualistischen Rechtfertigung des Urheberrechtsschutzes überzeugt allerdings auch der daraus abgeleitete Fokus auf den individuellen Urheber als Verständnisansatz für das Urheberrecht nicht. Denn faktisch sind häufig nicht mehr die Urheber die Nutznießer des Urheberrechtsschutzes, sondern die Verwerter. ${ }^{957}$ Das Urheberrecht ist damit schon ein „Recht der Kulturwirtschaft“958 geworden. Grund hierfür sind die gewandelten kulturwirtschaftlichen Rahmenbedingungen: Der Großteil der Urheber sind mittlerweile Arbeitnehmer. Die Arbeitgeber als Verwerter kontrollieren damit die tatsächliche Nutzung des Werkes, wohingegen die Urheber nur noch mittelbar über die angemessene Vergütung beteiligt sind. ${ }^{959}$ Eine urheberzentrierte Theorie lässt sich damit kaum noch mit der Entwicklung des Urheberrechts in der Praxis in Einklang bringen.

So zeigt sich auch der Grundsatz der engen Schrankenauslegung als eine konkrete Ausgestaltung des individualistischen Paradigmas als überholt. Ein Grundsatz der engen Schrankenauslegung ergibt sich nicht aus der Ge-

953 Ders., a.a.O., S. 167.

954 So auch Marl, Der Begriff der Öffentlichkeit im Urheberrecht, 2017, S. 71.

955 So Kirchhof, Der Gesetzgebungsauftrag zum Schutz des geistigen Eigentums gegenüber modernen Vervielfältigungstechniken, 1998, S. 35.

956 Ders., a.a.O.

957 Hansen, Warum Urheberrecht?, 2009, S. $40 \mathrm{f}$.

958 Schricker/Loewenheim/Loewenheim, 5. Aufl. 2017, Einl. Rn. 4.

959 Peukert, Der Schutzbereich des Urheberrechts und das Werk als öffentliches Gut, in: Hilty/Peukert (Hrsg.), Interessenausgleich im Urheberrecht, 2004, S. 11, 21. 
staltung der Schrankenbestimmungen als beschränkte Ausnahmen zu den umfassend formulierten Verwertungsrechten der Urheber. Die Schranken sind nicht eng, sondern nach ihrem Zweck und den durch sie geschützten Interessen auszulegen. Der Ausgestaltung dieses individualistischen Fokus ist damit wesentlicher Kritik ausgesetzt.

\section{Folgen für Aneignungshandlungen}

Doch wie schafft ein individualistischer Fokus Freiraum für urheberrechtlich relevante Handlungen? Ein Fokus auf den individuellen Urheber schafft Freiraum für den Urheber selbst, indem er ihn an der Verwertung seines Werkes stark wirtschaftlich beteiligt und indem den Verwertungsrechten durch eine enge Schrankenauslegung eine möglichst große Bedeutung zukommen soll. Ziel ist also ein umfassender Schutz des Werkes. Dies hätte für Aneignungen zur Folge, dass diese weiter so behandelt werden, wie es sich aus der Analyse der rechtlichen Einordnung im Dritten Kapitel bereits jetzt ergibt: Aneignungen würden fast immer in Urheberrechte eingreifen. Eine Beachtung des inneren Abstandes eines Werkes, gar eine kunstspezifische Auslegung des $\$ 24$ Abs. 1 UrhG wäre mit einem Fokus auf den individuellen Urheber ausgeschlossen. Der Fokus auf den individuellen Urheber stellt damit den status quo der herrschenden Meinung dar. Für das kulturelle Freihaltebedürfnis von Aneignungen hilft diese Strategie nicht nur nicht weiter, sie verhindert eine rechtliche Beachtung des kulturellen Freihaltebedürfnisses.

\section{B. Privilegierung des Künstlerischen}

\section{Definition}

Die Privilegierung des Künstlerischen als Strategie zielt darauf ab, Freiraum für künstlerische Tätigkeiten zu schaffen und diese dadurch zu fördern. Das Urheberrecht kann hier als Antrieb für einen regen Kultur- und Kunstbetrieb verstanden werden. Dafür ist zwar in Deutschland kein gesetzlicher Anknüpfungspunkt gegeben. Der Privilegierung des Künstlerischen liegt aber ein Urheberrechtsverständnis zugrunde, wie es im Copyright Clause der U.S.A. beschrieben ist: ,[the United States Congress shall have power] To promote the Progress of Science and useful Arts, by securing for limited Times to Authors and Investors the exclusive Right to their 
respective Writings and Discoveries." "60 Urheberrecht wird als Recht der Kulturschaffenden und Künstler verstanden. Es wird als Mittel gesehen, um eine lebendige Kulturlandschaft zu schaffen. Kultur fördere die menschliche Entwicklung und Identitätsbestimmung: Durch Kultur könnten sich Menschen in ihrer Umgebung und in der Welt verorten. ${ }^{961}$ Deshalb bedürfe Kultur der Förderung von Kunst durch das Urheberrecht. ${ }^{962}$

Die Kunstfreiheit gem. Art. 5 Abs. 3 GG verlangt vom Gesetzgeber, dass er Freiraum schafft, um künstlerisches Schaffen zu ermöglichen und es kommunikativ vermitteln zu können. ${ }^{963}$ Das Urheberrecht ist damit auch eine Ausgestaltung der verfassungsrechtlichen Garantie zum Schutze der Freiheitsausübung der Kunst gem. Art. 5 Abs. 3 GG. ${ }^{964}$ Hierbei ist jedoch zu beachten, dass der Kunstbegriff des Art. 5 Abs. 3 GG ein anderer ist als der Werkbegriff des $\$ 2$ Abs. 1, 2 UrhG. ${ }^{965}$ Ein urheberrechtlich schutzfähiges Werk liegt nur vor, wenn es sich um eine persönlich geistige Schöpfung handelt. ${ }^{966}$ Die Schutzfähigkeit von Kunst im Rahmen des Art. 5 Abs. 3 GG kann etwas großzügiger bejaht werden als im Urheberrecht. ${ }^{967}$ Durch ihre schöpferische Tätigkeit schaffen Urheber häufig Kunstwerke im Sinne des Art. 5 Abs. 3 GG. ${ }^{968}$ Umgekehrt sind Kunstwerke häufig auch Urheberrechtswerke. ${ }^{969}$ Allerdings werden von der herrschenden Meinung der Literatur, wie oben gesehen, viele Werke der modernen Kunst wie Ready-mades, Konzeptkunst oder Appropriation Art - obwohl bedeutende Kunstwerke - vom Urheberrechtsschutz ausgenommen. ${ }^{970}$

960 Copyright Clause, Art. I, Section 8, Clause 8 der United States Constitution.

961 Rupp, Culture \& Copyright, 2013, S. $11 \mathrm{ff}$.

962 Ders., a.a.O., S. 34 f., $46 \mathrm{ff}$.

963 Kirchhof, Der Gesetzgebungsauftrag zum Schutz des geistigen Eigentums gegenüber modernen Vervielfältigungstechniken, 1998, S. 11, $60 \mathrm{f}$.

964 Ders., a.a.O., S. 60 f.; Leinemann, Die Sozialbindung des „Geistigen Eigentums“, 1998, S. 53 f.; Schack, Kunst und Recht, 3. Aufl. 2017, Rn. 3.

965 Zum Unterschied zwischen dem verfassungsrechtlich geschützten Lebensbereich Kunst und dem urheberrechtlich geschützten Kunstwerk, vgl. von Schoenebeck, Moderne Kunst und Urheberrecht, 2003, S. 31, 182.

966 S. dazu oben S. 120 f.

967 Dreier/Schulze/Schulze, 6. Aufl. 2018, $\mathbb{2}$ UrhG Rn. 149; Schricker/Loewenheim/Loewenheim, 5. Aufl. 2017, \$2 UrhG Rn. 157.

968 Czernik, Die Collage in der urheberrechtlichen Auseinandersetzung zwischen Kunstfreiheit und Schutz des geistigen Eigentums, 2008, S. 192. Ausnahmen sind bei Werken der kleinen Münze denkbar, vgl. Dreier/Schulze/Schulze, 6. Aufl. 2018, $\$ 2$ UrhG Rn. 152.

969 Dreier/Schulze/Schulze, 6. Aufl. 2018, $\$ 2$ UrhG Rn. 2.

970 S. $124 \mathrm{ff} ., 178 \mathrm{ff}$. 


\section{Kunstförderung als Rechtfertigung des Urheberrechtsschutzes}

Zum Verständnis des künstlerischen Ansatzes soll auch hier auf die Begründungsmodelle für Urheberrechtsschutz zurückgegriffen werden. Dabei sind hier die kultur-basierte Rechtfertigung des Urheberrechts nach Fisher (1.) und der kulturelle Imperativ nach Senftleben (2.) von besonderer Bedeutung und sollen daher ausführlicher dargestellt werden. Beide sind als kollektivistische Begründungsmodelle einzustufen, da sie die Beziehung des Werks zum Kulturleben (bei Fisher) und die Beziehung des Werks zu nachfolgenden Urhebergenerationen (bei Senftleben) im Blick haben.

\section{Kultur-basierte Rechtfertigung nach Fisher}

Fisher sieht das Urheberrecht als Mittel für ein reichhaltiges Kulturleben. Es müsse so ausgestaltet sein, ,[...] to help foster the achievement of a just

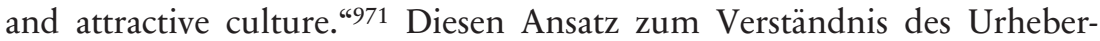
rechts bezeichnet er als „social-planning theory“972. Er nennt sieben Merkmale eines solchen reichhaltigen Kulturlebens, die gleichzeitig als Zielvorstellungen dienen sollen, um eine solche Kultur zu verwirklichen: „Consumer Welfare“, „A Cornucopia of Information and Ideas“, „A Rich Artistic Tradition“, „Distributive Justice“, „Semiotic Democracy“, „Sociability and Respect“. ${ }^{973}$ Mit einer Fülle an Informationen und Ideen würden kreatives Schaffen und geistiger Austausch ermöglicht. Dies sei nur möglich, wenn auch jeder Bürger Zugang zu dieser Mannigfaltigkeit von Informationen und Ideen habe. ${ }^{974}$ Der Zugang führe zu einer „rich artistic tradition“, die das Leben jedes Einzelnen bereichere und zu kultureller Vielfalt führe. ${ }^{975}$ Dabei wird der Zugang zu den Geisteswerken nicht nur als kulturell förderlich verstanden, sondern er sei auch Voraussetzungen für individuelle Selbstbestimmung und Selbstentfaltung. ${ }^{976}$ „Distributive Justice“ meint, dass , $[\ldots]$ to the greatest extent practicable, all persons should have access

971 Fisher, Property and Contract on the Internet, Chicago-Kent Law Review 73 (1998), S. 1203, 1214, 1215.

972 Ders., a.a.O., S. 1215.

973 Ders., a.a.O., S. $1216 \mathrm{ff}$.

974 Ders., a.a.O., S. 1216.

975 Ders., a.a.O., S. 1216.

976 Vgl. dazu Hansen, Warum Urheberrecht?, 2009, S. 252. 
to the informational and artistic resources described above. " ${ }^{977}$ Dies führe schließlich zu einer „semiotic democracy“, in der jeder die Möglichkeit habe, sich am kulturellen Leben aktiv zu beteiligen: „In an attractive society, all persons would be able to participate in the process of meaning-making. Instead of being merely passive consumers of cultural artifacts produced by others, they would be producers, helping to shape the world of ideas and symbols in which we live." ${ }^{\text {"978 }}$ Eine solche attraktive Kultur wiederum fördere den gesellschaftlichen Zusammenhalt. Dieser Partizipationsgedanke Fishers erinnert an Lessigs ${ }^{979}$ Leitbild der offenen Kultur: Lessig meint damit eine solche, in der nachfolgende Schöpfer und Innovatoren so frei wie möglich darin bleiben, auf ihre Vergangenheit aufzubauen..$^{980}$

\section{Der kulturelle Imperativ nach Senftleben}

Im Vordergrund des kulturellen Imperativs nach Senftleben steht die Beziehung eines urheberrechtlichen Werkes zu nachfolgenden schöpferisch tätigen Urhebern. Er versteht Urheberrecht als ein „Inspirationssystem“"981. Ziel des Urheberrechts sei es vor allem, dem individuellen Künstler das Fortbauen auf schon bestehenden Werken zu erleichtern, um auf diese Weise einen ununterbrochenen Kreislauf künstlerischer Produktionen auf der Basis bereits bestehender Ausdrucksformen zu sichern. ${ }^{982}$ Das Urheberrecht müsse daher ein Reservoir bestehenden künstlerischen Materials zulassen, das als Inspirationsquelle und Grundlage für weitere Schöpfungen dienen kann. ${ }^{983}$ Das Urheberrecht müsse so ausgestaltet sein, dass es optimale Bedingungen für geistig-schöpferische Prozesse schafft. Auf diese Weise sei ein großes Angebot neuer Ideen und Formen individuellen Aus-

977 Fisher, Property and Contract on the Internet, Chicago-Kent Law Review 73 (1998), S. 1203, 1217.

978 Ders., a.a.O., S. 1217.

979 Siehe Lessig, Freie Kultur, 2006, S. 8, 19.

980 S. 111. Der Gegensatz zu dieser offenen Kultur sei eine Erlaubniskultur, in der Schöpfer nur kreativ tätig werden können mit Einwilligung von Mächtigen, die den Zugang zu Werken kontrollieren können, oder Schöpfern der Vergangenheit, die die tatsächliche Nutzung ihrer Werke kontrollieren können, so Lessig, Freie Kultur, 2006, S. 8, 37.

981 Senftleben, Der kulturelle Imperativ des Urheberrechts, in: Weller/Kemle/Dreier/Lynen (Hrsg.), Kunst im Markt - Kunst im Recht, Tagungsband des Dritten Heidelberger Kunstrechtstages am 09. und 10. Oktober 2009, 2010, S. 75, 76.

982 Ders., a.a.O., S. 77.

983 Ders., a.a.O., S. 77. 
drucks sichergestellt, das zu Innovationsschüben führen und Wirtschaftswachstum ermöglichen kann. ${ }^{984}$ Das Urheberrecht müsse sich der Generationengleichheit verpflichten: Zukünftige Generationen von Werkschöpfern sollten im gleichen Maße über Möglichkeiten der Verwendung und Fortentwicklung bestehenden künstlerischen Materials verfügen wie ihre Vorgänger. ${ }^{985}$ Dabei sieht Senftleben den kulturellen Imperativ trotz seiner kollektivistischen Orientierung nicht als Bruch zu individualistischen Begründungstheorien: Auch Locke habe schon betont, dass Eigentum nur begründbar sei, sofern noch ausreichende Ressourcen für andere verblieben. ${ }^{986}$ Der kulturelle Imperativ betone jedoch im Gegensatz zu den individualistischen Ansätzen das übergeordnete Ziel der Aufrechterhaltung des Schöpfungszyklus und der Förderung neuer Werkschöpfungen. ${ }^{987}$ Mit seinem Ansatz deutet Senftleben den Begriff Urheberrecht um: Dieser wird nicht mehr als Schutzanspruch des Urhebers verstanden, sondern als Recht der Gebrauchsprivilegien. Der schöpfende Urheber soll das Recht haben, bereits Material zur Kenntnis zu nehmen und erforderlichenfalls in sein Werk einzubeziehen. ${ }^{988}$ Hier nennt Senftleben die Parodie und das Zitat, die bereits über Schrankenregelungen ermöglicht werden, also solche Gebrauchsrechte des schöpferischen Urhebers. ${ }^{989}$ Damit werden die Schrankenregelungen nicht mehr als Ausnahmen für die Interessen der Allgemeinheit am Werk gesehen, sondern als Rechte des schöpfenden Urhebers. ${ }^{990}$

984 Ders., Die Bedeutung der Schranken des Urheberrechts in der Informationsgesellschaft und ihre Begrenzung durch den Dreistufentest, in: Hilty/Peukert (Hrsg.), Interessenausgleich im Urheberrecht, 2004, S. 159, 161.

985 Ders., Der kulturelle Imperativ des Urheberrechts, in: Weller/Kemle/Dreier/ Lynen (Hrsg.), Kunst im Markt - Kunst im Recht, Tagungsband des Dritten Heidelberger Kunstrechtstages am 09. und 10. Oktober 2009, 2010, S. 75, 83.

986 Ders., a.a.O., S. 82.

987 Ders., a.a.O., S. 81.

988 Ders., a.a.O., S. 84.

989 Ders., a.a.O., S. $86 \mathrm{f}$.

990 Ders., a.a.O., S. 88; ebenso in: ders., Die Bedeutung der Schranken des Urheberrechts in der Informationsgesellschaft und ihre Begrenzung durch den Dreistufentest, in: Hilty/Peukert (Hrsg.), Interessenausgleich im Urheberrecht, 2004, S. 170 . 
III. Ausgestaltung des künstlerischen Ansatzes

\section{Neudefinition des Werkbegriffs}

Der künstlerische Ansatz kann so ausgestaltet werden, dass eine Neudefinition des Werkbegriffs vorgenommen wird, die vermehrt die künstlerischen Interessen zur Bestimmung des Urheberwerkes beachtet. $\$ 2$ Abs. 2 UrhG gerät bei moderner Kunst an seine Grenzen: Kunstwerke, die zu den wichtigsten des 21. Jahrhunderts gehören und Wendepunkte der Kunst markieren, werden vom Urheberschutz ausgenommen. ${ }^{991}$ Mit einem künstlerischen Verständnis von Urheberrecht könnte der Widerspruch der urheberrechtlichen und kunstwissenschaftlichen Bewertung von Kunst überwunden werden. ${ }^{992}$

Die Neugestaltung des Werkbegriffs könnte man sich auf verschiedene Weisen vorstellen. Zum einen könnte man die Person des Künstlers selbst entscheiden lassen, was Kunst ist. Ganz nach Kurt Schwitters könnte auch im Urheberrecht gelten: „Alles, was der Künstler spuckt, ist Kunst.“993 So könnte alles, was eine Signatur des Künstlers aufzeigt, als abgeschlossenes Werk verstanden werden, das der Künstler als Kunst verstanden wissen will. ${ }^{994}$ Wobei sich hier bereits die Frage stellt, wer überhaupt als Künstler anzusehen sei. Für die Schutzfähigkeit eines Werkes würde es nicht mehr auf eine objektive Individualität und spezifische Beschaffenheit ankommen, sondern auf die Bestimmung des Werkes durch den Künstlers. Thomaschki erklärt in dem Sinne, dass alle Bemühungen von Urheberrechtlern zum Scheitern verurteilt seien, die (zeitgenössische) Kunst mit Kriterien wie persönlicher geistiger Schöpfung, die zutiefst im humanistischen Weltbild verwurzelt sind, zu erfassen. ${ }^{995}$ Nur durch einen Verzicht auf alle spezifischen Anforderungen an die Beschaffenheit eines Kunstwerkes könne man der modernen Kunst gerecht werden. ${ }^{996}$ Es solle ausreichen, dass ein Werk als Bezugsobjekt spezifisch künstlerischer Kommunikation tauge

991 Fuchs, Avantgarde und erweiterter Kunstbegriff, 2000, S. 130; s. dazu auch bereits S. $124 \mathrm{ff} ., 178 \mathrm{ff}$.

992 Vgl. zu diesem Widerspruch auch von Schoenebeck, Moderne Kunst und Urheberrecht, 2003, S. 26.

993 Zitat nach Schack, Kunst und Recht, 3. Aufl. 2017, Rn. 5.

994 Vgl. Ders., a.a.O., Rn. 5.

995 Thomaschki, Das schwarze Quadrat. Zur urheberrechtlichen Schutzfähigkeit zeitgenössischer Kunst, 1995, S. 94.

996 Dies., a.a.O., S. 75. 
oder zumindest vom Künstler als Kunstwerk präsentiert werde. ${ }^{997}$ Hier findet ein Rückgriff auf die Präsentationslehre Kummers statt, der bereits die Auswahl gefundener Gegenstände und deren Anordnung als Kunstwerk im Ausstellungsraum als schutzfähig erachtet hatte. ${ }^{998}$ Würde man die künstlerische Gestaltungsabsicht und Präsentation als Kunstwerk als ausreichend erachten, würden mehr moderne und zeitgenössische Kunstwerke vom Werkbegriff erfasst werden (insbesondere auch Ready-mades und Appropriation Art).

Nicht ganz so weitreichend ist der Ansatz von Fuchs, die ebenfalls eine Aktualisierung des Werkbegriffs fordert, dabei allerdings nicht allein auf den Künstler selbst abstellt. Sie will den Werkbegriff des Urheberrechts mit Hilfe kunsteigener Kriterien aktualisieren und dafür auf die Fundamentalkonzeption eines Werkes abstellen als maßgebliches Kriterium der Individualität und damit Schutzfähigkeit. ${ }^{999}$ Mit Fundamentalkonzeption meint sie den künstlerisch-theoretischen Hintergrund der Arbeit. Moderne und zeitgenössische Kunst zeichne sich durch einen gesteigerten Reflexionsgehalt aus ${ }^{1000}$, der bisher nicht im Rahmen der Schutzfähigkeit beachtet werden könne. ${ }^{1001}$ Die Fundamentalkonzeption umfasse damit alle künstlerischen Entscheidungen, die die konkrete Form des Werkes begründen, also Gestaltungsentscheidungen sind. ${ }^{1002}$ Hier wird auch ein Werkbegriff gewählt, der direkt an der künstlerischen Tätigkeit ansetzt. Der Künstler kann zwar nicht selbst bestimmen, ob es sich um ein Werk handelt. Wenn er aber eine ausreichende Konzeption des Werkes vorgenommen hat, dann reicht dies für das Vorliegen eines schutzfähigen Werkes aus.

Ullrich möchte einen institutionalistischen Kunstbegriff in das Urheberrecht einbringen: Es soll nicht auf den Künstler selbst ankommen, sondern auf die Kunstinstitutionen, ob etwas ausreichend Individualität aufweist. ${ }^{1003}$ Auch er löst sich von einem objektiven Werkbegriff, der sich an

997 Dies., a.a.O., S. 79.

998 Kummer, Das urheberrechtlich schützbare Werk, 1968, S. 75.

999 Fuchs, Avantgarde und erweiterter Kunstbegriff, 2000, S. 136, 152.

1000 Siehe dazu auch bereits zur Auseinandersetzung mit dem Wesen der Kunst als ein Merkmal der modernen Kunst, S. 94.

1001 Fuchs, Avantgarde und erweiterter Kunstbegriff, 2000, S. 136, 139.

1002 Dies., a.a.O., S. 136.

1003 So Ullrich im Interview mit Steinhau, Wolfgang Ullrich: „Urheberrechte für die sozialen Netzwerke gänzlich suspendieren“, irights info vom 18.05.2015, https://irights.info/artikel/wolfgang-ullrich-urheberrechte-fuer-die-sozialen-net zwerke-gaenzlich-suspendieren/25429. 
Eigenschaften wie Schöpfungshöhe und Individualität aufhängt. Vielmehr solle das als Urheberwerk ${ }^{1004}$ gelten, „was an den Orten der Kunst auftaucht und verhandelt wird. Wenn etwas in einem Museum, in einer Galerie, auf einer Kunstmesse gezeigt wird, dann sind das Indizien dafür, dass es sich um Kunst handelt [...].“. ${ }^{1005}$ Dies müsse im Urheberrecht ausreichend berücksichtigt werden.

Jeder dieser drei Vorschläge zur Neudefinition des Werkbegriffs im Urheberrecht knüpft hierfür an den Künstler selbst oder an Institutionen des Kunstbetriebs an. Alle Vorschläge sind geprägt von einem Verständnis von Urheberrecht, bei dem das Produzieren von Kunst im Mittelpunkt steht und bei dem durch das Verleihen von Urheberrechtsschutz die Produktion von Kunst gefördert werden soll.

2. Verfassungskonforme Auslegung im Lichte der Kunstfreiheit gem. Art. 5 Abs. 3 GG

Auch die bereits im Dritten Kapitel ${ }^{1006}$ besprochene verfassungskonforme Auslegung von $\$ 24$ Abs. 1 UrhG im Lichte der Kunstfreiheit gem. Art. 5 Abs. 3 GG ist als eine Ausprägung des künstlerischen Ansatzes zum Verständnis von Urheberrecht anzusehen. Diese verfassungskonforme Auslegung lässt die Eigentumsinteressen des Urhebers oder Leistungsschutzberechtigten unter Umständen hinter der Kunstfreiheit zurücktreten. ${ }^{1007}$ Die kunstspezifische Betrachtungsweise verlangt hierbei, die Nutzung fremder Werke als künstlerisches Mittel anzuerkennen und den urheberrechtlichen Ausnahmeregelungen zu einem Anwendungsbereich zu verhelfen, „der weiter ist als bei einer anderen, nichtkünstlerischen Nutzung“1008. Es wird die künstlerische Nutzung urheberrechtlicher Werke privilegiert. Denn in-

1004 Ullrich spricht zwar von Kunstwerk, meint aber ein urheberrechtlich schutzfähiges Kunstwerk, sodass hier zur besseren Abgrenzung zum Kunstwerk im Sinne des Art. 5 Abs. 3 GG vom Urheberwerk gesprochen wird.

1005 Ullrich im Interview mit Steinhau, Wolfgang Ullrich: „Urheberrechte für die sozialen Netzwerke gänzlich suspendieren“, irights info vom 18.05.2015, https: //irights.info/artikel/wolfgang-ullrich-urheberrechte-fuer-die-sozialen-netzwerk e-gaenzlich-suspendieren/25429.

1006 Vgl. S. $192 \mathrm{ff}$.

1007 BVerfG GRUR 2016, S. 690, 693 Rn. 86 - Metall auf Metall; BVerfG GRUR 2001, S. 149, 151 - Germania 3.

1008 BVerfG GRUR 2016, S. 690, 693 Rn. 86 - Metall auf Metall; BVerfG GRUR 2001, S. 149, 151 - Germania 3. 
nerhalb der verfassungskonformen Auslegung ist zu beachten, dass ein Werk mit der Veröffentlichung in den gesellschaftlichen Raum tritt und „damit zu einem eigenständigen, das kulturelle und geistige Bild der Zeit mitbestimmenden Faktor" ${ }^{1009}$ wird. Das Werk löst sich von seiner privatrechtlichen Verfügbarkeit und wird geistiges und kulturelles Allgemeingut. ${ }^{1010}$ Als ein solches sind Eingriffe durch andere Künstler als Teil der sich mit dem Kunstwerk auseinandersetzenden Gesellschaft hinzunehmen. ${ }^{1011}$

Darüber hinaus sind genrespezifische Aspekte von Kunstrichtungen zu berücksichtigen: Für bestimmte Kunstrichtungen wird die künstlerische Betätigungsfreiheit noch einmal ausgeweitet verstanden. Da das Sampling - und damit der direkte Zugriff auf das Originaltondokument - als Mittel zur „ästhetischen Reformulierung des kollektiven Gedächtnisses kultureller Gemeinschaften" ${ }^{1012}$ und als kritische Auseinandersetzung mit dem Original ${ }^{1013}$ ein wesentliches Element des Hip-Hop ist, muss für diesen Bereich die kunstspezifische Betrachtung das Sampling schützen. Dies gilt allerdings nicht zwangsläufig für andere Bereiche der Kunst, die Sampling nutzen, sondern es ist für jeden Kunstbereich gesondert zu betrachten, ob der Einsatz des Samplings als Gestaltungsmittel derart stilprägend ist. ${ }^{1014}$ Die verfassungskonforme Auslegung verlangt damit, sich mit der spezifischen Kunstform auseinanderzusetzen und deren Notwendigkeiten zu beachten.

\section{Kritische Würdigung}

Der künstlerische Ansatz schafft Freiraum für künstlerische Betätigungen und beachtet auch nachfolgende Urheber, die künstlerisch tätig werden wollen und sich dafür Urheberwerke anderer aneignen. Im Rahmen dieser kritischen Würdigung des künstlerischen Ansatzes soll zunächst die Rechtfertigung des Urheberrechtsschutzes nach Fisher und Senftleben kritisch beleuchtet werden und dann die konkrete Ausgestaltung des künstlerischen Ansatzes untersucht werden.

1009 BVerfG GRUR 2001, S. 149, 151 - Germania 3.

1010 BVerfG GRUR 2001, S. 149, 151 - Germania 3.

1011 BVerfG GRUR 2001, S. 149, 151 - Germania 3.

1012 Großmann, Die Geburt des Pop aus dem Geist der phonographischen Reproduktion, in: Bielefeldt/Dahmen/ders. (Hrsg.), PopMusicology, 2008, S. 119 ff.

1013 BVerfG GRUR 2016, S. 690, 693 Rn. 96 - Metall auf Metall.

1014 BVerfG GRUR 2016, S. 690, 693 Rn. 99 - Metall auf Metall. 
Gegen die kultur-basierte Rechtfertigung von Urheberrechtsschutz durch Fisher ist vorzubringen, dass er sich der Vorstellung von einer Anreizwirkung oder eines Anreizpotenzials des Urheberrechts in Bezug auf die Produktion und Verbreitung geistiger Werke bedient, ohne dass eine solche Anreizwirkung weiter belegbar sei. ${ }^{1015}$ Es gibt keine klare Empirik dazu, ob das Urheberrecht Auswirkungen auf eine starke Quantität oder Qualität des Kulturlebens habe. ${ }^{1016}$ Damit bleibt diese Anreizwirkung eine Prämisse. Hansen kritisiert an Fishers Rechtfertigung, dass die Auswahl der angestrebten Ziele einer kulturreichen Gesellschaft und damit auch die Grundlage der Wertvorstellungen beliebig sei. ${ }^{1017}$ Außerdem seien Fishers Ziele so vage und konsenstauglich formuliert, dass sich auf sie sowieso eine Mehrheit der Gesellschaft einigen könnte. ${ }^{1018}$ Dies könne aber ebenso als eine Stärke der kultur-basierten Rechtfertigung verstanden werden. Die Ziele seien zwar so formuliert, dass sie zum Teil in Konflikt miteinander stehen. Damit stelle Fishers Rechtfertigung aber gerade einen integrativen Ansatz dar, der versucht, die unterschiedlichen Regelungsziele des Urheberrechts in Einklang zu bringen. ${ }^{1019}$ Damit kann Fishers kulturbasierte Rechtfertigung des Urheberrechtsschutzes insgesamt als ein bereichernder Begründungsansatz eingestuft werden. ${ }^{1020}$ Auch Senftlebens kultureller Imperativ stellt sich als gewinnbringend heraus, indem er zwar auf das Individuum abstellt, dabei aber einen ganzheitlichen Ansatz verfolgt, der das Urheberrecht als einen Schöpfungskreislauf versteht.

Die Ausgestaltung des künstlerischen Ansatzes durch eine Neudefinition des Werkbegriffs hingegen steht einiger Kritik gegenüber. Denn das Urheberrecht entsteht durch den Realakt der Schöpfung - und gerade nicht durch das Bewusstsein des Urhebers, Kunst zu schaffen. ${ }^{1021}$ Nach seiner Konstruktion schützt das Urheberrecht das Schaffen der Künstler nur mittelbar und nicht direkt, indem es an die Ergebnisse des Schaffens, das

1015 S. zu dieser Kritik Marl, Der Begriff der Öffentlichkeit im Urheberrecht, 2017, S. 97.

1016 Ders., a.a.O., S. 97.

1017 Dies erkennt allerdings auch Fisher selbst, s. Hansen, Warum Urheberrecht?, 2009, S. 253.

1018 Ders., a.a.O., S. 254.

1019 Marl, Der Begriff der Öffentlichkeit im Urheberrecht, 2017, S. 97.

1020 So auch Hansen, Warum Urheberrecht?, 2009, S. 256; Marl, Der Begriff der Öffentlichkeit im Urheberrecht, 2017, S. 97.

1021 OLG Frankfurt ZUM 1994, S. 28, 29 - Le Corbusier-Möbel; Schack, Kunst und Recht, 3. Aufl. 2017, Rn. 5. 
Werk, anknüpft. ${ }^{1022}$ Ein Deutungsmonopol des Künstlers über sein eigenes Schaffen würde sich zudem als schwierig gestalten und unterliegt der Gefahr, sich zu einem grenzenlosen Schutz unter dem Deckmantel der Kunst auszugestalten. Die Absicht des Künstlers kann daher nur ein Indiz für das Vorliegen von Kunst sein. ${ }^{1023}$ Gegen einen institutionalisierten Werkbegriff spricht, dass sich häufig erst Jahre später herausstellt, was beachtenswerte Kunst ist, und die Institutionen häufig auch nicht einschätzen, was als Kunst zu qualifizieren ist. So wurde Duchamps Ready-made „Fountain“ (1917) von der New Yorker Society of Independent Artists (SIA) von einer Ausstellung im April 1917 ausgeschlossen - und wurde später als ein Schlüsselwerk der modernen Kunst angesehen. Ein institutionalisierter Werkbegriff wird nicht die notwendige Flexibilität für den künstlerischen Schaffensprozess bewirken können.

\section{Folgen für Aneignungshandlungen}

Der künstlerische Ansatz schafft Freiraum für gewissen Aneignungshandlungen. Durch eine Neugestaltung des Werkbegriffs könnten einerseits noch mehr Kunstwerke auch als Urheberwerke schutzfähig sein, sodass sich Aneignungen an einem noch geringeren Bestand gemeinfreier Werke bedienen könnten. Aneignungen würden damit noch häufiger Eingriffe in Urheberrechte darstellen. Andererseits wird durch den künstlerischen Ansatz auch die Betätigungsfreiheit der Künstler gestärkt, indem solche Eingriffe in Urheberrechte gerade privilegiert behandelt werden durch eine verfassungskonforme Auslegung im Lichte der Kunstfreiheit gem. Art. 5 Abs. 3 GG. So würden beide Seiten künstlerischen Schaffens gestärkt werden. Der künstlerische Ansatz führt zu einem Verständnis von Urheberrecht, das heute schon für gewisse Bereiche so angewendet wird. Insgesamt schafft ein künstlerischer Ansatz allerdings nicht den kulturpolitisch wünschenswerten Freiraum für kommunikative digitale Aneignungen, da es sich zumeist weder nach Ansicht der Nutzer noch nach Ansicht der Institutionen um Kunst handeln wird. Für moderne und zeitgenössische Kunst wie die Appropriation Art ist der künstlerische Ansatz jedoch weiterführend.

1022 Fuchs, Avantgarde und erweiterter Kunstbegriff, 2000, S. 127; Ulmer, Urheberund Verlagsrecht, 3. Aufl. 1980, S. 1.

1023 Schack, Kunst und Recht, 3. Aufl. 2017, Rn. 5. 


\section{Kommunikativer Ansatz}

\section{Definition}

Der kommunikative Ansatz versteht das Urheberrecht als Mittel der Verständigung und des Austausches. Das Urheberrecht ist nicht als ausschließliches Recht, als Abgrenzungsrecht, zu verstehen, sondern als verbindendes Recht, als ein Kommunikationsrecht. ${ }^{1024}$ Das Urheberrecht dient damit dem Schutz „qualifizierter menschlicher Kommunikation“.1025 Das Werk ist ein geistiges Mitteilungsgut und stellt die kommunikative Nachricht dar, die der Sender (Urheber) den Empfängern (Nutzer des Werkes) übermitteln möchte. Deshalb ist Schutzbedingung im Urheberrecht auch immer die „kommunikative Aussage“ eines Werkes. ${ }^{1026}$ Ähnlich sieht Ahlberg das Werk als „Meinungsäußerung“ geschützt. ${ }^{1027}$ Genauer noch definiert es Stallberg, der das Urheberwerk als illokutionären Sprechakt verstehen will ${ }^{1028}$ und damit meint, dass das Werkschaffung als sprachliche Äußerung auch gleichzeitig eine Handlung des Urhebers ist, die mit einer Intention verbunden ist. ${ }^{1029}$ Das Urheberrecht schützt neben dem Werk als Kommunikation auch die Kommunikation des Werkes: Indem es dem Urheber die Hoheit über die Veröffentlichung belässt und ihm die Verwertung des Werkes in der Öffentlichkeit ausschließlich zuweist. ${ }^{1030}$

Neben dem kommunikativen Charakter des Werkes ist jedoch auch die gleichzeitige Kontextualisierung in der menschlichen Sprache und Kommunikation ein entscheidender Wesenskern des geistigen Werkes. ${ }^{1031}$ Für eine gelingende Kommunikation muss in das Urheberrecht ebenso der Kommunikationspartner einbezogen sein, damit dieser die Botschaft des Urhebers empfangen kann. Der kommunikative Ansatz des Urheberrechts hat somit die Interessen beider Kommunikationsparteien im Blick. Denn das geistige Werk besteht nicht für sich allein: Es kann überhaupt erst wie

1024 Leßmann, Die vertragliche Nutzungseinräumung an Datenbanken in der Informationsgesellschaft, ZUM 1999, S. 623, 624.

1025 Schricker/Loewenheim/Loewenheim, 5. Aufl. 2017, Einl. Rn.7; Schack, Urheber- und Urhebervertragsrecht, 9. Aufl. 2019, Rn. 6.

1026 Dreyer/Kotthoff/Meckel/Hentsch/Dreyer, 4. Aufl. 2018, Einl. Rn 12.

1027 BeckOK UrhG/Ablberg, 26. Ed. 2019, Einf. Rn. 9.

1028 Stallberg, Urheberrecht und moralische Rechtfertigung, 2006, S. $300 \mathrm{ff}$.

1029 Ausführlicher dazu sogleich, S. 263 ff.

1030 Marl, Der Begriff der Öffentlichkeit im Urheberrecht, 2017, S. 373.

1031 Rösler, Buchbesprechung zu Christian Gero Stallberg, Urheberrecht und moralische Rechtfertigung (2006), JZ 2007, S. 185, 186. 
Eigentum verteidigt werden, wenn es vom Kommunikationssystem anerkannt und dadurch hergestellt wird. ${ }^{1032}$ Erst dieser Kommunikationszusammenhang konstituiert das geistige Werk, es besteht also eine existentielle Abhängigkeitsbeziehung. ${ }^{1033}$ Nicht nur die Werkerstellung stellt qualifizierte Kommunikation des Urhebers dar, sondern es handelt sich auch erst dann um ein Werk, wenn die Kommunikationspartner es als solches anerkennen. ${ }^{1034}$ Das Werk entsteht also durch einen beiderseitigen Kommunikationsprozess.

Auch die Nutzung und Verwertung von urheberrechtlichen Werken erfolgt insbesondere durch Kommunikation. ${ }^{1035}$ Der Umgang mit geistigen Werken ist ein kommunikativer Vorgang, der potenziell zum Diskurs, zur Meinungsbildung über jene Werke führt. ${ }^{1036}$ Die Kommunikation über und auf Grundlage des Werkes ist ebenfalls vom Urheberrechtsschutz abgedeckt, insbesondere durch die Schrankenregelungen. ${ }^{1037}$ Das Urheberrecht lässt dieses Zirkulieren von kommunikativen Inhalten im kollektiven Gedächtnis jedoch oft noch nicht zu. ${ }^{1038}$ So weist Dreier darauf hin, dass Kommunikation beschränkt wird, wenn das in der Abbildung enthaltene Abbild ${ }^{1039}$ mit geschützt wird. Das ist immer dann der Fall, wenn der abgebildete Gegenstand nicht frei zugänglich ist und das Bild nicht anders als durch die Nutzung der betreffenden Abbildung und damit nur mit Eingriff in die Rechte an dieser Abbildung kommuniziert werden kann. ${ }^{1040}$ Für Zitate wurde dies nun über $\$ 51$ S. 3 UrhG gelöst, dies setzt jedoch immer das Vorliegen eines Zitatzwecks voraus ${ }^{1041}$, ansonsten ist das Kommunizieren mit der Abbildung noch nicht möglich. Für eine funktio-

1032 Roellecke, Das Kopieren zum eigenen wissenschaftlichen Gebrauch, UFITA 84 (1979), S. 79, 98.

1033 Ders., a.a.O., S. 99.

1034 Ders., a.a.O., S. 100.

1035 Marl, Der Begriff der Öffentlichkeit im Urheberrecht, 2017, S. 372.

1036 Ders., a.a.O., S. 372.

1037 Vgl. ders., a.a.O., S. 373.

1038 Dazu ausführlicher Dreier, Bilder im Zeitalter ihrer vernetzten Kommunizierbarkeit, ZGE 2017, S. 135, 138.

1039 Es ist zu unterscheiden zwischen abgebildetem Objekt, dessen immateriellen Abbild und der dieses verkörpernden materiellen Abbildung, s. auch S. 43.

1040 Dreier, Bilder im Zeitalter ihrer vernetzten Kommunizierbarkeit, ZGE 2017, S. $135,138$.

1041 Vgl. dazu S. $211 \mathrm{ff}$. 
nierende Kommunikation müsste der iconic turn auch im Urheberrecht nachvollzogen werden. ${ }^{1042}$

Im Zusammenhang des kommunikativen Verständnisses ist Ladeurs Grundrechtstheorie anzubringen, um die Einordnung des Urheberrechts als auch Dritte schützende Rechtsnorm zu begründen: Danach sollen Freiheitsrechte nicht nur zur Vermehrung der Freiheit für den Handelnden führen, sondern auch für Dritte. ${ }^{1043}$ Das Eigentum (auch das geistige Eigentum) sei gerade durch seine reflexive Form charakterisiert, die auf die Reproduktion von neuem Eigentum angelegt ist und dadurch auch den Nichteigentümern zugute kommt. ${ }^{1044}$ Es muss also auch den Nicht-Urheber im Blick haben, den Kommunikationsempfänger. Hier kann der kommunikative Ansatz auch eine Verbindung zum kulturellen Imperativ nach Senftleben ziehen, der ebenfalls nachfolgendenden Eigentümern die Kommunikation und damit die Nutzung des Werkes erlaubt, um später durch schöpferisches Tätigwerden selbst kommunizieren zu können.

Das urheberrechtliche Werk zeichnet sich nach diesem kommunikativen Ansatz also dadurch aus, dass es einen Akt der Kommunikation darstellt, in einen kommunikativen Prozess eingebunden ist und weitergehend Gegenstand von Kommunikation sein kann.

II. Kollektivistische Rechtfertigungsgründe des Urheberrechtsschutzes als Grundlage

Da der kommunikative Ansatz auch die Gesellschaft als Kommunikationsempfänger des urheberrechtlichen Werkes in den Schutzzweck mit einbezieht, sollen hier kollektivistische Rechtfertigungsgründe des Urheberrechts vorgestellt werden. Diese sind deshalb als kollektivistisch zu bezeichnen, da sie die rechtliche Beziehung zwischen der Gesellschaft und dem Werk in den Vordergrund stellen. Sie zeichnen sich durch eine folgenorientierte gesamtgesellschaftliche Herangehensweise aus. Moralische Quelle des Urheberrechts ist kollektivistischen Rechtfertigungsgründen zufolge ein Kollektiv - die Gesellschaft. ${ }^{1045}$ Statt als Autorenrecht wird das

1042 Dreier, Bilder im Zeitalter ihrer vernetzten Kommunizierbarkeit, ZGE 2017, S. $135,141$.

1043 Ladeur, Kritik der Abwägung in der Grundrechtsdogmatik, 2004, S. 24.

1044 Ders., a.a.O., S. 24.

1045 Stallberg, Urheberrecht und moralische Rechtfertigung, 2006, S. 48 f. 
Urheberrecht als Regelungskomplex betrachtet. ${ }^{1046}$ Auch wenn kollektivistische Rechtfertigungsgründe nicht die Kommunikationsbeziehung in den Vordergrund stellen, ist doch bei ihnen ebenso die Vermittlung des Werkes an die Gesellschaft und der Austausch innerhalb der Gesellschaft wesentlicher Grundgedanke für den Urheberrechtsschutz. Es wird zunächst die schranken-basierte Rechtfertigung (1.), folgend die effizienz-basierte (2.) und die demokratie-basierte Rechtfertigung nach Netanel (3.) und zum Schluss die universalistisch-transzendentale Rechtfertigung nach Stallberg (4.) zu den Gründen des Urheberrechtsschutzes vorgestellt.

\section{Schranken-basierte Rechtfertigung}

Die schranken-basierte Rechtfertigung sieht das Urheberrecht als konsensfähige Beschränkung der menschlichen Handlungsfreiheit. ${ }^{1047}$ Es sind nicht Schranken im Sinne von urheberrechtlichen Schrankenregelungen gemeint, sondern Handlungsschranken. Der Regelungszweck des Urheberrechts bestehe darin, dass gewisse universale Handlungsschranken nicht verletzt werden, also keine negativen Konsequenzen für die Gesellschaft hervorgerufen werden. ${ }^{1048}$ Der moralische Grund des Urheberrechts liege hiernach darin, keine universalen gesellschaftlichen Schranken zu verletzen. Diese schranken-basierte Rechtfertigung hat Stallberg unter Bezugnahme auf die Arbeiten von Moore ${ }^{1049}$ und Gordon ${ }^{1050}$ entwickelt. ${ }^{1051}$ Der schranken-basierte Rechtfertigungsansatz nimmt zudem Rückgriff auf John Lockes Eigentumstheorie und die darin enthaltene Sufficiency-Provisio: Danach ist die Aneignung von Eigentum nur dann legitim, „wo genug und ebenso gutes den anderen gemeinsam verbleibt. " ${ }^{1052}$ Hier wird auf das Selbsterhaltungsrecht aller Menschen verwiesen: Aneignungen müssen

1046 Marl, Der Begriff der Öffentlichkeit im Urheberrecht, 2017, S. 72.

1047 Stallberg, Urheberrecht und moralische Rechtfertigung, 2006, S. 206.

1048 Marl, Der Begriff der Öffentlichkeit im Urheberrecht, 2017, S. 74; Stallberg, Urheberrecht und moralische Rechtfertigung, 2006, S. 206.

1049 Moore, Towards a Lockean Theory of Intellectual Property Law, in: ders. (Hrsg.), Intellectual Property: moral, legal, and international dilemmas, 1997, S. $81 \mathrm{ff}$.

1050 Gordon, A Property Right in Self-Expression. Equality and Individualism in the Natural Law of Intellectual Property, The Yale Law Journal Bd. 102 (1993), S. $1533 \mathrm{ff}$.

1051 Stallberg, Urheberrecht und moralische Rechtfertigung, 2006, S. 206 ff.

1052 Locke, Zwei Abhandlungen über die Regierung [1690], 1977, S. 217 \27. 
sich auf einen Teil der bisher im Gemeineigentum stehenden Elemente begrenzen, damit andere Menschen nicht in der Verwirklichung ihres eigenen Selbsterhaltungsrecht behindert werden. ${ }^{1053}$ Die Eigentumsbegründung (und das gilt eben auch für das geistige Eigentum) sei demnach nur moralisch gerechtfertigt und damit legitim, wenn durch sie niemand eine Schädigung erleidet.

Stallberg geht hierbei von einem Moralprinzip aus, dem ein allgemeines Schädigungsverbot zugrunde liegt. ${ }^{1054} \mathrm{Er}$ entwickelt dazu einen Schädigungsbegriff auf zwei Ebenen: einen formal-analytischen und einen material-normativen. Eine Schädigung liege formal-analytisch dann vor, wenn die Situation eines anderen im Aneignungszustand negativ von der Situation im Ausgangszustand abweiche. Material-normativ liege eine Schädigung dann vor, wenn bei diesem Vergleich nur der Verlust faktischer, also aktueller oder potenzieller Handlungsmöglichkeiten des anderen berücksichtigt werden, die bereits im Ausgangszustand bestehen. ${ }^{1055}$ Urheberrecht wird als ein begrenzendes System verstanden: Es ist gerechtfertigt, weil es solche Schädigungen minimiere und nicht, weil es der Verwirklichung eines bestimmten Gesellschaftsideals zugute komme. Wichtig ist nach Stallberg die Begrenzung auf faktisch bestehende Handlungsmöglichkeiten. ${ }^{1056}$ Das Urheberrecht darf anderen Individuen also weder ihren potenziellen Status als Urheber - also eine Erschaffungsmöglichkeit noch ihren potenziellen Status als Nutzer - also eine Gebrauchsmöglichkeit - nehmen. ${ }^{1057}$

\section{Effizienz-basierte Rechtfertigung}

Dem effizienz-basierten Rechtfertigungsansatz liegt eine ökonomische Gesellschaftskonzeption zugrunde. ${ }^{1058}$ Aus einer ökonomischen Notwendigkeit des Urheberrechts wird auf dessen moralische Notwendigkeit geschlossen. Ausgangspunkt ist das bestehende Bedürfnis aller Menschen

1053 Stallberg, Urheberrecht und moralische Rechtfertigung, 2006, S. 206.

1054 Ders., a.a.O., S. $228 \mathrm{f}$.

1055 Ders., a.a.O., S. 211 ff.; Marl, Der Begriff der Öffentlichkeit im Urheberrecht, 2017, S. 78.

1056 Stallberg, Urheberrecht und moralische Rechtfertigung, 2006, S. 229, anders als Moore, der alle Arten von Handlungsmöglichkeiten einbeziehen will.

1057 Ders., a.a.O., S. 229.

1058 Marl, Der Begriff der Öffentlichkeit im Urheberrecht, 2017, S. 80; Hansen, Warum Urheberrecht?, 2009, S. $106 \mathrm{f}$. 
nach geistigen Werken, das so weit wie möglich erfüllt werden soll. Das Urheberrecht soll als Instrument zur Befriedigung dieser Bedürfnisse dienen, indem es Ressourcen effizient verteilt. ${ }^{1059}$

Diesem Ansatz liegt ein klassisches ökonomisches Problem zugrunde: Ressourcen sind knapp; diese begrenzten Ressourcen führen deshalb zu Verteilungskonflikten in der Gesellschaft, da die Bedürfnisse der Menschen umfassend sind. ${ }^{1060}$ Durch einen möglichst effizienten Einsatz der Ressourcen kann man jene Verteilungskonflikte verringern, indem möglichst keine Ressource verschwendet wird. ${ }^{1061}$ Der Idealzustand ist, ein Maximum an Bedürfnisbefriedigung aller Menschen zu erreichen (sog. Allokationseffizienz). ${ }^{1062}$

Bei Immaterialgütern besteht eine etwas andere Ausgangslage für dieses ökonomische Problem. Denn Immaterialgüter zeichnen sich durch ihre Ubiquität und Nicht-Rivalität aus: Sie können gleichzeitig an mehreren Orten genutzt werden, ohne dass sich die einzelnen Nutzungen gegenseitig behindern würden. ${ }^{1063}$ Von knappen Ressourcen, die angemessen verteilt werden müssen, kann daher hier nicht die Rede sein. Es sind aber zwei andere Arten des Marktversagens denkbar: die Tragedy of the Commons und die Tragedy of the Anti-Commons. ${ }^{1064}$ Die Tragedy of the Commons definiert sich durch eine Übernutzung und Unterproduktion von Werken. Im Gegensatz dazu zeichnet sich die Tragedy of the Anti-Commons durch eine Überproduktion und Unternutzung von Werken aus. In diesem Spannungsfeld soll das Urheberrecht einen Mechanismus bilden, um eine möglichst effiziente Produktion und Nutzung der Werke zu sichern. Diesem Ansatz liegt eine Anreizwirkung des Urheberrechts für die Produktion geistiger Werke zugrunde, denn er geht davon aus, dass bei einem richtigen Zuschnitt des Urheberrechts ein Anreiz zur Schaffung neuer Werke, aber auch zur Nutzungsoptimierung bestehender Werke ge-

1059 Marl, Der Begriff der Öffentlichkeit im Urheberrecht, 2017, S. 81.

1060 Ders., a.a.O., S. 81.; Stallberg, Urheberrecht und moralische Rechtfertigung, 2006, S. 233.

1061 Stallberg, Urheberrecht und moralische Rechtfertigung, 2006, S. 231.

1062 Ders., a.a.O., S. 231.

1063 Marl, Der Begriff der Öffentlichkeit im Urheberrecht, 2017, S. 84; Dreier/ Schulze/Dreier, 6. Aufl. 2018, Einl. Rn. 14.

1064 Schäfer/Ott, Lehrbuch der ökonomischen Analyse des Zivilrechts, 5. Aufl. 2012, S. 22 ff., S. 108 und 559; Ott/Schäfer, Die ökonomische Analyse des Rechts, JZ 1988, S. 213, 218; Stallberg, Urheberrecht und moralische Rechtfertigung, 2006, S. 238; Hansen, Warum Urheberrecht?, 2009, S. 129; Marl, Der Begriff der Öffentlichkeit im Urheberrecht, 2017, S. 84. 
boten wird. ${ }^{1065} \mathrm{Ob}$ eine solche Anreizwirkung tatsächlich dem Urheberrecht unterliegt und ob überhaupt ohne Urheberrecht ein Marktversagen vorliegt, sind empirische Frage, die hier nicht zu erörtern sind. ${ }^{1066}$

Effizienz allein ist jedoch noch keine moralische Rechtfertigung. Die Effizienz der möglichst ausgewogenen Ressourcenverteilung soll jedoch andere moralischen Ziele sichern. Nach Posner ist das Ziel der Effizienz die Konsensfähigkeit: Eine vermögensmäßige Besserstellung aller Beteiligten und die Befriedigung der Bedürfnisse möglichst aller sind gesellschaftlich mehrheitsfähig und daher moralisch geboten. ${ }^{1067}$ Ganz nach den Grundsätzen des Utilitarismus kann das Ziel auch das größtmögliche Glück der größtmöglichen Zahl von Menschen sein. ${ }^{1068}$ Ziel der Effizienz nach Ott/ Schäfer ist das Ermöglichen von Autonomie des Individuums ${ }^{1069}$ : Erst durch eine Mindestausstattung an Ressourcen kann ein Individuum autonom agieren, sodass eine effiziente Ressourcenverteilung die Autonomie möglichst vieler sichert. Autonomie wird hier sowohl intrinsisch als Selbstzweck verstanden, als auch extrinsisch als Mittel zur Erreichung von Wohlstand. ${ }^{1070}$

\section{Demokratie-basierte Rechtfertigung nach Netanel}

Nach der demokratie-basierten Rechtfertigung dient das Urheberrecht der demokratischen Entwicklung einer Gesellschaft, insbesondere dem öffentlichen Diskurs in der Zivilgesellschaft. ${ }^{1071}$ Das Urheberrecht soll die kommunikativen Grundlagen schaffen, derer es in einem demokratisch regierten Gemeinwesen bedarf. ${ }^{1072}$ Dieser Rechtfertigungsansatz des Urheberrecht stammt von Netanel für das U.S.-amerikanische Copyright und wur-

1065 Marl, Der Begriff der Öffentlichkeit im Urheberrecht, 2017, S. 86; Hansen, Warum Urheberrecht?, 2009, S. 129.

1066 Hinweise zur Empirik und Studienlage s. Hansen, Warum Urheberrecht?, 2009, S. 134 ff., 150 ff.; Stallberg, Urheberrecht und moralische Rechtfertigung, 2006, S. 260.

1067 Posner, The Ethical and Political Basis of the Efficiency Norm in Common Law Adjunction, in: Hofstra Law Review 8 (1980), S. 487, $492 \mathrm{ff}$.

1068 Stallberg, Urheberrecht und moralische Rechtfertigung, 2006, S. 232; vgl. zur Definition des Utilitarismus bereits S. 230 Fn. 874.

1069 Ott/Schäfer, Die ökonomische Analyse des Rechts, JZ 1988, S. 213, 220.

1070 Dies., a.a.O., S. 220.

1071 Marl, Der Begriff der Öffentlichkeit im Urheberrecht, 2017, S. 97.

1072 Stallberg, Urheberrecht und moralische Rechtfertigung, 2006, S. 271. 
de von ihm als "democratic paradigm“ bezeichnet. ${ }^{1073}$ In den U.S.A. wird das Urheberrecht häufig als Einschränkung der freien Rede verstanden. Dem setzt Netanel seinen Ansatz entgegen, der das Urheberrecht gleichzeitig als notwendige Bedingung für freie Rede erachtet. ${ }^{1074}$

Das Urheberrecht ist nach diesem Ansatz Voraussetzung für eine funktionierende Kommunikation in der Zivilgesellschaft. ${ }^{1075}$ Öffentlichkeit und öffentliche Kommunikation seien Bedingungen für das Funktionieren der Demokratien, gleichsam aber auch ihre kommunikative Grundlage. ${ }^{1076}$ Es besteht somit auch eine Wechselwirkung zwischen Öffentlichkeit und Demokratie. Diesem Rechtfertigungsansatz liegen damit einige argumentative Zwischenschritte zugrunde, denn er setzt ein bestimmtes Konzept eines demokratischen Systems voraus. So wird angenommen, dass bestimmte Formen von Öffentlichkeit und zivilgesellschaftlicher Kommunikation notwendig sind für eine demokratische Entwicklung der Gesellschaft. ${ }^{1077}$ Netanel legt dabei seinen Überlegungen das Verständnis einer lebendigen, partizipativen und pluralistischen Zivilgesellschaft zugrunde. ${ }^{1078}$ Eine solche Gesellschaft führe zu geistiger Unabhängigkeit und Selbstbestimmung, sozialem Verantwortungsgefühl und letztlich zu einem informierten und mündigen Bürger. ${ }^{1079}$ Netanel geht davon aus, dass Urheberrecht Wissen verbreite, was für den Erhalt einer freiheitlichen Verfassung wesentlich sei. ${ }^{1080}$ Erst mit diesem Wissen kenne der Bürger seine Rechte und könne sie wahrnehmen. ${ }^{1081}$ Ziel sei also die Partizipation des

1073 Netanel, Copyright and a Democratic Society, in: The Yale Law Journal 106 (1996), S. 283-387; Ders., Asserting Copyright's Democratic Principles in the Global Arena, in: Vanderbilt Law Review 51 (1998), S. 217-329.

1074 Ders., Asserting Copyright's Democratic Principles in the Global Arena, in: Vanderbilt Law Review 51 (1998), S. 217, 299; Ders., Copyright and a Democratic Society, in: The Yale Law Journal 106 (1996), S. 283, 288 f.; angedeutet wird dieses demokratiefördernde Potenzial des Urheberrechts bereits vom U.S. Supreme Court, der es als „engine of free expression“ bezeichnet in der Entscheidung Harper \& Row, Publishers, Inc. v. Nation Enterprises U.S. 471 (1985) 539, 558.

1075 Marl, Der Begriff der Öffentlichkeit im Urheberrecht, 2017, S. 99.

1076 Ders., a.a.O., S. 99; Stallberg, Urheberrecht und moralische Rechtfertigung, 2006, S. 271.

1077 Marl, Der Begriff der Öffentlichkeit im Urheberrecht, 2017, S. 100.

1078 Hansen, Warum Urheberrecht?, 2009, S. 258.

1079 Netanel, Copyright and a Democratic Society, in: The Yale Law Journal 106 (1996), S. 283, 342 ff.; Hansen, Warum Urheberrecht?, 2009, S. 258.

1080 Hansen, Warum Urheberrecht?, 2009, S. 289.

1081 Ders., a.a.O., S. 357. 
Bürgers an der Demokratie. ${ }^{1082}$ Das Urheberrecht stärke die freie Rede in der Zivilgesellschaft, sodass eine öffentliche Sphäre als Kommunikationsforum entstehen kann. ${ }^{1083}$ Durch die Zwischenstufen der Entwicklung Öffentlichkeit zu Kommunikation zu Zivilgesellschaft unterstütze und sichere das Urheberrecht letztlich die Demokratie. ${ }^{1084}$

Laut Netanel fördere das Urheberrecht die demokratische Zivilgesellschaft speziell durch seine drei Funktionen. Die Produktionsfunktion des Urheberrechts meint, dass das Urheberrecht kreatives Tätigwerden stimuliert: „Copyright provides an incentive for creative expression on a wide array of political, social and aesthetic issues, thus bolstering the discursive foundations for democratic culture and civic association." ${ }^{1085}$ Nach der Strukturfunktion fördert das Urheberrecht den demokratischen Charakter des öffentlichen Diskurses ${ }^{1086}$, da urheberrechtliche Werke autonom und divers sind. ${ }^{1087}$ Autonom bedeutet hier, dass urheberrechtliche Werke ohne Abhängigkeitsverhältnis vom Staat, also unabhängig von Fördergeldern und Subventionierungen, entstehen, sondern aufgrund einer herrschaftsfreien und markbasierten Anreizstruktur. ${ }^{1088}$ Zudem fördere das Urheberrecht die demokratische Zivilgesellschaft durch seine Symbolfunktion, indem es auf symbolische Weise den Wert individueller Ausdrucksformen huldigt. ${ }^{1089}$ Der Beitrag Einzelner zur öffentlichen Kommunikation wird in seiner Wichtigkeit unterstrichen und dadurch auch der Wert des Indivi-

1082 Ders., a.a.O., S. 386.

1083 Marl, Der Begriff der Öffentlichkeit im Urheberrecht, 2017, S. 99; Stallberg, Urheberrecht und moralische Rechtfertigung, 2006, S. 277.

1084 Marl, Der Begriff der Öffentlichkeit im Urheberrecht, 2017, S. 99.

1085 Netanel, Copyright and a Democratic Society, in: The Yale Law Journal 106 (1996), S. 283, 288.

1086 Hansen, Warum Urheberrecht?, 2009, S. 261.

1087 Netanel, Copyright and a Democratic Society, in: The Yale Law Journal 106 (1996), S. 283, 352.

1088 Vgl. auch Hansen, Warum Urheberrecht?, 2009, S. 261; Stallberg, Urheberrecht und moralische Rechtfertigung, 2006, S. 281.

1089 Netanel, Asserting Copyright's Democratic Principles in the Global Arena, in: Vanderbilt Law Review 51 (1998), S. 217, 272 ff.; Hansen, Warum Urheberrecht?, 2009, S. 264. Als Symbolfunktion wird dieser Aspekt nach Stallberg, Urheberrecht und moralische Rechtfertigung, 2006, S. 279 benannt; Netanel selbst spricht von „symbolic force“ oder „symbolic potency“, Netanel, Asserting Copyright's Democratic Principles in the Global Arena, in: Vanderbilt Law Review 51 (1998), S. 217, 273 f. 
duums selbst gestärkt. ${ }^{1090}$ Das Urheberrecht wird hier als kulturelles Material gedeutet, aus dem seinerseits Sozialnormen entspringen. ${ }^{1091}$

\section{Universalistisch-transzendentale Rechtfertigung nach Stallberg}

Stallberg stellt in seinem universalistisch-transzendentalen Rechtfertigungsansatz auf den kommunikativen Charakter urheberrechtlicher Werke ab. Dieses Dasein als kommunikative Handlung sei nicht nur das spezielle Charakteristikum der Werke, sondern auch ihre moralische Grundlage. ${ }^{1092}$ In der Regelungsbegründung des Urheberrechts müsse daher die kommunikative Qualität der geistigen Werke in den Mittelpunkt gestellt werden. ${ }^{1093}$ Hierbei will er das Urheberwerk als illokutionären, komplexen Sprechakt verstanden wissen. ${ }^{1094}$ Damit bezieht er sich auf die Sprechakttheorie von Searle, wonach eine sprachliche Äußerung zugleich der Vollzug einer Handlung ist, die aktiv die Realität verändert. ${ }^{1095}$ Nach Searle sind Sprechakte solche Handlungen, die intentional erfolgen. ${ }^{1096}$ Sprechakte unterliegen dabei gewissen Regeln oder auch Vollzugsbedingungen nur, wenn die Handlungen diesen Regeln entsprechen, haben sie Bedeutung. ${ }^{1097}$ Searle unterscheidet hierbei 1.) Eingabe- und Ausgabebedingungen, die das Sprechen (die Ausgabe) und das Verstehen (die Eingabe) betreffen; 2.) Bedingungen des propositionalen Gehalts, also der inhaltliche Bezug auf eine zukünftige Handlung; 3.) Einleitungsbedingungen, die im Vollzug des Sprechaktes bereits impliziert werden; und 4.) Aufrichtigkeitsbedingungen, die einen psychologischen Zustand zum Ausdruck bringen. ${ }^{1098}$ Wenn diese Bedingungen eingehalten sind, wird erfolgreich kommuniziert. Geistige Werke bezeichnet Stallberg als illokutionären Akt, da dies Handlungen meint, die durch Sprache bereits vollzogen werden, also die durch die Äußerung verfolgte kommunikative Absicht. Da geistige

1090 So Stallberg, Urheberrecht und moralische Rechtfertigung, 2006, S. 282.

1091 Ders., a.a.O., S. 282.

1092 Ders., a.a.O., S. 300.

1093 Ders., a.a.O., S. 301.

1094 Ders., a.a.O., S. 302 ff.

1095 J. Searle, Sprechakte. Ein sprachphilosophischer Essay [1969], 1971, S. 29 ff.

1096 Ders., a.a.O., S. 31.

1097 Stallberg, Urheberrecht und moralische Rechtfertigung, 2006, S. 305.

1098 J. Searle, Sprechakte. Ein sprachphilosophischer Essay [1969], 1971, S. 89 ff.; Stallberg, Urheberrecht und moralische Rechtfertigung, 2006, S. 305 f. 
Werke aus einer Verbindung mehrerer elementarer illokutionärer Akte bestehen, stellen sie komplexe illokutionäre Sprechakte dar. ${ }^{1099}$

Stallbergs Einordnung geistiger Werke bezieht sich nicht nur auf Texte, sondern auf alle Werkarten. ${ }^{1100}$ Insbesondere auf Gemälde bezieht sich Stallberg explizit, die deshalb komplexe Sprechakte seien, weil es sich auch bei Gemälden um Symbole handelt, da sie mehr sind, als der Gegenstand selbst, und ihre Bedeutung kraft dieses Symbolseins besitzen. ${ }^{1101}$ Symbolik unterliegt jedoch immer konstitutiven Regeln, die festlegen, unter welchen Umständen etwas als etwas gilt. ${ }^{1102}$ Solche Regeln sind immer sprachliche, weshalb auch die Möglichkeit der Existenz von Gemälden Sprechakte darstellen. ${ }^{1103}$

Stallberg selbst kategorisiert diesen Ansatz weder zu den individualistischen noch zu den kollektivistischen Rechtfertigungsgründen, sondern sieht ihn vielmehr als Überwindung dieser Kategorien an. ${ }^{104}$ Da er aber individualistische und kollektivistische Begründungsbausteine in Synthese zusammenführt, überwindet er diese Kategorien nicht, sondern sein Ansatz ist vielmehr als verbindender Ansatz zu verstehen. ${ }^{1105}$ Denn die universalistisch-transzendentale Rechtfertigung berücksichtigt beide Beziehung - Urheber/Werk und Gesellschaft/Werk -, da beide Beziehungen auf die menschliche Sprache und das, was sie ermöglicht, zurückzuführen sind. ${ }^{1106}$ Indem das Urheberrecht nicht aus moralischen Vorrechten von Urhebern oder von Gesellschaft, sondern aus einem „notwendigen Denken in linguistischen Regeln" abgeleitet wird, stellt dieser Ansatz einen Perspektivwechsel in der Debatte um die Rechtfertigung des Urheberrechts dar. ${ }^{1107}$

1099 Stallberg, Urheberrecht und moralische Rechtfertigung, 2006, S. 305.

1100 Anders Dreier, Urheberrecht und moralische Rechtfertigung. Besprechung, GRUR 2007, S. 128, 129, nach dem die Einordnung von Werken als Sprechakten sich nicht auf Bilder übertragen ließe.

1101 Stallberg, Urheberrecht und moralische Rechtfertigung, 2006, S. 309.

1102 J. Searle, Sprechakte. Ein sprachphilosophischer Essay [1969], 1971, S. 60, 61; Stallberg, Urheberrecht und moralische Rechtfertigung, 2006, S. 309.

1103 Zur ausführlichen Begründung vgl. J. Searle, Sprechakte. Ein sprachphilosophischer Essay [1969], 1971, S. 64 ff.

1104 Stallberg, Urheberrecht und moralische Rechtfertigung, 2006, S. 301.

1105 So Marl, Der Begriff der Öffentlichkeit im Urheberrecht, 2017, S. 171, 173; Rösler, Buchbesprechung zu Christian Gero Stallberg, Urheberrecht und moralische Rechtfertigung (2006), JZ 2007, S. 185, 185.

1106 Stallberg, Urheberrecht und moralische Rechtfertigung, 2006, S. 302.

1107 Rösler, Buchbesprechung zu Christian Gero Stallberg, Urheberrecht und moralische Rechtfertigung (2006), JZ 2007, S. 185, 186. 
III. Ausgestaltung des kommunikativen Verständnisses von Urheberrecht innerhalb des bestehenden Rechts

Nach dem kommunikativen Verständnis muss das Urheberrecht so ausgestaltet sein, dass es den Nutzern als Kommunikationspartner zugutekommt. Im Folgenden soll untersucht werden, wie ein kommunikatives Verständnis von Urheberrecht innerhalb des bestehenden Rechts angewendet werden kann, um Freiraum für Nutzungshandlungen zu schaffen. Dazu wird zunächst eine verfassungskonforme Auslegung des $\$ 24$ Abs. 1 UrhG anhand des Kommunikationsgrundrechts aus Art. 5 Abs. 1 GG vorgenommen (1.) und sodann eine Einwilligungslösung als Ausweitung der Vorschaubilder-Rechtsprechung entwickelt (2.).

1. Verfassungskonforme Auslegung des $₫ 24$ Abs. 1 UrhG anhand des Kommunikationsgrundrechts aus Art. 5 Abs. 1 GG

Da die verfassungskonforme Auslegung des $₫ 24$ Abs. 1 UrhG anhand der Kunstfreiheit gem. Art. 5 Abs. 3 GG für Phänomene der digitalen Aneignung wie Memes und GIFs nicht greift, da diese regelmäßig nicht von der Kunstfreiheit geschützt sind ${ }^{1108}$, soll nun eine Auslegung anhand des Kommunikationsgrundrechts aus Art. 5 Abs. 1 GG entwickelt werden.

a) Kommunikationsfreiheit als Meinungsfreiheit gem. Art. 5 Abs. 1 GG

Die Meinungsfreiheit gem. Art. 5 Abs. 1 GG schützt sowohl die Meinungsfreiheit im Interesse der Persönlichkeitsentfaltung des Einzelnen als auch im Interesse des demokratischen Prozesses. ${ }^{1109}$ Dieser Schutz der Äußerung und Verbreitung von Meinungen stellt gemeinsam mit der Informationsfreiheit als einander ergänzende Elemente den Schutz des Kommunikationsprozesses dar. ${ }^{1110}$ Objektivrechtlich ist der Prozess der Kommunikation geschützt, subjektivrechtlich die Freiheit, daran teilzunehmen. ${ }^{111}$

1108 S. dazu S. 206 ff.

1109 BVerfG NJW 1958, S. 257, 258 - Lüth; BVerfG NJW 2005, S. 1341, 1342 - vollzugsfeindlich; BeckOK GG/Schemmer, 41. Ed. 2019, Art. 5 GG Rn. 1.

1110 BeckOK GG/Schemmer, 41. Ed. 2019, Art. 5 GG Rn. 1.

1111 BVerfG NJW 1981, S.1774, 1775 - Landesmediengesetz Baden-Wüttemberg; BVerfG NJW 1991, S. 899, 899 - WDR. 
Grundrechtsträger des Art. 5 Abs. 1 GG ist jedermann, also jede natürliche Person. Auch juristische Personen können Grundrechtsträger sein, da die Meinungsfreiheit ihrem Wesen nach auf sie anwendbar ist gem. Art. 19 Abs. 3 GG. ${ }^{1112}$

Der Begriff der Meinung ist in Art. 5 Abs. 1 S. 1 GG grundsätzlich weit zu verstehen. ${ }^{1113}$ Eine Meinung ist durch das Element der Stellungnahme, des Dafürhaltens und der Beurteilung geprägt. ${ }^{1114}$ Der sachliche Schutzbereich schützt die Meinungsäußerung und -verbreitung in einem umfassenden Sinne der Informationsweitergabe ${ }^{1115}$ sowie die Möglichkeit, dass die Meinung empfangen werden kann. ${ }^{1116}$ Die Wahl des Ortes und der Zeit der Meinungsäußerung sind ebenfalls geschützt. ${ }^{1117}$

Digitale Kommunikation findet häufig im Privaten oder in Teilöffentlichkeiten statt. ${ }^{1118}$ Auch diese bloß soziale Interaktion müsste in den Schutzbereich der Meinungsfreiheit einbezogen sein. Der Schutzgrund der Meinungsfreiheit wird in ihrer Bedeutung für die freiheitliche Demokratie gesehen, da erst die Meinungsfreiheit eine ständige geistige Auseinandersetzung in der Gesellschaft ermöglicht. Nicht an einen Adressaten gerichtete Äußerungen, wie Selbstgespräche oder Tagebuchaufzeichnungen, sind daher keine Meinungsäußerungen im Sinne des Art. 5 Abs. 1 GG. ${ }^{1119}$ Es liegt also nur eine Meinungsäußerung vor, wenn es um die Teilnahme an einer geistigen Auseinandersetzung geht. Es ist insoweit abzuwägen, „ob die Äußerung lediglich eine private Auseinandersetzung zur Verfolgung von Eigeninteressen betrifft oder ob von der Meinungsfreiheit im Zusammenhang mit einer die Öffentlichkeit wesentlich berührenden Frage Gebrauch gemacht wird." ${ }^{1120}$ Handelt es sich um einen Beitrag zur öffentlichen Meinungsbildung, so spricht eine Vermutung zugunsten der Freiheit der Rede. ${ }^{1121}$ Dabei müssen jedoch Inhalt dieser geistigen Auseinander-

1112 BVerfG NJW 1989, S. 2877, 2877 - staatliche Presseförderung; BeckOK GG/ Schemmer, 41. Ed. 2019, Art. 5 GG Rn. 2.

1113 BeckOK GG/Schemmer, 41. Ed. 2019, Art. 5 GG Rn. 5.

1114 BVerfG NJW 1983, S. 1415, 1415 - Wablkampf.

1115 BeckOK GG/Schemmer, 41. Ed. 2019, Art. 5 GG Rn. 9.

1116 Maunz/Dürig/Grabenwarter, 86. EL 2019, Art. 5 Abs. 1, 2 GG Rn. 87.

1117 BeckOK GG/Schemmer, 41. Ed. 2019, Art. 5 GG Rn. 9.

1118 Vgl. zur Zersplitterung in Teilöffentlichkeiten und zum Wandel der Privatheit im öffentlichen Raum der sozialen Netzwerke S. 107 f., 150 ff.

1119 Maunz/Dürig/Grabenwarter, 86. EL 2019, Art. 5 Abs. 1, 2 GG Rn. 81.

1120 BVerfG GRUR-RS 2016, S. 45299 Rn. 24 - Fall Kachelmann.

1121 BVerfG GRUR-RS 2016, S. 45299 Rn. 24 - Fall Kachelmann; BVerfG NJW 1958, S. 257, 259 - Lüth; BVerfG NJW 1995, S. 3303, 3305 - Soldaten sind Mörder. 
setzung nicht nur öffentliche oder politische Angelegenheiten sein. ${ }^{1122}$ Denn die Meinungsfreiheit beschränkt sich nicht auf die Gewährleistung eines geistigen Meinungskampfes und auf ein rein funktionales Verständnis zur Förderung einer öffentlichen Debatte mit Gemeinbezug, sondern ist auch um ihrer Privatnützigkeit willen gewährleistet. ${ }^{1123}$ Das heißt bei Aneignungen durch digitale Technologien ist je nach Einzelfall zu entscheiden, ob es sich wirklich um eine Meinungsäußerung handelt. Memes oder GIFs können auch in rein privaten Kontexten versendet werden und sich gerade nicht an die Öffentlichkeit richten, beispielsweise in privaten Chats. Ansonsten werden kommunikative Aneignungen jedoch häufig in der Öffentlichkeit in sozialen Netzwerken oder auf öffentlichen Plattformen geteilt. Auch wenn dort gelegentlich ein Gefühl der Privatheit wahrgenommen wird, liegt das nicht an einer tatsächlichen Privatheit des Gesprächs, sondern vielmehr an dem gewandelten Verständnis von Privatheit. Mit den digitalen Technologien und sozialen Netzwerken wird Privatheit vermehrt in den öffentlichen Raum getragen: Geteilte Bilder sind öffentlich einsehbar oder zumindest von einer kaum überschaubaren Gruppe der Vernetzten eines sozialen Netzwerkes. Es handelt sich um private Selbstdarstellung im öffentlichen Raum. Digitale Aneignungen werden gerade zum Ziel der Kommunikation vorgenommen: Die Produktion dieser Aneignungen und deren Weiterverbreitung finden im Rahmen einer digitalen Bildkultur statt, die von ständiger Verbindung zueinander und ständigem Austausch geprägt ist. ${ }^{1124}$ Mit Blick auf diese Vermischung des Privaten und Öffentlichen ist bei digitalen Aneignungen in der Regel von einer Teilnahme an einem öffentlichen Diskurs auszugehen, sodass es sich bei diesen Aneignungen regelmäßig um Meinungsäußerungen im Sinne des Art. 5 Abs. 1 GG handelt.

Als Eingriff in die Meinungsfreiheit gilt jede staatliche Maßnahme, die die Meinungsäußerung und -verbreitung verbietet, behindert oder gebietet. ${ }^{1125}$

Ein Eingriff in die Meinungsfreiheit kann jedoch gerechtfertigt sein, denn gem. Art 5 Abs. 2 GG findet sie ihre Schranken in den Vorschriften der allgemeinen Gesetze, den gesetzlichen Bestimmungen zum Schutze der Jugend und in dem Recht der persönlichen Ehre. Das BVerfG versteht unter den „allgemeinen Gesetzen“ solche, die „nicht eine Meinung als sol-

1122 BeckOK GG/Schemmer, 41. Ed. 2019, Art. 5 GG Rn. 4.

1123 BVerfG GRUR-RS 2016, S. 45299 Rn. 24 - Fall Kachelmann.

1124 S. dazu ausführlich bereits S. $107 \mathrm{ff}$.

1125 BeckOK GG/Schemmer, 41. Ed. 2019, Art. 5 GG Rn. 18. 
che verbieten, die sich nicht gegen die Äußerung der Meinung als solche richten, die vielmehr dem Schutze eines schlechthin, ohne Rücksicht auf eine bestimmte Meinung, zu schützenden Rechtsguts dienen, dem Schutz eines Gemeinschaftswerts, der gegenüber der Betätigung der Meinungsfreiheit Vorrang hat $[\ldots]^{“ 1126}$. $\$ 24$ UrhG stellt zweifelslos ein solches allgemeines Gesetz dar.

b) Ausgestaltung der verfassungskonformen Auslegung

\$24 Abs. 1 UrhG könnte verfassungskonform im Lichte der Meinungsfreiheit gem. Art. 5 Abs. 1 GG ausgelegt werden. Denn $\$ 24$ UrhG schränkt die geistige Auseinandersetzung mit fremden Werken ein, wenn kein ausreichender äußerer oder innerer Abstand zum übernommenen Werk eingehalten wird. ${ }^{1127}$

Ähnlich wie die oben vorgenommene Auslegung des $\$ 24 \mathrm{UrhG}^{1128}$ anhand der Kunstfreiheit gem. Art. 5 Abs. 3 GG soll hier die verfassungskonforme Auslegung angewendet werden. Dabei ist zu beachten, dass eine solche Auslegung des $\$ 24$ UrhG anhand der Meinungsfreiheit von der Rechtsprechung bisher nicht vorgenommen wurde. Für Filmzitate und kleine Großzitate ${ }^{1129}$ wurde zwar $\$ 51 \mathrm{Nr} .2$ UrhG a.F. verfassungskonform ausgelegt anhand der Meinungsfreiheit, dabei spricht jedoch der BGH selbst nicht von einer solchen Auslegung, sondern von einer analogen Anwendung. ${ }^{1130}$ Diese Anwendung wird damit begründet, „daß der Urheber bei seinem Schaffen auf den kulturellen Leistungen seiner Vorgänger aufbaut" und ihm deshalb im Interesse der Allgemeinheit zugemutet wird, „einen verhältnismäßig geringfügigen Eingriff in sein ausschließliches Verwertungsrecht hinzunehmen, wenn dies der geistigen Kommunikation und damit der Förderung des kulturellen Lebens zum Nutzen der Allgemeinheit dient ${ }^{\text {"1131. }}$.

1126 BVerfG NJW 1958, S. 257, 258 - Lüth.

1127 S. dazu S. $184 \mathrm{ff} ., 187 \mathrm{ff}$.

1128 S. $192 \mathrm{ff}$.

1129 Filmzitate sind solche, bei denen das zitierte Werk ein Filmwerk ist, und kleine Großzitate solche, bei denen ganze Sprach- oder Bildwerke geringen Umfangs angeführt werden, vgl. Stieper, Rechtfertigung, Rechtsnatur und Disponibilität der Schranken des Urheberrechts, 2009, S. 49.

1130 BGH GRUR 1987, S. 362, 363 - Filmzitat.

1131 BGH GRUR 1987, S. 362, 363 - Filmzitat. 
Bilder sind in der Digitalkultur zum Rohstoff geworden - sie werden ständig verändert, kombiniert und in neuen Kontext gesetzt. Diese produktive und flexible Nutzungsmöglichkeit hat Bilder zu dem wichtigsten Kommunikationsmittel im Internet werden lassen. Die Übernahme eines Bildes dient hier der Kommunikation mit anderen und nicht dazu, den Wert des übernommenen Bildes auszunutzen. Auch diese geistige Kommunikation und Förderung des kulturellen Lebens ist im Rahmen des Art. 5 Abs. 1 GG schützenswert.

Bei der Auslegung des $₫ 24$ Abs. 1 UrhG anhand der Meinungsfreiheit ist die Wechselwirkungslehre zu beachten. Zwischen Schutzbereich und Schranken besteht eine Wechselwirkung dergestalt, „dass die Schranken zwar dem Wortlaut nach dem Grundrecht Grenzen setzen, ihrerseits aber aus der Erkenntnis der grundlegenden Bedeutung dieses Grundrechts im freiheitlich demokratischen Staat ausgelegt und so in ihrer das Grundrecht begrenzenden Wirkung selbst wieder eingeschränkt werden müssen" ${ }^{\text {"1132 }}$. Im Rahmen der Auslegung des $\$ 24$ UrhG als Schranke der Meinungsfreiheit ist also wiederum die besondere Bedeutung der Meinungsfreiheit für die geistige Auseinandersetzung in einer demokratischen Gesellschaft zu beachten. Der Inhalt der Wechselwirkungslehre entspricht einer vollumfänglichen Verhältnismäßigkeitsprüfung. ${ }^{133}$ Dies führt jedoch zu einer Einzelfallbezogenheit der Wechselwirkungslehre, sodass sich hier nur sehr grundsätzliche Entscheidungsleitlinien für die verfassungskonforme Auslegung des $\mathbb{2 4}$ Abs. 1 UrhG herleiten lassen. Denn als Prämisse des Verhältnismäßigkeitsgrundsatzes, der der Wechselwirkungslehre zugrunde liegt, ist gesichert, dass der Meinungsfreiheit kein allgemeiner Vorrang vor anderen Rechtsgütern zukommt. ${ }^{1134}$ Hier sind also alle konfligierenden Rechtsgüter in Abwägung aller wesentlichen Umstände zu berücksichtigen und nach dem Grundsatz der praktischen Konkordanz so in Ausgleich zu bringen, dass sie für alle Beteiligten möglichst weitgehen wirksam werden. ${ }^{1135}$ Das Ergebnis dieser Abwägung kann nicht generell und abstrakt vorwegge-

1132 BVerfG NJW 1958, S.257, 258 - Lüth; BVerfG NJW 1996, S. 1529, 1529 DGHS; BVerfG NJW 2003, S. 1787, 1789 - Handy-Überwachung.

1133 Maunz/Dürig/Grabenwarter, 86. EL 2019, Art. 5 Abs. 1, 2 GG Rn. 140.

1134 BVerfG NJW 1958, S. 257, 258 - Lüth; BVerfG NJW 1973, S. 1226, 1229 - Lebach-Fall; Maunz/Dürig/Grabenwarter, 86. EL 2019, Art. 5 Abs. 1, 2 GG Rn. 142.

1135 BVerfG GRUR 2016, S. 690, 691 Rn. 70 - Metall auf Metall; BVerfG NJW 1994, S. 36, 38 - Bürgschaft I; BVerfG NJW 2011, S.3428, 3432 - Le-Corbusier-Möbel; BVerfG GRUR 2014, S. 169, 170 Rn. 68 - Übersetzerhonorare. 
nommen werden. ${ }^{1136}$ Eine Grundrechtsverletzung durch die Regelung des $\$ 24$ Abs. 1 UrhG kann dabei nur festgestellt werden, wenn eine Grundrechtsposition den Interessen der Gegenseite in einer Weise untergeordnet wird, dass in Anbetracht der Bedeutung und Tragweite des betroffenen Grundrechts von einem angemessenen Ausgleich nicht mehr gesprochen werden kann. ${ }^{1137}$ Dies hat für Aneignungen durch digitale Technologien zur Folge, dass sie je nach Einzelfall ganz unterschiedlich bewertet werden können: Sowohl der Grad der Übernahme als auch die Verwendung des übernommenen Bildes als auch die dadurch entstehende Einschränkung der Verwertungsmöglichkeiten des Urhebers können je nach konkretem Einzelfall ganz unterschiedlich ausgeprägt sein.

\section{c) Kritische Würdigung}

Eine verfassungskonforme Auslegung des $\$ 24$ Abs. 1 UrhG anhand der Meinungsfreiheit gem. Art. 5 Abs. 1 S. 1 GG erscheint möglich. Ebenso wie bei der verfassungskonformen Auslegung anhand der Kunstfreiheit gem. Art. 5 Abs. 3 GG überwiegt im Rahmen der praktischen Konkordanz nicht regelmäßig ein Rechtsgut gegenüber dem anderen, sondern es sind jeweils umfassend die Umstände des Einzelfalles zu beachten.

Dennoch kann man davon ausgehen, dass die verfassungskonforme Auslegung anhand der Meinungsfreiheit regelmäßig nicht so weitgreifend die urheberrechtliche Wertung korrigieren wird wie dieselbe anhand der Kunstfreiheit. Denn erstens setzt die Kunstfreiheit oft voraus, dass die konkrete Aneignung eines Bildes vorgenommen wird, da die Ausübung einer bestimmten Kunstform ansonsten nicht möglich ist. ${ }^{1138}$ Viele Gestaltungsmittel in der Kunst sind gerade geprägt von Aneignungstechniken, wie der Replik, Pastiche, Hommage, Collage oder das Sampling. ${ }^{1139}$ Dies ist bei der Meinungsfreiheit nicht auf gleiche Art der Fall. Zwar ist von der Meinungsfreiheit auch umfasst, das Mittel zur Meinungsäußerung frei zu wählen. Allerdings sind wenige Aneignungsformen denkbar, die für bestimmte Meinungsäußerungen ähnlich konstitutiv sind wie bei bestimmten For-

1136 Maunz/Dürig/Grabenwarter, 86. EL 2019, Art. 5 Abs. 1, 2 GG Rn. 145.

1137 BVerfG GRUR 2016, S. 690, 691 Rn. 70 - Metall auf Metall; BVerfG NJW 1998, S. 1475, 1476 - Kleinbetriebsklausel; BVerfG GRUR 2014, S. 169, 170 Rn. 70 Übersetzerhonorare.

1138 So das BVerfG für das Sampling: BVerfG GRUR 2016, S. 690, 694 Rn. 96 ff. Metall auf Metall.

1139 Vgl. zu diesen Techniken der Aneignung S. 33 ff. 
men der Kunst. Man könnte jedoch auch hier argumentieren, dass der öffentliche Diskurs, der durch die Meinungsfreiheit erst ermöglicht wird, darunter leiden könnte, wenn bestimmte Aneignungsformen als Ausdruck einer Teilhabe an diesem Diskurs nicht mehr möglich sind.

In einem zweiten Punkt unterscheiden sich die beiden verfassungskonformen Auslegungen des $₫ 24$ Abs. 1 UrhG: Die Meinungsfreiheit steht gem. Art. 5 Abs. 2 GG unter einem Gesetzesvorbehalt. Die Einschränkbarkeit dieses Grundrechts ist also vorgesehen. Die Kunstfreiheit gem. Art. 5 Abs. 3 GG besteht demgegenüber vorbehaltslos. Sie findet ihre Grenzen lediglich verfassungsimmanent in den Rechtsgütern Dritter. Damit ist für die Kunstfreiheit die Möglichkeit des Gesetzgebers beschränkt, den Freiheitsgebrauch des Grundrechtes einzuschränken. Dass die Meinungsfreiheit also einfacher beschränkt werden kann, ist bei der Auslegung und Anwendung des Urheberrechts anhand von Grundrechtspositionen ebenfalls zu beachten.

Für die digitalen Aneignungshandlungen zur Kommunikation ergibt sich daher, dass bei einer verfassungskonformen Auslegung des $\$ 24$ Abs. 1 UrhG anhand der Meinungsfreiheit gem. Art. 5 Abs. 1 GG nur in Einzelfällen die Interessen des Aneignenden überwiegen werden gegenüber den Interessen des Urhebers. Das Problem digitaler Aneignungshandlungen als Massenphänomen ist damit nicht befriedigend gelöst, da hier lediglich in konkreten Einzelfällen je nach Umständen des Falles eine Rechtfertigung der Aneignungshandlung möglich erscheint.

\section{Einwilligungslösung: Ausweitung der Vorschaubilder-Rechtsprechung}

Das Prinzip der Einwilligungslösung aus der Vorschaubilder-Rechtsprechung des BGH könnte übertragen werden auf bildliche Aneignungen im Digitalen. Denn wie auch bei Vorschaubildern sind bildliche Kommunikationshandlungen sozialüblich im Internet und könnten deshalb freigestellt werden.

In den Entscheidungen Vorschaubilder I, II und III hat der BGH das Institut der sog. schlichten Einwilligung entwickelt. ${ }^{1140}$ Wer seine Bilder ohne technische Vorkehrung gegen Crawler frei zugänglich ins Internet stellt, erklärt sich demnach mit der Speicherung und Anzeige des Bildes in Such-

1140 BGH GRUR 2010, S. 628 - Vorschaubilder I; BGH GRUR 2012, S. 602 - Vorschaubilder II; BGH GRUR 2018, S. 178 - Vorschaubilder III. 
maschinen einverstanden. ${ }^{1141}$ Denn wer ein Bild ins Internet stellt, ohne Crawler technisch zu blockieren, müsse damit rechnen, dass Bildersuchmaschinen dieses Bild nutzen. Diese Funktion sei überdies für das Funktionieren des Internets unabdingbar. Deshalb wird mit dem Einstellen des Bildes ohne hinreichende Sicherung fingiert, dass eine Einwilligung erklärt worden sei.

Aus ähnlichen Gründen wurde im EuGH-Urteil GS Media Framing und Linking nicht als öffentliche Wiedergabe eines urheberrechtlich geschützten Werkes eingestuft. ${ }^{1142}$ Auch hier wurde deutlich gemacht, dass der Urheber tätig werden und technische Maßnahmen ergreifen muss, wenn er nicht möchte, dass auf sein Werk verlinkt oder dieses geframed wird. So wurde versucht, durch eine Verschiebung der Verantwortung auf den Urheber der digitalen Zugangskultur gerecht zu werden.

Für den Upload von Bildern hat der Generalstaatsanwalt beim EuGH Campos Sánchez-Bordona eine ähnliche Verantwortungsverteilung vorgeschlagen: Auch er sieht den Urheber in der Verantwortung, die Verbreitung seines Werke zu kontrollieren. ${ }^{1143}$ Er schlägt vor, dass dem Einstellen eines Bild frei ohne technischen Maßnahmen ins Internet der Erklärungswert zukomme, dass andere das Bild weiterverwenden dürfen, solange dies ohne Gewinnerzielungsabsicht erfolge. ${ }^{1144}$ Eine solche vermutete Einwilligung schließe die öffentliche Zugänglichmachung aus.

Eine solche vermutete Einwilligungslösung kommt auch für Aneignungshandlungen in Betracht, denn eine Aneignung im Internet stellt auch immer eine Vervielfältigung und öffentliche Zugänglichmachung des angeeigneten Werkes dar. Hier könnte man ebenfalls davon ausgehen, dass der Urheber des angeeigneten Werkes dieser Nutzung zustimmt, solange die Aneignung ohne Gewinnerzielungsabsicht erfolgt und er keine technischen Schutzmaßnahmen gegen die Aneignungen vornimmt. Dies dürfte sich allerdings schon deshalb schwierig gestalten, da kein vergleichbarer technischer Standard wie den Robots Exclusion Standard zur Verhinderung von Crawlern existiert, der das Herunterladen von Bildern verhindern könnte. Digitale Aneignungen zur Kommunikation sind überdies nicht ähnlich wie Framing, Linking oder Suchmaschinensammlungen für

1141 BGH GRUR 2010, S. 628 - Vorschaubilder I. Ausführlicher dazu bereits auf S. 153.

1142 EuGH GRUR 2016, S. 1152 - GS Media.

1143 Generalanwalt Campos Sánchez-Bordona, Schlussantrag vom 25.04.2018, Rs. C.161/17 (Cordoba), ECLI:EU:C:2018:279， ZUM 2018， S. 506， 512 Rn. 77 ff., 105.

1144 Ders., a.a.O., S. 512, 514 Rn. 78, 105. 
das Funktionieren des Internets verantwortlich. Letztere Mittel sind oft notwendig, um einen Inhalt überhaupt auffinden zu können in der Informationsflut des Internets. Solche Überlegungen greifen für Aneignungen zur Kommunikation nicht. Sie sind lediglich sozialüblich im Internet, nicht jedoch notwendig für dieses. Man könnte zwar auch argumentieren, dass diese Kommunikationsfunktion des Internets ähnlich bedeutsam ist wie die Auffindungs- und Informationsfunktion und der Urheber deshalb mit Aneignungen zu rechnen habe. Dagegen spricht jedoch, dass kein ähnlicher technischer Automatismus entsteht bei kommunikativen Handlungen wie bei Suchmaschinen oder Linking. Bei Letzteren wird auch argumentiert, dass ein individuelles Überprüfen, ob der Rechteinhaber mit der Vervielfältigung und öffentlichen Zugänglichmachung einverstanden sei, nicht möglich sei, da die Funktionen nur durch technische Automatismen überhaupt möglich sind. Eine solche Überprüfung ist jedoch vor Aneignungshandlungen möglich (auch wenn es eine andere Frage ist, ob es möglich ist, eine Einwilligung des Rechteinhabers durch Lizenzierung zu bekommen, denn erstens ist der Rechteinhaber oftmals schwer auffindbar und zweitens ist die Vergabe der Lizenz allein vom Rechteinhaber abhängig).

Weiterhin passt die vom Generalanwalt entwickelte Voraussetzung der akzessorischen Natur der öffentlichen Zugänglichmachung in seltenen Fällen zu kommunikativen Aneignungen. In seinem Schlussantrag würdigt er den akzessorischen Charakter des übernommenen Bildes als Bestandteil einer Schularbeit als eine Voraussetzung zur Annahme der vermuteten Einwilligung. ${ }^{145}$ Denn hier stehe die Werkverwertung des übernommenen Bildes gerade nicht im Vordergrund, sondern in erster Linie sollte das Schulreferat öffentlich zugänglich gemacht werden und das Bild dabei lediglich nebensächlich der Illustration dienen. ${ }^{1146}$ Aneignungen nutzen das übernommene Bild jedoch meist nicht nebensächlich, sondern stellen es präsent in den Vordergrund. Es soll zwar auch nicht allein der Wiedergabe des Werkes dienen, aber als akzessorische Nutzung können Aneignungen in der Regel nicht verstanden werden. Von einer untergeordneten Bedeutung der Aneignungshandlung kann man wohl nur ausgehen, wenn man auch ein Verblassen der individuellen Züge des übernom-

1145 Ders., a.a.O., S. 506, 511 Rn. 66.

$1146 \mathrm{Vgl}$. auch B. Raue, Kein öffentliches Zugänglichmachen eines urheberrechtlich geschützten Gegenstands durch Vorhalten auf dem eigenen Server? Anmerkung zu GA Sánchez-Bordona, Schlussanträge vom 25.4.2018 - C-161/17 Cordoba (ZUM 2018, 506), ZUM 2018, S. 517, 518. 
menen Werkes im Sinne des $₫ 24$ Abs. 1 UrhG annehmen kann. Nur dann steht das übernommene Werk nicht mehr im Vordergrund, sondern steht hinter den individuellen Zügen des neu geschaffenen Werkes zurück. Ein solches Verblassen liegt bei digitalen Aneignungen zur Kommunikation jedoch so gut wie nie vor: Vielmehr soll das übernommene Werk sichtbar bleiben und auch seine individuellen Züge in Gänze bestehen bleiben. ${ }^{1147}$

Insgesamt zeigt sich, dass sich die Grundzüge der schlichten und der vermuteten Einwilligung nicht für die Übertragung auf kommunikative Aneignungen eignen. Die Interessenverteilung und dahinterstehenden Schutzgedanken dieser Rechtsinstitute sind bei Aneignungen zur Kommunikation nicht in ähnlicher Weise anzufinden. Auch wäre es eine massive Verfälschung der eigentlichen Interessen der Urheber, von einer Einwilligung in aneignende Nutzungshandlungen auszugehen.

\section{Kritische Würdigung}

Der kommunikative Ansatz scheint besonders geeignet, den Realitäten der Kommunikation Rechnung zu tragen und rechtlichen Freiraum für kommunikative Aneignungen schaffen zu können.

Der schranken-basierte Ansatz zur Rechtfertigung des Urheberrechts stellt die Handlungsfreiheit auch der Nutzer in den Vordergrund und erachtet diese Handlungsfreiheit als natürliche Begrenzung der Freiheiten und Rechte des Urhebers. Die effizienz-basierte Rechtfertigung berücksichtigt die Bedürfnisse aller Mitglieder der Gesellschaft und damit auch das Bedürfnis nach Aneignungen als Mittel der Kunst und Kommunikation. Nach der demokratie-basierten Rechtfertigung kann der kommunikative Austausch von Bildern durch Aneignungen als öffentlicher Diskurs der Zivilgesellschaft verstanden werden, der eine wichtige Grundlage für die Meinungsbildung und damit Voraussetzung für das Funktionieren einer Demokratie darstellt. Die universalistisch-transzendentale Rechtfertigung stellt die kommunikative Qualität geistiger Werke in den Vordergrund und vermittelt damit ein Werkverständnis, das den tatsächlichen Stellenwert von Aneignungen zur Kommunikation berücksichtigt.

Der kommunikative Ansatz zeigt sich in besonderer Weise geeignet, das geänderte Kommunikationsverhalten mit Bildern im Digitalen rechtlich widerspiegeln zu können. Dies gelingt, indem das Urheberrecht als Kommunikationsrecht verstanden wird und damit auch die Rolle des Nutzers

1147 S. dazu bereits S. 186. 
als Kommunikationsempfänger an Bedeutung gewinnt - dieser wird als ein ebenbürtiger Adressat des Urheberrechtsschutzes verstanden. Dieser Ansatz setzt sich mit den Kommunikationsbedingungen und -normen auseinander, die das Urheberrecht vermittelt und gestalten kann. Dies kann digitalen Aneignungen rechtlichen Freiraum schaffen und so die Effektivität von Urheberrechtsschutz steigern.

\section{Folgen für Aneignungshandlungen}

Die Ausgestaltung eines kommunikativen Ansatzes durch das bestehende Recht schafft jedoch auch noch nicht ausreichend Freiraum für kommunikative Aneignungshandlungen. Das kommunikative Verständnis von Urheberrecht kann de lege lata nicht ausreichend berücksichtigt werden.

Eine verfassungskonforme Auslegung des $\$ 24$ Abs. 1 UrhG anhand der Meinungsfreiheit gem. Art. 5 Abs. 1 GG ist zwar grundsätzlich möglich, kann Aneignungen jedoch nur in bestimmten Einzelfällen privilegieren. Zunächst einmal ist die rein private Interaktion im Digitalen schon vom Schutzbereich nicht umfasst. Sodann ist im Rahmen der Wechselwirkungslehre jeweils eine Einzelfallabwägung anhand der konkreten Umstände vorzunehmen. Dabei umfasst die Meinungsfreiheit zwar ebenso wie die Kunstfreiheit gem. Art. 5 Abs. 3 GG einen weiten Schutzbereich, lässt sich jedoch im Gegensatz zu dieser aufgrund des Gesetzesvorbehalts leichter einschränken. Eine verfassungskonforme Auslegung des $\$ 24$ Abs. 1 GG im Hinblick auf die Meinungsfreiheit ist damit keine umfassende Umsetzung eines kommunikativen Verständnisses von Urheberrecht.

Eine Einwilligungslösung vermag digitalen Aneignungen auch nicht mehr rechtlichen Freiraum zu verschaffen. Eine Ausweitung der Vorschaubilder-Rechtsprechung auf kommunikative Aneignungen bietet sich deshalb nicht an, weil diese nicht ähnlich technisch zu verhindern sind wie Vorschaubilder oder Frame-Links. Überdies haben die Aneignungen nicht bloß akzessorischen Charakter, es wird gerade mehr als eine bloße Werkwiedergabe vorgenommen. Es würde auch der faktischen Interessenlage widersprechen, wenn man annähme, der Urheber würde sich auch mit Aneignungen einverstanden erklären, wenn er sein Werk ins Internet stellt. Dies würde letztlich zu einer Erschöpfungswirkung des Rechts der öffentlichen Zugänglichmachung hinauslaufen, was der herrschenden Meinung zur Erschöpfungsregel widerspräche. ${ }^{1148}$

1148 S. auch bereits S. 161, 219. 


\section{Fazit}

Es wurden drei Strategien untersucht, die dem Urheberrecht zugrunde gelegt werden können, um Freiraum für Handlungen zu schaffen. Jede dieser Strategien wurde daraufhin untersucht, wie sie mit Aneignungen umgehen und ob sie das kulturelle Freihaltebedürfnis für Aneignungsformen insbesondere im Digitalen rechtlich widerspiegeln können.

Dabei hat sich gezeigt, dass der individuelle Ansatz kaum überzeugen kann: Er lässt außer Acht, dass das Individualgut mit wiederholter Nutzung und allgemeiner Anerkennung zum Kulturgut wird. Der individuelle Ansatz schafft Freiraum für den Urheber selbst, indem er ihn möglichst stark wirtschaftlich an der Verwertung seines Werkes beteiligt und den Verwertungsrechten durch eine enge Schrankenauslegung möglichst große Bedeutung beimisst. Der Fokus auf den individuellen Urheber würde damit für Aneignungen wenig ändern, sondern die bisherige rechtliche Einordnung von Aneignungen beibehalten. Da Ziel des individuellen Ansatzes immer ein umfassender Schutz des Werkes ist, würden Aneignungen hiernach fast immer als Eingriffe in Urheberrecht verstanden werden.

Der künstlerische Ansatz schafft einen gewissen Freiraum für Aneignungshandlungen. Er stärkt die Betätigungsfreiheit der Künstler, indem Eingriffe in Urheberrecht als privilegiert behandelt werden können, die künstlerisch notwendig und durch die Kunstfreiheit gem. Art. 5 Abs. 3 GG geschützt sind. Diese künstlerischen Aneignungen wären durch eine kunstspezifische Auslegung des $₫ 24$ Abs. 1 UrhG freigestellt, wie es bereits jetzt für einige Kunstrichtungen durch die Literatur und Rechtsprechung anerkannt ist. Andererseits könnten durch einen neugestalteten, durch die Person des Künstlers definierten Werkbegriff auch noch mehr Kunstwerke als Urheberwerke geschützt werden, sodass sich Aneignungen an einem geringen Bestand gemeinfreier Werke bedienen könnten. Der künstlerische Ansatz mag insgesamt zwar für künstlerische Aneignungen weiterhelfen, bei digitalen, kommunikativen Aneignungen versagt jedoch auch der künstlerische Ansatz, da er nicht den kulturpolitisch wünschenswerten Freiraum schaffen kann.

Ein kommunikatives Verständnis von Urheberrecht erweist sich als der passende Ansatz, um die von Aneignungen betroffenen Interessen angemessen zu berücksichtigen und in einen Ausgleich zu bringen. Der kommunikative Ansatz bezieht sowohl den Urheber als Kommunikationssender, als auch die Gesellschaft als Kommunikationsempfänger in die Schutzgründe des Urheberrechts ein und berücksichtigt damit die Bedürfnisse aller Mitglieder der Gesellschaft. Das urheberrechtliche Werk wird 
als Medium des öffentlichen Diskurses verstanden, der grundlegend für die Meinungsbildung der Zivilgesellschaft und damit das Funktionieren einer Demokratie ist.

Das bestehende Recht erweist sich jedoch nicht als ausreichend flexibel, um ein kommunikatives Verständnis von Urheberrecht auszugestalten und rechtlichen Freiraum für digitale Nutzungsmöglichkeit zu schaffen. Zwar ist eine verfassungskonforme Auslegung des $\$ 24$ Abs. 1 UrhG anhand der Meinungsfreiheit gem. Art. 5 Abs. 1 GG grundsätzlich möglich, kann Aneignungen jedoch nur in bestimmten Einzelfällen privilegieren. Eine umfassende Umsetzung des kommunikativen Verständnisses ist de lege lata aber bisher nicht möglich. 


\section{Fünftes Kapitel: Regelungsvorschläge für Aneignungen}

In diesem Kapitel soll ausführlich analysiert werden, wie der im Vierten Kapitel entwickelte kommunikative Ansatz zum Verständnis von Urheberrecht umgesetzt werden kann. Dabei soll berücksichtigt werden, dass das Urheberrecht der gesellschaftlichen Realität massenhafter Aneignungen als Kommunikationshandlungen Rechnung tragen muss. Wie gesehen, schafft die Ausgestaltung eines kommunikativen Ansatzes durch das bestehende Recht noch nicht ausreichend Freiraum für kommunikative Aneignungshandlungen. Das kommunikative Verständnis von Urheberrecht kann de lege lata nicht ausreichend berücksichtigt werden. Daher sollen im Folgenden verschiedene Regelungsvorschläge gemacht werden, um ein kommunikatives Verständnis von Urheberrecht ausreichend umzusetzen.

Dafür wird zunächst eine Neugestaltung des $\$ 24$ UrhG anhand der Vorgaben des Art. 5 Abs. 3 InfoSoc-RL nach den Vorgaben des EuGH-Urteils Pelham/Hütter vorgestellt und untersucht, ob durch Einführung einer Pastiche-Schranke einem kommunikativen Verständnis von Urheberrecht Genüge getan werden kann (A.) Sodann wird die Einführung einer neuen Schrankenregelung vorgeschlagen (B.), die den Bildergebrauch im nichtkommerziellen Gebrauch freistellt. Zuletzt soll eine Ausgestaltung der Umsetzung des Art. 17 der DSM-RL 2019/7901149 vorgeschlagen werden, die einen möglichst großen Freiraum für kommunikative Aneignungshandlungen zulässt (C.).

\section{A. Neugestaltung des $\$ 24$ UrbG anhand der Vorgaben des Art. 5 Abs. 3 der InfoSoc-RL}

Mit dem Urteil Pelham/Hütter hat der EuGH klargestellt, dass ein Mitgliedstaat keine Urheberrechtsschranke vorsehen darf, die nicht in Art. 5 InfoSoc-RL vorgesehen ist. Damit ist nun fraglich, ob $\$ 24$ UrhG europarechtswidrig ist. Da es für die in dieser Arbeit vorgeschlagene Regelungsmöglich-

1149 Richtlinie (EU) 2019/790 des Europäischen Parlaments und des Rates vom 17. April 2019 über das Urheberrecht und die verwandten Schutzrechte im digitalen Binnenmarkt und zur Änderung der Richtlinien 96/9/EG und 2001/29/EG. 
keiten für bildliche Aneignungen auch auf den $\$ 24$ UrhG ankommt, insbesondere im Rahmen einer kunstspezifischen Auslegung des $\$ 24$ UrhG für Werke der Appropriation Art, ist die Geltung des $\$ 24$ UrhG nach dem Pelham/Hütter-Urteil von besonderer Relevanz für diese Arbeit. In diesem Kapitel soll daher das Verhältnis von $\$ 24$ UrhG und Art. 5 Abs. 3 InfoSocRL näher erläutert werden im Hinblick auf die Frage, ob der deutsche Gesetzgeber die Schrankenregelung des $\mathbb{2 4}$ UrhG anpassen muss. Wenn die Schranke neu gestaltet werden muss, könnte dies eine Chance sein, auch die rechtliche Einordnung von bildlichen Aneignungen neu zu regeln. Daher soll ein Vorschlag zur Gestaltung und Auslegung der Pastiche-Schranke des Art. 5 Abs. 3 lit. k InfoSoc-RL gemacht werden.

\section{Das EuGH-Urteil Pelham/Hütter}

Mit dem Urteil des EuGH vom 29.07.2019 wurde ein weiteres Urteil in dem jahrelangen Rechtsstreit Pelham/Hütter gefällt, der seit 1999 bereits das BVerfG, den BGH mehrfach und nun auch den EuGH beschäftigt hat. ${ }^{1150}$ Anlass des Rechtsstreits ist die Übernahme einer zwei Sekunden langen Tonfolge des Musikstücks „Metall auf Metall“ der Band Kraftwerk, das der Produzent Moses Pelham als Sample dem Titel „Nur mir" von Sabrina Setlur unterlegt hat. Die Tonsequenz wird im neuen Musikstück leicht verlangsamt fortlaufend wiederholt.

Der BGH hatte dem EuGH Fragen zum Umfang des Vervielfältigungsrechtes von Tonträgerherstellern, zum Zitatrecht und zu den Regelungsspielräumen der nationalen Gesetzgeber für Schrankenregelungen vorgelegt. ${ }^{1151} \mathrm{Im}$ Ergebnis geht der EuGH davon aus, dass unter bestimmten Voraussetzung das Sampling auch ohne Zustimmung des Tonträgerherstellers zulässig sein kann. ${ }^{1152}$

Zum Vervielfältigungsrecht von Tonträgerherstellern stellt der EuGH klar, dass auch die Nutzung eines sehr kurzen Audiosegments, wie hier

1150 EuGH GRUR 2019, S. 929 - Pelham/Hütter; BVerfG GRUR 2016, S. 690 - Metall auf Metall; BGH GRUR 2009, S. 403, 405 Rn. 21 - Metall auf Metall I; BGH GRUR 2013, S. 614 - Metall auf Metall II; BGH GRUR 2017, S. 895 - Metall auf Metall III.

1151 BGH GRUR 2017, S. 895 - Metall auf Metall III.

1152 Schonhofen, Die unendliche Geschichte um „Metall auf Metall“: Urheberrechtliche Zulässigkeit von Sampling vor dem EuGH, GRUR-Prax 2019, S. 432, 432. 
von zwei Sekunden, eine teilweise Vervielfältigung darstellen kann. ${ }^{1153}$ Eine Verletzung des Vervielfältigungsrechts liege jedoch dann nicht vor, wenn das gesampelte Werk nicht mehr wiedererkennbar sei. ${ }^{1154}$

Außerdem nimmt der EuGH an, dass Sampling durch das Zitatrecht des Art. 5 Abs. 3 lit. d InfoSoc-RL gerechtfertigt sein kann, wenn die Nutzung das Ziel habe, mit dem geschützten Werk zu interagieren und die weiteren Voraussetzungen erfüllt seien, insbesondere die Pflicht zur Quellenangabe. ${ }^{1155}$ Eine Interaktion sei jedoch nicht gegeben, wenn das zitierte Werk nicht zu erkennen sei. ${ }^{1156}$

Zur Frage, ob Mitgliedstaaten eine Bestimmung vorsehen können, die wie die Bestimmung des $₫ 24$ Abs. 1 UrhG - klarstellt, dass der Schutzbereich des ausschließlichen Rechts des Tonträgers zur Vervielfältigung und Verbreitung seines Tonträgers in der Weise immanent beschränkt ist, dass ein selbständiges Werk, das in freier Benutzung seines Tonträgers geschaffen worden ist, ohne seine Zustimmung verwertet werden darf, antwortet der EuGH, dass ein Mitgliedstaat in seinem nationalen Recht keine Ausnahme oder Beschränkung in Bezug auf das Recht des Tonträgerherstellers vorsehen darf, die nicht in Art. 5 InfoSoc-RL vorgesehen ist. ${ }^{1157}$ Damit rechnet der EuGH $\$ 24$ UrhG als urheberrechtliche Schrankenregelung ein ${ }^{1158}$, was in der Literatur zuvor streitig war. ${ }^{1159}$ Eine Schranke wie $\$ 24$ UrhG ist aber in Art. 5 InfoSoc-RL gerade nicht vorgesehen. Daher ist nun ungeklärt, ob oder wie $\$ 24$ UrhG noch gilt.

1153 Dies begründet der EuGH mit einer wörtlichen Auslegung des Art. 2 lit. c InfoSoc-RL, der dem Tonträgerhersteller auch das Recht zur teilweisen Vervielfältigung gibt. Aus den Erwägungsgründen 4, 9 und 10 der InfoSoc-RL ergebe sich außerdem das Ziel der Richtlinie, ein hohes Schutzniveau des Urheberrechts und der verwandten Schutzrechte zu erzielen, um die Investitionen des Tonträgerhersteller zu schützen, vgl. EuGH GRUR 2019, S. 929, 931 Rn. 29, 30 - Pelham/Hütter.

1154 EuGH GRUR 2019, S. 929, 931 Rn. 31 f. - Pelham/Hütter. Zur Begründung nimmt der EuGH bereits hier auf Tatbestandsebene eine grundrechtliche $\mathrm{Ab}$ wägung zwischen dem Recht des geistigen Eigentums aus Art. 17 Abs. 2 GrCh und der Kunstfreiheit gem. Art. 13 GrCh vor, s. EuGH GRUR 2019, S. 929, 931 Rn. 33, 34 - Pelham/Hütter.

1155 EuGH GRUR 2019, S. 929, 933 Rn. 72 - Pelham/Hütter.

1156 EuGH GRUR 2019, S. 929, 933 Rn. 73 - Pelham/Hütter.

1157 EuGH GRUR 2019, S. 929, 933 Rn. 65 -Pelham/Hütter.

1158 Leistner, „Ende gut, alles gut“... oder „Vorhang zu und alle Fragen offen“? Das salomonische Urteil des EuGH in Sachen "Pelham [Metall auf Metall]", GRUR 2019, S. 1008, 1011.

1159 Streitig war, ob es sich um eine Schrankenregelung oder um eine Schutzbereichsbestimmung handelt, s. dazu bereits S. 167 Fn. 612 . 


\section{Folgen des Urteils für die Geltung des $₫ 24$ UrhG}

Für die weitere Geltung des $\$ 24$ UrhG nach dem EuGH-Urteil Pelham/ Hütter kommen vier verschiedene Möglichkeiten in Betracht.

Erstens kommt in Betracht, dass $\$ 24$ UrhG zukünftig nicht mehr gelten kann, allerdings weiterhin für Altfälle vor dem EuGH-Urteil gilt. Die Auffangklausel des Art. 5 Abs. 3 lit. o InfoSoc-RL bestimmt, dass Mitgliedstaaten auch andere Ausnahmen oder Beschränkungen als die zuvor in Abs. 1 bis 3 genannten vorsehen können, soweit diese bereits vor der InfoSocRL im nationalen Recht vorgesehen waren. $\$ 24$ UrhG galt bereits vor Inkrafttreten der InfoSoc-RL im Jahr 2001. Doch nach seinem weiteren Wortlaut setzt die Anwendung des lit. o voraus, dass dies nur analoge Nutzungen in Fällen von geringer Bedeutung betreffen darf und der freie Waren- und Dienstleistungsverkehr in der Gemeinschaft nicht berührt werden darf. $\$ 24$ UrhG gilt allerdings gerade nicht nur für analoge Nutzungen, sondern umfassend für alle urheberrechtlichen Verwertungen. Außerdem kann wohl angesichts der Rechtsprechungsdichte und der breiten Erfassung verschiedenster Fallgruppen von $\$ 24$ UrhG kaum von Fällen geringer Bedeutung gesprochen werden.

Zweitens könnte $\$ 24$ UrhG weiterhin gelten für alle Fälle, die auch von Art. 5 Abs. 3 InfoSoc-RL umfasst sind, und der überschießende Teil von $\$ 24$ UrhG unwirksam sein. Dies entspräche einer teleologischen Reduktion. $\$ 24$ UrhG würde dann nur insoweit gelten, wie die Schrankenreglungen im Sinne der InfoSoc-RL umfasst sind. ${ }^{1160}$ So wurden beispielsweise Fälle der Parodie bisher von $\$ 24$ UrhG geregelt, und da sie ebenfalls in Art. 5 Abs. 3 lit. k InfoSoc-RL vorgesehen sind, würde die freie Benutzung hier weiterhin anwendbar sein. In diesem Sinne ist Ohly zu verstehen, der annimmt, dass $\$ 24$ UrhG die fehlende Parodieschranke im deutschen Recht ersetzt ${ }^{1161}$, weshalb die Rechtsprechung insoweit $\$ 24$ UrhG auch europarechtskonform auslegt. ${ }^{1162}$ Dann wäre $\$ 24$ UrhG aber allein am Maßstab des Art. 5 Abs. 3 lit. k InfoSoc-RL zu messen und alle darüberhinausgehenden Voraussetzungen des $\$ 24$ UrhG wären unionsrechtswidrig. Im Ergebnis müsste man dann $\$ 24$ UrhG entgegen seines Wortlauts an-

1160 So Dreier, Grundrechte und die Schranken des Urheberrechts. Anmerkungen zu EuGH „Funke Medien NRW“ und „Spiegel Online“, GRUR 2019, S. 1003, 1005.

1161 Ohly, Hip Hop und die Zukunft der „freien Benutzung“ im EU-Urheberrecht, GRUR 2017, S. 964, 967.

1162 Vgl. BGH GRUR 2016, S. 1157, 1159 Rn. 24 - auffett getrimmt. 
wenden, da es nicht mehr auf die Selbständigkeit des Werkes oder die freie Benutzung ankommen würde, sondern allein darauf, dass mit $\$ 24$ UrhG noch eine Schrankenregelung als Umsetzung des Art. 5 Abs. 3 lit. k InfoSoc-RL anzusehen sei. Eine solche Auslegung des $\$ 24$ UrhG entgegen seines Wortlauts scheint nur schwer vertretbar. Sie würde außerdem dem Grundsatz der InfoSoc-RL, den Binnenmarkt durch eine möglichst kohärente Auslegung der Schrankenregelungen zu verwirklichen, zuwiderlaufen. ${ }^{1163}$

Auch wenn man annimmt, $\mathbb{} 24$ UrhG lasse sich in einen Teil Schrankenregelung und in einen Teil Schutzbereichsbestimmung untergliedern, bleibt die Norm nicht dadurch wirksam. Davon abgesehen, ist gar fraglich, ob solch eine Unterteilung des $\$ 24$ UrhG möglich ist. Doch selbst wenn man $\$ 24$ UrhG wie der BGH mit seiner Vorlagefrage als ,immanente Beschränkung des Schutzbereichs" 1164 versteht, wäre eine solche nicht europarechtskonform, da die Verwertungsrechte der Art. 2-4 InfoSoc-RL vollharmonisiert sind und für eine weitere Beschränkung des Schutzbereichs keinen Raum lassen. ${ }^{1165}$

Als dritte Möglichkeit der Auslegung des EuGH-Urteils Pelham/Hütter ist $\$ 24$ UrhG als unionrechtswidrig anzusehen und eine neue Schrankenregelung im deutschen Urheberrechtsgesetz notwendig. Dieses Verständnis des EuGH-Urteils scheint sich in der deutschen Rechtswissenschaft durchzusetzen, die sich mehrheitlich für die Neuschaffung einer Schrankenregelung ausspricht. ${ }^{1166}$ Diese Schranke sollte den Art. 5 Abs. 3 lit. k InfoSoc-RL ins deutsche Recht umsetzen. Denn wie gesehen wäre es nur

1163 Leistner, „Ende gut, alles gut“... oder „Vorhang zu und alle Fragen offen“? Das salomonische Urteil des EuGH in Sachen „Pelham [Metall auf Metall]“, GRUR 2019, S. 1008, 1015.

1164 BGH GRUR 2017, S. 895, 897 Rn. 22 - Metall auf Metall III.

1165 Ohly, Hip Hop und die Zukunft der „freien Benutzung“ im EU-Urheberrecht, GRUR 2017, S. 964, 967.

1166 Leistner, „Ende gut, alles gut“... oder „Vorhang zu und alle Fragen offen“? Das salomonische Urteil des EuGH in Sachen „Pelham [Metall auf Metall]", GRUR 2019, S. 1008, 1015; Dreier, Grundrechte und die Schranken des Urheberrechts. Anmerkungen zu EuGH „Funke Medien NRW“ und „Spiegel Online“, GRUR 2019, S. 1003, 1005; Homar, Enge Handlungsspielräume für das Sampling, ZUM 2019, S. 731, 736; Schonhofen, Die unendliche Geschichte um „Metall auf Metall“: Urheberrechtliche Zulässigkeit von Sampling vor dem EuGH, GRUR-Prax 2019, S. 432, 433; Hauck, Kopieren oder Zitieren. Zur urheberrechtlichen Zulässigkeit des Samplings, GRUR-Prax 2019, S. 385, 385; Marly/Prinz, EuGH: Zulässigkeitsvoraussetzungen für ein Sampling, LMK $2019,421261$. 
schwer möglich, $\mathbb{S} 24$ UrhG als Umsetzung des Art. 5 Abs. 3 lit. k InfoSocRL auszulegen, da der Wortlaut des $\$ 24$ UrhG einer solchen Auslegung zuwiderläuft: $\mathbb{} 24$ UrhG nennt für die freie Benutzung andere und weitergehende Voraussetzungen als Art. 5 Abs. 3 lit. k InfoSoc-RL für Karikaturen, Parodien oder Pastiches. Da auch die Richtlinie 2019/7901167 zum Urheberrecht im digitalen Binnenmarkt (Copyright in the Digital Single Market, DSM-RL) die Mitgliedstaaten verpflichtet, sicherzustellen, dass sich Nutzer auf Schrankenregelungen für Zitate, Kritik und Rezensionen sowie Karikaturen, Parodien und Pastiches berufen können, ergibt sich ohnehin ein Reformbedarf für die deutschen Schrankenregelungen. ${ }^{1168}$

Zuletzt kommt auch eine freie Interessenabwägung anhand der Grundrechte aller betroffenen Rechteinhaber und Nutzer in Betracht. Eine solche Interessenabwägung unabhängig von konkreten Schrankenregelungen hatte Generalanwalt Szpunar im Fall Afghanistan Papiere befürwortet, da es „außergewöhnliche Situationen“ geben könne, in denen das Urheberrecht „hinter einem wichtigen, die Verwirklichung eines Grundrechts oder einer Grundfreiheit betreffenden Interesse zurücktreten“ müsse. ${ }^{1169}$ Der BGH hat bisher eine solche „freischwebende“ Güter- und Interessenabwägung abgelehnt und stattdessen diese Güter und Interessen bei der Auslegung der bestehenden Schranken berücksichtigt. ${ }^{1170}$ Auch der EuGH fordert im Urteil Pelham/Hütter, dass eine Interessenabwägung anhand von Grundrechten stets „in der Richtlinie 2001/29 selbst verankert“ sein muss, also im Rahmen des betreffenden Schrankentatbestands zu erfolgen hat. ${ }^{1171}$ Einer solchen freien Interessenabwägung allein anhand der betroffenen Grund-

1167 Richtlinie (EU) 2019/790 des Europäischen Parlaments und des Rates vom 17. April 2019 über das Urheberrecht und die verwandten Schutzrechte im digitalen Binnenmarkt und zur Änderung der Richtlinien 96/9/EG und 2001/29/EG.

1168 Leistner, „Ende gut, alles gut“... oder „Vorhang zu und alle Fragen offen“? Das salomonische Urteil des EuGH in Sachen „Pelham [Metall auf Metall]", GRUR 2019, S. 1008, 1015.

1169 Schlussanträge des EuGH Generalanwalts Szpunar vom 25.10.2018 zu Rs. C-469/17, BeckRS 2018, 26149 Rn. 40.

1170 BGH GRUR 2017, S. 901, 904 Rn. 41 f. - Afghanistan Papiere; BGH GRUR 2017, S. 1027, 1031 Rn. 30 f. - Reformistischer Aufbruch; BGH GRUR 2003, S. 956, 957 - Gies-Adler.

1171 Stieper, Der Trans Europa Express ist aus Luxemburg zurück - auf dem Weg zu einer Vollharmonisierung der urheberrechtlichen Schranken, ZUM 2019, S. 713, 714; EuGH GRUR 2019, S. 929, 933 Rn. 62 f. - Pelham/Hütter. S. dazu auch: EuGH GRUR 2019, S. 934, 938 Rn. 58, 62 - Funke Medien NRW/Deutschland; EuGH GRUR 2019, S. 940, 943 Rn. 43, 47 - Spiegel Online/Beck. 
rechte ist also eine klare Absage zu erteilen. Die Grundrechte der Rechteinhaber und Nutzer wurden bei Ausgestaltung der Schrankenregelungen bereits hinreichend berücksichtigt und können daher zur Auslegung dieser Schrankenregelungen herangezogen werden. Eine freie Interessenabwägung würde aber nicht die nach dem EuGH Pelham/Hütter-Urteil gewünschte Rechtssicherheit bringen.

Im Ergebnis ist also der dritten Möglichkeit zu folgen und $\$ 24$ UrhG als unionsrechtswidrig anzusehen. Damit wird eine Neuregelung der Schranken notwendig, um Art. 5 Abs. 3 lit. k InfoSoc-RL ins deutsche Recht umsetzen.

\section{Umsetzung der Pastiche-Schranke des Art. 5 Abs. 3 lit. k InfoSoc-RL}

Im Folgenden soll untersucht werden, ob durch eine Auslegung des Begriffes Pastiche des Art. 5 Abs. 3 lit. k InfoSoc-RL einem kommunikativen Verständnis von Urheberrecht Genüge getan werden kann. Die in lit. k genannten Begriffe der Karikatur und Parodie sind durch europäische Rechtsprechung bereits in gewissen Zügen greifbar gemacht worden und wurden außerdem bisher ebenfalls unter diesen Begriffen von $\$ 24$ UrhG geregelt. Die Pastiche-Schranke hat in der deutschen Literatur jedoch bisher wenig Beachtung gefunden. ${ }^{1172}$ Daher soll untersucht werden, ob die Pastiche-Ausnahme auch für Aneignungen nutzbar gemacht werden kann. Wenn die deutschen Schrankenregelungen sowieso neugestaltet werden müssen, könnte dies eine Chance sein, um kommunikative und künstlerische Aneignungen zu berücksichtigen und ein kommunikatives Verständnis von Urheberrecht umzusetzen.

Dazu soll ein Vorschlag zur Auslegung des Begriffes Pastiche entwickelt werden und die Auswirkungen einer Pastiche-Schranke auf die rechtliche Würdigung von Aneignungshandlungen verdeutlicht werden.

1172 So Ohly, Hip Hop und die Zukunft der „freien Benutzung“ im EU-Urheberrecht, GRUR 2017, S. 964, 969; Stieper, Fan Fiction als moderne Form der Pastiche, AfP 2015, S. 301, 304, die schon vor dem EuGH-Urteil Pelham/Hütter für eine Nutzbarmachung der Pastiche-Schranke plädiert haben. 


\section{Begriff des Pastiche}

Der Begriff des Pastiche im Sinne des Art. 5 Abs. 3 lit. k InfoSoc-RL ist als autonomer Begriff des Unionsrechts unionsweit einheitlich auszulegen. ${ }^{1173}$ Eine solche Auslegung nahm der EuGH für den Begriff der Parodie bisher nach dem gewöhnlichen Sprachgebrauch vor unter Berücksichtigung des Regelungsziels und Regelungszusammenhangs, mit dem er verwendet wird. ${ }^{1174}$

Im allgemeinen Sprachgebrauch ist der Begriff der Pastiche im Deutschen, anders als im Französischen oder Englischen, wenig verbreitet. ${ }^{1175}$ Im englischen Sprachraum wird das Pastiche als Oberbegriff unterschiedlichster Formen der Übernahme und Ähnlichkeit verwendet. ${ }^{1176} \mathrm{Im} \mathrm{Be}$ griffsverständnis der Aneignung im Ersten Kapitel wird Pastiche definiert als Nachahmung des Stils oder konkreter Werke eines Künstlers. Dies ergibt sich aus dem Pastiche-Verständnis in der Musik und in der Literatur.

In der Musik ist für das Pastiche der Begriff Pasticcio gebräuchlicher und meint ein Werk, das vorwiegend oder vollständig aus bereits vorhandener Musik zusammengesetzt ist. ${ }^{1177}$ Das Pastiche wird in der juristischen Literatur auch für neue musikalische Formen wie Remix oder Sampling nutzbar gemacht. ${ }^{1178}$

Der literarische Pastiche-Begriff meint ein Verfahren der stilistischen Nachahmung eines Autors oder einer Gruppe von Texten verschiedener Autoren, z.B. einer bestimmten Epoche oder Gattung. ${ }^{1179}$ Das Pastiche legt seine intertextuelle Struktur offen. ${ }^{1180}$ Ein solcher Pastiche-Begriff ist für die Auslegung des Art. 5 Abs. 3 lit. k InfoSoc-RL nicht übertragbar und kann von dieser Regelung nicht gemeint sein. Denn der Stil eines Werkes

1173 So der EuGH bisher zum Begriff der Parodie, vgl. EuGH GRUR 2014, S. 972 , 973 Rn. 17 - Deckmyn und Vrijheidsfonds.

1174 EuGH GRUR 2014, S. 972, 973 Rn. 19 - Deckmyn und Vrijheidsfonds.

1175 Dazu ausführlicher Stieper, Fan Fiction als moderne Form der Pastiche, AfP 2015, S. 301, 304.

1176 Brinkmann, Formen der Kopie. Von der Fälschung bis zur Hommage, in: Dreier/Jehle (Hrsg.), Original - Kopie - Fälschung, 2020, S. 54, 68 m.w.N.

1177 Stieper, Fan Fiction als moderne Form der Pastiche, AfP 2015, S. 301, 304.

1178 Pötzlberger, Pastiche 2.0: Remixing im Lichte des Unionsrechts, GRUR 2019, S. 675, 680 f.; Ohly, Hip Hop und die Zukunft der „freien Benutzung“ im EUUrheberrecht, GRUR 2017, S. 964, 968.

1179 So Stieper, Fan Fiction als moderne Form der Pastiche, AfP 2015, S. 301, 304 mit Verweis auf Antonsen in Müller (Hrsg.) Reallexikon der deutschen Literaturwissenschaft Bd. III, 2003, S. 34.

1180 Ders., a.a.O., S. 305. 
ist nicht urheberrechtlich geschützt ${ }^{1181}$, sodass es für die Übernahme eines Stils auch keiner gesetzlichen Schranke bedarf. ${ }^{1182}$

Art. 5 Abs. 3 lit. k InfoSoc-RL geht zurück auf das französische Urheberrecht (Art. L 122-5 Code de la propriété intellectuelle), das die drei Begriffe drei Werkgattungen zuordnet: Danach betrifft Karikatur die Kunst, Parodie die Musik, und Pastiche die Literatur. ${ }^{1183}$ Diese Unterscheidung erscheint doch zum einen wenig nützlich, da die Gattungen Kunst, Musik und Literatur im europäischen und auch im deutschen Urheberrecht nicht unterschiedlich gehandhabt werden, sondern alle demselben Werkbegriff unterfallen. Zudem wird der Begriff der Parodie nach der bisherigen EuGH Rechtsprechung bereits nicht gattungsspezifisch verstanden: Im Deckmyn-Urteil wurde eine Zeichnung, also ein Bildwerk, als Parodie eingeordnet. ${ }^{1184}$ Das Pastiche beschränkt sich damit nicht auf eine konkrete Werkart der Nachahmung. ${ }^{1185}$

Wenn die Begriffe Karikatur, Parodie und Pastiche also nicht verschiedenen Gattungen zuzuweisen sind, stellt sich die Frage, wie sie ansonsten voneinander abzugrenzen sind und welche Gemeinsamkeiten sie aufweisen. Da sie als Schrankenregelung zu den urheberrechtlichen Nutzungen ausgestalten sind, betreffen sie alle drei die Übernahme fremder Werkteile. Diese muss auch erkennbar sein, denn Karikatur, Parodie und Pastiche sind darauf ausgelegt, als solche erkannt zu werden. Alle drei Begriffe zeichnen sich durch ihren starken Referenzcharakter aus ${ }^{1186}$ und eine Referenz gelingt nur, wenn sie erkannt werden kann. Die Karikatur und die Parodie sind zudem von Humor und Verspottung geprägt. Daher wird in der Literatur teilweise davon ausgegangen, dass dies auch bei dem Pastiche

1181 S. dazu S. 129.

1182 So auch Stieper, Fan Fiction als moderne Form der Pastiche, AfP 2015, S. 301, 305; Pötzlberger, Pastiche 2.0: Remixing im Lichte des Unionsrechts, GRUR 2019, S. 675, 676; a.A.: Walter/Walter, Europäisches Urheberrecht, 2001, InfoSoc-RL Rn. 132, der meint, Pastiche im Sinne des Art. 5 Abs. 3 InfoSocRL meine nur Stilnachahmungen.

1183 S. Vlah, Parodie, Pastiche und Karikatur - Urheberrechte und ihre Grenzen, 2015, S. 43. Ähnlich auch Hess, Urheberrechtsprobleme der Parodie, 1993, S. 95, der die drei Begriffe ebenfalls nach den Gattungen der Vorlagen unterscheidet: Eine Karikatur sei demnach die Nachahmung von Personen, eine Parodie die Nachahmung von Gattungen/Stilen oder Werke der Kunstgeschichte und Satire nutze Situationen und Bräuche.

1184 EuGH GRUR 2014, S. 972, 973 Rn. 18 ff, 29 - Deckmyn und Vrijheidsfonds.

1185 Pötzlberger, Pastiche 2.0: Remixing im Lichte des Unionsrechts, GRUR 2019, S. 675,680 .

1186 Ders., a.a.O., S. 680; ders., Kreatives Remixing, 2018, S. 249. 
der Fall sein müsse. ${ }^{1187}$ Doch weder aus dem allgemeinen Sprachverständnis noch aus der Nutzung des Begriffs in der Musik oder Literatur lässt sich eine solche Voraussetzung des Pastiche entnehmen. Vielmehr scheint dies gerade der Unterschied von Pastiche zu Parodie und Karikatur zu sein: Das Pastiche entlehnt ebenso eigenschöpferische Züge der Vorlage, allerdings als ein künstlerisches Stilmittel des Kontrasts oder der Hommage ${ }^{1188}$ (das heißt, sie kann sowohl positiv als auch negativ besetzt sein). Die gedankliche Verbindung zur Vorlage ist damit die künstlerische und nicht die humoristische Ausdrucksform. ${ }^{1189}$

Man könnte auch überlegen, statt der künstlerischen auch die bloß kreative Umgestaltung für ein Pastiche ausreichen zu lassen. Das Pastiche würde dann weiter verstanden werden und könnte auch Fälle wie Memes oder GIFs in Ausnahmefällen erfassen. Das Wort Kreativität kann man zum einen als Neuheit oder Innovation, zum anderen als schöpferisches Tätigwerden verstehen. Der Fokus auf die Kreativität einer Nutzung würde einen Gehalt in das Urheberrecht bringen, der ihm eigentlich fremd ist. Im Urheberrecht kommt es gerade nicht auf die Neuheit eines Werkes an, sondern auf die eigenpersönliche Schöpfung. Das Urheberrecht schützt auch nicht die Kreativität, sondern das Werk selbst, also das Endprodukt einer möglichen Kreativität. Würde man andererseits Kreativität mit Schöpfung gleichsetzen, würde man nun von einem Pastiche verlangen gleichfalls eine eigenpersönliche Schöpfung zu sein, die urheberrechtlichen Werkcharakter hat. Dies wurde bisher für den Begriff der Parodie als nicht notwendig erachtet. ${ }^{1190}$ Ein Begriffsverständnis von Pastiche, dass das Pastiche ebenfalls ein urheberrechtlich geschütztes Werk darstelle, wäre eine höchst ungewöhnliche Schrankenkonstellation: Nur weil die Nutzung eines urheberrechtlichen Werkes ebenfalls selbst ein urheberrechtlich schützbares Werk darstellt, kann nicht auf die Notwendigkeit einer schrankengeschützten Nutzung geschlossen werden. Vielmehr haben bisher die $\$ \mathbb{S} 3,23$ und 24 UrhG deutlich gemacht, dass die Nutzung auch ein urheberrechtlich geschütztes Werk darstellen kann, aber dennoch die Verwendung des neuen, zweiten Werkes von der Einwilligung des Urhebers

1187 Vlah, Parodie, Pastiche und Karikatur - Urheberrechte und ihre Grenzen, 2015, S. 48.

1188 Stieper, Der Trans Europa Express ist aus Luxemburg zurück - auf dem Weg zu einer Vollharmonisierung der urheberrechtlichen Schranken, ZUM 2019, S. $713,720$.

1189 Vgl. ders., a.a.O., S. 720; Pötzlberger, Pastiche 2.0: Remixing im Lichte des Unionsrechts, GRUR 2019, S. 675, 680.

1190 EuGH GRUR 2014, S. 972, 974 Rn. 33 - Deckmyn und Vrijheidsfonds. 
des benutzten Werkes abhängen kann. Ein Pastiche kann damit nicht durch eine kreative Nutzung definiert werden, da es auf die Kreativität nicht ankommen kann.

Im Ergebnis ist ein Pastiche im Sinne des Art. 5 Abs. 3 lit.k InfosSoc$\mathrm{RL}$ als die künstlerische Umgestaltung vorbestehenden Materials zu verstehen. Das Kriterium des Künstlerischen schafft die notwendige Begriffsklarheit, indem auf das abgestellt wird, was durch die Kunstfreiheit des Art. 5 Abs. 3 GG und Art. 13 GrCh geschützt ist. Dadurch wird zugleich die Notwendigkeit für eine Pastiche-Schranke verdeutlicht: Durch sie soll die grundrechtlich geschützte Kunstfreiheit auch im Urheberrecht verankert werden. Im Unterschied zur Parodie oder Karikatur zeichnet sich das Pastiche also durch eine künstlerische Nutzung von Fremdmaterial aus. ${ }^{1191}$ Die Pastiche-Schranke kann damit durchaus für Kunstformen gelten, die ohne Einwilligung mit Referenzen und Übernahmen arbeiten.

\section{Aneignungen als Pastiche}

Damit die Pastiche-Schranke als rechtliche Gestaltungsmöglichkeit für Aneignungshandlungen in Betracht kommt, ist nun das Verhältnis der Begriffe Pastiche und Aneignung zu klären. Grundsätzlich können Aneignungen auch Pastiches sein. ${ }^{1192}$ Wenn jedoch das Pastiche die künstlerische Nachahmung voraussetzt, ist es enger zu verstehen als die Aneignung. Aneignungen setzen gerade nicht die künstlerische Übernahme fremden Materials voraus, sondern lediglich die Übernahme zu eigenen Zwecken. Das Pastiche ist damit eine Untergruppe der Aneignung.

Von den in dieser Arbeit untersuchten Fallgruppen würden lediglich die künstlerischen Aneignungen auch unter den Begriff des Pastiche fallen. Für kommunikative Aneignungen im Digitalen würden diese wohl nur unter den Begriff des Pastiche fallen, wenn sie auch als künstlerisch einzuordnen sind. Dies wird, wenn überhaupt, in Einzelfällen möglich sind. Regelmäßig sind kommunikative Aneignungen allerdings nicht als künstlerisch anzusehen und auch nicht von der Kunstfreiheit gem.

1191 So auch Pötzlberger, Pastiche 2.0: Remixing im Lichte des Unionsrechts, GRUR 2019, S. 675, 680; Senftleben, Filterverpflichtungen nach der Reform des europäischen Urheberrechts - Das Ende der freien Netzkultur?, ZUM 2019, S. 369, 374; a.A.: Ohly, Hip Hop und die Zukunft der „freien Benutzung“ im EU-Urheberrecht, GRUR 2017, S. 964, 968, der davon ausgeht, dass Art. 5 InfoSoc-RL eine Schranke für kreative Umgestaltungen fehle.

1192 So auch bereits zu den Begrifflichkeiten zu Beginn dieser Arbeit S. 39. 
Art. 5 Abs. 3 GG geschützt. ${ }^{193}$ Damit würde es auch bei Umsetzung einer Pastiche-Schranke ins deutsche Urheberrechtsgesetz zu der gleichen Unterschiedlichbehandlung kommen, zu der es nach bisherigem Recht auch über die kunstspezifische Auslegung des $\$ 24$ UrhG kam: Künstlerische Aneignungen wären über die Schranke gedeckt, kommunikative Aneignungen wären jedoch nicht erfasst. Die oben aufgeführten Probleme dieser Unterschiedlichbehandlung, insbesondere die Legitimationskrise des Urheberrechts durch eine Diskrepanz von Recht und Rechtswirklichkeit, würden auch bei Umsetzung des Art. 5 Abs. 3 lit. k InfoSco-RL in deutsches Recht weiterhin bestehen bleiben. Die notwendige Neuregelung des $\$ 24$ UrhG anhand der Vorgaben des Art. 5 Abs. 3 lit k. InfoSoc-RL bietet damit noch nicht den ausreichenden Raum für kommunikative Aneignungen. Es bedarf einer eigenen Regelung für kommunikative Aneignungshandlungen von Bildern.

\section{B. Regelungsvorschlag für den kommunikativen Bildergebrauch}

Im Folgenden soll ein Regelungsvorschlag für den kommunikativen Bildergebrauch gemacht werden. Dazu soll zunächst untersucht werden, auf welche verschiedenen Arten die Ausschließlichkeitsrechte des Urhebers eingeschränkt werden können, und es sollen die gesetzlichen Mechanismen vorgestellt werden, mit Hilfe derer die Grenze gezogen wird zwischen urheberrechtlich geschützten Nutzungen und solchen, die frei bleiben (I.). Sodann wird eine neue Schrankenregelung erarbeitet, die einen ausreichenden Interessenausgleich schafft und ein kommunikatives Verständnis von Urheberrecht ausgestalten soll (II.). Die urheberrechtlichen Schrankenregelungen sind zwar in Art. 5 Abs. 1-5 der InfoSoc-RL europarechtlich abschließend normiert ${ }^{1194}$, sodass auf nationaler Ebene kein Spielraum verbleibt für die Einführung einer neuen Schrankenregelung. Die vorgeschlagene Schrankenregelung müsste daher auch auf EU-Ebene eingeführt werden. Daher wird unter (III.) die Vereinbarkeit der vorgeschlagenen Schrankenregelung mit dem EU-Recht diskutiert.

1193 S. dazu bereits S. 206 f.

1194 S. EuGH GRUR 2019, S. 929, 932 Rn. 58 -Pelham/Hütter. 


\section{Einschränkbarkeit der Ausschließlichkeitsrechte des Urhebers}

Durch die Ausgestaltung der dem Urheber vorbehaltenen Nutzungen an Werken kann durch das Urheberrechtsgesetz selbst Freiraum geschaffen werden. Solche Grenzziehungen stellen einfachgesetzliche Ausgestaltungen der Sozialbindung des Geistigen Eigentums (Art. 14 Abs. 2 GG) dar, sie sind Inhaltsbestimmungen im Sinne Art. 14 Abs. 1 S. 2 GG. ${ }^{1195}$ Die Beschränkung des Ausschließlichkeitsrecht des Urhebers muss damit zur Förderung eines schutzwürdigen Interesses der Allgemeinheit verhältnismäßig, das heißt geeignet, erforderlich und angemessen, sein. ${ }^{1196}$

Der Urheber hat grundsätzlich für sein Werk ein Verfügungs- und Verwertungsrecht. Für beide sind Einschränkungen denkbar ${ }^{197}$ : Für das Verfügungsrecht bedeutet dies, dass der Verbotsanspruch aus dem Ausschließlichkeitsrecht nicht wahrgenommen werden kann, der Urheber also nicht das ausschließliche Recht an einer gewissen Nutzungsart hat. Für das Verwertungsrecht bedeutet es, dass für gewisse Nutzungsarten der Vergütungsanspruch entfallen kann. Hierbei sind Schrankenregelungen, die Freiraum für Nutzungsarten schaffen, nicht als „Belastung eines umfassend und fortbestehend gedachten Ausschließlichkeitsrechts des Urhebers zugunsten eines dinglich berechtigten Nutzers" zu verstehen. ${ }^{1198}$ Denn gem. $\$ 1$ UrhG genießt der Urheber Schutz für das von ihm geschaffene Werk nur nach Maßgabe des Gesetzes. Deshalb setzt sich die Inhaltsbestimmung des Urheberrechts aus einem einheitlichen gesetzgeberischen Akt zusammen, der sich nicht aufteilen lässt in einen Gewährungs- und einen Zurücknahmeakt. ${ }^{1199}$ Das heißt, der Schutzumfang des Urheberrechts ergibt sich erst aus einer zusammenfassenden Betrachtung der $\$ \mathbb{S} 15 \mathrm{ff}$. und $\$ \mathbb{S} 44 \mathrm{fff}$. UrhG. Denn Schranken begrenzen von vornherein den Schutzinhalt der Ausschließlichkeitsrechte des Urhebers, da sie deren Umfang und die erfassten Nutzungshandlungen mitbestimmen. ${ }^{1200}$ Daher kann der Nutzungswert, der sich aus der Ausübung einer Nutzungshand-

1195 Leinemann, Die Sozialbindung des „Geistigen Eigentums“, 1998, S. 69.

1196 Stieper, Rechtfertigung, Rechtsnatur und Disponibilität der Schranken des Urheberrechts, 2009, S. 43.

1197 Leinemann, Die Sozialbindung des „Geistigen Eigentums“, 1998, S. 69, 71; Stieper, Rechtfertigung, Rechtsnatur und Disponibilität der Schranken des Urheberrechts, 2009, S. 43.

1198 Stieper, Rechtfertigung, Rechtsnatur und Disponibilität der Schranken des Urheberrechts, 2009, S. 130.

1199 Ders., a.a.O., S. 131.

1200 Ders., a.a.O., S. 131. 
lung ergibt, auch freigestellt werden durch eine gesetzliche Schranke, denn der Nutzungswert ist von vornherein nicht ausschließlich dem Urheber zugewiesen. ${ }^{201}$

Für die rechtliche Gestaltung der Schrankenregelungen kommen drei Arten der Einschränkungen der Nutzungshandlungen in Betracht: die Freistellung, die gesetzliche Lizenz und die Zwangslizenz. ${ }^{1202} \mathrm{Da}$ diese drei Arten unterschiedlich intensiv die Rechte des Urhebers einschränken, zeigt sich hieran bereits, dass Nutzungshandlungen urheberrechtlich unterschiedlich behandelt werden können und der durch das Urheberrecht gestaltete Freiraum für Nutzungshandlungen unterschiedlich groß ausgestaltet sein kann. Durch die Arten der Einschränkungen können Abstufungen zwischen verschiedenen Nutzungshandlungen realisiert werden.

\section{Freistellung}

Die Freistellung ist die ersatzlose Aufhebung des ausschließlichen Nutzungsrechts. ${ }^{1203}$ Diese Nutzungsart wird also völlig freigestellt: Für die Nutzung ist weder die Zustimmung des Urhebers notwendig, noch muss eine Vergütung dafür gezahlt werden. ${ }^{1204}$ Das Zitatrecht gem. $\$ 51$ UrhG ist als eine solche Freistellung einzuordnen, denn es erklärt das Zitieren aus fremden geschützten Werken zu den dort genannten Zwecken und in dem genannten Umfang für zustimmungs- und vergütungsfrei. Diese Privilegierung dient dem Allgemeininteresse an freier geistiger Auseinandersetzung, an Dialog, Kritik und kultureller Entwicklung. ${ }^{1205}$

1201 Ders., a.a.O., S. 131.

1202 Ders., a.a.O., S. 6; Leinemann, Die Sozialbindung des „Geistigen Eigentums“, 1998, S. $92 \mathrm{ff}$.

1203 Stieper, Rechtfertigung, Rechtsnatur und Disponibilität der Schranken des Urheberrechts, 2009, S. 6.

1204 Leinemann, Die Sozialbindung des „Geistigen Eigentums“, 1998, S. 92.

1205 Vgl. Schricker/Loewenheim/Spindler, 5. Aufl. 2017, \51 UrhG Rn. 6 m.w.N.; Dreier/Schulze/Dreier, 6. Aufl. 2018, $\$ 51$ UrhG Rn. 1. 


\section{Gesetzliche Lizenz}

Die gesetzliche Lizenz erlaubt gewisse Nutzungshandlungen ohne Zustimmung des Urhebers, allerdings gegen Zahlung einer Vergütung. ${ }^{1206}$ Dieser Vergütungsanspruch kann regelmäßig nur durch eine Verwertungsgesellschaft geltend gemacht werden. Die gesetzliche Lizenz ist daher eng verbunden mit der Ersetzung der Befugnisausübung des Urhebers durch eine kollektive Wahrnehmung. So sieht beispielsweise $\$ 54$ UrhG eine Vergütungspflicht für die Nutzungen der $\$ 53$ Abs. 1, 2 UrhG oder der $\$ \$ 60$ af UrhG vor (Geräteabgabe). Dieser Vergütungsanspruch des $₫ 54$ UrhG kann gem. $\$ 54$ h Abs. 1 UrhG nur durch eine Verwertungsgesellschaft geltend gemacht werden.

\section{Zwangslizenz}

Bei einer Zwangslizenz bleibt weiterhin die Zustimmung durch den Urheber notwendig für eine Nutzungshandlung, der Urheber ist allerdings dazu verpflichtet, einen Nutzungsvertrag abzuschließen. ${ }^{1207}$ Der Urheber wird damit einem Kontrahierungszwang unterworfen. Im Unterschied zur gesetzlichen Lizenz bleibt hier das Verbotsrecht des Urhebers aber erhalten. ${ }^{1208}$ \$42a UrhG stellt eine solche Zwangslizenz dar für die Herstellung von Tonträgern, um verschiedene Interpretationen und Einspielungen desselben Musikwerkes zu ermöglichen (Coverversionen). ${ }^{1209}$

\section{Sonstige Regelungen}

\88 UrhG kann als weiteres Regelungsmodell betrachtet werden, um eine gewisse Abstufung an Freiraum für Nutzungshandlungen zuzulassen. Diese Norm stellt eine Auslegungsregel zugunsten des Filmherstellers dar, wonach mit der Gestattung zur Verfilmung im Zweifel auch das Recht eingeräumt wurde, das Werk unverändert oder unter Bearbeitung oder Umge-

1206 Leinemann, Die Sozialbindung des „Geistigen Eigentums“, 1998, S. 93; Stieper, Rechtfertigung, Rechtsnatur und Disponibilität der Schranken des Urheberrechts, 2009, S. 6.

1207 Leinemann, Die Sozialbindung des „Geistigen Eigentums“, 1998, S. 93.

1208 Stieper, Rechtfertigung, Rechtsnatur und Disponibilität der Schranken des Urheberrechts, 2009, S. 7.

1209 Dreier/Schulze/Schulze, 6. Aufl. 2018, \$42a UrhG Rn. 1. 
staltung zur Herstellung eines Filmwerkes zu benutzen und das Filmwerk sowie Übersetzungen und andere filmische Bearbeitung auf alle Nutzungsarten zu nutzen. Damit ist $\mathbb{8} 88$ Abs. 1 UrhG jedoch nicht bloß eine konkretisierte Zweckübertragungsregelung des $\$ 31$ Abs. V UrhG, sondern auch eine Bereichsausnahme ( $\$ 88$ Abs. 1 S. 2 UrhG) und eine Erwerbsvermutung für unbekannte Nutzungsarten für den Film. ${ }^{1210} \rrbracket 88$ UrhG ist deshalb urheberrechtliches Sonderrecht.

\section{Neue Schrankenregelung}

Für verschiedenste Techniken der Aneignungen wurden bereits neue Schrankenbestimmungen vorgeschlagen:

- Bauer für eine Schranke für User-generated Content ${ }^{1211}$

- Ziegler für eine Social Sharing Schranke ${ }^{1212}$

- Pötzlberger für einen $\$ 24 a$ UrhG für Kreatives Remixing1213

- Die Initiative Recht auf Remix für eine Schrankenregelung für Remi$\mathrm{xe}^{1214}$

- Kreutzer für eine Schrankenregelung für transformative Werknutzungen $^{1215}$

- Geiger für eine Schrankenregelung für kreative Nutzungen ${ }^{1216}$

- Vlah für eine Ergänzung des $\$ 51$ UrhG für Parodien ${ }^{1217}$

- Ohly für eine Umsetzung der Pastiche-Ausnahme des Art. 5 Abs. 3 lit. k der InfoSoc-RL in eine Schrankenregelung ${ }^{1218}$

1210 Wandtke/Bullinger/Manegold/Czernik, 5. Aufl. 2019, $\mathbb{8} 88$ UrhG Rn. 1; Dreier/ Schulze/Schulze, 6. Aufl. 2018, $\$ 88$ UrhG Rn. 1.

1211 C. Bauer, User-generated Content, 2011, S. 392 ff., 407.

1212 Ziegler, Urheberrechtverletzungen durch Social Sharing, 2016, S. 253.

1213 Pötzlberger, Kreatives Remixing, 2018, S. 298 ff.

1214 S. https://rechtaufremix.org, Datum des Zugriffs: 15.01.2020.

1215 Kreutzer, Verbraucherschutz im Urheberrecht, 2011, S. 73; ders., Remix-Culture und Urheberrecht, in: Djordjevic/Dobusch (Hrsg.), Generation Remix. Zwischen Popkultur und Kunst, 2014, S. 42, 62 ff.

1216 Geiger, Die Schranken des Urheberrechts als Instrumente der Innovationsförderung, GRUR Int. 2008, S. 459, 463 f., 467.

1217 Vlah, Parodie, Pastiche und Karikatur - Urheberrechte und ihre Grenzen, 2015, S. 193, $194 \mathrm{ff}$.

1218 Ohly, Hip Hop und die Zukunft der „freien Benutzung“ im EU-Urheberrecht, GRUR 2017, S. 964, 968. 
- Dobusch für eine analoge Anwendung des $\$ 8$ MarkenG bei Memes, wenn ein Bild in den „allgemeinen Gebrauch“ übergegangen ist ${ }^{1219}$

Dies zeigt zum einen das Bedürfnis, gesetzlichen Freiraum zu schaffen für die Nutzungen fremden Materials zu eigenen, oft kreativen Zwecken. Zum anderen zeigen diese Vorschläge aber auch auf, wie vereinzelt die Debatte um Techniken der Aneignungen bisher geführt wurde. Diese Techniken der Aneignung sollen nun gemeinsam unter dem Dach einer Schrankenregelung privilegiert werden.

Deshalb soll hier eine vergütungsfreie Schrankenregelung für den Bildgebrauch zu eigenen Zwecken im nicht-kommerziellen Bereich vorgeschlagen werden (1.). Für den kommerziellen Gebrauch von Bildern zu eigenen Zwecken wird eine gesetzliche Lizenz mit Vergütungspflicht vorgeschlagen (2.). Unter (3.) wird zu den Grenzen dieser Schranken der DreiStufen-Test, die Urheberpersönlichkeitsrechte und die Pflicht der Quellenangabe gem. $\$ 63$ UrhG genannt.

\section{Freistellung im nicht-kommerziellen Gebrauch}

Zum nicht-kommerziellen Gebrauch sollen für Aneignungshandlungen die entsprechenden Nutzungsrechte aufgehoben werden. Dies betrifft insbesondere die von Aneignungshandlungen betroffenen Rechte zur Vervielfältigung gem. $\$ 16$ UrhG, zur Verbreitung gem. $\$ 17$ UrhG und zur öffentlichen Zugänglichmachung gem. $\mathbb{1} 19 \mathrm{a}$ UrhG. Diese Nutzungen sollen freigestellt werden: Es ist weder die Zustimmung des Urhebers notwendig, noch muss eine Vergütung dafür gezahlt werden.

Unter Aneignungshandlungen sind hier alle direkt physischen oder indirekt unkörperlichen Übernahmen fremden Materials zu eigenen Zwecken, insbesondere zu künstlerischen und kommunikativen Zwecken, zu verstehen. ${ }^{1220}$ Eine Aneignung liegt damit bei der reinen Wiedergabe eines urheberrechtlich geschützten Werkes nicht vor. ${ }^{1221}$ Als Eingrenzung soll hier ebenfalls das im Rahmen der verfassungskonformen Auslegung des $\$ 24$ Abs. 1 UrhG anhand der Kunstfreiheit eingeführte Kriterium der

1219 Dobusch, Urheberrecht auf Memes? Getty Images, der „Socially Awkward Penguin" und eine Lösung aus dem Markenrecht, Netzpolitik.org vom 04.09.2015, https://netzpolitik.org/2015/urheberrecht-auf-memes-getty-imagesder-socially-awkward-penguin-und-eine-loesung-aus-dem-markenrecht.

1220 S. zur Herleitung dieser Definition S. $32 \mathrm{f}$.

1221 Vgl. S. 33. 
mangelnden Substitutionsfähigkeit dienen. Die Aneignungshandlung darf also die wirtschaftliche Nutzung des Werkes nicht ersetzen, es nicht auf seinem Markt ersetzen. ${ }^{1222}$ Freigestellt ist nicht nur die Nutzung von Ausschnitten oder kleinen Schnipsel des urheberrechtlich geschützten Werkes, sondern die Nutzung des gesamten Werkes.

Mit dem Kriterium „nicht-kommerziell“ ist gemeint, dass ohne Gewinnerzielungsabsicht gehandelt wird. In seinen Entscheidungen zur öffentlichen Wiedergabe hat der EuGH die Unterscheidung anhand der Gewinnerzielungsabsicht auch zu einer Leitunterscheidung für die digitale Nutzung von Werken bestimmt. ${ }^{1223}$ Diese Wertung kann daher hier übertragen werden. Auch der Generalanwalt Sánchez-Bordona hebt in seinen Schlussanträgen zum EuGH-Verfahren Cordoba das Kriterium der Gewinnerzielungsabsicht hervor für die Beurteilung der Kenntnis der Rechtswidrigkeit des Einstellens eines Werkes im Internet. ${ }^{1224}$ Was er unter Gewinnerzielungsabsicht genau versteht, definiert der EuGH allerdings nicht weiter.

Hier soll unter einer kommerziellen Nutzung eine solche verstanden werden, die die Erzielung von Gewinnen beabsichtigt. Dabei reicht es aus, dass lediglich die Absicht, Gewinne zu erzielen, vorliegt und es ist unbedeutend, ob tatsächlich Gewinne gemacht werden. Wie im Handelsrecht soll bei entgeltlichen Tätigkeiten eine Gewinnerzielungsabsicht vermutet werden. Ist der Preis offensichtlich sozial determiniert oder rein symbolisch, fehlt die Entgeltlichkeit. ${ }^{1225} \mathrm{Im}$ analogen Bereich liegt damit bei einem Verkauf oder Verleih in der Regel eine Gewinnerzielungsabsicht vor. Entgeltlichkeit kann aber auch in geldwerten Gegenleistungen beste-

1222 S. dazu bereits S. $199 \mathrm{ff}$.

1223 EuGH GRUR 2016, S. 1152, 1155 Rn. 51 - GS Media zum Framing; EuGH GRUR 2017, S. 610, 613 Rn. 49 ff. - Stichting Brein/Wullems zu einem multimedialen Medienabspieler, auf dem im Internet verfügbare Add-ons vorinstalliert wurden, die Hyperlinks zu für die Öffentlichkeit frei zugänglichen Webseiten enthalten; EuGH GRUR 2007, S. 225, 227 Rn. 44 - SGAE/Rafael zur Verbreitung eines Signals mittels in den Hotelzimmern aufgestellter Fernsehapparate, die ein Hotel für seine Gäste vornimmt; Dobusch, EuGH schränkt Linkfreiheit ein: Kommerzielle Nutzer können schon mit einem Link das Urheberrecht verletzen, Netzpolitik.org vom 08.09.2016, https://netzpolitik.org/2016/eugh-sc hraenkt-linkfreiheit-ein-kommerzielle-nutzer-koennen-schon-mit-einem-link-d as-urheberrecht-verletzen.

1224 Schlussanträge des EuGH Generalanwalts Sánchez-Bordona vom 25.4.2018 zu Rs. C-161/17, ZUM 2018, S. 506, 512 Rn. 80, 81. Der EuGH greift dies in seinem Urteil allerdings nicht auf.

1225 Koller/Kindler/Roth/Drüen/Roth, 9. Aufl. 2019, \$1 HGB Rn. 10. 
hen. ${ }^{1226}$ Dies ist besonders für die digitale Ökonomie von Bedeutung, in der die Kommerzialisierung in vielfältigen Formen auftritt. Hier kann zum einen Werbung geschaltet werden durch Bannerwerbung oder gesponserte Postings in sozialen Netzwerken, für die ein Entgelt gezahlt wird, sodass auch hier die Gewinnerzielungsabsicht vermutet wird. Aber auch neuartige Werbeformen in sozialen Netzwerken durch das Influencer Marketing können entgeltlich sein, wenn eine geldwerte Gegenleistung, wie das kostenlose Zuschicken von Konsumgütern oder eine kostenfreie Dienstleistung, erbracht wird. ${ }^{1227}$

Nach dieser Definition ist die Wiedergabe und die öffentliche Zugänglichmachung von Appropriation Art in der Regel eine kommerzielle Nutzung der angeeigneten Werke, da für das Werk der Appropriation Art ein Entgelt gezahlt wird. Ebenso wird für die Ausstellung des Werkes ein Entgelt gezahlt. Auch das Ausstellen zum Verkauf reicht aus, denn diese ist als Werbehandlung der Galerie als entgeltliche Tätigkeit einzustufen, bei der eine Gewinnerzielungsabsicht vorliegt. Das Herstellen von Appopriation Art, also die reine Vervielfältigungshandlung, erfolgt jedoch zu nicht-kommerziellen Zwecken, da damit zunächst lediglich das Werk der Appropriation Art geschaffen werden soll.

Aneignungen im Digitalen sind regelmäßig als nicht-kommerzielle Nutzungen einzustufen, wenn sie rein zu kommunikativen Zwecken erfolgen. Sollte vor das Aufrufen der Aneignung auf einer Webseite oder im sozialen Netzwerk allerdings Werbung geschaltet sein, liegt damit auch eine Gewinnerzielungsabsicht vor, sodass es sich dann um eine kommerzielle Tätigkeit handelt.

Die fehlende Vergütung dieser Schrankenregelung ist auch zulässig, da gesteigerte Gründe des Allgemeinwohls vorliegen. Das BVerfG hat erklärt, dass Beschränkungen des Vergütungsanspruch des Urhebers nur bei qualifizierten Gemeinwohlerwägungen zulässig sind: „Dem Interesse der Allgemeinheit, Zugang zu den Kulturgütern zu haben, ist mit dem Ausschluss des Verbotsrechts Genüge getan; dieser Ausschluss konkretisiert die soziale Bindung des Urheberrechts für den hier maßgeblichen Bereich. Aus Art. 14 Abs. 2 GG kann dagegen nicht die Forderung hergeleitet werden, dass der Urheber in diesen Fällen seine geistige Leistung der Allgemeinheit

1226 In der digitalen Ökonomie etwa in Form von Daten bei Suchmaschinen, vgl.

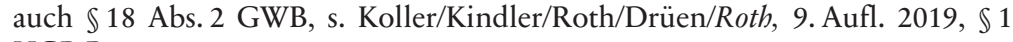
HGB Rn. 10.

1227 Lichtnecker, Neues aus dem Social Media-Marketing, MMR 2018, S. 512, 515. 
unentgeltlich zur Verfügung stellen müsste. "1228 Das heißt aber auch, dass es möglich ist, Verbots- und Vergütungsrechte des Urhebers einzuschränken, wenn wichtige Belange des Allgemeinwohls dies erfordern. Ein solcher Fall liegt hier vor. Denn die Kunstform der Appropriation Art wäre zu stark eingeschränkt, wenn sie nicht die Bilder anderer Urheber nutzen könnte. Sie könnte dann nur gemeinfreie oder nicht schutzfähige Bilder für ihre Kunst nutzen. Auch für die Kommunikation im Digitalen liegen besondere Allgemeinbelange vor. Bei kommunikativen Aneignungen handelt es sich mittlerweile um ein Massenphänomen. Bilder sind in der Digitalkultur ein Rohstoff, der ständiger Veränderung und Kombination unterliegt. Aufgrund ihrer produktiven und flexiblen Nutzungsmöglichkeiten eigenen sich Bilder daher besonders gut als Kommunikationsmittel im Internet und werden als solche millionenfach genutzt. Hinter diesem besonderen Interesse der Allgemeinheit, urheberrechtlich geschützte Bilder als Kommunikationsmittel zu nutzen, müssen die urheberrechtliche Verbots- und Vergütungsrechte zurücktreten, da diese Kommunikation ansonsten so nicht stattfinden kann.

Es reicht nicht aus, die Nutzer von Aneignungshandlungen auf die Lizenzierungsmöglichkeit beim Urheber zu verweisen. Denn eine solche Lizenzierung ist in den meisten Fällen praktisch kaum möglich: Zunächst müsste der Urheber eines Bildwerkes oder Lichtbildes überhaupt ausfindig gemacht werden und kontaktierbar sein. Dieser Rechercheaufwand und die anfallenden Transaktionskosten sind erheblich und schränken die Nutzer zu stark ein. ${ }^{1229}$ Zudem müsste der Urheber mit jedem einzelnen Nutzer einen Lizenzvertrag abschließen - gerade dies ist bei Aneignungen als Massenhandlung wie bei Memes und GIFs rein zahlenmäßig kaum zu leisten bei hundert Millionen Nutzungen tagtäglich und kann auch dem Urheber nicht zugemutet werden. Die Freistellung ist auch deshalb zulässig, weil lediglich die wirtschaftlichen Verwertungsrechte des Urhebers aufgehoben werden, die Urheberpersönlichkeitsrechte bleiben dagegen bestehen. ${ }^{1230}$

1228 BVerfG GRUR 1972, S. 481, 484 - Kirchen- und Schulgebrauch.

1229 Eine ähnliche Argumentation s. BVerfG GRUR 2016, S. 690, 694 Rn. $98-M e-$ tall auf Metall.

1230 S. dazu sogleich S. 299 ff. 
2. Gesetzliche Lizenz mit Vergütungspflicht im kommerziellen Gebrauch

Im kommerziellen Gebrauch von Aneignungen soll eine gesetzliche Lizenz mit Vergütungspflicht eingeführt werden. Der Urheber muss der Nutzungshandlung des Aneignenden also nicht zustimmen, der Nutzer muss die Nutzungshandlung allerdings vergüten. Damit verbleibt dem Urheber eine größere Herrschaft über sein Werk als bei der nicht-kommerziellen Aneignung, da er insbesondere ein Mitspracherecht bei der Höhe der Vergütung hat.

Diese Unterschiedlichbehandlung von kommerziellen und nicht-kommerziellen Aneignung ist dadurch gerechtfertigt, dass bei kommerziellen Aneignungen der aneignende Nutzer wirtschaftlich von der Aneignung profitiert. Daher ist es nur konsequent, in diesen Fällen auch den Urheber des angeeigneten Werkes wirtschaftlich an der Aneignung teilhaben zu lassen. Diese kommerziellen Aneignungshandlungen betreffen insbesondere den Verkauf von Werken der Appropriation Art, sodass dieser zumeist mithilfe der Zwangslizenz zu begegnen sei. ${ }^{1231}$

Diese gesetzliche Lizenz soll durch Verwertungsgesellschaften wahrgenommen werden. Damit würde die Verantwortlichkeit weg vom Nutzer hin zu den Urhebern und Verwertungsgesellschaften verschoben, was in Anbetracht massenhafter Nutzungen urheberrechtlicher Werke sinnvoll ist, da nun der jeweils Betroffene mit dem größten Wissensvorsprung tätig werden muss - der Urheber weiß, dass er Urheber des Werkes ist und kann sich so an die Verwertungsgesellschaften wenden. Diese gesetzliche Lizenz würde auch verhindern, dass Upload-Plattformen eine Rechteprüfung vornehmen müssten, so wie es in Art. 17 DSM-RL vorgesehen ist. ${ }^{1232}$ Ohne eine Automatisierung etwa durch Upload-Filter ist eine solche Rechteprüfung praktisch nicht durchführbar, gerade diese birgt aber die Gefahr des Overblocking urheberrechtlich zulässiger Inhalte. ${ }^{1233}$ Für diesen Regelungsvorschlag ist es notwendig, dass europaweit Urheber von Lichtbildern und Bildwerken sich an eine Verwertungsgesellschaft wenden, was

1231 Für eine Unterscheidung zwischen kommerzieller und nicht-kommerzieller Verwertung für die Privilegierung von Nutzungshandlungen urheberrechtlicher Werke im Digitalen auch Stieper, Fan Fiction als moderne Form der Pastiche, AfP 2015, S. 301, 305; Obly, Urheberrecht in der digitalen Welt, Gutachten F zum 70. Deutschen Juristentag, 2014, S. 90.

1232 Vgl. dazu S. $303 \mathrm{ff}$.

1233 S. dazu auch S. $309 \mathrm{ff}$. 
bisher nicht einheitlich der Fall ist. ${ }^{1234}$ Die Vergütung für die Lizenzen müssten im Falle kommunikativer Aneignungen im Digitalen die Plattformen an die Verwertungsgesellschaft entrichten, denn sie profitieren von der Verbreitung von Aneignungen und könnten diese Lizenzierung entsprechend einpreisen. Für andere Aneignungshandlungen müsste der Aneignende die Vergütung direkt an die Verwertungsgesellschaft entrichten. Die Verwertungsgesellschaft müsste diese eingezogenen Vergütungen dann wieder unter den Urhebern verteilen.

3. Grenzen: Urheberpersönlichkeitsrechte, Quellenangabe gem. $\$ 63$ UrhG und Drei-Stufen-Test

Neben der vorgeschlagenen Schrankenregelung bleiben die Urheberpersönlichkeitsrechte gem. $\mathbb{S} \mathbb{S} 12 \mathrm{ff}$. UrhG und das Gebot der Quellenangabe gem. \$63 UrhG bestehen. Durch das Recht auf Anerkennung der Urheberschaft gem. $\mathbb{\$} 13$ UrhG i.V.m. dem Gebot des $\$ 63$ UrhG muss der Aneignende deutlich machen, welches fremde Werk er verwendet hat, also was er sich angeeignet hat. Damit ist der Urheber des angeeigneten Werkes auch im Rechtsverkehr geschützt, da durch diese Regelungen einer Verwechslungsgefahr von angeeignetem Werk und Aneignungswerk entgegengewirkt wird. Auch der Schutz vor Entstellung gem. $\$ 14$ UrhG ist hier von Bedeutung, um den Urheber vor potenziell schädlichen Kontexten der Aneignungshandlungen zu schützen. Im Rahmen der Interessenabwägung des $\$ 14$ UrhG dürfte sich die Wertung der vorgeschlagene Schrankenregelung nicht durchsetzen, sondern es müsste in dieser Interessenabwägung die Interessen von Urheber und aneignendem Nutzer abgewogen und miteinander in Ausgleich gebracht werden. Diese nachgelagerte Interessenabwägung ist nach dem Deckmyn-Urteil des EuGH im Rahmen des $\$ 14$ UrhG wohl zulässig. Durch diese Prüfung könnte gegen Fälle der "Misappropriation“ vorgegangen werden, bei denen eine Substitutionsgefahr besteht, also das aneignende Werk Gefahr läuft, auf dem Markt das angeeignete Werk zu ersetzen. ${ }^{1235}$

1234 Vgl. dazu Wirtz, Rede der Staatssekretärin Christiane Wirtz bei der 6. Urheberrechtskonferenz der Initiative Urheberrecht am 19. November 2018 in Berlin, https://2018.konferenz-urheberrecht.de/sites/default/files/20181119_rede_wirtz .pdf.

1235 S. dazu bereits ausführlich S. 199 ff., 202 ff. 
Als Begrenzung der vorgeschlagenen Schrankenregelung ist zum anderen der Drei-Stufen-Test zu nennen, der bei einer Kodifizierung der Schrankenregelung auf Europäischer Ebene und auf deutscher Ebene anzuwenden ist. Er stellt eine Schranken-Schranke dar, der Schrankenregelungen unter bestimmte Voraussetzungen stellt. ${ }^{1236}$ Die auf Art. 13 TRIPS und Art. 9 Abs. 1 RBÜ basierende Umsetzung des Drei-Stufen-Tests in Art. 5 Abs. 5 der InfoSoc-RL für die dort genannten Schranken besagt, dass (1.) die Schrankenregelung nur in bestimmten Sonderfällen angewandt werden dürfen, in denen (2.) die normale Verwertung des Werkes oder des sonstigen Schutzgegenstandes durch die Schrankenregelung nicht beeinträchtigt werden darf und dass (3.) die berechtigten Interessen des Rechtsinhabers nicht ungebührlich verletzt werden dürfen. An diesem Maßstab sind auch die geforderte Freistellung und die gesetzliche Lizenz zu messen.

Die erste Stufe soll sicherstellen, dass die Schrankenregelung eine Ausnahme regelt, die nicht in die Regel umschlagen soll. ${ }^{1237}$ Hier werden nur nicht-kommerzielle Nutzungen vergütungsfrei gestellt mit der Ausnahme, dass die Nutzung zu eigenen Zwecken erfolgt und keine Substitutionskonkurrenz der beiden Werke entsteht, also $\$ 14$ UrhG nicht verletzt ist. Damit zielt dieser Regelungsvorschlag auf klar definierte Fälle ab, die so bestimmt sind, dass sie von anderen Nutzungszwecken abgrenzbar sind, sodass es sich um bestimmte Sonderfälle handelt. Diese dienen weiterhin einem qualifizierten berechtigten Nutzungsinteresse. ${ }^{1238}$

Nach der zweiten Stufe soll dem Urheber ein gesicherter Bestand an Werknutzungen verbleiben. ${ }^{1239}$ Schrankenregelungen sollen nicht der „normalen Verwertung“ des Urhebers zuwiderlaufen. Dabei kann die „normale Verwertung“ des Urhebers in manchen Fällen jedoch auch

1236 So geht der EuGH jedenfalls für die InfoSoc-RL von einer rein schrankenbegrenzenden Funktion des Drei-Stufen-Tests aus, s. EuGH GRUR 2019, S. 929, 933 Rn. 62 ff. - Pelham/Hütter; Leistner, „Ende gut, alles gut“... oder „Vorhang zu und alle Fragen offen“? Das salomonische Urteil des EuGH in Sachen „Pelham [Metall auf Metall]“, GRUR 2019, S. 1008, 1011.

1237 Vgl. Fischer, Digitale Kunst und freie Benutzung, 2018, S. 200.

1238 S. dazu ausführlich S. 107 ff. Das Vorliegen eines qualifizierten Nutzungszwecks wird teilweise in der Literatur gefordert, so Fiscor, The Law of Copyright and the Internet: The 1996 WIPO Treaties, their Interpretation and Implementation, 2002, S. 284; von Lewinski, International Copyright Law and Policy, 2008, S. 161; Senftleben, Grundprobleme des urheberrechtlichen Dreistufentests, GRUR Int. 2004, S. 200, 207 f.; Fischer, Digitale Kunst und freie Benutzung, 2018, S. 200.

1239 Fischer, Digitale Kunst und freie Benutzung, 2018, S. 200. 
durch schrankengekoppelte Vergütungsansprüche erreicht werden ${ }^{1240}$, so wie es hier der Fall ist. Ein greifbarer Einkommensverlust für den Urheber ist nicht denkbar, da bisher auch keine Lizenzierungen dieser Nutzungen erfolgt und auch in Zukunft nicht erfolgen wird, da sie für Fälle der kommunikativen Aneignung praktisch kaum handhabbar oder gar unmöglich ist. ${ }^{1241}$ Wenn im Rahmen dieser Stufe nach einer Gesamtbewertung zu ermitteln ist, ob die betroffene Nutzung typischerweise ein erhebliches Gewicht für Werke dieser Art besitzt ${ }^{1242}$, womit die Erzielung nennenswerter Einnahmen gemeint ist, dann ist zu beachten, dass ein solches Gewicht durch das Kriterium der Substitutionskonkurrenz ausgeschlossen wird. Nur wenn das aneignende Werk auf dem Markt nicht als Substitut des angeeigneten Werkes fungiert, ist die Aneignung nach dem oben ausgeführten Regelungsvorschlag freizustellen.

In der dritten Stufe des Drei-Stufen-Tests wird eine Interessenabwägung vorgenommen. Das Überwiegen der Reche der Nutzer von Aneignungen wurde bereits oben mehrfach bejaht in den bestimmten Fällen der nichtkommerziellen Nutzung und fehlenden Substitutionskonkurrenz. ${ }^{1243}$ Insbesondere da hier eine ausgewogene Regelung mit Abstufungen der Nutzungsmöglichkeiten bei kommerzieller und nicht-kommerzieller Nutzung der Aneignung vorgeschlagen wird, wird das Vergütungsinteresse des Urhebers nicht in einem ungebührlichen Maße verletzt.

Mithilfe dieser Begrenzungen des vorgeschlagenen Regelungsvorschlages können die Interessen aller Beteiligten von Aneignungshandlungen hinreichend berücksichtigt werden.

\section{Vereinbarkeit mit EU-Recht}

Art. 5 Abs. 1-5 InfoSoc-RL führt einen einzelfallbezogenen und abschließenden Katalog von Schrankenregelungen auf. ${ }^{1244}$ Erwägungsgrund 32 InfoSoc-RL macht deutlich, dass "die Ausnahmen und Beschränkungen in Bezug auf das Vervielfältigungsrecht und das Recht der öffentlichen Wie-

1240 So Geiger, Die Schranken des Urheberrechts als Instrumente der Innovationsförderung, GRUR Int. 2008, S. 459, 468.

1241 S. dazu bereits S. 220 ff., 305.

1242 Senftleben, Grundprobleme des urheberrechtlichen Dreistufentests, GRUR Int. 2004, S. 200, 209.

1243 Vgl. bereits die Interessenabwägungen auf S. 197 ff., $199 \mathrm{ff}$. und S. $274 \mathrm{f}$.

1244 Vgl. Obly, Hip Hop und die Zukunft der „freien Benutzung“ im EU-Urheberrecht, GRUR 2017, S. 964, 967. 
dergabe [...] erschöpfend aufgeführt [sind].“ Denn das Ziel der InfoSocRL ist gerade, rechtlicher Inkohärenz und Zersplitterung des Binnenmarktes entgegenzuwirken. Erwägungsgrund 7 InfoSoc-RL macht deutlich, dass die Richtlinie die Rechtsvorschriften anpassen will, „die sich von Mitgliedstaat zu Mitgliedstaat beträchtlich unterscheiden oder eine derartige Rechtsunsicherheit bewirken, dass der Binnenmarkt in seiner Funktionsfähigkeit beeinträchtigt und die Informationsgesellschaft in Europa in ihrer Entwicklung behindert wird“, sodass ein „uneinheitliches Vorgehen der Mitgliedstaaten gegenüber technischen Entwicklungen vermieden [wird]“. Diese erschöpfende Nennung der Ausnahmen und Beschränkungen in Art. 5 InfoSoc-RL betont der EuGH in seinem Urteil Pelham/Hütter unter Verweis auf den 32. Erwägungsgrund. ${ }^{1245}$ Er begründet diese abschließende Regelung mit der Sicherung der Funktionsfähigkeit des Binnenmarktes, wie es auch in Erwägungsgrund 31 InfoSoc-RL angeführt wird.

Damit verbleibt auf nationaler Ebene kein Spielraum für die Einführung der vorgeschlagenen neuen Schrankenregelung. Vielmehr müsste eine solche Schrankenregelung auch auf EU-Ebene eingeführt werden. Der Art. 5 Abs. 3 InfoSoc-RL müsste also erweitert werden. Eine solche Umsetzung wäre möglich, der politische Wille dazu ist allerdings nicht absehbar.

\section{Regelungsvorschlag zur Umsetzung des Art. 17 der DSM-RL in nationales Recht}

Der Art. 17 DSM-RL soll die Nutzungsmöglichkeiten im Internet im Hinblick auf kreative Gestaltungsformen steuern ${ }^{1246}$ und betrifft damit kommunikative Aneignungen im besonderen Maße. Bereits im Vorfeld hat diese Norm für Diskussion gesorgt ${ }^{1247}$, insbesondere mit der Verpflichtung, Upload-Filter einzusetzen. Die Gegner dieser Reform befürchten das Ende des freien Internets ${ }^{1248}$ und haben ihren Unmut durch Petitionen ${ }^{1249}$ und

1245 S. EuGH GRUR 2019, S. 929, 932 Rn. 58 - Pelham/Hütter.

1246 Stieper, Die Richtlinie über das Urheberrecht im digitalen Binnenmarkt, ZUM 2019, S. 211, 211.

1247 Auf den Nachweis der umfangreichen Abhandlungen aus dem Vorfeld der Verabschiedung der RL ist hier verzichtet worden.

1248 S. Kaesling, Die EU-Urheberrechtnovelle - der Untergang des Internets?, JZ 2019, S. 586, 587.

1249 Insbesondere durch die Kampagne SavetheInternet, https://savetheinternet.inf o, Datum des Zugriffs: 15.01.2020. 
in europaweiten Demonstrationen kundgetan. ${ }^{1250}$ Durch den Art. 17 DSM-RL wird sich die oben ausgemachte Legitimationskrise des Urheberrechts verschärfen, die in der unterschiedlichen Handhabung massenhafter bildhafter Kommunikationen im Digitalen im Recht und in der Rechtswirklichkeit ihren Grund findet. ${ }^{1251}$ Um ein kommunikatives Verständnis des Urheberrechts umzusetzen, soll hier ein Vorschlag gemacht werden, wie die Umsetzung des Art. 17 DSM-RL ausgestaltet werden kann, um noch einen möglichst großen Freiraum für kommunikative Aneignungshandlungen zuzulassen.

\section{Die Regelung des Art. 17 der DSM-RL}

Durch die Regelung des Art. 17 DSM-RL sollen die Urheber an der Wertschöpfung durch die digitale Nutzung ihrer Werke beteiligt werden und Online-Plattformen, die über Werbeeinnahmen vom Nutzerverhalten wirtschaftlich profitieren ${ }^{1252}$, verantwortlich gemacht werden für urheberrechtliche Verletzungen durch die auf ihren Plattformen bereitgestellten Inhalten.

\section{Verantwortlichkeit der Diensteanbieter}

Der Art. 17 DSM-RL gilt für Diensteanbieter für das Teilen von Online-Inhalten. Nach Art. 2 Nr. 6 DSM-RL bezeichnet dies „den Anbieter eines Dienstes der Informationsgesellschaft, bei dem der Hauptzweck bzw. einer der Hauptzwecke darin besteht, eine große Menge an von seinen Nutzern hochgeladenen, urheberrechtlich geschützten Werken oder sonstigen Schutzgegenständen zu speichern und der Öffentlichkeit Zugang hierzu zu verschaffen, wobei dieser Anbieter diese Inhalte organisiert und zum

1250 S. https://www.heise.de/newsticker/meldung/Save-the-Internet-Europaweite-De mos-gegen-neues-Urheberrecht-und-Artikel-13-4347138.html; Datum des Zugriffs: 15.01.2020. Allein in München waren etwa 40.000 Demonstration bei des Aktionsbündnisses \#saveyourinternet, vgl. -, 40000 protestieren in München gegen EU-Urheberrechtsreform, SZ vom 23.03.2019, https:/www.su eddeutsche.de/muenchen/demo-muenchen-urheberrecht-1.4380419, Datum des Zugriffs: 15.01.2020.

1251 S. dazu bereits ausführlich S. $223 \mathrm{ff}$.

1252 Hofmann, Die Plattformverantwortlichkeit nach dem neuen europäischen Urheberrecht - „Much Ado About Nothing“?, ZUM 2019, S. 617, 618. 
Zwecke der Gewinnerzielungsabsicht bewirbt" ${ }^{1253}$ Nicht-kommerzielle Angebote, wie etwa Online-Enzyklopädien, Online-Marktplätze und Cloud-Dienste sind nach Art. 2 Nr. 6 und Erwägungsgrund 62 DSMRL vom Anwendungsbereich ausgenommen.

Art. 17 DSM-RL erweitert den Begriff der Wiedergabe und der öffentlichen Zugänglichmachung und regelt, dass nun Diensteanbieter selbst einen Akt der öffentlichen Wiedergabe oder Zugänglichmachung ausführen können. Damit wird das eigentlich eingreifende Haftungsprivileg des Art. 14 E-Commerce-RL durchbrochen. ${ }^{1254}$ Der Diensteanbeiter haftet nun nicht mehr lediglich als Störer, sondern als Täter durch eigene Handlung. Diese Haftungsverschiebung stellt einen Paradigmenwechsel im Urheberrecht dar. ${ }^{1255}$ Sie wird damit begründet, dass aufgrund der Möglichkeit des anonymen Hochladens von Inhalten die Wahrscheinlichkeit erhöht wird, dass die einzelnen Nutzer von Urheberrechtsverletzungen nicht zur Rechenschaft gezogen werden. ${ }^{1256}$ Durch das Abstellen auf die Ermöglichung des Hochladens von urheberrechtlich geschützten Inhalten wird die Ver-

1253 Auf die Vielzahl unbestimmter Rechtsbegriffe wie der "großen Menge“ urheberrechtlicher Werke, „organisiert", „Gewinnerzielungsabsicht" etc. soll hier nicht weiter eingegangen werden.

1254 Spindler, Die neue Urheberrechts-Richtlinie der EU (Teil 2), WRP 2019, S.951, 956.

1255 Wandtke, Grundsätze der Richtlinie über das Urheberrecht im digitalen Binnenmarkt, NJW 2019, S. 1841, 1845; Gerpott, Artikel 17 der neuen EU-Urheberrechtsrichtlinie: Fluch oder Segen?, MMR 2019, S. 420, 422; Dreier, Die Schlacht ist geschlagen - ein Überblick. Zum Ergebnis des Copyright Package der EU-Kommission, GRUR 2019, S. 771, 775; Wandtke/Hauck, Art. 17 DSMRichtlinie. Ein neues Haftungssystem im Urheberrecht, ZUM 2019, S.627, 627; a.A. aufgrund des bisherigen "notice and stay down"-Verfahrens: Hofmann, Die Plattformverantwortlichkeit nach dem neuen europäischen Urheberrecht - „Much Ado About Nothing“?, ZUM 2019, S. 617, 617, 625, wenn man lediglich die Unterlassungsansprüche betrachtet. Das deutsche Recht hat das Modell bisher über die Störerhaftung mit dem genannten „notice and stay down"-Verfahren gelöst, also einer Haftung des Plattforminhabers bei Kenntnis der Verletzung, regelmäßig nach Hinweis durch den Rechteinhaber („notice“), für das Löschen der Urheberrechtsverletzung („take down“) und das Unterlassen des zukünftigen Uploads auf die Plattform („stay down“). Mit seinem Vorlagenbeschluss YouTube hat der BGH die Vereinbarkeit dieses Modells mit dem Unionsrecht dem EuGH zur Prüfung überlassen, s. BGH GRUR 2018, S. 1132 - YouTube.

1256 Stieper, Die Richtlinie über das Urheberrecht im digitalen Binnenmarkt, ZUM 2019, S. 211, 217. 
antwortlichkeit der Diensteanbieter vorverlagert und besteht unabhängig davon, ob sie Kenntnis von der rechtswidrigen Handlung haben. ${ }^{1257}$

Gem. Art. 17 Abs. 1 DSM-RL sollen sich Diensteanbieter um eine „Erlaubnis“, also eine Lizenzeinholung durch die Rechteinhaber, kümmern. Dieses Ziel nennt auch Erwägungsgrund 61, wonach durch die DSMRL „die Entwicklung eines Marktes für die Vergabe von Lizenzen zwischen Rechteinhabern und Diensteanbietern für das Teilen von Online-Inhalten gefördert werden" soll. Von Diensteanbietern eingeholte Lizenzen erstrecken sich gem. Art. 17 Abs. 2 DSM-RL auch auf die Handlungen, die von Nutzern ausgeführt werden und in den Geltungsbereich des Art. 3 InfoSoc-RL fallen. Doch eine individuelle Lizenzierung ist praktisch kaum durchführbar ${ }^{1258}$, denn ihr stehen hohe Transaktionskosten entgegen und eine schier unüberschaubare Menge hochgeladenen Materials mit komplexen Inhalten und unterschiedlichen Schutzgegenständen von Urhebern, die nicht alle über Verwertungsgesellschaften organisiert sind. Insbesondere Werke für ein kleines Publikum wie solche aus kleine Sprach- und Kulturgruppen und Minderheiten oder ausgefallene Schöpfungen werden Lizenzschwierigkeiten ausgesetzt und deren Inhaltsvielfalt in Zukunft wohl eingeschränkt. ${ }^{1259}$ Die Lizenzeinholung ist damit unwahrscheinlich ${ }^{1260}$ und wenn überhaupt sind nur die großen Plattforminhaber wie Google oder Facebook in der Lage, großflächig solche Lizenzvereinbarungen abzuschließen. ${ }^{261}$ Die Lizenzeinholung soll nach der Systematik des Art. 17 DSM-RL zwar zum Regelfall werden, tatsächlich wird wohl die Nutzung von Upload-Filter zum Regelfall der Haftungsexkulpation.

\section{Der Einsatz von Upload-Filtern}

Wenn die Diensteanbieter keine Lizenz für die von Nutzern hochgeladenen urheberrechtlichen Werke oder Schutzgegenstände erhalten, verbleibt

1257 Wandtke, Grundsätze der Richtlinie über das Urheberrecht im digitalen Binnenmarkt, NJW 2019, S. 1841, 1845.

1258 Stieper, Die Richtlinie über das Urheberrecht im digitalen Binnenmarkt, ZUM 2019, S. 211, 216.

1259 Senftleben, Filterverpflichtungen nach der Reform des europäischen Urheberrechts - Das Ende der freien Netzkultur?, ZUM 2019, S. 369, 371.

1260 Kaesling, Die EU-Urheberrechtnovelle - der Untergang des Internets?, JZ 2019, S. 586, 589.

1261 Stieper, Die Richtlinie über das Urheberrecht im digitalen Binnenmarkt, ZUM 2019, S. 211, 216. 
ihnen zur Abwendung ihrer Haftung die Filterlösung gem. Art. 17 Abs. 4 DSM-RL. Diensteanbieter können sich gem. Art. 17 Abs. 4 DSM-RL von der Haftung exkulpieren, wenn sie den Nachweis erbringen, dass sie erstens alle Anstrengungen unternommen haben, um eine Erlaubnis für die Nutzung der Inhalte einzuholen, und zweitens nach Maßgabe hoher branchenüblicher Standards für die berufliche Sorgfalt alle Anstrengungen unternommen haben, um sicherzustellen, dass bestimmte Werke und sonstige Schutzgegenstände, zu denen die Rechteinhaber den Anbietern dieser Dienste einschlägige und notwendige Informationen bereitgestellt haben, nicht verfügbar sind. Drittens müssen sie nach Erhalt eines hinreichend begründeten Hinweises von den Rechteinhabern unverzüglich gehandelt haben, um den Zugang zu den entsprechenden Werken oder sonstigen Schutzgegenständen zu sperren bzw. sie von ihren Internetseiten zu entfernen, und alle Anstrengungen unternommen haben, um das künftige Hochladen dieser Werke oder Schutzgegenstände zu verhindern. Eine Ausnahme ist in Art. 17 Abs. 6 DSM-RL vorgesehen für Start-Ups mit weniger als zehn Mio. Euro Jahresumsatz und monatlich weniger als fünf Mio. Nutzern während der ersten drei Jahre nach Markeintritt. Diese sind lediglich dazu verpflichtet, sich um Lizenzen zu bemühen und bei Hinweis auf eine Rechtsverletzung das "notice and take/stay down"-Prinzip zu beachten.

Upload-Filter sind damit nicht direkt vorgeschrieben, gehören jedoch mittlerweile zu den genannten „branchenüblichen Standards“.1262 Da Filtertechnologien dem Stand der Technik entsprechen, ist nicht zu erkennen, wie Diensteanbieter ihrer Sorgfaltspflicht nachkommen können ohne Einsatz von Upload-Filtern. ${ }^{1263}$ Nur durch sie kann sichergestellt werden, dass die Verbotsrechte der Rechteinhaber durchgesetzt werden können. Die Obliegenheit der Diensteanbieter, den branchenüblichen Standard be-

1262 Hier zeigt sich bereits das Problem dieses unbestimmten Rechtsbegriffs und der Definitionshoheit über „branchenübliche Standards“, s. dazu Spindler, Die neue Urheberrechts-Richtlinie der EU (Teil 2), WRP 2019, S. 951, 957.

1263 So ganz h.M.: Dreier, Die Schlacht ist geschlagen - ein Überblick. Zum Ergebnis des Copyright Package der EU-Kommission, GRUR 2019, S. 771, 776; Pravemann, Art. 17 der Richtlinie zum Urheberrecht im digitalen Binnenmarkt, GRUR 2019, S. 783, 784; Becker, Von der Freiheit, rechtswidrig handeln zu können. „Upload-Filter“ und technische Rechtsdurchsetzung, ZUM 2019, S. 636, 637; Kaesling, Die EU-Urheberrechtnovelle - der Untergang des Internets?, JZ 2019, S. 586, 589. 
ruflicher Sorgfalt zu wahren, kommt damit einem Verweis auf den Einsatz von Filtertechnologien gleich. ${ }^{1264}$

Upload-Filtern selektieren Inhalte präventiv und verhindern so eine $\mathrm{Zu}$ gänglichmachung auf den Plattformen. ${ }^{1265}$ Sie nutzen meist sog. Fingerprint-Technologien. Dazu müssen der Plattform Referenzen der geschützten Werke durch die Rechteinhaber zur Verfügung gestellt werden, die in eine Referenzdatenbank eingepflegt werden. ${ }^{1266}$ Die optischen oder akustischen Charakteristika eines Werkes werden in numerische Werte gewandelt, sog. Hashwerte, die wie ein digitaler Fingerabdruck die wesentlichen Merkmale dieser Datei kennzeichnen. ${ }^{1267}$ Beim Upload wird ein Vergleich des hochgeladenen Inhalts mit diesen numerischen Werten vorgenommen. ${ }^{1268}$

a) Absicherung von Schranken gem. Art. 17 Abs. 7 DSM-RL

Nach Art. 17 Abs. 7 DSM-RL dürfen die Maßnahmen von Diensteanbietern nicht dazu führen, dass Inhalte nicht mehr verfügbar sind, die im Rahmen einer Ausnahme oder Beschränkung des Urheberrechts erlaubt sind, insbesondere als Zitat, Kritik und Rezension sowie zum Zwecke von Karikaturen, Parodien oder Pastiches. Erwägungsgrund 70 stellt deshalb fest, dass dies verpflichtend für die Mitgliedstaaten gilt. Ob eine solche Regelung jedoch kommunikative Aneignungen im Digitalen erfasst, ist nicht eindeutig. Die Regelung des Art. 17 Abs. 7 DSM-RL, insbesondere die Pastiche-Ausnahme, wird zwar in der Literatur immer wieder angeführt, um Memes, GIFs und andere digitalen Phänomene weiterhin zu ermöglichen. ${ }^{1269}$ Für den Begriff des Pastiche besteht jedoch weder auf EU- noch

1264 Kaesling, Die EU-Urheberrechtnovelle - der Untergang des Internets?, JZ 2019, S. 586, 588.

1265 Dies., a.a.O., S. 588.

1266 S. ausführlich zur Funktionsweise von Filtertechnologien Maier, Remixe auf Hosting-Plattformen, 2018, S. 149.

1267 Dies., a.a.O., S. 149; Kaesling, Die EU-Urheberrechtnovelle - der Untergang des Internets?, JZ 2019, S. 586, 588.

1268 Maier, Remixe auf Hosting-Plattformen, 2018, S. 149.

1269 Volkmann, Art. 17 Urh-RL und die Upload-Filter: verschärfte Störerhaftung oder das Ende der Freiheit im Internet?, CR 2019, S. 376, 381 für nutzergenerierte Inhalte wie Memes, Remixe, Mash-Ups, Fan Fiction und Collagen und Hofmann, Die Plattformverantwortlichkeit nach dem neuen europäischen Urheberrecht - „Much Ado About Nothing“?, ZUM 2019, S. 617, 626, der auf \$24 UrhG verweist. 
auf Bundesebene ein klares Begriffsverständnis. ${ }^{1270}$ In der Literatur wurden bisher auch nur wenige Auslegungsvorschläge gemacht. Diese sind meist, so auch in dieser Arbeit, auf die künstlerische Gestaltung von Aneignungen beschränkt. Ein so weites Verständnis von Pastiche, dass auch kommunikative Aneignungen zu nicht-kommerziellen Zwecken darunter zu verstehen sind, scheint kaum vertretbar, wie bereits oben ausführlicher dargelegt. ${ }^{1271}$ Von daher passt es nicht zusammen, dass in der Literatur zu Art. 17 Abs. 7 DSM-RL zwar immer wieder betont wird, Memes und GIFs seien nicht in Gefahr, auf der anderen Seite aber die Pastiche-Schranke gerade keine Schranke für kreative Umnutzungen ist, sondern vielmehr der Kunstfreiheit des Art. 13 GrCh und Art. 5 Abs. 3 GG dienen soll. Digitale Phänomene wie Memes oder GIFs werden damit regelmäßig nicht als Pastiche zu verstehen sein. ${ }^{1272}$

Ebenso fraglich ist, ob Filter-Technologien überhaupt in der Lage sind, die genannten Ausnahmen zu erkennen und dadurch deren Vorrang zu gewährleisten. Es besteht Grund zur Annahme, dass automatisierte Filter regelmäßig Zitate, Kritik, Rezensionen, Karikaturen, Parodien und Pastiches als Urheberrechtsverletzungen flaggen werden. ${ }^{1273}$ Denn bei der Beurteilung dieser Ausnahmen geht es um komplexe semantische Fragen und gewichtende Wertungen, die sich kaum anhand quantitativer Parameter programmieren lassen. ${ }^{1274}$ Es müsste eine qualitative Bewertung der Inhalte unter Einbezug des Subtextes oder gesellschaftlichen Kontextes vorgenommen werden. ${ }^{1275}$ Die Technik müsste den semantischen Gehalt, die Bedeutung verstehen. Eine solch intelligente Filtersoftware existiert noch nicht. ${ }^{1276}$ Dazu bräuchte es Bewusstsein, denn erst Bewusstsein versieht In-

1270 S. oben S. $285 \mathrm{f}$.

1271 Vgl. S. $288 \mathrm{f}$.

1272 S. dazu oben S. $288 \mathrm{f}$.

1273 Maier, Remixe auf Hosting-Plattformen, 2018, S. 151

1274 Dreier, Die Schlacht ist geschlagen - ein Überblick. Zum Ergebnis des Copyright Package der EU-Kommission, GRUR 2019, S. 771, 777; Becker, Von der Freiheit, rechtswidrig handeln zu können. „Upload-Filter“ und technische Rechtsdurchsetzung, ZUM 2019, S. 636, 644.

1275 Maier, Remixe auf Hosting-Plattformen, 2018, S. 150.

1276 Dies., a.a.O., S.150; Volkmann, Art. 17 Urh-RL und die Upload-Filter: verschärfte Störerhaftung oder das Ende der Freiheit im Internet?, CR 2019, S.376, 382; Senftleben, Filterverpflichtungen nach der Reform des europäischen Urheberrechts - Das Ende der freien Netzkultur?, ZUM 2019, S.369, 372; Dreier, Die Schlacht ist geschlagen - ein Überblick. Zum Ergebnis des Copyright Package der EU-Kommission, GRUR 2019, S. 771, 777; Becker, Von der 
formation mit Bedeutung, mit Verständnis im menschlichen Sinne. ${ }^{1277}$ Eine Technik also, die das Vorliegen einer Parodie u.a. beurteilen könnte, ginge in Richtung einer „starken“ Künstlichen Intelligenz, von der die Forschung bislang weit entfernt ist. ${ }^{1278}$ Spindler bezeichnet es daher zu Recht als „Quadratur des Kreises“, dass Plattformen technische Maßnahmen zum Schutz von Urheberrechtsverletzungen ergreifen müssen, andererseits aber die Meinungsfreiheit insbesondere in Form von Karikaturen und Parodien im Rahmen der geistigen Auseinandersetzung aufrechterhalten sollen. ${ }^{1279}$

\section{b) Gefahr des Overblocking}

Die Warnungen vor der Gefahr des „Overblocking“ durch Filtertechnologien sind daher begründet. Overblocking meint die Sperrung von „false positives" durch die Diensteanbieter, da es bei der Beurteilung bei der Vorlage von Ausnahmen gem. Art. 17 Abs. 7 DSM-RL auf deren Entscheidungskompetenz ankommt. Zwar gibt es bisher keine empirischen Erhebungen zum Problem des Overblockings durch bereits genutzte Filtersysteme wie YouTube's Content ID. ${ }^{1280}$ Es besteht jedoch die Befürchtung, dass Diensteanbieter im Zweifelsfall kein finanzielles Risiko eingehen wollen und lieber großzügiger als notwendig filtern werden. ${ }^{1281}$ Als Gegenargument wird hier zwar angeführt, dass eine Gefahr des Overblocking nicht besteht, weil es den betriebswirtschaftlichen Interessen der Diensteanbieter auf gleiche Weise entgegenlaufen würde, wenn Anzahl und Verweildauer der Nutzer sich verringern aufgrund des Overblockings. ${ }^{1282}$ Ebenfalls wird häufig angeführt, dass sich für YouTube kaum etwas ändern wird, die bereits eine Filtertechnologie nutzen um die hochgeladenen Inhalte ihrer

Freiheit, rechtswidrig handeln zu können. „Upload-Filter“ und technische Rechtsdurchsetzung, ZUM 2019, S. 636, 644.

1277 Becker, Von der Freiheit, rechtswidrig handeln zu können. „Upload-Filter“ und technische Rechtsdurchsetzung, ZUM 2019, S. 636, 644.

1278 Ders., a.a.O., S. 644.

1279 Spindler, Die neue Urheberrechts-Richtlinie der EU (Teil 2), WRP 2019, S. 951, 956.

1280 Maier, Remixe auf Hosting-Plattformen, 2018, S. 152.

1281 Volkmann, Art. 17 Urh-RL und die Upload-Filter: verschärfte Störerhaftung oder das Ende der Freiheit im Internet?, CR 2019, S. 376, 382.

1282 Gerpott, Artikel 17 der neuen EU-Urheberrechtsrichtlinie: Fluch oder Segen?, MMR 2019, S. 420, 422. 
Nutzer auf Urheberrechtsverletzungen zu überprüfen. ${ }^{1283}$ Doch mit der durch Art. 17 DSM-RL eingeführten Haftung als Täter besteht nun auch das Risiko, für Schadensersatz in Anspruch genommen zu werden und nicht lediglich auf Unterlassung zu haften wie durch die vorherige Störerhaftung. Damit hat sich das Interesse der Diensteanbieter verschärft, die Filtertechnologie so einzusetzen, dass sie nicht belangt werden können und strittige Fälle, wie die in Art. 17 Abs. 7 lit. a, b DSM-RL genannten, so auszulegen, dass sie im Zweifel nicht haften - also im Zweifel von einer Urheberrechtsverletzung durch die hochgeladenen Inhalte auszugehen und diese zu blockieren. Darüber hinaus ist der Verweis auf die bereits genutzte Filtertechnologie wenig ermutigend, da sich bereits jetzt gravierende Fälle des Overblockings zeigen. So wurde Tom Hillenbrand satirischer Tweet ${ }^{1284}$ zu den Europawahlen von Twitter gelöscht und sein Account gesperrt unter Berufung auf eine Richtlinie für politische Tweets, die Wahlbeeinflussung verhindern soll. Dabei weist Twitter jedoch auch ausdrücklich darauf hin, dass Satiren und Kommentare zur Wahl erlaubt sind. Per einstweiliger Verfügung untersagte das LG München I Twitter die Löschung des Tweets und des Accounts. ${ }^{1285}$ Bei YouTube wurde das Video der Kampagne gegen Sexismus „Not Heidi’s Girls“ gesperrt, weil der Protestsong fälschlicherweise als geistiges Eigentum von RTL eingestuft wurde. ${ }^{1286}$ Hier zeigt sich, wie schwer sich Filtertechnologien mit der Einordnung von Parodie und Kritik tun. Aber auch schon offensichtlichere Fälle haben Filtersysteme fälschlicherweise geblockt: Beispielsweise das Video eines Klavier-Stücks von Bach, das ein Pianist bei Facebook hochgeladen hat, und bei dem Sony Music Global eingestuft hat, die Rechte an der Auf-

1283 Dreier, Die Schlacht ist geschlagen - ein Überblick. Zum Ergebnis des Copyright Package der EU-Kommission, GRUR 2019, S. 771, 777; Hofmann, Die Plattformverantwortlichkeit nach dem neuen europäischen Urheberrecht „Much Ado About Nothing“"?, ZUM 2019, S. 617, 627.

1284 „Alle AfD-Wähler sollten: -ihren Wahlzettel fotografieren -ihn unterschreiben -Foto auf Insta posten -Wahlzettel danach aufessen“, @tomhillenbrand vom 06.05.2019, s. dazu Breithut, Bei Wahlen versteht Twitter keinen Spaß, Spiegel Online vom 09.05.2019, https:/www.spiegel.de/netzwelt/netzpolitik/twitter-u nd-seine-account-sperren-bei-wahlwitzen-hoert-der-spass-auf-a-1266633.html.

1285 LG München I, Beschl. v. 17.06.2019, Az. 10 O 7388/19.

1286 Dachwitz/Fanta, Not Heidis Girl: Wie Youtube eine Kampagne gegen Sexismus ausbremste, Netzpolitik.org vom 06.03.2018, https:/netzpolitik.org/2018/not-h eidis-girl-wie-youtube-eine-kampagne-gegen-sexismus-ausbremste. 
führung zu besitzen. ${ }^{1287}$ Oder die Blockade eines Videos mit 10-stündigem weißen Rauschen, dem gleich fünf Urheberrechtsverletzungen vorgeworfen wurden. ${ }^{1288}$

Um dem fälschlichen Blockieren hochgeladener Inhalte vorzubeugen, haben Diensteanbieter ein wirksames Beschwerde- und Rechtsbehelfsverfahren einzurichten nach Art. 17 Abs. 9 und Erwägungsgrund 70 DSMRL. Ähnlich wie beim NetzDG ${ }^{1289}$ entscheiden über die Beschwerden die Diensteanbieter selbst. ${ }^{1290}$ Sollte der Diensteanbieter der Beschwerde nicht stattgeben, muss der Nutzer den Rechtsweg bestreiten, um eine aus seiner Sicht rechtmäßige Nutzung wiederherzustellen. ${ }^{1291}$ Damit wird ein Rollentausch vorgenommen: Klagen muss nun der Nutzer und die Klage ist nicht darauf gerichtet, eine Urheberrechtsverletzung abzuwehren (wie bisher vor der DSM-RL, wo der Rechteinhaber tätig werden muss), sondern darauf, eine Nichtverletzung festzustellen. ${ }^{1292}$ Private Nutzer werden aber oft nicht einschätzen können, ob ein Vorgehen gegen die Maßnahme des Diensteanbieters erfolgversprechend ist. ${ }^{1293}$ Außerdem ist die digitale Kommunikation derart von Schnelligkeit und Aktualität geprägt, dass allein der zeitliche Abstand durch das Freiklagen von beispielsweise politischen Parodien oder Karikaturen einen schwerwiegenden Eingriff in die Rechte der Nutzer darstellen kann, da der entscheidende Moment der Parodie oder Karikatur bereits vorbei sein kann. ${ }^{1294}$

1287 Mrohs, Uploadfilter: Eine Geschichte voller Fails, Netzpolitik.org vom 24.04.2019, https://netzpolitik.org/2019/uploadfilter-eine-geschichte-voller-fails /.

1288 Ders., a.a.O., https://netzpolitik.org/2019/uploadfilter-eine-geschichte-voller-fail s/, wo noch weitere Beispiele zu finden sind; Maier, Remixe auf Hosting-Plattformen, 2018, S. 153 Fn. 36 für Beispiele des Overblocking von Remix-Filmen.

1289 Gesetz zur Verbesserung der Rechtsdurchsetzung in sozialen Netzwerken, Netzwerkdurchsetzungsgesetz vom 01.10.2017, BGBl. I S. 3352.

1290 Wie auch beim NetzDG bleibt der Vorwurf, dass komplizierte rechtliche Entscheidungen in die Hände von privaten Unternehmen gelegt werden, s. Pravemann, Art. 17 der Richtlinie zum Urheberrecht im digitalen Binnenmarkt, GRUR 2019, S. 783, 787.

1291 Volkmann, Art. 17 Urh-RL und die Upload-Filter: verschärfte Störerhaftung oder das Ende der Freiheit im Internet?, CR 2019, S. 376, 382.

1292 Becker, Von der Freiheit, rechtswidrig handeln zu können. „Upload-Filter“ und technische Rechtsdurchsetzung, ZUM 2019, S. 636, 641.

1293 Kaesling, Die EU-Urheberrechtnovelle - der Untergang des Internets?, JZ 2019, S. $586,589$.

1294 Senftleben, Filterverpflichtungen nach der Reform des europäischen Urheberrechts - Das Ende der freien Netzkultur?, ZUM 2019, S. 369, 373. 
c) Grundrechtsverletzung durch Art. 17 DSM-RL

Da der Nutzer individuell gegenüber den Diensteanbietern seine Rechte durchsetzen muss, indem er die Einhaltung der Schrankenregelungen geltend machen muss, kann dies zu "chilling effects" gegenüber der Meinungsfreiheit führen. ${ }^{1295}$ Art. 17 DSM-RL wird in der Literatur immer wieder dafür kritisiert, kein angemessenes Gleichgewicht zwischen dem Schutz von Urheberrechten (Art. 17 Abs. 2 GrCh), dem Recht auf unternehmerische Freiheit (Art. 16 GrCh), der Kunstfreiheit (Art. 13 GrCh) und der Meinungsfreiheit (Art. $11 \mathrm{GrCh}$ ) herzustellen. ${ }^{1296} \mathrm{Ob}$ die DSM-RL, insbesondere Art. 17, die Meinungsfreiheit unverhältnismäßig beeinträchtigt, lässt nun die polnische Regierung durch eine Klage vor dem EuGH klären. ${ }^{1297}$

\section{Spielraum zur Umsetzung der DSM-RL}

Die CDU äußerte, dass es „in der nationalen Umsetzung keine Uploadfilter geben" wird. ${ }^{1298}$ Sie möchte stattdessen eine Bagatellgrenze einführen, sodass Uploads unterhalb einer zeitlichen Grenze lizenzfrei bleiben. Im Übrigen soll eine „Pauschallizenz" greifen, aufgrund der die individuelle Überprüfbarkeit durch Upload-Filter entbehrlich wird. ${ }^{1299}$ Doch besteht dieser Spielraum den Mitgliedstaaten bei der Umsetzung der DSM-RL?

Art. 17 Abs. 4 DSM-RL nennt die branchenübliche Sorgfalt und die beinhaltet derzeit Filtertechnologien. ${ }^{1300}$ Ein Verbot von Upload-Filtern wür-

1295 Spindler, Die neue Urheberrechts-Richtlinie der EU (Teil 2), WRP 2019, S.951, 958.

1296 Maier, Remixe auf Hosting-Plattformen, 2018, S. 175 ff.; Kaesling, Die EU-Urheberrechtnovelle - der Untergang des Internets?, JZ 2019, S. 586, 589; Spindler, Haftung ohne Ende?, MMR 2018, S. 48, 52.

1297 -, Polen zieht gegen EU-Richtlinie zum Urheberrecht vor EuGH, beck-aktuell vom 24.05.2019, https://rsw.beck.de/aktuell/meldung/polen-zieht-gegen-eu-ric htline-zum-urheberrecht-vor-eugh, Datum des Zugriffs: 15.01.2020.

1298 CDU, Kompromiss zum Urheberrecht: Keine Uploadfilter!, 15.03.2019, https:// www.cdu.de/artikel/kompromiss-zum-urheberrecht-keine-uploadfilter, Datum des Zugriffs: 15.01 .2020$.

$1299 C D U$, Kompromiss zum Urheberrecht: Keine Uploadfilter!, 15.03.2019, https:// www.cdu.de/artikel/kompromiss-zum-urheberrecht-keine-uploadfilter, Datum des Zugriffs: 15.01 .2020$.

1300 Kaesling, Die EU-Urheberrechtnovelle - der Untergang des Internets?, JZ 2019, S. 586, 591 . 
de die praktische Wirksamkeit (effet utile, Art. 4 Abs. 3 EUV) der Richtlinie einschränken, die gerade die Verwirklichung des Binnenmarkts und eine Vereinheitlichung der rechtlichen Regelung bezweckt. ${ }^{1301} \mathrm{Nach}$ Art. 288 Abs. 3 AEUV ist Deutschland außerdem verpflichtet, die Richtlinie umzusetzen. Eine Pauschallizenz, wie von der CDU vorgeschlagen, wäre als neue Schranke zu qualifizieren. Der Schrankenkatalog der InfoSocRL ist jedoch abschließend und sieht eine solche Regelung gerade nicht vor. ${ }^{1302}$ Der Vorschlag der CDU ist daher nicht mit der InfoSoc-RL und mit der DSM-RL vereinbar. ${ }^{1303}$

III. Vorschläge zur Umsetzung des Art. 17 DSM-RL in nationales Recht

Wenn sich Upload-Filter in der nationalen Umsetzung nicht verbieten lassen, soll nun geklärt werden, wie Art. 17 DSM-RL umgesetzt werden kann, um noch einen möglichst großen Freiraum für kommunikative Aneignungshandlungen zuzulassen.

Der Umsetzungsgesetzgeber könnte klarstellen, wie der Lizenzierungsprozess nach Art. 17 Abs. 1 DSM-RL abläuft und ab wann die Ausnahme des Abs. 4 lit. a DSM-RL greift. Man kann die Norm so verstehen, dass der Diensteanbieter bereits haftet, wenn der Nutzer urheberrechtlich geschütztes Material hochlädt und der Upload von der Plattform öffentlich zugänglich gemacht wird. ${ }^{1304}$ Es könnte klargestellt werden, dass der Diensteinhaber das Hochladen dann zulassen darf, sobald er ernsthaft begonnen hat, sich um den Rechtserwerb zu bemühen und der Rechteinhaber bereits die entsprechende Referenzdatei zur Verfügung gestellt hat. ${ }^{1305}$ Dafür, dass dies bereits für die Exkulpation des Art. 17 Abs. 4 lit. a DSM-RL ausreicht, spricht, dass es gem. Art. 17 Abs. 9 DSM-RL keine allgemeine Überwa-

1301 Dies., a.a.O., S. 591.

1302 Vgl. zum abschließenden Schrankenkatalog der InfoSoc-RL bereits S. $301 \mathrm{f}$.

1303 Spindler, Die neue Urheberrechts-Richtlinie der EU (Teil 2), WRP 2019, S. 951, 958; Volkmann, Art. 17 Urh-RL und die Upload-Filter: verschärfte Störerhaftung oder das Ende der Freiheit im Internet?, CR 2019, S. 376, 380; Gerpott, Artikel 17 der neuen EU-Urheberrechtsrichtlinie: Fluch oder Segen?, MMR 2019, S. 420, 423.

1304 Pravemann, Art. 17 der Richtlinie zum Urheberrecht im digitalen Binnenmarkt, GRUR 2019, S. 783, 786.

1305 Dreier, Die Schlacht ist geschlagen - ein Überblick. Zum Ergebnis des Copyright Package der EU-Kommission, GRUR 2019, S. 771, 776. 
chungspflicht von Diensteinhabern geben soll. ${ }^{1306}$ Das heißt die Überwachungspflicht des Diensteinhabers ist eine beschränkte, einzelfallbezogene hinsichtlich der von Rechteinhabern bereitgestellten Dateien. ${ }^{1307}$

Für die Erlaubniseinholung von Diensteanbietern sollte zudem eine erweitere kollektive Lizenzierung im Sinne des Art. 12 und Erwägungsgründe $44 \mathrm{ff}$. DSM-RL angewandt werden. Nach Art. 12 Abs. 1 lit. a DSMRL kann die Geltung einer Lizenzvereinbarung mit den Verwertungsgesellschaften auch auf die Rechte von Rechteinhabern ausgeweitet werden, die der Verwertungsgesellschaft keine Rechte zur Wahrnehmung erteilt haben. Alternativ kann nach lit. b die Vermutung gelten, dass die Verwertungsgesellschaft die Rechteinhaber vertritt, die ihr bisher kein entsprechendes Mandat erteilt haben. Mit diesen Mechanismen können also Lizenzvereinbarung auch auf Außenstehende angewendet werden. Nach Art. 12 Abs. 2 DSM-RL darf dies dann Anwendung finden, wenn „die Einholung der Erlaubnis der Rechteinhaber in jedem Einzelfall normalerweise beschwerlich und in einem Maße praxisfern ist, dass die erforderliche Erteilung der Lizenz aufgrund der Art der Nutzung oder des Typs der jeweiligen Werke oder sonstigen Schutzgegenstände unwahrscheinlich wird." Dies ist bei der Erlaubniseinholung im Sinne des Art. 17 Abs. 1 DSM-RL der Fall. Denn den Diensteanbietern ist es unmöglich, an jedem erdenklichen urheberrechtlich geschützten Inhalt individuelle Lizenzen zu erwerben auf den bloßen Verdacht einer eventuellen Nutzung hin. ${ }^{1308}$ Problematisch sind auch die inhaltliche und territoriale Fragmentierung der Rechte bei Verwertungsgesellschaften. ${ }^{1309}$ Die inhaltliche Fragmentierung zeigt sich insbesondere bei Filmwerken, bei denen regelmäßig mehrere Verwertungsgesellschaften für die verschiedenen schöpferischen Beiträge zuständig sind. ${ }^{1310}$ Pan-europäische Lizenzen sind außerdem immer noch die Ausnahme. ${ }^{1311}$ Es besteht daher ein großes praktisches Problem darin, flächendeckende Lizenzen für Nutzerhandlungen zu

1306 So auch zuvor der EuGH in EuGH GRUR 2012, S. 265 - Scarlet/SABAM; EuGH GRUR 2012, S. 382, 385 - SABAM/Netlog.

1307 Pravemann, Art. 17 der Richtlinie zum Urheberrecht im digitalen Binnenmarkt, GRUR 2019, S. 783, 786; Wandtke/Hauck, Art. 17 DSM-Richtlinie. Ein neues Haftungssystem im Urheberrecht, ZUM 2019, S. 627, 635.

1308 Volkmann, Art. 17 Urh-RL und die Upload-Filter: verschärfte Störerhaftung oder das Ende der Freiheit im Internet?, CR 2019, S. 376, 378.

1309 Dies., a.a.O., S. 379.

1310 Senftleben, Filterverpflichtungen nach der Reform des europäischen Urheberrechts - Das Ende der freien Netzkultur?, ZUM 2019, S. 369, 370.

1311 Ders., a.a.O., S. 370. 
erwerben, da hohe Transaktionskosten durch die Zersplitterung entstehen. ${ }^{1312}$ Mit einer erweiterten kollektiven Lizenzierung wird den Verwertungsgesellschaften auferlegt, Nutzungsverträge für alle Rechteinhaber einer Klasse von Werken auszuhandeln und abzuschließen, unabhängig davon, ob diese Rechteinhaber die Verwertungsgesellschaft zur Wahrnehmung ihrer Rechte ermächtigt haben. ${ }^{1313}$ Dazu müssten jedoch alle Mitgliedstaaten vom Art. 12 DSM-RL für die Fälle des Art. 17 DSM-RL Gebrauch machen, denn nur dann können die Verwertungsgesellschaften die Rechte mit Hilfe von Gegenseitigkeitsverträgen im Ergebnis EU-weit wahrnehmen. ${ }^{1314}$ Auch hilft die erweiterte kollektive Lizenzierung nicht mehr weiter, sobald einzelne Rechteinhaber von ihrem Opt-Out Gebrauch machen und ihre Werke von diesem Lizenzvergabesystem ausschließen gem. Art. 12 Abs. 3 lit. c DSM-RL.

Der nationale Gesetzgeber hat in der Umsetzung der DSM-RL zudem die Chance, die Ausnahme des Art. 17 Abs. 7 DSM-RL detailliert umzusetzen und ein weites Verständnis von Pastiche zu etablieren. Dies ist zwar ein autonomer Begriff des Unionsrechts, sodass er autonom vom Bundesrecht auszulegen ist. Wie oben bereits vorgeschlagen, kann man Pastiche so verstehen, dass künstlerische Umgestaltungen fremder Werke davon erfasst sind. ${ }^{1315}$ Sollten also digitale Phänomene von der Kunstfreiheit des Art. 13 GrCh bzw. Art. 5 Abs. 3 GG geschützt sein, können sie als Pastiche auch urheberrechtlich erlaubt sein. Dies ist aber regelmäßig die Ausnahme, da kommunikative Aneignungen im Digitalen häufig nicht von der Kunstfreiheit geschützt sind. ${ }^{1316}$ Eine weitergehende Regelung basierend auf einer Pastiche-Schranke, die partizipative, kreative Nutzungen ermöglicht, ist mit dem bisherigen Art. 5 InfoSoc-RL ausgeschlossen. ${ }^{1317}$ Ohne eine weitere Schrankenregelung für kommunikative Aneignungen von Bildern, die ebenfalls im Rahmen des Art. 17 DSM-RL beachtet werden müss-

1312 Kaesling, Die EU-Urheberrechtnovelle - der Untergang des Internets?, JZ 2019, S. 586, 589 .

1313 Dies., a.a.O., S. 589.

1314 Dreier, Die Schlacht ist geschlagen - ein Überblick. Zum Ergebnis des Copyright Package der EU-Kommission, GRUR 2019, S. 771, 777.

1315 S. dazu bereits S. 285 ff., 288.

1316 Vgl. dazu S. 206 f.

1317 S. dazu S. 289.; a.A.: Senftleben, Filterverpflichtungen nach der Reform des europäischen Urheberrechts - Das Ende der freien Netzkultur?, ZUM 2019, S. 369, 374, der eine Nutzbarmachung des Pastiche-Begriffs für nutzergenerierte Kommunikation vorschlägt. 
te, können Memes, GIFs und andere digtiale Phänomene nicht durch Filtertechnologien vor dem Blockieren und Löschen geschützt werden.

Zur Vorbeugung des Overblocking sollte überlegt werden, die Schadensersatzhaftung von Diensteanbietern für die Wiedergabe und öffentliche Zugänglichmachung von Werken auf grob fahrlässiges Verhalten zu beschränken, um sie von einer allgemeinen Gefährdungshaftung abzugrenzen. ${ }^{1318}$ Auch sollten die Beschwerde- und Rechtsbehelfsverfahren mit Blick auf die Bedeutung der dahinterstehenden Grundrechte ausgestaltet werden ${ }^{1319}$ und deren Durchsetzbarkeit sichern.

Insgesamt zeigen sich nur wenige Mechanismen in der Umsetzung des Art. 17 DSM-RL, um noch einen Freiraum für kommunikative Aneignungshandlungen zu belassen. Deutlich ist, dass die DSM-RL nicht von dem Gedanken eines kommunikativen und partizipativen Internets getragen ist. Es besteht damit die Gefahr, dass sie die bereits bestehende Divergenz von Recht und Rechtswirklichkeit in Bezug auf kommunikative Aneignungshandlungen ${ }^{1320}$ festigt und die Legitimationskrise des Urheberrechts verschärft. Auch hier wird das Bedürfnis nach einer neuen Schrankenregelung für kommunikative Aneignungshandlungen deutlich, die im Rahmen der DSM-RL beachtet werden müsste. Wenn solch kommunikative Aneignungshandlungen im nicht-kommerziellen Bereich einwilligungsfrei gestellt würden, könnte man Diensteanbieter auch verpflichten, diese Einwilligungsfreiheit in der Ausgestaltung ihrer Filtertechnologien zu beachten.

1318 Volkmann, Art. 17 Urh-RL und die Upload-Filter: verschärfte Störerhaftung oder das Ende der Freiheit im Internet?, CR 2019, S. 376, 384.

1319 Kaesling, Die EU-Urheberrechtnovelle - der Untergang des Internets?, JZ 2019, S. 586, 591.

1320 Genauer dazu S. 224 ff. 


\section{Zusammenfassende Thesen}

1. Der Begriff der Aneignung eignet sich als urheberrechtlicher Sammelbegriff für Nutzungen fremder Werke zu eigenen Zwecken.

Der Begriff der Aneignung soll der Vereinzelung der urheberrechtlichen Debatte zur Nutzung fremden Materials entgegengesetzt werden. Er umfasst als Sammelbegriff unterschiedliche kulturelle Praktiken. Eine Aneignung bezeichnet die direkte physische oder indirekte unkörperliche Übernahme fremden Materials zu eigenen Zwecken. Der Begriff ist umfassend zu verstehen und unabhängig vom Ausgangsmaterial, auch wenn in dieser Arbeit lediglich bildliche Aneignungen untersucht wurden. Eine Übernahme zu eigenen Zwecken liegt dann vor, wenn das fremde Material nicht lediglich zum Werkgenuss wiedergegeben wird, sondern eine Änderung des Zuweisungscharakter des Werkes vorliegt. Das ist der Fall, wenn das fremde Material produktiv für eigene Zwecke genutzt wird. Eine Selbstaneignung von früheren eigenen Werken ist nicht möglich, da dabei nicht der Zuweisungscharakter des Werkes geändert würde.

\section{Die Aneignung von Bildern hat sich im Digitalen zu einem Massenphänomen entwickelt.}

Die Aneignung ist seit jeher ein künstlerisches Mittel. Sie diente ursprünglich dazu, einem künstlerischen Vorbild nahe zu kommen, indem Ähnlichkeiten bewusst übernommen wurden oder durch das Kopieren künstlerische Techniken erlernt wurden. In der Moderne entwickelte sich die Kunst zur Nichtgegenständlichkeit und zur Selbstreflexion über das Wesen der Kunst. Aneignungen wurden genutzt, um eigene Reflexionen über das Original auszudrücken. Als Höhepunkt dieser Entwicklung ist schließlich die Appropriation Art anzusehen, bei der sich das komplette Werk eines anderen angeeignet wurde. Das Aneignen avancierte zu einer künstlerischen Strategie und die Aneignung selbst zu Kunst.

Mit der Digitalisierung entwickelte sich die Aneignung von einer vereinzelt durchgeführten künstlerischen Strategie mit theoretischem Fundament hin zu einem Mittel der Kommunikation. Die Kommunikation durch Aneignung stellt nun alltägliches Nutzerverhalten im Digitalen dar. Bilder werden in der Digitalkultur als Rohstoff genutzt: Sie werden ständig verändert, kombiniert und in neue Kontexte gesetzt. Durch diese pro- 
duktive und flexible Nutzungsmöglichkeit von Bildern eignen sie sich besonders gut als Kommunikationsmittel im Internet. Die Kommunikation verlagert sich also nicht nur ins Digitale, sondern auch das Kommunikationsverhalten ändert sich. Die Aneignung wird nun zu Zwecken der Kommunikation vorgenommen, sie wird zu einem kommunikativen Medium. Die Aneignung wird aus dem Kontext der Kunst gelöst und funktional als Werkzeug genutzt.

3. Die Entwicklung der Aneignung zum Massenphänomen spiegelt sich in der rechtlichen Bewertung von Aneignungshandlungen nicht wider, denn Aneignungen sind regelmäßig Verletzungen des Urheberrechts.

Aneignungen verletzten häufig sowohl Urheberpersönlichkeitsrechte als auch Verwertungsrechte. Die Urhebernennung gem. $\$ 13$ UrhG ist bei der Appropriation Art selten verletzt, jedoch häufig bei kommunikativen Aneignungen, da der ursprüngliche Urheber hier meist nicht genannt wird. Eine Verletzung der Urheberpersönlichkeitsrechte der $\$ 13$ und $\$ 14$ UrhG liegt jedoch dann nicht vor, wenn eine Nutzung über eine Schrankenregelung gerechtfertigt ist, also in Fällen der Aneignung eine freie Benutzung gem. $\$ 24$ UrhG vorliegt. Dies ist bei der Appropriation Art fast immer, bei kommunikativen Aneignungen fast nie der Fall.

Das Vervielfältigungsrecht gem. $\$ 16$ UrhG ist durch künstlerische und durch kommunikative Aneignungen üblicherweise verletzt, da beide ihre angeeigneten Vorlagen übernehmen. Das Recht zur öffentlichen Zugänglichmachung gem. $\$ 19$ a UrhG ist bei kommunikativen Aneignungen häufig verletzt. Mangels neuen Publikums stellen zwar Frame-Links zum Teilen in sozialen Netzwerken bei mit Erlaubnis des Urhebers ins Internet gestellten Inhalten keine Verletzungshandlung dar. Anders sieht es aus, wenn die Erlaubnis des Urhebers nie vorlag oder wieder entzogen wurde oder wenn technische Schutzmaßnahmen umgangen wurden. Diese Erlaubnis des Urhebers fehlt häufig. Der erneute Upload eines urheberrechtlich geschützten Werkes zur digitalen Kommunikation stellt in jedem Fall eine öffentliche Wiedergabe dar. Dies betrifft insbesondere Bildmontagen, aber auch Museumselfies, GIFs, Memes und das Teilen in sozialen Netzwerken.

4. Der fehlende Schutz der Idee im Urheberrecht steht dem urheberrechtlichen Schutz der Appropriation Art nicht entgegen.

In der Literatur werden der Grundsatz der Schutzlosigkeit der Idee und der Grundsatz der Dichotomie von Inhalt und Form häufig vermischt. 
Nach hier vertretener Ansicht ist die Unterscheidung von schutzloser Idee und bereits schutzfähigem Inhalt anhand der Konkretisierung des Werkes festzumachen, die wiederum abhängig vom Gestaltungsspielraum ist, der bei der Konkretisierung bestehen kann. Der Grundsatz der Dichotomie von Inhalt und Form ist nicht mehr sinnvoll und sollte aufgegeben werden, da der Inhalt des Werkes auch heute bereits häufig als Schutzgegenstand anerkannt ist, insbesondere bei literarischen Werken. Bei abstrakten Kunstwerken ist die Verbindung von äußerer Form und Inhalt des Werkes ebenfalls besonders stark, da die Form kein Korrelat in der tatsächlichen Welt hat und damit die Form selbst auch immer gleichzeitig Inhalt des Werkes ist. Für die Schutzfähigkeit der Appropriation Art kommt es daher nur darauf an, dass sich die Idee bereits ausreichend im Inhalt des Werkes konkretisiert hat: Es muss also ausreichend Gestaltungsspielraum verbleiben, um die Idee auch durch andere Möglichkeiten auszuführen. Dies ist bei der Appropriation Art regelmäßig der Fall.

5. Mit einer kunstspezifischen Auslegung des $\$ 24$ UrbG ist eine Rechtfertigung künstlerischer Aneignungen denkbar, nicht allerdings eine Rechtfertigung kommunikativer Aneignungen.

Neben der Verblassensprüfung hat sich auch eine Prüfung des inneren Abstandes bei $\mathbb{2} 24$ Abs. 1 UrhG durchgesetzt. Hierbei muss die Kunstfreiheit gem. Art. 5 Abs. 3 GG ausreichend berücksichtigt werden und entsprechend zur Geltung kommen. Daher können Eigentumsinteressen des Urhebers aus Gründen der Kunstfreiheit zurückgedrängt werden. Appropriation Art ist nach allen Kunstbegriffen als Kunst im Sinne des Art. 5 Abs. 3 GG zu verstehen. Regelmäßig überwiegt die Kunstfreiheit die Interessen des Urhebers, da die Appropriation Art nur umgesetzt werden kann, wenn sie 1:1 Werke anderer übernimmt. Die Appropriation Art kann ihre künstlerische Zielsetzung nur erreichen, wenn sie das angeeignete Werk auch in seinem vollen Umfang nutzen darf.

Kommunikative Aneignungen wie Memes oder GIFs sind nur in seltenen Fällen von der Kunstfreiheit geschützt, da sie zumeist nicht als Ausdruck der Persönlichkeit des Kunstschaffenden angefertigt werden und sie auch nicht ausreichend interpretationsfähig sind, sodass sie zu einem Nachsinnen über ihren Sinn und ihre Aussagen anregen würden. Vielmehr sollen sie von möglichst vielen Kommunikationspartner schnell verstanden werden, denn diese Bilder haben sich aufgrund ihrer Effizienz als Kommunikationsmedium durchgesetzt. 
6. Zur Verhinderung der rechtsmissbräuchlichen Nutzung kann die kunstspezifische Auslegung des $\$ 24$ UrhG dann nicht greifen, wenn eine Substitutionskonkurrenz zum Original besteht.

Eine kunstspezifische Auslegung des $\mathbb{2 4}$ Abs. 1 UrhG birgt die Gefahr, dass die Abgrenzung zu Nachahmungen, die lediglich den Wert des Originals ausnutzen wollen und keinen eigenständigen Mehrwert schaffen, schwer zu ziehen ist. Rein nach der äußeren Form wird man Aneignungen nicht von solchen ausnutzenden Nachahmungen auseinanderhalten können, da Aneignungen ebenfalls ein komplettes Werk äußerlich nutzen und dennoch inhaltlich etwas anderes damit aussagen können als das ursprüngliche Werk. In der Metall auf Metall-Entscheidung stellt das BVerfG klar, dass die Kunstfreiheit nur dann im Rahmen der Abwägung mit den Urheberrechten überwiegt, wenn dem Werk keine Konkurrenz gemacht wird und dem Urheber keine Nachteile zugefügt werden. Diese Konkurrenz soll im Rahmen der Interessenabwägung der praktischen Konkordanz vorgenommen werden und als Nachfragesubstituierbarkeit verstanden werden. Das heißt, es kommt darauf an, ob das neue Werk das Original auf dem Markt ersetzen kann. Ist dies der Fall, dann legt das eine Zielsetzung der Aneignung nahe, die missbräuchlich ist und Investitionen sparen will. Wenn der Markt der Aneignung jedoch ein anderer ist, tritt das Werk der Appropriation Art nicht in Konkurrenz, sodass von einer missbräuchlichen Nutzung des Originalwerkes nicht ausgegangen werden kann. In der Regel führen Werke der Appropriation Art nicht zu einer Nachfragesubstitution, da sie das Original meist leicht ändern und an ihrem Titel oder der Signatur zeigen, dass es sich nicht um eine Ersetzung des Originals handeln soll, und deshalb ein Werk der Appropriation Art auf dem Markt nicht als Ersatz für das angeeignete Werk angesehen wird.

\section{Obne eine rechtliche Freistellung kommunikativer Aneignungen verschärft} sich die Legitimationskrise des Urheberrechts.

Das Auseinanderfallen von Recht und Rechtswirklichkeit begründet und verschärft die schon oft ausgemachte Legitimationskrise des Urheberrechts. Kommunikative Aneignungen sind zwar ein Massenphänomen, urheberrechtlich aber zumeist nicht zulässig. Das Urheberrecht trägt damit der Realität der Kommunikation keine Rechnung. Die Legitimationskrise des Urheberrechts findet ihren Grund in der Diskrepanz zwischen einem Rechtssystem, das für das analoge Zeitalter entwickelt wurde, und einer Rechtswirklichkeit des digitalen Zeitalters. Wenn das Urheberrecht aber nicht mehr die gesellschaftliche Realität widerspiegelt, dann wird es nicht 
mehr vom gesellschaftlichen Konsens getragen. Dies gefährdet die Durchsetzbarkeit des Urheberrechts.

\section{Das Urheberrecht kann als Kommunikationsrecht verstanden werden und da- durch Aneignungen privilegieren.}

Die Auslegung und Anwendung des Urheberrechts sind in hohem Maße davon abhängig, welcher moralischen Konzeption des Urheberrechts gefolgt wird. Mit verschiedenen Strategien zur Auslegung des Urheberrechts kann unterschiedlich viel Freiraum für einzelne Akteure des Urheberrechts geschaffen werden. Um Freiräume für Handlungen zu ermöglichen, kommen der Fokus auf den individuellen Urheber, die Privilegierung des Künstlerischen und ein kommunikativer Ansatz in Betracht. Ein kommunikatives Verständnis von Urheberrecht zeigt sich als besonders geeignet, das geänderte Kommunikationsverhalten mit Bildern im Digitalen rechtlich widerzuspiegeln. Dies gelingt, indem das Urheberrecht als Kommunikationsrecht verstanden wird und damit auch die Rolle des Nutzers als Kommunikationsempfänger an Bedeutung gewinnt - er wird als ein ebenbürtiger Adressat des Urheberrechtsschutzes verstanden. Dies kann digitalen Aneignungen rechtlichen Freiraum schaffen und so die Effektivität von Urheberrechtsschutz steigern.

9. Die Auslegungen des geltenden Rechts reichen nicht aus, um kommunikativen Aneignungen den notwendigen rechtlichen Freiraum zu schaffen.

Das kommunikative Verständnis von Urheberrecht kann de lege lata nicht ausreichend berücksichtigt werden. Eine verfassungskonforme Auslegung des $\mathbb{2} 2$ Abs. 1 UrhG anhand der Meinungsfreiheit gem. Art. 5 Abs. 1 GG ist zwar grundsätzlich möglich. Sie kann Aneignungen jedoch nur in bestimmten Einzelfällen privilegieren, da die Meinungsfreiheit aufgrund ihres Gesetzesvorbehalt leichter einzuschränken ist. Auch eine Einwilligungslösung vermag digitalen Aneignungen nicht mehr rechtlichen Freiraum zu verschaffen. Eine Ausweitung der Vorschaubilder-Rechtsprechung auf kommunikative Aneignungen bietet sich deshalb nicht an, weil diese nicht ähnlich technisch zu verhindern sind wie Vorschaubilder oder Frame-Links. Überdies haben Aneignungen nicht bloß akzessorischen Charakter, es wird gerade mehr als eine bloße Werkwiedergabe vorgenommen. Letztlich würde eine Einwilligungslösung auf eine Erschöpfung des Rechts zur öffentlichen Zugänglichmachung hinauslaufen, die nicht gewollt ist. 
10. Eine Neugestaltung des $\$ 24$ UrhG im Sinne einer Umsetzung der PasticheSchranke des Art. 5 Abs. 3 lit. $k$ InfoSoc-RL könnte nur künstlerische Aneignungen privilegieren, jedoch nicht kommunikative.

Nach dem EuGH Pelham/Hütter-Urteil ist $\$ 24$ UrhG als unionsrechtswidrig anzusehen. Es wird daher eine Neuregelung der Schranken notwendig sein, um Art. 5 Abs. 3 lit. k InfoSoc-RL ins deutsche Recht umzusetzen, der eine Ausnahme für Karikatur, Parodie und Pastiche vorsieht. Der bisher wenig beachtete Begriff des Pastiche zeichnet sich ebenso wie die anderen Begriffe dieser Norm durch seinen starken Referenzcharakter zu anderen Werken aus. Pastiche wird hier als künstlerische Umgestaltung vorbestehenden Materials verstanden. Nur das Kriterium der Kunst schafft die notwendige Begriffsklarheit, indem auf das abgestellt wird, was durch die Kunstfreiheit des Art. 5 Abs. 3 GG und Art. 13 GrCh geschützt ist. Selbst wenn also der Begriff des Pastiche in Zukunft im deutschen Recht nutzbar gemacht wird, werden lediglich künstlerische Aneignungen, nicht aber kommunikative, darunter zu fassen sein. Die Umsetzung einer PasticheSchranke in das deutsche Urheberrechtsgesetz folgt damit der rechtlichen Einordnung, zu der auch $\mathbb{2 4}$ Abs. 1 UrhG bisher gekommen ist.

11. Eine neue Schrankenregelung zur Freistellung nicht-kommerzieller Aneignungen erweist sich insbesondere für digitale kommunikative Aneignungen als die effizienteste Lösung.

Es wird vorgeschlagen, eine vergütungsfreie Schrankenregelung für den Bildgebrauch zu eigenen Zwecken im nicht-kommerziellen Bereich einzuführen. Für den kommerziellen Gebrauch von Bildern zu eigenen Zwecken wird eine gesetzliche Lizenz mit Vergütungspflicht vorgeschlagen. Mit dem Kriterium „nicht-kommerziell“ ist gemeint, dass ohne Gewinnerzielungsabsicht gehandelt wird. In seinen Entscheidungen zur öffentlichen Wiedergabe hat der EuGH die Unterscheidung anhand der Gewinnerzielungsabsicht $\mathrm{zu}$ einer Leitunterscheidung für die digitale Nutzung von Werken bestimmt, weshalb sich dieses Kriterium für eine einheitliche Handhabung zur Nutzung fremden Materials anbietet.

Europarechtlich besteht zwar kein Spielraum für die Einführung einer solchen neuen Schrankenregelung, da Art. 5 InfoSoc-RL die Ausnahmen zum Vervielfältigungsrecht und zum Recht der öffentlichen Zugänglichmachung abschließend regeln. Diese Schrankenregelung müsste daher auch auf EU-Ebene eingeführt und Art. 5 InfoSoc-RL entsprechend erweitert werden. 
12. Art. 17 DSM-RL kann nicht so ausgelegt werden, dass noch Freiraum für kommunikative Aneignungen verbleibt, und wird dazu führen, die Legitimationskrise des Urheberrechts zu verschärfen.

Art. 17 DSM-RL schreibt zwar Upload-Filter nicht vor, setzt diese aber als Stand der Technik voraus, damit Diensteanbieter sich von ihrer Haftung exkulpieren können. Dies birgt die Gefahr des Overblocking von Inhalten, die an sich urheberrechtlich erlaubt sind, damit Diensteanbieter sich nicht der Gefahr der Haftung aussetzen müssen. Ein solches Overblocking ist insbesondere bei Aneignungen zu erwarten, da deren rechtliche Einschätzung vollständig von der Einzelfallabwägung grundrechtlicher Interessen abhängt. Die Pastiche-Ausnahme des Art. 17 Abs. 7 DSM-RL wird zwar in der Literatur häufig angeführt, um Schrankenregelungen des Urheberrechts auch durch die Diensteanbieter gewahrt zu wissen. Eine solch weite Auslegung des Begriffs Pastiche, dass auch Memes und GIFs darunter zu fassen seien, ist jedoch nicht möglich. Vielmehr ist Pastiche als eine künstlerische Übernahme zu verstehen.

Deutlich ist, dass die DSM-RL nicht von dem Gedanken eines kommunikativen und partizipativen Internets getragen ist und damit die Divergenz von Recht und Rechtswirklichkeit in Bezug auf kommunikative Aneignungshandlungen festigt. Nur mithilfe einer neuen Schrankenregelung für kommunikative Aneignungen, wie oben vorgeschlagen, könnte man Diensteanbieter verpflichten, diese Schrankenregelung auch in der Ausgestaltung ihrer Upload-Filter zu beachten. 


\section{Literaturverzeichnis}

Ablberg, Hartwig/ Götting, Horst-Peter, Beck'scher Online-Kommentar Urheberrecht, begründet von Möhring/Nicolini, 26. Edition, München 2019.

(zit.: BeckOK UrhG/Bearbeiter)

Almeroth, Thomas, Kunst- und Antiquitätenfälschung, München 1987.

Ansley, Frances Lee, Stirring the Ashes. Race, Class and the Future of Civil Rights Scholarship, Cornell Law Review 74 (1989), S. 993-1077.

Aragon, Louis, The Challenge to Painting [1930], in: David Evans (Hrsg.), Appropriation. Documents of Contemporary Art, London und Cambridge 2009, S. 27-29.

Aristoteles, Poetik, gr.-dt. übersetzt von Manfred Fuhrmann, 3. Auflage, Leipzig 1972.

Asmuth, Christoph, Bilder über Bilder. Bilder ohne Bilder. Eine neue Theorie der Bildlichkeit, Darmstadt 2011.

Augustinus, Aurelius, Dreiundachtzig verschiedene Fragen. De diversis quaestionibus octoginta tribus, lat.-dt. übersetzt von C.J. Perl, Paderborn 1972.

Barbanera, Marcello, Original und Kopie. Bedeutungs- und Wertewandel eines intellektuellen Begriffspaares seit dem 18. Jahrhundert in der Klassischen Archäologie, in: Akzidenzen 17. Flugblätter der Winckelmann-Gesellschaft, Tübingen 2006.

Barthes, Roland, Der Tod des Autors [1967], in: Fotis Jannidis (Hrsg.), Texte zur Theorie der Autorschaft, Stuttgart 2012, S. 185-198.

Baudrillard, Jean, The Precession of Simulacra [1981], in: David Evans (Hrsg.), Appropriation. Documents of Contemporary Art, London und Cambridge 2009, S. 80-81.

Bauer, Barbara, aemulatio, in: Gert Ueding (Hrsg.), Historisches Wörterbuch der Rhetorik, Tübingen 1992, S. 141-187.

Bauer, Christian Alexander, User-generated Content. Urheberrechtliche Zulässigkeit nutzergenerierter Medieninhalte, Berlin 2011.

Becker, Maximilian, Von der Freiheit, rechtswidrig handeln zu können. „UploadFilter" und technische Rechtsdurchsetzung, ZUM 2019, S. 636-648.

Belting, Hans, Bild-Anthropologie. Entwürfe für eine Bildwissenschaft, 4. Auflage, Paderborn 2011.

Benjamin, Walter, Das Kunstwerk im Zeitalter seiner technischen Reproduzierbarkeit [1936], 4. Auflage, Berlin 2015.

Bentham, Jeremy, An Introduction to the Principles of Morals and Legislation [1789], Oxford 1996.

Berking, Christina, Die Unterscheidung von Inhalt und Form im Urheberrecht, Baden-Baden 2002. 
Betzler, Monika/ Cojocaru, Maria-Daria/ Nida-Rümelin, Julian, Ästhetik und Kunstphilosophie in Einzeldarstellungen. Von der Antike bis zur Gegenwart, Stuttgart 2002.

Bidlo, Mike, Im Gespräch mit Andrea Juno, in: Thomas Deecke (Hrsg.), Originale echt/falsch. Nachahmung, Kopie, Zitat, Aneignung, Fälschung in der Gegenwartskunst, Ausstellungskatalog des Neuen Museum Weserburg, Bremen 1999, S. 145-149.

Black, Max, Wie stellen Bilder dar?, in: Ernst H. Gombrich/ Julian Hochberg/ Max Black (Hrsg.), Kunst, Wahrnehmung, Wirklichkeit, Frankfurt am Main 1977, S. 115-154.

Blunck, Lars, Wann ist ein Original?, in: Julian Nida-Rümelin/ Jakob Steinbrenner (Hrsg.), Kunst und Philosophie. Original und Fälschung, Osterfildern 2011, S. 9-29.

Boehm, Gottfried, Ein Briefwechsel, in: Marius Rimmele/ Klaus Sachs-Hombach/ Bernd Stiegler (Hrsg.), Bildwissenschaft und Visual Culture, Berlin 2014, S. 19-40.

Boehm, Gottfried, Jenseits der Sprache? Anmerkungen zur Logik der Bilder, in: Marius Rimmele/ Klaus Sachs-Hombach/ Bernd Stiegler (Hrsg.), Bildwissenschaft und Visual Culture, Berlin 2014, S. 67-82.

Boehm, Gottfried, Die Wiederkehr der Bilder, in: Gottfried Boehm (Hrsg.), Was ist ein Bild?, München 1994, S. 11-38.

Bosse, Heinrich, Autorschaft ist Werkherrschaft. Über die Entstehung des Urheberrechts aus dem Geiste der Goethezeit, Paderborn 2014.

Bredekamp, Horst, Das Bild als Leitbild. Gedanken zur Überwindung des Anikonismus, in: Ute Hoffmann/ Bernward Joerges/ Ingrid Severin (Hrsg.), LogIcons. Bilder zwischen Theorie und Anschauung, Berlin 1997, S. 225-245.

Breithut, Jörg, Bei Wahlen versteht Twitter keinen Spaß, Spiegel Online vom 9.5.2019, https://www.spiegel.de/netzwelt/netzpolitik/twitter-und-seine-accountsperren-bei-wahlwitzen-hoert-der-spass-auf-a-1266633.html, Datum des Zugriffs: 15.1.2020.

Brinkmann, Franziska, Formen der Kopie. Von der Fälschung bis zur Hommage. Eine Begriffsbestimmung und ihre Grenzen, in: Thomas Dreier/ Oliver Jehle (Hrsg.), Original - Kopie - Fälschung, Baden-Baden 2020, S. 57-104.

Brunn, Inka Frederike, Cache me if you can. Verfassungsrechtliche Aspekte der urheberrechtlichen Einordnung von Suchmaschinen, Baden-Baden 2013.

Bruns, Andreas, What is Wrong with Copying from Other Cultures?, Jahrbuch für Recht und Ethik Band 26 (2018), S. 25-39.

Bucknell, Alice, What Memes Owe to Art History, Artsy vom 30.5.2017, https://ww w.artsy.net/article/artsy-editorial-memes-owe-art-history, Datum des Zugriffs: 15.1.2020.

Bullinger, Winfried/ Garbers-von Boehm, Katharina, Der Blick ist frei. Nachgestellte Fotos aus urheberrechtlicher Sicht, GRUR 2008, S. 24-30.

Burda, Hubert, In media res. Zehn Kapitel zum Iconic Turn, München u.a. 2010. 
Cennini, Cennino, Das Buch von der Kunst oder Il Libro dell'Arte [1871], Kiel 2015.

Chakraborty, Martin, Das Rechtsinstitut der freien Benutzung im Urheberrecht, Baden-Baden 1997.

Colman David, Interview mit Jeff Koons, Interview Magazine vom 23.11.2008, https://www.interviewmagazine.com/film/jeff-koons, Datum des Zugriffs: 15.1.2020.

Cords, Suzanne, Der „Museum Selfie Day“ sorgt für Besucherandrang, Deutsche Welle vom 17.1.2018, http://www.dw.com/de/der-museum-selfie-day-sorgt-für-b esucherandrang/a-42176075, Datum des Zugriffs: 15.1.2020.

Crimp, Douglas, Pictures [1979], in: David Evans (Hrsg.), Appropriation. Documents of Contemporary Art, London und Cambridge 2009, S. 76-80.

Czernik, Ilja, Die Collage in der urheberrechtlichen Auseinandersetzung zwischen Kunstfreiheit und Schutz des geistigen Eigentums, Berlin 2008.

Dachwitz, Ingo/ Fanta, Alexander, Not Heidis Girl: Wie Youtube eine Kampagne gegen Sexismus ausbremste, Netzpolitik.org vom 6.3.2018, https://netzpolitik.org/ 2018/not-heidis-girl-wie-youtube-eine-kampagne-gegen-sexismus-ausbremste, Datum des Zugriffs: 15.1.2020.

Dawkins, Richard, The Selfish Gene [1976], Oxford 2006.

De Boor, Hans Otto, Urheberrecht und Verlagsrecht. Ein Beitrag zur Theorie der ausschließlichen Rechte, Stuttgart 1917.

De la Rosa, Sybille, Aneignung und interkulturelle Repräsentation. Grundlagen einer kritischen Theorie politischer Kommunikation, Wiesbaden 2012.

De Vries, Gerd, Gerd de Vries im Interview mit Lena Maculan, in: Lena Maculan, Udo Kittelmann (Hrsg.), Elaine Sturtevant. Catalogue raisonné 1964-2004, Ostfildern 2004, S. 23-31.

Decker, Bernhard, Dürer. Konstruktion eines Vorbildes, in: Herbert Beck (Hrsg.), Dürers Verwandlung in der Skulptur zwischen Renaissance und Barock, Ausstellungskatalog des Liebighaus, Frankfurt am Main 1981, S. 397-431.

Diener, Andrea, 90.000 Dollar für ein Instagram-Foto, Frankfurter Allgemeine Zeitung vom 26.5.2015, http://www.faz.net/aktuell/feuilleton/kunst/kuenstler-richa rd-prince-verkauft-instagram-fotos-13612527.html, Datum des Zugriffs: 15.1.2020.

Dirksen, Jens, Der Fälscher Beltracchi als Filou und Genie, Der Westen vom 26.1.2014, https://www.derwesten.de/kultur/der-faelscher-beltracchi-als-filou-un d-genie-id8917443.html, Datum des Zugriffs: 15.1.2020.

Dobusch, Leonhard, EuGH schränkt Linkfreiheit ein: Kommerzielle Nutzer können schon mit einem Link das Urheberrecht verletzen, Netzpolitik.org vom 8.9.2016, https://netzpolitik.org/2016/eugh-schraenkt-linkfreiheit-ein-kommerzi elle-nutzer-koennen-schon-mit-einem-link-das-urheberrecht-verletzen, Datum des Zugriffs: 15.1.2020.

Dobusch, Leonhard, Digitale Remixkultur, in: Dominik Landwehr (Hrsg.) Public Domain. Edition Digital Culture 3, Basel 2015, S. 82-91. 
Dobusch, Leonhard, Urheberrecht auf Memes? Getty Images, der „Socially Awkward Penguin“ und eine Lösung aus dem Markenrecht, Netzpolitik.org vom 4.9.2015, https://netzpolitik.org/2015/urheberrecht-auf-memes-getty-images-der-s ocially-awkward-penguin-und-eine-loesung-aus-dem-markenrecht, Datum des Zugriffs: 15.1.2020.

Dobusch, Leonhard, Generation Remix. Popkultur und Kunst im rechtsfreien Raum?, in: Valie Djordjevic/ Leonhard Dobusch (Hrsg.), Generation Remix. Zwischen Popkultur und Kunst, Berlin 2014, S. 9-14.

Doehmer, Klaus, Zur Soziologie der Kunstfälschung, Zeitschrift für Ästhetik und allgemeine Kunstwissenschaft 1978, S. 76-96.

Dreier, Thomas, Bild und Recht. Versuch einer programmatischen Grundlegung, Baden-Baden 2019.

Dreier, Thomas, Die Schlacht ist geschlagen - ein Überblick. Zum Ergebnis des Copyright Package der EU-Kommission, GRUR 2019, S. 771-779.

Dreier, Thomas, Grundrechte und die Schranken des Urheberrechts. Anmerkungen zu EuGH „Funke Medien NRW“ und „Spiegel Online“, GRUR 2019, S. 1003-1008.

Dreier, Thomas, Bilder im Zeitalter ihrer vernetzten Kommunizierbarkeit, ZGE 2017, S. 135-148.

Dreier, Thomas, Bilder und die Werkzeuge des Rechts. Normative Bilderregeln und Visual Images, in: Matthias Weller/Nicolai Kemle (Hrsg.), Kultur im Recht. Recht als Kultur, Baden-Baden 2016, S. 113-143.

Dreier, Thomas, Vom urheberrechtlichen Dürfen und den technischen sowie vertraglichen Grenzen des Könnens, in: Wolfgang Büscher/ Willi Erdmann/ Maximilian Haedicke/ Helmut Köhler/ Michael Loschelder (Hrsg.), Festschrift für Joachim Bornkamm zum 65. Geburtstag, München 2014, S. 749-760. (zit.: FS Bornkamm)

Dreier, Thomas, Urheberrecht und moralische Rechtfertigung. Besprechung, GRUR 2007, S. 128-130.

Dreier, Thomas/ Leistner, Matthias, Urheberrecht im Internet: die Forschungsherausforderungen, GRUR 2013, S. 881-897.

Dreier, Thomas/ Schulze, Gernot, Urheberrechtsgesetz Kommentar, 6. Auflage, München 2018.

(zit.: Dreier/Schulze/Bearbeiter)

Dreyer, Gundal Kotthoff, Jost/ Meckel, Astrid/ Hentsch, Christian-Henner, Urheberrecht, Heidelberger Kommentar, 4. Auflage, Heidelberg 2018.

(zit.: Dreyer/Kotthoff/Meckel/Hentsch/Bearbeiter)

Duchamp, Marcel, Apropos of Ready Mades [1961], in: David Evans (Hrsg.) Appropriation. Documents of Contemporary Art, London und Cambridge 2009, S. 40.

Eidenmüller, Horst, Effizienz als Rechtsprinzip. Möglichkeiten und Grenzen der ökonomischen Analyse des Rechts, 4. Auflage, Tübingen 2015.

Elster, Alexander, Idee und Formgebung, UFITA Band 8 (1935), S. 44-57. 
Elster, Alexander, Gewerblicher Rechtsschutz, umfassend Urheber- und Verlagsrecht, Patent- und Musterschutzrecht, Warenzeichenrecht und Wettbewerbsrecht, Berlin 1921.

Epping, Volker/ Hillgruber, Christian (Hrsg.), Beck'scher Online-Kommentar Grundgesetz, 41. Edition, München 2019. (zit.: BeckOK GG/Bearbeiter)

Esser, Josef, Vorverständnis und Methodenwahl in der Rechtsfindung. Rationalitätsgarantien der richterlichen Entscheidungspraxis, Frankfurt am Main 1970.

Evans, David, Seven Types of Appropriation, in: ders. (Hrsg.), Appropriation. Documents of Contemporary Art, London und Cambridge 2009, S. 12-23.

Fabl, Constantin, Die Bilder-und Nachrichtensuche im Internet. Urheber-, persönlichkeits- und wettbewerbsrechtliche Aspekte, Göttingen 2010.

Fechner, Frank, Geistiges Eigentum und Verfassung. Schöpferische Leistungen unter dem Schutz des Grundgesetzes, Tübingen 1999.

Feudner, Bernd, Die Möglichkeiten eines Ideenschutzes nach deutschem und englischem Recht, Frankfurt am Main 1966.

Fichte, Johann Gottlieb, Beitrag zur Berichtigung der Urtheile des Publicums über die französische Revolution [1793], in: Hans Schulz/Reinhard Strecker (Hrsg.), Werke. Erster Ergänzungsband, Staatsphilosophische Schriften, Leipzig 1919.

Fichte, Johann Gottlieb, Beweis der Unrechtmäßigkeit des Büchernachdrucks [1793], Nachdruck in: UFITA Band 106 (1987), 155-172.

Fischer, Veronika, Digitale Kunst und freie Benutzung. Systematisierung und Flexibilisierung, Baden-Baden 2018.

Fiscor, Mihály, The Law of Copyright and the Internet: The 1996 WIPO Treaties, their Interpretation and Implementation, New York 2002.

Fisher, William W. III., Property and Contract on the Internet, Chicago-Kent Law Review Band 73 (1998), Buffalo, NY, S. 1203-1256.

Foucault, Michel, Was ist ein Autor? [1969], in: Fotis Jannidis (Hrsg.), Texte zur Theorie der Autorschaft, Stuttgart 2012, S. 198-233.

Franz, Michael, Aneignung, in: Karlheinz Barck/ Martin Fontius/ Dieter Schlenstedt/ Burkhart Steinwachs/ Friedrich Wolfzettel (Hrsg.), Ästhetische Grundbegriffe. Historisches Wörterbuch in sieben Bänden, Band 1: Absenz-Darstellung, Stuttgart 2010, S. 153-193.

Fritz, Nicole, Comeback. Kunsthistorische Renaissancen in der Gegenwart, in: Kunsthalle Tübingen/Nicole Fritz (Hrsg.), Comeback. Kunsthistorische Renaissancen, Ausstellungskatalog der Kunsthalle Tübingen, Bielefeld und Berlin 2019, S. 11-19.

Fröhlich, Michael, Zentrale Institutionen des deutschen Urheberrechts und des französischen Droit d'auteur auf dem Prüfstand der elektronischen Netzwerke, Frankfurt am Main 2001.

Fromm, Friedrich/ Nordemann, Wilhelm, Urheberrecht, hrsg. von Axel Nordemann/ Jan Bernd Nordemann/ Christian Czychowski, 12. Auflage, Stuttgart 2018. (zit.: Fromm/Nordemann/Bearbeiter) 
Fuchs, Christine, Avantgarde und erweiterter Kunstbegriff. Eine Aktualisierung des Kunst- und Werkbegriffs im Verfassungs- und Urheberrecht, Baden-Baden 2000.

Gabler, Mariella, Die urheberrechtliche Drittnutzung zwischen Vervielfältigung, Bearbeitung und freier Benutzung, Baden-Baden 2018.

Ganz, David/ Thürlemann, Felix, Singular und Plural der Bilder, in: Ganz/Thürlemann (Hrsg.), Das Bild im Plural. Mehrteilige Bildformen zwischen Mittelalter und Gegenwart, Berlin 2010, S. 7-38.

Gebauer, Gunter/ Wulf, Christoph, Mimesis. Kultur, Kunst, Gesellschaft, 2. Auflage, Hamburg 1998.

Geiger, Christophe, Die Schranken des Urheberrechts als Instrumente der Innovationsförderung. Freie Gedanken zur Ausschließlichkeit im Urheberrecht, GRUR Int. 2008, S. 459-468.

Geiger, Christophe, Die Schranken des Urheberrechts im Lichte der Grundrechte. Zur Rechtsnatur der Beschränkungen des Urheberrechts, in: Reto M. Hilty/ Alexander Peukert (Hrsg.), Interessenausgleich im Urheberrecht, Baden-Baden 2004, S. 143-158.

Gelke, Erik, Mashups im Urheberrecht, Baden-Baden 2013.

Gerpott, Torsten J., Artikel 17 der neuen EU-Urheberrechtsrichtlinie: Fluch oder Segen?. Einordnung des Streits um „Upload-Filter“ auf Online-Sharing-Plattformen, MMR 2019, S. 420-426.

Gilbert, Annette, Wiederaufgelegt. Zur Appropriation von Texten und Büchern in Büchern, Bielefeld 2012.

Godfrey, Tony, Konzeptuelle Kunst, Berlin 2005.

Goldsmith, Kenneth, Uncreative Writing. Sprachmanagement im digitalen Zeitalter, Berlin 2017.

Goodman, Nelson, Sprachen der Kunst. Entwurf einer Symboltheorie [1973], 8. Auflage, Frankfurt am Main 2015.

Gordon, Wendy J., A Property Right in Self-Expression. Equality and Individualism in the Natural Law of Intellectual Property, The Yale Law Journal Bd. 102 (1993), New Haven, S. 1533-1609.

Großmann, Rolf, Die Geburt des Pop aus dem Geist der phonographischen Reproduktion, in: Christian Bielefeldt/Udo Dahmen/ders. (Hrsg.), PopMusicology. Perspektiven der Popmusikwissenschaft, Bielefeld 2008, S. 119-134.

Grünberger, Michael, Einheit und Vielfalt im Recht der öffentlichen Wiedergabe. Zugleich Besprechung von EuGH „Reha Training/GEMA“ und BGH „Königshof“, GRUR 2016, S. 977-983.

Grünberger, Michael, Bedarf es einer Harmonisierung der Verwertungsrechte und Schranken? Ein Beitrag zur Entwicklung dogmatischer Bausteine eines umweltsensiblen Urheberrechts, ZUM 2015, S. 273-290.

Grünewald-Schukalla, Lorenz/ Fischer, Georg, Überlegungen zu einer textuellen Definition von Internet-Memes, kommunikation @ gesellschaft 19 (2018), Beitrag 2. 
Haberstumpf, Helmut, Nichtgegenständliche Werke im Urheberrecht, in: Thomas Dreier/ Karl-Nikolaus Pfeifer/ Louisa Specht (Hrsg.), Anwalt des Urheberrechts. Festschrift für Gernot Schulze zum 70. Geburtstag, München 2017, S. 3-12. (zit.: FS Schulze)

Haberstumpf, Helmu, Die Paradoxien des Werkbegriffs. Können fiktionale Figuren urheberrechtlich geschützt sein?, ZGE 2012, S. 284-320.

Haberstumpf, Helmu, Anmerkungen zu BGH, Urteil vom 1. Dezember 2010 - I ZR 12/08 - Perlentaucher, ZUM 2011, S. 158-161.

Haberstumpf, Helmu, Handbuch des Urheberrechts, 2. Auflage, Neuwied 2000.

Haberstumpf, Helmu, Zur Individualität wissenschaftlicher Sprachwerke, Freiburg 1982.

Haedicke, Maximilian, Beschränkung der Parodiefreiheit durch europäisches Urheberrecht?, GRUR Int. 2015, S. 664-670.

Han, Byung-Chul, Im Schwarm. Ansichten des Digitalen, 4. Auflage, Berlin 2017.

Hansen, Gerd, Warum Urheberrecht? Die Rechtfertigung des Urheberrechts unter besonderer Berücksichtigung des Nutzerschutzes, Baden-Baden 2009.

Hartel, Zita, Ein Selfie mit Mona Lisa. Alte Meister in der Populärkultur, in: Kunsthalle Tübingen/Nicole Fritz (Hrsg.), Comeback. Kunsthistorische Renaissancen, Ausstellungskatalog der Kunsthalle Tübingen, Bielefeld und Berlin 2019, S. 47-57.

Hauck, Ronny, Kopieren oder Zitieren. Zur urheberrechtlichen Zulässigkeit des Samplings, GRUR-Prax 2019, S. 385-385.

Haug, Wolfgang Fritz, Aneignung, in: ders./Frigga Haug/ Peter Jehle/ Wolfgang Küttler (Hrsg.), Historisch-Kritisches Wörterbuch des Marxismus, Hamburg 1994, Rn. 233-249.

Hegel, Georg Wilhelm Friedrich, Grundlinien der Philosophie des Rechts. Oder Naturrecht und Staatswissenschaft im Grundrisse [1821], 14. Auflage, Frankfurt am Main 2015.

Hemsley, Jeff/ Mason, Robert M., The Nature of Knowledge in the Social Media Age. Implications for Knowledge Management Models, Journal of Organizational Computing and Electronic Commerce, Nr 1-2 (2013), S. 138-176.

Hertin, Paul W., Das Musikzitat im deutschen Urheberrecht, GRUR 1989, S. 159-167.

Herwig, Jana, Viralität als Sonderfall: über Selfies, Serialität und die Wahrscheinlichkeit der Kommunikation im Social Web, kommunikation @ gesellschaft 19 (2018), Beitrag 4.

Hess, Gangolf, Urheberrechtsprobleme der Parodie, Baden-Baden 1993.

Heyman, Jessie, SuicideGirls Respond to Richard Prince in the Best Way Possible, Vogue vom 28.5.2015, https:/www.vogue.com/article/suicidegirls-richard-princ e, Datum des Zugriffs: 15.1.2020.

Hochberg, Julian/ Peterson, Mary, Bildanalyse in der menschlichen Informationsverarbeitung, in: Martin Schuster/ Bernhard P. Woschek (Hrsg.), Nonverbale Kommunikation durch Bilder, Stuttgart 1989, S. 33-51. 
Höfinger, Frank Michael, Anmerkung zu EuGH, Urteil vom 13. Februar 2014 C-446/12 - Nils Svensson u.a./Retriever Sverige AB, ZUM 2014, S. 293-295.

Hofmann, Franz, Die Plattformverantwortlichkeit nach dem neuen europäischen Urheberrecht - „Much Ado About Nothing“?, ZUM 2019, S. 617-627.

Homar, Philipp, Enge Handlungsspielräume für das Sampling. Anmerkung zu EuGH, Urteil vom 29.7.2019 - C-476/17 - Pelham u.a./Hütter u.a. (ZUM 2019, 738), ZUM 2019, S. 731-737.

Hubmann, Heinrich, Urheber- und Verlagsrecht. Ein Studienbuch, München 1978.

Hubmann, Heinrich, Das Recht des schöpferischen Geistes, Berlin 1954.

Humboldt, Wilhelm von, Über das Studium des Altertums und des Griechischen insbesondere [1793], Leipzig 1932.

Hunt, Elle, Chanel's \$2,000 boomerang criticised for 'humiliating' Indigenous Australian culture, The Guardian vom 16.5.2017, https:/www.theguardian.com/fas hion/2017/may/16/chanels-2000-boomerang-criticised-for-humiliating-indigenou s-australian-culture, Datum des Zugriffs: 15.1.2020.

Hüper, Melanie, Zum Schutz vor Nachfotografie und Nachbildungen von urheberrechtlich geschützten Fotoaufnahmen, AfP 2004, S. 511-513.

Huss, Till Julian/ Winkler, Elena, Wiederholung. Revision eines ästhetischen Grundbegriffs, in: Till Julian Huss/ Elena Winkler (Hrsg.), Kunst \& Wiederholung. Strategie, Tradition, ästhetischer Grundbegriff, Berlin 2017, S. 7-27.

Huttenlauch, Anna Blume, Appropriation Art. Kunst an den Grenzen des Urheberrechts, Baden-Baden 2010.

Jaeggi, Rahel, Aneignung braucht Fremdheit, Texte zur Kunst Nr. 46 (Juni 2002), S. 60-69, https://www.textezurkunst.de/46/aneignung-braucht-fremdheit/, Datum des Zugriffs: 15.1.2020.

Jani, Ole/ Leenen, Frederik, Anmerkung zu EuGH Nils Svensson u.a./Retriever Sverige, GRUR 2014, S. 362-363.

Jaworski, Stanislaus/ Nordemann, Jan Bernd, Gehilfenhaftung von Intermediären bei Rechtsverletzungen im Internet. BGH Rechtsprechung und neuste Entwicklungen in den Instanzen, GRUR 2017, 567-572.

Jenkins, Henry, Fans, Bloggers, and Gamers. Exploring Participatory Culture, New York und London 2006.

Jenkins, Henry/ Ito, Mizuko/ Boyd, Danah, Participatory Culture in a Networked Era. A Conversation on Youth, Learning, Commerce and Politics, Cambridge 2016.

Jonas, Hans, Homo pictor. Von der Freiheit des Bildens, in: Gottfried 1994 (Hrsg.), Was ist ein Bild?, München 1994, S. 105-124.

Jones, Lisa, Appropriation and Derogation: When is it wrong to appropriate?, in: Darren Hicks/ Reinold Schmücker (Hrsg.), The Aesthetics and Ethics of Copying, London 2016, S. 187-211.

Kaesling, Katharina, Die EU-Urheberrechtnovelle - der Untergang des Internets?, JZ 2019, S. 586-591.

Kakies, Celia, Kunstzitate in Malerei und Fotografie, Köln 2007. 
Kant, Immanuel, Kritik der Urteilskraft [1790], in: Immanuel Kant, Wilhelm Weischelde (Hrsg.), Werkausgabe, Band 10, 13. Auflage, Frankfurt am Main 1994.

Kant, Immanuel, Von der Unrechtmäßigkeit des Büchernachdrucks [1785], Nachdruck in: UFITA Band 106 (1987), S. 137-144.

Karl, Christian, Wettlauf von Technik und Recht. Geschichte der Rechtswissenschaft am Karlsruher Institut für Technologie (KIT) als Technische Hochschule, Berlin 2018.

Kastner, Karl, Das Plagiat - literarische und rechtliche Aspekte, NJW 1983, S. 1151-1158.

Kehrli, Thomy, Der urheberrechtliche Werkbegriff im Bereich der bildenden Kunst, Bern 1989.

Kelsen, Hans, Reine Rechtslehre, 2. Auflage, Wien 1960.

Kemp, Wolfgang, Disegno. Beiträge zur Geschichte des Begriffs zwischen 1547 und 1607, Marburger Jahrbuch für Kunstwissenschaft 19 (1974), S. 219-240.

Kennedy, Randy, If the Copy is an Artwork, then what's the Original?, The New York Times vom 6.12.2007, https:/www.nytimes.com/2007/12/06/arts/design/06 prin.html, Datum des Zugriffs: 15.1.2020.

Kirchhof, Paul, Der Gesetzgebungsauftrag zum Schutz des geistigen Eigentums gegenüber modernen Vervielfältigungstechniken, Heidelberg 1998.

Klass, Nadine, Werkgenuss und Werknutzung in der digitalen Welt: Bedarf es einer Harmonisierung des Urheberpersönlichkeitsrechts?, ZUM 2015, S. 290-308.

Klass, Nadine, Neue Internettechnologien und das Urheberrecht: Die schlichte Einwilligung als Rettungsanker?, ZUM 2013, S. 1-10.

Knöbl, Harald Peter, Die „kleine Münze“ im System des Immaterialgüter- und Wettbewerbsrechts. Eine rechtsvergleichende Analyse des deutschen, schweizerischen, französischen und US-amerikanischen Rechts, Hamburg 2002.

Kohler, Josef, Die Idee des geistigen Eigentums, Buschs Archiv für Theorie und Praxis des Allgemeinen Deutschen Handels- und Wechselrechts 47 (1887), S. 169-190, abgedruckt in UFITA Band 123 (1993), S. 81-167.

Kohler, Josef, Das Autorrecht. Eine zivilistische Abhandlung. Zugleich ein Beitrag zur Lehre von Eigenthum, von Miteigenthum, vom Rechtsgeschäft und vom Individualrecht, Jena 1880.

Koller, Ingo/ Kindler, Peter/ Roth, Wulf-Henning/ Drüen, Klaus-Dieter, Handelsgesetzbuch Kommentar, 9. Auflage, München 2019.

(zit.: Koller/Kindler/Roth/Drüen/Bearbeiter)

Kölzer, Theo, Urkundenfälschungen im Mittelalter, in: Karl Corino (Hrsg.), Gefälscht! Betrug in Politik, Literatur, Wissenschaft, Kunst und Musik, Frankfurt am Main 1994, S. 15-26.

Kopp, Lisa, Die Freiheit der Idee und der Schutz von Schriftwerken, Tübingen 2014. 


\section{Literaturverzeichnis}

Kosuth, Joseph, Theft after Kant, in: Friedrich Tietjen/ Peter Weibel (Hrsg.), Kunst ohne Unikat. Multiple und Sampling als Medium: Techno-Transformationen der Kunst, Ausstellungskatalog der Neuen Galerie am Landesmuseum Joanneum, im Künstlerhaus Graz, Köln 1998, S. 91-99.

Krämer, Sybille, „Schriftbildlichkeit“ oder: Über eine (fast) vergessene Dimension der Schrift, in: Sybille Krämer/ Horst Bredekamp (Hrsg.), Bild, Schrift, Zahl, 2. Auflage, München 2009, S. 157-176.

Kreutzer, Till, Remix-Culture und Urheberrecht, in: Valie Djordjevic/ Leonhard Dobusch (Hrsg.), Generation Remix. Zwischen Popkultur und Kunst, Berlin 2014, S. 42-67.

Kreutzer, Till, Verbraucherschutz im Urheberrecht. Vorschläge für eine Neuregelung bestimmter Aspekte des geltenden Urheberrechts auf Basis einer Analyse aus verbraucherschutzrechtlicher Sicht, Berlin 2011.

Kristeva, Julia, Le mot, le dialoque et le roman, in: dies. (Hrsg.), Semeiotike. Recherches pour une sémanalyse, Paris 1969, S. 143-173.

Kroker, Michael, Was Nutzer in sozialen Netzwerken teilen - und warum: Fotos vor Status-Updates und Artikeln, WiWo Blog vom 13.10.2014, http://blog.wiwo.de/l ook-at-it/2014/10/13/was-nutzer-in-sozialen-netzwerken-teilen-und-warum-fotosvor-status-updates-und-artikeln/, Datum des Zugriffs: 15.1.2020.

Kühl, Eike, Socially Awkward Urheberrecht, Die Zeit vom 4.9.2015, https://www.ze it.de/digital/internet/2015-09/getty-images-urheberrecht-meme-socially-awkward -penguin/komplettansicht, Datum des Zugriffs: 15.1.2020.

Kulenkampff, Jens, Die ästhetische Bedeutung der Unterscheidung von Original und Fälschung, in: Julian Nida-Rümelin/ Jakob Steinbrenner (Hrsg.), Kunst und Philosophie. Original und Fälschung, Ostfildern 2011, S. 31-50.

Kummer, Max, Das urheberrechtlich schützbare Werk, Bern 1968.

Kur, Annettel von Bomhard, Verenal Albrecht, Friedrich (Hrsg.), Beck'scher OnlineKommentar zum Markenrecht, 19. Edition, München 2019.

(zit.: BeckOK Markenrecht/Bearbeiter)

Ladeur, Karl-Heinz, Das Medienrecht und die Ökonomie der Aufmerksamkeit. In Sachen Dieter Bohlen, Maxim Biller, Caroline von Monaco u.a., Köln 2007.

Ladeur, Karl-Heinz, Kritik der Abwägung in der Grundrechtsdogmatik. Plädoyer für eine Erneuerung der liberalen Grundrechtstheorie, Tübingen 2004.

Lafreniere, Steve, 80's then: Richard Prince talks to Steve Lafreniere, Artforum Nr. 71 (März 2003), S. 70-71.

Larenz, Karl, Methodenlehre der Rechtswissenschaft, 6. Auflage, Berlin/Heidelberg 1991.

Leinemann, Felix, Die Sozialbindung des „Geistigen Eigentums“. Zu den Grundlagen der Schranken des Urheberrechts zugunsten der Allgemeinheit, Baden-Baden 1998.

Leistner, Matthias, Das Urteil des EuGH in Sachen „Funke Medien NRW/Deutschland“ - gute Nachrichten über ein urheberrechtliches Tagesereignis, ZUM 2019, S. 720-726. 
Leistner, Matthias, „Ende gut, alles gut“... oder „Vorhang zu und alle Fragen offen“? Das salomonische Urteil des EuGH in Sachen „Pelham [Metall auf Metall]“, GRUR 2019, S. 1108-1015.

Leistner, Matthias, „In jedem Ende liegt ein neuer Anfang“. Das BGH Urteil „Vorschaubilder III“, seine Bedeutung für die Bildersuche und für die weitere Entwicklung des Haftungssystems im Urheberrecht, ZUM 2018, S. 286-292.

Leistner, Matthias, Urheberrecht an der Schnittstelle zwischen Unionsrecht und nationalem Recht. Werkbegriff und Recht der öffentlichen Wiedergabe, GRUR 2014, S. 1145-1155.

Leistner, Matthias/ Hansen, Gerd, Die Begründung des Urheberrechts im digitalen Zeitalter. Versuch einer Zusammenführung von individualistischen und utilitaristischen Rechtfertigungsbemühungen, GRUR 2008, S. 479-490.

Leistner, Matthias/Stang, Felix, Die Bildersuche im Internet aus urheberrechtlicher Sicht - Einige grundlegende Überlegungen aus Anlass des Urteils des OLG Jena vom 27.2.2008, CR 2008, S. 499-507.

Lessig, Lawrence, Remix. Making Art and Commerce Thrive in the Hybrid Economy, New York 2008.

Lessig, Lawrence, Freie Kultur. Wesen und Zukunft der Kreativität, München 2006.

Leßmann, Andreas, Die vertragliche Nutzungseinräumung an Datenbanken in der Informationsgesellschaft, ZUM 1999, S. 623-628.

Levine, Sherrie, Statement [1982], in: Charles Harrison/ Paul Wood (Hrsg.), Art in theory 1900-1990. An anthology of changing ideas, Oxford und Cambridge 1997, S. 1066-1067.

LeWitt, Sol, Paragraphs on Conceptual Art [1928], in: Charles Harrison/ Paul Wood (Hrsg.), Art in theory 1900-1990. An anthology of changing ideas. Oxford und Cambridge 1997, S. 834-837.

Lichtnecker, Florian, Neues aus dem Social Media-Marketing. Aktuelle wettbewerbs-, urheber- und markenrechtliche Problemstellungen, MMR 2018, S. 512-517.

Linguet, Simon Nicolas Henri, Des Herrn Linguets Betrachtungen über die Rechte des Schriftstellers und seines Verlegers. Aus dem Französischen. Leipzig 1778.

Locke, John, Zwei Abhandlungen über die Regierung [1690], Hrsg. von Walter Euchner, übersetzt von Hans Jörn Hoffmann, Frankfurt am Main 1977.

Loeffler, Joachim, Künstlersignatur und Kunstfälschung - Zugleich ein Beitrag zur Funktion des $\$ 107$ UrhG, NJW 1993, S. 1421-1429.

Loschelder, Michael, Vervielfältigung oder Bearbeitung? Zum Verhältnis des \$16 UrhG zu \$23 UrhG, GRUR 2011, S. 1078-1083.

Lucas, Kate, Jeff Koons reaches settlement in recent Lawsuit, but Richard Prince is in the Hot Seat again on Fair Use, Art Law Blog Grossman LLP vom 19.5.2018, https:/www.grossmanllp.com/jeff-koons-reaches-settlement-in-recent-lawsuit, Datum des Zugriffs: 15.1.2020.

Maar, Christa/ Burda, Hubert (Hrsg.), Iconic Turn. Die neue Macht der Bilder, Köln 2004. 
Maaßen, Wolfgang, Plagiat, freie Benutzung oder Kunstzitat? Erscheinungsformen der urheberrechtlichen Leistungsübernahme in Fotografie und Kunst, in: Anke Schierholz/ Ferdinand Melichar (Hrsg.), Kunst, Recht und Geld. Festschrift für Gerhard Pfennig zum 65. Geburtstag, München 2012, S. 135-178.

(zit.: FS Pfennig)

Magauer, Hannah, Vom Teilen und Stehlen. Künstlerische Aneignung in der digitalen Bildkultur, in: Till Julian Huss/ Elena Winkler (Hrsg.), Kunst \& Wiederholung. Strategie, Tradition, ästhetischer Grundbegriff, Berlin 2017, S. 203-221.

Mahro, Annette, Wolfgang Beltracchi: Ein gefallenes Genie, Badische Zeitung vom 9.6.2017, http://www.badische-zeitung.de/kunst-1/wolfgang-beltracchi-ein-gefall enes-genie--137860549.html, Datum des Zugriffs: 15.1.2020.

Maier, Henrike, Remixe auf Hosting-Plattformen. Eine urheberrechtliche Untersuchung filmischer Remixe zwischen grundrechtsrelevanter Schranken und Inhaltefiltern, Tübingen 2018.

Maier, Henrike, Meme und Urheberrecht, GRUR-Prax 2016, S. 397-398.

Malik, Kenan, In Defense of Cultural Appropriation, The New York Times vom 14.6.2017, https:/www.nytimes.com/2017/06/14/opinion/in-defense-of-culturalappropriation.html, Datum des Zugriffs: 15.1.2020.

Marl, Johannes, Der Begriff der Öffentlichkeit im Urheberrecht. Eine aus den Regelungszwecken hergeleitete, soziologisch untermauerte Untersuchung eines urheberrechtlichen Schlüsselbegriffs im Kontext der demokratischen Informationsgesellschaft, Tübingen 2017.

Marly, Jochen/ Prinz, Matthias, EuGH: Zulässigkeitsvoraussetzungen für ein Sampling, LMK 2019, 421261.

Marx, Karl, Nationalökonomie und Philosophie, in: Siegfried Landshut (Hrsg.), Die Frühschriften, Stuttgart 1971, S. 225-316.

Marx, Karl, Privateigentum und Kommunismus, in: Institut für Marxismus-Leninismus beim ZK der SED (Hrsg.), Ökonomisch-philosophische Manuskripte aus dem Jahr 1844, Marx-Engels-Werke (MEW), Ergänzungsband, Berlin 1968, S. $465-588$.

Marzorati, Gerald, ART in the (Re)Making, Art News Nr. 5 (Mai 1986), S. 90-99.

Maunz, Theodor/ Dürig, Günter, Grundgesetz Kommentar, hrsg. von Roman Herzog, Rupert Scholz, Matthias Herdegen und Hans H. Klein, 86. Ergänzungslieferung, München 2019.

(zit.: Maunz/Dürig/Bearbeiter)

Mayr, Gesa, Zappeln, was das Zeug hält, Spiegel Online vom 13.2.2013, http://www .spiegel.de/panorama/gesellschaft/harlem-shake-erobert-das-internet-a-882955.ht ml, Datum des Zugriffs: 15.1.2020.

Meier, Anika, Geplantes Museum of Selfies. Die Hölle ist Millenial Pink, Monopol Magazin vom 30.1.2018, https://www.monopol-magazin.de/das-museum-selfiesdie-hoelle-ist-millennial-pink, Datum des Zugriffs: 15.1.2020. 
Mensger, Ariane, Kontexte, Motive und Funktionen des Kopierens in Stichworten, in: Ariane Mensger (Hrsg.), Déjà-vu? Die Kunst der Wiederholung von Dürer bis Youtube, Ausstellungskatalog der Staatlichen Kunsthalle Karlsruhe, Bielefeld 2012, S. 159-161.

Miller, Vincent, Understanding Digital Culture, Los Angeles 2011.

Mills, Charles W., White supremacy as sociopolitical system. A philosophical perspective, in: Ashley Doane/ Eduardo Bonilla-Silva (Hrsg.), White Out. The Continuing Significance of Racism, London 2013, S. 35-48.

Mitchell, W.J.T., Bildtheorie, Hrsg. und mit einem Nachwort von Gustav Frank, Berlin 2008.

Mitchell, W.J.T., The Pictorial Turn, Art Forum Nr. 30 (1992), S. 89-95.

Möbius, Hanno, Montage und Collage. Literatur, bildende Künste, Film, Fotografie, Musik, Theater bis 1933, München 2000.

Moore, Adam D., Towards a Lockean Theory of Intellectual Property Law, in: ders. (Hrsg.), Intellectual Property: moral, legal, and international dilemmas, New York u.a. 1997, S. 81-103.

Moser, Sybille-Karin, Sinnbild und Abbild. Zur Funktion des Bildes, in: Paul Naredi-Rainer (Hrsg.), Sinnbild und Abbild. Zur Funktion des Bildes, Innsbruck 1994, S. 3-23.

Mrohs, Lorenz, Uploadfilter: Eine Geschichte voller Fails, Netzpolitik.org vom 24.4.2019, https://netzpolitik.org/2019/uploadfilter-eine-geschichte-voller-fails/, Datum des Zugriffs: 15.1.2020.

Müller, Friedrich, Freiheit der Kunst als Problem der Grundrechtsdogmatik, Berlin 1969.

Müller, Jan Dirk/ Pfisterer, Ullrich, Der allgegenwärtige Wettstreit in den Künsten der Frühen Neuzeit, in: dies. (Hrsg.), Aemulatio. Kulturen des Wettstreits in Text und Bild (1450-1620), Berlin und Boston 2011, S. 1-35.

Netanel, Neil Weinstock, Asserting Copyright's Democratic Principles in the Global Arena, in: Vanderbilt Law Review, Band 51 (1998), Nashville, S. 217-329.

Netanel, Neil Weinstock, Copyright and a Democratic Society, in: The Yale Law Journal Band 106 (1996), New Haven, S. 283-387.

Oberndörfer, Pascal, Die philosophische Grundlage des Urheberrechts, Baden-Baden 2005.

Oechsler, Jürgen, Die Idee als persönliche geistige Schöpfung. Von Fichtes Lehre vom Gedankeneigentum zum Schutz von Spielideen, GRUR 2009, S. 1101-1107.

Ohly, Ansgar, Anmerkung zu BGH Vorschaubilder III, GRUR 2018, S. 187-189.

Ohly, Ansgar, Unmittelbare und mittelbare Verletzung des Rechts der öffentlichen Wiedergabe nach dem „Córdoba“-Urteil des EuGH, GRUR 2018, S. 996-1004.

Ohly, Ansgar, Hip Hop und die Zukunft der „freien Benutzung“ im EU-Urheberrecht. Anmerkungen zu Vorlagebeschluss des BGH „Metall auf Metall III“, GRUR 2017, S. 964-969.

Ohly, Ansgar, Anmerkung zu EuGH GS Media/Sanoma u.a, GRUR 2016, S. 1155-1157. 
Obly, Ansgar, Urheberrecht in der digitalen Welt. Brauchen wir neue Regelungen zum Urheberrecht und dessen Durchsetzung?, Gutachten F zum 70. Deutschen Juristentag, München 2014.

Osenberg, Ralph, Die Unverzichtbarkeit des Urheberpersönlichkeitsrechts, Freiburg 1985.

Osterwold, Tilman, Vorwort, in: Bill Arning/ Zdenek Felix/ u.a. (Hrsg.), Sturtevant. Ausstellungskatalog des Württembergischen Kunstvereins Stuttgart, der Deichtorhallen Hamburg und der Villa Arson Nizza, München-Stuttgart 1992, S. 6-7.

Ott, Claus/ Schäfer, Hans-Bernd, Die ökonomische Analyse des Rechts. Irrweg oder Chance wissenschaftlicher Rechtserkenntnis?, JZ 1988, S. 213-223.

Ott, Stephan, Urheber- und wettbewerbsrechtliche Probleme von Linking und Framing, Stuttgart 2004.

Pachali, David, Die Kommerzialisierung der Gifs, irights info vom 29.3.2018, https:/ /irights.info/artikel/die-kommerzialisierung-der-gifs/29036, Datum des Zugriffs: 15.1.2020.

Pahud, Eric, Zur Begrenzung des Urheberrechts im Interesse Dritter und der Allgemeinheit, UFITA Band 2000/I (2000), S. 99-137.

Panofsky, Erwin, Sinn und Deutung in der bildenden Kunst, Köln 1975.

Passavant, Johann David, Ansichten über die bildenden Künste und Darstellung des Ganges derselben in Toscana, Heidelberg und Speyer 1820.

Peirce, Charles Sanders, Phänomen und Logik der Zeichen, hrsg. von Helmut Pape, Frankfurt am Main 1983.

Pendzich, Marc, Von der Coverversion zum Hit-Recycling. Historische, ökonomische und rechtliche Aspekte eines zentralen Phänomens der Pop- und Rockmusik, Berlin 2008.

Perrin, Frank, Der Sturtevant-Moment, in: Bill Arning/ Zdenek Felix/ u.a. (Hrsg.), Sturtevant. Ausstellungskatalog des Württembergischen Kunstvereins Stuttgart, der Deichtorhallen Hamburg und der Villa Arson Nizza, München-Stuttgart 1992, S. 20-31.

Petri, Grischka, Der Fall Dürer vs. Raimondi. Vasaris Erfindung, in: Birgit Ulrike Münch/ Andreas Tacke/ Markwart Herzog/ Sylvia Heudecker (Hrsg.), Fälschung - Plagiat - Kopie. Künstlerische Praktiken der Vormoderne, Petersberg 2014, S. 52-69.

Peukert, Alexander, Das Urheberrecht und die zwei Kulturen der Online-Kommunikation, GRUR-Beilage 2014, S. 77-93.

Peukert, Alexander, Der Schutzbereich des Urheberrechts und das Werk als öffentliches Gut. Insbesondere: die urheberrechtliche Relevanz des privaten Werkgenusses, in: Reto M. Hilty/ Alexander Peukert (Hrsg.), Interessenausgleich im Urheberrecht, Baden-Baden 2004, S. 11-46.

Pfeifer, Karl-Nikolaus, Urheberrechtliche Zulässigkeit der Weiterverwertung von im Internet abrufbaren Fotos, NJW 2018, S. 3490-3493. 
Pfeifer, Karl-Nikolaus, Appropriation und Fan Art - geknebelte Kreativität oder klare Urheberrechtsverletzung?, in: Winfried Bullinger/ Eike Grunert/ Claudia Ohst/ Kristen-Inger Wöhrn (Hrsg.), Festschrift für Artur-Axel Wandtke zum 70. Geburtstag am 26. März 2013, Berlin 2013, S. 99-109.

(zit.: FS Wandtke)

Pfeifer, Karl-Nikolaus, Individualität im Zivilrecht. Der Schutz persönlicher, gegenständlicher und wettbewerblicher Individualität im Persönlichkeitsrecht, Immaterialgüterrecht und Recht der Unternehmen, Tübingen 2001.

Pfennig, Gerhard, Kunstfälschung - eine besondere Art der Werkrezeption, in: Winfried Bullinger/ Eike Grunert/ Claudia Ohst/ Kristen-Inger Wöhrn (Hrsg.), Festschrift für Artur-Axel Wandtke zum 70. Geburtstag am 26. März 2013, Berlin 2013, S. 79-89.

(zit.: FS Wandtke)

Pichler, Michalis, Statements zur Appropriation, in: Annette Gilbert (Hrsg.), Wiederaufgelegt. Zur Appropriation von Texten und Büchern in Büchern, Bielefeld 2012, S. 27-28.

Pitzke, Marc, Mädchen, Mythen und der Marlboro-Mann, Der Spiegel vom 29.9.2007, http://www.spiegel.de/kultur/gesellschaft/us-kuenstler-richard-princemaedchen-mythen-und-der-marlboro-mann-a-508512.html, Datum des Zugriffs: 15.1.2020.

Platon, Der Staat (Politeia), gr.-dt. übersetzt von Karl Vretska, Stuttgart 2012.

Podszun, Rupprecht, Postmoderne Kreativität im Konflikt mit dem Urheberrechtsgesetz und die Annäherung an „fair use“. Besprechung zu BVerfG ZUM 2016, 626 - Sampling, ZUM 2016, S. 606-612.

Posner, Richard A., The Ethical and Political Basis of the Efficiency Norm in Common Law Adjunction, in: Hofstra Law Review Band 8 (1980), Hempstead, S. 487-508.

Pötzlberger, Florian, Kreatives Remixing. Musik im Spannungsfeld von Urheberrecht und Kunstfreiheit, Baden-Baden 2018.

Pötzlberger, Florian, Pastiche 2.0: Remixing im Lichte des Unionsrechts. Zu $\$ 24$ UrhG und Art. 5 III Buchst. k InfoSoc-RL im Kontext der „Metall auf Metall“Rechtsprechung, GRUR 2018, S. 675-681.

Pravemann, Timm, Art. 17 der Richtlinie zum Urheberrecht im digitalen Binnenmarkt. Eine Analyse der neuen europäischen Haftungsregelung für Diensteanbieter für das Teilen von Online-Inhalten, GRUR 2019, S. 783-788.

Prince, Richard, Why I go to the movies alone, New York 1994.

Raue, Benjamin, Kein öffentliches Zugänglichmachen eines urheberrechtlich geschützten Gegenstands durch Vorhalten auf dem eigenen Server? Anmerkung zu GA Sánchez-Bordona, Schlussanträge vom 25.4.2018 - C-161/17 - Cordoba (ZUM 2018, 506), ZUM 2018, S. 517-519.

Raue, Benjamin, Das subjektive Vervielfältigungsrecht. Eine Lösung für den digitalen Werkgenuss?, ZGE 2017, S. 515-538.

Raue, Benjamin, Informationsfreiheit und Urheberrecht, JZ 2013, S. 280-288. 
Raue, Peter, Ready-Mades und Appropriation Art. „Werke“ im Sinne des Urhebergesetzes?, in: Anke Schierholz/ Ferdinand Melichar (Hrsg.), Kunst, Recht und Geld. Festschrift für Gerhard Pfennig zum 65. Geburtstag, München 2012, S. 199-205. (zit.: FS Pfennig)

Raue, Peter, Zum Dogma von der restriktiven Auslegung der Schrankenbestimmungen des Urheberrechtsgesetztes, in: Ulrich Loewenheim (Hrsg.), Urheberrecht im Informationszeitalter, Festschrift für Wilhelm Nordemann zum 70. Geburtstag, München 2004, S. 327-339.

(zit.: FS Nordemann)

Rebbelmund, Romana, Appropriation Art - Die Kopie als Kunstform im 20. Jahrhundert, Frankfurt am Main u.a. 1999.

Rebbinder, Manfred, Felix Dahn und Karl Gareis zur Theorie des Urheberrechts, UFITA Band 129 (1995), S. 69-81.

Rebbinder, Manfred/ Peukert, Alexander, Urheberrecht und verwandte Schutzrechte. Ein Studienbuch, 18. Auflage, München 2018.

Rebkämper, Klaus, Bilder, Ähnlichkeit und Perspektive. Auf dem Weg zu einer neuen Theorie der bildhaften Repräsentation, Wiesbaden 2002.

Rengier, Rudolf, Strafrecht Besonderer Teil I, 19. Auflage, München 2017.

Reyburn, Scott, What the Mona Lisa Tells Us About Art in the Instagram Era, New York Times vom 27.4.2018, https://www.nytimes.com/2018/04/27/arts/design/m ona-lisa-instagram-art.html, Datum des Zugriffs: 15.1.2020.

Riesenhuber, Karl, Der Schutzgegenstand und die Rechtsinhaber, in: ders. (Hrsg.), Systembildung im Europäischen Urheberrecht, Berlin 2007.

Rimmele, Marius/Sachs-Hombach, Klaus/Stiegler, Bernd (Hrsg.), Bildwissenschaft und Visual Culture, Bielefeld 2014.

Roder, Verena, Die Methodik des EuGH im Urheberrecht. Die autonome Auslegung des Gerichtshofs der Europäischen Union im Spannungsverhältnis zum nationalen Recht, Tübingen 2016.

Roellecke, Gerd, Das Kopieren zum eigenen wissenschaftlichen Gebrauch. Rechtliche und rechtspolitische Überlegungen, UFITA Band 84 (1979), S. 79-145.

Römer, Stefan, Künstlerische Strategien des Fake. Kritik von Original und Fälschung, Köln 2001.

Roos, Gerd/ Mensger, Ariane, Giorgio de Chirico, in: Ariane Mensger (Hrsg.), Déjàvu? Die Kunst der Wiederholung von Dürer bis Youtube, Ausstellungskatalog der Staatlichen Kunsthalle Karlsruhe, Bielefeld 2012, S. 254.

Rosenbaum, Birgit/ Tölle, Dennis, Aktuelle rechtliche Probleme im Bereich Social Media - Überblick über die Entscheidungen der Jahre 2011 und 2012, MMR 2013, S. 209-212.

Rösler, Hannes, Buchbesprechung zu Christian Gero Stallberg, Urheberrecht und moralische Rechtfertigung (2006), JZ 2007, S. 185-186.

Rupp, Hajo, Culture \& Copyright. Towards an Integrated Justification of Copyright between Cultural Theory, Eonomic Theory and Reality, Berlin 2013. 
Rüthers, Bernd/Fischer, Christian/ Birk, Axel, Rechtstheorie mit juristischer Methodenlehre, 10. Auflage, München 2018.

Sachs-Hombach, Klaus, Das Bild als kommunikatives Medium. Elemente einer allgemeinen Bildwissenschaft, 3. Auflage, Köln 2013.

Säcker, Franz Jürgen/ Rixecker, Roland/ Oetker, Hartmut/ Limperg, Bettina (Hrsg.), Münchener Kommentar zum Bürgerlichen Gesetzbuch, 8. Auflage, München 2020. (zit: MüKo/Bearbeiter)

Sammer, Günther, Der Öffentlichkeitsbegriff im Urheberrecht, Graz 2009.

Schack, Haimo, Urheber- und Urhebervertragsrecht, 9. Auflage, Tübingen 2019.

Schack, Haimo, Kunst und Recht, 3. Auflage, Tübingen 2017.

Schack, Haimo, Weniger Urheberrecht ist mehr, in: Winfried Bullinger/ Eike Grunert/ Claudia Ohst/ Kristen-Inger Wöhrn (Hrsg.), Festschrift für Artur-Axel Wandtke zum 70. Geburtstag am 26. März 2013, Berlin 2013, S. 9-20.

(zit.: FS Wandtke)

Schack, Haimo, Wissenschaftsplagiat und Urheberrecht, in: Thomas Dreier/ Ansgar Ohly (Hrsg.), Plagiate. Wissenschaftsethik und Recht, Tübingen 2013, S. 81-98.

Schack, Haimo, Urheberrechtliche Schranken, übergesetzlicher Notstand und verfassungskonforme Auslegung, in: Ansgar Ohly/Theo Bodewig/ Thomas Dreier/ Horst-Peter Götting/ Maximilian Haedicke/ Michael Lehmann (Hrsg.), Perspektiven des Geistigen Eigentums und Wettbewerbsrecht, Festschrift für Gerhard Schricker zum 70. Geburtstag, München 2005, S. 511-522. (zit.: FS Schricker)

Schack, Haimo, Appropriation Art und Urheberrecht, in: Ulrich Loewenheim (Hrsg.), Urheberrecht im Informationszeitalter. Festschrift für Wilhelm Nordemann zum 70. Geburtstag, München 2004, S. 107-113.

(zit.: FS Nordemann)

Schack, Haimo, Neuregelung des Urhebervertragsrechts. Kritische Anmerkungen zum Professorenentwurf, ZUM 2001, S. 453-466.

Schack, Haimo, Urheberrechtliche Gestaltung von Webseiten unter Einsatz von Links und Frames, MMR 2001, S. 9-17.

Schäfer, Hans-Bernd/Ott, Claus, Lehrbuch der ökonomischen Analyse des Zivilrechts, 5. Auflage, Berlin und Heidelberg 2012.

Schjedahl, Peter, After image. The New Yorker vom 24.11.2014, https://www.newyo rker.com/magazine/2014/11/24/image-3, Datum des Zugriffs: 15.1.2020.

Schmidt, Jan-Hinrik, Social Media, Wiesbaden 2013.

Schmidt, Jochen, Die Geschichte des Genie-Gedankens in der deutschen Literatur, Philosophie und Politik: 1750-1945. Von der Aufklärung bis zum Idealismus, 3. Auflage, Heidelberg 2004.

Schneider, Matthias, Offene Fragen zur Urheberbenennung nach Pixelio. Widersprüche in der aktuellen Rechtsprechung zum Urheberbenennungsrecht und Lösungsmöglichkeiten, CR 2016, S. 37-43.

Scholz, Oliver R., Bild, Darstellung, Zeichen. Philosophische Theorien bildlicher Darstellung, 2. Auflage, Frankfurt am Main 2004. 
Schonhofen, Sven, Die unendliche Geschichte um „Metall auf Metall“: Urheberrechtliche Zulässigkeit von Sampling vor dem EuGH, GRUR-Prax 2019, S. 432-434.

Schrader, Paul T. / Rautenstrauch, Birthe, Urheberrechtliche Verwertung von Bildern durch Anzeige von Vorschaugrafiken (sog. „thumbnails“) bei Internetsuchmaschinen, UFITA 2007/III (2007), S. 761-781.

Schricker, Gerhard, Abschied von der Gestaltungshöhe im Urheberrecht, in: Jürgen Becker/ Peter Lerche/ Ernst-Joachim Mestmäcker (Hrsg.), Wanderer zwischen Musik, Politik und Recht. Festschrift für Reinhold Kreile zum 65. Geburtstag, Baden-Baden 1994, S. 715-721.

(zit.: FS Kreile)

Schricker, Gerhard/ Loewenheim, Ulrich, Urheberrecht Kommentar, hrsg. von Ulrich Loewenheim, Matthias Leistner und Ansgar Ohly, 5. Auflage, München 2017. (zit.: Schricker/Loewenheim/Bearbeiter)

Schulze, Gernot, Beuys-Aktion 1964. Aspekte zum Urheberrechtsschutz bei multimedialen Werken, in: Peter Mosimann/ Beat Schönenberger (Hrsg.), Kunst \& Recht 2013, Bern 2014, S. 35-59.

Schulze, Gernot, Spielraum und Grenzen richterlicher Rechtsfortbildung im Urheberrecht, in: Hans-Jürgen Ahrens/ Joachim Bornkamm/ Wolfgang Gloy/ Joachim Starck/ Joachim v. Ungern-Sternberg (Hrsg.), Festschrift für Willi Erdmann zum 65. Geburtstag, Köln u.a. 2002, S. 173-194.

(zit.: FS Erdmann)

Schulze, Gernot, Die kleine Münze und ihre Abgrenzungsproblematik bei den Werkarten des Urheberrechts, Freiburg 1983.

Searle, Adrian, Elaine Sturtevant: queen of copycats, The Guardian vom 1.7.2013, https://www.theguardian.com/artanddesign/2013/jul/01/elaine-sturtevant-queencopycats, Datum des Zugriffs: 15.1.2020.

Searle, John R., Sprechakte. Ein sprachphilosophischer Essay [1969], Frankfurt am Main 1971.

Seibel, Wolfgang, Die Formenwelt der Fertigteile. Künstlerische Montagetechnik und ihre Anwendung im Drama, Würzburg 1988.

Sellnick, Hans-Joachim, Der Gegenstand des Urheberrechts. Der urheberrechtliche Werkbegriff aus Sicht der analytischen Philosophie, Semiotik und Wissenschaftstheorie, Sinzheim 1995.

Senftleben, Martin, Filterverpflichtungen nach der Reform des europäischen Urheberrechts - Das Ende der freien Netzkultur? Vortrag auf dem III. ZUM-Symposion „EU-Urheberrechtsreform - Ergebnisse und Analysen“ des Instituts für Urheber- und Medienrecht am 1.2.2019 in München, ZUM 2019, S. 369-374.

Senftleben, Martin, Der kulturelle Imperativ des Urheberrechts, in: Matthias Weller/ Nicolai Kemle/ Thomas Dreier/ Michael Lynen (Hrsg.), Kunst im Markt - Kunst im Recht, Tagungsband des Dritten Heidelberger Kunstrechtstages am 09. und 10. Oktober 2009, Baden-Baden 2010, S. 75-105. 
Senftleben, Martin, Die Bedeutung der Schranken des Urheberrechts in der Informationsgesellschaft und ihre Begrenzung durch den Dreistufentest, in: Reto M. Hilty/ Alexander Peukert (Hrsg.), Interessenausgleich im Urheberrecht, BadenBaden 2004, S. 159-186.

Senftleben, Martin, Grundprobleme des urheberrechtlichen Dreistufentests, GRUR Int. 2004, S. 200-211.

Shifman, Limor, Meme. Kunst, Kultur und Politik im digitalen Zeitalter, Berlin 2014.

Siegel, Jeanne, After Sherrie Levine. Interview mit Sherrie Levine, Arts Magazine New York (Juni 1985), S. 141-144.

Sievers, Bahne, Ist erlaubt, was gefällt? Urheberrechtsverletzungen und Verantwortlichkeit beim Social Sharing, GRUR-Prax 2012, S. 229-232.

Sollfrank, Cornelia, Originale... und andere unethische AutorInnenschaften in der Kunst, in: Valie Djordjevic/ Leonhard Dobusch (Hrsg.), Generation Remix. Zwischen Popkultur und Kunst, Berlin 2014, S. 107-117.

Specht, Louisa/ Koppermann, Ilona, Vom Verhältnis der $\mathbb{S} 14$ und 24 UrhG nach dem „Deckmyn“-Urteil des EuGH, ZUM 2016, S. 19-24.

Spindler, Gerald, Die neue Urheberrechts-Richtlinie der EU (Teil 2), WRP 2019, S. 951-959.

Spindler, Gerald, Haftung ohne Ende?. Über Stand und Zukunft der Haftung von Providern, MMR 2018, S. 48-52.

Spindler, Gerald, Bildersuchmaschinen, Schranken und konkludente Einwilligung im Urheberrecht. Besprechung der BGH-Entscheidung „Vorschaubilder“, GRUR 2010, S. 785-792.

Stadler, Felix, Kultur der Digitalität, Berlin 2016.

Stähli, Adrian, Die Kopie. Überlegungen zu einem methodischen Leitkonzept der Plastikforschung, in: Klaus Junker/ Adrian Stähli/ Christian Kunze (Hrsg.), Original und Kopie. Formen und Konzepte der Nachahmungen in der antiken Kunst. Akten des Kolloqiums in Berlin, 17.-19. Februar 2005, Wiesbaden 2008, S. 15-35.

Stallberg, Christian Gero, Urheberrecht und moralische Rechtfertigung, Berlin 2006.

Stamer, Britta, Der Schutz der Idee unter besonderer Berücksichtigung von Unterhaltungsproduktionen für das Fernsehen, Baden-Baden 2007.

Steinhau, Henry, Interview mit Wolfgang Ullrich, Wolfgang Ullrich: „Urheberrechte für die sozialen Netzwerke gänzlich suspendieren", irights info vom 18.5.2015, https://irights.info/artikel/wolfgang-ullrich-urheberrechte-fuer-die-soz ialen-netzwerke-gaenzlich-suspendieren/25429, Datum des Zugriffs: 15.1.2020.

Stiegler, Christian, Selfies und Selfie Sticks. Automedialität des digitalen Selbstmanagements, in: Christian Stiegler/ Patrick Breitenbach/ Thomas Zorbach (Hrsg.), New Media Culture, Mediale Phänomene der Netzkultur, Bielefeld 2015, S. 67-82. 
Stieper, Malte, Der Trans Europa Express ist aus Luxemburg zurück - auf dem Weg zu einer Vollharmonisierung der urheberrechtlichen Schranken. Zugleich Anmerkung zu EuGH, Urteile vom 29.7.2019 - C-469/17, C-476/17, C-516/17 (ZUM 2019, 751- Funke Medien NRW/Deutschland; ZUM 2019, 738 - Pelham u.a./Hütter u.a. und EuGH 2019, 759 - Spiegel Online/Beck, ZUM 2019, S. 713-720.

Stieper, Malte, Die Richtlinie über das Urheberrecht im digitalen Binnenmarkt. Keynote auf der Konferenz „Perspektiven des Urheberrechts im Informationszeitalter" am 19.11.2018 in Berlin, ZUM 2019, S. 211-217.

Stieper, Malte, Anmerkung zu BVerfG, Urteil vom 31. Mai 2016 - 1 BvR 1585/13, ZUM 2016, S. 637-639.

Stieper, Malte, Fan Fiction als moderne Form der Pastiche. Zur Abgrenzung von Vervielfältigung, Bearbeitung und freier Benutzung im Lichte des Unionsrechts, AfP 2015, S. 301-305.

Stieper, Malte, Rechtfertigung, Rechtsnatur und Disponibilität der Schranken des Urheberrechts, Tübingen 2009.

Stolzenberger, Jana, Höfisches Sammeln und internationale Tendenzen in der Kunst um 1600, in: Daniel Hess/ Dagmar Hirschfelder (Hrsg.), Renaissance, Barock, Aufklärung. Kunst und Kultur vom 16. bis zum 18. Jahrhundert, Nürnberg 2010, S. 270-283.

Stoschek, Jeanette, Anfänge der vervielfältigten Kunst und die leidige Frage nach dem Original, in: Friedrich Tietjen/ Peter Weibel (Hrsg.), Kunst ohne Unikat. Multiple und Sampling als Medium: Techno-Transformationen der Kunst, Ausstellungskatalog der Neuen Galerie am Landesmuseum Joanneum, im Künstlerhaus Graz, Köln 1998, S. 13-25.

Sturtevant, Elaine, Fälschung/Original, in: Thomas Deecke (Hrsg.), Originale echt/ falsch. Nachahmung, Kopie, Zitat, Aneignung, Fälschung in der Gegenwartskunst, Ausstellungskatalog des Neuen Museum Weserburg, Bremen 1999, S. 149-155.

Sturtevant, Elaine, Elaine Sturtevant im Gespräch mit Bill Arning, in: Bill Arning/ Zdenek Felix/ u.a. (Hrsg.), Sturtevant. Ausstellungskatalog des Württembergischen Kunstvereins Stuttgart, der Deichtorhallen Hamburg und der Villa Arson Nizza, München-Stuttgart 1992, S. 8-19.

Summerer, Claudia, „Illegale Fans“. Die urheberrechtliche Zulässigkeit von Fan Art, Berlin 2015.

Tanriverdi, Hakan, Ein Gif sagt mehr als 1000 Worte, Süddeutsche Zeitung vom 14.9.2015, http://www.sueddeutsche.de/digital/bewegte-bilder-ein-gif-sagt-mehrals-worte-1.2643863, Datum des Zugriffs: 15.1.2020.

Thomaschki, Kathrin E., Das schwarze Quadrat. Zur urheberrechtlichen Schutzfähigkeit zeitgenössischer Kunst, Konstanz 1995.

Thoms, Frank, Der urheberrechtliche Schutz der kleinen Münze, München 1980.

Toffler, Alvin, The Third Wave. The Classic Study of Tomorrow, New York 1980.

Troller, Alois, Immaterialgüterrecht Band I, 3. Auflage, Basel 1983. 
Troller, Alois, Rechtwirklichkeit und Rechtskonstruktion im Gewerblichen Rechtsschutz und Urheberrecht, GRUR 1980, S. 522-526.

Ullmann, Eike, Schutz der Elemente - elementarer Schutz der immaterialen Güter?, GRUR 1993, S. 334-338.

Ullich, Wolfgang, Selfies. Die Rückkehr des öffentlichen Lebens, Berlin 2019.

Ullrich, Wolfgang, Das Wetteifern der Bilder: Eine Archäologie der Mem-Kultur, irights info vom 26.4.2016, https://irights.info/artikel/das-wetteifern-der-bilder-ei ne-archaeologie-der-mem-kultur/27306, Datum des Zugriffs: 15.1.2020.

Ullrich, Wolfgang, Der kreative Mensch. Streit um eine Idee, Salzburg und Wien 2016.

Ullrich, Wolfgang, Rebloggen als Kulturtechnik, in: Dominik Landwehr (Hrsg.) Public Domain. Edition Digital Culture 3, Basel 2015, S. 92-102.

Ullrich, Wolfgang, Selfies als Weltsprache, in: Pia Müller-Tamm/ Dorit Schäfer (Hrsg.), Ich bin hier! Von Rembrandt zum Selfie, Ausstellungskatalog der Staatlichen Kunsthalle Karlsruhe, des Musée des Beaux-Arts in Lyon und der National Galleries of Scotland in Edinburgh, Köln 2015, S. 32-41.

Ullrich, Wolfgang, Tiefer hängen. Über den Umgang mit der Kunst, 5. Auflage, Berlin 2013.

Ullrich, Wolfgang, Gurkyesque: Das Web 2.0, das Ende des Originalitätszwangs und die Rückkehr des nachahmenden Künstlers, in: Julian Nida-Rümelin/ Jakob Steinbrenner (Hrsg.), Kunst und Philosophie. Original und Fälschung, Ostfildern 2011, S. 93-112.

Ullich, Wolfgang, Raffinierte Kunst. Übung vor Reproduktionen, Berlin 2009.

Ulmer, Eugen, Urheber- und Verlagsrecht, 3. Auflage, Berlin 1980.

Ulmer, Eugen, Der urheberrechtliche Werkbegriff und die moderne Kunst - Rezensionsabhandlung, GRUR 1968, S. 527-530.

Vahrson, Viola, Die Radikalität der Wiederholung. Interferenzen und Paradoxien im Werk Sturtevants, München 2006.

Vlah, Tudor, Parodie, Pastiche und Karikatur - Urheberrechte und ihre Grenzen. Eine rechtsvergleichende Untersuchung des deutschen und spanischen Urheberrechts, Frankfurt am Main, 2015.

Vogt, Margrit, Von Kunstworten und -werten. Die Entstehung der deutschen Kunstkritik in Periodika der Aufklärung, Berlin 2010.

Volkmann, Caroline, Art. 17 Urh-RL und die Upload-Filter: verschärfte Störerhaftung oder das Ende der Freiheit im Internet? Zugleich ein konkreter Lösungsvorschlag zur "Quadratur des Kreises“ bei der nationalen Umsetzung von Art. 17 Urh-RL, CR 2019, S. 376-384.

Von Becker, Bernhard, Die entstellende Parodie. Das EuGH-Urteil „Vrijheidsfonds/ Vandersteen" und die Folgen für das deutsche Recht, GRUR 2015, S. 336-339.

Von Becker, Bernhard, Parodiefreiheit und Güterabwägung. Das „Gies-Adler“-Urteil des BGH, GRUR 2004, S. 104-109. 


\section{Literaturverzeichnis}

Von Becker, Peter, Genie des Künstlers, Wahnsinn des Marktes, Der Tagesspiegel vom 8.3.2012, https://www.tagesspiegel.de/kultur/kunst-genie-des-kuenstlers-wa hnsinn-des-markts/6299652.html, Datum des Zugriffs: 15.1.2020.

Von Geblen, Dirk, Mashup. Lob der Kopie, Berlin 2011.

Von Gierke, Otto, Deutsches Privatrecht Band I: Allgemeiner Teil und Personenrecht, Leipzig 1895, S.748-848, Nachdruck in UFITA Band 125 (1994), S. 103-200.

Von Goethe, Johann Wolfgang, Werke. Hamburger Ausgabe in 14 Bänden, München 1998.

Von Heintschel-Heinegg, Bernd (Hrsg.), Beck'scher Online-Kommentar zum StGB, 44. Edition, München 2019. (zit.: BeckOK StGB/Bearbeiter)

Von Hildebrand, Adolf, Das Problem der Form in der Bildenden Kunst, Straßburg 1893.

Von Lewinski, Silke, International Copyright Law and Policy, New York 2008.

Von Schoenebeck, Astrid, Moderne Kunst und Urheberrecht. Zur urheberrechtlichen Schutzfähigkeit von Werken der modernen Kunst, Berlin 2003.

Von Ungern-Sternberg, Joachim, Die Rechtsprechung des EuGH und des BGH zum Urheberrecht und zu den verwandten Schutzrechten im Jahr 2017, GRUR 2018, S. 225-241.

Walter, Michael M. (Hrsg.), Europäisches Urheberrecht. Kommentar, Wien 2001. (zit.: Walter/Bearbeiter)

Wandtke, Artur-Axel, Grundsätze der Richtlinie über das Urheberrecht im digitalen Binnenmarkt, NJW 2019, S. 1841-1847.

Wandtke, Artur-Axel, Persönlichkeitsschutz versus Internet. Politiker und Prominente im Fadenkreuz der Persönlichkeitsrechte, MMR 2019, S. 142-147.

Wandtke, Artur-Axel/ Bullinger, Winfried (Hrsg.), Praxiskommentar zum Urheberrecht, 4. Auflage, München 2014.

(zit.: Wandkte/Bullinger/Bearbeiter)

Wandtke, Artur-Axel/ Hauck, Ronny, Art. 17 DSM-Richtlinie. Ein neues Haftungssystem im Urheberrecht, ZUM 2019, S. 627-636.

Warhol, Andy, Interview mit Gene Swensson 1963, in: Charles Harrison/ Paul Wood (Hrsg.), Art in theory 1900-1990. An anthology of changing ideas. Oxford und Cambridge 1997, S. 730-733.

Weber, Max, Wissenschaft als Beruf [1919], in: Max Weber, Schriften 1894-1922, ausgewählt von Dirk Kaesler, Stuttgart 2002, S. 474-511.

Weber, Max, Wirtschaft und Gesellschaft [1922], 5. Auflage, Tübingen 1972.

Wegmann, Katrin, Der Rechtsgedanke der freien Benutzung des $\$ 24$ UrhG und die verwandten Schutzrechte, Baden-Baden 2013.

Weibel, Peter, Ortlosigkeit und Bilderfülle. Auf dem Weg zur Telegesellschaft, in: Hubert Burda/ Christa Maar (Hrsg.), Iconic Turn. Die neue Macht der Bilder, Köln 2004, S. 216-226. 
Welsch, Wolfgang, Transkulturalität. Lebensformen nach der Auflösung der Kulturen, Information Philosophie (Heft 2, 1992), S. 5-20.

Whistler, Catherine, Raffaels Hände, in: Achim Gnann (Hrsg.), Raffael, Ausstellungskatalog der Albertina Wien, Wien 2017, S. 41-57.

Willsher, Kim, Jeff Koons plagiarised French photographer for Naked sculpture, The Guardian vom 9.3.2017, https://www.theguardian.com/artanddesign/2017/ mar/09/jeff-koons-plagiarised-french-photographer-for-naked-sculpture, Datum des Zugriffs: 15.1.2020.

Winckelmann, Johann Joachim, Gedancken über die Nachahmung der Griechischen Wercke in der Mahlerey und Bildhauer-Kunst [1755], hrsg. von Max Kunze, Stuttgart 2013.

Wirtz, Christiane, Rede der Staatssekretärin Christiane Wirtz bei der 6. Urheberrechtskonferenz der Initiative Urheberrecht am 19. November 2018 in Berlin, https://2018.konferenz-urheberrecht.de/sites/default/files/20181119_rede_wirtz. pdf, Datum des Zugriffs: 15.1.2020.

Wittgenstein, Ludwig, Tractatus logico-philosophicus [1921], Frankfurt am Main 2003.

Wunsch, Thorsten, Schriftenwelten zwischen Konstruktion und Ästhetik. Zur Dialektik der typographischen Form in ihrem räumlichen Kontext, Berlin 2012.

Young, James O., Cultural Appropriation and the Arts, Malden 2010.

Zaunschirm, Thomas, Kunst als Sündenfall. Die Tabuverletzungen des Jeff Koons, Freiburg 1996.

Ziegler, Katharina, Urheberrechtsverletzungen durch Social Sharing. Urheber- und haftungsrechtliche Aspekte sozialer Netzwerke am Beispiel der Plattform Facebook, Tübingen 2016.

Zilsel, Edgar, Die Entstehung des Geniebegriffes. Ein Beitrag zur Ideengeschichte der Antike und des Frühkapitalismus, Tübingen 1926.

Zuschlag, Christoph, Die Kopie ist das Original - über Appropriation Art, in: Ariane Mensger (Hrsg.), Déjà-vu? Die Kunst der Wiederholung von Dürer bis Youtube, Ausstellungskatalog der Staatlichen Kunsthalle Karlsruhe, Bielefeld 2012, S. 126-135.

Anstelle eines Abkürzungsverzeichnisses verweise ich darauf, dass die verwendeten Abkürzungen Hildebert Kirchner / Cornelie Butz, Abkürzungsverzeichnis der Rechtssprache, 8. Auflage, Berlin 2015, entsprechen. 
